\title{
Radium isotopes as tracers of boundary inputs of nutrients and trace elements to the coastal and open ocean
}

\author{
by \\ Lauren Elizabeth Kipp \\ B.S. Chemistry, University of North Carolina Wilmington, 2013 \\ Submitted in partial fulfillment of the requirements for the degree of \\ Doctor of Philosophy \\ at the \\ MASSACHUSETTS INSTITUTE OF TECHNOLOGY \\ and the \\ WOODS HOLE OCEANOGRAPHIC INSTITUTION
}

September 2018

(C) 2018 Lauren Elizabeth Kipp. All rights reserved.

The author hereby grants to MIT and WHOI permission to reproduce and to distribute publicly paper and electronic copies of this thesis document in whole or in part in any medium now known or hereafter created.

Signature of Author

Joint Program in Oceanography/Applied Ocean Science and Engineering Massachusetts Institute of Technology and Woods Hole Oceanographic Institution

Certified by

August 3, 2018

Dr. Matthew A. Charette

Thesis supervisor

Accepted by

Woods Hole Oceanographic Institution

Dr. Shuhei Ono

Chair, Joint Committee for Chemical Oceanography

Massachusetts Institute of Technology 


\title{
Radium isotopes as tracers of boundary inputs of nutrients and trace elements to the coastal and open ocean
}

by

\author{
Lauren Elizabeth Kipp
}

Submitted to the Massachusetts Institute of Technology and the Woods Hole Oceanographic Institution on August 3, 2018, in partial fulfillment of the requirements for the degree of Doctor of Philosophy in Chemical Oceanography.

\begin{abstract}
Nutrients and trace metals are vital for supporting life in the ocean, but the boundary processes that control the distributions of these elements are poorly constrained. Radium isotopes are well suited to studying inputs of elements from ocean margins because they are produced in sediments and soluble in seawater. The half-lives of the four isotopes $\left({ }^{223} \mathrm{Ra},{ }^{224} \mathrm{Ra},{ }^{228} \mathrm{Ra},{ }^{226} \mathrm{Ra}\right)$ range from days to thousands of years, thus these isotopes can be used to study oceanographic processes occurring over a range of time scales. In this thesis I have applied the quartet of radium isotopes to investigate boundary inputs, including seafloor hydrothermal vents, continental shelves, and rivers.

First, radium isotope ratios were used to constrain the age of hydrothermal plumes emanating from vents along the Mid-Atlantic Ridge and East Pacific Rise. These radium-derived ages were applied to determine the iron residence time in the Pacific plume that emanates from near $15^{\circ} \mathrm{S}$, providing an important constraint on the hydrothermal delivery of iron to the deep ocean. Next, ${ }^{228} \mathrm{Ra}$ was used to show that shelf inputs to the Arctic Ocean have increased over the last decade, implying that the fluxes of other shelf-derived materials are also increasing and could impact primary production in this basin. The ratio of ${ }^{228} \mathrm{Ra}$ and ${ }^{226} \mathrm{Ra}$ was also applied to determine the ventilation time of Arctic intermediate waters with respect to shelf inputs, and the first measurements of ${ }^{226} \mathrm{Ra}$ in the deep Canada Basin were used to estimate the residence time of deep waters with respect to benthic sediment inputs. Finally, a study of the Mackenzie River Estuary illustrated the importance of deltaic and estuarine processing on the ultimate delivery of nutrients, trace metals, dissolved organic matter, and radium to the Arctic Ocean. By applying radium isotopes as tracers of boundary inputs in these diverse environments, the work presented in this thesis improves our understanding of nutrient and trace metal inputs to the coastal and open ocean.
\end{abstract}

Thesis supervisor: Dr. Matthew A. Charette Title: Senior Scientist, Woods Hole Oceanographic Institution 


\section{ACKNOWLEDGEMENTS}

No one achieves anything alone, and this thesis represents the culmination of five years of support and encouragement from the people mentioned below and many others.

My advisor, Matthew Charette, has been an excellent teacher, role model, editor, and mentor, and has helped me grow into an independent and confident scientist. I am very grateful for all of the opportunities Matt has given me to conduct interesting research, travel all over the world, and become part of the GEOTRACES community. I have learned so much from Matt during my time here, and I will continue to learn from his example as I work to become a successful scientist and advisor myself.

Paul Henderson provided essential logistical and technical assistance for all of the research presented in this thesis, but more importantly he has been a great friend and lab mate over the last five years. No matter how busy he was Paul always made time to answer my questions and help me with whatever I needed, whether it was preparing for a cruise, chipping away at permafrost, or putting up Christmas decorations. Steven Pike was also a huge help during my time at WHOI, particularly during the Arctic GEOTRACES cruise, and taught me a lot about working at sea.

I am very thankful for the support of my committee, Billy Moore, Meg Tivey, Bob Pickart, and David McGee, who always made time to discuss my work and provide thoughtful feedback. In addition to offering insights that improved my thesis, Billy, Meg, Bob, and David have all been great mentors and helped me navigate important career decisions. I am also grateful for the mentorship of multiple senior scientists at WHOI and in the GEOTRACES community; in particular, the support and encouragement of Scott Doney, Bob Anderson, Phoebe Lam, and Michiel Rutgers van der Loeff have helped me build my confidence as a scientist and made me feel welcome in the oceanographic community.

I owe many thanks to the members of the Academic Programs Office (Jim Yoder, Meg Tivey, Delia Oppo, Julia Westwater, Christine Charette, Lea Fraser, and Valerie Caron) for keeping this program running smoothly and having an open door policy that made me feel welcome to seek advice on anything from travel reimbursements to postdoc decisions. The Marine Chemistry \& Geochemistry administrative staff (Sheila Clifford, Donna Mortimer, Mary Murphy, and Mary Zawoysky) were similarly willing to answer any and all of my questions, and brightened my days on the fourth floor of Clark. I have also appreciated the support of the MC\&G department chairs and education coordinators during my time here: Jeff Seewald, Bernhard PeuckerEhrenbrink, and Scott Doney.

These have been the best five years of my life, thanks in large part to the people I have been able to spend them with. To my friends, Gabriela Farfan, Danielle Gruen, Tyler Rohr, Gualtiero Spiro Jaeger, Virginie Sanial, Megan May, Net Charoenpong, Cristina Schultz, Paul Lerner, Alison Agather, and Jessica Dabrowski: thank you for keeping me sane, making me laugh, and being the best cheerleaders when I was having a rough day. To Erin Black: put simply, I don't know what I would have done without you. Thank for you teaching me so much about life in the Joint 
Program, chemical oceanography, and life at sea. You continue to be a fantastic role model and mentor, and you inspire me to be a better scientist and person.

My love for the ocean is thanks to my parents, who brought my brother Jonathan and I on family vacations to Sea World and Cape Cod when we were kids, and who brought me to visit WHOI when I told them I wanted to be an oceanographer. Thank you Mom and Dad for teaching me that I could do whatever I set my mind to, and giving me the confidence to pursue my dreams. Jonathan, you have kept me inspired and motivated to achieve this goal through the bravery and dedication with which you have pursued your own ambitions.

My husband, Ryan Murphy, has been an essential source of love and laughter in my life long before I decided to pursue this PhD. Despite the fact that the last few years have included workfilled weekends, long periods of time when I was away at sea, and lots of parties where the main topic of conversation was some aspect of oceanography, his support and encouragement has never wavered. Ryan, I cannot express how thankful I am that you have always supported my career goals, no matter where in the world they take me. Being able to come home and share my day with you has gotten me through the rough parts of this program and made the good parts even better. Thank you for being there through all of it.

\section{Financial support}

Funding for the GEOTRACES work was provided by the U.S. National Science Foundation (awards OCE-1232669, OCE-0925158, and OCE-148305 to Matthew Charette; and OCE1231221, OCE-0926559, and OCE-1458424 to Willard Moore). The Mackenzie River study was funded by a Graduate Student Research Award from the North Pacific Research Board, and awards from the Woods Hole Oceanographic Institution Ocean Ventures Fund. I completed most of the work presented in this thesis while being supported by a DoD, Air Force Office of Scientific Research, National Defense Science and Engineering Graduate (NDSEG) Fellowship, 32 CFR 168a. 


\section{TABLE OF CONTENTS}

$\begin{array}{ll}\text { Abstract } & 3\end{array}$

Acknowledgements $\quad 5$

List of Figures $\quad 10$

List of Tables $\quad 14$

Ch 1: Introduction $\quad 15$

1.1 Radioactive isotopes as oceanographic tracers 16

1.2 Radium isotopes as tracers of boundary inputs 17

1.3 Introduction to this thesis 18

References 19

Ch 2: Radium isotopes as tracers of hydrothermal inputs and neutrally buoyant plume dynamics in the deep ocean $\quad 27$

$\begin{array}{ll}\text { Abstract } & 27\end{array}$

2.1 Introduction 28

2.2 Methods 29

2.2.1 Sample Collection 29

2.2.2 Sample Analysis 30

2.3 Results and discussion $\quad 32$

$\begin{array}{lll}\text { 2.3.1 Radium in vent fluids } & 32\end{array}$

2.3.2 Radium in neutrally buoyant plumes $\quad 35$

2.3.3 On-axis plume dynamics 37

2.3.4 Off-axis plume dynamics 38

$\begin{array}{ll}2.4 \text { Conclusions } & 42\end{array}$

Acknowledgements $\quad 43$

References $\quad 44$

Ch 3: Increased fluxes of shelf-derived materials to the central Arctic Ocean 65

$\begin{array}{ll}\text { Abstract } & 65\end{array}$

3.1 Introduction $\quad 66$

3.2 Results and discussion 66

3.2.1 Radium-228 distribution in surface waters and comparison to historical studies $\quad 66$

3.2.2 Sources and sinks of ${ }^{228} \mathrm{Ra}$ in surface waters 67

$\begin{array}{ll}\text { 3.2.3 Changing shelf inputs } & 69\end{array}$

3.3 Materials and methods $\quad 71$

3.3.1 Surface sample collection and processing $\quad 71$

3.3.2 Water column samples collection and processing 71

$\begin{array}{lll}3.3 .3 & \text { Ice back-trajectories } & 72\end{array}$

$\begin{array}{lll}\text { 3.3.4 Surface water age } & 72\end{array}$

$\begin{array}{ll}\text { 3.3.5 Meteoric water fraction } & 73\end{array}$

3.3.6 Surface water inventory of ${ }^{228} \mathrm{Ra} \quad 74$

3.3.7 Mass balance model: sinks $\quad 74$

$\begin{array}{lll}\text { 3.3.8 Mass balance model: sources } & 74\end{array}$ 
$\begin{array}{lll}\text { 3.3.9 Open water days } & 77\end{array}$

$\begin{array}{ll}\text { Acknowledgements } & 77\end{array}$

Funding $\quad 77$

$\begin{array}{ll}\text { Competing interests } & 78\end{array}$

$\begin{array}{ll}\text { Author contributions } & 78\end{array}$

$\begin{array}{ll}\text { Data and materials availability } & 78\end{array}$

$\begin{array}{ll}\text { References } & 79\end{array}$

Ch 4: Shelf-basin interactions and water mass residence times in the Western Arctic Ocean 105

$\begin{array}{ll}\text { Abstract } & 105\end{array}$

4.1 Introduction 106

$\begin{array}{ll}\text { 4.2 Methods } & 108\end{array}$

$\begin{array}{lll}\text { 4.2.1 Sample collection } & 108\end{array}$

$\begin{array}{ll}\text { 4.2.2 Sample analysis } & 108\end{array}$

$\begin{array}{ll}\text { 4.2.3 Sampling procedures for historical datasets } & 109\end{array}$

4.2.4 Chukchi sea model 109

4.3 Results 110

$\begin{array}{ll}\text { 4.3.1 Radium-228 } & 110\end{array}$

$\begin{array}{ll}\text { 4.3.2 Radium-226 } & 111\end{array}$

4.3.3 Chukchi sea model 111

4.4 Discussion $\quad 112$

4.4.1 Seasonal variability in ${ }^{228} \mathrm{Ra}$ and ${ }^{226} \mathrm{Ra}$ in the Chukchi Sea $\quad 112$

4.4.2 Shelf inputs at the surface and in the halocline 113

$\begin{array}{ll}\text { 4.4.3 Radium variability in the Canada Basin } & 117\end{array}$

$\begin{array}{ll}\text { 4.4.4 Recent ventilation of the Makarov Basin } & 118\end{array}$

$\begin{array}{ll}\text { 4.4.5 } & 119 \\ { }^{226} \mathrm{Ra}-\mathrm{Si} \text { correlations } & 118\end{array}$

$\begin{array}{ll}\text { 4.4.6 Deep water residence times } & 120\end{array}$

$\begin{array}{ll}4.5 \text { Conclusions } & 122\end{array}$

\begin{tabular}{lr} 
Acknowledgements & 122 \\
\hline
\end{tabular}

$\begin{array}{ll}\text { References } & 124\end{array}$

Ch 5: Nutrients, trace metals, and radium isotopes in the Mackenzie River delta and estuary 161

Abstract 161

5.1 Introduction 162

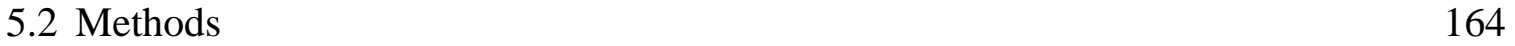

$\begin{array}{lll}\text { 5.2.1 Sample collection } & 164\end{array}$

$\begin{array}{ll}\text { 5.2.2 Sample analysis } & 166\end{array}$

$\begin{array}{ll}5.3 \text { Results } & 168\end{array}$

$\begin{array}{lll}\text { 5.3.1 Water chemistry } & 168\end{array}$

$\begin{array}{ll}\text { 5.3.2 Radium isotopes } & 169\end{array}$

$\begin{array}{lll}\text { 5.3.3 Nutrients } & 170\end{array}$

$\begin{array}{lll}\text { 5.3.4 Dissolved organic matter } & 171\end{array}$

$\begin{array}{ll}\text { 5.3.5 Dissolved inorganic carbon and alkalinity } & 172\end{array}$

$\begin{array}{lll}\text { 5.3.6 Trace metals } & 172\end{array}$

$\begin{array}{ll}5.4 \text { Discussion } & 173\end{array}$

$\begin{array}{lll}\text { 5.4.1 The freshwater endmember } & 173\end{array}$ 
5.4.2 Changes across the delta

5.4.3 Changes in the estuary

5.4.4 Fluxes of Ra, DOM, and trace metals from the Mackenzie River to the coastal ocean

\subsubsection{Conclusions}

Acknowledgements

References

Ch 6: Summary and future research directions

Appendix: Chemistry of permafrost porewaters in the Mackenzie River Delta

A.1 Motivation

A.2 Sample collection

A.3 Experimental procedures and results

A.3.1 Sediment-bound ${ }^{228} \mathrm{Ra}$ and ${ }^{226} \mathrm{Ra}$ activities (DH1-3, TS1-3) 233

A.3.2 Desorbable ${ }^{228} \mathrm{Ra}$ and ${ }^{226} \mathrm{Ra}$ activities (DH1-3, TS1-3) 234

A.3.3 ${ }^{226} \mathrm{Ra}$ activity and water isotopes in TS3 porewater

A.3.4 Solutes in NR2 and AC permafrost porewaters 


\section{LIST OF FIGURES}

\section{Chapter 1}

1. Diagram of the ${ }^{238} \mathrm{U},{ }^{235} \mathrm{U}$, and ${ }^{232} \mathrm{Th}$ decay chains

\section{Chapter 2}

1. Locations of GP16 stations and hydrothermal vents references in this study

2. Activities of the four Ra isotopes in hydrothermal fluids as a function of temperature 54

3. The ${ }^{224} \mathrm{Ra} /{ }^{228} \mathrm{Ra}$ and ${ }^{223} \mathrm{Ra} /{ }^{226} \mathrm{Ra}$ activity ratios in hydrothermal fluids as a function of temperature

4. The ${ }^{224} \mathrm{Ra} /{ }^{228} \mathrm{Ra}$ activity ratios observed in high temperature vent fluids as a function of $\mathrm{Mg}$ concentration

5. Light transmission and ${ }^{3} \mathrm{He}_{\mathrm{xs}}$, and particulate and dissolved ${ }^{226} \mathrm{Ra}$ measured at station 20 of GP16

6. Light transmission and ${ }^{3} \mathrm{He}_{\mathrm{xs}},{ }^{223} \mathrm{Ra}_{\mathrm{xs}}$ and ${ }^{224} \mathrm{Ra}_{\mathrm{xs}}$, and ${ }^{226} \mathrm{Ra}_{\mathrm{ht}}$ and ${ }^{228} \mathrm{Ra}_{\mathrm{ht}}$ measured over TAG at station 16 of GA03

7. Light transmission and ${ }^{3} \mathrm{He}_{\mathrm{xs}},{ }^{223} \mathrm{Ra}_{\mathrm{xs}}$ and ${ }^{224} \mathrm{Ra}_{\mathrm{xs}}$, and ${ }^{226} \mathrm{Ra}_{\mathrm{ht}}$ and ${ }^{228} \mathrm{Ra}_{\mathrm{ht}}$ measured over the EPR at station 18 of GP16

8. Models of Ra activity ratios as a function of plume age

9. Radium-228 activities measured in the neutrally buoyant plume on the GP16 transect 61

10. ${ }^{228} \mathrm{Ra} /{ }^{3} \mathrm{He}_{\mathrm{xs}}$ in the neutrally buoyant plume as a function of distance from Station 18 , located over the EPR

11. Concentrations of total $\mathrm{Fe}$ and ${ }^{228} \mathrm{Ra}$ in the neutrally buoyant hydrothermal plume from the ridge axis station to $2200 \mathrm{~km}$ west of the EPR

12. $\mathrm{Fe} /{ }^{3} \mathrm{He}_{\mathrm{xs}}$ as a function of the ${ }^{228} \mathrm{Ra}$-derived age

\section{Chapter 3}

1. Radium-228 activities in surface waters of the Arctic Ocean

2. Radium-228 activities in surface waters above $85^{\circ} \mathrm{N}$ as a function of percent meteoric water

3. Activities of ${ }^{228} \mathrm{Ra}$ and ${ }^{226} \mathrm{Ra}$ measured in surface waters in 2015 , shown with historical measurements of shelf and river endmembers

4. The coastal flux of ${ }^{228} \mathrm{Ra}$ to each ocean basin in atoms $\mathrm{y}^{-1}$ and normalized to the area of each basin in atoms $\mathrm{km}^{-2} \mathrm{y}^{-1}$

S1. Activities of ${ }^{228} \mathrm{Ra}$ in the upper $500 \mathrm{~m}$ of the water column with contours indicating the fraction of meteoric water

$\mathrm{S} 2$. Surface water activities of ${ }^{228}$ Ra from GN01 shown with activities of ${ }^{228}$ Ra measured on historical expeditions in the Arctic

S3. Profiles of ${ }^{228} \mathrm{Ra}$ on the GN01 cruise (2015) compared to the surface samples collected on the GIPY11 cruise (2007)

S4. Radium-228 activities in surface waters in 1994, 2007 and 2015

S5. Radium-228 activities in surface waters sampled on the GN01 transect in 2015

S6. Radium-228 activities in surface waters on the GIPY11 transect in 2007 
S7. The activities of ${ }^{228} \mathrm{Ra}$ and ${ }^{228} \mathrm{Th}$, and the ${ }^{228} \mathrm{Th} /{ }^{228} \mathrm{Ra}$ activity ratio as a function of time since leaving the shelf

S8. Inventory of ${ }^{228} \mathrm{Ra}$ in the top $500 \mathrm{~m}$ at each of the stations where water column samples were collected and the bottom depth was $\geq 1,000 \mathrm{~m}$

S9. Dissolved ${ }^{228} \mathrm{Ra}$ activities measured in the Mackenzie River

S10. Dissolved ${ }^{228} \mathrm{Ra}$ activities in the Mackenzie River Estuary (East Channel)

S11. Number of open water days averaged over the five year periods prior to the GIPY11 and GN01 expeditions, and the difference in the number of open water days between the two periods

S12. Dissolved ${ }^{226}$ Ra activities in surface water above $85^{\circ} \mathrm{N}$ as a function of the fraction of meteoric water in each sample

S13. Surface water activities of ${ }^{226} \mathrm{Ra}$ from GN01 shown along with activities of ${ }^{226} \mathrm{Ra}$ measured on historical expeditions in the Arctic

\section{Chapter 4}

1. Schematic of water circulation in the Chukchi Sea

2. Locations sampled on the HLY1502 expedition

3. Domain of the sediment tracer model, with bottom topography shown as filled contours

4. Radium-228 activities in surface waters on the northbound and southbound transects

5. Radium-228 activities on the northbound and southbound transects

6. Depth profiles of ${ }^{226} \mathrm{Ra},{ }^{228} \mathrm{Ra}$, and the ${ }^{228} \mathrm{Ra} /{ }^{226} \mathrm{Ra}$ activity ratio at station 19 , located over the Mendeleyev Ridge

7. Depth profiles of ${ }^{226} \mathrm{Ra},{ }^{228} \mathrm{Ra}$, and the ${ }^{228} \mathrm{Ra} /{ }^{226} \mathrm{Ra}$ activity ratio at station 36 , located in the Amundsen Basin

8. Average ${ }^{228} \mathrm{Ra}$ and ${ }^{226} \mathrm{Ra}$ activities measured on the HLY1502 and SBI transects in T-S space

9. Radium-226 activities on the northbound and southbound transects

10. Radium-226 activities measured at stations in the deep Makarov and Canada Basins

11. Modeled tracer concentrations, salinity, temperature, and zonal velocity as a function of depth and time

12. Modeled zonal velocity and tracer concentrations averaged over January - June and July - December of year 3 of the model run

13. Concentrations of the sediment tracer in bottom waters over the Chukchi Shelf in year 3 of the model run

14. ${ }^{228} \mathrm{Ra}$ and ${ }^{226} \mathrm{Ra}$ activities measured over the Chukchi shelf

15. Locations of stations from the HLY1502 and SBI expeditions that were used to create mean section plots

16. Mean section plots of salinity, temperature, absolute geostrophic velocity, and

${ }^{228} \mathrm{Ra}$ activity, along with CTD and ${ }^{228} \mathrm{Ra}$ sampling locations

17. Seasonally averaged mean section plots 
18. ${ }^{228} \mathrm{Ra} /{ }^{226} \mathrm{Ra}$ activity ratio as a function of salinity for samples collected in Western Arctic surface waters, and the positions of the shelfbreak jet, PSL, and Atlantic endmembers in ${ }^{228} \mathrm{Ra}^{-226} \mathrm{Ra}$ - salinity space

19. ${ }^{226} \mathrm{Ra}$ and ${ }^{228} \mathrm{Ra}$ profiles measured at the CESAR ice station in 1983 and on the HLY1502 expedition in 2015

20. Radium-228 profiles measured in the Canada Basin in 2000 and 2015

21. Radium-226 versus silica for samples shallower than $400 \mathrm{~m}$ and deeper than $400 \mathrm{~m} 152$

S1. Radium-228 profiles measured at all stations

S2. Radium-226 profiles measured at all stations

S3. Concentrations of the sediment tracer at $37.5 \mathrm{~m}$ over the Chukchi Shelf in year 3 of the model run

S4. Depth-integrated concentrations of the sediment tracer over the Chukchi Shelf in year 3 of the model run

S5. Modeled tracer concentrations, salinity, temperature, and zonal velocity as a function of depth and time

S6. Radium-228, temperature, and salinity measured at AWS-2000 station 3 and HLY1502 stations 56, 52, and 60

S7. ${ }^{226} \mathrm{Ra}-\mathrm{Si}$ relationship for samples collected in shelf-modified Pacific waters on the HLY1502 transect and in the North Pacific and Bering Sea during the GEOSECS expedition

\section{Chapter 5}

1. Sampling locations in the Mackenzie River Delta 206

2. Water discharge data 207

3. Salinity and temperature in the East Channel in June 2016

208

4. Water isotope values of groundwater and water samples collected at Tsiigehtchic and in the East Channel

5. Time series of ${ }^{228} \mathrm{Ra}$ and ${ }^{226} \mathrm{Ra}$, the ${ }^{228} \mathrm{Ra} /{ }^{226} \mathrm{Ra}$ activity ratio, and nitrate and total suspended solids in the Mackenzie River at Tsiigehtchic

6. The ratio of downstream concentration or activity to the upstream concentration of activity

7. Radium activities and isotope ratios in the East Channel

8. Nutrient, dissolved organic carbon, and dissolved organic nitrogen concentrations measured in this study compared to June averages measured by the Arctic Great Rivers Observatory and Environment and Climate Change Canada

9. Nutrient, dissolved organic carbon, and dissolved organic nitrogen concentrations in the East Channel

10. Dissolved inorganic carbon and alkalinity concentrations in the East Channel

11. Trace metal concentrations measured in this study compared to June averages measured by the Arctic Great Rivers Observatory and Environment and Climate Change Canada

12. Trace metal concentrations in the East Channel

13. ${ }^{228} \mathrm{Ra}$ and ${ }^{226} \mathrm{Ra}$ activities in North American and Eurasian Arctic rivers

14. Relationship between ${ }^{226} \mathrm{Ra}$ and total suspended solids and ${ }^{228} \mathrm{Ra}$ and total suspended solids in the Mackenzie River 
15. The ${ }^{224} \operatorname{Ra}_{\mathrm{xs}}{ }^{223} \mathrm{Ra}_{\mathrm{xs}}$ activity ratio in the East Channel

S1. Time series of ${ }^{228} \mathrm{Ra}$ and ${ }^{226} \mathrm{Ra}$, and the ${ }^{228} \mathrm{Ra} /{ }^{226} \mathrm{Ra}$ activity ratio in the Yukon River at Pilot Station

S2. Dissolved inorganic nitrogen concentrations in the East Channel

\section{Chapter 6}

1. Schematic of climate-driven changes affecting the flux of shelf derived materials in the Arctic

\section{Appendix}

1. Distribution of permafrost in the Arctic

2. Detector efficiency for the $1.8 \mathrm{~g}$ fiber standard

3. Water isotopes measured in permafrost samples, compared to those measured in the Mackenzie River Delta 


\section{LIST OF TABLES}

\section{Chapter 2}

1. Radium activities in hydrothermal vent fluids

2. ${ }^{228} \mathrm{Ra} /{ }^{3} \mathrm{He}_{\mathrm{xs}}$ and ${ }^{228} \mathrm{Ra}$-derived plume ages for GP16 stations west of the East Pacific Rise

\section{Chapter 3}

1. Radium-228 sources and sinks (all in $10^{22}$ atoms $\mathrm{y}^{-1}$ ) in the Arctic surface ocean 84

S1. Locations of stations used to determine the surface water ${ }^{228}$ Ra inventory 90

S2. Activities of ${ }^{228} \mathrm{Ra}$ and ${ }^{226} \mathrm{Ra}$ measured in ice rafted sediments and melted ice $\quad 91$

\section{Chapter 4}

1. HLY1502 station locations, bottom depths, and type of samples collected

\section{Chapter 5}

1. Locations, collection dates, water isotope concentrations, and water properties of freshwater and groundwater samples, estuary samples, and suspended sediment samples

2. Results of estuarine standard reference material (SLRS-6) analysis

3. Time series of ${ }^{228} \mathrm{Ra},{ }^{226} \mathrm{Ra}$, and the ${ }^{228} \mathrm{Ra} /{ }^{226} \mathrm{Ra}$ activity ratio in the Mackenzie River (Tsiigehtchic) and the Yukon River (Pilot Station)

4. Radium isotope activities and activity ratios in freshwater and groundwater samples, estuary samples, and on suspended sediments

5. Nutrients, organic matter, dissolved inorganic carbon, and alkalinity in freshwater and groundwater samples and estuary samples

6. Trace metal concentrations in freshwater and groundwater samples and estuary samples

7. Annual fluxes and June 2016 fluxes of solutes from the Mackenzie River

\section{Appendix}

1. Sample descriptions and collection locations

2. The activities of ${ }^{228} \mathrm{Ra}$ and ${ }^{226} \mathrm{Ra}$ and the ${ }^{228} \mathrm{Ra} /{ }^{226} \mathrm{Ra}$ activity ratios measured in permafrost and active layer sediments

3. Gamma detector efficiencies for a $1.8 \mathrm{~g}$ fiber standard

4. The ${ }^{228} \mathrm{Ra}$ and ${ }^{226} \mathrm{Ra}$ activities and the ${ }^{228} \mathrm{Ra} /{ }^{226} \mathrm{Ra}$ activity ratio measured in desorption experiment filtrate

5. Chemistry of permafrost porewaters 


\section{Chapter 1: Introduction}




\subsection{RADIOACTIVE ISOTOPES AS OCEANOGRAPHIC TRACERS}

The supply of macro nutrients like nitrogen and phosphorous is a well-established control on marine heterotrophic food webs, but in the last few decades it has been hypothesized that the availability of trace metals such as iron, cobalt, and zinc can also limit oceanic productivity (Moore et al., 2013). However, the sources and sinks that create the observed basin scale distributions of these elements are still poorly constrained. Identifying boundary sources and sinks of nutrients and trace elements and isotopes (TEIs), and the rates of input and removal associated with each, will not only yield insights into the current distributions of these species, but also into how they might change in response to a changing climate. The quantification of boundary processes, such as hydrothermal circulation and sediment inputs, is also vital to providing constraints on global biogeochemical models. Such models could help predict the impacts of climate change on the world's oceans, as well as the ways in which the oceans may help moderate rising $\mathrm{CO}_{2}$ levels, but they are currently hindered by inaccurate representations of the cycling of important TEIs such as iron (Tagliabue et al., 2016).

Radioactive isotopes (radionuclides) are valuable tools for studying the sources, sinks, and cycling of TEIs. Radionuclides decay at known rates determined by their half-lives, which can range from seconds to billions of years. They also exhibit a range of geochemical properties: some are strongly particle reactive while others are soluble, some are gases, and many have wellknown sources or sinks. Radionuclides can therefore be used to study the cycling of elements that have similar geochemical properties or sources and sinks, because they will exhibit the same behavior as the TEI of interest while decaying at a predictable rate, thus providing a time constraint on the process being investigated. Examples of radionuclides that have been applied to study oceanographic processes include thorium isotopes, which have been used to model particle exchange and trace carbon and trace metal export from the euphotic zone (e.g. Bacon and Anderson, 1982; Black, 2017; Buesseler et al., 1992; Lerner et al., 2017), beryllium-7, which has been applied to determine rates of nitrate upwelling and to quantify atmospheric deposition fluxes of trace metals (e.g. Kadko, 2017; Shelley et al., 2017), and anthropogenic radionuclides such as iodine-129, which have well-constrained point sources and conservative behavior that allow us to trace ocean circulation (e.g. Karcher et al., 2012; Smith et al., 2011).

In this thesis I use the quartet of naturally occurring radium isotopes $\left({ }^{223} \mathrm{Ra}: \mathrm{t}_{1 / 2}=11.4 \mathrm{~d}\right.$,

${ }^{224} \mathrm{Ra}: \mathrm{t}_{1 / 2}=3.66 \mathrm{~d},{ }^{226} \mathrm{Ra}: \mathrm{t}_{1 / 2}=1600 \mathrm{y},{ }^{228} \mathrm{Ra}: \mathrm{t}_{1 / 2}=5.75 \mathrm{y}$ ) to identify and quantify boundary inputs to the coastal and open ocean. Radium isotopes are often applied as radioactive tracers of TEI inputs from ocean boundaries to the open ocean (e.g. Charette et al., 2007; Moore, 2000a, 2000b; Moore et al., 1995; Sanial et al., 2018). They are produced through the decay of thorium (Figure 1), which has a high particle affinity and is sourced from continental crust and sediments. Radium is soluble in seawater and behaves largely conservatively once it is produced and released into overlying waters. The main controls on the distribution of Ra isotopes in the ocean are thus radioactive decay and physical mixing. Radium can be removed from solution through biological uptake and mineral precipitation of siliceous or calcareous tests (Moore and Dymond, 1991; van Beek et al., 2007), however the removal rate is minor relative to the loss through decay for ${ }^{223} \mathrm{Ra},{ }^{224} \mathrm{Ra}$, and ${ }^{228} \mathrm{Ra}$, and is only relevant for the longest-lived isotope, ${ }^{226} \mathrm{Ra}$. The range in the four half-lives allows for the quantification of both short- and long-term ocean processes. 


\subsection{RADIUM ISOTOPES AS TRACERS OF BOUNDARY INPUTS}

\subsubsection{Hydrothermal vents}

During the circulation of seawater through the oceanic crust, fluids become heated and undergo reactions with the basalt causing them to become enriched in many metals, gases, and isotopes (Campbell et al., 1988; Edmond et al., 1982; Jenkins et al., 1978; Kadko and Moore, 1988; Von Damm et al., 1985). Radionuclides, including Ra, become enriched in hydrothermal fluids through the alteration of basalt by high-temperature, low-pH fluids, in situ decay of parent isotopes, and recoil effects from the decay of parents in the basalt (Hammond et al., 1988; Kadko and Moore, 1988; Krishnaswami et al., 1982). Radioactive isotopes have been applied in hydrothermal systems to constrain the time scales of processes such as the circulation of fluids through the crust, formation of chimneys, and particle scavenging rates in hydrothermal plumes (see Kadko, 1996 for a review).

Hydrothermal plumes are significant sources of TEIs to the deep ocean, and may even support primary productivity in surface waters through the upwelling of hydrothermally-sourced trace metals in the Southern Ocean (Resing et al., 2015; Tagliabue et al., 2010). However, scavenging and oxidation processes that occur during transport in the neutrally buoyant plume affect the ultimate delivery of solutes to the ocean (Edmond et al., 1979; German et al., 1991b, 1991a, 1990). It is therefore important to study the timescales of neutrally buoyant plume transport and TEI removal in order to quantify the ultimate impact of hydrothermal inputs. Because Ra isotopes are enriched in hydrothermal fluids (Kadko, 1996; Kadko et al., 2007; Kadko and Moore, 1988; Moore et al., 2008; Rudnicki and Elderfield, 1992), they can be applied to study plume dynamics in both young (days - months; ${ }^{223} \mathrm{Ra}$ and ${ }^{224} \mathrm{Ra}$ ) and old (years decades; ${ }^{228} \mathrm{Ra}$ ) neutrally buoyant plumes. Normalizing the shorter-lived Ra isotopes to the longlived ${ }^{226} \mathrm{Ra}$ or a conservative tracer (e.g. ${ }^{3} \mathrm{He}$ ) corrects for the effects of dilution, such that any decrease in Ra can be attributed to radioactive decay and be used to determine the age of the plume.

\subsubsection{Sediment inputs}

Benthic sediments act as reservoirs of TEIs and nutrients, which can become mobilized by benthic boundary layer processes and influence primary productivity in overlying waters (Charette et al., 2007; Dulaiova et al., 2009; Wang et al., 2006). Because of their common shelf source, Ra isotopes have been applied as tracers of nutrient exchange across the seafloor, helping to quantify the fluxes of dissolved nitrogen and phosphorus in coastal zones (Moore and Shaw, 1998; Moore et al., 2002) and the supply of trace metals from shelf sediments (Charette et al., 2007, 2016; Sanial et al., 2018).

Radium isotopes are also useful for tracking shelf inputs to the open ocean (Charette et al., 2015; Kadko and Muench, 2005; Key et al., 1985; Rutgers van der Loeff et al., 1995). The shorter-lived isotopes, ${ }^{223} \mathrm{Ra}$ and ${ }^{224} \mathrm{Ra}$, can be applied to determine costal mixing rates (Moore, 2000a, 2000b), while the longer-lived ${ }^{228} \mathrm{Ra}$ and ${ }^{226} \mathrm{Ra}$ have been used to determine the time elapsed since a water mass left the shelf (Kadko and Aagaard, 2009; Kadko and Muench, 2005). These time constraints provide a way to estimate the residence times of other shelf-derived materials in the open ocean (Hansell et al., 2004; Letscher et al., 2013). 


\subsubsection{Rivers and estuaries}

Rivers are vital conduits of solute delivery to the oceans; they are the main sources of major ions and elements to the oceans (Mackenzie and Garrels, 1966; Martin and Meybeck, 1979) and can also be important inputs of trace elements in certain environments, for example, rivers are a significant source of iron and manganese in the Arctic (Klunder et al., 2012; Middag et al., 2011). Concentrations of riverine solutes often become modified through estuarine and near-shore biogeochemical processing (Boyle et al., 1974, 1982; Sharp et al., 1982; Shiller and Boyle, 1987; Sholkovitz et al., 1978), thus it is essential to take these coastal processes into account when quantifying fluvial fluxes to the ocean.

Radium is primarily adsorbed to particles in freshwater but dissolved in seawater; this difference in chemistry results from a change in the adsorption coefficient of $\mathrm{Ra}$ in fresh and saline water, and the decrease in particle concentration in open ocean waters (Li et al., 1977; Moore et al., 1995). Due to desorption from particles in the estuary and resuspension events that release $\mathrm{Ra}$ produced in estuarine and shelf sediments, estuaries are usually a source of $\mathrm{Ra}$ to the open ocean (Elsinger and Moore, 1980; Key et al., 1985; Krest et al., 1999; Li et al., 1977; Li and Chan, 1979; Moore, 1992, 1981; Moore et al., 1995). The activity ratios of the short-lived to long-lived isotopes can be used to differentiate between different solute sources in the estuary; shorter-lived $\mathrm{Ra}$ isotopes are regenerated more quickly in sediments due to their shorter halflives, resulting in high short- to long-lived ratios in porewaters and groundwaters (Charette, 2007; Moore, 1981; Moore et al., 1995; Rodellas et al., 2017). Radium-223 and ${ }^{224}$ Ra can also be applied to determine the water age at the mouth of a river, as they decay on timescales similar to that of river plume mixing (e.g. Moore and Krest, 2004).

\subsection{INTRODUCTION TO THIS THESIS}

The following chapters present an investigation of Ra isotopes as tracers of three different boundary sources across three ocean basins. To study TEI inputs from hydrothermal vents, oceanic sediments, and rivers, I utilized datasets covering both large and small spatial scales. The GEOTRACES program, which was designed to improve our understanding of the cycling and distributions of TEIs in the oceans through large-scale ocean transects (www.geotraces.org), provided the opportunity to map Ra distributions in the open ocean in unprecedented spatial resolution, while more detailed process studies of Ra activities in hydrothermal fluids and in the Mackenzie River helped me constrain the Ra signature of these sources. This work serves as an example of the versatility and utility of Ra isotopes as tracers of margin inputs in diverse aquatic environments, from high-temperature hydrothermal fluids to fresh, ice covered Arctic surface waters.

In Chapter 2, hydrothermal inputs are studied using samples collected from neutrally buoyant plumes in the Atlantic and Pacific Oceans during the US GEOTRACES North Atlantic and East Pacific Zonal Transects, and a compilation of historical Ra measurements in hydrothermal fluids. The short-lived Ra isotopes are applied to determine the age of young (days - weeks) hydrothermal plumes emanating from sections of the Mid-Atlantic Ridge and East Pacific Rise (EPR), providing important time scales for quantifying TEI modifications in the early stages of neutrally buoyant plume spreading. The longer-lived ${ }^{228} \mathrm{Ra}$ is also employed to quantify iron residence times in the hydrothermal plume emanating from the EPR near $15^{\circ} \mathrm{S}$ and 
extending thousands of kilometers across the South Pacific (Resing et al., 2015), showing the utility of $\mathrm{Ra}$ isotopes for constraining trace metal residence times.

In Chapters 3 and 4, samples collected during the US GEOTRACES Arctic transect are used to examine shelf inputs in the Arctic Ocean, where $\mathrm{Ra}$ is a particularly useful tool due to the large influence of land-ocean interactions on this small ocean basin. A mass balance of ${ }^{228} \mathrm{Ra}$ in Arctic surface waters is used in Chapter 3 to show that shelf-derived material inputs to the Arctic have increased over the last decade, indicating that climate change is impacting the chemistry of Arctic Ocean surface waters. In Chapter $4,{ }^{228} \mathrm{Ra}$ is applied to determine ventilation time scales of intermediate waters with respect to shelf inputs, and the first profiles of ${ }^{226} \mathrm{Ra}$ in the deep (>2000 m) Canadian Basin provide estimates of bottom water residence times.

Chapter 5 presents an investigation of nutrients, dissolved organic matter, trace metals, and $\mathrm{Ra}$ isotopes in the Mackenzie River Delta, a large Arctic river draining into the Beaufort Sea. Although the Arctic Ocean receives 10\% of global river discharge (Aagard and Carmack, 1989; McClelland et al., 2012), few studies have documented the impact of Arctic estuaries on the ultimate delivery of TEIs to this ocean. This study provides the first measurements of Ra isotopes in a Western Arctic river and greatly improves our understanding of TEIs in an important Arctic estuary. Radium isotope ratios in the estuary indicate solute additions from both suspended sediment and benthic inputs, which also appear to increase the concentrations of nutrients and trace metals. Concentration changes through the delta and estuary provide evidence that solute fluxes based on freshwater concentrations alone are not representative of actual solute delivery to the coastal Arctic Ocean. As a compliment to the river water chemistry, an appendix presents measurements of TEIs in the porewaters of active layer and permafrost sediments collected from the Mackenzie River basin.

Finally, Chapter 6 presents a summary of the results described in this thesis, along with suggestions for future research directions. 


\section{References}

Aagaard, K., Carmack, E.C., 1989. The role of sea ice and other fresh water in the Arctic circulation. J. Geophys. Res. 94, 14485-14498.

Bacon, M.P., Anderson, R.F., 1982. Distribution of thorium isotopes between dissolved and particulate forms in the deep sea. J. Geophys. Res. 87, 2045-2056. doi:10.1029/JC087iC03p02045

Black, E.E., 2017. An investigation of basin-scale controls on upper ocean export and remineralization. Massachusetts Institute of Technology, Woods Hole Oceanographic Institution.

Bourdon, B., Turner, S., Henderson, G.M., Lundstrom, C.C., 2003. Introduction to U-series Geochemistry. Rev. Mineral. Geochemistry 52, 1-21.

Boyle, E., Collier, R., Dengler, A.T., 1974. On the chemical mass- balance in estuaries. Geochim. Cosmochim. Acta 38, 1719-1728. doi:10.1016/0016-7037(74)90188-4

Boyle, E.A., Huested, S.S., Grant, B., 1982. The chemical mass balance of the amazon plume-II. Copper, nickel, and cadmium. Deep Sea Res. Part A, Oceanogr. Res. Pap. 29, 1355-1364. doi:10.1016/0198-0149(82)90013-9

Buesseler, K.O., Bacon, M.P., Cochran, J.K., Livingston, H.D., 1992. Carbon and nitrogen export during the JGOFS North Atlantic Bloom Expiriment estimated from ${ }^{234} \mathrm{Th}:{ }^{238} \mathrm{U}$ disequlibria. Deep. Res. 39, 1,115-1,137.

Campbell, A.C., Palmer, M.R., Klinkhammer, G.., Bowers, T.S., Edmond, J., Lawrence, J.R., Casey, J.F., Thompson, G., Humphris, S., Rona, P., Karson, J.A., 1988. Chemistry of hot springs on the Mid-Atlantic Ridge. Nature 335, 514-519. doi:10.1038/335514a0

Charette, M.A., Gonneea, M.E., Morris, P.J., Statham, P., Fones, G., Planquette, H., Salter, I., Garabato, A.N., 2007. Radium isotopes as tracers of iron sources fueling a Southern Ocean phytoplankton bloom. Deep Sea Res. Part II Top. Stud. Oceanogr. 54, 1989-1998. doi:10.1016/j.dsr2.2007.06.003

Charette, M.A., 2007. Hydrologic forcing of submarine groundwater discharge: Insight from a seasonal study of radium isotopes in a groundwater-dominated salt marsh estuary. Limnol. Oceanogr. 52, 230-239. doi:10.4319/lo.2007.52.1.0230

Charette, M.A., Lam, P.J., Lohan, M.C., Kwon, E.Y., Hatje, V., Jeandel, C., Shiller, A.M., Cutter, G.A., Thomas, A., Boyd, P.W., Homoky, W.B., Milne, A., Thomas, H., Andersson, P.S., Porcelli, D., Tanaka, T., Geibert, W., Dehairs, F., Garcia-Orellana, J., 2016. Coastal ocean and shelf-sea biogeochemical cycling of trace elements and isotopes: lessons learned from GEOTRACES. Philos. Trans. R. Soc. A Math. Phys. Eng. Sci. 374. doi:10.1098/rsta.2016.0076

Charette, M.A., Morris, P.J., Henderson, P.B., Moore, W.S., 2015. Radium isotope distributions during the US GEOTRACES North Atlantic cruises. Mar. Chem. 177, 184-195. doi:10.1016/j.marchem.2015.01.001

Dulaiova, H., Ardelan, M. V., Henderson, P.B., Charette, M.A., 2009. Shelf-derived iron inputs drive biological productivity in the southern Drake Passage. Global Biogeochem. Cycles 23. doi:10.1029/2008GB003406

Edmond, J.M., Measures, C., McDuff, R.E., Chan, L.H., Collier, R., Grant, B., 1979. Ridge crest hydrothermal activity and the balances of the major and minor elements in the ocean: The Galapagos data. Earth Planet. Sci. Lett. 46, 1-18. doi:10.1016/0012-821X(79)90061-X 
Edmond, J.M., Von Damm, K.L., McDuff, R.E., Measures, C.I., 1982. Chemistry of hot springs on the East Pacific Rise and their effluent dispersal. Nature 297, 187-191. doi:10.1038/297187a0

Elsinger, R.J., Moore, W.S., 1980. ${ }^{226}$ Ra behavior in the Pee Dee River-Winyah Bay estuary. Earth Planet. Sci. Lett. 48, 239-249. doi:10.1016/0012-821X(80)90187-9

German, C.R., Campbell, A.C., Edmond, J., 1991a. Hydrothermal scavenging at the MidAtlantic Ridge: Modification of trace element dissolved fluxes. Earth Planet. Sci. Lett. 107, 101-114.

German, C.R., Fleer, A.P., Bacon, M.P., Edmond, J.M., 1991b. Hydrothermal scavenging at the Mid-Atlantic Ridge: Radionuclide distributions. Earth Planet. Sci. Lett. 105, 170-181. doi:10.1016/0012-821X(91)90128-5

German, C.R., Klinkhammer, G.P., Edmond, J.M., Mitra, A., Elderfield, H., 1990. Hydrothermal scavenging of rare-earth elements in the ocean. Nature 345, 516-518. doi: $10.1038 / 345516 \mathrm{a} 0$

Hammond, D.E., Zukin, J.G., Ku, T.-L., 1988. The kinetics of radioisotope exchange between brine and rock in a geothermal system. J. Geophys. Res. Solid Earth 93, 13175-13186. doi:10.1029/JB093iB11p13175

Hansell, D.A., Kadko, D., Bates, N.R., 2004. Degradation of Terrigenous Dissolved Organic Carbon in the Western Arctic Ocean. Science 304, 858-861. doi:10.1126/science.1096175

Jenkins, W.J., Edmond, J.M., Corliss, J.B., 1978. Excess ${ }^{3} \mathrm{He}$ and ${ }^{4} \mathrm{He}$ in Galapagos submarine hydrothermal waters. Nature 272, 156-158. doi:10.1038/272156a0

Kadko, D., 1996. Radioisotopic studies of submarine hydrothermal vents. Rev. Geophys. 34, 349-366. doi:10.1029/96RG01762

Kadko, D., 2017. Upwelling and primary production during the U.S. GEOTRACES East Pacific Zonal Transect. Global Biogeochem. Cycles 31, 218-232. doi:10.1002/2016GB005554

Kadko, D., Aagaard, K., 2009. Glimpses of Arctic Ocean shelf-basin interaction from submarine-borne radium sampling. Deep Sea Res. Part I Oceanogr. Res. Pap. 56, 32-40. doi:10.1016/j.dsr.2008.08.002

Kadko, D., Gronvold, K., Butterfield, D., 2007. Application of radium isotopes to determine crustal residence times of hydrothermal fluids from two sites on the Reykjanes Peninsula, Iceland. Geochim. Cosmochim. Acta 71, 6019-6029. doi:10.1016/j.gca.2007.09.018

Kadko, D., Moore, W.S., 1988. Radiochemical constraints on the crustal residence time of submarine hydrothermal fluids: Endeavour Ridge. Geochim. Cosmochim. Acta 52, 659668. doi:10.1016/0016-7037(88)90328-6

Kadko, D., Muench, R., 2005. Evaluation of shelf-basin interaction in the western Arctic by use of short-lived radium isotopes: The importance of mesoscale processes. Deep. Res. Part II Top. Stud. Oceanogr. 52, 3227-3244. doi:10.1016/j.dsr2.2005.10.008

Karcher, M., Smith, J.N., Kauker, F., Gerdes, R., Smethie, W.M., 2012. Recent changes in Arctic Ocean circulation revealed by iodine-129 observations and modeling. J. Geophys. Res. Ocean. 117. doi:10.1029/2011JC007513

Key, R.M., Stallard, R.F., Moore, W.S., Sarmiento, J.L., 1985. Distribution and Flux of ${ }^{226}$ Ra and ${ }^{228} \mathrm{Ra}$ in the Amazon River Estuary. J. Geophys. Res. 90, 6995-7004. doi:10.1029/JC090iC04p06995

Klunder, M.B., Bauch, D., Laan, P., De Baar, H.J.W., Van Heuven, S., Ober, S., 2012. Dissolved iron in the Arctic shelf seas and surface waters of the central Arctic Ocean: Impact of Arctic river water and ice-melt. J. Geophys. Res. Ocean. 117. doi:10.1029/2011JC007133 
Krest, J.M., Moore, W.S., Rama, 1999. ${ }^{226} \mathrm{Ra}$ and ${ }^{228} \mathrm{Ra}$ in the mixing zones of the Mississippi and Atchafalaya Rivers: indicators of groundwater input. Mar. Chem. 64, 129-152. doi:10.1016/S0304-4203(98)00070-X

Krishnaswami, S., Graystein, W.C., Turekian, K.K., 1982. Radium, Thorium and Radioactive Lead Isotopes in Groundwaters: Application to the in Situ Determination of AdsorptionDesorption Rate Constants and Retardation Factors. Water Resour. Res. 18, 1663-1675.

Lerner, P., Marchal, O., Lam, P.J., Buesseler, K., Charette, M., 2017. Kinetics of thorium and particle cycling along the U.S. GEOTRACES North Atlantic Transect. Deep. Res. Part I Oceanogr. Res. Pap. 125, 106-128. doi:10.1016/j.dsr.2017.05.003

Letscher, R.T., Hansell, D.A., Kadko, D., Bates, N.R., 2013. Dissolved organic nitrogen dynamics in the Arctic Ocean. Mar. Chem. 148, 1-9. doi:10.1016/j.marchem.2012.10.002

Li, Y., Chan, L., 1979. Desorption of Ba and ${ }^{226} \mathrm{Ra}$ from river-borne sediments in the Hudson Estuary. Earth Planet. Sci. Lett. 43, 343-350. doi:10.1016/0012-821X(79)90089-X

Li, Y., Mathieu, G., Biscaye, P., Simpson, H.J., 1977. The Flux of ${ }^{226}$ Ra from estuarine and continental shelf sediments. Earth Planet. Sci. Lett. 37, 237-241. doi:10.1016/0012821X(77)90168-6

Mackenzie, F.T., Garrels, R.M., 1966. Chemical mass balance between rivers and oceans. Am. J. Sci. doi:10.2475/ajs.264.7.507

Martin, J., Meybeck, M., 1979. Elemental mass-balance of material carried by major world rivers. Mar. Chem. 7, 173-206. doi:10.1016/0304-4203(79)90039-2

McClelland, J.W., Holmes, R.M., Dunton, K.H., Macdonald, R.W., 2012. The Arctic Ocean Estuary. Estuaries and Coasts 35, 353-368. doi:10.1007/s12237-010-9357-3

Middag, R., de Baar, H.J.W., Laan, P., Klunder, M.B., 2011. Fluvial and hydrothermal input of manganese into the Arctic Ocean. Geochim. Cosmochim. Acta 75, 2393-2408. doi:10.1016/j.gca.2011.02.011

Moore, C.M., Mills, M.M., Arrigo, K.R., Berman-Frank, I., Bopp, L., Boyd, P.W., Galbraith, E.D., Geider, R.J., Guieu, C., Jaccard, S.L., Jickells, T.D., La Roche, J., Lenton, T.M., Mahowald, N.M., Marañón, E., Marinov, I., Moore, J.K., Nakatsuka, T., Oschlies, A., Saito, M.A., Thingstad, T.F., Tsuda, A., Ulloa, O., 2013. Processes and patterns of oceanic nutrient limitation. Nat. Geosci. 6, 701-710. doi:10.1038/ngeo1765

Moore, W.S., Shaw, T.J., 1998. Chemical signals from submarine fluid advection onto the continental shelf. J. Geophys. Res. 103, 21543-21552.

Moore, W.S., 1981. Radium isotopes in the Chesapeake Bay. Estuar. Coast. Shelf Sci. 12, $713-$ 723. doi:10.1016/S0302-3524(81)80067-9

Moore, W.S., 1992. Radionuclides of the uranium and thorium decay series in the estuarine environment, in: Ivanovich, M., Harmon, R.S. (Eds.), Uranium-Series Disequilibrium: Applications to Earth, Marine, and Environmental Science. Oxford University Press, New York, pp. 397-422.

Moore, W.S., 2000a. Determining coastal mixing rates using radium isotopes. Cont. Shelf Res. 20, 1993-2007. doi:10.1016/S0278-4343(00)00054-6

Moore, W.S., 2000b. Ages of continental shelf waters determined from ${ }^{223} \mathrm{Ra}$ and ${ }^{224} \mathrm{Ra}$. J. Geophys. Res. Ocean. 105, 22117-22122. doi:10.1029/1999JC000289

Moore, W.S., Astwood, H., Lindstrom, C., 1995. Radium isotopes in coastal waters on the Amazon shelf. Geochim. Cosmochim. Acta 59, 4285-4298. doi:10.1016/00167037(95)00242-R 
Moore, W.S., Dymond, J., 1991. Fluxes of ${ }^{226}$ Ra and barium in the Pacific Ocean: The importance of boundary processes. Earth Planet. Sci. Lett. 107, 55-68. doi:10.1016/0012$821 \mathrm{X}(91) 90043-\mathrm{H}$

Moore, W.S., Krest, J., 2004. Distribution of ${ }^{223} \mathrm{Ra}$ and ${ }^{224} \mathrm{Ra}$ in the plumes of the Mississippi and Atchafalaya Rivers and the Gulf of Mexico. Mar. Chem. 86, 105-119. doi:10.1016/j.marchem.2003.10.001

Moore, W.S., Krest, J., Taylor, G., Roggenstein, E., Joye, S., Lee, R., 2002. Thermal evidence of water exchange through a coastal aquifer: Implications for nutrient fluxes. Geophys. Res. Lett. 29. doi:10.1029/2002GL014923

Moore, W.S., Ussler, W., Paull, C.K., 2008. Short-lived radium isotopes in the Hawaiian margin: Evidence for large fluid fluxes through the Puna Ridge. Mar. Chem. 109, 421-430. doi:10.1016/j.marchem.2007.09.010

Resing, J.A., Sedwick, P.N., German, C.R., Jenkins, W.J., Moffett, J.W., Sohst, B.M., Tagliabue, A., 2015. Basin-scale transport of hydrothermal dissolved metals across the South Pacific Ocean. Nature 523, 200-203. doi:10.1038/nature14577

Rodellas, V., Garcia-Orellana, J., Trezzi, G., Masqué, P., Stieglitz, T.C., Bokuniewicz, H., Cochran, J.K., Berdalet, E., 2017. Using the radium quartet to quantify submarine groundwater discharge and porewater exchange. Geochim. Cosmochim. Acta 196, 58-73. doi:10.1016/j.gca.2016.09.016

Rudnicki, M., Elderfield, H., 1992. Helium, radon and manganese at the TAG and Snakepit hydrothermal vent fields, $26^{\circ}$ and $23^{\circ} \mathrm{N}$, Mid-Atlantic Ridge. Earth Planet. Sci. Lett. 113, 307-321. doi:10.1016/0012-821X(92)90136-J

Rutgers van der Loeff, M., Key, R.M., Scholten, J., Bauch, D., Michel, A., $1995 .{ }^{228}$ Ra as a tracer for shelf water in the Arctic Ocean. Deep Sea Res. Part II Top. Stud. Oceanogr. 42, 1533-1553.

Sanial, V., Kipp, L.E., Henderson, P.B., van Beek, P., Reyss, J.-L., Hammond, D.E., Hawco, N.J., Saito, M.A., Resing, J.A., Sedwick, P., Moore, W.S., Charette, M.A., 2018. Radium228 as a tracer of dissolved trace element inputs from the Peruvian continental margin. Mar. Chem. 201, 20-34. doi:10.1016/j.marchem.2017.05.008

Sharp, J.H., Culberson, C.H., Church, T.M., 1982. The chemistry of the Delaware estuary. General considerations. Limnol. Oceanogr. 27, 1015-1028. doi:10.4319/lo.1982.27.6.1015

Shelley, R.U., Roca-Martí, M., Castrillejo, M., Sanial, V., Masqué, P., Landing, W.M., van Beek, P., Planquette, H., Sarthou, G., 2017. Quantification of trace element atmospheric deposition fluxes to the Atlantic Ocean ( $>40^{\circ} \mathrm{N}$; GEOVIDE, GEOTRACES GA01) during spring 2014. Deep Sea Res. Part I Oceanogr. Res. Pap. 119, 34-49. doi:10.1016/j.dsr.2016.11.010

Shiller, A.M., Boyle, E.A., 1987. Variability of dissolved trace metals in the Mississippi River. Geochim. Cosmochim. Acta 51, 3273-3277. doi:10.1016/0016-7037(87)90134-7

Sholkovitz, E.R., Boyle, E.A., Price, N.B., 1978. The removal of dissolved humic acids and iron during estuarine mixing. Earth Planet. Sci. Lett. 40, 130-136. doi:10.1016/0012$821 X(78) 90082-1$

Smith, J.N., McLaughlin, F.A., Smethie, W.M., Moran, S.B., Lepore, K., 2011. Iodine-129, ${ }^{137} \mathrm{Cs}$, and CFC-11 tracer transit time distributions in the Arctic Ocean. J. Geophys. Res. 116. doi:10.1029/2010JC006471

Tagliabue, A., Aumont, O., DeAth, R., Dunne, J.P., Dutkiewicz, S., Galbraith, E., Misumi, K., Moore, J.K., Ridgewell, A., Sherman, E., Stock, C., Vichi, M., Volker, C., Yool, A., 2016. 
How well do global ocean biogeochemistry models simulate dissolved iron distributions? Global Biogeochem. Cycles 30, 149-174. doi:10.1002/2015GB005289

Tagliabue, A., Bopp, L., Dutay, J.-C., Bowie, A.R., Chever, F., Jean-Baptiste, P., Bucciarelli, E., Lannuzel, D., Remenyi, T., Sarthou, G., Aumont, O., Gehlen, M., Jeandel, C., 2010.

Hydrothermal contribution to the oceanic dissolved iron inventory. Nat. Geosci. 3, 252-256. doi:10.1038/ngeo818

van Beek, P., François, R., Conte, M., Reyss, J.L., Souhaut, M., Charette, M., $2007 .{ }^{228} \mathrm{Ra} /{ }^{226} \mathrm{Ra}$ and ${ }^{226} \mathrm{Ra} / \mathrm{Ba}$ ratios to track barite formation and transport in the water column. Geochim. Cosmochim. Acta 71, 71-86. doi:10.1016/j.gca.2006.07.041

Von Damm, K.L., Edmond, J.M., Grant, B., Measures, C.I., Walden, B., Weiss, R.F., 1985. Chemistry of submarine hydrothermal solutions at $21^{\circ} \mathrm{N}$, East Pacific Rise. Geochim. Cosmochim. Acta 49, 2197-2220. doi:10.1016/0016-7037(85)90222-4

Wang, D., Henrichs, S.M., Guo, L., 2006. Distributions of nutrients, dissolved organic carbon and carbohydrates in the western Arctic Ocean. Cont. Shelf Res. 26, 1654-1667.

doi:10.1016/j.csr.2006.05.001 

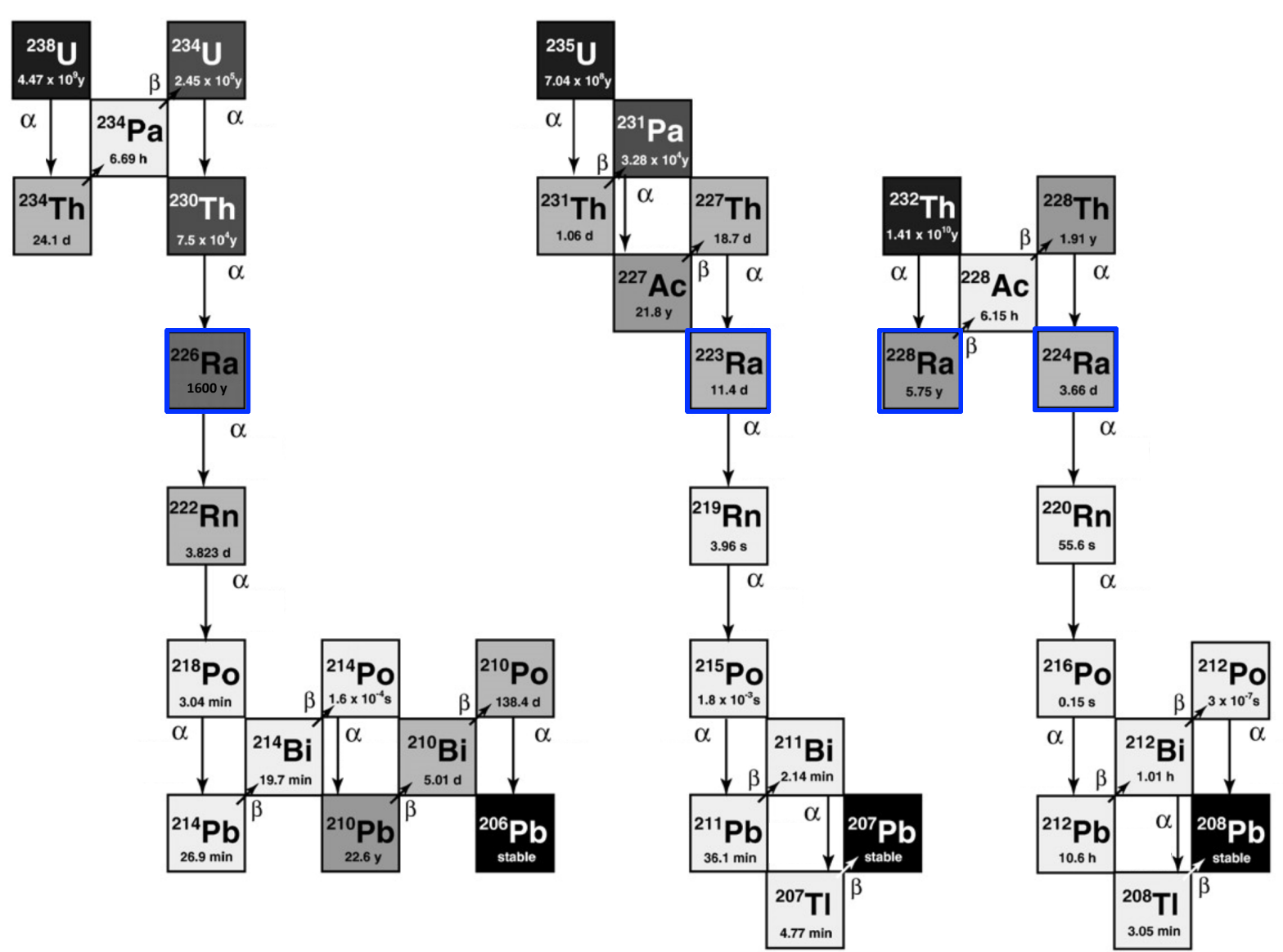

Figure 1. Diagram of the ${ }^{238} \mathrm{U},{ }^{235} \mathrm{U}$, and ${ }^{232}$ Th decay chains, modified from Bourdon et al. (2003). Radium isotopes are outlined in blue. Diagonal arrows represent beta $(\beta)$ decay events, straight arrows represent alpha $(\alpha)$ decay events. The greyscale reflects the half-life of the isotope, with darker shades indicating longer half-lives. 


\title{
Chapter 2: Radium isotopes as tracers of hydrothermal inputs and neutrally buoyant plume dynamics in the deep ocean
}

\begin{abstract}
Radium ( $\mathrm{Ra}$ ) isotopes are enriched in hydrothermal fluids, have a wide range of half-lives and are minimally impacted by scavenging removal processes; therefore, they have the ability to provide key information on the fate of trace elements in both near- and far- field hydrothermal plumes. To expand our understanding of Ra isotopes and their usefulness as tracers of hydrothermal activity, we measured Ra isotopes in both high and low temperature vent fluids, and in neutrally buoyant plumes. The time scales of plume transport were derived from Ra isotopes in neutrally buoyant plumes emanating from $15^{\circ} \mathrm{S}$ on the East Pacific Rise (EPR) and the TAG vent field on the Mid Atlantic Ridge (MAR) relative to their source ratio in hightemperature vent fluids. In near-field ( $<100 \mathrm{~km}$ from vent) neutrally buoyant plumes, the shortlived $\mathrm{Ra}$ isotopes $\left({ }^{223} \mathrm{Ra}: \mathrm{t}_{1 / 2}=11.4 \mathrm{~d},{ }^{224} \mathrm{Ra}\right.$ : $\left.\mathrm{t}_{1 / 2}=3.66 \mathrm{~d}\right)$ suggest plume ages of $\sim 1$ month and $\sim 5$ days over the EPR and MAR, respectively. Farther afield ( $>100 \mathrm{~km}$ from vent), the distribution of the longer-lived ${ }^{228} \mathrm{Ra}\left(\mathrm{t}_{1 / 2}=5.75 \mathrm{y}\right)$ is indicative of hydrothermal plumes with different points of origin along the EPR. Radium-228 derived plume ages were used to calculate the residence time of hydrothermal dissolved Fe, which was in the range of $9-20 \mathrm{y}$ (with an upper limit of $50 \mathrm{y}$ depending on model assumptions). These are shorter than typical deep ocean Fe residence times, a result of scavenging removal of Fe from the neutrally buoyant plume during transport. This study highlights the utility of Ra isotopes in providing time-scales of hydrothermally derived trace element cycling in the deep ocean.
\end{abstract}

This chapter was originally published in Marine Chemistry by Elsevier in 2018 and is reproduced here with their permission.

Kipp, L.E., Sanial, V., Henderson, P.B., van Beek, P., Reyss, J.-L., Hammond, D.E., Moore, W.S., Charette, M.A., 2018. Radium isotopes as tracers of hydrothermal inputs and neutrally buoyant plume dynamics in the deep ocean. Mar. Chem. 201, 51-65.

doi:10.1016/j.marchem.2017.06.011 


\subsection{INTRODUCTION}

Since their discovery in 1977, seafloor hydrothermal vents have been recognized as important sources and sinks for elements in the deep ocean (Corliss et al., 1978; Edmond et al., 1979). During the hydrothermal circulation of seawater through the crust, water-rock reactions enrich circulating fluids in certain metals, gases, and radionuclides (Campbell et al., 1988; Edmond et al., 1982; Jenkins et al., 1978; Kadko and Moore, 1988; Von Damm et al., 1985). Radionuclide enrichment processes include the alteration of basalt by hydrothermal fluids, in-situ decay of parent isotopes, and recoil effects from the decay of parents in the basalt (Hammond et al., 1988; Kadko and Moore, 1988; Krishnaswami et al., 1982). These properties have been used to constrain the time scales of processes such as the circulation of fluids through the crust, formation of chimneys, and particle scavenging and settling rates (see Kadko, 1996 for a review).

In the case of radium isotopes, elevated activities of ${ }^{228} \mathrm{Ra}\left(\mathrm{t}_{1 / 2}=5.75 \mathrm{y}\right)$ and ${ }^{226} \mathrm{Ra}\left(\mathrm{t}_{1 / 2}=\right.$ $1600 \mathrm{y}$ ) have been observed in high-temperature hydrothermal fluids of the Mid-Atlantic Ridge (MAR; Rudnicki and Elderfield, 1992) and the Endeavour Segment (Kadko and Moore, 1988) and Cleft Segment (Kadko, 1996) of the Juan de Fuca Ridge (JDFR). As high-temperature, low$\mathrm{pH}$ modified seawater interacts with basalt, Ra may be released into the circulating fluids. The activity observed in vented fluids is determined by fluid residence time, circulation depth in the crust, and composition of the host rock.

For example, the activity ratio of ${ }^{228} \mathrm{Ra} /{ }^{226} \mathrm{Ra}$ has been used to measure fluid crustal residence times (e.g. Kadko and Moore, 1988; Kadko et al., 2007). Because they are solubilized during basalt alteration, radium isotopes are useful in constraining the time elapsed between the onset of high-temperature basalt-seawater interaction and venting at the seafloor. The half-life of ${ }^{228} \mathrm{Ra}$ makes it an appropriate tracer for this process, which has been estimated to occur on time scales of $<5 \mathrm{y}$. Normalizing the activity of ${ }^{228} \mathrm{Ra}$ to the long-lived ${ }^{226} \mathrm{Ra}$ corrects for any secondary chemical reactions or removal processes that may occur during circulation (Kadko and Moore, 1988; Kadko et al., 2007).

There have been fewer studies involving the short-lived isotopes ${ }^{223} \mathrm{Ra}\left(\mathrm{t}_{1 / 2}=11.4 \mathrm{~d}\right)$ and

${ }^{224} \mathrm{Ra}\left(\mathrm{t}_{1 / 2}=3.66 \mathrm{~d}\right)$ in hydrothermal systems. Moore et al. (2008) observed activities of ${ }^{223} \mathrm{Ra}$ well in excess of its parent ${ }^{227} \mathrm{Ac}\left(\mathrm{t}_{1 / 2}=21.8 \mathrm{y}\right)$ above the Puna Ridge (Hawaii, USA), a site with low-temperature hydrothermal activity, and used the inventory of this isotope to quantify the fluid flux through the ridge. They proposed that excess ${ }^{223} \mathrm{Ra}$ may be useful in assessing the relative importance of low-temperature hydrothermal venting to ocean chemistry. Kadko et al. (2007) used the ${ }^{224} \mathrm{Ra} /{ }^{223} \mathrm{Ra}$ activity ratios in fluids in the Reykjanes hydrothermal system to conclude that mixing and secondary precipitation reactions during upwelling were minimal, which permitted a tighter constraint on the water-rock ratio in the Reykjanes system.

Above hydrothermally active ridges, neutrally buoyant plumes are an important source of trace elements and isotopes (TEIs) to the deep ocean (e.g. Lilley et al., 1995). The scavenging and oxidation processes that occur within the plume can affect the concentrations of TEIs that are eventually delivered farther afield (Edmond et al., 1979; German et al., 1991a, 1991b, 1990). Therefore, in order to understand the ultimate impact of hydrothermal vents on deep ocean chemistry, it is important to constrain neutrally buoyant plume transport rates away from the ridge as well as the removal rates of TEIs from the plume.

In the past, ${ }^{222} \mathrm{Rn}$ has been used to estimate spreading rates of neutrally buoyant plumes; using this method Runicki and Elderfield (1992) found that plume material sampled $1 \mathrm{~km}$ away 
from the TAG hydrothermal vent field was 1-10 days old. The half-lives of ${ }^{223} \mathrm{Ra}$ and ${ }^{224} \mathrm{Ra}$, being similar to that of ${ }^{222} \mathrm{Rn}$, make these isotopes another possible tool for dating young (daysmonths) plume material. For older plumes (years-decades), ${ }^{228} \mathrm{Ra}\left(\mathrm{t}_{1 / 2}=5.75 \mathrm{y}\right.$ ) can be used in a similar manner. In both applications, the Ra isotope is normalized to either a longer-lived $\mathrm{Ra}$ isotope (e.g. ${ }^{226} \mathrm{Ra}$ ) or a conservative tracer (e.g. ${ }^{3} \mathrm{He}$ ) in order to correct for the effects of dilution such that any decrease in Ra activity is primarily due to decay. Most importantly, these $\mathrm{Ra}$ ages can be applied to determine the transport rates and residence times of trace metals in the plume.

Here we add to and review measurements of the Ra quartet in both high and low temperature vent fluids. We then combine the measurements of Ra in high-temperature hydrothermal vent fluids with recent measurements of the Ra quartet in neutrally buoyant plumes over the East Pacific Rise (EPR) and MAR to investigate the utility of Ra isotopes as tracers of hydrothermal plume dynamics.

\subsection{METHODS}

\subsubsection{Sample collection}

Samples of the Trans Atlantic Geotraverse (TAG) neutrally buoyant plume were collected aboard the $R / V$ Knorr at Station 16 of the 2011 US GEOTRACES North Atlantic Transect (GA03; $26.136 \mathrm{~N}, 44.826 \mathrm{~W}$ ), $0.15 \mathrm{~km}$ northeast from the TAG active hydrothermal mound (26.135 N, 44.825 W; Fig. 1a). Results of the Ra measurements conducted on this cruise have been previously reported in Charette et al. (2015). Samples from the EPR were collected on the $R / V$ Thomas Thompson during the 2013 US GEOTRACES East Pacific Zonal Transect (GP16). This transect was designed to capture the large hydrothermal plume known to emanate from this ridge at $15^{\circ} \mathrm{S}$ (e.g. Lupton, 1998; Lupton and Craig, 1981) and follow its westward transport. The station locations of the western half of the GP16 transect are shown in Figure 1c.

On both GA03 and GP16, samples were collected using McLane in situ pumps (McLane WRT-LV) deployed on a 3/8" plastic coated Vectran line. Seawater was pumped through $1 \mu \mathrm{m}$ filters to remove particles, and then passed through a $\mathrm{MnO}_{2}$ coated cellulose cartridge to collect dissolved Ra, Th, and Ac isotopes (see Henderson et al., 2013 for details of cartridge preparation). Pumps were programmed to run for $4 \mathrm{~h}$, filtering $1500-1700 \mathrm{~L}$ of seawater at an average flow rate of $6.5 \mathrm{~L} \mathrm{~min}^{-1}$. After collection, cartridges were rinsed with Ra-free water and dried with filtered compressed air to remove excess moisture. To determine the cartridge scavenging efficiency, smaller volume samples of ${ }^{226} \mathrm{Ra}(15-25 \mathrm{~L})$ were collected using a Niskin bottle mounted above the pumps, and the activities of Ra measured on these samples were compared to those determined on the cartridges. The average cartridge collection efficiency was $66 \pm 17 \%(1 \sigma, \mathrm{n}=347)$.

Because it was not possible to sample endmember vent fluids on the GA03 and GP16 cruises, fluids used for this study were collected from other hydrothermal systems on several cruises in the northeast Pacific (Fig. 1b). Specific locations include vents within the High Rise vent field (HRF), Main Endeavour Field (MEF), and Clam Bed site, all on the Endeavour Segment of the Juan de Fuca Ridge (Delaney et al., 1992; Robigou et al., 1993), from Axial Seamount (Embley et al., 1990), and from off-axis vents at Baby Bare Seamount and Ocean Drilling Program (ODP) Hole 1026B (Davis and Becker, 1998; Davis et al., 1992). All high temperature vent samples were collected with a 1-liter titanium syringe following the procedure 
of Edmond et al. (1979). Low temperature, large volume samples were collected by pumping water into a $120 \mathrm{~L}$ barrel originally filled with deionized water. Radium was concentrated from the large volume samples by passing the sample through a column of $\mathrm{MnO}_{2}$ coated fiber at a flow rate $<1 \mathrm{~L} \mathrm{~min}^{-1}$.

Vent fluids were also collected during a 1991 voyage of the $R / V$ Atlantis (AII-125, Leg 33) using the $H O V$ Alvin include high-temperature vent fluids from the Godzilla, Boardwalk, Park Place, Ventnor, and Fairycastle edifices (HRF) and samples of diffuse flow from the Clam Bed site, located between the Main Endeavour and High Rise fields. Additional fluid samples were collected during a 2002 expedition of the R/V Atlantis (ATV7L20) using the ROV Jason II. At the MEF, high temperature fluids were sampled at the Dudley edifice, and low temperature fluids were sampled from the Dudley edifice and the Easter Island area (just north of the Peanut edifice). Low temperature fluids were also collected from Axial Seamount (Bag-city area), Baby Bare Seamount and ODP Hole 1026B, located about $6 \mathrm{~km}$ north of the Baby Bare Seamount. On the Baby Bare Seamount, basalt groundwater was sampled by driving a piston core barrel into the weathered basalt (Johnson, 2003). The ROV attached a hose to the end of the probe and allowed the water flow to flush a $120 \mathrm{~L}$ barrel originally filled with DI water. These samples are designated as Probe 3 and Probe 4 and were re-sampled in 2003 using the same procedures.

\subsubsection{Sample analysis}

\subsubsection{Analysis of Ra isotopes on large volume water column samples}

Dissolved Ra isotopes were measured using the Radium Delayed Coincidence Counter (RaDeCC) system (Moore and Arnold, 1996). Samples were first counted on board the ship less than 24 hours after collection to measure the short-lived ${ }^{223} \mathrm{Ra}$ and ${ }^{224} \mathrm{Ra}$. Cartridges were then reanalyzed after 4 weeks and again after 2 months to determine the activities of ${ }^{224} \mathrm{Ra}$ and ${ }^{223} \mathrm{Ra}$ supported by ${ }^{228} \mathrm{Th}\left(\mathrm{t}_{1 / 2}=1.91 \mathrm{y}\right)$ and ${ }^{227}$ Ac, respectively. The efficiency of the RaDeCC system was determined using a set of cartridge standards as described in Henderson et al. (2013).

After RaDeCC analysis was complete, the cartridges were ashed in a muffle furnace at $820^{\circ} \mathrm{C}$ for 48 hours. The cartridge ash was then transferred to polystyrene vials, sealed with epoxy (to prevent ${ }^{222} \mathrm{Rn}$ loss), and counted on high purity, well-type germanium detectors to measure ${ }^{228} \mathrm{Ra}$ using the lines of ${ }^{228} \mathrm{Ac}(338,911$, and $969 \mathrm{keV})$ and ${ }^{226} \mathrm{Ra}$ using the lines of ${ }^{214} \mathrm{~Pb}$ (295 and $352 \mathrm{keV}$ ) and ${ }^{214} \mathrm{Bi}(609 \mathrm{keV})$. Gamma analyses for the GP16 water column samples were conducted at the Laboratoire Souterrain de Modane (LSM, France). The lab is located within a tunnel through the French Alps, which serve to minimize detector background from cosmic radiation thereby reducing detection limits (Reyss et al., 1995). Three blank samples were analyzed twice during the course of sample analysis, and contained no measurable ${ }^{228} \mathrm{Ra}$ activity within an uncertainty of $0.004 \mathrm{dpm}(2 \sigma)$. Due to limited detector time at this facility, we were unable to measure ${ }^{228} \mathrm{Ra}$ on all samples. Samples were selected for analysis based on their proximity to the hydrothermal plume, as determined by local maxima in other tracers $\left({ }^{3} \mathrm{He}_{\mathrm{xs}}\right.$, Jenkins et al. 2018; ${ }^{227}$ Ac, Hammond et al., 2016). All samples collected at station 18 (nearest to the EPR), and 9 samples collected within the core of the neutrally buoyant plume at stations west of the EPR were chosen for analysis. All analyses for the GA03 water column samples were completed at Woods Hole Oceanographic Institution following the procedures described above (see Charette et al., 2015). 
Detector efficiencies were determined by measuring ashed cartridge standards, which were prepared by soaking cartridges in a standard solution containing ${ }^{226} \mathrm{Ra}$ and ${ }^{232} \mathrm{Th}$ with daughters in equilibrium. Analytical uncertainties are reported as one sigma.

\subsubsection{Determination of ${ }^{226} \mathrm{Ra}$ on small volume water column samples}

A small volume $(15-25 \mathrm{~L})$ of water from the Niskin bottles mounted above the McLane pumps was filtered through a $\mathrm{MnO}_{2}$ coated acrylic fiber, which quantitatively scavenges $\mathrm{Ra}$ from seawater. Fibers were rinsed with Ra-free water, partially dried, and sealed in a fiber housing for at least two weeks to allow for ${ }^{222} \mathrm{Rn}$ ingrowth. Samples were then analyzed via ${ }^{222} \mathrm{Rn}$ emanation and scintillation counting (Key et al., 1979). On average, samples were counted for approximately 200 minutes, resulting in an analytical error of less than 5\%. Fiber standards containing $20 \mathrm{dpm}{ }^{226} \mathrm{Ra}$ (NIST certified) were analyzed in the same way as the samples; standard reproducibility was $\sim 3 \%$ for GA03 and $\sim 4 \%$ for GP16.

\subsubsection{Measurement of ${ }^{226} \mathrm{Ra}$ in plume particles}

To investigate the possible loss of Ra by precipitation with Mn-oxides in the hydrothermal plume, we measured ${ }^{226} \mathrm{Ra}$ on small size $(1-51 \mu \mathrm{m})$ particles collected on quartz fiber (Whatman QMA) filters from the McLane pumps. One sample collected at the depth of the maximum ${ }^{226} \mathrm{Ra}$ activity in the neutrally buoyant plume at station 16 on GA03 (3400 m) and all samples from station 20 on GP16 $(n=15$, collected between $2000-3140$ m) were selected for analysis. Filters were dampened with Ra-free water and sealed in He-purged fiber cartridges to allow for ${ }^{222} \mathrm{Rn}$ ingrowth. Samples were then analyzed following the ${ }^{222} \mathrm{Rn}$ scintillation procedure outlined above and blank corrected using unused QMA filters prepared in the same manner as the samples. We note that this method can only detect ${ }^{226} \mathrm{Ra}$ on particle surfaces where ${ }^{222} \mathrm{Rn}$ can emanate into the cartridge headspace; these particle ${ }^{226} \mathrm{Ra}$ activities should therefore be considered lower limit values, as there may be additional ${ }^{226} \mathrm{Ra}$ within the crystal lattices.

\subsubsection{Analysis of vent fluid samples}

For all vent fluid samples except those collected in 1991, dissolved Ra isotopes were measured within days of collection using the RaDeCC procedure described in section 2.2.2.1. Prior to processing the 2002 Dudley samples were diluted ten-fold with DI water to prevent possible $\mathrm{BaSO}_{4}$ precipitation. In several cases a second column followed the first; activities on the second column were negligible. After $\mathrm{RaDeCC}$ the $\mathrm{MnO}_{2}$ fiber samples were leached to remove $\mathrm{Ra}$ and then precipitated with $\mathrm{BaSO}_{4}$. The precipitate was then analyzed on well-type germanium gamma detectors to measure ${ }^{228} \mathrm{Ra}$ and ${ }^{226} \mathrm{Ra}$.

For samples collected on the 1991 expedition (pre RaDeCC), a known volume of water from the sampling syringe $(0.5$ to $1.1 \mathrm{~L})$ was transferred to a beaker and $400 \mathrm{mg}$ Ba carrier was added. $\mathrm{BaSO}_{4}$ was precipitated by adding an excess of $\mathrm{H}_{2} \mathrm{SO}_{4}$. The precipitate was allowed to settle and the water was decanted and reserved. The precipitate was transferred to a small vial and immediately measured at sea in a well-shaped germanium detector (Moore, 1984). Each sample was re-analyzed at least 3 times over the next several days and again at least 3 weeks later. The initial counts were used to calculate the activity of ${ }^{224} \mathrm{Ra}$ in the sample through the measurement of its daughter, ${ }^{212} \mathrm{~Pb}\left(\mathrm{t}_{1 / 2}=10.2 \mathrm{~h}\right)\left(\right.$ Elsinger et al., 1982). We found that the ${ }^{212} \mathrm{~Pb}$ 
activity of the sample did not change much during the first 30 hours, indicating that ${ }^{212} \mathrm{~Pb}$ was in close radioactive equilibrium with ${ }^{224} \mathrm{Ra}$ in the sample and that little fractionation of $\mathrm{Ra}$ and $\mathrm{Pb}$ occurred during the $\mathrm{BaSO}_{4}$ precipitation. The final count of the sample was used to calculate the

${ }^{226} \mathrm{Ra}$ and ${ }^{228} \mathrm{Ra}$ activities. We estimate one sigma counting errors for ${ }^{224} \mathrm{Ra}$ and ${ }^{228} \mathrm{Ra}$ to be about $8 \%$, for ${ }^{223} \mathrm{Ra}$ to be about $12 \%$, and for ${ }^{226} \mathrm{Ra}$ to be about $6 \%$. In five cases the water reserved from the first precipitation was reprocessed by adding more Ba carrier. In these cases the Ra activity was below the detection limit, indicating complete precipitation during the initial measurement.

\subsection{RESULTS AND DISCUSSION}

\subsubsection{Radium in vent fluids}

The Ra activities observed in the vent fluids are reported in Table 1, along with all known published measurements of short-lived Ra activities in hydrothermal fluids (Kadko et al., 2007; Kadko and Butterfield, 1998; Moore et al., 2008). The new data presented herein provide a substantial addition to the existing catalog of short-lived Ra activities in hydrothermal fluids by approximately doubling the number of available ${ }^{224} \mathrm{Ra}$ measurements and quadrupling the number of ${ }^{223} \mathrm{Ra}$ measurements.

As hydrothermal fluids circulate through the crust, particle reactive species like Th remain adsorbed to mineral surfaces whereas the more soluble Ra will partition into the aqueous phase. The partitioning of Ra between the aqueous and solid phase is controlled by the composition of the solid phase as well as the salinity, temperature and $\mathrm{pH}$ of the water. For example, when riverine sediments enter an estuary, partial desorption of Ra from clay particles occurs in the saline water (Li et al., 1977). Additional studies show that substantial desorption of Ra from clay occurs as temperature changes from $2{ }^{\circ} \mathrm{C}$ to $70^{\circ} \mathrm{C}$ (Rama and Moore, 1996). We suspect that at temperatures $>300^{\circ} \mathrm{C}$ and $\mathrm{pH}<4$, conditions typical of hydrothermal fluids, virtually all of the Ra released during rock dissolution and alpha recoil will remain in the aqueous phase.

In general, the activities of all four Ra isotopes increased with increasing temperature (Fig. 2), consistent with enhanced input of Ra in high-temperature, low-pH fluids from midocean ridge basalts (MORB; Campbell et al., 1988; Edmond et al., 1982, 1979; Kadko and Moore, 1988; Turekian and Cochran, 1986). The ${ }^{223} \mathrm{Ra}$ and ${ }^{224} \mathrm{Ra}$ activities presented in this study are similar to values previously observed on the North Cleft of the JDFR and the Reykjanes Ridge.

There is a wide range of variability among the high-temperature samples, though here we only present ${ }^{228} \mathrm{Ra}$ and ${ }^{226} \mathrm{Ra}$ data from studies that included at least one short-lived Ra isotope. Radium-226 activities between $2.40-89.1 \mathrm{dpm} \mathrm{L}{ }^{-1}$ and $12.6-16.6 \mathrm{dpm} \mathrm{L}^{-1}$ have been observed on the JDFR and MAR, respectively (Kadko, 1996; Kadko and Butterfield, 1998; Rudnicki and Elderfield, 1992), while ${ }^{228}$ Ra activities between $2.03-62.87 \mathrm{dpm} \mathrm{L}^{-1}$ have been recorded on the JDFR (Kadko and Butterfield, 1998; Kadko and Moore, 1988). Some of the variability in activities may be explained by the surrounding basalt composition; Kadko and Butterfield (1998) found that basalts on the southern JDFR were more enriched in ${ }^{226} \mathrm{Ra}$ than those on the Endeavour segment, a reflection of the basalt age. Two samples collected 11 years apart from the Dudley high temperature vent contained virtually the same activities of ${ }^{228} \mathrm{Ra}$ and ${ }^{226} \mathrm{Ra}$. 
To correct for the effects of dilution and secondary precipitation reactions, we normalize the shorter-lived $\mathrm{Ra}$ isotopes to the longer-lived isotopes (Fig. 3). In high temperature fluids (excluding Clam Bed), the ${ }^{224} \mathrm{Ra} /{ }^{228} \mathrm{Ra}$ activity ratio was near one, while in low temperature fluids most of the observed ${ }^{224} \mathrm{Ra} /{ }^{228} \mathrm{Ra}$ activity ratios were elevated- up to 5.5 at the HRF of the Endeavour Segment (Fig. 3a). At the Clam Bed site, where diffuse flow was observed at a small white smoker, the activity ratio was 14 . In contrast, the low temperature sample collected on the Puna Ridge had the lowest ${ }^{224} \mathrm{Ra} /{ }^{228} \mathrm{Ra}$ activity ratio, 0.25 .

The ${ }^{223} \mathrm{Ra} /{ }^{226} \mathrm{Ra}$ activity ratios measured on the JDFR, Puna Ridge, and Axial Seamount fell between $0.048-0.084$, similar to previous measurements of $0.016-0.044$ on the Reykjanes Ridge (Kadko et al., 2007). In these samples there is no clear distinction between high- and lowtemperature fluids. In contrast, samples collected at the Baby Bare Seamount exhibit ${ }^{223} \mathrm{Ra} /{ }^{226} \mathrm{Ra}$ activity ratios of $0.19-0.41$, significantly higher than the values observed in other vent fluids.

The residence time of high temperature fluid in the crust is on the order of years (Kadko and Butterfield, 1998; Kadko et al., 2007), which is long enough to allow secular equilibrium (activity ratio $=1$ ) to develop between ${ }^{224} \mathrm{Ra}$ and ${ }^{228} \mathrm{Ra}$ during transit to the surface. This assumes that ${ }^{228} \mathrm{Th}$ is not significantly redistributed within the crust and that the ${ }^{232} \mathrm{Th}$ source for ${ }^{228} \mathrm{Ra}$ is proximal. In the case of ${ }^{223} \mathrm{Ra} /{ }^{226} \mathrm{Ra}$, the expected vent fluid ratio is the MORB ${ }^{231} \mathrm{~Pa} /{ }^{226} \mathrm{Ra}$ ratio, which is typically between $0.02-0.11$ (Bourdon et al., 2000; Lundstrom et al., 1999; Lundstrom et al., 1998; Sims et al., 2002). In addition to the ${ }^{231} \mathrm{~Pa}$ already present in the basalt, it has been noted that ${ }^{231} \mathrm{~Pa}$ from seawater may be deposited on mineral surfaces during hydrothermal circulation; this would lead to circulating fluids enriched in ${ }^{227} \mathrm{Ac}$ and ${ }^{223} \mathrm{Ra}$ (Kipp et al., 2015; Moore et al., 2008). This process could explain the existence of fluid ${ }^{223} \mathrm{Ra} /{ }^{26} \mathrm{Ra}$ ratios that are higher than the ${ }^{231} \mathrm{~Pa} /{ }^{226} \mathrm{Ra}$ ratios observed in MORB. Alternatively, if the subsurface fluid residence time is short compared to the half-lives of ${ }^{228} \mathrm{Ra}$ and ${ }^{226} \mathrm{Ra}$, then the recoil input of the short-lived isotopes would exceed that of the long lived isotopes, resulting in fluid ${ }^{223} \mathrm{Ra} /{ }^{226} \mathrm{Ra}$ and ${ }^{224} \mathrm{Ra} /{ }^{228} \mathrm{Ra}$ ratios well above those of the solid source. If the primary radium input mechanism is weathering and dissolution of radium-rich phases, the activity ratios may be lower than the solid source ratio (Hammond et al., 1988). Because the activity ratios observed here are similar to those expected in the basalt, we cannot conclude which process dominates the release of $\mathrm{Ra}$ in this system.

The distinction between the activity ratios in Baby Bare and ODP Hole 1026B fluids versus on-axis low-temperature fluids suggests that different processes are controlling the shortlived isotope enrichments at these locations. At the Baby Bare and ODP sites, both the ${ }^{224} \mathrm{Ra} /{ }^{228} \mathrm{Ra}$ and ${ }^{223} \mathrm{Ra} /{ }^{226} \mathrm{Ra}$ activity ratios are elevated, while the low-temperature samples collected from the Main Endeavour Field and the Axial Seamount only exhibit elevated ${ }^{224} \mathrm{Ra} /{ }^{228} \mathrm{Ra}$ activity ratios. There are multiple mechanisms that could lead to ${ }^{224} \mathrm{Ra} /{ }^{228} \mathrm{Ra}$ activity ratios greater than 1 . For example, if fluid residence times are short and $\mathrm{Ra}$ is frequently flushed from the system, the shorter-lived isotopes will regenerate faster than the longer-lived isotopes due to their shorter half-lives (Charette, 2007); in this scenario both the ${ }^{224} \mathrm{Ra} /{ }^{228} \mathrm{Ra}$ and ${ }^{223} \mathrm{Ra} /{ }^{226} \mathrm{Ra}$ activity ratios will be elevated. Alternatively, some of the ${ }^{228} \mathrm{Ra}$ in circulating fluids may become sorbed to the vent walls or precipitated along the flow path, reducing the ${ }^{228} \mathrm{Ra}$ activity in solution; this sorbed ${ }^{228} \mathrm{Ra}$ would then decay to produce ${ }^{228} \mathrm{Th}$, which would remain adsorbed, and ${ }^{224} \mathrm{Ra}$, which would be added back into circulating fluids through recoil. Because the half-life of ${ }^{224} \mathrm{Ra}$ is short and sorption is slow, it is unlikely that ${ }^{224} \mathrm{Ra}$ would be removed by sorption before decay. Thus ${ }^{224} \mathrm{Ra} /{ }^{228} \mathrm{Ra}$ ratios greater than 1 could be the result of significant ${ }^{228} \mathrm{Ra}$ sorption or precipitation, and efficient ${ }^{224} \mathrm{Ra}$ recoil. The final mechanism that could 
increase ${ }^{224} \mathrm{Ra} /{ }^{228} \mathrm{Ra}$ activity ratios is fluid transport of ${ }^{228} \mathrm{Th}$ with high sorption in the final portion of the flow path. Any ${ }^{228}$ Th that is introduced to the walls of the final path would produce ${ }^{224} \mathrm{Ra}$, which could be recoiled in to circulating fluids and result in fluid ${ }^{224} \mathrm{Ra}$ activities greater than those that would be produced by in situ ${ }^{228} \mathrm{Ra}$ decay alone. However, due to the high particle affinity of ${ }^{228} \mathrm{Th}$, it is unlikely that this isotope would be carried to the end of the flow path without being sorbed during transport.

The Baby Bare outcrop and ODP Hole 1026b are located on 3.5 million year old crust $100 \mathrm{~km}$ to the east of the Juan de Fuca Ridge. At this location, a hydrothermal siphon acts to move water from the Grizzly Bare outcrop through a crustal aquifer to the Baby Bare outcrop (Fisher et al., 2003; Wheat et al., 2000; Winslow et al., 2016; Winslow and Fisher, 2015). As water moves through the aquifer and accumulates soluble $\mathrm{Ra}$, the ${ }^{223} \mathrm{Ra}$ and ${ }^{224} \mathrm{Ra}$ in the aquifer will regenerate faster than ${ }^{228} \mathrm{Ra}$ and ${ }^{226} \mathrm{Ra}$ due to their shorter half-lives (Charette, 2007). This leaves the circulating fluids with ${ }^{223} \mathrm{Ra} /{ }^{226} \mathrm{Ra}$ and ${ }^{224} \mathrm{Ra} /{ }^{228} \mathrm{Ra}$ activity ratios well in excess of the rock ratio, as described in the first scenario outlined above. The similarity of values for ODP Hole 1026B fluids suggests similar processes are occurring at that site.

The other low-temperature samples shown in Figure 3 were diffuse flows collected on the Puna Ridge and at the Dudley Edifice (MEF), the Easter Island area (MEF), and Bag City area (South Rift Zone, Axial Seamount). The Puna Ridge sample does not exhibit elevated ${ }^{224} \mathrm{Ra} /{ }^{228} \mathrm{Ra}$ or ${ }^{223} \mathrm{Ra} /{ }^{226} \mathrm{Ra}$ activity ratios, while the Dudley, Easter Island, and Bag City samples have elevated ${ }^{224} \mathrm{Ra} /{ }^{228} \mathrm{Ra}$ activity ratios, but do not exhibit high ${ }^{223} \mathrm{Ra} /{ }^{226} \mathrm{Ra}$ activity ratios. We propose that for the latter group, elevated ${ }^{224} \mathrm{Ra} /{ }^{228} \mathrm{Ra}$ ratios are acquired through the second mechanism outlined above as fluids percolate through sulfates in the near sub-surface prior to venting. Hydrothermal sulfates are enriched in Ra through barite co-precipitation (Reyes et al., 1995; Stakes and Moore, 1991). Circulating fluids will become preferentially enriched in ${ }^{224} \mathrm{Ra}$ over ${ }^{223} \mathrm{Ra}$ because ${ }^{224} \mathrm{Ra}$ has a Ra parent $\left({ }^{228} \mathrm{Ra}\right)$ that accumulates in the barite. Radium-228 decays to produce ${ }^{228} \mathrm{Th}$, which is insoluble and remains adsorbed to the mineral surface, even if sulfates are replaced by sulfides (Stakes and Moore, 1991). The adsorbed ${ }^{228} \mathrm{Th}$ then decays to produce ${ }^{224} \mathrm{Ra}$, which is solubilized through recoil and diffusion. Circulating fluids acquire a high ${ }^{224} \mathrm{Ra} /{ }^{228} \mathrm{Ra}$ ratio because (1) after the mineral structures have been flushed with fluids the shorter-lived ${ }^{224} \mathrm{Ra}$ will regenerate faster than ${ }^{228} \mathrm{Ra}$, similar to the aquifer system described above, and (2) mobilization of ${ }^{228} \mathrm{Ra}$ during the replacement of sulfates with sulfides will leave sulfide structures enriched in ${ }^{228} \mathrm{Th}$ (and ${ }^{224} \mathrm{Ra}$ ) over ${ }^{228} \mathrm{Ra}$. In contrast, we do not expect barite to be a source of ${ }^{223} \mathrm{Ra}$ because the larger charge and smaller atomic radius of $\mathrm{Ac}\left(3^{+}, \mathrm{r}=111 \mathrm{pm}\right)$ make this element less likely than $\operatorname{Ra}\left(2^{+}, r=148 \mathrm{pm}\right)$ to substitute for $\mathrm{Ba}\left(2^{+}, \mathrm{r}=142 \mathrm{pm}\right)$ in the crystal structure, although the mechanisms of REE enrichment in barite may not depend solely on co-precipitation (Guichard et al., 1979). We therefore assume there is no production of ${ }^{223} \mathrm{Ra}$ in barite, and any initial ${ }^{223} \mathrm{Ra}$ would have long since decayed, thus the ${ }^{223} \mathrm{Ra} /{ }^{226} \mathrm{Ra}$ ratio of hydrothermal fluids that circulate through sulfates will be preserved.

The ${ }^{224} \mathrm{Ra} /{ }^{228} \mathrm{Ra}$ activity ratio measured at Clam Bed is much higher than any of the other vent fluid samples $\left({ }^{223} \mathrm{Ra}\right.$ was not measured). Clam Bed is an isolated vent field located between the Main Endeavour and High Rise vent fields, and is characterized as a lower temperature (sample was $262^{\circ} \mathrm{C}$ ) white smoker surrounded by barite-rich structures (Reyes et al., 1995). This sample was collected from within a bed of tubeworms immediately after the ROV broke off the top of a spire, allowing fluid to flow freely. In spite of the care taken to collect the fluid sample it contained over $40 \%$ seawater, based on the $\mathrm{Mg}^{2+}$ concentration. A second sample from the same spire collected a few minutes later contained virtually $100 \%$ seawater; ${ }^{224} \mathrm{Ra}$ and ${ }^{228} \mathrm{Ra}$ were 
below detection. We suspect that ${ }^{228}$ Th was enriched on the surface of the tubeworms and surrounding barite due to continued decay of sequestered or possibly precipitated ${ }^{228} \mathrm{Ra}$. This would produce relatively high activities of ${ }^{224} \mathrm{Ra}$ in the seawater initially surrounding the tubeworms. When flow was initiated by breaking the spire, the first sample collected contained a large fraction of seawater enriched in ${ }^{224} \mathrm{Ra}$; however, the second sample only contained fresh seawater that had not been in contact with the tubeworms or barite long enough to acquire an elevated ${ }^{224} \mathrm{Ra}$ signal. Because the sample may represent secondary enrichment of ${ }^{224} \mathrm{Ra}$, we omit it from our discussion of endmembers.

In high-temperature hydrothermal systems, $\mathrm{Mg}$ is quantitatively removed from solution (e.g. Bischoff and Dickson, 1975; Mottl, 1983); thus, Mg concentration can be used to determine the high-temperature end-member trace element concentrations (Von Damm et al., 1985). By examining the $\mathrm{Ra}$ activity ratios in samples collected at high temperatures $\left(>250^{\circ} \mathrm{C}\right)$ containing low $\mathrm{Mg}(<20 \mathrm{mM})$, we can establish typical ${ }^{224} \mathrm{Ra} /{ }^{228} \mathrm{Ra}$ and ${ }^{223} \mathrm{Ra} /{ }^{226} \mathrm{Ra}$ activity ratios that we would expect to find in high-temperature vent fluids (Fig. 4). Three of the samples collected along the Cleft Segment of the JDFR by Kadko and Butterfield (1998) do not have accompanying temperature data but are included as examples of endmember ratios because the low $\mathrm{Mg}$ concentrations in these samples indicate that they likely represent high temperature vent fluids. The average ${ }^{224} \mathrm{Ra} /{ }^{228} \mathrm{Ra}$ activity ratio was $1.1 \pm 0.5(1 \sigma, \mathrm{n}=14)$, which is consistent with the long residence time of circulating fluids in MORB discussed earlier. While the composition of the crust does differ along ridges, our assumption is that because ${ }^{224} \mathrm{Ra}$ and ${ }^{228} \mathrm{Ra}$ are from the same decay series, fluid residence time in the crust, not host rock geochemistry, should be the main driver of the vent fluid ratio. Mineral precipitation of phases such as barite may sequester some ${ }^{228} \mathrm{Ra}$ from circulating fluids, and subsequent alpha recoil of ${ }^{224} \mathrm{Ra}$ progeny may cause fluid ratios of ${ }^{224} \mathrm{Ra} /{ }^{228} \mathrm{Ra}$ greater than 1 ; however, this appears to be more important in lowtemperature systems, as highlighted above.

There are fewer data for the ${ }^{223} \mathrm{Ra} /{ }^{226} \mathrm{Ra}$ activity ratio, but the observed ratios of 0.044 and 0.073 are similar to the ${ }^{231} \mathrm{~Pa} /{ }^{226} \mathrm{Ra}$ activity ratio in MORB, suggesting that the ratio of these two $\mathrm{Ra}$ isotopes in hydrothermal fluids is controlled mainly by the surrounding basalt composition. More measurements of the ${ }^{223} \mathrm{Ra} /{ }^{226} \mathrm{Ra}$ activity ratio at vent sites in different geological settings are necessary to better constrain this ratio in different rock compositions.

\subsubsection{Radium in neutrally buoyant plumes}

\subsubsection{Particulate radium activities}

Particulate ${ }^{226} \mathrm{Ra}$ in the TAG neutrally buoyant plume at station 16 on GA03 was $0.01 \pm$ $0.01 \mathrm{dpm} 100 \mathrm{~L}^{-1}$ at $3400 \mathrm{~m}, 0.04 \%$ of the dissolved ${ }^{226} \mathrm{Ra}$ activity at this depth. Particulate ${ }^{226} \mathrm{Ra}$ in the plume emanating from the EPR at station 20 on GP16 ranged from $0.004 \pm 0.002 \mathrm{dpm}$ $100 \mathrm{~L}^{-1}$ (above the neutrally buoyant plume) to $0.019 \pm 0.001 \mathrm{dpm} 100 \mathrm{~L}^{-1}$ (in the core of the plume). We were not able to detect particulate ${ }^{228} \mathrm{Ra}$ due to the low activities, however we expect that its solid-solution partitioning would be on the same order as ${ }^{226} \mathrm{Ra}$. These activities are 0.02 $-0.06 \%$ of the dissolved ${ }^{226}$ Ra measured on the corresponding fiber samples (Fig. 5). Because particulate ${ }^{226} \mathrm{Ra}$ was $<0.1 \%$ of dissolved ${ }^{226} \mathrm{Ra}$ for all samples measured, we consider the scavenging of Ra on particles in the far-field plume to be a negligible loss of Ra. However, we recognize that we may be underestimating the importance of this process because our analytical method does not detect ${ }^{226} \mathrm{Ra}$ locked within crystal lattices. 
The suspended particles $(1-51 \mu \mathrm{m})$ in the neutrally buoyant plumes sampled at these two stations were primarily Fe-oxyhydroxides (52\% at station 16 on GA03, Lam et al., 2015; 60\% at station 20 on GP16, Lam et al., 2018) and were not highly enriched in Mn-oxides (no $\mathrm{MnO}_{2}$ enrichment at station 16 on GA03, Lam et al., 2015; <10\% at station 20 of GP16, Lam et al., 2018). Radium has a high affinity for Mn-oxides (Moore and Reid, 1973; Reid et al., 1979), but is not scavenged to a significant degree by Fe-oxyhydroxides (Moore and Reid, 1973); hence, the low particulate activities of $\mathrm{Ra}$ are thus consistent with the composition of the plume particles at these two stations.

When hydrothermal fluids are vented, some Ra will be removed from the plume through co-precipitation with barite (Reyes et al., 1995; Stakes and Moore, 1991) and scavenging on to Mn-oxides (Moore and Reid, 1973; Reid et al., 1979). If the Ra removal is rapid compared to the isotope decay rate, this will lower the activities of Ra isotopes in vented hydrothermal fluids, but not affect the $\mathrm{Ra}$ isotope activity ratios because these precipitation and scavenging reactions are unlikely to result in isotope fractionation.

\subsubsection{Dissolved radium activities}

Elevated activities of Ra isotopes were measured in the neutrally buoyant plume emanating from the TAG hydrothermal vent field on the MAR (Fig. 6; Charette et al., 2015). The decreased light transmission and increased ${ }^{3} \mathrm{He}_{\mathrm{xs}}$ at $3300-3400 \mathrm{~m}$ indicate the influence of the neutrally buoyant hydrothermal plume at this depth (Fig. 6a; ${ }^{3} \mathrm{He}_{\mathrm{xs}}$ measured by Jenkins et al., 2014). The shorter-lived ${ }^{223} \mathrm{Ra}$ and ${ }^{224} \mathrm{Ra}$ activities (Fig. 6b) are those measured in excess of their parent radionuclides, ${ }^{227} \mathrm{Ac}$ and ${ }^{228} \mathrm{Th}$, respectively. Hydrothermal ${ }^{228} \mathrm{Ra}$ activities (Fig. 6c) were calculated by subtracting the average background ${ }^{228} \mathrm{Ra}$ activity from nearby off-axis stations $\left(0.12 \pm 0.14 \mathrm{dpm} 100 \mathrm{~L}^{-1}, 1 \sigma, \mathrm{n}=45\right)$. We assumed the background ${ }^{228} \mathrm{Ra}$ activity to be constant and did not propagate the standard deviation with the measurement errors on individual samples. Unlike ${ }^{228} \mathrm{Ra}$, deep ocean ${ }^{226} \mathrm{Ra}$ activities are largely controlled by water mass mixing. Therefore, hydrothermal ${ }^{226} \mathrm{Ra}$ activities (Fig. 6c) were determined by interpolating the expected ${ }^{226} \mathrm{Ra}$ activity at the depth of the plume (based on samples above and below the hydrothermal influence) and subtracting this value from the observed activities. To account for the error in the interpolation, a $25 \%$ error was assigned to hydrothermal ${ }^{226} \mathrm{Ra}$ activities. When compared to the transmissometry and ${ }^{3} \mathrm{He}_{\mathrm{xs}}$ profiles, the hydrothermal $\mathrm{Ra}$ anomalies appear about $100 \mathrm{~m}$ deeper in the water column; this may be due to cast-to-cast variability in the plume height (Rudnicki et al., 1994 showed that the neutrally buoyant plume at TAG can vary by as much as $150 \mathrm{~m}$ over a 9 hour period) or to the lower sampling resolution of the pump casts (16 depths for pumps v. 24 depths for other tracers).

The Ra profiles indicate clear hydrothermal influence on ${ }^{224} \mathrm{Ra},{ }^{228} \mathrm{Ra}$, and ${ }^{226} \mathrm{Ra}$, while a strong benthic source of ${ }^{223} \mathrm{Ra}$ obscures any hydrothermal signal of this isotope. It has recently been shown that ${ }^{227} \mathrm{Ac}$, the parent of ${ }^{223} \mathrm{Ra}$, is enriched in hydrothermal vent fluids (Kipp et al., 2015); scavenging of ${ }^{227} \mathrm{Ac}$ and ${ }^{231} \mathrm{~Pa}$ onto plume particles and subsequent deposition along the ridge could act as a source of ${ }^{223} \mathrm{Ra}$ and explain the unusually high benthic activity of this isotope.

Hydrothermal influence is also apparent on the profiles of Ra measured over the EPR (Fig. 7). The patterns of light transmission and ${ }^{3} \mathrm{He}_{\mathrm{xs}}$ (Fig. 7a; ${ }^{3} \mathrm{He}_{\mathrm{xs}}$ measured by Jenkins et al., 2018) indicate the presence of a neutrally buoyant hydrothermal plume between 2400 and $2500 \mathrm{~m}$. The

background ${ }^{228} \mathrm{Ra}$ activity in this basin (based on stations to the east of the ridge) was $0.048 \pm$ 
$0.029 \mathrm{dpm} 100 \mathrm{~L}^{-1}(1 \sigma, \mathrm{n}=13)$. Similar to the MAR, the background corrected long-lived ${ }^{228} \mathrm{Ra}$ and ${ }^{226} \mathrm{Ra}$ were enriched in the neutrally buoyant plume (Fig. 7c), however at this station there was a measurable anomaly in ${ }^{223} \mathrm{Ra}$, while any potential hydrothermal input of ${ }^{224} \mathrm{Ra}$ was obscured by (1) an apparent large benthic source of this isotope and (2) plume ages that were significantly longer than its mean life (Fig. 7b).

\subsubsection{On-axis plume dynamics}

Normalizing ${ }^{224} \mathrm{Ra}_{\mathrm{xs}}$ in the core of the TAG plume to the long-lived ${ }^{228} \mathrm{Ra}$ to correct for mixing loss, combined with an estimate of the ${ }^{224} \mathrm{Ra} /{ }^{228} \mathrm{Ra}$ activity ratio in endmember vent fluid (from section 2.3.1), allows for the calculation of the time elapsed since venting $(t)$, assuming the flow path is continuous and steady state:

$$
\left[\frac{{ }^{224} \mathrm{Ra}_{\mathrm{xs}}}{{ }^{228} \mathrm{Ra} \mathrm{ht}}\right]_{\text {plume }}=\left[\frac{{ }^{224} \mathrm{Ra}}{{ }^{228} \mathrm{Ra}}\right]_{\text {vent fluids }} \mathrm{e}^{-\lambda_{224} \mathrm{t}}
$$

where $\left[\frac{{ }^{224} \mathrm{Ra}_{\mathrm{xs}}}{{ }^{228} \mathrm{Ra}_{\mathrm{ht}}}\right]_{\text {plume }}$ is the activity ratio measured in the neutrally buoyant plume, $\left[\frac{{ }^{224} \mathrm{Ra}}{{ }^{228} \mathrm{Ra}}\right]_{\text {vent fluids }}$ is the activity ratio in the undiluted vent fluids, and $\lambda_{224}$ is the ${ }^{224} \mathrm{Ra}$ decay constant. Because high-temperature vent fluids become diluted with surrounding ambient seawater as the plume rises, the ${ }^{224} \mathrm{Ra} /{ }^{228} \mathrm{Ra}$ ratio in the plume was calculated using the excess activities of these isotopes. Vent fluid Ra isotope measurements were not made during the GA03 transect so we use the values from section 2.3.1. Because ${ }^{224} \mathrm{Ra}$ and ${ }^{228} \mathrm{Ra}$ are from the same decay series and should be in secular equilibrium in vent fluids, we assumed that the ${ }^{224} \mathrm{Ra} /{ }^{228} \mathrm{Ra}$ activity ratio in TAG fluids is similar to fluids collected from other vents (Figure 4a, section 2.3.1).

Using a vent fluid ${ }^{224} \mathrm{Ra} /{ }^{228} \mathrm{Ra}$ activity ratio of $1.1 \pm 0.5$, and the ${ }^{224} \mathrm{Ra}_{\mathrm{xs}} /{ }^{228} \mathrm{Ra}$ ratio of $0.38 \pm$ 0.32 observed at $3400 \mathrm{~m}$ above TAG, the age of the plume at the time of sampling was estimated to be $2.7-7.5$ days old (Fig. 8a). The range in this value reflects the uncertainty in the starting vent fluid activity ratio, but the measurement error on the ratio observed in the neutrally buoyant plume could also lead to slightly younger or older ages. This relatively young age is consistent with the location of our sampling station, which was $0.15 \mathrm{~km}$ northeast of the TAG active mound. On the MAR, the high axial valley walls can restrict the lateral movement of the neutrally buoyant plume (German and Von Damm, 2006; German et al., 1998); as a result, some aged hydrothermal material can be recycled in the plume and mixed with new, young hydrothermal fluids (German and Sparks, 1993). If older material were recycled in the plume it would have a low ${ }^{224} \mathrm{Ra}_{\mathrm{xs}} / 228 \mathrm{Ra}$ ratio and therefore an older apparent age. This process does not appear to have been important for the TAG samples. Unfortunately a large benthic source of ${ }^{223} \mathrm{Ra}_{\mathrm{xs}}$ (Kipp et al., 2015) obscured the hydrothermal signal of this isotope to the point that the plume ${ }^{223} \mathrm{Ra}_{\mathrm{xs}} /{ }^{226} \mathrm{Ra}$ was higher than the initial vent fluid ratio. Hence, this $\mathrm{Ra}$ isotope pair may not be used as a further constraint on the TAG plume age.

For the EPR plume, we applied the ${ }^{223} \mathrm{Ra}_{\mathrm{xs}} /{ }^{226} \mathrm{Ra}$ activity ratio because there was no discernable hydrothermal ${ }^{224} \mathrm{Ra}_{\mathrm{xs}}$ anomaly. The few measurements of the ${ }^{223} \mathrm{Ra} /{ }^{226} \mathrm{Ra}$ ratio in high-temperature fluids were made on the Reykjanes Ridge and JDFR, but the similarity of these ratios to ${ }^{231} \mathrm{~Pa} /{ }^{226} \mathrm{Ra}$ ratios observed on the EPR ( 0.04; Bourdon et al., 2000; Lundstrom et al., 
1999; Sims et al., 2002) suggest that these values represent a reasonable range of initial ${ }^{223} \mathrm{Ra} /{ }^{226} \mathrm{Ra}$ ratios for EPR vent fluid. Using these two values $(0.044$ and 0.073$)$, and the ${ }^{223} \mathrm{Ra}_{\mathrm{xs}}:{ }^{226} \mathrm{Ra}$ activity ratio of $0.010 \pm 0.009$ observed at $2400 \mathrm{~m}$ over the EPR, the age of the plume was estimated to be $24-32$ days old (Fig. 8b). This is consistent with the lack of ${ }^{224} \mathrm{Ra}_{\mathrm{xs}}$, which would have decayed below background by $\sim 5$ half-lives or $\sim 18$ days. Further, unlike the MAR, EPR plumes are not confined to the axial valley (Fitzsimmons et al., 2014; German and Von Damm, 2006; Klinkhammer and Hudson, 1986; Resing et al., 2015; Wu et al., 2011) such that age calculations are less likely to be biased by the presence of younger material. If the neutrally buoyant plume was moving laterally at a rate of $0.2-0.5 \mathrm{~cm} \mathrm{~s}^{-1}$ (Hautala and Riser, 1993), then an age of $24-32$ days indicates that the plume was sampled $4-14 \mathrm{~km}$ from the site of venting.

\subsubsection{Off-axis plume dynamics}

\subsubsection{Spreading rate of the neutrally buoyant plume originating on the EPR}

The longer half-life of ${ }^{228} \mathrm{Ra}$ makes this isotope an appropriate tracer of off-axis plume dynamics. The ${ }^{228} \mathrm{Ra}$ activities between $2450-2550 \mathrm{~m}$ in the GP16 plume were used to determine the rate at which the neutrally buoyant plume was transported away from the ridge (Fig. 9). To correct for the effects of dilution and mixing, the activities of ${ }^{228} \mathrm{Ra}$ were normalized to ${ }^{3} \mathrm{He}_{\mathrm{xs}}$ (measured by Jenkins et al., 2018) and each was corrected for its respective background concentration in the deep Pacific. The spreading rate of the neutrally buoyant plume was then determined from the slope of the exponential curve of the ${ }^{228} \mathrm{Ra} /{ }^{3} \mathrm{He}_{\mathrm{xs}}$ ratio, as shown in Equation 2:

$$
\frac{\left({ }^{228} \mathrm{Ra}\right)_{\mathrm{x}}}{\left[{ }^{3} \mathrm{He} \mathrm{es}_{\mathrm{x}}\right]_{\mathrm{x}}}=\frac{\left({ }^{228} \mathrm{Ra}\right)_{0}}{\left[{ }^{3} \mathrm{He}_{\mathrm{xs}}\right]_{0}} \cdot \mathrm{e}^{-\mathrm{bx}}
$$

where $\frac{\left({ }^{228} \mathrm{Ra}\right)_{0}}{\left[{ }^{3} \mathrm{He}_{\mathrm{xs}}\right]_{0}}$ is the background-corrected initial ratio over the ridge crest, $\frac{\left({ }^{228} \mathrm{Ra}\right)_{\mathrm{x}}}{\left[{ }^{3} \mathrm{He}_{\mathrm{xs}}\right]_{\mathrm{x}}}$ is the background-corrected ratio at a distance, $x$, from the ridge, and the slope, $b$, represents the ${ }^{228} \mathrm{Ra}$ decay constant $\left(\lambda_{228}\right)$ divided by the velocity of the spreading plume $(v)$, as shown in Equation 3:

$$
\mathrm{b}=\frac{\lambda_{228}}{v}
$$

The curve fits were weighted by the measurement error on the individual ${ }^{228}$ Ra activities.

The GP16 transect was designed to follow the hydrothermal signal emanating from the EPR, so it is difficult to determine the background concentrations of these species based on data from this transect alone. Further, to the west of the ridge, ${ }^{228} \mathrm{Ra}$ was only measured within the core of the plume. As a test of the model's sensitivity to the background correction, we examined model results under a range of background assumptions for both ${ }^{228} \mathrm{Ra}$ and ${ }^{3} \mathrm{He}_{\mathrm{xs}}$. Given the net westward transport of the plume in this region (Lupton, 1998), the ${ }^{3} \mathrm{He}_{\mathrm{xs}}$ concentrations to the west of GP16 may be considered the minimum ${ }^{3} \mathrm{He}_{\mathrm{xs}}$ background. Station $245\left(18.58^{\circ} \mathrm{N}\right.$, $167.58^{\circ} \mathrm{E}$ ) on the World Ocean Circulation Experiment section P21 (1994) was located approximately $4400 \mathrm{~km}$ west of GP16 station 36 ; the ${ }^{3} \mathrm{He}_{\mathrm{xs}}$ concentration at this station was $0.677 \pm 0.009 \mathrm{fM}$ (Millero et al., 1994). To our knowledge there are no available measurements 
of ${ }^{228} \mathrm{Ra}$ in the deep western Pacific, however ${ }^{228} \mathrm{Ra}$ should not vary much in the deep ocean interior away from benthic and coastal inputs. Consequently, the minimum ${ }^{228} \mathrm{Ra}$ activity observed between $1000-3000 \mathrm{~m}$ to the east of the ridge (GP16 stations 11-17) was used as the minimum background ${ }^{228}$ Ra activity $\left(0.023 \pm 0.023 \mathrm{dpm} 100 \mathrm{~L}^{-1}\right.$; observed at $2250 \mathrm{~m}$ at station 11). As there was no measurable analysis blank (see Section 2.2.1), this background ${ }^{228} \mathrm{Ra}$ is likely derived from benthic inputs that have been transported vertically through mixing or laterally from topographic highs to the north and south of the transect. The background ${ }^{228} \mathrm{Ra}$ supported by water column ${ }^{232} \mathrm{Th}$ decay alone is negligible since deep ocean ${ }^{232} \mathrm{Th}$ activities are $10^{-4} \mathrm{dpm} \mathrm{100L^{-1 }}$ (Roy-Barman et al., 1996). The maximum possible background concentrations of ${ }^{3} \mathrm{He}_{\mathrm{xs}}$ and ${ }^{228} \mathrm{Ra}$ are the lowest concentrations observed in the plume; the ${ }^{3} \mathrm{He}_{\mathrm{xs}}$ concentration at $2500 \mathrm{~m}$ at station 36 was $1.040 \pm 0.005 \mathrm{fM}$, and the lowest ${ }^{228}$ Ra activity in the measured plume samples was $0.066 \pm 0.024 \mathrm{dpm} 100 \mathrm{~L}^{-1}$ at station 23 . Finally, as an estimate of the local background, we used the average values to the east of the ridge that do not appear to have been hydrothermally influenced: ${ }^{3} \mathrm{He}_{\mathrm{xs}}$ and ${ }^{228} \mathrm{Ra}$ between $1000-3000 \mathrm{~m}$ at stations $11-17$ (0.91 \pm

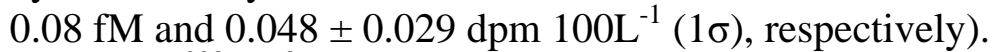

The ${ }^{228} \mathrm{Ra} /{ }^{3} \mathrm{He}_{\mathrm{xs}}$ ratio after making each of the three background corrections (referred to hereafter as "min", "max", and "east") was highest over the ridge crest at station 18, and decreased away from the ridge due to decay of ${ }^{228} \mathrm{Ra}$ (Fig. 10). However, approximately $1300 \mathrm{~km}$ from the EPR, there was an increase in ${ }^{228} \mathrm{Ra} /{ }^{3} \mathrm{He}_{\mathrm{xs}}$, Fe and Mn (Resing et al., 2015), suggesting an additional input of younger hydrothermal material at this location. This finding is supported by the abundance of hydrothermal vents on this ridge crest and the prevailing westward currents at this latitude (Hautala and Riser, 1993; Lupton, 1998; Talley and Johnson, 1994). Further, the multitude of hydrothermal plumes near $15^{\circ} \mathrm{S}$ are known to be focused by the deep circulation patterns into one westward moving jet (Lupton, 1998). The ${ }^{231} \mathrm{~Pa} /{ }^{230} \mathrm{Th}$ activity ratio was also elevated at stations 25 and 26 compared to adjacent stations, indicating an input of younger plume material (Pavia et al., 2016). The apparent younger tracer signals at station 25 indicate that a 1-D steady-state approach may not be applicable for the entire section west of the ridge crest. We therefore use only the stations $<1000 \mathrm{~km}$ from the ridge to calculate the spreading rate of the neutrally buoyant plume.

When the minimum background concentrations of ${ }^{3} \mathrm{He}_{\mathrm{xs}}$ and ${ }^{228} \mathrm{Ra}$ were assumed, the plume spreading rate was $0.40 \mathrm{~cm} \mathrm{~s}^{-1}\left(\mathrm{r}^{2}=0.50\right)$; using background concentrations to the east of the ridge yielded a similar rate $\left(0.25 \mathrm{~cm} \mathrm{~s}^{-1}, \mathrm{r}^{2}=0.63\right)$. When the maximum background concentrations were used in the model, the spreading rate was slower, $0.08 \mathrm{~cm} \mathrm{~s}^{-1}\left(\mathrm{r}^{2}=0.88\right)$. These values are in reasonable agreement with RAFOS floats, which recorded westward transport of $0.3 \mathrm{~cm} \mathrm{~s}^{-1}$ (Lupton and Jenkins, 2017), and numerical physical models that predict current speeds of $0.2-0.5 \mathrm{~cm} \mathrm{~s}^{-1}$ at this depth and latitude (Hautala and Riser, 1993). In addition, these results agree well with a spreading rate of $0.37 \mathrm{~cm} \mathrm{~s}^{-1}$ reported by Hammond et al. (2016) using ${ }^{227}$ Ac measurements from GP16. Although the coarse resolution of our sampling does not allow the calculation of definitive spreading rates along the entire transect, the ${ }^{228} \mathrm{Ra}$ distributions clearly indicate the presence of multiple hydrothermal plumes along the GP16 track.

\subsubsection{Residence time of $\mathrm{Fe}$ in the off- axis plume originating on the EPR}

We examined the relationship between $\mathrm{Fe}$ and ${ }^{228} \mathrm{Ra}$ in samples collected in the neutrally buoyant plume up to $2200 \mathrm{~km}$ away from the EPR during GP16 (Fig. 11; Fe from Resing et al., 
2015). The data coalesce into two groupings: (1) high Fe concentrations and ${ }^{228} \mathrm{Ra}$ activities within $100 \mathrm{~km}$ of the ridge crest and (2) lower concentrations over $100 \mathrm{~km}$ from the ridge. The concentrations of $\mathrm{Fe}$ and activities of $\mathrm{Ra}$ in the near-field plume are significantly greater than those in the far-field plume at the $95 \%$ confidence level $(\mathrm{p}<0.05)$.

To assign a time-scale to Fe removal from the plume, the apparent ${ }^{228} \mathrm{Ra}$-derived age of the plume at a given distance from the ridge crest can be calculated using the same approach as for ${ }^{224} \mathrm{Ra}$ in Equation 1, where the ${ }^{228} \mathrm{Ra} /{ }^{3} \mathrm{He}_{\mathrm{xs}}$ ratio in the neutrally buoyant plume over the ridge is taken as the initial ratio. Because the ${ }^{228} \mathrm{Ra}$ tracer operates on time scales of years, decay during transport along the ridge is unlikely to appreciably affect the initial ${ }^{228} \mathrm{Ra}^{3} \mathrm{He}_{\mathrm{xs}}$ ratio, but variation in the ${ }^{228} \mathrm{Ra} /{ }^{3} \mathrm{He}_{\mathrm{xs}}$ ratio between vents would impact the calculated rate. To our knowledge, no studies have examined the variation in this ratio along a ridge. Kadko and Butterfield (1998) examined the ${ }^{228} \mathrm{Ra} /{ }^{226} \mathrm{Ra}$ activity ratio of vent fluids along the JDFR and found that the activity ratio was similar in samples separated by $<1.5^{\circ}$ of latitude, but was more variable over greater distances. We also assume that the ${ }^{228} \mathrm{Ra} /{ }^{3} \mathrm{He}_{\mathrm{xs}}$ ratio in vent fluids is constant through time; previous measurements of ${ }^{228} \mathrm{Ra}$ on the JDFR and Reykjanes Ridge provide evidence that the ${ }^{228} \mathrm{Ra}$ activity of the same vent is consistent on time scales $<10$ years (Table 1; Kadko and Butterfield, 1998; Kadko et al., 2007), although longer time series and accompanying ${ }^{3} \mathrm{He}_{\mathrm{xs}}$ concentrations are not available.

The ${ }^{228}$ Ra-derived ages for GP16 stations west of the EPR under the three background assumption scenarios are reported in Table 2. Because the ${ }^{228} \mathrm{Ra} /{ }^{3} \mathrm{He}_{\mathrm{xs}}$ ratio at station 18 is being used as the initial ratio, the age of station 18 in all cases is assumed to be zero. At station 20, the plume is estimated to be $2.4-5.5$ years old, and at station 21 the plume age is $5.2-11.1 \mathrm{y}$. In the max background case, the ${ }^{228}$ Ra activity at station 23 was used as the background activity, thus the hydrothermal ${ }^{228} \mathrm{Ra}$ at this station is zero and an age cannot be calculated (but must be greater than $\sim 25-30$ years). However, the min and east background assumptions suggest that the age at this station may be as young as $5.5-9.0$ years.

The age of the plume at stations 25 and 28 is surprisingly young given the distance of these stations from the ridge crest. For example, at station 25 , located $\sim 1350 \mathrm{~km}$ from station 18 , the plume is estimated to be $2.7-5.4$ years old; if this material was transported directly from station 18 , current speeds of $0.8-1.6 \mathrm{~cm} \mathrm{~s}^{-1}$ would be required. While currents along the JDFR and the southern EPR $\left(>25^{\circ} \mathrm{S}\right.$ ) may reach speeds greater than $1 \mathrm{~cm} \mathrm{~s}^{-1}$ (Cannon et al., 1991; Fujio and Imasato, 1991), those near $15^{\circ} \mathrm{S}$ are not expected to be above $0.5 \mathrm{~cm} \mathrm{~s}^{-1}$ (Faure and Speer, 2012; Hautala and Riser, 1993; Johnson and Talley, 1997). It is therefore likely that some of the hydrothermal material was sourced from a different vent; further, we cannot rule out that such a vent had a different initial ${ }^{228} \mathrm{Ra} /{ }^{3} \mathrm{He}_{\mathrm{xs}}$ ratio. Because the age of the plume at these stations is likely an underestimate, we exclude stations 25 and 28 from our discussion of the far-field Fe removal trends below.

Rapid near-field removal is most apparent when $\mathrm{Fe}$ (normalized to ${ }^{3} \mathrm{He}_{\mathrm{xs}}$ ) is plotted against the ${ }^{228}$ Ra-derived plume age (Fig. 12). The dichotomy between the steep slope of the Fe-age relationship in the young plume and the shallower slope in the older plume suggests that there are different removal processes with contrasting removal rates acting on $\mathrm{Fe}$ in the near- and farfield plumes. The Fe concentrations used in the $\mathrm{Fe} /{ }^{3} \mathrm{He}_{\mathrm{xs}}$ ratios have been corrected for the background concentration of Fe in the deep Pacific using the same approaches as those described above for ${ }^{228} \mathrm{Ra}$ and ${ }^{3} \mathrm{He}_{\mathrm{xs}}$. The minimum background concentration was assumed to be $0.42 \pm$ $0.04 \mathrm{nM}$; this is the lowest concentration of Fe observed between $1000-3000 \mathrm{~m}$ to the east of the EPR (measured at $2400 \mathrm{~m}$ at station 11), and is similar to the minimum Fe concentrations 
observed in the deep North Pacific (Boyle et al., 2005; Bruland et al., 1994). The maximum possible background concentration is assumed to be the concentration observed at $2500 \mathrm{~m}$ at station 36: $0.61 \pm 0.06 \mathrm{fM}$. The average concentration to the east of the ridge was $0.70 \pm 0.13 \mathrm{fM}$ $(1 \sigma)$, but because this concentration is higher than at station $36,0.61 \mathrm{fM}$ was used in both the max and east background corrections.

If $\mathrm{Fe}$ behaved conservatively in the plume, both $\mathrm{Fe}$ and ${ }^{3} \mathrm{He}_{\mathrm{xs}}$ would be lost at the same rate and the $\mathrm{Fe} /{ }^{3} \mathrm{He}_{\mathrm{xs}}$ ratio would remain constant through time. Alternatively, if $\mathrm{Fe}$ was lost to scavenging as well as dilution, the $\mathrm{Fe} /{ }^{3} \mathrm{He}_{\mathrm{xs}}$ ratio would decrease with time (Saito et al., 2013). Though Resing et al. (2015) suggested that the basin-scale hydrothermal plume Fe was being transported in a conservative manner, even the far-field samples show a trend of decreasing $\mathrm{Fe} /{ }^{3} \mathrm{He}_{\mathrm{xs}}$ with age, indicative of a slow $\mathrm{Fe}$ removal process from the large-scale plume. The time scales provided by $\mathrm{Ra}$ isotopes allow us to discern Fe loss that was not evident based on concentration data alone, because slow removal may not cause a significant deviation from the apparent linear relationship between $\mathrm{Fe}$ and ${ }^{3} \mathrm{He}_{\mathrm{xs}}$. Assuming first order kinetics, the removal rate of Fe from the neutrally buoyant plume may be calculated using the relationship between the natural logarithm of the $\mathrm{Fe} /{ }^{3} \mathrm{He}_{\mathrm{xs}}$ ratio and plume age:

$$
\ln \left[\frac{\mathrm{Fe}}{{ }^{3} \mathrm{He}_{\mathrm{xs}}}\right]_{\mathrm{t}}=-\mathrm{k} \cdot \mathrm{t}+\ln \left[\frac{\mathrm{Fe}}{{ }^{3} \mathrm{He}_{\mathrm{xs}}}\right]_{0}
$$

where $\left[\frac{\mathrm{Fe}}{{ }^{3} \mathrm{He}_{\mathrm{xs}}}\right]_{0}$ is the initial ratio of the $\mathrm{Fe} /{ }^{3} \mathrm{He}_{\mathrm{xs}}$ in either the near-field or far-field plume, $\left[\frac{\mathrm{Fe}}{{ }^{3} \mathrm{He}_{\mathrm{xs}}}\right]_{\mathrm{t}}$ is the ratio at year $\mathrm{t}$, and $\mathrm{k}$ is the removal rate. The trendline for this linear relationship was calculated using a weighted total least squares technique that considers the errors in both coordinates (Krystek and Anton, 2008). This technique considers equal weights in the positive and negative directions, however the errors on the natural log of the ${ }^{228} \mathrm{Ra}^{3} \mathrm{He}_{\mathrm{xs}}$ relationship are slightly larger in the positive direction, so equally weighted errors were determined for this calculation using the approximation $\delta \ln (\mathrm{x})=\delta \mathrm{x} / \mathrm{x}$. The removal rate can then be used to determine the Fe residence time $(\tau)$ using Equation 5:

$$
\tau=1 / \mathrm{k}
$$

Using this approach, the removal rate of Fe from the far-field plume ( $>100 \mathrm{~km}$ from ridge) was determined to be $0.12 \mathrm{y}^{-1}, 0.021 \mathrm{y}^{-1}$, and $0.044 \mathrm{y}^{-1}$, under the min, max, and east background conditions, respectively. These removal rates correspond to Fe residence times of $9 \mathrm{y}, 50 \mathrm{y}$, and $20 \mathrm{y}$, which are lower than typical deep ocean residence times for Fe (70 - $270 \mathrm{y}$; Bruland et al., 1994; Bergquist and Boyle, 2006). In the max background condition, we assume that the species in the plume will not be diluted below the concentrations we observed on GP16; this is likely an overestimate of the actual background concentrations, so we consider the residence time of $50 \mathrm{y}$ to be an upper limit. Thus our best estimate of the Fe residence time in the far-field plume is $9-$ $20 \mathrm{y}$.

The removal rates in the near-field plume were also determined using the relationship between the Fe concentrations at stations 18 and 20, and were found to be $0.42 \mathrm{y}^{-1}, 0.28 \mathrm{y}^{-1}$, and $0.34 \mathrm{y}^{-1}$, under the max, min, and east background conditions, respectively. The resulting residence times of $2 \mathrm{y}, 4 \mathrm{y}$, and $3 \mathrm{y}$ carry significant uncertainty due to the large decrease in $\mathrm{Fe}$ 
concentration between adjacent stations and should therefore be considered upper limits; however, these results are similar to estimates for scavenging removal of Fe in the surface ocean (2 - 13 y, Landing and Bruland, 1987).

Possible mechanisms for Fe removal from the neutrally buoyant plume include scavenging removal of dissolved Fe and sinking of colloidal Fe. In the deep Pacific, Fe may continue to be oxidized and scavenged well after the plume reaches neutral buoyancy (Field and Sherrell, 2000; Fitzsimmons et al., 2014). Recent studies have also shown that Fe may be stabilized in neutrally buoyant plumes by ligands and colloids (Bennett et al., 2008; Fitzsimmons et al., 2015; Fitzsimmons et al., 2014; Gartman et al., 2014; Hawkes et al., 2013; Sander and Koschinsky, 2011; Yücel et al., 2011); the slow sinking and/or aggregation of these colloids would remove dissolved Fe from the plume but not necessarily the water column over the scale of our study, depending on mean sinking velocities.

The speciation of colloidal Fe in the GP16 plume was dominated by Fe-oxyhydroxides near the ridge axis and organic complexes in the far- field plume (Fitzsimmons et al., 2017). Assuming Stokesian settling, over the 15 year time scale considered here, the largest Feoxyhydroxide colloids $\left(0.2 \mu \mathrm{m}, \rho=4.25 \mathrm{~g} / \mathrm{cm}^{3}\right)$ would only sink $\sim 20 \mathrm{~m}$; for the lighter organically-complexed colloids sinking would be negligible over this time scale. Fitzsimmons et al. (2017) have suggested that organically-complexed colloidal Fe in the off-axis plume reversibly exchanges with slowly sinking particulate Fe species; this is more likely to be the process that drives the slow removal of dissolved Fe from the core of the plume.

A better understanding of the mechanisms controlling Fe removal from neutrally buoyant plumes is essential in constraining the hydrothermal Fe source to the deep ocean. Assuming conservative behavior of Fe in the far-field plume, Resing et al. (2015) estimated that hydrothermally sourced Fe may support between $15-30 \%$ of primary production in the Southern Ocean. Rates derived from $\mathrm{Ra}$ isotope distributions here indicate that this may be an overestimate, which should be considered in future iterations of Fe transport models in the deep ocean.

\subsection{CONCLUSIONS}

Radium enrichments in hydrothermal fluids make these isotopes valuable tracers of hydrothermal processes on time scales of days to decades. Short- to long- lived Ra activity ratios in neutrally buoyant plumes, combined with the activity ratios measured in low-Mg hightemperature vent fluids, have been applied to determine the time elapsed since hydrothermal fluids were vented.

In high temperature vent fluids $\left(>250{ }^{\circ} \mathrm{C}\right)$, the ${ }^{224} \mathrm{Ra} /{ }^{228} \mathrm{Ra}$ activity ratio was close to 1 , suggesting that the residence time of fluids in the crust is long enough (on the order of years) to allow these isotopes to reach secular equilibrium. The ${ }^{223} \mathrm{Ra} /{ }^{226} \mathrm{Ra}$ in high temperature fluids was similar to the expected ${ }^{231} \mathrm{~Pa} /{ }^{226} \mathrm{Ra}$ activity ratios in MORB, however the scarcity of data highlights the need for additional measurements of this ratio. Using the average ${ }^{224} \mathrm{Ra} /{ }^{228} \mathrm{Ra}$ vent fluid ratios as an initial value, the age of the near field plume at the TAG vent field on the MAR was found to be approximately 5 days, reflecting the proximity of the sampling location to the active mound. Over the EPR, ${ }^{223} \mathrm{Ra} /{ }^{226} \mathrm{Ra}$ activity ratios were used to determine that the age of the neutrally buoyant plume was on the order of a month, indicating that the sampling occurred 4-14 km away from the location of venting. Combined with measurements of trace metals in 
endmember vent fluids and the plume, this method has the potential to be a powerful tool for determining the removal rates of metals in the near-field plume.

Using the ${ }^{228} \mathrm{Ra}$-derived age of a basin-scale, off-axis plume emanating from $15^{\circ} \mathrm{S}$ on the EPR, the residence time of hydrothermal Fe was estimated to be $9-20 \mathrm{y}$ (with an upper limit $=$

$50 \mathrm{y}$ ). The relationship between $\mathrm{Fe}$ and the ${ }^{228} \mathrm{Ra}$-derived ages indicates removal of Fe from the plume, contrary to a recent study that suggested Fe behaves conservatively during plume advection (Resing et al., 2015). Knowledge of the residence time of metals in hydrothermal plumes is vital to constraining the impact of hydrothermal inputs on global ocean trace element budgets as well as the ocean carbon cycle for essential micronutrients like Fe.

\section{Acknowledgements}

The authors thank the chief scientists, captains, and crews of the $R / V$ Thomas Thompson (GP16), $R / V$ Knorr (GA03), and $R / V$ Atlantis (AII-125, Leg 33 and ATV7L20), as well as the operators and engineers of the HOV Alvin and ROV Jason II. Thanks to members of the pump team during the GP16 and GA03 cruises, including D. Onhemus, E. Black, S. Nicholas, P. Morris, S. Rigaud, S. Owens, and S. Pike for their help in sample collection, and to P. Morris for help in sample analysis. P. Johnson, D. Butterfield, D. Stakes and J. Edmond assisted in the vent fluid sampling. We thank P. Sedwick and J. Resing for sharing Fe data, P. Lam for sharing particle composition data, and W. Jenkins for sharing He data. We thank Evelyne Garçon for technical assistance at the underground laboratory of Modane (LSM, French Alps). We are grateful to W. Jenkins, J. Lupton, C. German, and M. Tivey for thoughtful discussions that improved this manuscript. The constructive comments of two anonymous reviewers helped strengthen the manuscript. This study was funded by the NSF Chemical Oceanography program (OCE-1232669 and OCE-0925158 to M.A.C., OCE-1231211, OCE-0926559 to W.S.M., and OCE-1235124 to D.E.H.). 


\section{References}

Baker, E.T., Massoth, G.J., 1986. Hydrothermal plume measurements: a regional perspective. Science 234, 980-2. doi:10.1126/science.234.4779.980

Bennett, S.A., Achterberg, E.P., Connelly, D.P., Statham, P.J., Fones, G.R., German, C.R., 2008. The distribution and stabilisation of dissolved Fe in deep-sea hydrothermal plumes. Earth Planet. Sci. Lett. 270, 157-167. doi:10.1016/j.epsl.2008.01.048

Bergquist, B.A., Boyle, E.A., 2006. Dissolved iron in the tropical and subtropical Atlantic Ocean. Global Biogeochem. Cycles 20. doi:10.1029/2005GB002505

Bischoff, J.L., Dickson, F.W., 1975. Seawater-basalt interaction at $200^{\circ} \mathrm{C}$ and 500 bars: Implications for origin of sea-floor heavy-metal deposits and regulation of seawater chemistry. Earth Planet. Sci. Lett. 25, 385-397. doi:10.1016/0012-821X(75)90257-5

Bourdon, B., Goldstein, S.J., Bourles, D., Murrell, M.T., Langmuir, C.H., 2000. Evidence from

${ }^{10} \mathrm{Be}$ and $\mathrm{U}$ series disequilibria on the possible contamination of mid-ocean ridge basalt glasses by sedimentary material. Geochemistry, Geophys. Geosystems 1. doi:10.1029/2000GC000047

Boyle, E.A., Bergquist, B.A., Kayser, R.A., Mahowald, N., 2005. Iron, manganese, and lead at Hawaii Ocean Time-series station ALOHA: Temporal variability and an intermediate water hydrothermal plume. Geochim. Cosmochim. Acta 69, 933-952. doi:10.1016/j.gca.2004.07.034

Bruland, K.W., Orians, K.J., Cowen, J.P., 1994. Reactive Trace-Metals in the Stratified Central North Pacific. Geochim. Cosmochim. Acta 58, 3171-3182. doi:10.1016/00167037(94)90044-2

Campbell, A.C., Palmer, M.R., Klinkhammer, G.., Bowers, T.S., Edmond, J.., Lawrence, J.R., Casey, J.F., Thompson, G., Humphris, S., Rona, P., Karson, J.A., 1988. Chemistry of hot springs on the Mid-Atlantic Ridge. Nature 335, 514-519. doi:10.1038/335514a0

Cannon, G.A., Pashinski, D.J., Lemon, M.R., 1991. Middepth flow near hydrothermal venting sites on the southern Juan de Fuca Ridge. J. Geophys. Res. 96, 12815-12831. doi:10.1029/91JC01023

Charette, M.A., 2007. Hydrologic forcing of submarine groundwater discharge: Insight from a seasonal study of radium isotopes in a groundwater-dominated salt marsh estuary. Limnol. Oceanogr. 52, 230-239. doi:10.4319/lo.2007.52.1.0230

Charette, M.A., Morris, P.J., Henderson, P.B., Moore, W.S., 2015. Radium isotope distributions during the US GEOTRACES North Atlantic cruises. Mar. Chem. 177, 184-195. doi:10.1016/j.marchem.2015.01.001

Corliss, J.B., Lyle, M., Dymond, J., Crane, K., 1978. The chemistry of hydrothermal mounds near the Galapagos Rift. Earth Planet. Sci. Lett. 40, 12-24. doi:10.1016/0012821X(78)90070-5

Davis, E., Becker, K., 1998. Borehole observatories record driving forces for hydrotheraial circulation in young oceanic crust. Eos, Trans. Am. Geophys. Union 79, 369-370. doi:10.1029/98EO00275

Davis, E.E., Chapman, D.S., Mottl, M.J., Bentkowski, W.J., Dadey, K., Forster, C., Harris, R., Nagihara, S., Rohr, K., Wheat, G., Whiticar, M., 1992. FlankFlux: an experiment to study the nature of hydrothermal circulation in young oceanic crust. Can. J. Earth Sci. 29, 925952. doi:10.1139/e92-078

Delaney, J.R., Robigou, V., McDuff, R.E., Tivey, M.K., 1992. Geology of a vigorous 
hydrothermal system on the Endeavour Segment, Juan de Fuca Ridge. J. Geophys. Res. 97, 19663-19682. doi:10.1029/92jb00174

Edmond, J.M., Measures, C., McDuff, R.E., Chan, L.H., Collier, R., Grant, B., 1979. Ridge crest hydrothermal activity and the balances of the major and minor elements in the ocean: The Galapagos data. Earth Planet. Sci. Lett. 46, 1-18. doi:10.1016/0012-821X(79)90061-X

Edmond, J.M., Von Damm, K.L., McDuff, R.E., Measures, C.I., 1982. Chemistry of hot springs on the East Pacific Rise and their effluent dispersal. Nature 297, 187-191. doi:10.1038/297187a0

Elderfield, H., Schultz, A., 1996. Mid-Ocean Ridge Hydrothermal Fluxes and the Chemical Composition of the Ocean. Annu. Rev. Earth Planet. Sci. 24, 191-224. doi:10.1146/annurev.earth.24.1.191

Elsinger, R.J., King, P.T., Moore, W.S., 1982. Radium-224 in natural waters measured by $\gamma$-ray spectrometry. Anal. Chim. Acta 144, 277-281. doi:10.1016/S0003-2670(01)95545-X

Embley, R.W., Murphy, K.M., Fox, C.G., 1990. High-Resolution Studies of the Summit of Axial Volcano. J. Geophys. Res. 95, 12,785-12,812. doi:10.1029/JB095iB08p12785

Faure, V., Speer, K.G., 2012. Deep circulation in the eastern South Pacific Ocean. J. Mar. Res. 70, 748-778. doi:https://doi.org/10.1357/002224012806290714

Field, M.P., Sherrell, R.M., 2000. Dissolved and particulate Fe in a hydrothermal plume at $9^{\circ} 45^{\prime}$ N, East Pacific Rise: Geochim. Cosmochim. Acta 64, 619-628. doi:10.1016/S00167037(99)00333-6

Fisher, A.T., Davis, E.E., Hutnak, M., Spiess, V., Zühlsdorff, L., Cherkaoui, A., Christiansen, L., Edwards, K., Macdonald, R., Villinger, H., Mottl, M.J., Wheat, C.G., Becker, K., 2003. Hydrothermal recharge and discharge across $50 \mathrm{~km}$ guided by seamounts on a young ridge flank. Nature 421, 618-621. doi:10.1038/nature01352

Fitzsimmons, J.N., Boyle, E.A., Jenkins, W.J., 2014. Distal transport of dissolved hydrothermal iron in the deep South Pacific Ocean. Proc. Natl. Acad. Sci. U. S. A. 111, 16654-16661. doi:10.1073/pnas.1418778111

Fitzsimmons, J.N., Carrasco, G.G., Wu, J., Roshan, S., Hatta, M., Measures, C.I., Conway, T.M., John, S.G., Boyle, E.A., 2015. Partitioning of dissolved iron and iron isotopes into soluble and colloidal phases along the GA03 GEOTRACES North Atlantic Transect. Deep. Res. Part II Top. Stud. Oceanogr. 116, 130-151. doi:10.1016/j.dsr2.2014.11.014

Fitzsimmons, J.N., John, S.G., Marsay, C.M., Hoffman, C.L., Nicholas, S.L., Toner, B.M., German, C.R., Sherrell, R.M., 2017. Iron persistence in a distal hydrothermal plume supported by dissolved-particulate exchange. Nature Geoscience 10, 195-201. doi:10.1038/ngeo2900

Fujio, S., Imasato, N., 1991. Diagnostic calculation for circulation and water mass movement in the deep Pacific. J. Geophys. Res. Ocean. 96, 759-774. doi:10.1029/90JC02130

Gartman, A., Findlay, A.J., Luther, G.W., 2014. Nanoparticulate pyrite and other nanoparticles are a widespread component of hydrothermal vent black smoker emissions. Chem. Geol. 366, 32-41. doi:10.1016/j.chemgeo.2013.12.013

German, C., Von Damm, K., 2006. Hydrothermal processes, in: Treatsie on Geochemistry. pp. 181-222.

German, C.R., Campbell, A.C., Edmond, J., 1991a. Hydrothermal scavenging at the MidAtlantic Ridge: Modification of trace element dissolved fluxes. Earth Planet. Sci. Lett. 107, 101-114. doi: 10.1016/0012-821X(91)90047-L

German, C.R., Fleer, A.P., Bacon, M.P., Edmond, J.M., 1991b. Hydrothermal scavenging at the 
Mid-Atlantic Ridge: Radionuclide distributions. Earth Planet. Sci. Lett. 105, 170-181. doi:10.1016/0012-821X(91)90128-5

German, C.R., Klinkhammer, G.P., Edmond, J.M., Mitra, A., Elderfield, H., 1990. Hydrothermal scavenging of rare-earth elements in the ocean. Nature 345, 516-518.

doi:10.1038/345516a0

German, C.R., Richards, K.J., Rudnicki, M.D., Lam, M.M., Charlou, J.-L., 1998. Topographic control of a dispersing hydrothermal plume. Earth Planet. Sci. Lett. 156, 267-273. doi:10.1016/S0012-821X(98)00020-X

German, C.R., Sparks, R.S.J., 1993. Particle recycling in the TAG hydrothermal plume. Earth Planet. Sci. Lett. 116, 129-134. doi:10.1016/0012-821X(93)90049-F

Guichard, F., Church, T.M., Treuil, M., Jaffrezic, H., 1979. Rare earths in barites: distribution and effects on aqueous partitioning. Geochim. Cosmochim. Acta 43, 983-997. doi:10.1016/0016-7037(79)90088-7

Hammond, D.E., Charette, M.A., Moore, W.S., Henderson, P.B., Sanial, V., Kipp, L.E., Anderson, R.F., Primeau, F., 2016. ${ }^{227}$ Ac in the Deep South Pacific along the Peru-Tahiti GEOTRACES Transect: Mixing and Transport Rates, in: Ocean Sciences Meeting. New Orleans, Louisiana, USA.

Hammond, D.E., Zukin, J.G., Ku, T.-L., 1988. The kinetics of radioisotope exchange between brine and rock in a geothermal system. J. Geophys. Res. Solid Earth 93, 13175-13186. doi:10.1029/JB093iB11p13175

Hautala, S.L., Riser, S.C., 1993. A Nonconservative $\beta$-Spiral Determination of the Deep Circulation in the Eastern South Pacific. J. Phys. Oceanogr. 23, 1975-2000. doi:10.1175/1520-0485(1993)023<1975:ANSDOT>2.0.CO;2

Hawkes, J.A., Connelly, D.P., Gledhill, M., Achterberg, E.P., 2013. The stabilisation and transportation of dissolved iron from high temperature hydrothermal vent systems. Earth Planet. Sci. Lett. 375, 280-290. doi:10.1016/j.epsl.2013.05.047

Henderson, P.B., Morris, P.J., Moore, W.S., Charette, M.A., 2013. Methodological advances for measuring low-level radium isotopes in seawater. J. Radioanal. Nucl. Chem. 296, 357-362. doi:10.1007/s10967-012-2047-9

Jenkins, W.J., Edmond, J.M., Corliss, J.B., 1978. Excess ${ }^{3} \mathrm{He}$ and ${ }^{4} \mathrm{He}$ in Galapagos submarine hydrothermal waters. Nature 272, 156-158. doi:10.1038/272156a0

Jenkins, W.J., Lott, D.E., Longworth, B.E., Curtice, J.M., Cahill, K.L., 2014. The distributions of helium isotopes and tritium along the U.S. GEOTRACES North Atlantic sections (GEOTRACES GAO3). Deep Sea Res. Part II Top. Stud. Oceanogr. doi:10.1016/j.dsr2.2014.11.017

Jenkins, W.J, Lott, D.E., German, C.R., Cahill, K.L, Goudreau, J., Longworth, B., 2018. The deep distributions of helium isotopes, noble gases, and radiocarbon along the U.S. GEOTRACES East Pacific Zonal transect (GP16). Mar. Chem. 201, 167-182. doi:10.1016/j.marchem.2017.03.009

Johnson, G.C., Talley, L.D., 1997. Deep tracer and dynamical plumes in the tropical Pacific Ocean. J. Geophys. Res. Ocean. 102, 24953-24964. doi:10.1029/97JC01913

Johnson, H.P., 2003. Probing for life in the ocean crust with the LEXEN program. Eos Trans. AGU 84, 109. doi:10.1029/2003EO120001

Kadko, D., 1996. Radioisotopic studies of submarine hydrothermal vents. Rev. Geophys. 34, 349-366. doi:10.1029/96RG01762

Kadko, D., Butterfield, D., 1998. The relationship of hydrothermal fluid composition and crustal 
residence time to maturity of vent fields on the Juan de Fuca Ridge. Geochim. Cosmochim. Acta 62, 1521-1533. doi:10.1016/S0016-7037(98)00088-X

Kadko, D., Gronvold, K., Butterfield, D., 2007. Application of radium isotopes to determine crustal residence times of hydrothermal fluids from two sites on the Reykjanes Peninsula, Iceland. Geochim. Cosmochim. Acta 71, 6019-6029. doi:10.1016/j.gca.2007.09.018

Kadko, D., Moore, W., 1988. Radiochemical constraints on the crustal residence time of submarine hydrothermal fluids: Endeavour Ridge. Geochim. Cosmochim. Acta 52, 659668. doi:10.1016/0016-7037(88)90328-6

Kadko, D.C., Rosenberg, N.D., Lupton, J.E., Collier, R.W., Lilley, M.D., 1990. Chemical reaction rates and entrainment within the Endeavour Ridge hydrothermal plume. Earth Planet. Sci. Lett. 99, 315-335.

Key, R.M., Brewer, R.L., Stockwell, J.H., Guinasso, N.L., Schink, D.R., 1979. Some improved techniques for measuring radon and radium in marine sediments and in seawater. Mar. Chem. 7, 251-264. doi:10.1016/0304-4203(79)90042-2

Kipp, L.E., Charette, M.A., Hammond, D.E., Moore, W.S., 2015. Hydrothermal vents: A previously unrecognized source of actinium-227 to the deep ocean. Mar. Chem. 177, 583590. doi:10.1016/j.marchem.2015.09.002

Klinkhammer, G., Hudson, A., 1986. Dispersal patterns for hydrothermal plumes in the South Pacific using manganese as a tracer. Earth Planet. Sci. Lett. 79, 241-249. doi:10.1016/0012$821 X(86) 90182-2$

Krishnaswami, S., Graystein, W.C., Turekian, K.K., 1982. Radium, Thorium and Radioactive Lead Isotopes in Groundwaters: Application to the in Situ Determination of AdsorptionDesorption Rate Constants and Retardation Factors. Water Resour. Res. 18, 1663-1675.

Krystek, M., Anton, M., 2008. A weighted total least-squares algorithm for fitting a straight line. Meas. Sci. Technol. 19, 3438-3422. doi:10.1088/0957-0233/19/7/079801

Lam, P.J., Ohnemus, D.C., Auro, M.E., 2015. Size-fractionated major particle composition and concentrations from the US GEOTRACES North Atlantic Zonal Transect. Deep. Res. Part II Top. Stud. Oceanogr. 116, 303-320. doi:10.1016/j.dsr2.2014.11.020

Lam, P.J., Lee, J.-M., Heller, M.I., Mehic, S., Xiang, Y., Bates, N.R., 2018. Size-fractionated distributions of suspended particle concentration and major phase composition from the U.S. GEOTRACES Eastern Pacific Zonal Transect (GP16). Mar. Chem. 201, 90-107. doi:10.1016/j.marchem.2017.08.013

Lilley, M.D., Feely, R.A., Trefry, J.H., 1995. Chemical and Biochemical Transformations in Hydrothermal Plumes, in: Seafloor Hydrothermal Systems: Physical, Chemical, Biological, and Geological Interactions. American Geophysical Union, pp. 369-391. doi:10.1029/GM091p0369

Lundstrom, C.C., Sampson, D.E., Perfit, M.R., Gill, J., Williams, Q., 1999. Insights into midocean ridge basalt petrogenesis: U-series disequilibria from the Siqueiros Transform, Lamont Seamounts, and East Pacific Rise. J. Geophys. Res. 104, 13035-13048. doi:10.1029/1999JB900081

Lundstrom, C.C., Williams, Q., Gill, J.B., 1998. Investigating solid mantle upwelling rates beneath mid-ocean ridges using U-series disequilibria, I: a global approach. Earth Planet. Sci. Lett. 157, 151-165. doi:10.1016/S0012-821X(98)00038-7

Lupton, J., 1998. Hydrothermal helium plumes in the Pacific Ocean. J. Geophys. Res. 103, 15853-15868. doi:10.1029/98JC00146

Lupton, J.E., Craig, H., 1981. A major Helium-3 source at $15^{\circ} \mathrm{S}$ on the East Pacific Rise. Science 
214, 13-18. doi:10.1126/science.214.4516.13

Lupton, J.E. and Jenkins, W.J., 2017. Evolution of the South Pacific helium plume over the past three decades. Geochemistry, Geophys., Geosystems. doi: 10.1002/2017GC006848

Millero, F., C. Winn, C. Goyet. 1994. Hydrographic, Chemical and Carbon Data Obtained During the R/V Melville cruise in the Pacific Ocean during WOCE Section P21EW (EXPOCODE 318MWESTW_4_5), (27 March - 25 June, 1994). http://cdiac.ornl.gov/ftp/oceans/p21woce/. Carbon Dioxide Information Analysis Center, Oak Ridge National Laboratory, US Department of Energy, Oak Ridge, Tennessee. doi: 10.3334/CDIAC/otg.318MWESTW_4_5

Moore, W.S., 1984. Radium isotope measurements using germanium detectors. Nucl. Instrum. Methods Phys. Res. 223, 407-411. doi:10.1016/0167-5087(84)90683-5

Moore, W.S., Arnold, R., 1996. Measurement of ${ }^{223} \mathrm{Ra}$ and ${ }^{224} \mathrm{Ra}$ in coastal waters using a delayed coincidence counter. J. Geophys. Res. 101, 1321-1329. doi:10.1029/95JC03139

Moore, W.S., Reid, D.F., 1973. Extraction of radium from natural waters using manganeseimpregnated acrylic fibers. J. Geophys. Res. 78, 8880-8886. doi:10.1029/JC078i036p08880

Moore, W.S., Ussler, W., Paull, C.K., 2008. Short-lived radium isotopes in the Hawaiian margin: Evidence for large fluid fluxes through the Puna Ridge. Mar. Chem. 109, 421-430. doi:10.1016/j.marchem.2007.09.010

Mottl, M.J., 1983. Metabasalts, axial hot springs, and the structure of hydrothermal systems at mid-ocean ridges. Geol. Soc. Am. Bull. 161-180. doi:10.1130/0016-7606(1983)94<161

Mottl, M.J., Wheat, C.G., 1994. Hydrothermal circulation through mid-ocean ridge flanks: Fluxes of heat and magnesium. Geochim. Cosmochim. Acta 58, 2225-2237. doi:10.1016/0016-7037(94)90007-8

Pavia, F.J., Anderson, R.F., Vivancos, S.M., Fleisher, M.Q., Lu, Y., Zhang, P., Cheng, H., Edwards, R.L., 2016. Continuous, Rapid Scavenging of Thorium and Protactinium During Westward Avection of the East Pacific Rise Hydrothermal Plume, in: Ocean Sciences Meeting. New Orleans, Louisiana, USA.

Peters, B., Casciotti, K., Jenkins, W. J., Swift, J., German, C., Moffet, J., Cutter, G. and Brzezinski, M. A., 2018. Water mass analysis of the 2013 US GEOTRACES Eastern Pacific Zonal Transect (GP16). Mar. Chem. 201, 6-19. doi:10.1016/j.marchem.2017.09.007

Reid, D.F., Key, R.M., Schink, D.R., 1979. Radium, thorium, and actinium extraction from seawater using an improved manganese-oxide-coated fiber. Earth Planet. Sci. Lett. 43, 223 226. doi:10.1016/0012-821X(79)90205-X

Resing, J.A., Sedwick, P.N., German, C.R., Jenkins, W.J., Moffett, J.W., Sohst, B.M., Tagliabue, A., 2015. Basin-scale transport of hydrothermal dissolved metals across the South Pacific Ocean. Nature 523, 200-203. doi:10.1038/nature14577

Reyes, A.O., Moore, W.S., Stakes, D.S., 1995. ${ }^{228} \mathrm{Th} /{ }^{228}$ Ra ages of a barite-rich chimney from the Endeavour Segment of the Juan de Fuca Ridge. Earth Planet. Sci. Lett. 131, 99-113. doi:10.1016/0012-821X(95)00009-2

Reyss, J.L., Schmidt, S., Legeleux, F., Bonté, P., 1995. Large, low background well-type detectors for measurements of environmental radioactivity. Nucl. Inst. Methods Phys. Res. A 357, 391-397. doi:10.1016/0168-9002(95)00021-6

Robigou, V., Delaney, J.R., Stakes, D.S., 1993. Large massive sulfide deposits in a newly discovered active hydrothermal system, The High-Rise Field, Endeavour Segment, Juan De Fuca Ridge. Geophys. Res. Lett. 20, 1887-1890. doi:10.1029/93GL01399

Roy-Barman, M., Chen, J.H., Wasserburg, G.J., 1996. ${ }^{230} \mathrm{Th}-{ }^{232}$ Th systematics in the central 
Pacific Ocean: The sources and the fates of thorium. Earth Planet. Sci. Lett. 139, 351-363. doi:10.1016/0012-821X(96)00017-9

Rudnicki, M., Elderfield, H., 1992. Helium, radon and manganese at the TAG and Snakepit hydrothermal vent fields, $26^{\circ}$ and $23^{\circ} \mathrm{N}$, Mid-Atlantic Ridge. Earth Planet. Sci. Lett. 113, 307-321. doi:10.1016/0012-821X(92)90136-J

Rudnicki, M.D., James, R.H., Elderfield, H., 1994. Near-field variability of the TAG nonbuoyant plume, $26^{\circ} \mathrm{N}$, Mid-Atlantic Ridge. Earth Planet. Sci. Lett. 127, 1-10. doi:10.1016/0012-821X(94)90193-7

Saito, M.A., Noble, A.E., Tagliabue, A., Goepfert, T.J., Lamborg, C.H., Jenkins, W.J., 2013. Slow-spreading submarine ridges in the South Atlantic as a significant oceanic iron source. Nat. Geosci. 6, 775-779. doi:10.1038/ngeo1893

Sander, S.G., Koschinsky, A., 2011. Metal flux from hydrothermal vents increased by organic complexation. Nat. Geosci. 4, 145-150. doi:10.1038/ngeo1088

Sims, K.W.W., Goldstein, S.J., Blichert-Toft, J., Perfit, M.R., Kelemen, P., Fornari, D.J., Michael, P., Murrell, M.T., Hart, S.R., DePaolo, D.J., Layne, G., Ball, L., Jull, M., Bender, J., 2002. Chemical and isotopic constraints on the generation and transport of magma beneath the East Pacific Rise. Geochim. Cosmochim. Acta 66, 3481-3504. doi:10.1016/S0016-7037(02)00909-2

Stakes, D., Moore, W.S., 1991. Evolution of hydrothermal activity on the Juan de Fuca Ridge: observations, mineral ages, and Ra isotope ratios. J. Geophys. Res. 96, 21739-21752.

Talley, L.D., Johnson, G.C., 1994. Deep, zonal subequatorial currents. Science. 263, 1125-1128. doi:10.1126/science.263.5150.1125

Turekian, K.K., Cochran, J.K., 1986. Flow rates and reaction rates in the Galapagos Rise spreading center hydrothermal system as inferred from $\mathrm{Ra} / \mathrm{Ra}$ in vesicomyid clam shells. Proc. Natl. Acad. Sci. U. S. A. 83, 6241-4.

Von Damm, K.L., 1990. Seafloor Hydrothermal Activity: Black Smoker Chemistry and Chimneys. Annu. Rev. Earth Planet. Sci. 18, 173-204. doi:10.1146/annurev.ea.18.050190.001133

Von Damm, K.L., Edmond, J.M., Grant, B., Measures, C.I., Walden, B., Weiss, R.F., 1985. Chemistry of submarine hydrothermal solutions at $21^{\circ} \mathrm{N}$, East Pacific Rise. Geochim. Cosmochim. Acta 49, 2197-2220. doi:10.1016/0016-7037(85)90222-4

Wheat, C.G., Elderfield, H., Mottl, J., Monnin, C., 2000. Chemical composition of basement fluids within an oceanic ridge flank: Implications for along-strike and across-strike hydrothermal circulation. J. Geophys. Res. 105. doi:10.1029/2000JB900070

Winslow, D.M., Fisher, A.T., 2015. Sustainability and dynamics of outcrop-to-outcrop hydrothermal circulation. Nat. Commun. 6, 7567. doi:10.1038/ncomms 8567

Winslow, D.M., Fisher, A.T., Stauffer, P.H., Gable, C.W., Zyvoloski, G.A., 2016. Threedimensional modeling of outcrop-to-outcrop hydrothermal circulation on the eastern flank of the Juan de Fuca Ridge. J. Geophys. Res. Solid Earth 121, 1365-1382. doi:10.1002/2015JB012606

Wu, J., Wells, M.L., Rember, R., 2011. Dissolved iron anomaly in the deep tropical-subtropical Pacific: Evidence for long-range transport of hydrothermal iron. Geochim. Cosmochim. Acta 75, 460-468. doi:10.1016/j.gca.2010.10.024

Yücel, M., Gartman, A., Chan, C.S., Luther, G.W., 2011. Hydrothermal vents as a kinetically stable source of iron-sulphide-bearing nanoparticles to the ocean. Nat. Geosci. 4, 367-371. doi:10.1038/ngeo1148 


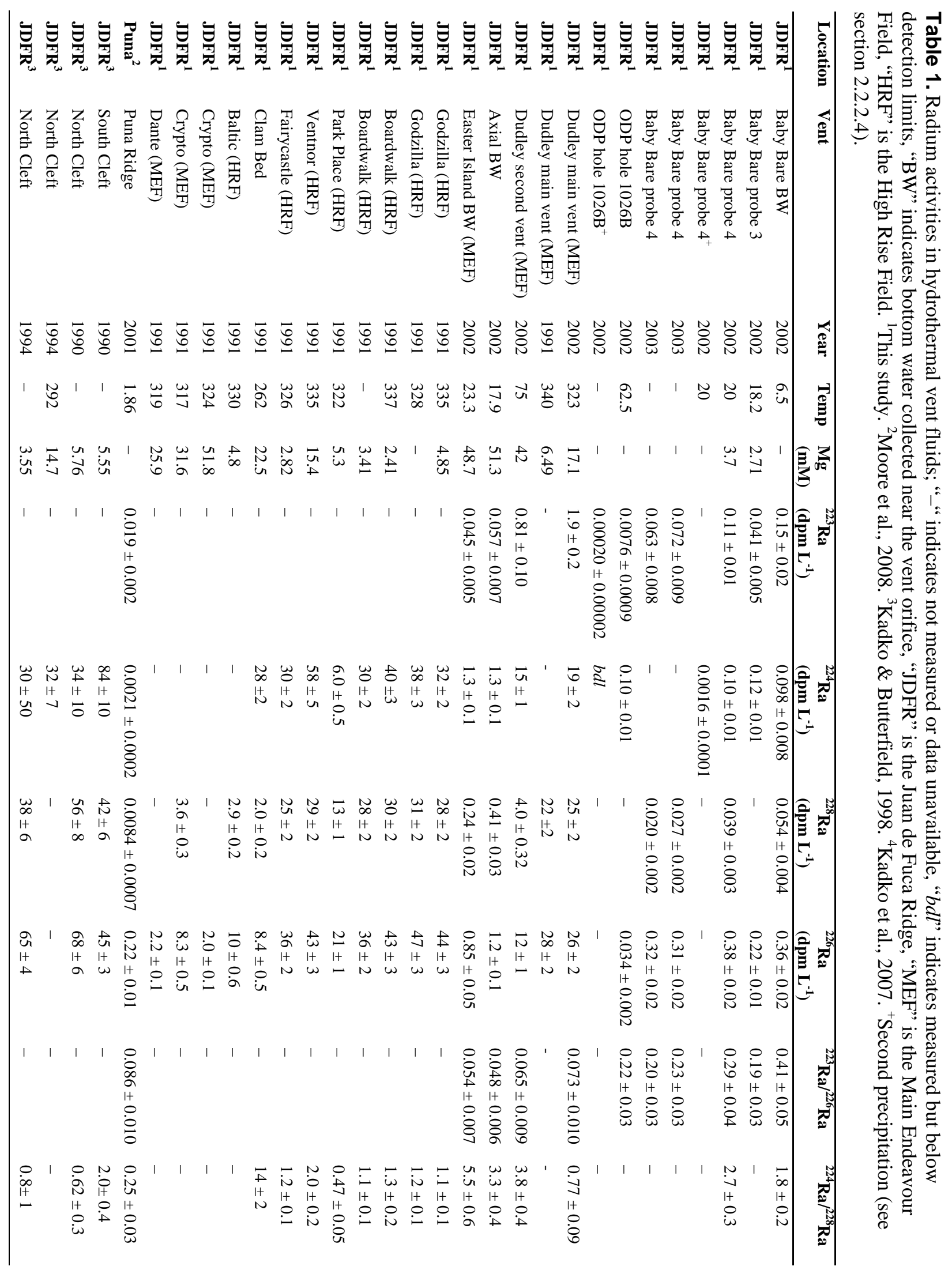




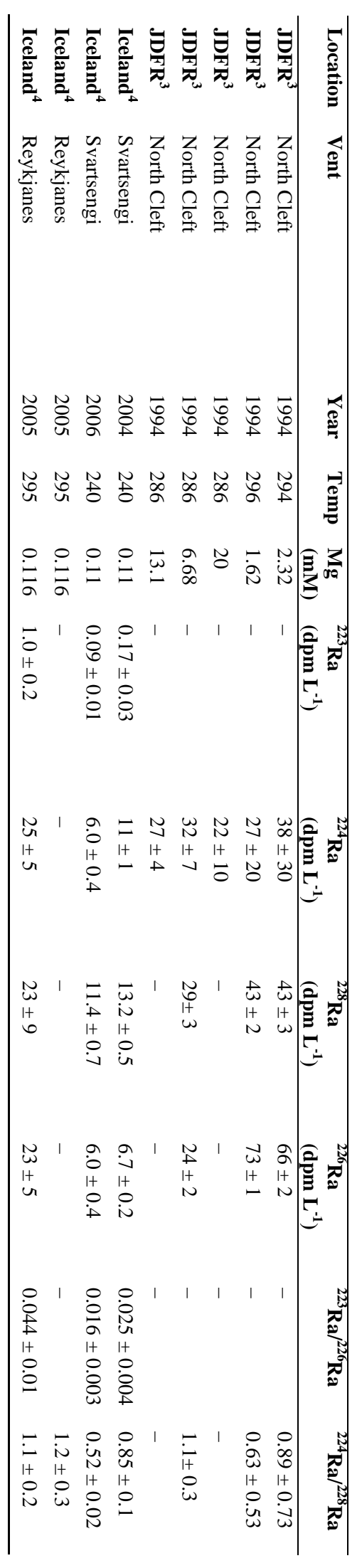




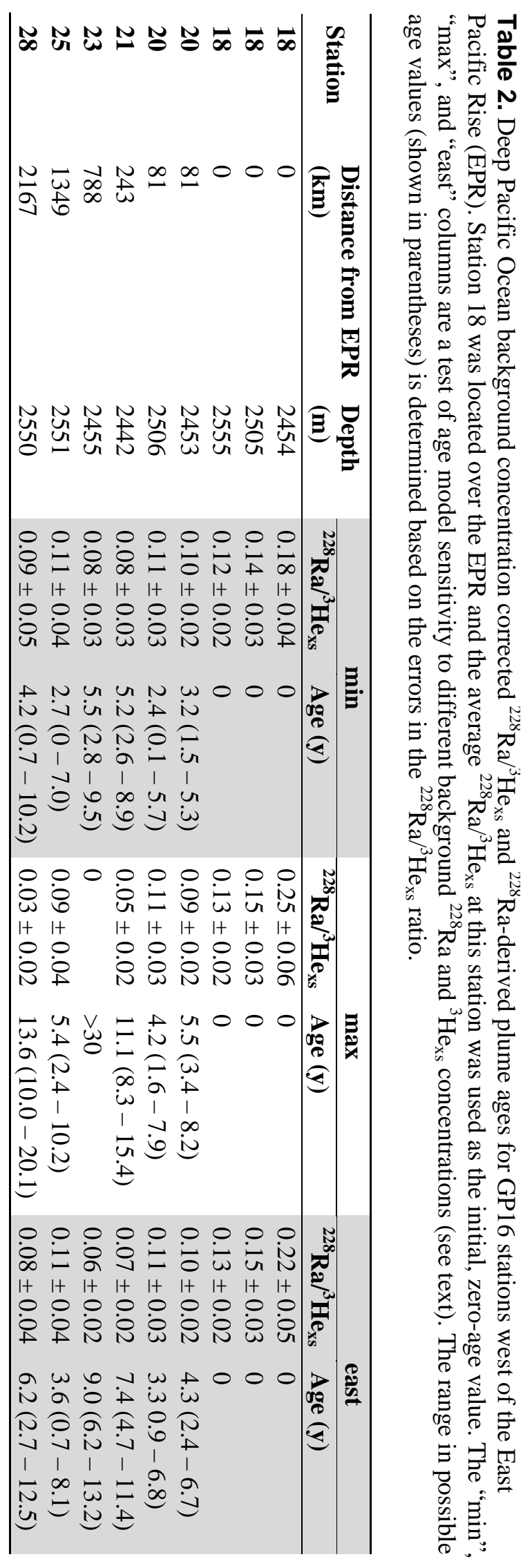



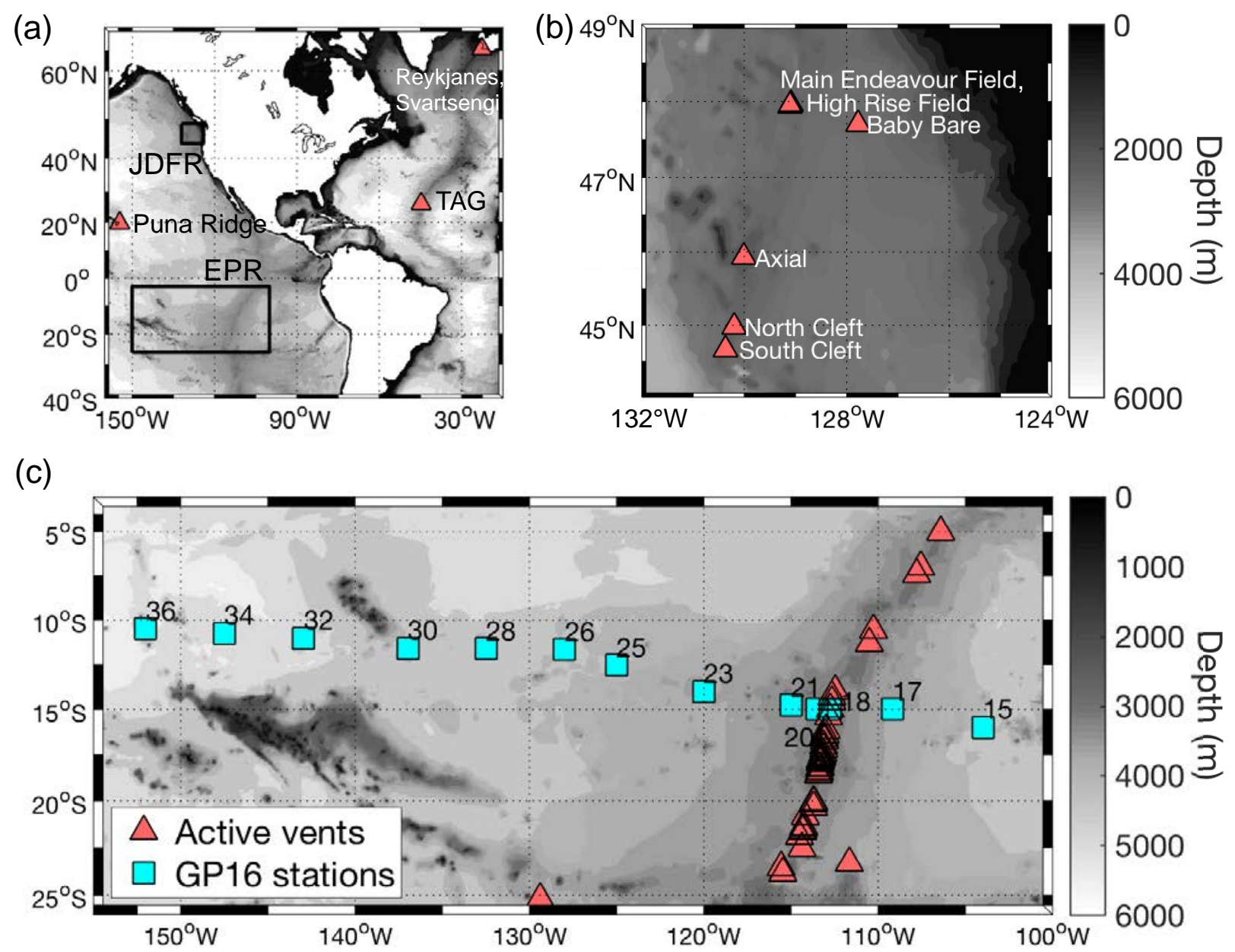

Figure 1. (a) The location of the TAG, Reykjanes, Svartsengi, and Puna Ridge vents; boxes labeled JDFR and EPR indicate the locations of the areas shown in detail in (b) and (c), respectively. (b) Vent fields on the Juan de Fuca Ridge (JDFR) that are referenced in this study. (c) Locations of the U.S. GEOTRACES GP16 stations (blue squares) and active hydrothermal vents on the Southern East Pacific Rise (EPR; red triangles). Vent locations were compiled from the Ridge 2000 database (www.ridge2000.org). 

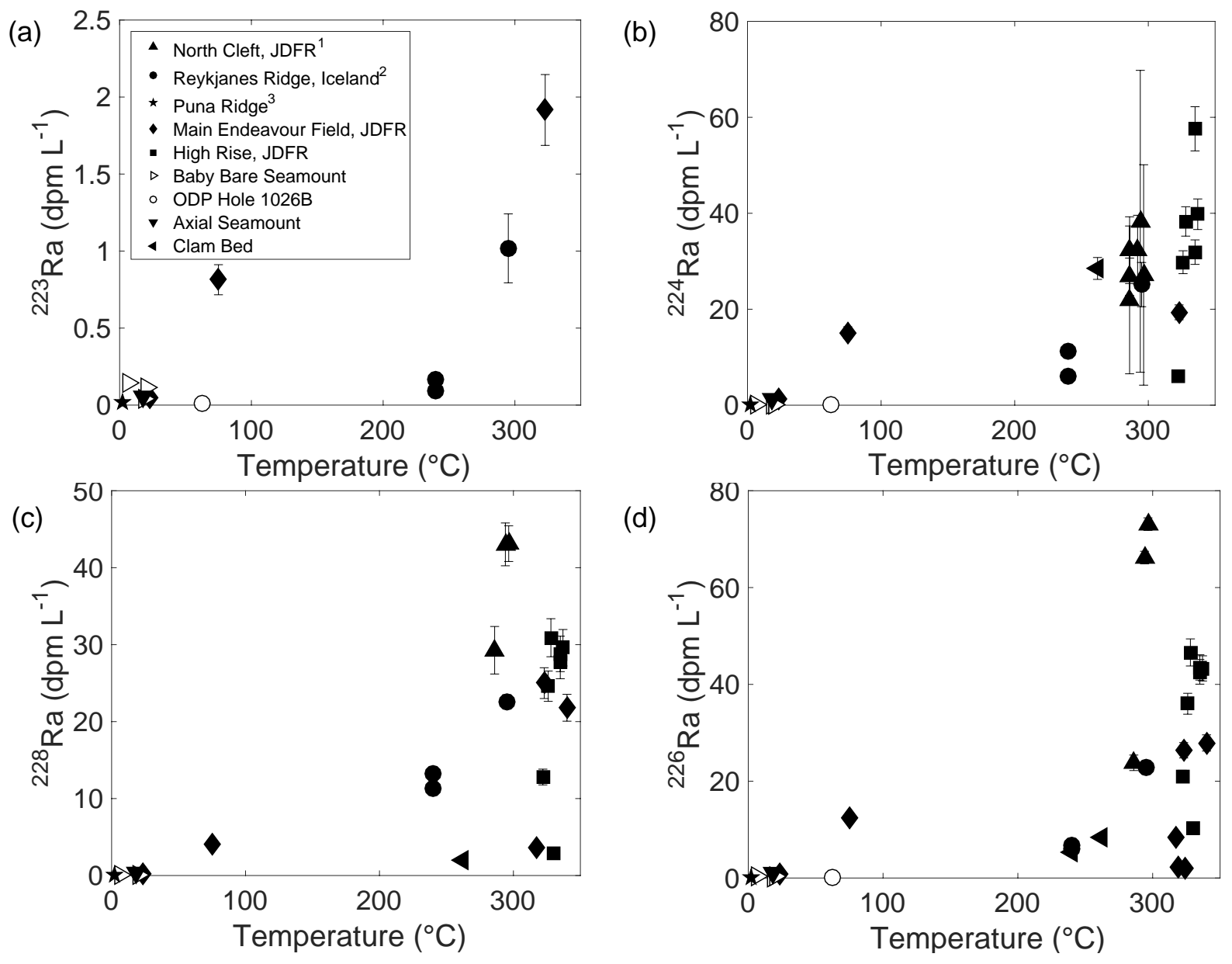

Figure 2. Activities of the four Ra isotopes in hydrothermal fluids as a function of temperature. ${ }^{1}$ Kadko and Butterfield, 1998. ${ }^{2}$ Kadko et al., 2007. ${ }^{3}$ Moore et al., 2008. 

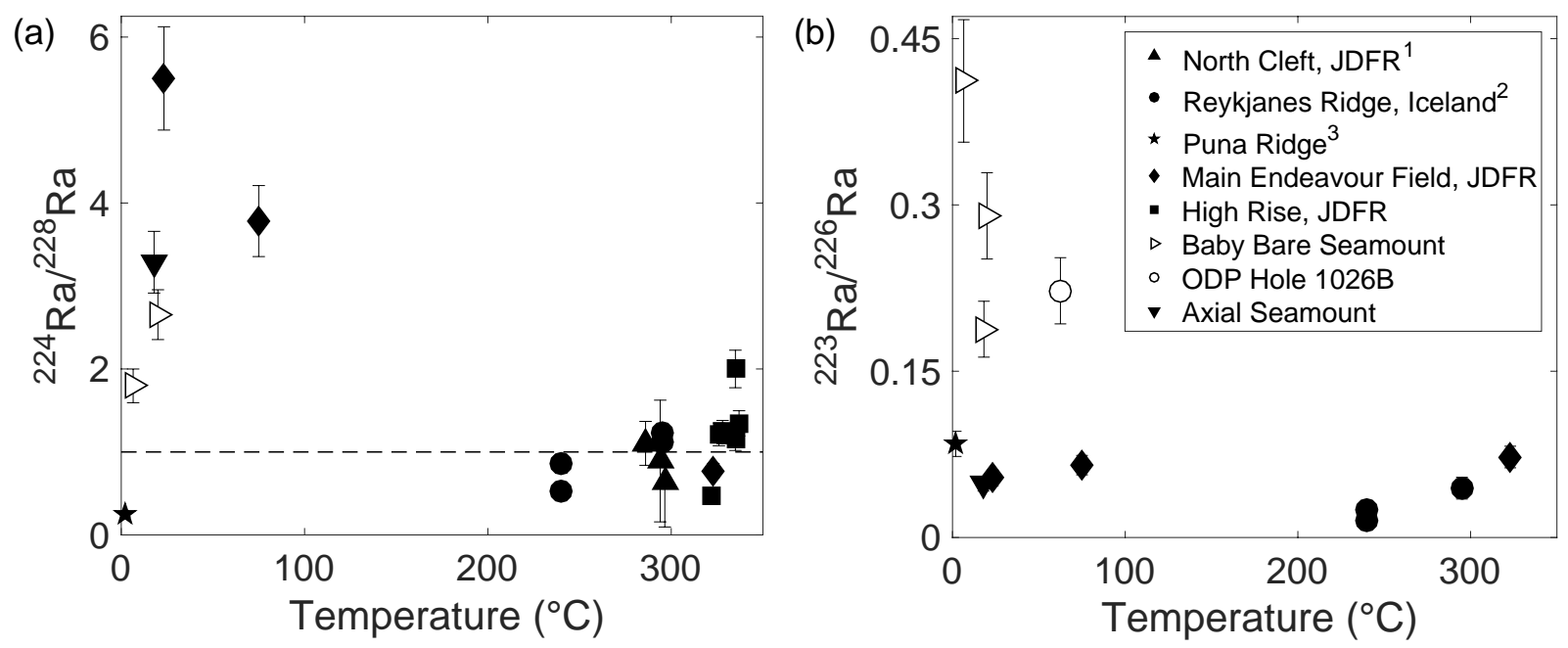

Figure 3. The (a) ${ }^{224} \mathrm{Ra} /{ }^{228} \mathrm{Ra}$ and (b) ${ }^{223} \mathrm{Ra} /{ }^{226} \mathrm{Ra}$ activity ratios in hydrothermal fluids as a function of temperature. The dashed line in (a) is set at a ${ }^{224} \mathrm{Ra} /{ }^{228} \mathrm{Ra}$ equal to one, representing secular equilibrium between the two isotopes. Samples collected from Clam Bed are not shown because they were compromised due to seawater entrainment during sampling. ${ }^{1}$ Kadko and Butterfield, 1998. ${ }^{2}$ Kadko et al., 2007. ${ }^{3}$ Moore et al., 2008. 

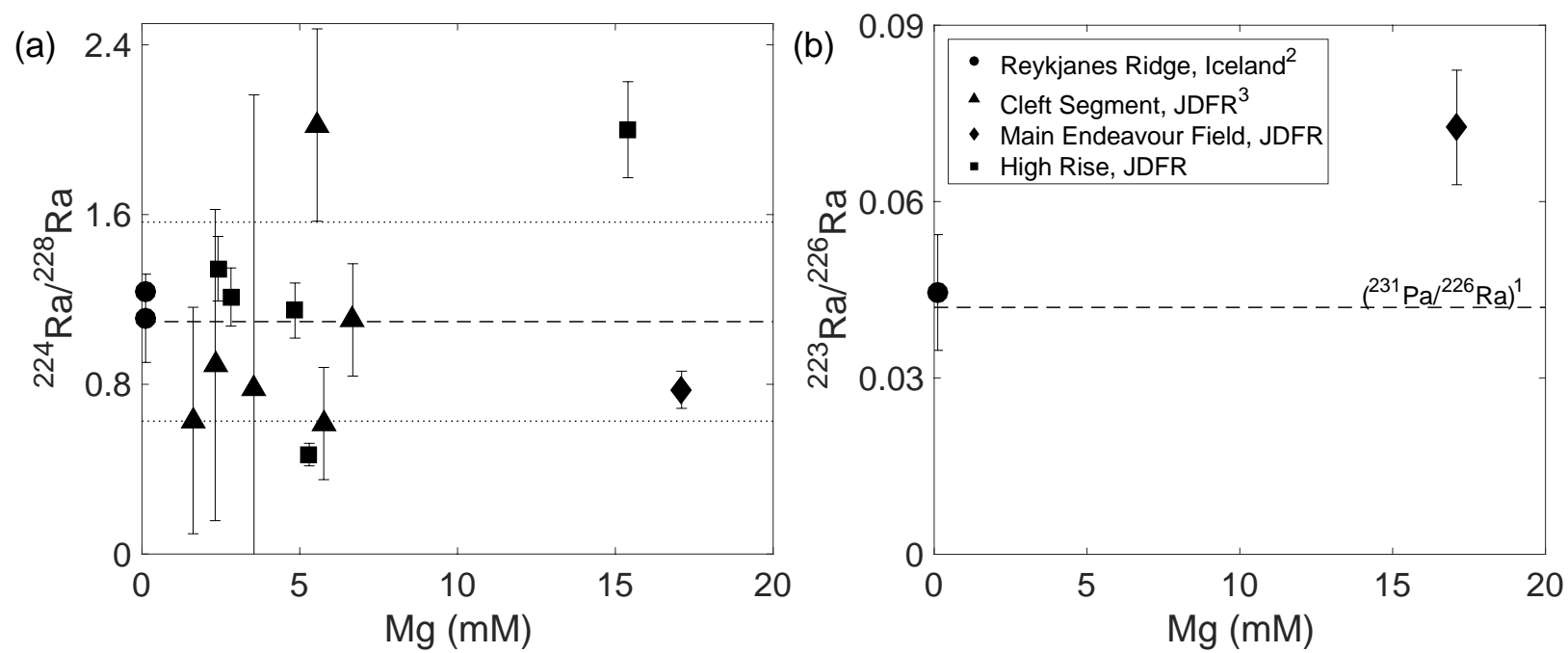

Figure 4. (a) The ${ }^{224} \mathrm{Ra} /{ }^{228} \mathrm{Ra}$ activity ratios observed in high temperature vent fluids as a function of $\mathrm{Mg}$ concentration. The dashed and dotted lines represent the average ratio and standard deviation $(1.1 \pm 0.5, \mathrm{n}=14)$. (b) $\mathrm{The}{ }^{223} \mathrm{Ra} /{ }^{226} \mathrm{Ra}$ activity ratios observed in high temperature vent fluids as a function of $\mathrm{Mg}$. Also shown is the average basalt ${ }^{231} \mathrm{~Pa} /{ }^{226} \mathrm{Ra}$ activity ratio observed on the EPR (dashed line). ${ }^{1}$ Lundstrom et al. (1999), Bourdon et al. (2000), and Sims et al. (2002). ${ }^{2}$ Kadko et al. (2007). ${ }^{3}$ Kadko and Butterfield, 1998. 


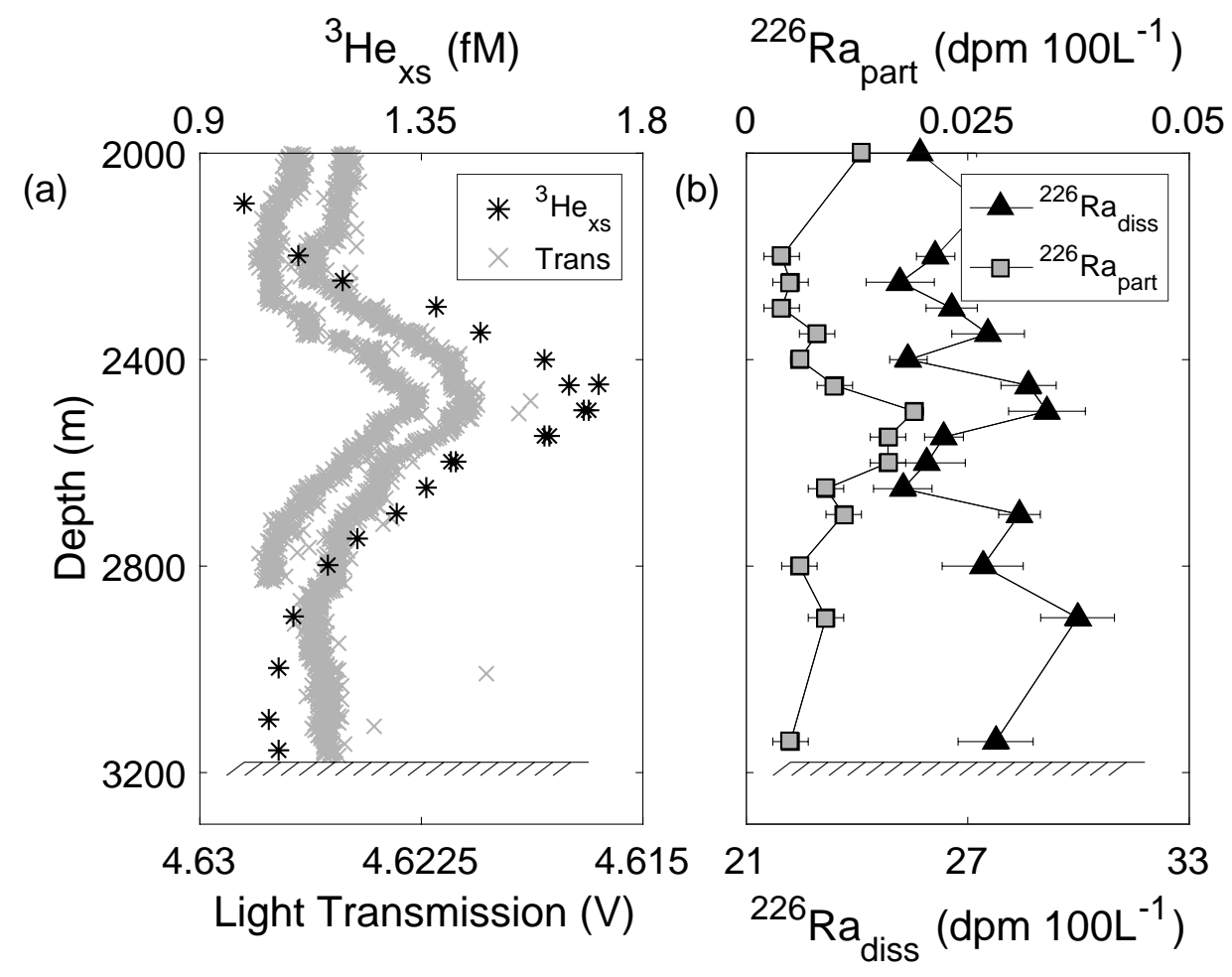

Figure 5. (a) Light transmission and ${ }^{3} \mathrm{He}_{\mathrm{xs}}$, and (b) particulate and dissolved ${ }^{226} \mathrm{Ra}$ measured at station 20 of GP16. ${ }^{3} \mathrm{He}_{\mathrm{xs}}$ concentrations are taken from Jenkins et al. (2018). The hatched lines represent the depth of the seafloor. 


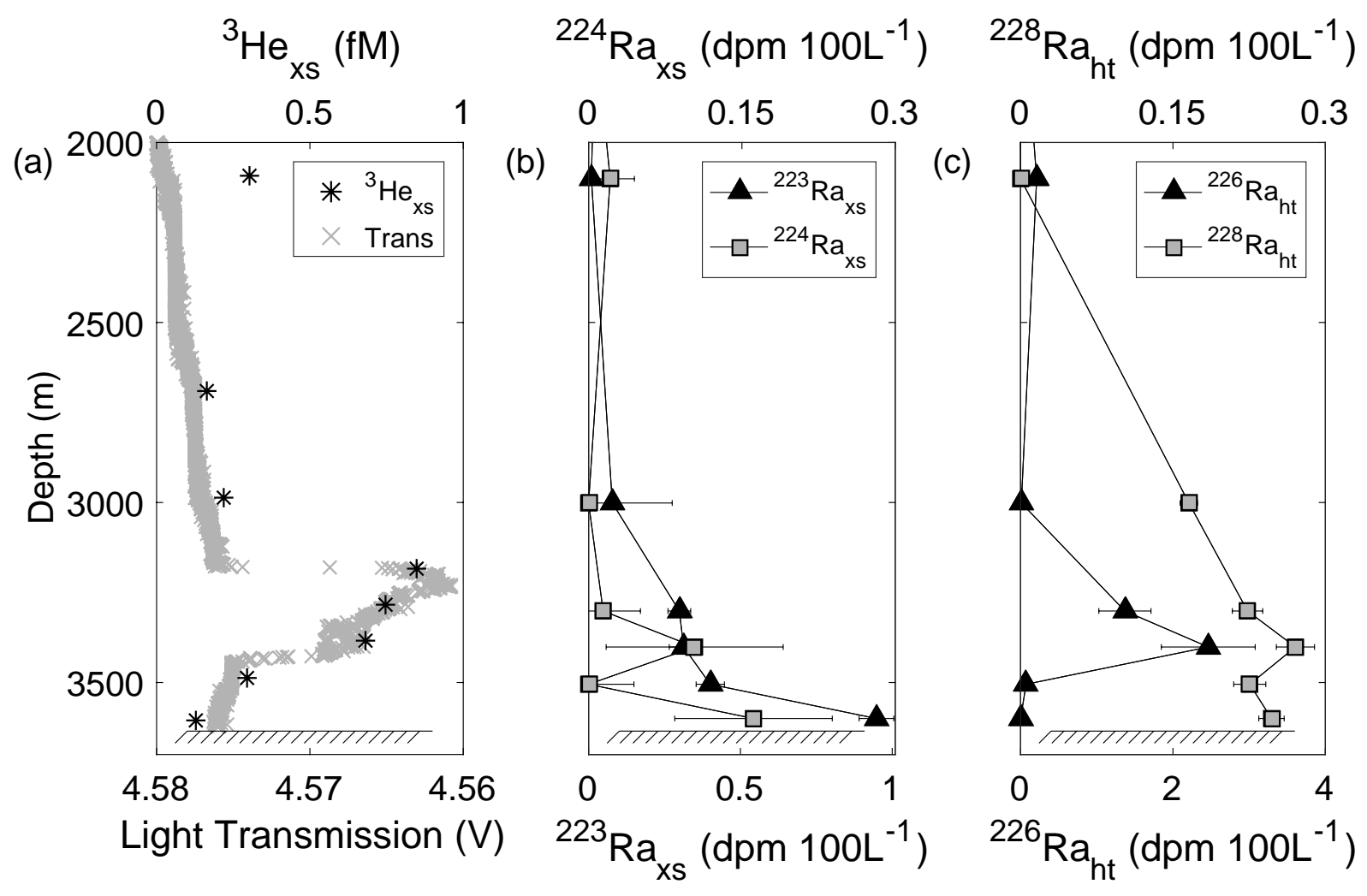

Figure 6. (a) Light transmission and ${ }^{3} \mathrm{He}_{\mathrm{xs}}$, (b) ${ }^{223} \mathrm{Ra}_{\mathrm{xs}}$ and ${ }^{224} \mathrm{Ra}_{\mathrm{xs}}$, and (c) ${ }^{226} \mathrm{Ra}_{\mathrm{ht}}$ and ${ }^{228} \mathrm{Ra}_{\mathrm{ht}}$ measured over TAG at station 16 of GA03. The slight increase in ${ }^{226} \mathrm{Ra}^{224}{ }^{22} \mathrm{Ra}_{\mathrm{xs}}$, and ${ }^{3} \mathrm{He}_{\mathrm{xs}}$ around $2000 \mathrm{~m}$ may be due to the stronger influence of Labrador Sea Water at this depth (see Jenkins et al., 2014), or possibly to influence from shallower hydrothermal inputs elsewhere on the ridge. ${ }^{3} \mathrm{He}_{\mathrm{xs}}$ concentrations were reported in Jenkins et al. (2014). The hatched lines represent the depth of the seafloor. Radium data from this station were previously published by Charette et al. (2015). 


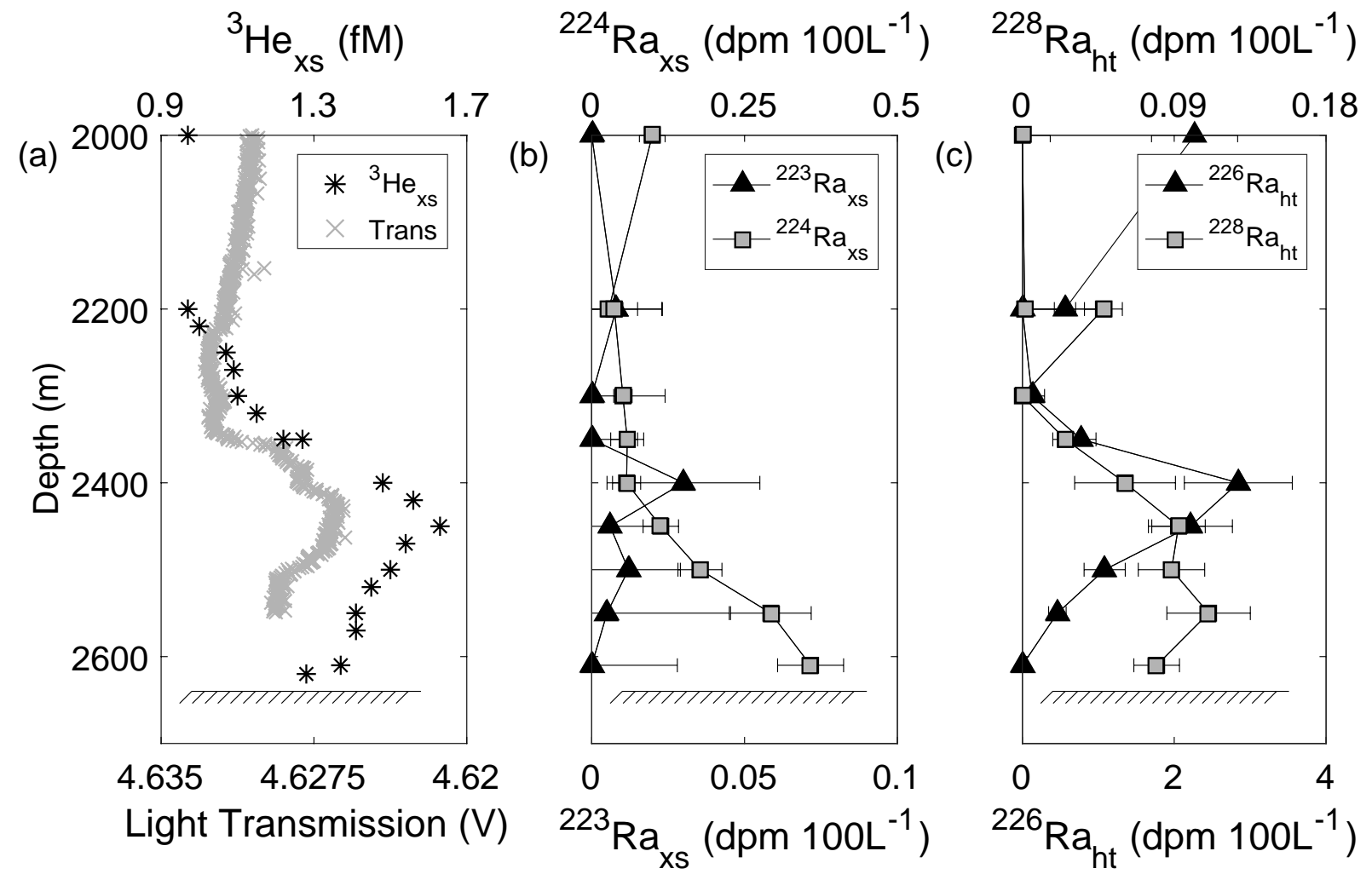

Figure 7. (a) Light transmission and ${ }^{3} \mathrm{He}_{\mathrm{xs}}$, (b) ${ }^{223} \mathrm{Ra}_{\mathrm{xs}}$ and ${ }^{224} \mathrm{Ra}_{\mathrm{xs}}$, and (c) ${ }^{226} \mathrm{Ra}_{\mathrm{ht}}$ and ${ }^{228} \mathrm{Ra}_{\mathrm{ht}}$ measured over the EPR at station 18 of GP16. See text for explanation of how excess and hydrothermal activities were calculated. The excess ${ }^{226} \mathrm{Ra}$ observed at $2000 \mathrm{~m}$ is due to the presence of a different water mass (Peters et al., 2018), not hydrothermal influence. ${ }^{3} \mathrm{He}_{\mathrm{xs}}$ concentrations are reported in Jenkins et al. (2018). The hatched lines represent the depth of the seafloor. 

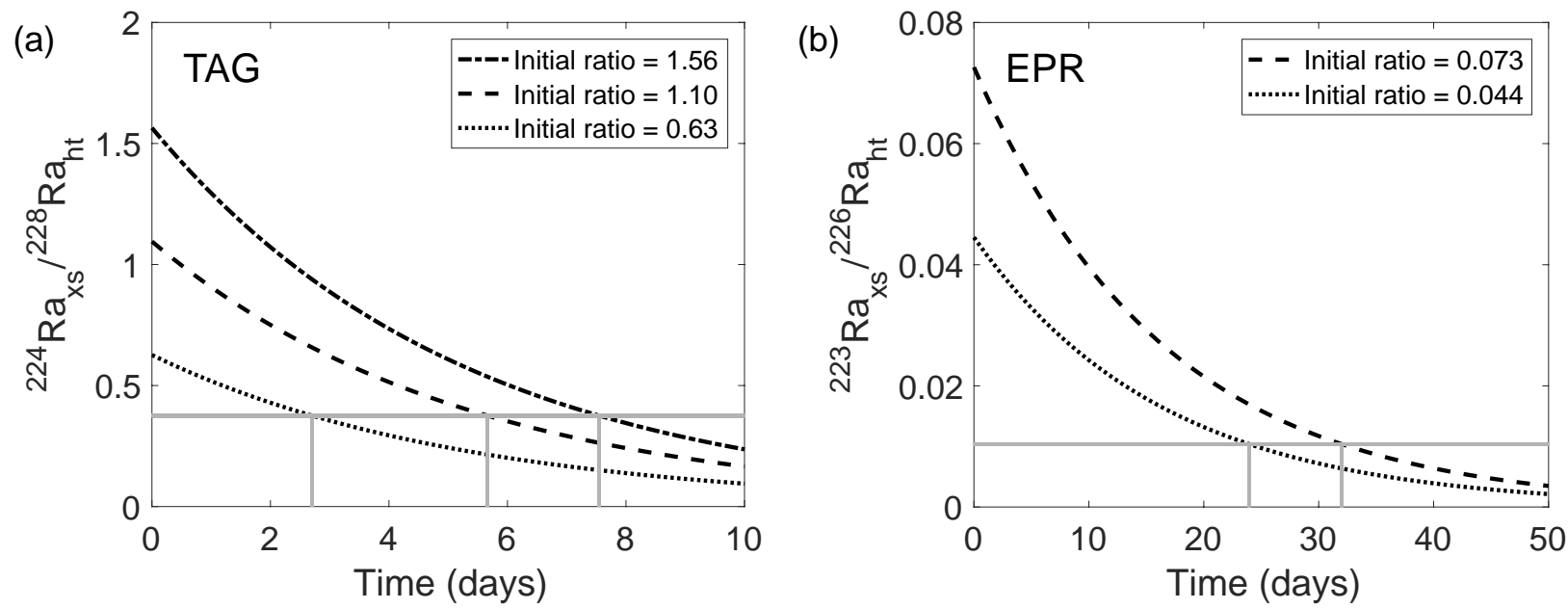

Figure 8. Models of Ra activity ratios as a function of plume age. The age of the neutrally buoyant plume is calculated using endmember vent fluid activity ratios (dotted lines) and the observed activity ratios in the neutrally buoyant plume (solid grey lines). (a) Based on the ${ }^{224} \mathrm{Ra}_{\mathrm{xs}} \rho^{228} \mathrm{Ra}$ at activity ratio, the age of the plume over TAG is estimated to be $2.7-7.5$ days. (b) Using the ${ }^{223} \mathrm{Ra}_{\mathrm{xs}}{ }^{226} \mathrm{Ra}_{\mathrm{ht}}$ activity ratio, the plume emanating from the EPR is estimated to be $24-$ 32 days old at the time of sampling. 


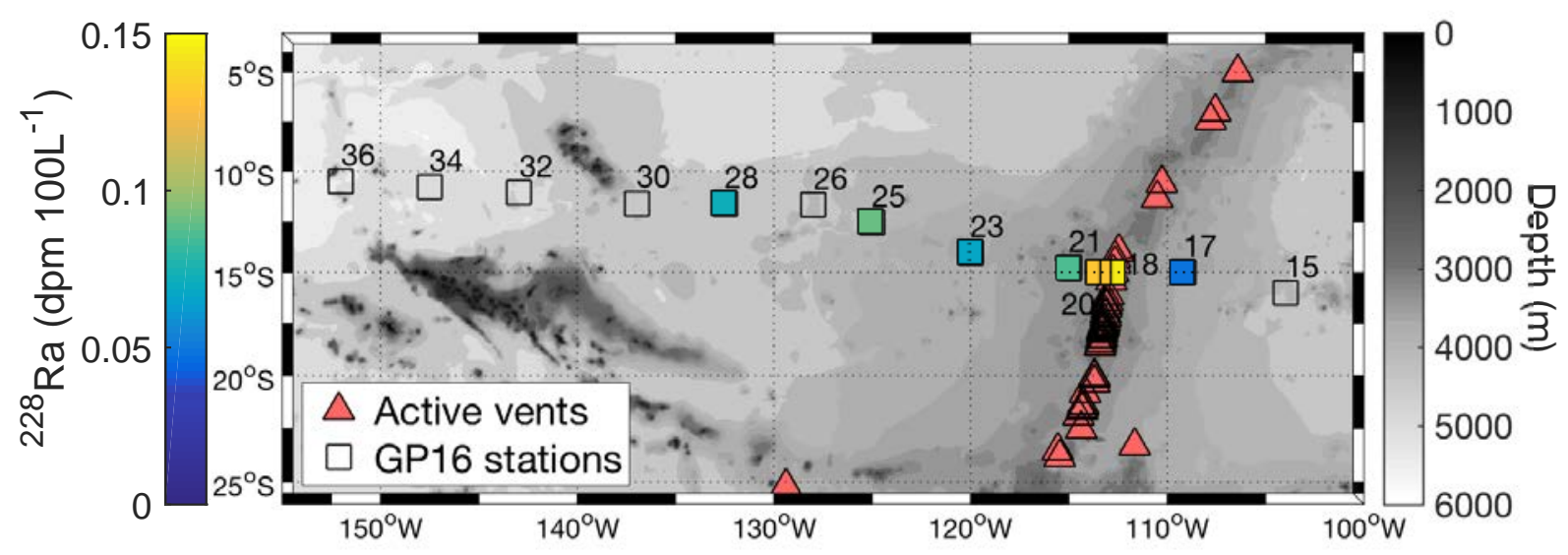

Figure 9. Radium-228 activities measured in the neutrally buoyant plume on the GP16 transect. Because multiple samples were collected within the plume (approx. $2450-2550 \mathrm{~m}$ ), the average activity measured at each station is shown. GP16 stations where samples were not analyzed for ${ }^{228} \mathrm{Ra}$ at the depth of the plume are shown as open squares and active hydrothermal vents on the East Pacific Rise are indicated with red triangles. Vent locations were compiled from the Ridge 2000 database (www.ridge2000.org). 

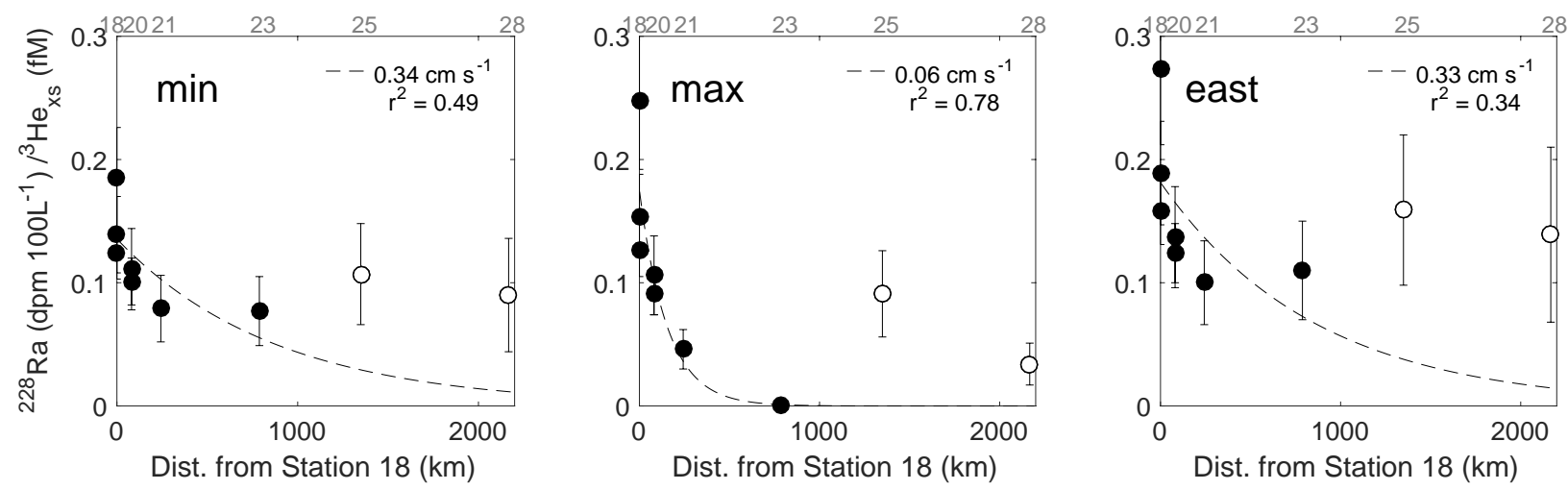

Figure 10. ${ }^{228} \mathrm{Ra}^{3} \mathrm{He}_{\mathrm{xs}}$ in the neutrally buoyant plume $(2450-2550 \mathrm{~m})$ as a function of distance from Station 18, located over the EPR. Exponential curves fit to the ${ }^{228} \mathrm{Ra}^{3} \mathrm{He}_{\mathrm{xs}}$ data are used to calculate current speeds, shown in the legend. The ${ }^{228} \mathrm{Ra}^{3} \mathrm{He}_{\mathrm{xs}}$ ratios have been corrected for background concentrations of ${ }^{3} \mathrm{He}_{\mathrm{xs}}$ and ${ }^{228} \mathrm{Ra}$; the labels on each of the panels designate the method by which background concentrations were calculated (see text). Station numbers are shown along the top axis in grey. Samples from stations 25 and 28, shown as open symbols, were not included in the trendline fit. ${ }^{3} \mathrm{He}_{\mathrm{xs}}$ concentrations are taken from Jenkins et al. (2018). 


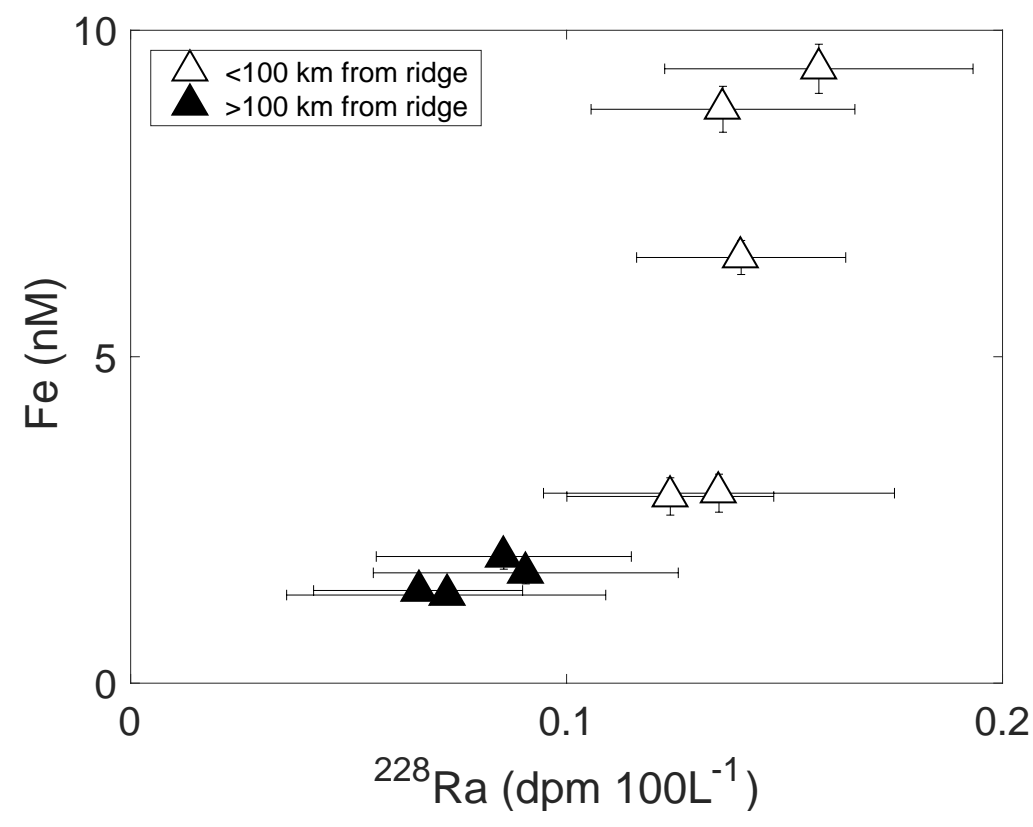

Figure 11. Concentrations of total $\mathrm{Fe}$ and ${ }^{228} \mathrm{Ra}$ in the neutrally buoyant hydrothermal plume from the ridge axis station to $2200 \mathrm{~km}$ west of the EPR. Open triangles indicate samples collected in the near-field plume $(<100 \mathrm{~km}$ from the ridge crest) while solid triangles indicate samples in the far-field plume $(>100 \mathrm{~km}$ from the ridge crest). Fe concentrations were taken from Resing et al. (2015). 

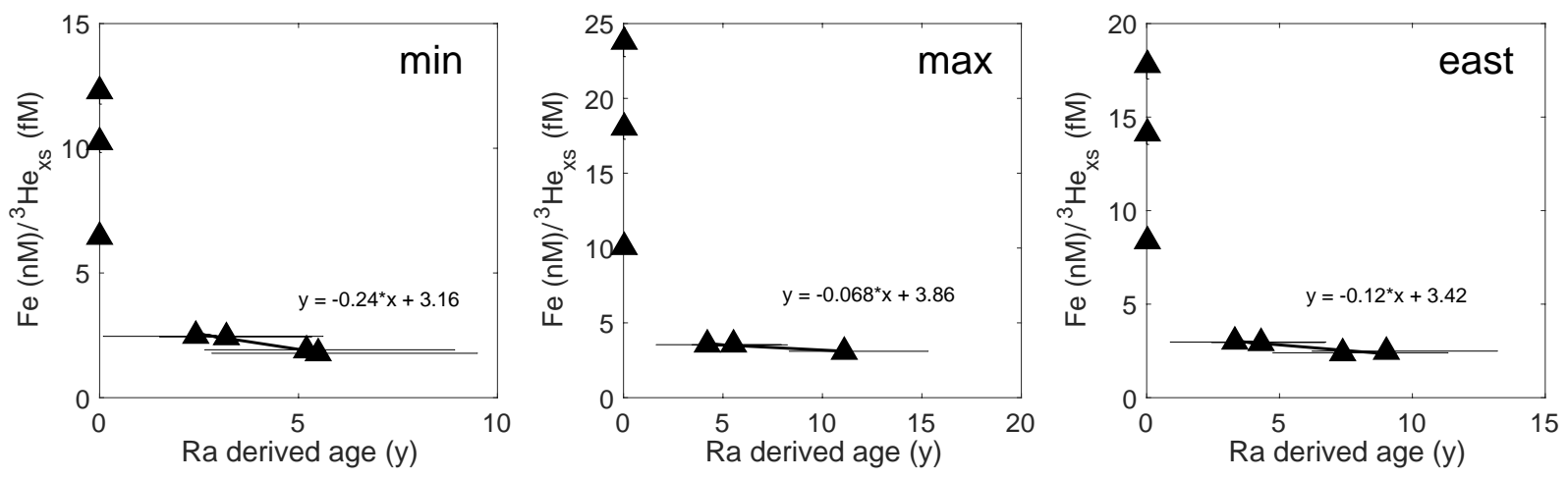

Figure 12. $\mathrm{Fe}^{3} \mathrm{He}_{\mathrm{xs}}$ as a function of the ${ }^{228} \mathrm{Ra}$-derived age. The equation of the trendline for the far-field samples is shown. Samples from stations 25 and 28 are not shown and were not included in the trendline fit. The $\mathrm{Fe} /{ }^{3} \mathrm{He}_{\mathrm{xs}}$ ratios have been corrected for background concentrations of ${ }^{3} \mathrm{He}_{\mathrm{xs}}$ and $\mathrm{Fe}$; the labels on each of the panels designate the method by which background concentrations were calculated (see text). ${ }^{3} \mathrm{He}_{\mathrm{xs}}$ concentrations were measured by Jenkins et al. (2018), and Fe concentrations were measured by Resing et al. (2015). 


\title{
Chapter 3: Increased fluxes of shelf-derived materials to the central Arctic Ocean
}

\begin{abstract}
Rising temperatures in the Arctic Ocean region are responsible for changes such as reduced ice cover, permafrost thawing, and increased river discharge, which together are altering nutrient and carbon cycles over the vast Arctic continental shelf. Here we show that the concentration of radium-228, sourced to seawater through sediment-water exchange processes, has increased substantially in surface waters of the central Arctic Ocean over the past decade. A mass balance model for ${ }^{228} \mathrm{Ra}$ suggests that this increase is due to an intensification of shelfderived material inputs to the central basin, a source that would also carry elevated concentrations of dissolved organic carbon and nutrients. We therefore suggest that significant changes in the nutrient, carbon, and trace metal balances of the Arctic Ocean are underway, with the potential to affect biological productivity and species assemblages in Arctic surface waters.
\end{abstract}

This chapter was originally published in Science Advances by AAAS in 2018 and is reproduced here with their permission.

Kipp, L.E., Charette, M.A., Moore, W.S., Henderson, P.B., Rigor, I.G., 2018. Increased fluxes of shelf-derived materials to the central Arctic Ocean. Sci. Adv. 4. doi:10.1126/sciadv.aao1302 


\subsection{INTRODUCTION}

The Arctic Ocean is heavily influenced by margin sources, in part due to the wide continental shelves that make up over $50 \%$ of its area (Jakobsson, 2002). Rising temperatures are causing shifts in the Arctic system, notably permafrost thawing on land and on continental shelves (Luo et al., 2016), increased river discharge (Rawlins et al., 2010), and reduced ice cover (Serreze et al., 2007); these changes serve to increase the communication between the shelves and the central basin. Permafrost thaw can release solutes from previously frozen mineral soils into groundwater and river waters-evidence of permafrost-derived carbon has recently been observed in river basins of the Eurasian Arctic (Feng et al., 2013). Rivers deliver terrestrial material including carbon and trace metals to the coastal ocean, some of which is exported to the central Arctic through the Transpolar Drift (TPD) (Klunder et al., 2012; Wheeler et al., 1997). The loss of sea ice will enhance the influence of wind stress on river plumes and coastal waters, which may increase offshore transport (Williams and Carmack, 2015) and lead to upwelling (Carmack and Chapman, 2003) and increased turbulence over shelves. Because the transport of shelf-derived nutrients and trace metals to the open ocean is vital in supporting primary productivity, it is important to understand how shelf inputs are changing in response to these drivers.

Radium isotopes are produced through the decay of naturally-occurring thorium isotopes in sediments. Unlike thorium, radium is relatively soluble in seawater (Key et al., 1985), hence short-lived radium concentrations in ocean surface waters are a first order indicator of shelf and margin-derived sediment-water exchange processes. Since thorium isotopes remain largely bound in sediments, ocean margin sediments provide a continuous source of radium, with each radium isotope being regenerated on a time scale determined by its half-life, such that shorterlived isotopes are renewed more quickly than longer-lived isotopes. Radium-228 $\left({ }^{228} \mathrm{Ra} ; \mathrm{t}_{1 / 2}=\right.$ $5.75 \mathrm{y}$ ) is well suited for monitoring changes in the shelf inputs, as it can integrate over large spatial scales and respond to changes on sub-decadal time periods. As such, this isotope has been applied as a flux gauge for sedimentary trace element inputs (Charette et al., 2016), and used to examine the relative importance of coastal inputs to the Atlantic, Pacific, and Indian Ocean basins (Kwon et al., 2014). Here we use ${ }^{228} \mathrm{Ra}$ to show that the flux of materials from shelves to the central Arctic has increased substantially over the last decade, indicating changes in surface water chemistry that could impact primary productivity in this basin.

\subsection{RESULTS AND DISCUSSION}

\subsubsection{Radium-228 distribution in surface waters and comparison to historical studies}

We measured the distribution of Ra isotopes in the Arctic Ocean from the Chukchi Shelf to the North Pole during the 2015 U.S. GEOTRACES Arctic Transect (GN01). Surface water samples $(2 \mathrm{~m})$ were collected at 69 stations (Fig. 1), while full water column profiles were obtained from 20 stations (Fig. S1). The ${ }^{228}$ Ra activities measured on the Chukchi Shelf were similar to activities measured in 2002 (Kadko and Muench, 2005; Trimble et al., 2004); however, in the upper $100 \mathrm{~m}$ of the central basin $(\mathrm{n}=30),{ }^{228} \mathrm{Ra}$ activities were higher than those observed in $1994(n=7)$ (Smith et al., 2003) and $2007(n=11)$ (Rutgers van der Loeff et al., 2012) (Figs. $2, \mathrm{~S} 2, \mathrm{~S} 3$ ). A period of abnormally strong and consistent cyclonic circulation conditions preceded 
sampling in 1994 (McLaughlin et al., 1996), causing the maximum ${ }^{228}$ Ra activities to be observed farther south $\left(80^{\circ} \mathrm{N}\right)$ than in 2007 and 2015 (Fig. S4). The 2015 data presented here and the 2007 study completed by Rutgers van der Loeff et al. (2012) are the two most extensive datasets of ${ }^{228} \mathrm{Ra}$ in the central Arctic, thus we will focus on the comparison between these two years.

Ice drift back-trajectories, used here as a proxy for mixed layer water mass transport (Alkire et al., 2007), suggest that water above $85^{\circ} \mathrm{N}$ originated from the East Siberian Arctic Shelf seas (Laptev and East Siberian Seas; ESAS) via the TPD (Figs. 1, S5) (see section 3.3). Radium-228 likely accumulated during the transport of water across the wide and shallow ESAS (Rutgers van der Loeff et al., 2003, 1995). Ice drift in 2007 followed a similar trajectory (Fig. S6), thus changing source waters cannot explain the difference in activities. Additionally, changes due to decay during transit can be ruled out since the transport time from the shelf to the central Arctic was similar in both years: ice back-trajectories suggest transport times of $4-16$ months and $8-18$ months for 2007 and 2015, respectively, and surface water ages based on the ingrowth of thorium-228 ( $\left.\mathrm{t}_{1 / 2}=1.91 \mathrm{y}\right)$ with ${ }^{228} \mathrm{Ra}$ suggest similar timescales of $6-12$ months for 2015 and $1-\geq 3$ y for 2007 (see section 3.3; Rutgers van der Loeff et al., 2012) (Fig. S7).

A Eurasian shelf source is supported by the relationship of ${ }^{228} \mathrm{Ra}$ with the longer-lived radium-226 $\left({ }^{226} \mathrm{Ra}, \mathrm{t}_{1 / 2}=1600 \mathrm{y}\right)$; this shelf endmember has a high ${ }^{228} \mathrm{Ra} /{ }^{226} \mathrm{Ra}$ ratio similar to that measured in the TPD (Fig. 3). A strong indication of shelf origin is also evident in the correlation between ${ }^{228} \mathrm{Ra}$ and the meteoric water fraction (Fig. 2). However, this indicator of terrestrial freshwater input was in the same range for 2007 and 2015, thus increased river discharge cannot fully account for the increase in ${ }^{228} \mathrm{Ra}$. Therefore, the change must be due to an increase in the input of ${ }^{228} \mathrm{Ra}$ from Arctic shelves.

\subsubsection{Sources and sinks of ${ }^{228} \mathrm{Ra}$ in surface waters}

Most ${ }^{228}$ Ra present in the upper $500 \mathrm{~m}$ of the ocean is due to shelf inputs (Sarmiento et al., 1982); the 2015 Arctic Ocean ${ }^{228} \mathrm{Ra}$ inventory for this layer is $(6.8 \pm 1.4) \times 10^{23}$ atoms. This inventory was determined by multiplying the average of the individual station inventories $((7.1 \pm$ $1.4) \times 10^{10}$ atoms $\mathrm{m}^{-2}$; Fig. S8) by the area of the Arctic as defined by Jakobsson (2002) $(9.54 \times$ $10^{12} \mathrm{~m}^{2}$; see section 3.3) (Fig. S8). Because this study provides an extensive dataset of ${ }^{228} \mathrm{Ra}$ in the upper water column, this inventory estimate is fairly robust. However, it is biased towards Western Arctic activities and could be improved with inventory measurements in the Eastern Arctic.

Arctic Ocean removal processes (sinks) for ${ }^{228} \mathrm{Ra}$ include loss via radioactive decay and transport from the Arctic basin. Applying the decay rate $\left(0.12 \mathrm{y}^{-1}\right)$ to the ${ }^{228} \mathrm{Ra}$ inventory yields a loss of $8.2 \times 10^{22}$ atoms $\mathrm{y}^{-1}$ (estimated range of $6.6 \times 10^{22}-9.9 \times 10^{22}$ atoms $^{-1}$; see section 3.3). The transport loss of ${ }^{228} \mathrm{Ra}$ is estimated by dividing the inventory of ${ }^{228} \mathrm{Ra}$ by the residence time of surface water, approximately 3 - 10 years (Schlosser et al., 1999). For a conservative estimate we use 10 years, resulting in a sink of $6.8 \times 10^{22}$ atoms $\mathrm{y}^{-1}\left(5.4 \times 10^{22}-1.6 \times 10^{23}\right.$ atoms $\left.\mathrm{y}^{-1}\right)$. Thus the total loss of ${ }^{228} \mathrm{Ra}$ from the surface ocean is $1.5 \times 10^{23}$ atoms $\mathrm{y}^{-1}\left(1.2 \times 10^{23}-2.6 \times 10^{23}\right.$ atoms $\mathrm{y}^{-1}$ ).

At steady-state, the ${ }^{228}$ Ra sinks are balanced by upper ocean sources. Sediments transported by ice to the central Arctic basin are a potential source of ${ }^{228} \mathrm{Ra}$ to the surface layer. Samples of ice containing visible sediment were collected on the GN01 transect and ${ }^{228} \mathrm{Ra}$ activities were measured in the melted ice and sediment fractions (see section 3.3). The highest 
sediment activity measured was $3.1 \pm 0.3 \mathrm{dpm} \mathrm{g}^{-1}\left((1.3 \pm 0.1) \times 10^{7}\right.$ atoms $\left.\mathrm{g}^{-1}\right)$ (Table S2), and $21 \%$ of the ${ }^{228} \mathrm{Ra}$ desorbed upon ice melting, though this percentage could vary depending on salinity and sediment properties. This sediment activity is similar to that measured on suspended and bottom sediments of the Amazon River (2 - $3 \mathrm{dpm} \mathrm{g}^{-1}$; Moore et al., 1995) and suspended sediments collected from the Mackenzie River ( $2.9 \mathrm{dpm} \mathrm{g}^{-1}$; see section 3.3). The concentration of ice rafted debris in the central Arctic is thought to vary between $8-84 \mathrm{t} \mathrm{km}^{-2}$ (Tucker et al., 1999), and seasonal ice melt equals $\sim 1.0 \times 10^{7} \mathrm{~km}^{2}$ (the average difference in September-March ice extent for 2010 - 2015; NOAA Sea Ice Index, Version 2). Using an average ice sediment concentration of $32 \mathrm{t} \mathrm{km}^{-2}$, and assuming $21 \%$ of the ${ }^{228} \mathrm{Ra}$ desorbed from the sediments upon melting, we estimate the flux of ${ }^{228} \mathrm{Ra}$ from ice rafted sediments to be $8.9 \times 10^{20}$ atoms $\mathrm{y}^{-1}(1.2 \times$ $10^{20}-4.0 \times 10^{21}$ atoms $\left.\mathrm{y}^{-1}\right)$. Though there is significant spatial and temporal variability associated with this source, this input is $<1 \%$ of the flux of ${ }^{228} \mathrm{Ra}$ to the surface layer.

Rivers supply ${ }^{228} \mathrm{Ra}$ to the ocean through the freshwater dissolved load and desorption of ${ }^{228} \mathrm{Ra}$ from suspended particles in the river estuaries (Moore et al., 1995). To investigate the dissolved river flux of ${ }^{228} \mathrm{Ra}$ to the Arctic, we collected bi-monthly water samples from the Mackenzie River in Tsiigehtchic, Northwest Territories, Canada, from April 2015 to June 2016 (Fig. S9). The average measured ${ }^{228}$ Ra activity, $16.8 \pm 3.7 \mathrm{dpm} 100 \mathrm{~L}^{-1}$, is similar to activities measured in the Lena River in September $1999\left(11.1-24.9 \mathrm{dpm} 100 \mathrm{~L}^{-1}\right)$ but significantly lower than the activity measured in the Ob River in September $1999\left(40.9 \pm 3.7 \mathrm{dpm} 100 \mathrm{~L}^{-1}\right)$ (Rutgers van der Loeff et al., 2003). The weighted average dissolved ${ }^{228} \mathrm{Ra}$ in major Arctic Rivers was determined to be $24 \pm 13 \mathrm{dpm} 100 \mathrm{~L}^{-1}$ based on the activities and discharge of these three rivers (see section 3.3). Scaling this activity by total Arctic river runoff $\left((4.2 \pm 0.42) \times 10^{12} \mathrm{~m}^{3} \mathrm{y}^{-1}\right.$; Haine et al., 2015) yields a dissolved ${ }^{228}$ Ra flux of $4.4 \times 10^{21}$ atoms $\mathrm{y}^{-1}\left(1.8 \times 10^{21}-7.4 \times 10^{21}\right.$ atoms $\mathrm{y}^{-1}$ ). However, this may be an overestimate because Ra removal through flocculation during estuarine mixing has been observed in the Lena and Ob Rivers (Rutgers van der Loeff et al., 2003), in contrast to the excess ${ }^{228}$ Ra observed in the Mackenzie River estuary (Fig. S10).

The flux of ${ }^{228} \mathrm{Ra}$ due to desorption from riverine particles was examined through sampling across the salinity gradient of the Mackenzie River Estuary in June 2016. The activity of ${ }^{228} \mathrm{Ra}$ measured in suspended riverine particles in the Mackenzie River was $2.9 \pm 0.3 \mathrm{dpm} \mathrm{g}^{-1}$, and approximately 32\% desorbed during estuarine mixing (see section 3.3) (Fig. S10). Scaling these values by the total sediment delivery from 13 of the largest Arctic rivers $\left(2.8 \times 10^{14} \mathrm{~g} \mathrm{y}^{-1}\right.$; Holmes et al., 2013) yields a river particle desorption flux of $1.1 \times 10^{21}$ atoms $\mathrm{y}^{-1}\left(2.5 \times 10^{20}-\right.$ $2.5 \times 10^{21}$ atoms $\left.\mathrm{y}^{-1}\right)$. Thus, the total riverine source is $5.5 \times 10^{21}$ atoms $\mathrm{y}^{-1}\left(2.0 \times 10^{21}-9.9 \times\right.$ $10^{21}$ atoms $\mathrm{y}^{-1}$ ), or about $4 \%$ of the total surface loss terms. There are significant seasonal variations in ${ }^{228} \mathrm{Ra}$ (Fig. S9) as well as river sediment and water discharge (Holmes et al., 2013), though they are unlikely to make Arctic rivers a major contributor to the surface ${ }^{228}$ Ra inventory. Inflowing Pacific and Atlantic Ocean waters supply ${ }^{228} \mathrm{Ra}$ to the surface Arctic Ocean. The Pacific inflow was estimated by multiplying the ${ }^{228} \mathrm{Ra}$ activity measured in the Bering Strait on the GN01 transect $\left(7.05 \pm 0.02 \mathrm{dpm} 100 \mathrm{~L}^{-1} ; 1 \sigma, \mathrm{n}=2\right)$ by the volume transport, $(3.5 \pm 0.3) \times$ $10^{13} \mathrm{~m}^{3} \mathrm{y}^{-1}$; Woodgate et al., 2012). While the Bering Strait inflow is well constrained, ${ }^{228} \mathrm{Ra}$ activities in the Bering Sea may vary seasonally as a result of physical processes over the shelf such as deep winter mixing. The Atlantic inflow is more difficult to constrain, but because the ${ }^{228} \mathrm{Ra}$ activities are relatively low, variations in this source will not significantly change its contribution to the surface ${ }^{228} \mathrm{Ra}$ inventory. The addition of ${ }^{228} \mathrm{Ra}$ from Atlantic inflow was determined using historical ${ }^{228} \mathrm{Ra}$ measurements in the Greenland and Norwegian Seas (Key et al., 1992) (1.35 $\left.\pm 0.72 \mathrm{dpm} 100 \mathrm{~L}^{-1} ; 1 \sigma, \mathrm{n}=14\right)$ and a transport rate of $2.0 \times 10^{14} \mathrm{~m}^{3} \mathrm{y}^{-1}$ 
(estimated range of $1.4 \times 10^{14}-2.1 \times 10^{14} \mathrm{~m}^{3} \mathrm{y}^{-1}$ ) through the Fram Strait and Barents Sea (Rudels et al., 2015). Thus the total input of ${ }^{228} \mathrm{Ra}$ through advection is $2.2 \times 10^{22}$ atoms ${ }^{-1}(1.4$ $\times 10^{22}-3.1 \times 10^{22}$ atoms $\mathrm{y}^{-1}$ ), accounting for $15 \%$ of the total ${ }^{228} \mathrm{Ra}$ input to the surface layer.

The combination of sources above leaves approximately $80 \%$ of the total ${ }^{228} \mathrm{Ra}$ input unaccounted for $\left(1.2 \times 10^{23}\right.$ atoms $\mathrm{y}^{-1}$, estimated range of $7.5 \times 10^{22}-2.5 \times 10^{23}$ atoms $^{-1}$; Table 1). The only other source with a ${ }^{228}$ Ra inventory large enough to close the ${ }^{228} \mathrm{Ra}$ budget is continental margin sediments. The sharp increase in ${ }^{228} \mathrm{Ra}$ activities observed between 2007 and 2015 indicates that the inputs of ${ }^{228} \mathrm{Ra}$ to Arctic surface waters are not currently in steady state; if shelf sediments are the major source of ${ }^{228} \mathrm{Ra}$ to surface waters this implies radical changes in near-shore sediment-water exchange processes.

\subsubsection{Changing shelf inputs}

Shelf processes that could supply significant amounts of ${ }^{228} \mathrm{Ra}$ to the water column include coastal erosion, permafrost thaw, and increased exchange between shelf sediments and overlying waters. Coastline erosion rates on the ESAS are some of the highest in the Arctic (Lantuit et al., 2012), and are rising due to increased storm frequency and higher air and sea temperatures (Günther et al., 2013). The amount of sediment added to the Arctic Ocean due to erosion is estimated to be $4.3 \times 10^{8} \mathrm{t}^{-1}$ (Stein and MacDonald, 2004). Assuming the ${ }^{228} \mathrm{Ra}$ activity of coastal sediments is the same as that of the suspended sediments measured in the Mackenzie River $\left(2.9 \pm 0.3 \mathrm{dpm} \mathrm{g}^{-1}\right)$, and that the same percentage desorbs when sediments are added to the ocean $(32 \%)$, the amount of ${ }^{228} \mathrm{Ra}$ added to the coastal ocean via erosion is on the order of $1.7 \times 10^{21}$ atoms $\mathrm{y}^{-1}$. The addition of ${ }^{228} \mathrm{Ra}$ from this process alone appears to be too small to close the ${ }^{228} \mathrm{Ra}$ budget.

Permafrost contains a reservoir of Ra that may be liberated as a consequence of deepening active layers (Luo et al., 2016) and a higher frequency and magnitude of coastal and inland thermokarst processes (Jorgenson et al., 2006; Lantz and Kokelj, 2008). The transport of solutes liberated through permafrost thaw has been observed on catchment wide scales (Kokelj et al., 2013) and could result in an increase in solute fluxes, including ${ }^{228} \mathrm{Ra}$, to Arctic shelf seas (Feng et al., 2013). Measurements of ${ }^{228} \mathrm{Ra}$ in permafrost collected from Inuvik and Tuktoyaktuk, Northwest Territories, Canada, show that ${ }^{228} \mathrm{Ra}$ activities in permafrost sediments $(2.5 \pm 0.4 \mathrm{dpm}$ $\left.\mathrm{g}^{-1} ; 1 \sigma, \mathrm{n}=4\right)$ are higher than those in the active (seasonally thawed) layer $\left(1.5 \pm 0.5 \mathrm{dpm} \mathrm{g}^{-1}\right.$; $1 \sigma, \mathrm{n}=6$ ) (see section 3.3). To our knowledge, these are the first Ra measurements in permafrost. Further studies on the spatial variability and desorption of radium isotopes from permafrost sediments are needed in order to estimate the magnitude of this source in the Arctic Ocean Ra budget under changing climate conditions. In addition to mobilization in runoff and river discharge, solutes can be transported to the coast through submarine groundwater discharge, which has been observed on the Laptev Shelf (Charkin et al., 2017) and may increase in the future as permafrost coverage is reduced (Walvoord et al., 2012), though the spatial variability of this source is poorly constrained.

Because of the large reservoir of $\mathrm{Ra}$ in shelf sediments, enhanced wind-driven vertical mixing over the shelves, a result of sea ice loss and a longer open water season (Rainville and Woodgate, 2009), has perhaps the greatest potential to impact the ${ }^{228}$ Ra budget. Over the inner ESAS, this process has the potential to increase sediment-water exchange over an extensive area. During the five year period preceding the 2015 survey, parts of the Laptev Sea experienced twice as many ice free days as the five year period preceding the 2007 study (Fig. S11), supporting the 
possibility for increased vertical mixing over the shelf between 2011 and 2015. The loss of ice cover and the presence of more mobile ice causes more surface stress, leading to increased vertical mixing as well as upwelling and/or downwelling over the shelf (Williams and Carmack, 2015); these vertical exchange processes bring ${ }^{228} \mathrm{Ra}$ sourced from shelf sediments to surface waters. Additionally, the retreat of the ice edge beyond the shelf break allows for wind-driven upwelling of deeper slope waters on to the shelf (Carmack and Chapman, 2003), which could transport additional ${ }^{228} \mathrm{Ra}$ released from slope sediments (such as the ${ }^{228} \mathrm{Ra}$ plumes observed off the Chukchi Slope; Fig. S1) to the surface. This mechanism of enrichment may also explain why activities over the Chukchi Shelf have not increased between 2002 (Kadko and Muench, 2005) and 2015, as there has not been a significant change in the number of ice free days over this shelf in the past decade (Fig. S11).

Shelf inputs are also supported by the ${ }^{226}$ Ra activities measured in 2007 and 2015 (Figs. $\mathrm{S} 12$ and S13). Because of the longer half-life of ${ }^{226} \mathrm{Ra}$, this isotope has a larger inventory in surface waters, and a substantial change in inputs is required to shift the observed activities. Radium-226 is also regenerated more slowly in shelf sediments such that a ${ }^{228} \mathrm{Ra} /{ }^{226} \mathrm{Ra}$ flux ratio greater than 1 is typical of a shelf sediment porewater source; ratios as high as 3.9 have been observed over the Laptev Shelf (Rutgers van der Loeff et al., 2003). Ratios between 0.9 and 2.1 were observed in the TPD in 2015 (Fig. 3), while the maximum ratio recorded in 2007 was 1.3 (Rutgers van der Loeff et al., 2012). The smaller increase in ${ }^{226} \mathrm{Ra}$ over this time period compared to ${ }^{228} \mathrm{Ra}$ is consistent with shelves being a relatively larger source of ${ }^{228} \mathrm{Ra}$; thus the major change in ${ }^{228} \mathrm{Ra}$ cannot be fully explained by a process that would affect both Ra isotopes in the same way (such as changes in biological uptake, remineralization, or coastal erosion). A longer residence time over the shelf could also increase the activities of both Ra isotopes in surface waters, but a doubling of the ${ }^{228} \mathrm{Ra}$ inventory over the shelf would require a similar increase in the shelf water residence time. This is unlikely given the rising freshwater fluxes to the shelves (Rawlins et al., 2010), and increasing wind stress resulting from longer open water seasons (Williams and Carmack, 2015).

Based on these two datasets alone, we cannot conclusively determine the mechanism driving increased shelf inputs. Measurements of ${ }^{228} \mathrm{Ra}$ over the shelves and in the central Arctic must be collected over multiple years and seasons in order to elucidate the temporal variability of this tracer, and more data from the endmember shelf seas are needed to constrain the spatial variability of the shelf source.

This study provides the first direct estimate of the Arctic shelf flux of ${ }^{228} \mathrm{Ra}$, which will act as an important baseline with which future changes in Arctic shelf-basin exchange can be monitored. While the current flux is similar to that in other ocean basins (Kwon et al., 2014) (Fig. 4A), when normalized to basin area it is apparent that shelf inputs have a disproportionately large impact in the Arctic (Fig. 4B). The increase in the supply of ${ }^{228} \mathrm{Ra}$ to the central Arctic implies that the fluxes of other shelf-derived species, including carbon, nutrients, and trace metals, must also be rising, with the potential for significant changes to the biogeochemistry of the central basin, as shelf waters are eventually transported to the central Arctic via the TPD. Indeed, historical observations of dissolved organic carbon and dissolved iron concentrations in the central Arctic show that these species are elevated in the TPD (Klunder et al., 2012; Wheeler et al., 1997). Varying nutrient and trace metal concentrations in the TPD will have a direct impact on primary productivity because this pathway delivers nutrients directly to the surface layer; if concentrations increase significantly, this intensified source may minimize the importance of the vertical mixing supply of nutrients from deep water. At present, productivity is 
low in the central Arctic due to both light and nutrient limitation (Codispoti et al., 2013). However, decreasing sea ice coverage will increase primary productivity and allow for a longer growing season (Arrigo et al., 2008); growth will also be supported by rising nutrient fluxes. Changing light and nutrient conditions may cause shifts in the dominant plankton species in surface waters, which in turn could impact higher trophic levels including fish species and marine mammals (Bluhm and Gradinger, 2008; McFarlane and Beamish, 1992). Continued monitoring of shelf inputs to Arctic surface waters is therefore vital to understanding how the changing climate will affect the chemistry, biology, and economic resources of the Arctic Ocean.

\subsection{MATERIALS AND METHODS}

\subsubsection{Surface sample collection and processing}

Surface water Ra samples $(280 \mathrm{~L}$ ) were collected from $\sim 2 \mathrm{~m}$ using a submersible surface pump and filtered through a $\mathrm{MnO}_{2}$ coated acrylic fiber, which quantitatively scavenges $\mathrm{Ra}$ from the seawater. Fiber samples were then ashed in a muffle furnace at $820^{\circ} \mathrm{C}$ for 24 hours and the fiber ash was transferred to polystyrene vials, sealed with epoxy (to prevent ${ }^{222} \mathrm{Rn}$ loss), aged for at least 3 weeks, and counted on a high purity, well-type germanium detector to measure ${ }^{228} \mathrm{Ra}$, using the lines of ${ }^{228} \mathrm{Ac}(338 \mathrm{KeV}$ and $911 \mathrm{KeV})$, and ${ }^{226} \mathrm{Ra}$, using the line for ${ }^{214} \mathrm{~Pb}(352 \mathrm{KeV})$. Detector efficiency was determined by measuring ashed fiber standards prepared with a standard solution containing ${ }^{226} \mathrm{Ra}$ and ${ }^{232} \mathrm{Th}$ with daughters in equilibrium. Analytical uncertainties are reported as $1 \sigma$.

\subsubsection{Water column sample collection and processing}

Water column Ra samples were collected using McLane in situ pumps (McLane WTSLV) deployed on a 3/8" plastic coated Vectran line. Seawater was filtered through $1 \mu \mathrm{m}$ filters to remove particles, and then pumped through a $\mathrm{MnO}_{2}$ coated cellulose cartridge to collect dissolved Ra, Th, and Ac isotopes (see Henderson et al., 2013) for details of cartridge preparation). Pumps were programmed to run for $4 \mathrm{~h}$, typically filtering $1200-1600 \mathrm{~L}$ of seawater at an average flow rate of $5.6 \mathrm{~L} \mathrm{~min}^{-1}$. After collection, cartridges were rinsed with Rafree fresh water and dried with filtered compressed air to remove excess moisture. To determine the cartridge scavenging efficiencies, small volume samples of ${ }^{226} \mathrm{Ra}(15-25 \mathrm{~L})$ were collected using a Niskin bottle mounted either on the CTD rosette (shallow casts) or above the pumps (deep casts), and the activities of Ra measured on these samples were compared to those determined on the cartridges.

Cartridges were ashed and analyzed by gamma spectrometry using the same method as the surface samples. Detector efficiencies were determined using ashed cartridge standards, and analytical uncertainties are reported as $1 \sigma$.

The small volume ${ }^{226} \mathrm{Ra}$ samples were filtered through $\mathrm{MnO}_{2}$ coated acrylic fibers. Fibers were then rinsed with Ra-free fresh water, partially dried, and sealed in a fiber housing for at least two weeks to allow for ${ }^{222} \mathrm{Rn}$ ingrowth. Samples were analyzed for ${ }^{226} \mathrm{Ra} v{ }^{2}{ }^{222} \mathrm{Ra}$ emanation and scintillation counting (Key et al., 1979). On average, samples were counted for approximately 230 minutes, resulting in an analytical error of less than $5 \%$. Fiber standards containing $20 \mathrm{dpm}{ }^{226} \mathrm{Ra}$ (NIST certified) were analyzed in the same way as the samples at least once every two weeks; standard reproducibility was $\sim 3 \%$. 
Comparisons between the unfiltered surface samples and the filtered near-surface samples revealed no consistent differences between filtered and unfiltered samples.

The Charette and Moore (GN01) and Rutgers van der Loeff (GIPY11) laboratories participated in the 2008 GEOTRACES intercalibration exercise and good agreement was found among the ${ }^{228} \mathrm{Ra}$ activities measured by all three labs (Charette et al., 2012).

\subsubsection{Ice back-trajectories}

The origin of the ice at each of the stations in the central Arctic was determined using back-trajectories of buoys deployed on sea ice and the open ocean as part of the International Arctic Buoy Program (IABP; http://iabp.apl.washington.edu/). The average lifetime of a buoy is $\sim 2$ years, and there are typically $20-30$ buoys drifting on pack ice at any given time. The location of each buoy is transmitted to the Argos or Iridium satellite system, which can determine the geographic position of the buoy with an accuracy of $\leq 300 \mathrm{~m}$ (Rigor et al., 2002). Sea ice motion was determined using monthly displacements as described in Rigor et al. (2002), and was projected back in time 36 months or until the buoy reached the coast. The estimated error on the back-trajectories is $\sim 100 \mathrm{~km} \mathrm{y}^{-1}$ (Pfirman et al., 1997).

We assume that the trajectories of ice drift are representative of large-scale circulation features of surface waters, such as the Transpolar Drift and Beaufort Gyre (Alkire et al., 2007). Ekman transport may also impact the movement of surface waters; at $7 \mathrm{~m}$ (the depth of sample collection in 2007 ) this may cause a $\sim 35^{\circ}$ offset between the ice and water movement (Cole et al., 2014).

\subsubsection{Surface water age}

Surface water transport times from the shelf to the location of sampling were estimated using ice back-trajectories by determining the number of months elapsed since the ice was over the shelf $(<200 \mathrm{~m})$. For the 2007 data this yielded a transport time of $4-16$ months; the estimated transport time in 2015 was $8-18$ months.

Surface water ages were also determined through the ingrowth of thorium- $228\left({ }^{228} \mathrm{Th}, \mathrm{t}_{1 / 2}\right.$ $=1.91 \mathrm{y}$ ), using the model derived by Rutgers van der Loeff et al. (2012) and briefly described here. Radium-228 decays to ${ }^{228} \mathrm{Th}$, which is particle reactive and efficiently scavenged in coastal waters; this results in low ${ }^{228} \mathrm{Th} /{ }^{228} \mathrm{Ra}$ activity ratios over continental shelves. Once water is advected off the shelf, decreased scavenging rates allow ${ }^{228}$ Th to grow toward equilibrium with its parent, ${ }^{228} \mathrm{Ra}$. Thus, the ${ }^{228} \mathrm{Th}$ activity away from the shelf $\left({ }^{228} \mathrm{Th}_{\mathrm{t}}\right)$ can be determined using Equation S1:

$$
\left({ }^{228} \mathrm{Th}_{\mathrm{t}}\right)=\left({ }^{228} \mathrm{Th}_{0}\right) \mathrm{e}^{-\left(\lambda_{\mathrm{Th}}+\lambda_{\mathrm{s}}\right) \mathrm{t}}+\frac{\lambda_{\mathrm{Th}}}{\lambda_{\mathrm{Th}}+\lambda_{\mathrm{s}}-\lambda_{\mathrm{Ra}}}\left({ }^{228} \mathrm{Ra}_{0}\right)\left(\mathrm{e}^{-\lambda_{\mathrm{Ra}} \mathrm{t}}-\mathrm{e}^{-\left(\lambda_{\mathrm{Th}}+\lambda_{\mathrm{s}}\right) \mathrm{t}}\right)
$$

where $\lambda_{s}$ is the scavenging rate constant once the water parcel leaves the shelf, ${ }^{228} \mathrm{Th}_{0}$ and ${ }^{228} \mathrm{Ra}_{0}$ are the initial ${ }^{228} \mathrm{Th}$ and ${ }^{228} \mathrm{Ra}$ activities over the shelf, $\lambda_{\mathrm{Th}}$ and $\lambda_{\mathrm{Ra}}$ are the ${ }^{228} \mathrm{Th}$ and ${ }^{228} \mathrm{Ra}$ decay constants, and $t$ is the time since the water parcel has left the shelf.

The activities of ${ }^{228} \mathrm{Ra}$ and ${ }^{228} \mathrm{Th}$ over the shelf were determined by finding the average activity of the surface samples collected at stations over the Chukchi Sea shelf (bottom depth $<50 \mathrm{~m} ; \mathrm{n}=4)$. The average ${ }^{228} \mathrm{Ra}$ activity was $7.17 \pm 0.52 \mathrm{dpm} 100 \mathrm{~L}^{-1}$ and the average ${ }^{228} \mathrm{Th}$ activity was $0.26 \pm 0.28 \mathrm{dpm} 100 \mathrm{~L}^{-1}$, corresponding to a ${ }^{228} \mathrm{Th} /{ }^{228} \mathrm{Ra}$ activity ratio of $0.04 \pm 0.04$ 
$(1 \sigma)$. This value is in agreement with previous studies: Kaufman et al. (1981) noted that the ratio is typically $<0.05$ in coastal waters, Kadko and Muench (2005) observed a ratio of $<0.06$ in Bering Strait inflow, and Lepore and Moran (2007) observed ratios of $0.2 \pm 0.2$ and $0.1 \pm 0.1$ over the Chukchi shelf break in the summers of 2002 and 2004, respectively. Rutgers van der Loeff et al. (2012) used a slightly higher shelf ratio of $0.15 \pm 0.05$ to calculate the age of waters originating over the Eastern Arctic shelves, but also noted that the model is not very sensitive to the initial ratio. A higher initial ratio would result in shorter transport times.

The scavenging rate constant is estimated using the ${ }^{234} \mathrm{Th}-{ }^{238} \mathrm{U}$ parent-daughter pair, with the assumption that the scavenging rate is the same for both Th isotopes. Equation S2 was used to determine the scavenging rate based on the ${ }^{234} \mathrm{Th} /{ }^{238} \mathrm{U}$ ratio observed in the shallowest samples from each station (5 $\mathrm{m}$ depth).

$$
\lambda_{S}=\frac{\lambda_{234 \mathrm{Th}}\left({ }^{1-}{ }^{234} \mathrm{Th} / 238 \mathrm{U}\right)}{{ }^{234} \mathrm{Th} / 238} \mathrm{U}
$$

where $\lambda_{s}$ is the scavenging rate constant, $\lambda_{234 \mathrm{Th}}$ is the ${ }^{234} \mathrm{Th}$ decay constant, and ${ }^{234} \mathrm{Th}$ and ${ }^{238} \mathrm{U}$ are the activities of total ${ }^{234} \mathrm{Th}$ and dissolved ${ }^{238} \mathrm{U}$, respectively.

Because the ${ }^{234} \mathrm{Th} /{ }^{238} \mathrm{U}$ ratio varied along the GN01 transect, we used the range in the observed ratios to determine the range of possible scavenging rates. Above $85^{\circ} \mathrm{N}$, the average scavenging rate was $0.43 \pm 0.46 \mathrm{y}^{-1}(1 \sigma)$; for the rest of the stations north of the shelf (stations 14-57) the minimum scavenging rate was $0 \mathrm{y}^{-1}$, and the maximum rate was $1.07 \mathrm{y}^{-1}$. Using these rates, the age of the water above $85^{\circ} \mathrm{N}$ was determined to be in the range of $0.52-0.95$ y $(6-12$ months) (Fig. S7). The ages derived from the ${ }^{228} \mathrm{Th} /{ }^{228} \mathrm{Ra}$ model are in good agreement with those determined from the ice back-trajectories ( 8 - 18 months).

Using the ${ }^{228} \mathrm{Th} /{ }^{228} \mathrm{Ra}$ ingrowth model, Rutgers van der Loeff et al. (2012) estimated the age of the surface waters in the TPD in 2007 to be $1-\geq 3$ y. This is slightly longer than the transport time based on ice drift. Both the ice back-trajectories and ${ }^{228} \mathrm{Th} /{ }^{228} \mathrm{Ra}$ ingrowth model require assumptions, but the generally good agreement between both methods and both years suggests that the surface water transport times in 2007 and 2015 were not drastically different. Because the difference in ${ }^{228} \mathrm{Ra}$ activities measured in these two years is about a factor of two, it would require a difference in transport time equal to one half-life, or $5.75 \mathrm{y}$, to explain the offset; based on the transport times derived here, we do not think this is likely.

\subsubsection{Meteoric water fraction}

Assuming the four main water masses present in the Arctic (Pacific, Atlantic, meteoric, and sea ice melt waters) have consistent and distinct properties, the contribution of each to the water sampled on the GN01 transect was determined using a system of linear equations. The properties of salinity, $\delta^{18} \mathrm{O}$, and nutrient concentrations were used to differentiate the contributions using the endmember compositions and "Arctic N-P" tracer method of Newton et al. (2013). The meteoric water fractions for the GIPY11 cruise in 2007 were determined by Bauch et al. (2011) using the same approach but slightly different endmember nutrient concentrations. Using the GN01 endmembers for the GIPY11 dataset would result in a difference of $<1.2 \%$ in the calculated meteoric water fraction. 


\subsubsection{Surface water inventory of ${ }^{228} \mathrm{Ra}$}

The ${ }^{228} \mathrm{Ra}$ inventory in surface waters was calculated using 10 stations in the central basin (bottom depth $>1,000 \mathrm{~m}$ ) where water column data for the upper $500 \mathrm{~m}$ were available (Table $\mathrm{S} 1)$. Two stations with bottom depths $>1,000 \mathrm{~m}$ were excluded from the inventory calculation due to poor sampling resolution. A depth threshold of $500 \mathrm{~m}$ was chosen because ${ }^{228} \mathrm{Ra}$ released from deep sea sediments is unlikely to reach the top $500 \mathrm{~m}$ (Sarmiento et al., 1982), thus any

${ }^{228} \mathrm{Ra}$ present in this layer must be from one of the margin sources included in the mass balance (rivers, ice rafted sediments, advection, continental shelves). Depth-integrated inventories were calculated for each station by summing the products of the average activity of two consecutive samples and the depth interval between those samples.

\subsubsection{Mass balance model: sinks}

\subsubsection{Decay}

The decay rate of ${ }^{228} \mathrm{Ra}$ is $0.12 \mathrm{y}^{-1}$; multiplying this rate by the surface inventory of ${ }^{228} \mathrm{Ra}$, $(6.8 \pm 1.4) \times 10^{23}$ atoms, results in a loss of $8.2 \times 10^{22}$ atoms $\mathrm{y}^{-1}$. As the decay rate of this isotope is well characterized, the uncertainty in this sink is a function of the error in the inventory estimate alone. The variability in the decay estimate was assessed using the standard deviation in the ${ }^{228} \mathrm{Ra}$ inventory, resulting in a range of $6.6 \times 10^{22}-9.9 \times 10^{22}$ atoms $\mathrm{y}^{-1}$.

\subsubsection{Transport}

The range in the ${ }^{228} \mathrm{Ra}$ transport sink $\left(5.4 \times 10^{22}-1.6 \times 10^{23}\right.$ atoms $\left.^{-1}\right)$ was determined by subtracting the standard deviation from the inventory and using a residence time of 10 years to find the minimum loss, and adding the standard deviation to the inventory and using a residence time of 5 years to find the maximum loss. We use a lower limit of 5 years for the residence time because the ${ }^{228} \mathrm{Ra}$ inventory was determined for the upper $500 \mathrm{~m}$ of the water column, which includes both the surface mixed layer (residence time of $3-5$ years) and part of the halocline (residence time of $\sim 10$ years; Schlosser et al., 1999). Additionally, the tritiumhelium age method used to determine the residence time likely underestimates the age of the surface layer, where some gaseous ${ }^{3} \mathrm{He}$ may have escaped to the atmosphere. Because of the range in possible residence times, the transport sink estimate is less robust than the decay term. For a conservative shelf flux estimate we use a residence time of 10 years in the model; using a shorter residence time would result in a larger sink and require a greater flux of ${ }^{228} \mathrm{Ra}$ from the shelves to close the mass balance.

\subsubsection{Mass balance model: sources}

\subsubsection{Ice rafted sediment}

Two samples of ice containing visible sediment were collected near $88^{\circ} \mathrm{N}$ during the GN01 transect. Ice was allowed to melt and samples were stored for approximately one year to allow for ${ }^{228} \mathrm{Ra}$ equilibration between the sediment and water phases. The melted ice and sediment fractions were separated by decanting the water and drying the sediments. The water 
was filtered through a small amount of $\mathrm{MnO}_{2}$ coated fiber, and the fiber was packed and epoxied in a small vial for direct measurement on a gamma detector. The activities of ${ }^{228} \mathrm{Ra}$ and ${ }^{226} \mathrm{Ra}$ were measured in both the melted ice and sediment fractions, using the lines of ${ }^{228} \mathrm{Ac}(911 \mathrm{KeV})$ and ${ }^{214} \mathrm{~Pb}(352 \mathrm{KeV})$ for ${ }^{228} \mathrm{Ra}$ and ${ }^{226} \mathrm{Ra}$, respectively. Detector efficiencies were determined with a fiber standard spiked with a solution of known ${ }^{228} \mathrm{Ra}$ and ${ }^{226} \mathrm{Ra}$ and prepared in the same geometry as the sample. The activity of ${ }^{228} \mathrm{Ra}$ in the sediments was determined to be $3.1 \pm 0.3$ $\mathrm{dpm} \mathrm{g}{ }^{-1}$ and $2.0 \pm 0.1 \mathrm{dpm} \mathrm{g}^{-1}$ and the activities in the corresponding melted ice samples were $0.55 \pm 0.17 \mathrm{dpm} \mathrm{L}^{-1}$ and below our detection limits, respectively (Table S2). To determine the amount of ${ }^{228} \mathrm{Ra}$ that desorbed from ice rafted sediments, the melted ice activity was converted to units of dpm $\mathrm{g}^{-1}$ by dividing by the volume of water filtered and multiplying by the amount of sediment present, and then this activity was divided by the activity measured in the sediments. The ${ }^{226} \mathrm{Ra}$ activities of the sediments were $1.4 \pm 0.1 \mathrm{dpm} \mathrm{g}^{-1}$ and $2.3 \pm 0.1 \mathrm{dpm} \mathrm{g}^{-1}$, and the respective melted ice activities were $0.38 \pm 0.15 \mathrm{dpm} \mathrm{L}^{-1}$ and $0.41 \pm 0.09 \mathrm{dpm} \mathrm{L}^{-1}$ (Table S2). Baskaran (2005) observed similar ${ }^{226} \mathrm{Ra}$ activities in ice rafted sediments collected in the Canada Basin in $2000\left(1.76-2.17 \mathrm{dpm} \mathrm{g}^{-1}\right)$.

A sample of surface sediments was also collected from the Chukchi Shelf on the GN01 transect $\left(68.0900^{\circ} \mathrm{N},-168.1055^{\circ} \mathrm{E}\right)$ using a multicorer device, and ${ }^{228} \mathrm{Ra}$ and ${ }^{226} \mathrm{Ra}$ activities were measured on the dried sediments. Six aliquots of sediment ( $\sim \mathrm{g}$ each) were analyzed using highpurity, well-type germanium gamma detectors, and the average activity of the six samples was $1.1 \pm 0.2 \mathrm{dpm}^{228} \mathrm{Ra} \mathrm{g}^{-1}$ and $1.2 \pm 0.1 \mathrm{dpm}^{226} \mathrm{Ra} \mathrm{g}^{-1}$. The suspended sediments collected in the Mackenzie River in 2016 had ${ }^{228} \mathrm{Ra}$ and ${ }^{226} \mathrm{Ra}$ activities of $2.9 \pm 0.3 \mathrm{dpm} \mathrm{g}^{-1}$ and $3.2 \pm 0.1 \mathrm{dpm} \mathrm{g}^{-}$ ${ }^{1}$, respectively. Based on these other measurements of ${ }^{228} \mathrm{Ra}$ and ${ }^{226} \mathrm{Ra}$ in Arctic sediments, we conclude that the ${ }^{228} \mathrm{Ra}$ activities measured in the ice rafted sediment samples are reasonable, and possibly even on the upper limit of what we would expect for Arctic sediments.

For the mass balance calculation we use the higher activity $\left(3.1 \pm 0.3 \mathrm{dpm}^{228} \mathrm{Ra} \mathrm{g}^{-1}\right)$ and propagate the errors on the melted ice and sediment fractions with the standard deviation in the amount of ice melt $\left((1.02 \pm 0.08) \times 10^{7} \mathrm{~km}^{2} \mathrm{y}\right.$; NOAA Sea Ice Index, Version 2) and the range in possible ice rafted sediment concentrations $\left(8-71 \mathrm{t} \mathrm{km}^{-2}\right.$; Tucker et al., 1999) to determine a final range of $1.2 \times 10^{20}-4.0 \times 10^{21}$ atoms $\mathrm{y}^{-1}$. This range of ice rafted sediment concentration was determined from samples collected during a transect from the Chukchi Sea to the central Arctic (similar to the path of the GN01 expedition). Based on the patterns of ice drift in 2015 (Fig. 1) it is possible that the ice sampled on the GN01 transect may have formed in the Laptev or East Siberian Seas; ice rafted sediment concentrations in the Laptev Sea have been found to vary between $9-45 \mathrm{t} \mathrm{km}^{-2}$ (average of $16 \mathrm{t} \mathrm{km}^{-2}$; Eicken et al., 1997), which is within the range used here.

\subsubsection{Rivers}

Bi-monthly river water samples were collected from the Mackenzie River in Tsiigehtchic, Northwest Territories, Canada between April 2015 and June 2016. A 20 L sample of surface water was collected and suspended sediments were allowed to settle overnight. Approximately 1 $\mathrm{L}$ of water was drained to remove most of the suspended sediments, then the remaining water was filtered through a raw acrylic fiber to remove most remaining sediment and through a $\mathrm{MnO}_{2}$ coated acrylic fiber to collect Ra. Fiber samples were then processed as described above. The annual weighted average ${ }^{228} \mathrm{Ra}$ activity of the Mackenzie River was determined to be $16.8 \pm 3.7$ dpm $100 \mathrm{~L}^{-1}(1 \sigma)$ (Fig. S9). Rutgers van der Loeff et al. (2003) measured similar activities in the 
Lena River $\left(11.1-24.9 \mathrm{dpm} 100 \mathrm{~L}^{-1}\right)$ but a significantly higher activity in the Ob River $(40.9 \pm$ $\left.3.7 \mathrm{dpm} 100 \mathrm{~L}^{-1}\right)$. The weighted average ${ }^{226} \mathrm{Ra}$ activity of the Mackenzie River was $17.2 \pm 4.0$ dpm $100 \mathrm{~L}^{-1}(1 \sigma)$, which falls between the activities previously observed in the $\mathrm{Ob}(27.3 \pm 0.6$ dpm $100 \mathrm{~L}^{-1}$ ) and the Lena (8.5 - $13.1 \mathrm{dpm} 100 \mathrm{~L}^{-1}$ ) (Rutgers van der Loeff et al., 2003).

A weighted average of the ${ }^{228} \mathrm{Ra}$ activities from these three rivers was calculated based on the amount of discharge from each river (Holmes et al., 2013). This average $\left(24 \pm 13 \mathrm{dpm} 100 \mathrm{~L}^{-}\right.$ ${ }^{1}$ ) was scaled by the runoff estimate of Haine et al. $(2015),(4.2 \pm 0.42) \times 10^{12} \mathrm{~m}^{3} \mathrm{y}^{-1}$, to yield a dissolved ${ }^{228}$ Ra flux of $4.4 \times 10^{21}$ atoms $\mathrm{y}^{-1}$. The error on this flux was calculated by propagating the standard deviations on each of the individual river activities with the error in the discharge estimate, resulting in a range of possible flux values between $1.8 \times 10^{21}-7.4 \times 10^{21}$ atoms $\mathrm{y}^{-1}$.

In June 2016, samples were collected across the salinity gradient in Kugmallit Bay, part of the East Channel of the Mackenzie River Delta. For salinities up to 15, surface water was collected using a surface submersible pump. For salinities 20 and 25, a Niskin bottle was used to collect water from $5 \mathrm{~m}$ and $9 \mathrm{~m}$, respectively. Each $20 \mathrm{~L}$ sample was pre-filtered through $10 \mu \mathrm{m}$ and $1 \mu \mathrm{M}$ Hytrex cartridges to remove suspended sediments before being filtered through an acrylic fiber coated with $\mathrm{MnO}_{2}$ to scavenge $\mathrm{Ra}$ isotopes. Fibers were then rinsed with Ra-free fresh water to remove salt and any remaining sediment, and ashed in a muffle furnace at $820^{\circ} \mathrm{C}$ for 24 hours. Fiber ash was transferred to polystyrene vials, sealed with epoxy (to prevent ${ }^{222} \mathrm{Rn}$ loss), and counted on high purity, well-type germanium detectors to measure ${ }^{228} \mathrm{Ra}$, using the line of ${ }^{228} \mathrm{Ac}(911 \mathrm{KeV})$, and ${ }^{226} \mathrm{Ra}$, using the line for ${ }^{214} \mathrm{~Pb}(352 \mathrm{KeV})$. Detector efficiencies were determined by measuring ashed fiber standards prepared with a standard solution containing ${ }^{226} \mathrm{Ra}$ and ${ }^{232} \mathrm{Th}$ with daughters in equilibrium.

The amount of ${ }^{228} \mathrm{Ra}$ released from suspended particles was determined to be $0.94 \pm 0.25$ $\mathrm{dpm} \mathrm{g}^{-1}$ by dividing the difference between the highest ${ }^{228} \mathrm{Ra}$ activities observed in the estuarine mixing zone (salinity $=3-9 ; 35 \pm 4 \mathrm{dpm} 100 \mathrm{~L}^{-1}, 1 \sigma, \mathrm{n}=3$ ) and the average ${ }^{228} \mathrm{Ra}$ activity in freshwater samples (salinity $<0.5 ; 19 \pm 4,1 \sigma, \mathrm{n}=7$ ) by the concentration of suspended particles in fresh Mackenzie River water $\left(0.17 \pm 0.02 \mathrm{~g} \mathrm{~L}^{-1}\right)$. This suspended sediment loading was determined by filtering a known amount of river water through a $0.22 \mu \mathrm{m}$ polyethersulfone membrane filter and dividing the weight of the dried sediments captured on the filter by the amount of water filtered. Due to the variability in the ${ }^{228} \mathrm{Ra}$ activity of the freshwater endmember (Figs. S9, S10), this estimate of desorbed ${ }^{228}$ Ra could be improved by further sampling in the Mackenzie River and in Eurasian Rivers.

The activity of ${ }^{228} \mathrm{Ra}$ measured in suspended particles was $2.9 \pm 0.3 \mathrm{dpm} \mathrm{g}^{-1}$, thus approximately $32 \%$ of the particulate ${ }^{228} \mathrm{Ra}$ desorbed during estuarine mixing; this is similar to previous estimates of ${ }^{228} \mathrm{Ra}$ desorption from riverine particles (Moore et al., 1995). However, this estimate is higher than the percentage of ${ }^{226} \mathrm{Ra}$ released from suspended sediments, which was determined to be $15 \%$ based on a difference in freshwater and estuarine activities of $8.2 \pm 0.7$ $\mathrm{dpm}{ }^{226} \mathrm{Ra} 100 \mathrm{~L}^{-1}$ and a particulate activity of $3.2 \pm 0.1 \mathrm{dpm}^{226} \mathrm{Ra} \mathrm{g}^{-1}$. Because the desorption of both $\mathrm{Ra}$ isotopes is expected to be similar, the larger release of ${ }^{228} \mathrm{Ra}$ in the estuarine mixing zone suggests that there is an additional input of ${ }^{228} \mathrm{Ra}$ from bottom sediments (Moore et al., 1995). Here we do not separate the addition of ${ }^{228} \mathrm{Ra}$ due to desorption from fresh riverine particles and the ${ }^{228} \mathrm{Ra}$ sourced from diffusion from benthic sediments or submarine groundwater discharge; this may overestimate the riverine source of ${ }^{228} \mathrm{Ra}$ and result in a more conservative estimate of the shelf source.

The activity of ${ }^{228} \mathrm{Ra}$ desorbed from suspended particles was scaled by the amount of sediment delivery from Arctic Rivers, $2.8 \times 10^{14} \mathrm{~g} \mathrm{y}^{-1}$ (Holmes et al., 2013), yielding a 
desorption flux of $1.1 \times 10^{21}$ atoms $\mathrm{y}^{-1}$. Holmes et al. (2013) did not provide an error estimate for sediment delivery, but the range in compiled literature values is $\pm 70 \%$. By propagating this variability with the errors on the ${ }^{228} \mathrm{Ra}$ measurements, we conclude that the range in the derived desorption flux is $2.5 \times 10^{20}-2.5 \times 10^{21}$ atoms $\mathrm{y}^{-1}$. Adding the dissolved ${ }^{228} \mathrm{Ra}$ flux and the flux of ${ }^{228} \mathrm{Ra}$ from desorption yields a best estimate of the total riverine flux of ${ }^{228} \mathrm{Ra}$ of $5.5 \times 10^{21}$ atoms $\mathrm{y}^{-1}$, with a possible range of $2.0 \times 10^{21}-9.9 \times 10^{21}$ atoms $\mathrm{y}^{-1}$.

\subsubsection{Permafrost}

Samples of active layer and permafrost sediments were collected from Inuvik and Tuktoyaktuk in the Northwest Territories, Canada, in June 2016. Sediments were dried and homogenized, and three $3 \mathrm{~g}$ aliquots from each sample were placed in polystyrene vials for analysis on high-purity well-type germanium gamma detectors. For the Tuktoyaktuk permafrost, only one $5 \mathrm{~g}$ aliquot of sediment was analyzed due to a scarcity of sediment. The activity of ${ }^{228} \mathrm{Ra}$ in the sediments was measured using the line of ${ }^{228} \mathrm{Ac}(911 \mathrm{KeV})$ and ${ }^{226} \mathrm{Ra}$ was measured using the line for ${ }^{214} \mathrm{~Pb}(352 \mathrm{KeV})$.

Similar to the pattern observed for ${ }^{228} \mathrm{Ra}$, activities of ${ }^{226} \mathrm{Ra}$ were higher in permafrost compared to active layer sediments: average activities of $2.2 \pm 0.3 \mathrm{dpm} \mathrm{g}^{-1}(1 \sigma, \mathrm{n}=4)$ and $1.8 \pm$ $0.3 \mathrm{dpm} \mathrm{g}^{-1}(1 \sigma, \mathrm{n}=6)$ were observed in permafrost and active layer sediments, respectively.

\subsubsection{Open water days}

The number of open water days was determined using daily bootstrap sea ice concentrations from Nimbus-7 SMMR and DMSP SSM/I-SSMIS data provided by the National Snow \& Ice Data Center (Comiso, 2015). An open water day was defined as any day during which the sea ice concentration was less than $15 \%$.

\section{Acknowledgements}

We thank the captain and crew of the USCGC Healy (HLY1502), and the chief scientists, D. Kadko and B. Landing, for their support during this expedition. We thank P. Lam, S. Pike, E. Black, M. Heller, Y. Xiang, P. Aguilar, and M. Stephens for their assistance in sample collection on the GN01 expedition; P. Schlosser, R. Newton, T. Koffman, and A. Pasqualini for sharing the water mass fraction data; E. Black and K. Buesseler for sharing the ${ }^{234} \mathrm{Th}$ and ${ }^{238} \mathrm{U}$ data; and L. Kutny for his help with the Mackenzie River sampling. I. Rigor (UW-APL) determined the ice back trajectories and the number of open water days.

\section{Funding}

This work was funded by US National Science Foundation awards OCE-1458305 to M.A.C. and OCE-1458424 to W.S.M. The Mackenzie River sampling was supported by a Graduate Student Research Award from the North Pacific Research Board to L.E.K. L.E.K. also acknowledges support from a National Defense Science \& Engineering Graduate Fellowship. 


\section{Competing interests}

The authors declare that they have no competing interests.

\section{Author contributions}

M.A.C. and W.S.M. designed the GN01 study. L.E.K. carried out GN01 sampling, analyzed samples, and wrote the first draft of the manuscript. W.S.M. and P.B.H. analyzed GN01 samples. I.G.R. determined ice back-trajectories and the number of ice-free days. L.E.K. and M.A.C. designed the Mackenzie River study, and L.E.K. and P.B.H. collected and analyzed samples from that expedition. All authors contributed to the interpretation of the data and the writing of the manuscript.

\section{Data and materials availability}

Data are available for download from the Biological \& Chemical Oceanography Data Management Office (BCO-DMO) at the following address: https://www.bcodmo.org/dataset/718440. 


\section{References}

Alkire, M.B., Falkner, K.K., Rigor, I., Steele, M., Morison, J., 2007. The return of Pacific waters to the upper layers of the central Arctic Ocean. Deep. Res. Part I Oceanogr. Res. Pap. 54, 1509-1529. doi:10.1016/j.dsr.2007.06.004

Arrigo, K.R., van Dijken, G., Pabi, S., 2008. Impact of a shrinking Arctic ice cover on marine primary production. Geophys. Res. Lett. 35, L19603. doi:10.1029/2008GL035028

Bacon, M.P., Huh, C.A., Moore, R.M., 1989. Vertical profiles of some natural radionuclides over the Alpha Ridge, Arctic Ocean. Earth Planet. Sci. Lett. 95, 15-22. doi:10.1016/0012821X(89)90164-7

Baskaran, M., 2005. Interaction of sea ice sediments and surface sea water in the Arctic Ocean: Evidence from excess ${ }^{210} \mathrm{~Pb}$. Geophys. Res. Lett. 32. doi:10.1029/2004GL022191

Bauch, D., van der Loeff, M.R., Andersen, N., Torres-Valdes, S., Bakker, K., Abrahamsen, E.P., 2011. Origin of freshwater and polynya water in the Arctic Ocean halocline in summer 2007. Prog. Oceanogr. 91, 482-495. doi:10.1016/j.pocean.2011.07.017

Bluhm, B.A., Gradinger, R., 2008. Regional variability in food availability for Arctic marine mammals. Ecol. Appl. 18, S77-S96. doi:10.1890/06-0562.1

Carmack, E., Chapman, D.C., 2003. Wind-driven shelf/basin exchange on an Arctic shelf: The joint roles of ice cover extent and shelf-break bathymetry. Geophys. Res. Lett. 30, 1778. doi:10.1029/2003GL017526

Charette, M.A., Dulaiova, H., Gonneea, M.E., Henderson, P.B., Moore, W.S., Scholten, J.C., Pham, M.K., 2012. GEOTRACES radium isotopes interlaboratory comparison experiment. Limnol. Oceanogr. Methods 10, 451-463. doi:10.4319/lom.2012.10.451

Charette, M.A., Lam, P.J., Lohan, M.C., Kwon, E.Y., Hatje, V., Jeandel, C., Shiller, A.M., Cutter, G.A., Thomas, A., Boyd, P.W., Homoky, W.B., Milne, A., Thomas, H., Andersson, P.S., Porcelli, D., Tanaka, T., Geibert, W., Dehairs, F., Garcia-Orellana, J., 2016. Coastal ocean and shelf-sea biogeochemical cycling of trace elements and isotopes: lessons learned from GEOTRACES. Philos. Trans. R. Soc. A Math. Phys. Eng. Sci. 374. doi:10.1098/rsta.2016.0076

Charkin, A.N., Rutgers van der Loeff, M., Shakhova, N.E., Gustafsson, Ö., Dudarev, O. V., Cherepnev, M.S., Salyuk, A.N., Koshurnikov, A. V., Spivak, E.A., Gunar, A.Y., Semiletov, I.P., 2017. Discovery and characterization of submarine groundwater discharge in the Siberian Arctic seas: A case study in Buor-Khaya Gulf, Laptev Sea. Cryosph. Discuss. doi:10.5194/tc-2017-33

Codispoti, L.A., Kelly, V., Thessen, A., Matrai, P., Suttles, S., Hill, V., Steele, M., Light, B., 2013. Synthesis of primary production in the Arctic Ocean: III. Nitrate and phosphate based estimates of net community production. Prog. Oceanogr. 110, 126-150. doi:10.1016/j.pocean.2012.11.006

Cole, S.T., Timmermans, M.-L., Toole, J.M., Krishfield, R.A., Thwaites, F.T., 2014. Ekman Veering, Internal Waves, and Turbulence Observed under Arctic Sea Ice. J. Phys. Oceanogr. 44, 1306-1328. doi:10.1175/JPO-D-12-0191.1

Comiso, J., 2015 Bootstrap Sea Ice Concentrations from Nimbus-7 SMMR and DMSP SSM/ISSMIS. Version 2. Daily. Boulder, Colorado USA: NASA DAAC at the National Snow and Ice Data Center.

Eakins, B.W., Sharman, G.F., 2010. Volumes of the World's Oceans from ETOPO1. NOAA National Geophysical Data Center, Boulder, CO. 
Eicken, H., Reimnitz, E., Alexandrov, V., Martin, T., Kassens, H., Viehoff, T., 1997. Sea-ice processes in the Laptev Sea and their importance for sediment export. Cont. Shelf Res. 17, 205-233. doi:10.1016/S0278-4343(96)00024-6

Feng, X., Vonk, J.E., van Dongen, B.E., Gustafsson, Ö., Semiletov, I.P., Dudarev, O. V, Wang, Z., Montluçon, D.B., Wacker, L., Eglinton, T.I., 2013. Differential mobilization of terrestrial carbon pools in Eurasian Arctic river basins. Proc. Natl. Acad. Sci. U.S.A. 110, 14168-14173. doi:10.1073/pnas.1307031110

Günther, F., Overduin, P.P., Sandakov, A. V., Grosse, G., Grigoriev, M.N., 2013. Short- and long-term thermo-erosion of ice-rich permafrost coasts in the Laptev Sea region.

Biogeosciences 10, 4297-4318. doi:10.5194/bg-10-4297-2013

Haine, T.W.N., Curry, B., Gerdes, R., Hansen, E., Karcher, M., Lee, C., Rudels, B., Spreen, G., de Steur, L., Stewart, K.D., Woodgate, R., 2015. Arctic freshwater export: Status, mechanisms, and prospects. Glob. Planet. Change 125, 13-35. doi:10.1016/j.gloplacha.2014.11.013

Henderson, P.B., Morris, P.J., Moore, W.S., Charette, M.A., 2013. Methodological advances for measuring low-level radium isotopes in seawater. J. Radioanal. Nucl. Chem. 296, 357-362. doi:10.1007/s10967-012-2047-9

Holmes, R.M., Coe, M.T., Fiske, G.J., Gurtovaya, T., McClelland, J.W., Shiklomanov, A.I., Spencer, R.G.M., Tank, S.E., Zhulidov, A. V., 2013. Climate Change Impacts on the Hydrology and Biogeochemistry of Arctic Rivers, in: Climatic Change and Global Warming of Inland Waters. John Wiley \& Sons, Ltd, Chichester, UK, pp. 3-26. doi:10.1002/9781118470596.ch1

Jakobsson, M., 2002. Hypsometry and volume of the Arctic Ocean and its constituent seas. Geochemistry, Geophys. Geosystems 3, 1-18. doi:10.1029/2001GC000302

Jorgenson, M.T., Shur, Y.L., Pullman, E.R., 2006. Abrupt increase in permafrost degradation in Arctic Alaska. Geophys. Res. Lett. 33, L02503. doi:10.1029/2005GL024960

Kadko, D., Muench, R., 2005. Evaluation of shelf-basin interaction in the western Arctic by use of short-lived radium isotopes: The importance of mesoscale processes. Deep. Res. Part II Top. Stud. Oceanogr. 52, 3227-3244. doi:10.1016/j.dsr2.2005.10.008

Kaufman, A., Li, Y.-H., Turekian, K.K., 1981. The removal rates of ${ }^{234}$ Th and ${ }^{228}$ Th from waters of the New York Bight. Earth Planet. Sci. Lett. 54, 385-392. doi:10.1016/0012821X(81)90054-6

Key, R.M., Brewer, R.L., Stockwell, J.H., Guinasso, N.L., Schink, D.R., 1979. Some improved techniques for measuring radon and radium in marine sediments and in seawater. Mar. Chem. 7, 251-264. doi:10.1016/0304-4203(79)90042-2

Key, R.M., Moore, W.S., Sarmiento, J.L., 1992. Transient tracers in the ocean north Atlantic study final data report for ${ }^{228} \mathrm{Ra}$ and ${ }^{226} \mathrm{Ra}$. Technical Report \#92-2. Princeton.

Key, R.M., Stallard, R.F., Moore, W.S., Sarmiento, J.L., 1985. Distribution and Flux of ${ }^{226}$ Ra and ${ }^{228} \mathrm{Ra}$ in the Amazon River Estuary. J. Geophys. Res. 90, 6995-7004. doi:10.1029/JC090iC04p06995

Klunder, M.B., Bauch, D., Laan, P., De Baar, H.J.W., Van Heuven, S., Ober, S., 2012. Dissolved iron in the Arctic shelf seas and surface waters of the central Arctic Ocean: Impact of Arctic river water and ice-melt. J. Geophys. Res. Ocean. 117. doi:10.1029/2011JC007133

Kokelj, S. V., Lacelle, D., Lantz, T.C., Tunnicliffe, J., Malone, L., Clark, I.D., Chin, K.S., 2013. Thawing of massive ground ice in mega slumps drives increases in stream sediment and solute flux across a range of watershed scales. J. Geophys. Res. Earth Surf. 118, 681-692. 
doi:10.1002/jgrf.20063

Kwon, E.Y., Kim, G., Primeau, F., Moore, W.S., Cho, H.-M., DeVries, T., Sarmiento, J.L., Charette, M.A., Cho, Y.-K., 2014. Global estimate of submarine groundwater discharge based on an observationally constrained radium isotope model. Geophys. Res. Lett. 41, 8438-8444. doi:10.1002/2014GL061574

Lantuit, H., Overduin, P.P., Couture, N., Wetterich, S., Aré, F., Atkinson, D., Brown, J., Cherkashov, G., Drozdov, D., Donald Forbes, L., Graves-Gaylord, A., Grigoriev, M., Hubberten, H.W., Jordan, J., Jorgenson, T., Ødegård, R.S., Ogorodov, S., Pollard, W.H., Rachold, V., Sedenko, S., Solomon, S., Steenhuisen, F., Streletskaya, I., Vasiliev, A., 2012. The Arctic Coastal Dynamics Database: A New Classification Scheme and Statistics on Arctic Permafrost Coastlines. Estuaries and Coasts 35, 383-400. doi:10.1007/s12237-0109362-6

Lantz, T.C., Kokelj, S. V., 2008. Increasing rates of retrogressive thaw slump activity in the Mackenzie Delta region, N.W.T., Canada. Geophys. Res. Lett. 35, L06502. doi:10.1029/2007GL032433

Lepore, K., Moran, S.B., 2007. Seasonal changes in thorium scavenging and particle aggregation in the western Arctic Ocean. Deep Sea Res. Part I Oceanogr. Res. Pap. 54, 919-938. doi:10.1016/j.dsr.2007.03.001

Luo, D., Wu, Q., Jin, H., Marchenko, S.S., Lü, L., Gao, S., 2016. Recent changes in the active layer thickness across the northern hemisphere. Environ. Earth Sci. 75. doi:10.1007/s12665015-5229-2

McFarlane, G.A., Beamish, R.J., 1992. Climatic Influence Linking Copepod Production with Strong Year-Classes in Sablefish, Anoplopoma fimbria. Can. J. Fish. Aquat. Sci. 49, 743753. doi:10.1139/f92-083

McLaughlin, F.A., Carmack, E.C., Macdonald, R.W., Bishop, J.K.B., 1996. Physical and geochemical properties across the Atlantic/Pacific water mass front in the southern Canadian Basin. J. Geophys. Res. 101. doi:10.1029/95JC02634

Moore, M., Smith, N., 1986. Disequilibria between ${ }^{226} \mathrm{Ra},{ }^{210} \mathrm{~Pb}$ and ${ }^{210} \mathrm{Po}$ in the Arctic Ocean and the implications for chemical modification of the Pacific water inflow. Earth Planet. Sci. Lett. 77, 285-292.

Moore, W.S., Astwood, H., Lindstrom, C., 1995. Radium isotopes in coastal waters on the Amazon shelf. Geochim. Cosmochim. Acta 59, 4285-4298. doi:10.1016/00167037(95)00242-R

Newton, R., Schlosser, P., Mortlock, R., Swift, J., MacDonald, R., 2013. Canadian Basin freshwater sources and changes: Results from the 2005 Arctic Ocean Section. J. Geophys. Res. Ocean. 118, 2133-2154. doi:10.1002/jgrc.20101

Pfirman, S.L., Colony, R., Nürnberg, D., Eicken, H., Rigor, I., 1997. Reconstructing the origin and trajectory of drifting Arctic sea ice. J. Geophys. Res. Ocean. 102, 12575-12586. doi:10.1029/96JC03980

Rainville, L., Woodgate, R.A., 2009. Observations of internal wave generation in the seasonally ice-free Arctic. Geophys. Res. Lett. 36, L23604. doi:10.1029/2009GL041291

Rawlins, M.A., Steele, M., Holland, M.M., Adam, J.C., Cherry, J.E., Francis, J.A., Groisman, P.Y., Hinzman, L.D., Huntington, T.G., Kane, D.L., Kimball, J.S., Kwok, R., Lammers, R.B., Lee, C.M., Lettenmaier, D.P., McDonald, K.C., Podest, E., Pundsack, J.W., Rudels, B., Serreze, M.C., Shiklomanov, A., Skagseth, Ø., Troy, T.J., Vörösmarty, C.J., Wensnahan, M., Wood, E.F., Woodgate, R., Yang, D., Zhang, K., Zhang, T., 2010. 
Analysis of the Arctic System for Freshwater Cycle Intensification: Observations and Expectations. J. Clim. 23, 5715-5737. doi:10.1175/2010JCLI3421.1

Rigor, I.G., Wallace, J.M., Colony, R.L., 2002. Response of Sea Ice to the Arctic Oscillation. J. Clim. 15, 2648-2663. doi:10.1175/1520-0442(2002)015<2648:ROSITT>2.0.CO;2

Rudels, B., Korhonen, M., Schauer, U., Pisarev, S., Rabe, B., Wisotzki, A., 2015. Circulation and transformation of Atlantic water in the Eurasian Basin and the contribution of the Fram Strait inflow branch to the Arctic Ocean heat budget. Prog. Oceanogr. 132, 128-152. doi:10.1016/j.pocean.2014.04.003

Rutgers van der Loeff, M., Cai, P., Stimac, I., Bauch, D., Hanfland, C., Roeske, T., Moran, S.B., 2012. Shelf-basin exchange times of Arctic surface waters estimated from ${ }^{228} \mathrm{Th} /{ }^{228} \mathrm{Ra}$ disequilibrium. J. Geophys. Res. 117, C03024. doi:10.1029/2011JC007478

Rutgers van der Loeff, M., Key, R.M., Scholten, J., Bauch, D., Michel, A., 1995. ${ }^{228}$ Ra as a tracer for shelf water in the Arctic Ocean. Deep Sea Res. Part II Top. Stud. Oceanogr. 42, $1533-1553$.

Rutgers van der Loeff, M., Kuhne, S., Wahsner, M., Holtzen, H., Frank, M., Ekwurzel, B., Mensch, M., Rachold, V., 2003. ${ }^{228} \mathrm{Ra}$ and ${ }^{226} \mathrm{Ra}$ in the Kara and Laptev seas. Cont. Shelf Res. 23, 113-124. doi:10.1016/S0304-4203(98)00070-X

Sarmiento, J.L., Rooth, C.G.H., Broecker, W.S., 1982. Radium 228 as a tracer of basin wide processes in the abyssal ocean. J. Geophys. Res. Ocean. 87, 9694-9698. doi:10.1029/JC087iC12p09694

Schlosser, P., Bayer, R., Bönisch, G., Cooper, L.W., Ekwurzel, B., Jenkins, W.J., Khatiwala, S., Pfirman, S., Smethie, W.M., 1999. Pathways and mean residence times of dissolved pollutants in the ocean derived from transient tracers and stable isotopes. Sci. Total Environ. 237-238, 15-30. doi:10.1016/S0048-9697(99)00121-7

Serreze, M.C., Holland, M.M., Stroeve, J., 2007. Perspectives on the Arctic's Shrinking Sea-Ice Cover. Science. 315, 1533-1536. doi:10.1126/science.1139426

Smith, J.N., Moran, S.B., Macdonald, R.W., 2003. Shelf-basin interactions in the Arctic Ocean based on ${ }^{210} \mathrm{~Pb}$ and $\mathrm{Ra}$ isotope tracer distributions. Deep Sea Res. Part I Oceanogr. Res. Pap. 50, 397-416. doi:10.1016/S0967-0637(02)00166-8

Stein, R., MacDonald, R.W. (Eds.), 2004. The Organic Carbon Cycle in the Arctic Ocean. Springer Berlin Heidelberg, Berlin, Heidelberg. doi:10.1007/978-3-642-18912-8

Trimble, S.M., Baskaran, M., Porcelli, D., 2004. Scavenging of thorium isotopes in the Canada Basin of the Arctic Ocean. Earth Planet. Sci. Lett. 222, 915-932. doi:10.1016/j.epsl.2004.03.027

Tucker, W.B., Gow, A.J., Meese, D.A., Bosworth, H.W., Reimnitz, E., 1999. Physical characteristics of summer sea ice across the Arctic Ocean. J. Geophys. Res. Ocean. 104, 1489-1504. doi:10.1029/98JC02607

Walvoord, M.A., Voss, C.I., Wellman, T.P., 2012. Influence of permafrost distribution on groundwater flow in the context of climate-driven permafrost thaw: Example from Yukon Flats Basin, Alaska, United States. Water Resour. Res. 48, W07524. doi:10.1029/2011WR011595

Wheeler, P.A., Watkins, J.M., Hansing, R.L., 1997. Nutrients, organic carbon and organic nitrogen in the upper water column of the Arctic Ocean: implications for the sources of dissolved organic carbon. Deep Sea Res. Part II Top. Stud. Oceanogr. 44, 1571-1592.

Williams, W.J., Carmack, E.C., 2015. The "interior" shelves of the Arctic Ocean: Physical oceanographic setting, climatology and effects of sea-ice retreat on cross-shelf exchange. 
Prog. Oceanogr. 139, 24-41. doi:10.1016/j.pocean.2015.07.008

Woodgate, R.A., Weingartner, T.J., Lindsay, R., 2012. Observed increases in Bering Strait oceanic fluxes from the Pacific to the Arctic from 2001 to 2011 and their impacts on the Arctic Ocean water column. Geophys. Res. Lett. 39, L24603. doi:10.1029/2012GL054092 
Table 1. Radium-228 sources and sinks (all in $10^{22}$ atoms $y^{-1}$ ) in the Arctic surface ocean. The shelf flux was determined by difference, assuming that at steady state, the sources of ${ }^{228} \mathrm{Ra}$ to the surface layer must be balanced by sinks. The best estimate for each term was used in the mass balance calculation; see section 3.3 for details on how the minimum and maximum flux estimates were determined.

\begin{tabular}{|c|c|c|c|c|}
\hline Sinks & $\begin{array}{l}\text { Best Estimate Flux } \\
\left(10^{22} \text { atoms } y^{-1}\right)\end{array}$ & $\begin{array}{l}\text { Minimum Flux } \\
\left(10^{22} \text { atoms } y^{-1}\right)\end{array}$ & $\begin{array}{l}\text { Maximum Flux } \\
\left(10^{22} \text { atoms } y^{-1}\right)\end{array}$ & $\%$ of total sinks \\
\hline Decay & 8.2 & 6.6 & 9.9 & $55 \%$ \\
\hline Advection & 6.8 & 5.4 & 16 & $45 \%$ \\
\hline
\end{tabular}

\begin{tabular}{|c|c|c|c|c|}
\hline Sources & $\begin{array}{l}\text { Best Estimate Flux } \\
\left(10^{22} \text { atoms } y^{-1}\right)\end{array}$ & $\begin{array}{l}\text { Minimum Flux } \\
\left(10^{22} \text { atoms } y^{-1}\right)\end{array}$ & $\begin{array}{l}\text { Maximum Flux } \\
\left(10^{22} \text { atoms } y^{-1}\right)\end{array}$ & $\%$ of total sources \\
\hline Ice rafted sediment & 0.089 & 0.012 & 0.40 & $<1 \%$ \\
\hline Advection & 2.2 & 1.4 & 3.1 & $15 \%$ \\
\hline Rivers & 0.55 & 0.20 & 0.99 & $4 \%$ \\
\hline Shelf & 12 & 7.5 & 25 & $81 \%$ \\
\hline
\end{tabular}




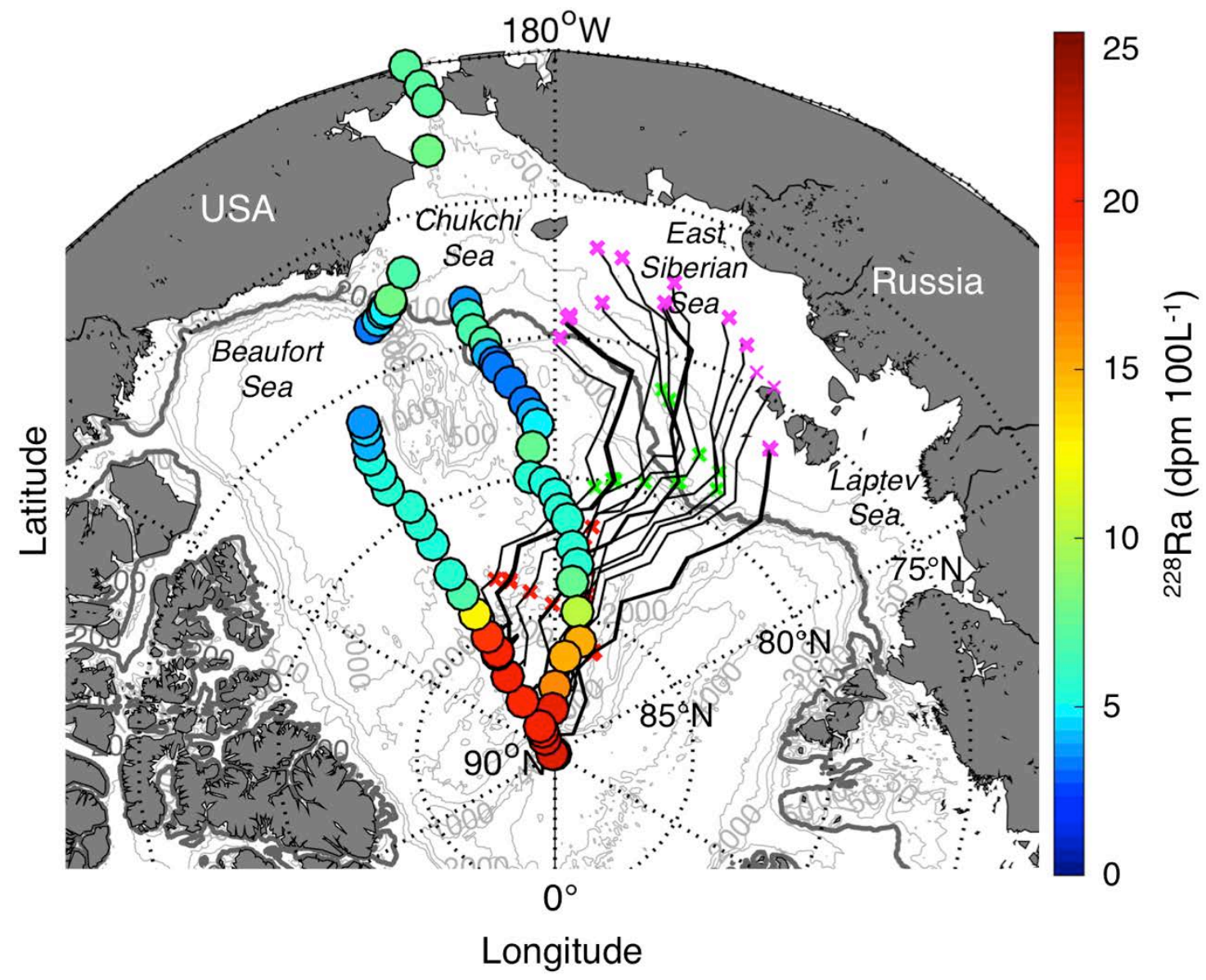

Figure 1. Radium-228 activities in surface waters $(2 \mathrm{~m})$ of the Arctic Ocean. Ice backtrajectories determined for each of the sampling stations are shown in black. The red, green, and magenta symbols indicate the position of the ice 6,12 , and 18 months before each sample was collected, respectively. The $200 \mathrm{~m}$ isobath is highlighted in bold. 


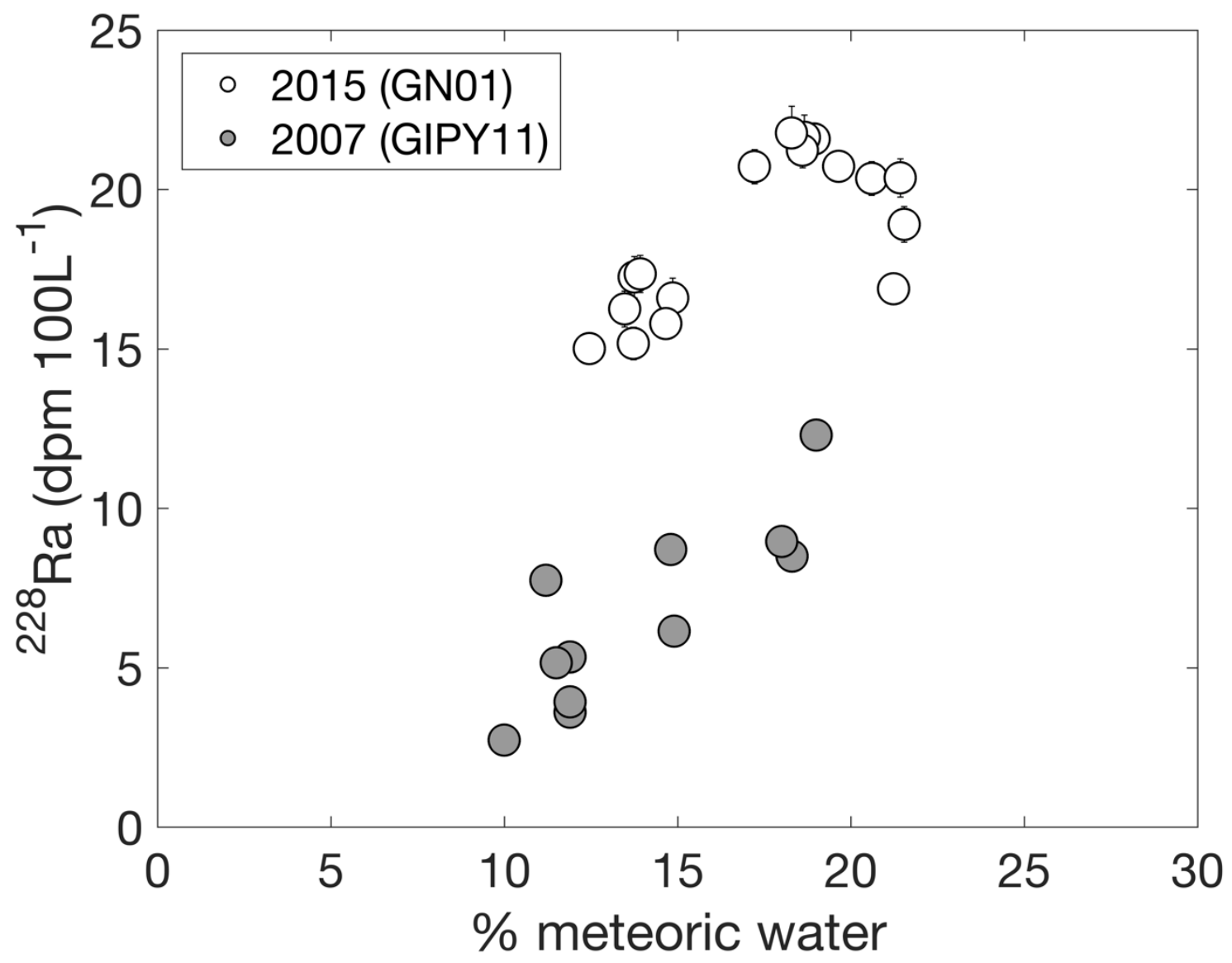

Figure 2. Radium-228 activities in surface waters $(<50 \mathrm{~m})$ above $85^{\circ} \mathrm{N}$ as a function of percent meteoric water. Open symbols represent samples collected in 2015 on the GN01 transect, and closed symbols represent samples collected in 2007 on the GIPY 11 transect (Rutgers van der Loeff et al., 2012). Error bars for the data collected in 2007 are smaller than the symbols. 


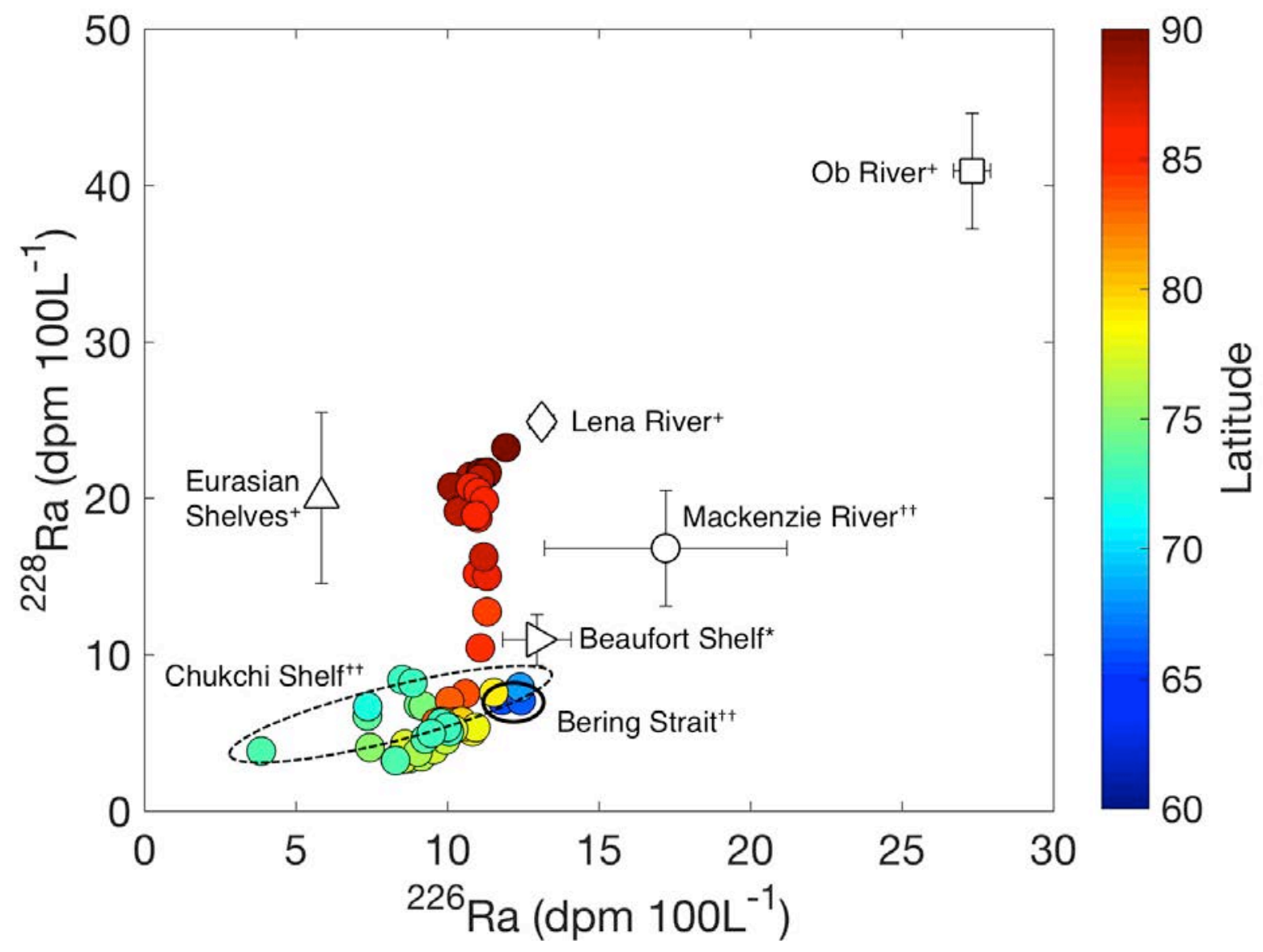

Figure 3. Activities of ${ }^{228} \mathrm{Ra}$ and ${ }^{226} \mathrm{Ra}$ measured in surface waters in 2015 (circles), shown with historical measurements of shelf and river endmembers. Error bars for the 2015 data are smaller than the symbols. ${ }^{\dagger \dagger}$ This study; ${ }^{+}$Rutgers van der Loeff et al. (2003), *Smith et al. (2003). 

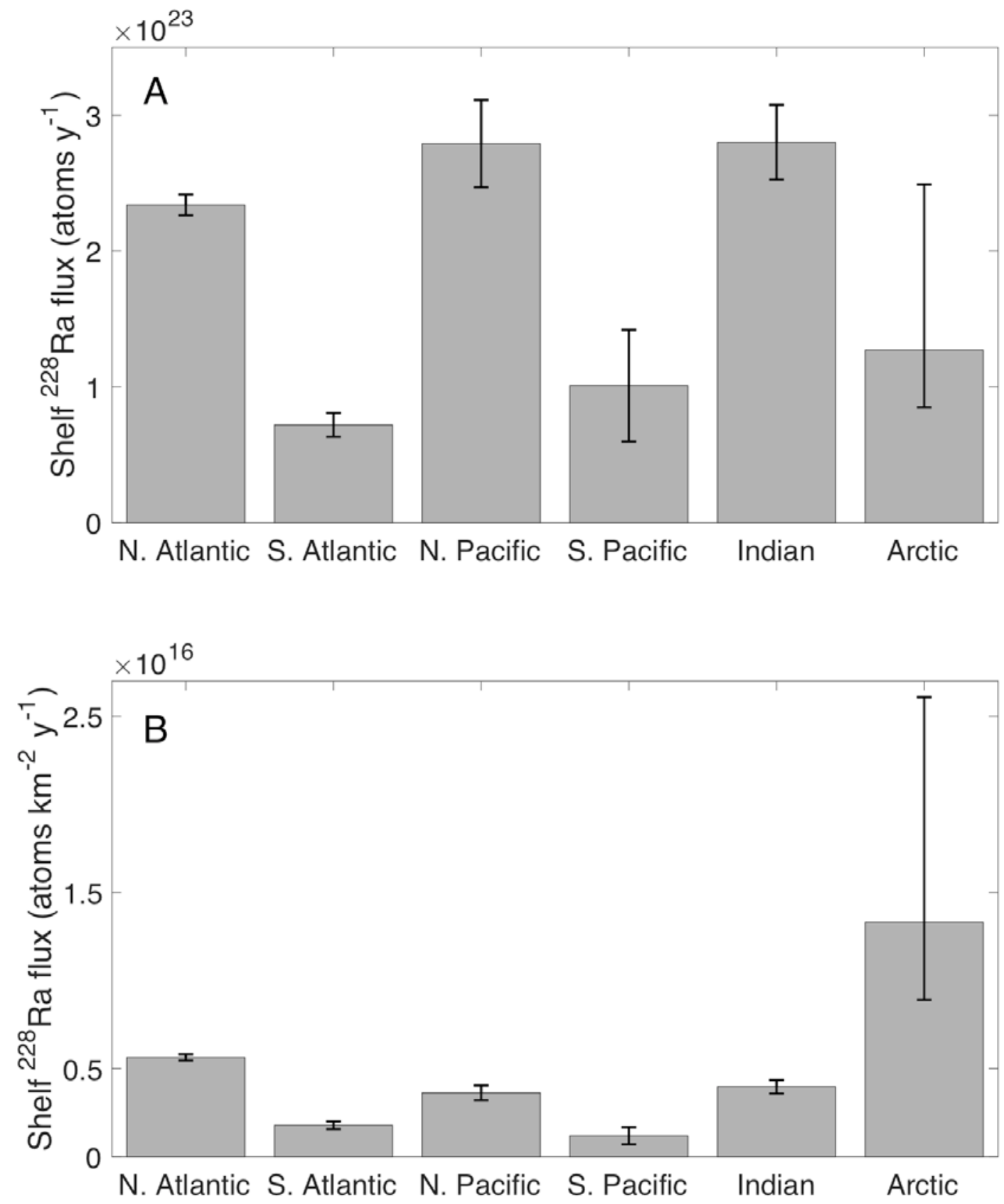

Figure 4. The coastal flux of ${ }^{228} \mathrm{Ra}$ to each ocean basin (A) in atoms $\mathrm{y}^{-1}$ and (B) normalized to the area of each basin in atoms $\mathrm{km}^{-2} \mathrm{y}^{-1}$. The fluxes from basins other than the Arctic are from Kwon et al. (2014), and areas are from the ETOPO1 surface relief model (Eakins and Sharman, 2010). The area of the Arctic basin is from Jakobsson (2002). 
Supplementary Tables \& Figures 
Table S1. Locations of stations used to determine the surface water ${ }^{228}$ Ra inventory.

\begin{tabular}{|l|l|l|}
\hline Station & Latitude $\left({ }^{\circ} \mathbf{N}\right)$ & Longitude $\left({ }^{\mathbf{} E}\right)$ \\
\hline 19 & 79.9860 & -174.9760 \\
\hline 26 & 83.7550 & 174.8170 \\
\hline 30 & 87.5300 & -180.0000 \\
\hline 32 & 89.9888 & 37.8428 \\
\hline 38 & 87.8257 & -149.5010 \\
\hline 43 & 85.1348 & -149.9952 \\
\hline 46 & 82.4835 & -149.9952 \\
\hline 48 & 80.3837 & -149.7666 \\
\hline 52 & 77.5122 & -148.0137 \\
\hline 57 & 73.4039 & -156.7731 \\
\hline
\end{tabular}


Table S2. Activities of ${ }^{228} \mathrm{Ra}$ and ${ }^{226} \mathrm{Ra}$ measured in ice rafted sediments and melted ice. 'bdl' indicates that activities were below the detection limit.

\begin{tabular}{|c|c|c|c|c|c|c|}
\hline $\begin{array}{l}\text { Sample } \\
\text { location }\end{array}$ & $\begin{array}{l}\text { Sample } \\
\text { volume }(\mathrm{L})\end{array}$ & $\begin{array}{l}\text { Weight of } \\
\text { sediment }(g)\end{array}$ & $\begin{array}{l}{ }^{228} \mathbf{R a} \text { in } \\
\text { melted ice } \\
\left(\mathrm{dpm} \mathrm{L} \mathbf{L}^{-1}\right)\end{array}$ & 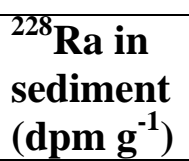 & $\begin{array}{l}{ }^{226} \mathrm{Ra} \text { in } \\
\text { melted ice } \\
\left(\mathrm{dpm} \mathrm{L} \mathrm{L}^{-1}\right)\end{array}$ & 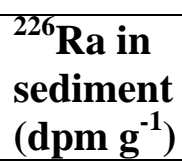 \\
\hline $\begin{array}{l}88.973^{\circ} \mathrm{N} \\
150.413^{\circ} \mathrm{W}\end{array}$ & 0.96 & 8.0 & $0.55 \pm 0.17$ & $3.1 \pm 0.3$ & $0.41 \pm 0.09$ & $2.3 \pm 0.1$ \\
\hline $\begin{array}{l}87.752^{\circ} \mathrm{N} \\
179.724^{\circ} \mathrm{W}\end{array}$ & 0.92 & 0.79 & bdl & $2.0 \pm 0.1$ & $0.38 \pm 0.15$ & $1.4 \pm 0.1$ \\
\hline
\end{tabular}



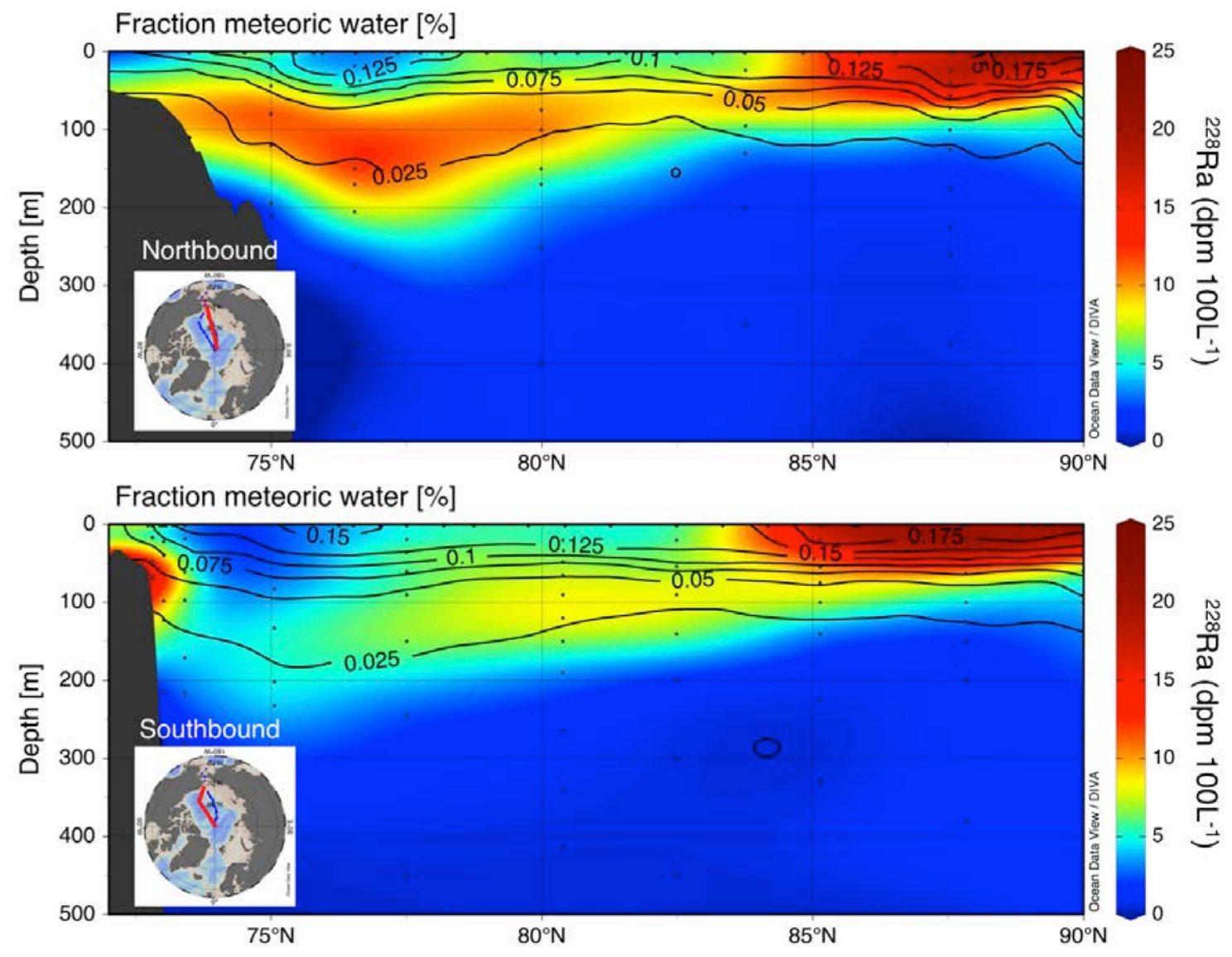

Figure S1. Activities of ${ }^{228} \mathrm{Ra}$ in the upper $500 \mathrm{~m}$ of the water column with contours indicating the fraction of meteoric water. 


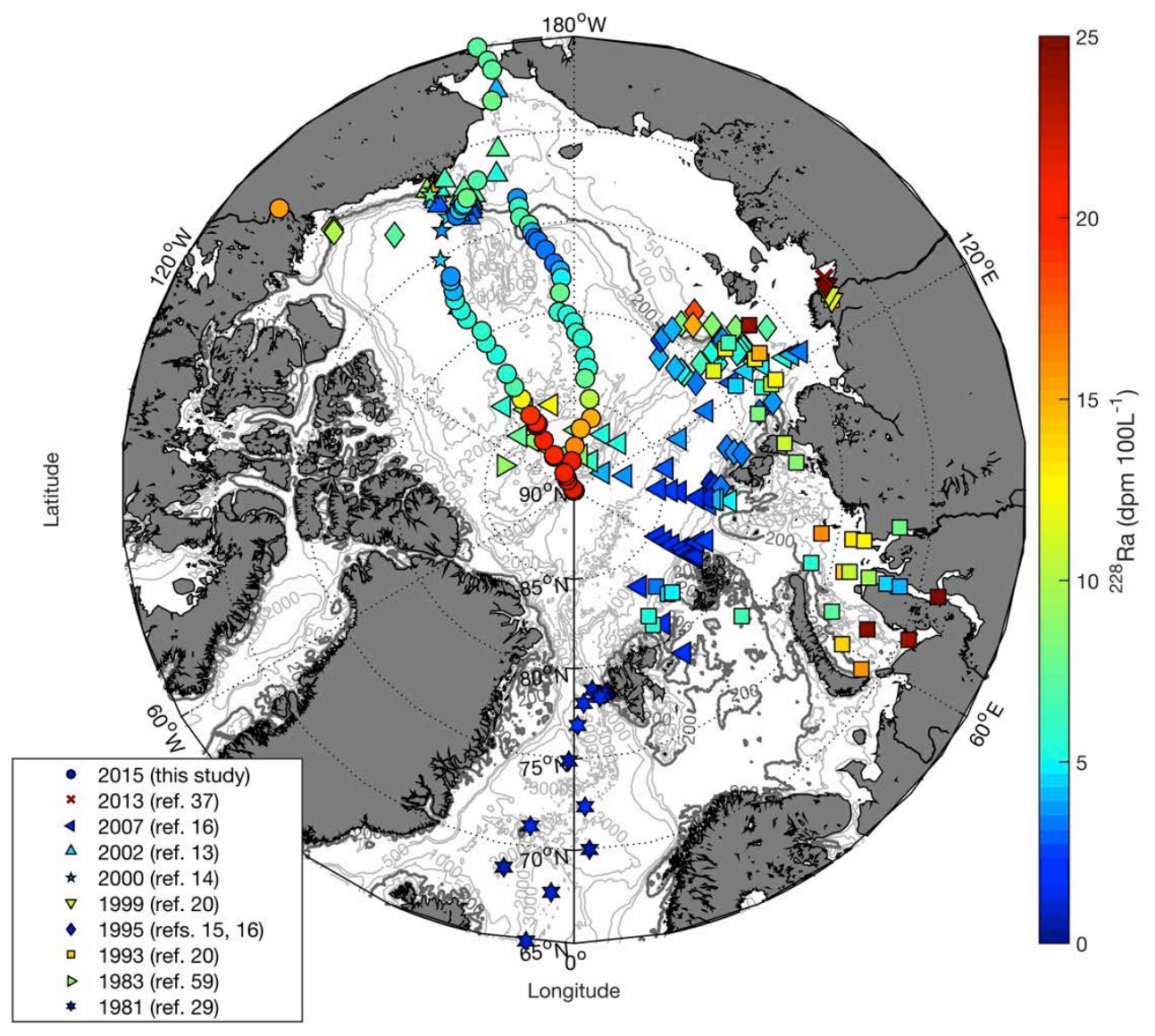

Figure S2. Surface water ( $<15 \mathrm{~m}$ ) activities of ${ }^{228} \mathrm{Ra}$ from GN01 (circles) shown with activities of ${ }^{228} \mathrm{Ra}$ measured on historical expeditions in the Arctic. All activities shown are less than 25 dpm $100 \mathrm{~L}^{-1}$ with the exception of one sample collected in the Ob River $\left(73.68^{\circ} \mathrm{N}, 68.99^{\circ} \mathrm{N}\right)$ that had an activity of $40.9 \pm 3.7 \mathrm{dpm} 100 \mathrm{~L}^{-1}$ (Rutgers van der Loeff et al., 2003) and a sample collected in the Buor-Khaya Gulf $\left(71.78^{\circ} \mathrm{N}, 130.09^{\circ} \mathrm{E}\right)$ in 2013 that had an extremely high activity of $77 \pm 4 \mathrm{dpm} 100 \mathrm{~L}^{-1}$ (Charkin et al., 2017). The $200 \mathrm{~m}$ isobath is highlighted in bold. 

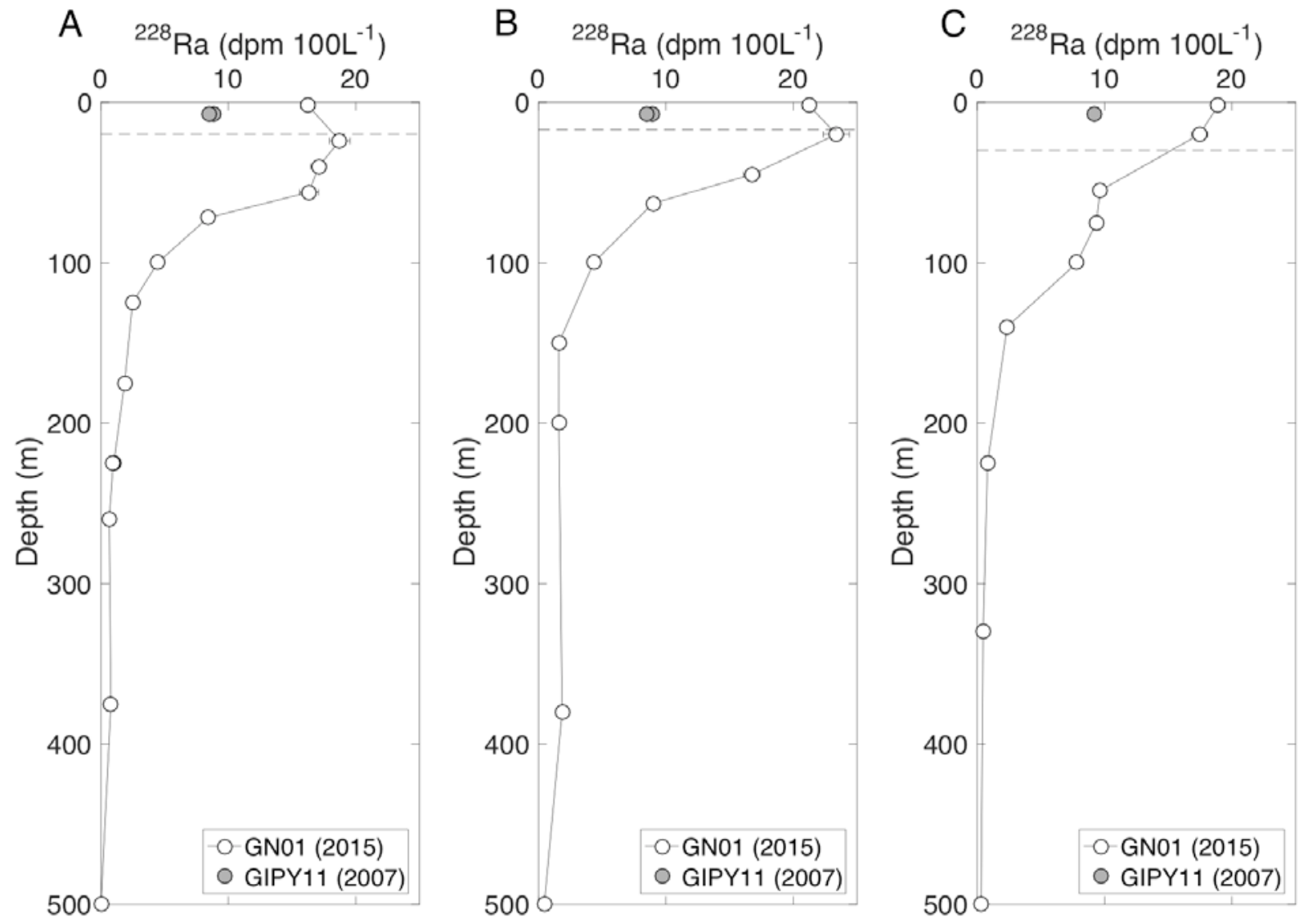

Figure S3. Profiles of ${ }^{228} \mathrm{Ra}$ on the GN01 cruise (2015) compared to the surface samples collected on the GIPY11 cruise (2007) (Rutgers van der Loeff et al., 2012). (A) GN01 station 30, GIPY11 stations 326 and 328; (B) GN01 station 38, GIPY11 stations 328 and 338; (C) GN01 station 43, GIPY11 station 346. The dashed line indicates the approximate depth of the mixed layer at each station in 2015. Surface samples were collected from $2 \mathrm{~m}$ and $7 \mathrm{~m}$ depth in 2015 and 2007, respectively, which are both located within the surface mixed layer. 

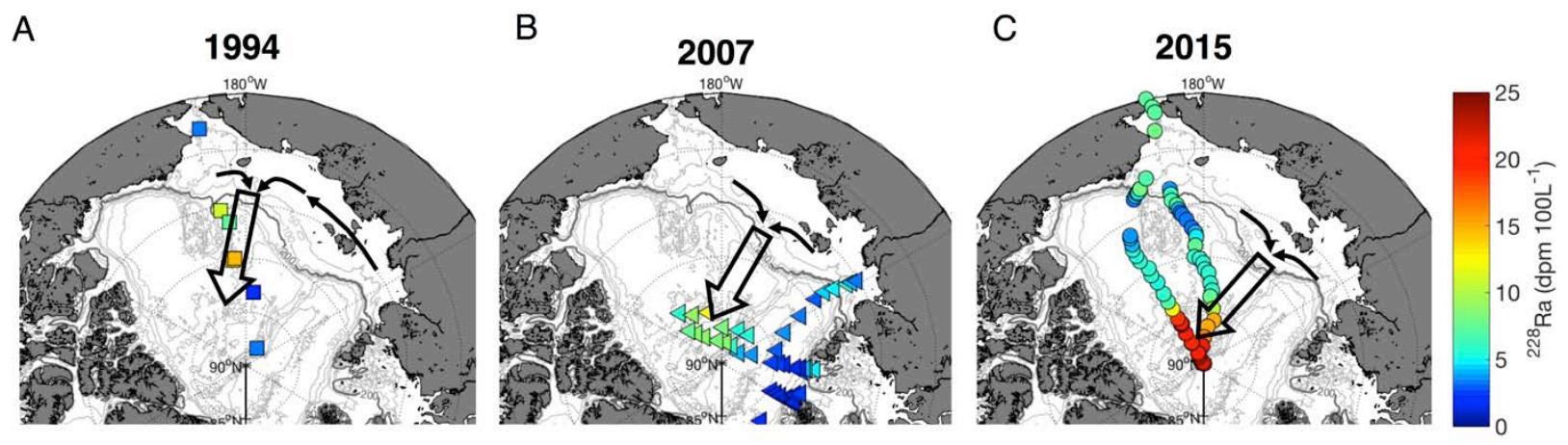

Figure S4. Radium-228 activities in surface waters in (A) 1994 (Smith et al., 2003; 10 - $30 \mathrm{~m}$ ), (B) 2007 (Rutgers van der Loeff et al, 2012; 7 m), and (C) 2015 (this study; 2 m). Open arrows show the approximate location of the Transpolar Drift in each year, based on figures in Smith et al. (2003) and Rutgers van der Loeff et al. (2012), and ice back-trajectories determined for 2007 and 2015 (see section 3.3). In 1994, the Transpolar Drift was positioned over the Mendeleyev Ridge instead of the Lomonosov Ridge (McLaughlin et al., 1996), and the highest ${ }^{228} \mathrm{Ra}$ activities were observed farther south $\left(80^{\circ} \mathrm{N}\right)$. Due to this shifted circulation regime, surface waters likely spent a longer time over the East Siberian Sea before being advected to the central Arctic; this would result in different (likely higher) ${ }^{228} \mathrm{Ra}$ activities in the water leaving the shelf. 

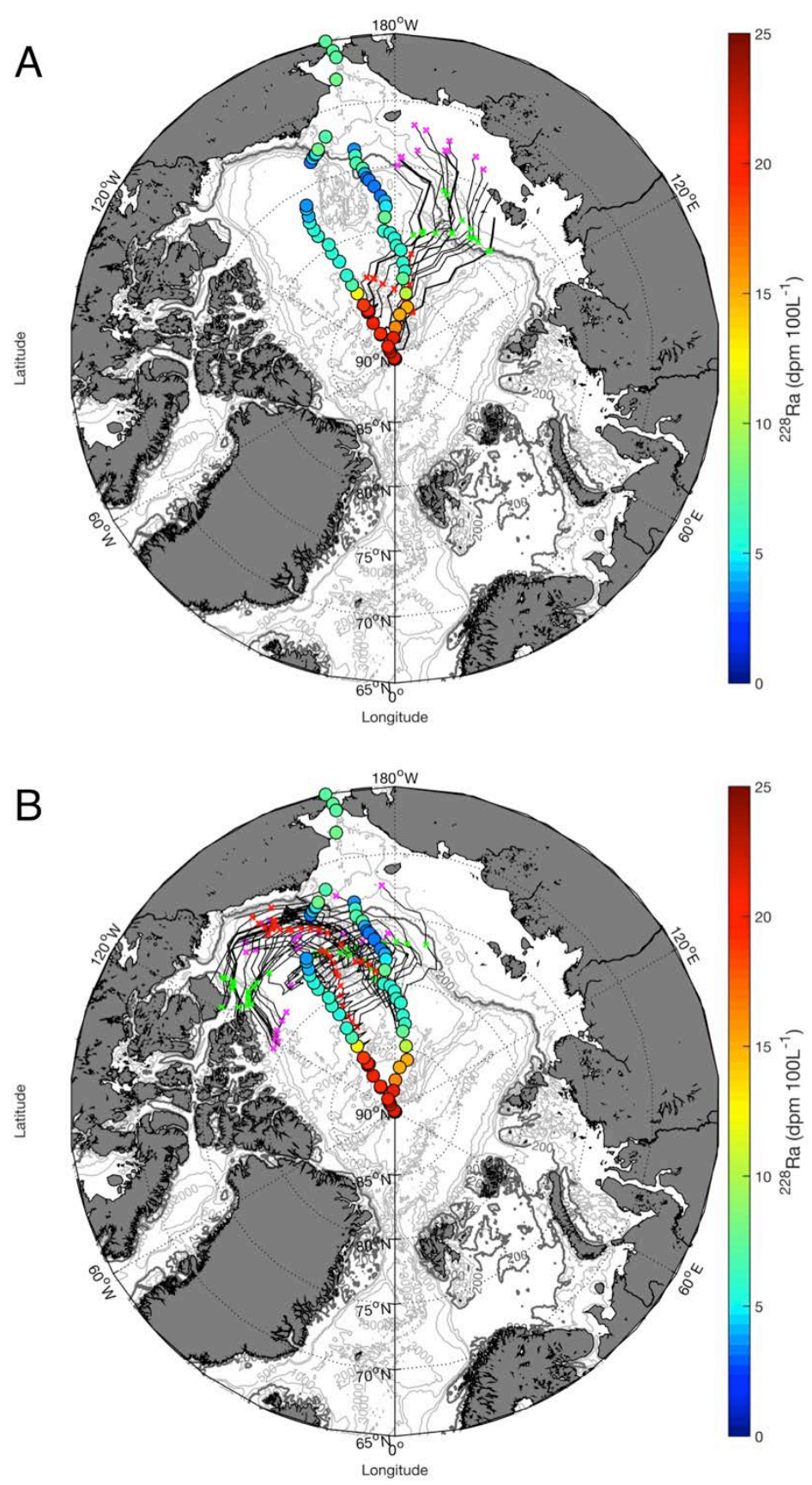

Figure S5. Radium-228 activities in surface waters ( $2 \mathrm{~m}$ depth) sampled on the GN01 transect in 2015. Ice back-trajectories determined for each of the sampling locations (A) above $85^{\circ} \mathrm{N}$ and (B) below $85^{\circ} \mathrm{N}$ are shown in black. The red, green, and magenta symbols indicate the position of the ice 6,12 , and 18 months before each sample was collected, respectively. The $200 \mathrm{~m}$ isobath is highlighted in bold. 


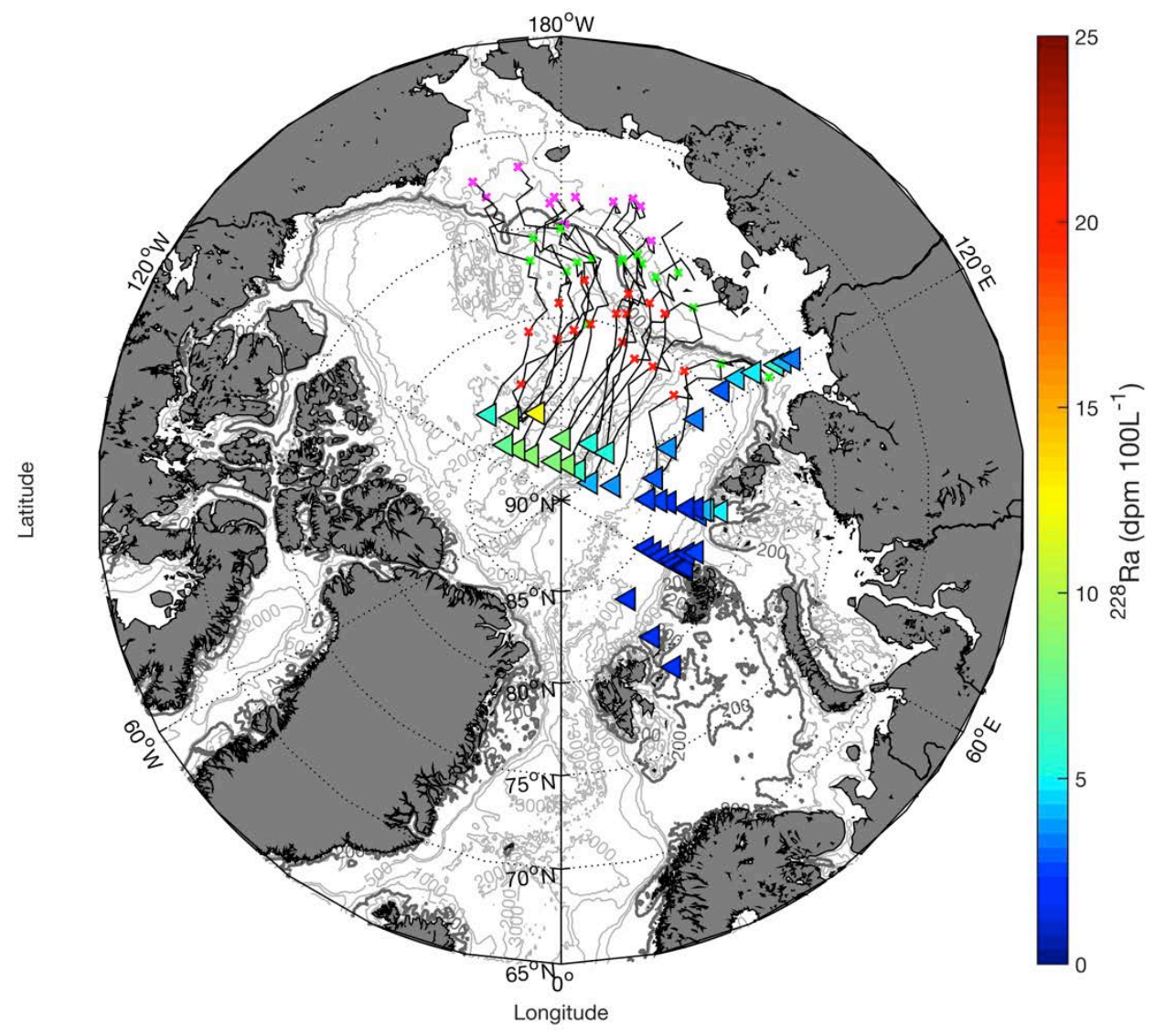

Figure S6. Radium-228 activities in surface waters ( $7 \mathrm{~m}$ depth) on the GIPY11 transect in 2007, measured by Rutgers van der Loeff et al. (2012). Ice back-trajectories determined for each of the sampling locations are shown in black. The red, green, and magenta symbols indicate the position of the ice 6,12 , and 18 months before each sample was collected, respectively. The 200 $\mathrm{m}$ isobath is highlighted in bold. 

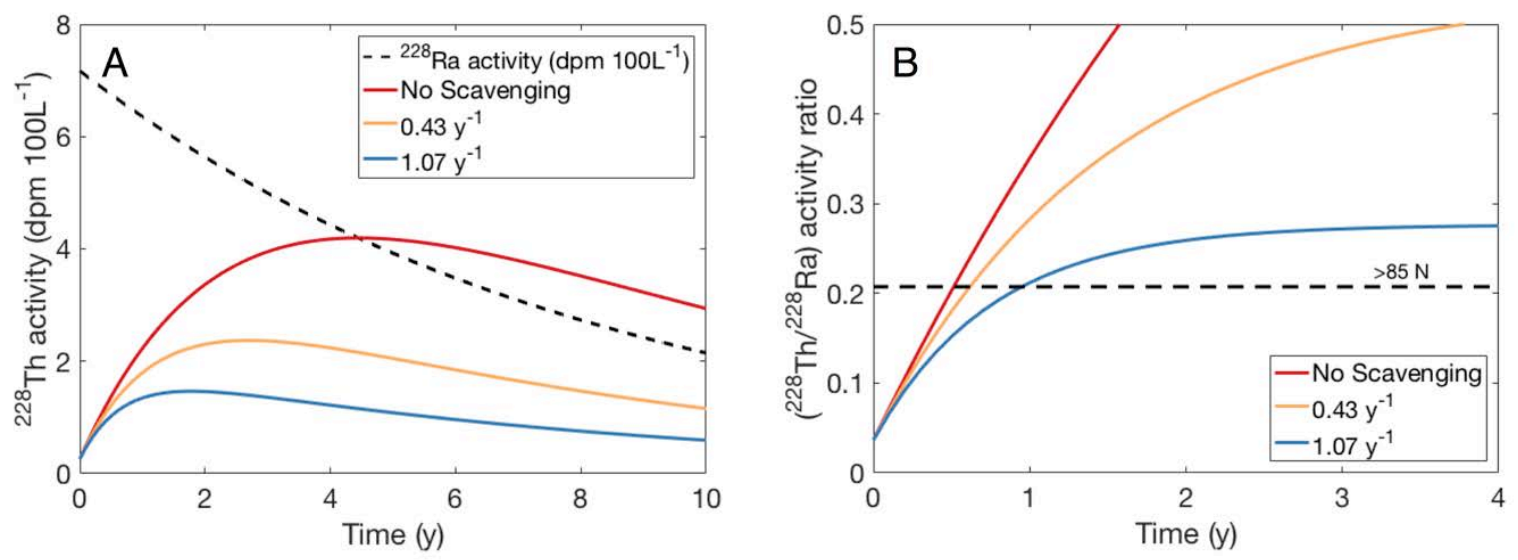

Figure S7. The activities of (A) ${ }^{228} \mathrm{Ra}$ and ${ }^{228} \mathrm{Th}$ and (B) the ${ }^{228} \mathrm{Th} /{ }^{228} \mathrm{Ra}$ activity ratio as a function of time since leaving the shelf. The average, minimum, and maximum scavenging rates observed on the GN01 transect are shown with the yellow, red, and blue lines, respectively. The average ${ }^{228} \mathrm{Th} /{ }^{228} \mathrm{Ra}$ activity ratio observed above $85^{\circ} \mathrm{N}$ is shown with a dashed line in panel B. The intersection of the ${ }^{228} \mathrm{Th}$ ingrowth (lines with different scavenging rates) with the measured ${ }^{228} \mathrm{Th} /{ }^{228} \mathrm{Ra}$ activity ratio yields the apparent age since the water mass left the shelf $(0.5-1 \mathrm{y}$ for $\left.>85^{\circ} \mathrm{N}\right)$. 


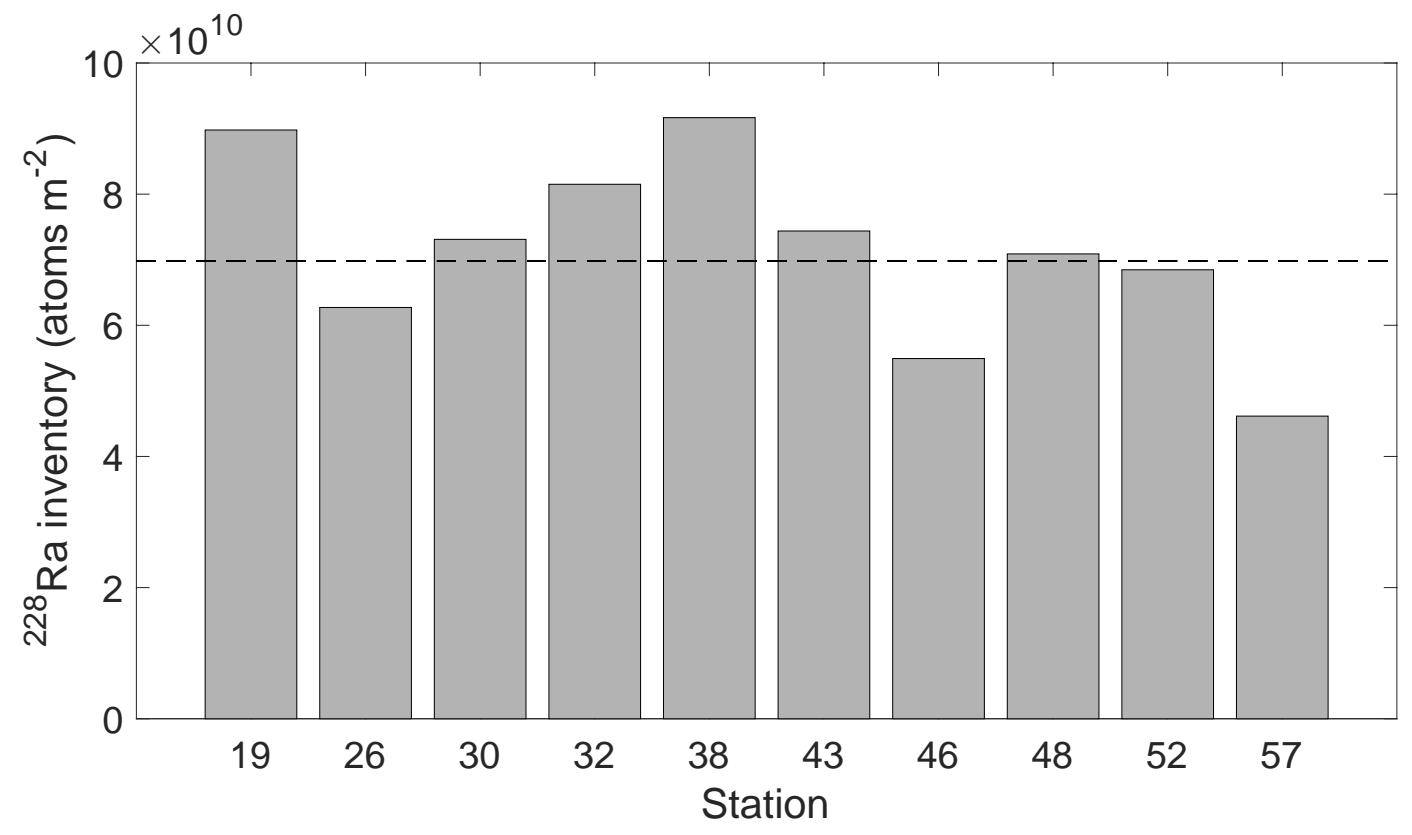

Figure S8. Inventory of ${ }^{228} \mathrm{Ra}$ in the top $500 \mathrm{~m}$ at each of the stations where water column samples were collected and the bottom depth was $\geq 1,000 \mathrm{~m}$. The dashed line indicates the average Arctic surface inventory. 


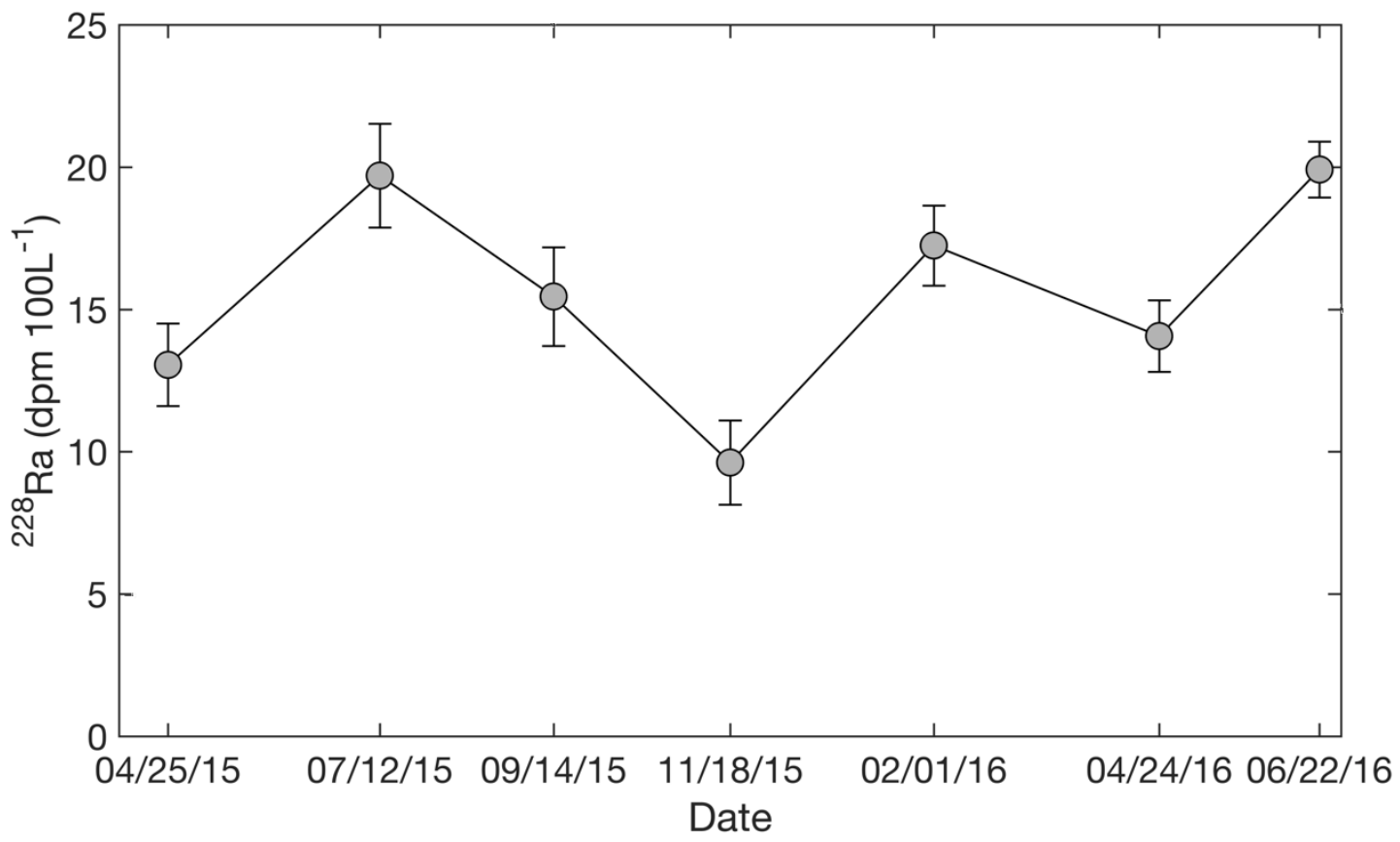

Figure S9. Dissolved ${ }^{228} \mathrm{Ra}$ activities measured in the Mackenzie River. 


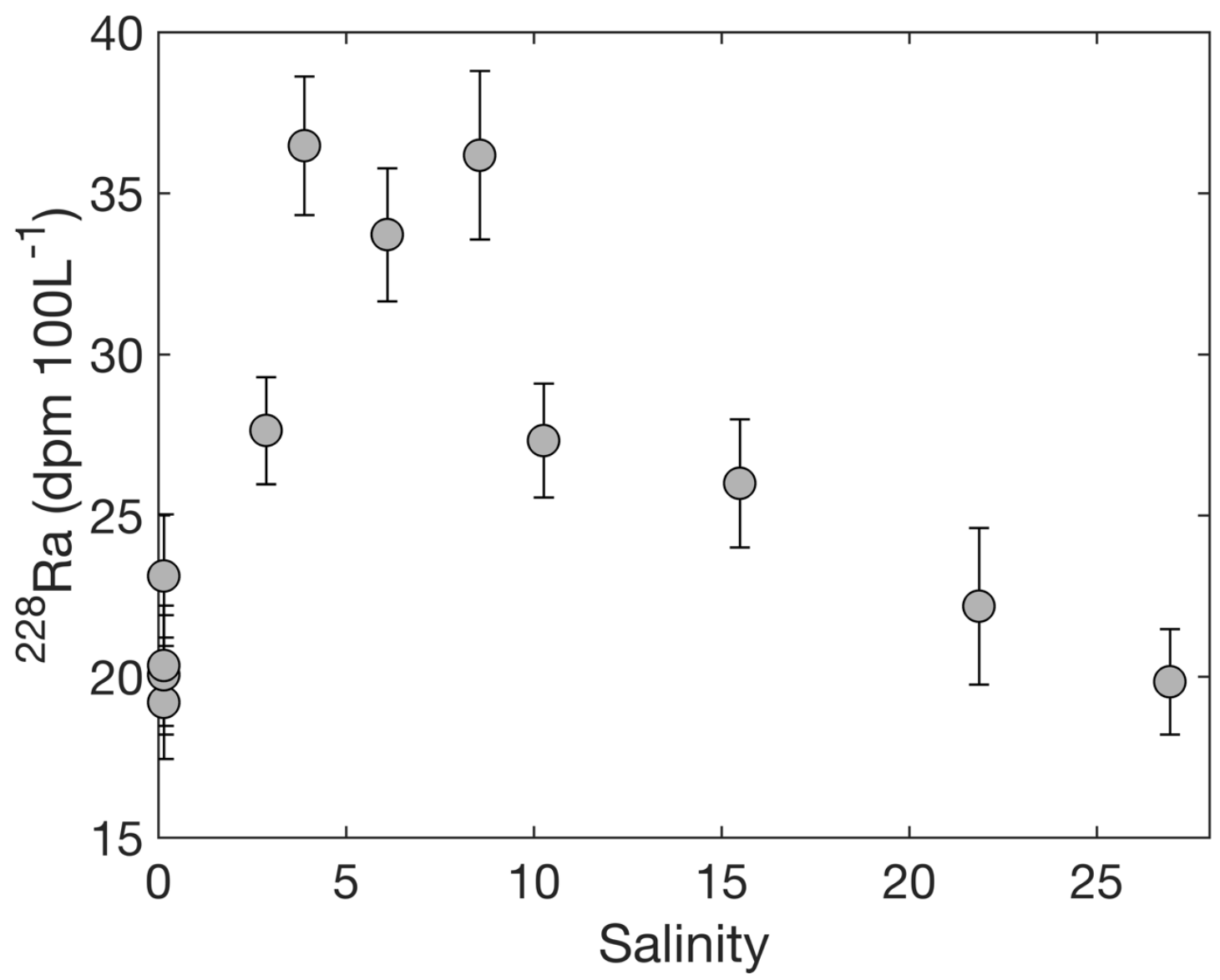

Figure S10. Dissolved ${ }^{228}$ Ra activities in the Mackenzie River Estuary (East Channel). The peak in ${ }^{228} \mathrm{Ra}$ around salinity $5-10$ is due to desorption from suspended particles. 
Average open water days per year, $2003-2007$

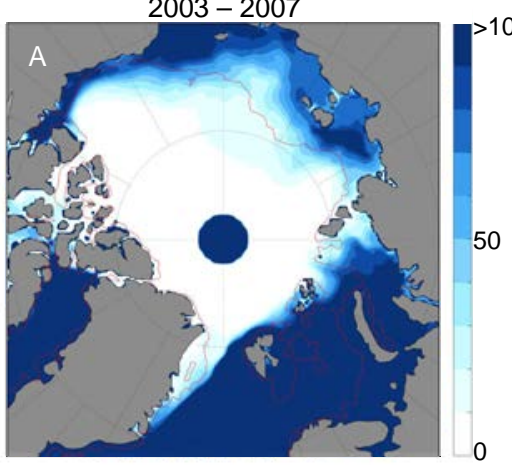

Average open water days per year, $2011-2015$

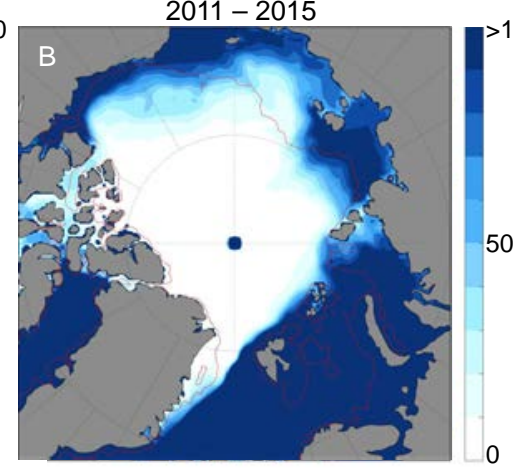

Difference in average open water days,

$(2011-2015)$ minus $(2003-2007)>50$

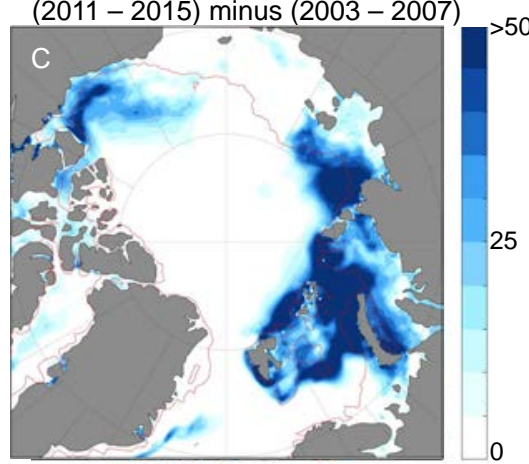

Figure S11. Number of open water days averaged over the five year periods prior to the GIPY11 (September 2007; A) and GN01 (September 2015; B) expeditions, and the difference in the number of open water days between the two periods (C). An ice concentration of less than $15 \%$ was considered open water. The red contour indicates the $200 \mathrm{~m}$ isobath. The gap in the center of figures A and B results from a lack of satellite coverage due to the orbit and view angle of the satellite. 


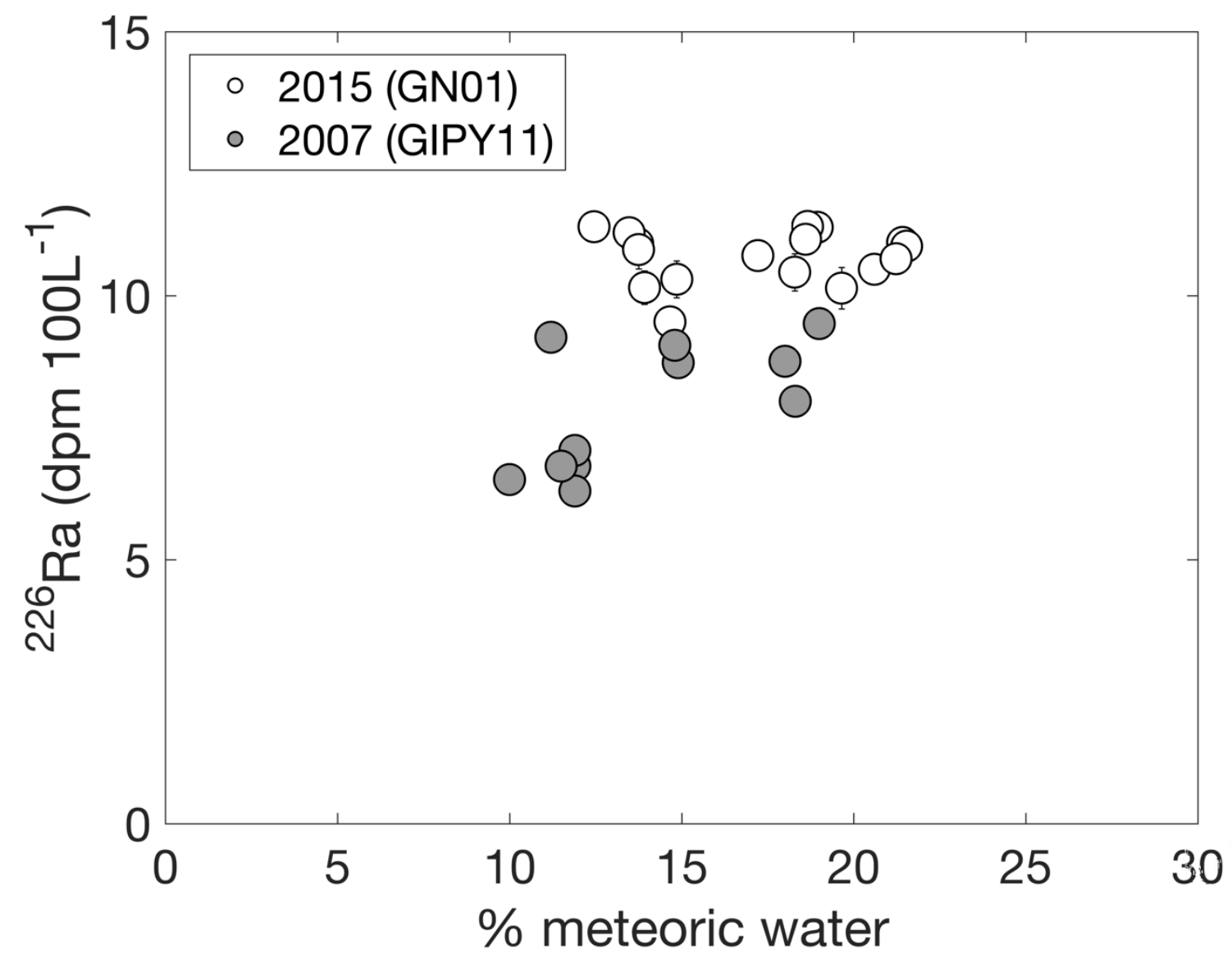

Figure S12. Dissolved ${ }^{226} \mathrm{Ra}$ activities in surface water $(<50 \mathrm{~m})$ above $85^{\circ} \mathrm{N}$ as a function of the fraction of meteoric water in each sample. Open symbols represent samples collected in 2015 on the GN01 transect, and closed symbols represent samples collected in 2007 on the GIPY11 transect (Rutgers van der Loeff et al., 2012). 


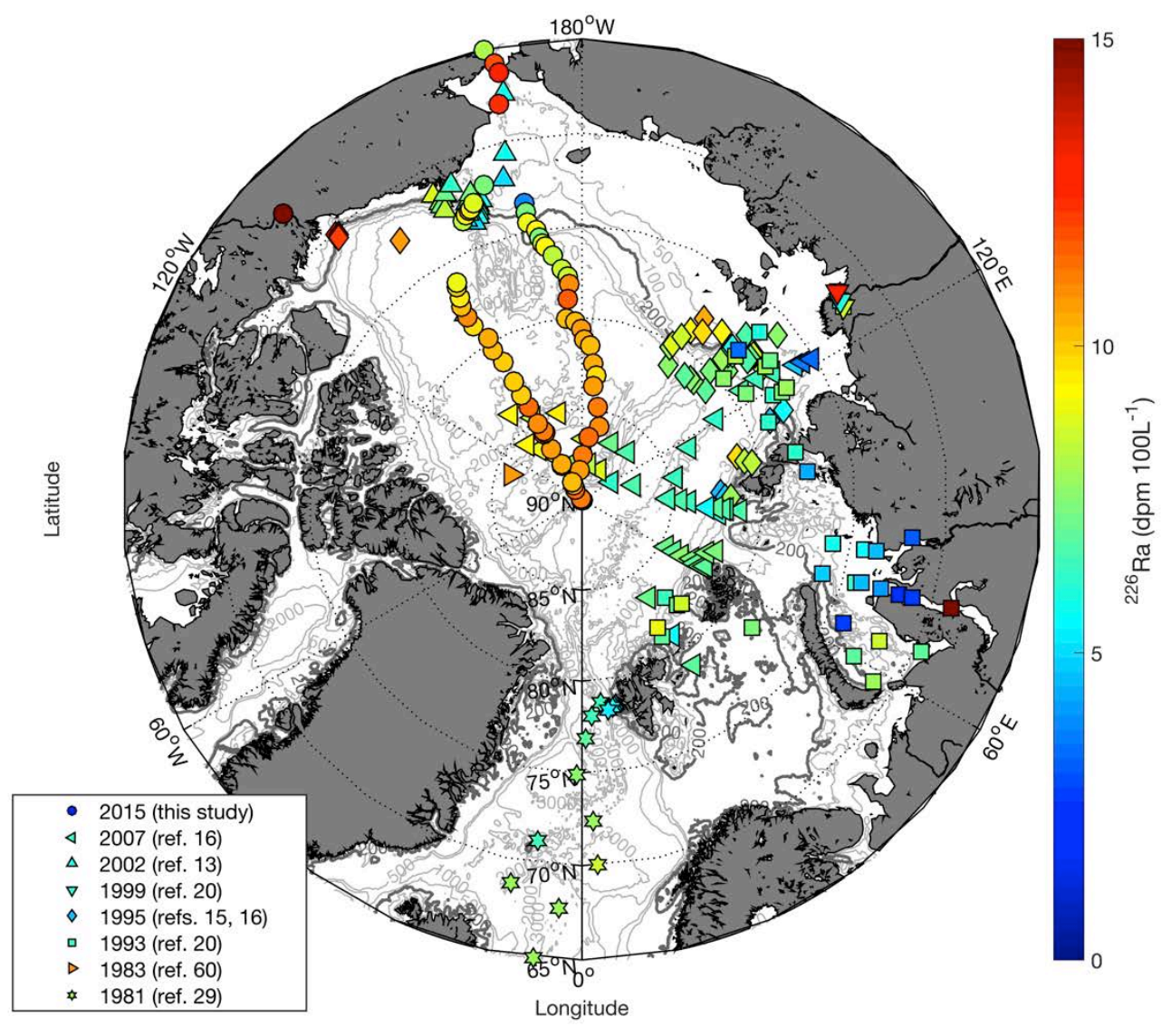

Figure S13. Surface water $(<15 \mathrm{~m})$ activities of ${ }^{226} \mathrm{Ra}$ from GN01 (circles) shown along with activities of ${ }^{226} \mathrm{Ra}$ measured on historical expeditions in the Arctic. All activities shown are less than $15 \mathrm{dpm} 100 \mathrm{~L}^{-1}$ with the exception of one sample collected in the Ob River $\left(73.68^{\circ} \mathrm{E}\right.$, $68.99^{\circ} \mathrm{N}$ ) that had an activity of $27.3 \pm 0.6 \mathrm{dpm} 100 \mathrm{~L}^{-1}$ (Rutgers van der Loeff et al., 2003), and the average Mackenzie River activity of $15.6 \pm 3.7 \mathrm{dpm} 100 \mathrm{~L}^{-1}\left(133.75^{\circ} \mathrm{E}, 67.46^{\circ} \mathrm{N}\right.$; this study). The $200 \mathrm{~m}$ isobath is highlighted in bold. 


\title{
Chapter 4: Shelf-basin interactions and water mass residence times in the Western Arctic Ocean
}

\begin{abstract}
Radium isotopes are produced through the decay of thorium in sediments and are soluble in seawater, thus they are useful for tracing ocean boundary-derived inputs to the ocean. Here we apply radium isotopes to study continental inputs and water residence times in the Arctic Ocean, where land-ocean interactions are currently changing in response to rising air and sea temperatures. We present the distributions of radium-228 and radium-226 measured on the 2015 US GEOTRACES transect in the Western Arctic Ocean, and combine this dataset with historical radium observations and a regional model of the Chukchi Sea. The highest activities of radium228 were observed in the Transpolar Drift and the Chukchi shelfbreak jet, signaling that these currents are heavily influenced by interactions with shelf sediments. Observations and modeling results indicate that the Chukchi shelf inputs of radium are strongest in the fall. The ventilation of the halocline with respect to inputs from the shelfbreak jet was estimated to occur on timescales $\leq 14-17 \mathrm{y}$. Intermediate water ventilation time scales for the Makarov and Canada Basins were determined to be $\sim 20 \mathrm{y}$ and $>30 \mathrm{y}$, respectively, while deep water residence times in these basins were on the order of centuries. The radium distributions and residence times described in this study serve as a baseline for future studies investigating the impacts of climate change on the Arctic Ocean.
\end{abstract}




\subsection{INTRODUCTION}

The Arctic is strongly influenced by continental inputs. Over $50 \%$ of the area of this ocean is dominated by continental shelves (Jakobsson, 2002), and although it contains only $1 \%$ of the ocean volume, the Arctic basin receives over 10\% of global river discharge (Aagaard and Carmack, 1989; McClelland et al., 2012). Currently, terrestrial influences on the Arctic are increasing as a result of climate change. The loss of sea ice over continental shelves allows increased coastal erosion (Günther et al., 2013) and vertical mixing (Carmack and Chapman, 2003; Rainville and Woodgate, 2009; Williams and Carmack, 2015), which may be contributing to intensified shelf-derived material fluxes to the central Arctic (Kipp et al., 2018; Rutgers van der Loeff et al., 2018). Rising temperatures are also leading to increased river discharge (Rawlins et al., 2010) and permafrost degradation (Luo et al., 2016). As permafrost has historically been considered a barrier to submarine groundwater discharge (SGD) in the Arctic, this degradation may result in larger SGD inputs to the coastal ocean (Walvoord et al., 2012). It is vital to understand the modern Arctic Ocean so that we may predict how it will be impacted by these changing continental inputs.

River runoff and ice melt contribute to a fresh, cold surface water layer (typically $10-50$ $\mathrm{m}$ thick) extending over the Arctic basin. In the Western Arctic, this layer is underlain by Pacific inflow through the Bering Strait, which becomes modified by interactions with sediments during transit over the Chukchi Shelf (e.g. Carmack and Wassmann, 2006; Pickart et al., 2016). Seasonal warming and cooling, brine formation, and changing flow paths result in distinct temperature and salinity characteristics that can be used to distinguish the modified water masses in the Chukchi Sea. Chukchi winter water (WW) forms as a result of brine rejection during the fall and winter (Muench et al., 1988; Weingartner et al., 1998; Woodgate et al., 2005a). This water mass is cold, saline, and becomes enriched in sediment-derived materials, including regenerated nutrients, through water column convection induced by brine rejection (Arrigo et al., 2017; Lowry et al., 2015; Pickart et al., 2016; Pacini et al., submitted). In the summer, solar heating of this water mass transforms it into remnant winter water (RWW) (Gong and Pickart, 2016). Alaskan Coastal Water (ACW) is the warmest water in the Chukchi Sea (Paquette and Bourke, 1974; Woodgate et al., 2005a); this water mass originates south of the Bering Strait and follows the coast of Alaska (Figure 1), thus it is influenced by Yukon River outflow and possibly groundwater inputs. Bering Summer Water (BSW) also originates in the Bering Sea, but is typically colder and saltier than the ACW (Shimada et al., 2001).

Observational and modeling studies suggest that these Chukchi water masses typically transit the shelf through one of three pathways: the eastern pathway follows the coast of Alaska and flows through Barrow Canyon, the central pathway moves north between Herald and Hanna Shoals, and the western pathway flows through Herald Canyon (Pickart et al., 2016; Spall, 2007; Weingartner et al., 2005, 1998). Some of the water that flows through Herald Canyon travels along the Chukchi shelfbreak from west to east, forming a shelfbreak jet (Corlett and Pickart, 2017; Mathis et al., 2007; Pickart et al., 2010, 2005). Recently, it was discovered that much of the outflow from Barrow Canyon can be steered to the left and form a slope current moving from east to west, offshore of the shelfbreak jet (Corlett and Pickart, 2017). Eddies transporting shelfinfluenced waters into the Canada Basin are also common (Mathis et al., 2007; Muench et al., 2000; Pickart et al., 2005; Timmermans et al., 2008).

Beneath the halocline, intermediate waters are ventilated by Atlantic inflows from the Eurasian Basin. Brine rejection on the shelves contributes to deep water formation (Aagaard et 
al., 1981; Rudels et al., 1994), transporting continentally-influenced Atlantic water to intermediate depths. The movement of deep waters is restricted by bathymetry. The Lomonosov Ridge splits the Arctic into the Canadian (also referred to as Amerasian) and Eurasian Basins. The Fram Strait connects the Eurasian Basin and the North Atlantic and provides the sole deep water exchange pathway in the Arctic, thus deep waters in the Canadian Basin are generally isolated below the sill depth of the Lomonosov Ridge $(\sim 1700 \mathrm{~m})$ and have longer residence times than those in the Eurasian Basin (Schlosser et al., 1997; Tanhua et al., 2009). The Alpha Mendeleyev Ridge further divides the Canadian Basin into the Canada and Makarov Basins, while the Gakkel Ridge acts as a barrier between the Amundsen and Nansen Basins in the Eurasian Basin.

Radium isotopes are constantly produced through the decay of thorium in sediments and are soluble in seawater, so they act as tracers of continental and benthic inputs to the open ocean and are particularly useful in the shelf-dominated Arctic Ocean. Once removed from their sediment source, radium isotopes decay with characteristic half-lives, thus they can be used to determine time scales of water transport and residence times. The two longer-lived isotopes of radium, ${ }^{228} \mathrm{Ra}\left(\mathrm{t}_{1 / 2}=5.75 \mathrm{y}\right)$ and ${ }^{226} \mathrm{Ra}\left(\mathrm{t}_{1 / 2}=1600 \mathrm{y}\right)$, have appropriate half-lives for tracing shelf inputs to the water column and for determining the residence times of deep waters, respectively (Kadko and Aagaard, 2009; Rutgers van der Loeff et al., 2018, 2012, 1995; Smith et al., 2003).

Radium-228 was first established as a tracer of shelf inputs in the Arctic by Rutgers van der Loeff et al. (1995). These authors observed elevated ${ }^{228} \mathrm{Ra}$ activities in surface waters over the Lomonosov Ridge and concluded that the Ra-enriched water had been transported from the Eurasian shelves via the Transpolar Drift. High ${ }^{228} \mathrm{Ra}$ activities in the Transpolar Drift have since been observed during other expeditions (Rutgers van der Loeff et al., 2012; Smith et al., 2003), and have risen in recent years, signaling increased shelf-basin interaction (Kipp et al., 2018; Rutgers van der Loeff et al., 2018).

Radium-228 enrichments have also been used to identify recently ventilated intermediate waters in the Arctic (Kadko and Aagaard, 2009; Rutgers van der Loeff et al., 1995). Due to its sediment source, Rutgers van der Loeff et al. (1995) noted the usefulness of using ${ }^{228} \mathrm{Ra}$ as a tracer of intermediate waters formed via brine rejection and shelf outflows. Based on ${ }^{228} \mathrm{Ra} /{ }^{226} \mathrm{Ra}$ activity ratios, Kadko and Aagaard (2009) recorded inputs from both the Eurasian and Chukchi shelves in the Canada Basin halocline, and estimated a transit time of $5-7 \mathrm{y}$ for Pacific inflow to reach the interior Canada Basin. Most recently, elevated ${ }^{228} \mathrm{Ra}$ activities between $1000-1500$ $\mathrm{m}$ in the Amundsen Basin were used to determine a ventilation time scale of $15-18 \mathrm{y}$ (Rutgers van der Loeff et al., 2018).

Radium-226 accumulates in deep water masses as a result of the remineralization of sinking particles and diffusion from benthic sediments (Broecker et al., 1976; Chan et al., 1976; Chung and Craig, 1980). These two sources can theoretically be separated by employing another remineralization tracer, such as silica $(\mathrm{Si})$ or barium $(\mathrm{Ba})$, and the accumulation of ${ }^{226} \mathrm{Ra}$ from benthic inputs can then be used to determine water mass residence times. Relatively small sediment enrichments (Broecker et al., 1976) and variability of the Ra-Ba-Si relationships over basin-wide scales (Chung, 1980) preclude the use of this method in most ocean basins. However, the long water residence times in the small, enclosed Arctic Canadian Basin result in significant accumulation of benthic-sourced ${ }^{226} \mathrm{Ra}$, and this tracer was recently applied to estimate a deep water residence time of $\sim 550 \mathrm{y}$ in the Makarov Basin (Rutgers van der Loeff et al., 2018).

Here we present the most extensive dataset of ${ }^{228} \mathrm{Ra}$ and ${ }^{226} \mathrm{Ra}$ in the Western Arctic to date. We apply these tracers to identify significant shelf inputs to the water column and 
determine time scales of intermediate and deep water ventilation in the Makarov and Canada Basins.

\subsection{METHODS}

\subsubsection{Sample collection}

Samples were collected between Dutch Harbor, Alaska, and the North Pole during the US GEOTRACES Arctic expedition on the USCGC Healy from August 6 to October 10, 2015 (HLY1502, GN01). The northbound transect (stations 1 - 32; Figure 2, Table 1) sampled the Bering Sea, Bering Strait, and Chukchi Shelf, and then crossed the Mendeleyev Ridge into the Makarov Basin, following the $180^{\circ} \mathrm{W}$ meridian. The southbound transect (stations $32-66$; Figure 2, Table 1) crossed the Alpha Ridge into the Canada Basin, generally following the $150^{\circ} \mathrm{W}$ meridian between $75^{\circ} \mathrm{N}$ and $90^{\circ} \mathrm{N}$, before crossing back over the Chukchi Shelf near Barrow Canyon. In this chapter I include only the data collected north of the Bering Strait (stations 4 - 66); the results of the Bering Sea sampling will be discussed elsewhere.

Surface water samples were collected with a deck-mounted pump with an intake hose deployed at $2 \mathrm{~m}$ below the sea surface. Approximately $280 \mathrm{~L}$ of water was pumped into plastic barrels then filtered at $<1 \mathrm{~L} \mathrm{~min}^{-1}$ through an acrylic fiber coated with manganese oxide $\left(\mathrm{MnO}_{2}\right)$ to quantitatively scavenge Ra isotopes. For shelf stations, the water was first filtered through a 1 $\mu \mathrm{m}$ Hytrex cartridge filter to remove particles that would otherwise clog the Mn fiber and reduce sample processing times.

Water column samples were collected using McLane in-situ pumps deployed on a plastic coated Vectran line. Pumps were programmed to operate for 4 hours at the target depths, typically filtering $1200-1600 \mathrm{~L}$ for each sample at an average flow rate of $5.6 \mathrm{~L} \mathrm{~min}^{-1}$. Water was first passed through a series of filters to collect small and large particles, and then through cellulose cartridges coated with $\mathrm{MnO}_{2}$ to collect $\mathrm{Ra}$, Th, and Ac isotopes (Henderson et al., 2013).

Small volume (15 - 20 L) samples of water were also collected to determine the cartridge collection efficiencies. These samples were collected from Niskin bottles either mounted on the CTD rosette (shallow casts, typically $<1000 \mathrm{~m}$ ) or above the in-situ pumps (deep casts, typically $>1000 \mathrm{~m}$ ), and were filtered through Mn fiber.

\subsubsection{Sample analysis}

After collection, filters and cartridges were rinsed with Ra-free deionized water to remove any particles and partially dried with filtered, compressed air. Fibers and cartridges were then ashed in a muffle furnace at $820^{\circ} \mathrm{C}$ for $12 \mathrm{~h}$ and $48 \mathrm{~h}$, respectively. The ash was packed into polystyrene vials, sealed with epoxy to prevent ${ }^{222} \mathrm{Rn}$ loss, and aged for at least 3 weeks to allow daughter isotopes to reach equilibrium. Samples were analyzed on high-purity well-type germanium detectors; surface samples were analyzed in the Moore lab at the University of South Carolina and water column samples were analyzed in the Charette lab at the Woods Hole Oceanographic Institution. Radium-228 was measured using the lines of ${ }^{228} \mathrm{Ac}(338 \mathrm{keV}$ and 911 $\mathrm{keV})$ and ${ }^{226} \mathrm{Ra}$ was measured using the line for ${ }^{214} \mathrm{~Pb}(352 \mathrm{keV})$. Detector efficiencies were determined using a set of ashed standards spiked with ${ }^{226} \mathrm{Ra}$ and ${ }^{232} \mathrm{Th}$ with daughters in equilibrium and prepared in the same way as the samples. 
The ${ }^{226}$ Ra activities of the small volume samples were analyzed using an alpha scintillation technique described by Key et al. (1979). Briefly, fibers were sealed in $125 \mathrm{~mL}$ PVC housings for a minimum of three weeks to allow ${ }^{222} \mathrm{Rn}$ to reach equilibrium with its parent ${ }^{226} \mathrm{Ra}$. The ${ }^{222} \mathrm{Rn}$ was then purged from the housing with helium at a flow rate of $250 \mathrm{~mL} \mathrm{~min}{ }^{-1}$ and trapped in a cryo-loop cooled with liquid nitrogen. After purging for $15 \mathrm{~min}$, the cryo-loop was isolated and heated, and the trapped ${ }^{222} \mathrm{Rn}$ was transferred to an alpha scintillation cell to be analyzed on a radon counting system (Model AC/DC-DRC-MK 10-2). Samples were analyzed for $\sim 230 \mathrm{~min}$, resulting in counting uncertainties of $<8 \%$. The ${ }^{226} \mathrm{Ra}$ measurement efficiency was determined using fiber standards containing $20 \mathrm{dpm}{ }^{226} \mathrm{Ra}$ (NIST-certified SRM\#4967A) that were analyzed the same way as the samples.

The ${ }^{226} \mathrm{Ra}$ activities measured on the small volume samples were compared to those on the cartridges collected from the corresponding depths in order to determine the Ra collection efficiencies. The collection efficiency of individual cartridges ranged from $19 \%$ to $99 \%$, with an average of $70 \pm 19 \%(1 \sigma)$. The errors on the determined cartridge collection efficiencies were propagated with counting errors to produce the errors on the reported activities.

\subsubsection{Sampling procedures for historical datasets}

In addition to the samples collected on the 2015 HLY1502 transect, we also present previously unpublished Ra data collected by David Kadko during the Shelf-Basin Interactions (SBI) expeditions in 2002 and 2004 on the USCGC Healy (HLY0201, HLY0203, HLY0402, HLY0403, HLY0404), the Arctic West Summer (AWS) 2000 expedition on the USCGC Polar Star (hereafter referred to as AWS-2000), and the 1998 Surface Heat Budget of the Arctic Ocean (SHEBA) ice camp. Some of the SBI data have been previously published, and a detailed description of sampling and analytical methods for these expeditions can be found in Kadko et al. (2008) and Kadko and Muench (2005). Sampling on the other expeditions was conducted in the same manner.

\subsubsection{Chukchi sea model}

A regional circulation model was used to aid in the interpretation of the ${ }^{228}$ Ra distribution on the Chukchi Sea shelf and slope. The model has been used previously by Spall (2007) and Spall et al. (manuscript in revision for JGR-Oceans) and is briefly summarized here. The regional version of the MIT general circulation model (Marshall et al., 1997) was coupled to a sea ice model and forced with surface fluxes of surface heat, freshwater, and momentum from the daily North American Regional Reanalysis product (www.esrl.noaa.gov/psd/data/gridded/ data.narr.html). The model was also forced by volume fluxes and the temperature and salinity characteristics of inflowing water through Bering Strait, which are seasonally variable and based on long-term measurement records from this region (Weingartner et al., 2005; Woodgate et al., $2005 b)$. The model was run for four years and forced with daily climatology from January 2002 to December 2005 to facilitate comparison with the seasonal trends captured by the SBI cruises.

The model domain was set on an f-plane with the Coriolis parameter set to $1.2 \times 10^{-4} \mathrm{~s}^{-1}$. The domain begins at $63^{\circ} \mathrm{N}$ and $180^{\circ} \mathrm{W}$ and extends $1440 \mathrm{~km}$ to the east and $2160 \mathrm{~km}$ to the north (Figure 3). The horizontal grid spacing was $10 \mathrm{~km}$, and the vertical grid was as follows: 5 $\mathrm{m}$ spacing in the upper $80 \mathrm{~m}, 10 \mathrm{~m}$ spacing between $80-110 \mathrm{~m}, 20 \mathrm{~m}$ spacing between $110-$ $150 \mathrm{~m}, 30 \mathrm{~m}$ spacing between $150-210 \mathrm{~m}$, and grid points at $250 \mathrm{~m}, 300 \mathrm{~m}, 375 \mathrm{~m}, 475 \mathrm{~m}, 625$ 
$\mathrm{m}, 800 \mathrm{~m}$, and $1000 \mathrm{~m}$. Bottom topography was interpolated from the ETOPOv2 two-minute gridded bathymetry (www.ngdc.noaa.gov/mgg/global/etopo2.html).

A generic tracer designed to represent benthic ${ }^{228} \mathrm{Ra}$ inputs was injected from sediments north of Bering Strait, with a flux proportional to the amount of mixing at the bottom, as defined by Equation 1:

$$
\mathrm{F}=1-\mathrm{e}^{-\kappa / \kappa_{\max }}
$$

where $F$ is the tracer flux, $\kappa$ is the vertical diffusion coefficient, and $\kappa_{\max }=0.1 \mathrm{~m}^{2} \mathrm{~s}^{-1}$. A minimum background mixing coefficient of $10^{-5} \mathrm{~m}^{-2} \mathrm{~s}^{-1}$ was specified, which represents diffusion of the tracer through the water column. The vertical mixing coefficient was determined by the KPP parameterization (Large et al., 1994). The tracer is represented in arbitrary units.

\subsection{RESULTS}

\subsubsection{Radium-228}

Radium-228 activities in Arctic surface waters are some of the highest in the open ocean due to the strong continental influence in this basin. The ${ }^{228} \mathrm{Ra}$ activities measured at the surface on the HLY 1502 transect ranged from 3 to $23 \mathrm{dpm} \mathrm{100L}^{-1}$ (Figure 4, Figure S1); comparatively, the highest activities in Atlantic and Pacific surface waters are typically below $5 \mathrm{dpm} 100 \mathrm{~L}^{-1}$ and $1 \mathrm{dpm} 100 \mathrm{~L}^{-1}$, respectively (Charette et al., 2015; Sanial et al., 2018). The highest ${ }^{228} \mathrm{Ra}$ activities on the HLY 1502 transect $\left(\sim 23 \mathrm{dpm} 100 \mathrm{~L}^{-1}\right)$ were observed between $85^{\circ}$ and $90^{\circ} \mathrm{N}$ from the surface to approximately $50 \mathrm{~m}$ (Figure 4, Figure S1). Minimum values in surface water $(\sim 3-4$ dpm $\left.100 \mathrm{~L}^{-1}\right)$ were observed near $77^{\circ} \mathrm{N}$ on the northbound transect and $75^{\circ} \mathrm{N}$ on the southbound transect.

Activities were generally $5-15 \mathrm{dpm} 100 \mathrm{~L}^{-1}$ in the shelf-modified Pacific layer and were

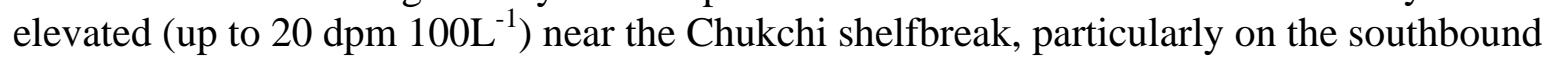
transect. The apparent difference between the two shelf crossings may simply be due to the higher sampling resolution on the southbound transect, which allowed samples to be collected closer to the shelfbreak and slope. Below the halocline, activities were below $5 \mathrm{dpm} 100 \mathrm{~L}^{-1}$, reflecting the isolation of deeper waters from the shelf source of ${ }^{228} \mathrm{Ra}$ (Figure 5, Figure S1). There was a mid-water column maximum in ${ }^{228} \mathrm{Ra}$ (up to $2 \mathrm{dpm} 100 \mathrm{~L}^{-1}$ ) between $500-1500 \mathrm{~m}$ evident in the Makarov Basin, particularly at station 19 over the Mendeleyev Ridge, and at station 32 in the Amundsen Basin (Figures 6 and 7). A similar pattern was not observed in Canada Basin intermediate waters. Some samples were below detection, particularly in the deep Canada Basin (black symbols in Figure 5). A few stations showed influence of benthic inputs, with activities near the bottom increasing up to $\sim 1 \mathrm{dpm} 100 \mathrm{~L}^{-1}$. These inputs were particularly evident at stations 14 (in the Chukchi Abyssal Plain), 30 (in the Makarov Basin), and 43 and 46 (above the Alpha Ridge). Bottom water values at the other stations were $\sim 0.5 \mathrm{dpm} 100 \mathrm{~L}^{-1}$. Benthic ${ }^{228} \mathrm{Ra}$ activities in the Arctic were similar to those observed in the Atlantic $(0.5-1.0$ dpm 100L $\mathrm{L}^{-1}$; Charette et al., 2015), but higher than those in the Pacific $\left(<0.6 \mathrm{dpm} 100 \mathrm{~L}^{-1}\right)$, where activities are low due to dilution and decay in the large Pacific basin (Sanial et al., 2018).

To examine the ${ }^{228} \mathrm{Ra}$ signature of various Arctic water masses, the ${ }^{228} \mathrm{Ra}$ activities measured during the SBI transects and the HLY1502 transect were used to create a mean T-S diagram, where the symbol color represents the average ${ }^{228} \mathrm{Ra}$ activity for each $0.1^{\circ} \mathrm{C} \times 0.1^{\circ} \mathrm{C}$ 
cell (Figure 8a; Figure 8c indicates the number of samples used to compute the average for each corresponding cell). Here we define the water masses according to the T-S characteristics outlined in Pickart et al. (submitted), but note that these boundaries serve as guidelines and can be variable. The highest ${ }^{228} \mathrm{Ra}$ activities were observed in a handful of samples collected in the melt water, around $-1.5^{\circ} \mathrm{C}$ and salinity 28 ; these samples were collected in the Transpolar Drift (see section 4.4.2.1). Apart from these Transpolar Drift samples, the highest ${ }^{228} \mathrm{Ra}$ activities were associated with the WW and RWW. The lowest activities were found in AW, while MW, BSW, and ACW displayed variable ${ }^{228} \mathrm{Ra}$ activities.

\subsubsection{Radium-226}

Radium-226 activities were lowest in the fresh surface layer, ranging between $7-10 \mathrm{dpm}$

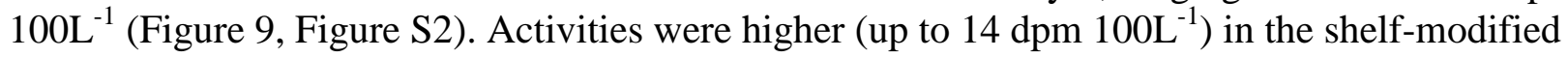
Pacific inflow; these activities are similar to those observed in the upper $1000 \mathrm{~m}$ of the North

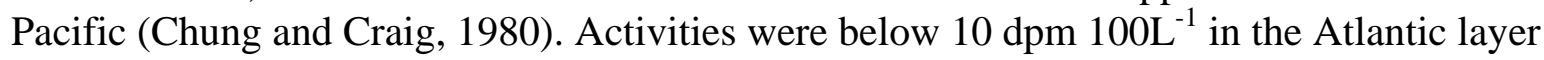
between approximately $500-1500 \mathrm{~m}$, and then increased with depth. The deep Makarov and Canada Basins had the highest ${ }^{226} \mathrm{Ra}$ activities, reaching up to $17 \mathrm{dpm} \mathrm{100L}{ }^{-1}$ (Figures 9 and 10). To the best of our knowledge, this study presents the first measurements of ${ }^{226}$ Ra below $2000 \mathrm{~m}$ in the Canada Basin. The activities measured at the sole Eurasian Basin station (station 32) were

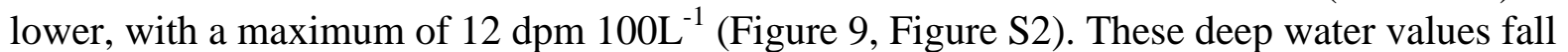

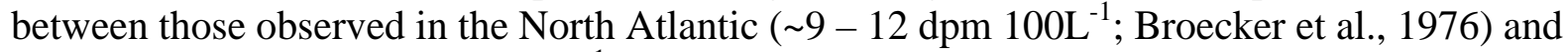

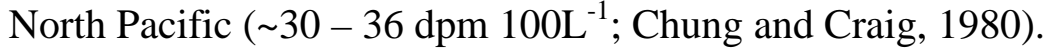

Similar to ${ }^{228} \mathrm{Ra},{ }^{226} \mathrm{Ra}$ activities were elevated in the WW, RWW, and cold MW around salinity 28. There were variable activities in the BSW, ACW, and the other MW samples (Figure 8b; data density shown in Figure 8c). Radium-226 activities were also elevated in the deep AW, with the highest activities associated with Canada Basin Deep Waters.

\subsubsection{Chukchi Sea model}

The numerical model was able to reproduce the main circulation features and seasonal variability in temperature, salinity, and ice coverage in the Chukchi Sea (Spall, 2007). The seasonal change in the modeled temperature was similar to the trend observed in the data for spring, summer, and fall transects, with the coldest temperatures $\left(<-1.5^{\circ} \mathrm{C}\right)$ in the spring and maximum values $\left(\sim 1^{\circ} \mathrm{C}\right)$ in the upper water column in the fall (Figure 11; see section 4.4.2.2). The modeled salinity re-created the observed mean salinity, with values $\sim 32$ below $20 \mathrm{~m}$ and fresher waters at the surface (Figure 11; see section 4.4.2.2). Similarly, the modeled velocity of the shelfbreak jet matched the observed mean velocity, $\sim 5-10 \mathrm{~cm} \mathrm{~s}^{-1}$ (Figures 11 and 12; see section 4.4.2.2).

The concentration of the tracer at the bottom of the water column is shown in Figure 13; the concentration at $37.5 \mathrm{~m}$ and depth-integrated concentrations exhibited similar trends, though the depth integrated tracer concentrations were not as variable and were highest over the midshelf between Herald and Hanna Shoals in early spring (Figures S3 and S4). The concentration of the sediment tracer generally increased with distance from Bering Strait and was highest in the fall (Figure 13). The highest concentrations were observed in Kotzebue Sound, Alaska, which has very shallow bathymetry $(<20 \mathrm{~m})$, and near Hanna Shoal. Elevated concentrations were also observed near the coast of Russia in the fall (Figure 13d). 
To facilitate a comparison with the available data, a cross-section of the model near the SBI and GEOTRACES southbound shelf crossings was examined (white box in Figure 3). This shows that the shelfbreak jet carries elevated tracer concentrations (Figure 12, Figure S5). Seasonal variability in the tracer was apparent in this location, with the highest concentrations observed in the fall, coincident with warmer temperatures and higher velocities in the shelfbreak jet (Figure 11).

\subsection{DISCUSSION}

\subsubsection{Seasonal variability in ${ }^{228} \mathrm{Ra}$ and ${ }^{226} \mathrm{Ra}$ in the Chukchi Sea}

Our 2015 observations were compared to previous studies of ${ }^{228} \mathrm{Ra}$ and ${ }^{226} \mathrm{Ra}$ in the Chukchi Sea to investigate seasonal trends. HLY1502 station $6\left(68.09^{\circ} \mathrm{N}, 168.11^{\circ} \mathrm{W}\right)$ was located north of the Bering Strait near Point Hope, Alaska, in close proximity to a station repeatedly occupied during the SBI cruises $\left(\sim 67.5^{\circ} \mathrm{N}, 168.9^{\circ} \mathrm{W}\right)$, and a station sampled during the 2014 CHINARE expedition $\left(69.60^{\circ} \mathrm{N}, 169.01^{\circ} \mathrm{W}\right.$; Li et al., 2017) (Figure 14). The ${ }^{228} \mathrm{Ra}$ activities measured at this location in fall 2015 were approximately double those observed during the spring 2002, summer 2002, and summer 2004 cruises (HLY0201, HLY0203, HLY0403), but similar to the activities recorded during spring 2004 and late summer 2014 (HLY0402, CHINARE) (Figure 14a). Radium-228 activities in Bering Sea surface water are typically $1-3$ dpm 100L ${ }^{-1}$ (Charette and Moore, 2017; Li et al., 2017), similar to the low end of the historical data. The higher ${ }^{228} \mathrm{Ra}$ activities could be due to an increased ${ }^{228} \mathrm{Ra}$ flux from sediments as a result of water column mixing, or to the influence of $\mathrm{ACW}$. This water mass is transported into the Eastern Chukchi via the Alaskan Coastal Current in summer and early fall, and is influenced by the Yukon River outflow (Woodgate et al., 2005a); ${ }^{228} \mathrm{Ra}$ activities in the Yukon can be as

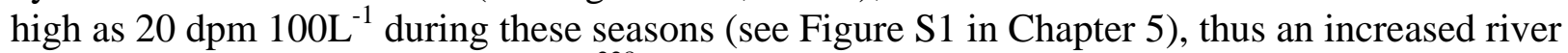
influence could contribute to higher ${ }^{228} \mathrm{Ra}$ activities in the Chukchi Sea later in the year. The high

${ }^{228} \mathrm{Ra}$ activities observed in the fall of 2015 are near the T-S space occupied by ACW (Figure $8 \mathrm{a})$, indicating possible influence from this water mass. An enhanced presence of ACW during spring 2004 compared to spring 2002 might also have contributed to the higher Ra activities observed during this season (Codispoti et al., 2009). However, based on the activities in the river and Bering Sea endmembers, a mixture of $\sim 30 \%$ river water and $\sim 70 \%$ Bering Sea water is required to achieve ${ }^{228} \mathrm{Ra}$ activities of $\sim 8 \mathrm{dpm} 100 \mathrm{~L}^{-1}$ over the shelf. This amount of river input is improbable given the salinity of the water at this station $(\sim 32)$, thus river input is unlikely to be the sole driver of the increased ${ }^{228} \mathrm{Ra}$ activities.

Water column mixing may be a more important control on the Ra activities; the cooling and brine rejection that occurs during ice formation (Muench et al., 1988; Weingartner et al., 1998) leads to convective overturning that can transport Ra, nutrients, and other sedimentderived materials into the water column (Arrigo et al., 2017; Lowry et al., 2015; Pickart et al., 2016; Pacini et al., submitted). Sediment inputs are strongest in the late fall when ice formation occurs (Figure 11), thus the high activities observed during the CHINARE (July - September) and HLY1502 (August) expeditions could be supported by convective overturning and mixing resulting from brine formation or storms passing through the Chukchi Sea during the open water season. The HLY0402 transect took place in the spring (May - June), when the Chukchi is still extensively ice covered, but Pacini et al. (submitted) have recently shown that refreezing leads in 
late-May can drive convection and stir sediment-derived solutes into the overlying water column; this could explain the elevated ${ }^{228} \mathrm{Ra}$ activities observed during this expedition.

Radium-226 activities were highest in the fall of 2015 (HLY1502), and lowest in the surface during the 2002 and 2004 summer transects (HLY0203, HLY0403) (Figure 14b). The

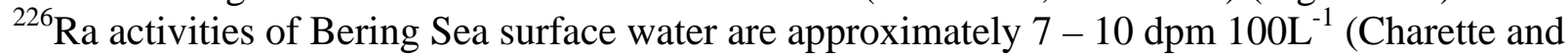
Moore, 2017; Chung and Craig, 1980; Li et al., 2017), therefore the Chukchi Sea activities below $7 \mathrm{dpm} 100 \mathrm{~L}^{-1}$ are likely due to removal of ${ }^{226} \mathrm{Ra}$. Radium can be depleted in surface waters due to co-precipitation with barite or uptake in calcareous or siliceous tests (Moore and Dymond, 1991; van Beek et al., 2007), thus the low summer activities may be the result of biological uptake and subsequent particle export. Low concentrations of $\mathrm{Ba}$, a chemical analog of Ra, have been previously observed in the Bering Strait and were attributed to biological uptake (Kenison Falkner et al., 2013). However, these authors observed only a $20 \%$ depletion of Ba, while the summer ${ }^{226} \mathrm{Ra}$ activities of $\sim 3 \mathrm{dpm} 100 \mathrm{~L}^{-1}$ observed in this study would require $\sim 60 \%{ }^{226} \mathrm{Ra}$ decrease from typical Bering Sea surface water values. This is a surprisingly large depletion, given that particulate ${ }^{226} \mathrm{Ra}$ is typically $<1 \%$ of dissolved values (van Beek et al., 2007). However, strong biological uptake (48\% depletion) of ${ }^{226} \mathrm{Ra}$ has also been observed on the Laptev and Barents Seas (Rutgers van der Loeff et al., 2012). The elevated ${ }^{226}$ Ra activities in fall 2015 could be influenced by ACW carrying Yukon River outflow; summer and fall ${ }^{226} \mathrm{Ra}$

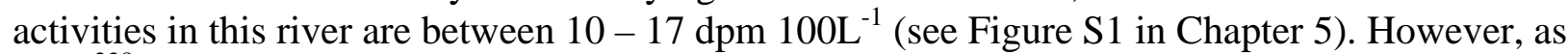
with ${ }^{228} \mathrm{Ra}$ above, this would require an unlikely contribution of $\sim 30 \%$ river water, so sources such as sediment inputs or groundwater may also have played a role in creating the fall 2015 ${ }^{226}$ Ra profile.

\subsubsection{Shelf inputs at the surface and in the halocline}

The strong ${ }^{228} \mathrm{Ra}$ enrichments in the surface and halocline waters are due to shelf inputs that have accumulated in this layer. Kadko and Aagaard (2009) suggested that heterogeneity in the halocline distribution of ${ }^{228} \mathrm{Ra}$ may arise from a combination of episodic shelf inputs, eddies, and downwelling. Based on the extensive dataset provided by the HLY1502 and SBI expeditions, some specific shelf influences in the Western Arctic can be identified.

\subsubsection{Distinct surface water sources indicated by ${ }^{228} \mathrm{Ra}$}

Radium-228 activities were highest in surface waters near the North Pole; this ${ }^{228} \mathrm{Ra}-$ enriched water was transported from the East Siberian and Laptev Shelf Seas via the Transpolar Drift. These wide and shallow Eurasian Seas are a large source of ${ }^{228} \mathrm{Ra}$ to the overlying waters, and are transported on time scales of 6-12 months to the central Arctic (Kipp et al., 2018). The activities observed in the Transpolar Drift in 2015 were approximately double those observed in 2007; because the shelves are the largest source of ${ }^{228} \mathrm{Ra}$ to the surface ocean, this indicates a substantial increase of shelf-derived materials to the Arctic over the last decade (Kipp et al., 2018; Rutgers van der Loeff et al., 2018) (see Chapter 2).

The relatively low ${ }^{228} \mathrm{Ra}$ activities observed in surface waters near $77^{\circ} \mathrm{N}$ on the northbound transect and $75^{\circ} \mathrm{N}$ on the southbound transect are associated with low salinity $(<27)$ and high fractions of meteoric water (>0.15; Pasqualini et al., 2017). This water is part of the southern arm of the Beaufort Gyre, which accumulates and stores river runoff (Carmack et al., 2016). The low ${ }^{228} \mathrm{Ra}$ activities result from decay during circulation in the gyre. Back trajectories 
determined for the ice at these sample locations supports transport in the gyre, and surface water ages based on the ingrowth of ${ }^{228} \mathrm{Th}$ with its parent ${ }^{228} \mathrm{Ra}$ indicate that this water mass has been removed from the shelf for at least 3 years (Kipp et al., 2018).

\subsubsection{Influence of the shelfbreak jet}

The HLY1502 southbound transect and the SBI spring and summer 2002 and 2004 transects (HLY0201, HLY0203, HLY0402, HLY0403) crossed the Chukchi shelfbreak in similar locations, west of Barrow Canyon (Figure 15). These 8 transects were used to compute composite mean sections of the Ra activities, absolute geostrophic velocity, temperature, and salinity across the Chukchi shelfbreak using the MATLAB approach described in Corlett and Pickart (2017) (Figure 16). These mean plots illustrate that the high ${ }^{228} \mathrm{Ra}$ activities observed near the shelfbreak are associated with cold water moving from west to east. This suggests that ${ }^{228} \mathrm{Ra}$-enriched WW is being transported from the Chukchi Shelf via the Chukchi shelfbreak jet (Corlett and Pickart, 2017; Pickart et al., 2005; Li et al., submitted). The WW advected by the shelfbreak jet likely becomes enriched in ${ }^{228}$ Ra during its residence time over the Chukchi Shelf. As mentioned in section 4.4.1, convective overturning as a result of brine rejection during ice formation and lead refreezing can transport sediment-derived materials such as ${ }^{228} \mathrm{Ra}$ into the overlying water column (Arrigo et al., 2017; Lowry et al., 2015; Pickart et al., 2016; Pacini et al., submitted). The modeled tracer concentrations were elevated in the shelfbreak jet, similar to the trend observed in the data, and were highest over the northern part of the shelf (Figure 12). The data and the model demonstrate that the advection of WW in the shelfbreak jet plays a key role in transporting sediment-derived materials off the Chukchi Shelf.

When the data are separated by season, ${ }^{228} \mathrm{Ra}$ activities near the shelfbreak increase from spring to summer to fall (Figure 17). Interestingly, this is opposite to the trend in WW presence, which is most prevalent in the spring (but present throughout the year). The rise in ${ }^{228} \mathrm{Ra}$ during the year could be due to a longer WW residence time over the shelf: assuming that ice formation (and thus WW formation) occurs at approximately the same time across the shelf, and that the flushing rate is similar throughout the year, WW formed farther south will take longer to reach the northern part of the shelf and/or be carried to the sampling location via the shelfbreak jet. The water reaching the shelfbreak in the fall would therefore have a longer residence time over the shelf, during which time it could become more enriched in $\mathrm{Ra}$, than the water reaching the shelfbreak in the spring. Because these seasonal mean sections are based on fewer data than the annually averaged plot - in the case of fall, the section is based only on HLY1502 data - we cannot rule out variability due to interannual differences or sampling resolution. However, the seasonal variability in the sediment tracer model matches the seasonal changes observed in the data; specifically, the highest concentrations are observed on the northern part of the shelf during the fall and were associated with warmer water temperatures (Figures $11-13$ ). The model therefore supports the idea that there is an accumulation of Ra in WW over the course of the year, and indicates that there is a seasonal cycle in the export of sediment-derived materials from the Arctic shelves.

Similar to ${ }^{228} \mathrm{Ra}$, activities of ${ }^{226} \mathrm{Ra}$ are highest in the shelfbreak jet, and increase through the year (Figure 17). Because of its long half-life, this isotope of Ra can be noticeably impacted by biological uptake and mineral precipitation of siliceous or calcareous tests (Moore and Dymond, 1991; van Beek et al., 2007); these processes decrease ${ }^{226}$ Ra activities in the water column but would increase activities in the sediments if biological production was followed by 
particle export. Biological uptake and particle cycling could therefore impact the ${ }^{226}$ Ra activities over the Chukchi Shelf in addition to the sediment inputs of Ra. The elevated ${ }^{226} \mathrm{Ra}$ activities extend into the halocline in fall, while the off-shelf ${ }^{228} \mathrm{Ra}$ activities are fairly similar in all sampling periods. This may reflect the longer half-life of ${ }^{226} \mathrm{Ra}$. Residence times in the halocline have been estimated to be $\sim 3-10$ y (Schlosser et al., 1999), which would allow a significant amount of ${ }^{228} \mathrm{Ra}$ to decay but would not measurably affect the ${ }^{226} \mathrm{Ra}$ activities. However, this explanation contrasts with the seasonal variability observed in the ${ }^{226} \mathrm{Ra}$ activities; if ${ }^{226} \mathrm{Ra}$ is not appreciably affected by decay in the halocline, then the ${ }^{226} \mathrm{Ra}$ activities should be similar in all seasons. More data in the fall time period are needed to elucidate the controls on this isotope in the halocline and determine whether the high ${ }^{226} \mathrm{Ra}$ activities observed in 2015 are due to a seasonal trend or interannual changes.

Because both isotopes increase seasonally in the shelfbreak jet, the ${ }^{228} \mathrm{Ra} /{ }^{226} \mathrm{Ra}$ activity ratio of this water mass remains fairly constant, at approximately $0.9-1.1$ (Figure 17). This ratio, along with the T-S characteristics of the $\mathrm{WW}$, can therefore be used to identify a shelfbreak jet endmember (see section 4.4.2.3).

\subsubsection{3 ${ }^{228} \mathrm{Ra} /{ }^{226} \mathrm{Ra}$ signatures in the halocline}

The combination of strong shelf influences and decay of ${ }^{228} \mathrm{Ra}$ on subdecadal timescales leads to variability in the ${ }^{228} \mathrm{Ra} /{ }^{226} \mathrm{Ra}$ activity ratios observed in Western Arctic surface and halocline waters; this variability can be used to identify specific shelf inputs to the upper water column and determine the time elapsed since water was in contact with the shelf. Because of the shorter half-life of ${ }^{228} \mathrm{Ra}$, this isotope regenerates more quickly than ${ }^{226} \mathrm{Ra}$ in sediments. This can result in ${ }^{228} \mathrm{Ra} /{ }^{226} \mathrm{Ra}$ activity ratios greater than 1 over continental shelves; ratios as high as 3.9 have been observed over the Laptev Shelf (Rutgers van der Loeff et al., 2003). After water leaves the shelf, residence times in the surface and halocline are long enough $(\sim 3-10$ years; Schlosser et al., 1999) that the ${ }^{228} \mathrm{Ra} /{ }^{226} \mathrm{Ra}$ activity ratio will decrease due to ${ }^{228} \mathrm{Ra}$ decay. The change in the ${ }^{228} \mathrm{Ra} /{ }^{226} \mathrm{Ra}$ activity ratio can therefore be used to determine the time elapsed since the water mass advected off the shelf.

However, the ${ }^{228} \mathrm{Ra} /{ }^{226} \mathrm{Ra}$ ratio can also change due to mixing between water masses in Western Arctic surface and halocline waters. The upper water column in the Western Arctic contains multiple endmembers: water recently in contact with the shelf (including ACW, BSW, RWW, and WW), fresh surface MW, and saline AW beneath the halocline. Shelf water has high ${ }^{228} \mathrm{Ra} /{ }^{226} \mathrm{Ra}$ activity ratios, and is typically associated with low salinities due to rivers inputs over shelves (Rutgers van der Loeff et al., 2003; Smith et al., 2003). The MW endmember has low ${ }^{228} \mathrm{Ra} /{ }^{226} \mathrm{Ra}$ ratios due to ${ }^{228} \mathrm{Ra}$ decay during circulation in the Beaufort Gyre, and low salinities due to ice melt and river discharge. The ${ }^{228} \mathrm{Ra} /{ }^{226} \mathrm{Ra}$ activity ratio of 0.29 measured at the T3 ice station in the Canada Basin in 1968 (Kaufman et al., 1973) is often used to represent the MW endmember (Kadko and Muench, 2005; Rutgers van der Loeff et al., 1995; Smith et al., 2003). The AW endmember represents saline water deeper in the halocline that has low ${ }^{228} \mathrm{Ra} /{ }^{226} \mathrm{Ra}$ activity ratios $(<0.2)$ due to decay.

The ${ }^{228} \mathrm{Ra} /{ }^{226} \mathrm{Ra}$ activity ratios measured in Western Arctic surface waters $(\leq 200 \mathrm{~m})$ over the last two decades range between $\sim 0-2.1$ and generally fall within salinities of $23-35$ (Figure 18a). This compilation of datasets allows for a more robust analysis of the endmembers described above than was possible in previous studies. The HLY1502 transect included many measurements in the Canada Basin, capturing the MW endmember. A handful of samples 
collected between stations $53-57\left(73.4^{\circ}-77.0^{\circ} \mathrm{N}\right)$ displayed ${ }^{228} \mathrm{Ra} /{ }^{226} \mathrm{Ra}$ activity ratios of 0.30 - 0.46 at salinities of 25.30 - 26.34; several samples from the AWS2000 and SBI expeditions fell within this range as well. We identify this cluster of samples as the MW endmember, representing low-salinity, aged surface waters (dashed circle on Figure 18). The activity ratio of this newly defined PSL endmember is similar to that of the T3 ice station, but with a lower salinity. This is likely due to freshening of Arctic surface waters over the last few decades (Swift et al., 2016). The HLY1502 transect also provided high-resolution water column measurements that can be used to determine the AW endmember. This endmember was determined by taking the mean of HLY1502 samples with temperatures $<1^{\circ} \mathrm{C}$ and salinities $>34(\mathrm{n}=143)$; this resulted in an average ${ }^{228} \mathrm{Ra} /{ }^{226} \mathrm{Ra}$ activity ratio of 0.064 and an average salinity of 34.86 (black square in Figure 18).

As mentioned above, previous studies have identified the shelf endmember through high ${ }^{228} \mathrm{Ra} /{ }^{226} \mathrm{Ra}$ activity ratios and low salinities (Rutgers van der Loeff et al., 1995; Smith et al., 2003). The lack of a direct freshwater input to the Chukchi precludes the use of this approach here, and we cannot define a general Chukchi Shelf endmember. The range of ${ }^{228} \mathrm{Ra} /{ }^{226} \mathrm{Ra}$ activity ratios measured over the Chukchi Shelf (defined as stations with bottom depths $\leq 200 \mathrm{~m}$ ) during HLY1502 was $0.51-1.23$ at salinities of $22.8-32.8$. The cluster of HLY1502 samples with ${ }^{228} \mathrm{Ra} /{ }^{226} \mathrm{Ra}$ activity ratios around 2 were collected in the Transpolar Drift $\left(>85^{\circ} \mathrm{N}\right)$, which carries the high ${ }^{228} \mathrm{Ra} /{ }^{226} \mathrm{Ra}$ - low salinity shelf signal from the Kara and Laptev Seas (Rutgers van der Loeff et al., 2003, 1995). Despite the variability over the Chukchi shelf, the shelfbreak jet exhibits a fairly consistent ${ }^{228} \mathrm{Ra} /{ }^{226} \mathrm{Ra}$ activity ratio of $0.9-1.2$, which is associated with salinities of $\sim 32.4-32.8$ (see section 4.4.2.2); we use these values to denote a shelfbreak jet endmember in lieu of a general Chukchi shelf endmember (black rectangle on Figure 18). Because the shelfbreak jet carries WW and RWW, this can also be considered a WW endmember.

Lines drawn between endmembers represent rapid mixing between them, with little ${ }^{228} \mathrm{Ra}$ decay. Water carried in the shelfbreak jet contributes to the ventilation of the halocline (Aagaard et al., 1981; Pickart et al., 2005; Weingartner et al., 1998), and mixing with MW and AW in the halocline will modify the ${ }^{228} \mathrm{Ra} /{ }^{226} \mathrm{Ra}$ activity ratio and salinity of this water mass. The ${ }^{228} \mathrm{Ra} /{ }^{226} \mathrm{Ra}$ activity ratio of the shelfbreak jet endmember will also decrease due to decay during its residence time in the halocline. The modified ratios should fall within the envelope defined by the mixing curves shown in Figure 18b. Although ratios do not mix linearly, we assume that mixing biases do not introduce a significant amount of error because the range of ${ }^{226} \mathrm{Ra}$ activities is small compared to the range of ${ }^{228} \mathrm{Ra}$ activities in surface waters (Kadko and Muench, 2005; Rutgers van der Loeff et al., 1995). The mixing line drawn between the MW and AW endmembers identifies the lower limit of ${ }^{228} \mathrm{Ra} /{ }^{226} \mathrm{Ra}$ activity ratios expected in the halocline, as this denotes mixing between two aged water masses. The difference between the ${ }^{228} \mathrm{Ra} /{ }^{226} \mathrm{Ra}$ activity ratio in the shelfbreak jet and the ratio at the corresponding salinity on this $\mathrm{MW}-\mathrm{AW}$ line therefore represents the maximum amount of ${ }^{228} \mathrm{Ra}$ decay expected in the halocline for water originating in this water mass. This decay can be used to determine the halocline ventilation timescale with respect to inputs from the shelfbreak jet (Equation 2):

$$
\left(\frac{{ }^{228} \mathrm{Ra}}{{ }^{226} \mathrm{Ra}}\right)_{t}=\left(\frac{{ }^{228} \mathrm{Ra}}{{ }^{226} \mathrm{Ra}}\right)_{0} \mathrm{e}^{-\lambda_{228} \cdot \mathrm{t}}
$$


In Equation 2, $\left(\frac{228 \mathrm{Ra}}{{ }^{226} \mathrm{Ra}}\right)_{\mathrm{t}}$ is the activity ratio of ${ }^{228} \mathrm{Ra} /{ }^{226} \mathrm{Ra}$ on the MW-AW endmember mixing line determined at a given salinity, $\left(\frac{{ }^{228} \mathrm{Ra}}{{ }^{226} \mathrm{Ra}}\right)_{0}$ is the ratio of the shelfbreak jet endmember, $\lambda_{228}$ is the decay constant for ${ }^{228} \mathrm{Ra}$, and $\mathrm{t}$ is the time elapsed. Using the range of ${ }^{228} \mathrm{Ra} /{ }^{226} \mathrm{Ra}$ activity ratios in the shelfbreak jet $(0.9-1.2)$ as the initial ratios, and the ratios on the MW-AW line at salinities $32.4-32.8$ as the minimum expected ratios in the halocline $(0.16-0.14)$, the halocline ventilation timescale was determined to be $14-17 \mathrm{y}$. Because the MW-AW mixing line represents the lower limit of expected ${ }^{228} \mathrm{Ra} /{ }^{226} \mathrm{Ra}$ ratios in the halocline, this estimate is an upper limit of the halocline ventilation timescale with respect to inputs from the shelfbreak jet. Many samples fall above the MW-AW mixing line, indicating that less ${ }^{228} \mathrm{Ra}$ has decayed and less time has elapsed. This ventilation timescale is specifically for water that has originated over the Chukchi Shelf and was transported to the basin via the shelfbreak jet (WW and RWW), however Figure 18 shows that many samples fall outside the mixing lines constrained by this endmember. This reflects the variability in the ${ }^{228} \mathrm{Ra} /{ }^{226} \mathrm{Ra}$ activity ratios of Chukchi shelf waters, which may reach the Canada Basin through different pathways (e.g. the slope current, eddies) and ventilate the halocline over different timescales.

The five datasets compiled for this analysis span two decades and exhibit similar relationships between ${ }^{228} \mathrm{Ra} /{ }^{226} \mathrm{Ra}$ activity ratios, salinity, and depth. The ventilation timescale of $\leq 14-17$ years is thus likely to be representative for shelfbreak jet inputs to the Canada Basin halocline between 1995 - 2015. However, rising ${ }^{228} \mathrm{Ra}$ activities in the Transpolar Drift indicate that climate change has impacted Ra inputs from the Eastern Arctic shelves over the last decade (Kipp et al., 2018; Rutgers van der Loeff et al., 2018). This change is likely driven by intensified wind-driven vertical mixing as a result of an increased number of open water days over the Laptev and East Siberian Seas. A similar change in the number of open water days was not observed over the Chukchi Shelf (Chapter 3 Figure S11), and the ${ }^{228}$ Ra activities observed over the Chukchi Shelf during our 2015 transect are similar to those measured on previous expeditions (Figure 14, Chapter 3 Figure S2). Changing shelf inputs are therefore unlikely to bias our estimate of the ventilation timescale.

\subsubsection{Radium variability in the Canada Basin}

While multiple studies have examined the Ra activities over the Chukchi shelf, only a few historical profiles of Ra in the Canada Basin exist. Both ${ }^{228} \mathrm{Ra}$ and ${ }^{226} \mathrm{Ra}$ were measured over the Alpha Ridge $\left(85.83^{\circ} \mathrm{N}, 108.83^{\circ} \mathrm{W}\right)$ during the Canadian Expedition to Study the Alpha Ridge (CESAR) in the spring of 1983 (Bacon et al., 1989; Moore and Smith, 1986). HLY1502 station $43\left(85.13^{\circ} \mathrm{N}, 150.00^{\circ} \mathrm{W}\right)$ was located $\sim 362 \mathrm{~km}$ west of the CESAR floating ice camp but was also positioned over the Alpha Ridge. The ${ }^{228} \mathrm{Ra}$ and ${ }^{226} \mathrm{Ra}$ profiles from HLY1502 station 43 are generally similar to those from CESAR, but display higher ${ }^{228} \mathrm{Ra}$ activities in the surface and lower ${ }^{226} \mathrm{Ra}$ activities in the halocline (Figure 19). The elevated ${ }^{228} \mathrm{Ra}$ surface activities in 2015 are due to increased shelf inputs of this isotope, which were transported to the central Arctic via the Transpolar Drift (Kipp et al., 2018). The offset in ${ }^{226} \mathrm{Ra}$ activities between spring 1983 and fall 2015 must result from differences in the shelf-modified Pacific layer. The nutrient maximum was slightly shallower in 2015 ( 100 $\mathrm{m}$ in 2015, 130 $\mathrm{m}$ in 1983), and Si concentrations were also lower in 2015 ( $\sim 32 \mu \mathrm{M}$ in 2015, 40 $\mu \mathrm{M}$ in 1983) (Kadko et al., 2016; Moore and Smith, 1986). As these stations were separate in both space and time, there may have a been a stronger 
influence of Pacific waters on the CESAR station in 1983 due to seasonal or interannual differences in circulation (e.g. the strength of the Arctic Oscillation). Alternatively, the ${ }^{226} \mathrm{Ra}$ activities and Si concentrations may have been higher in the 1983 profile due to a longer residence time of Pacific water over the Chukchi shelf, or to differences in biological productivity. A particularly productive season would decrease the ${ }^{226} \mathrm{Ra}$ activities and $\mathrm{Si}$ concentrations in the water transiting the shelf via biological uptake and subsequent particle export, while an unproductive biological season would remove less ${ }^{226} \mathrm{Ra}$ and $\mathrm{Si}$ from the water column.

A profile of ${ }^{228} \mathrm{Ra}$ was also measured in the Canada Basin as part of the AWS-2000 expedition (Trimble et al., 2004). This AWS-2000 station $\left(75.22^{\circ} \mathrm{N}, 149.90^{\circ} \mathrm{W}\right)$ was located $\sim 21$ $\mathrm{km}$ from HLY1502 station $56\left(75.06^{\circ} \mathrm{N}, 150.32^{\circ} \mathrm{W}\right)$. The ${ }^{228} \mathrm{Ra}$ activities measured below $100 \mathrm{~m}$ at both stations are similar; the peak ${ }^{228} \mathrm{Ra}$ activity in the cold Pacific winter water $(\sim 130-230 \mathrm{~m})$

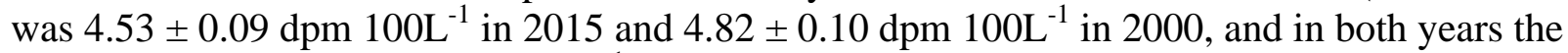
activities decreased to $<1 \mathrm{dpm} 100 \mathrm{~L}^{-1}$ in the underlying Atlantic layer (Figures 20 and S6). However, in 2000, high ${ }^{228} \mathrm{Ra}$ activities were observed in Pacific summer water, reaching $\sim 7$ dpm $100 \mathrm{~L}^{-1}$ between $50-100 \mathrm{~m}$, coincident with a temperature maximum. A similar ${ }^{228} \mathrm{Ra}$ peak was not observed at HLY1502 station 56, or at any other HLY1502 stations (Figures S1 and S6). There were elevated ${ }^{228} \mathrm{Ra}$ activities associated with local temperature maxima at HLY1502 stations 52 and 60, however these were located at shallower depths (36 m and $22 \mathrm{~m}$, respectively) and lower salinities than the peak observed on AWS-2000 (Figure S6). These local maxima may therefore be related to the ACW, while the deeper, saltier water mass associated with the ${ }^{228}$ Ra peak observed on AWS-2000 is more likely BSW (Steele et al., 2004). The warmer temperatures observed at HLY1502 station 60 support the presence of ACW at this station, but a similar temperature maximum is not observed at station 52 (Figure S6). A wide range of ${ }^{228} \mathrm{Ra}$ activities have been measured in BSW over the shelf (Figure 8a), so the difference between the 2015 and 2000 profiles could also reflect the variability of ${ }^{228} \mathrm{Ra}$ in this water mass. It is also possible that the BSW measured in 2015 had a longer transit time, and thus more ${ }^{228} \mathrm{Ra}$ decayed before reaching this location. Alternatively, the high ${ }^{228} \mathrm{Ra}$ activities observed in 2000 could have been influenced by eddies, which are prevalent in the Western Arctic (Mathis et al., 2007; Muench et al., 2000; Pickart et al., 2005; Timmermans et al., 2008).

\subsubsection{Recent ventilation of the Makarov Basin}

The enrichment of ${ }^{228} \mathrm{Ra}$ between $500-1500 \mathrm{~m}$ on the northbound transect is evidence of recent shelf contact (Figures 6 and 7). Elevated ${ }^{228} \mathrm{Ra}$ activities and ${ }^{228} \mathrm{Ra} /{ }^{226} \mathrm{Ra}$ activity ratios have been used to identify recently ventilated waters as they move along isopycnals (Kim et al., 2003; Rutgers van der Loeff et al., 1995), and ${ }^{228} \mathrm{Ra} /{ }^{226} \mathrm{Ra}$ activity ratios have been applied in the Arctic to determine the time elapsed since intermediate waters were last in contact with the shelf (Kadko and Aagaard, 2009; Rutgers van der Loeff et al., 2018). If the shelf endmember is known, the time elapsed since the water mass was ventilated can be estimated using equation 2 . In this case, $\left(\frac{{ }^{228} \mathrm{Ra}}{{ }^{226} \mathrm{Ra}}\right)_{\mathrm{t}}$ is the activity ratio of ${ }^{228} \mathrm{Ra} /{ }^{226} \mathrm{Ra}$ observed in the intermediate water, and $\left(\frac{{ }^{228} \mathrm{Ra}}{{ }^{226} \mathrm{Ra}}\right)_{0}$ is the ratio of the shelf endmember. The ratio of ${ }^{228} \mathrm{Ra} /{ }^{226} \mathrm{Ra}$ is used instead of the absolute ${ }^{228}$ Ra activity in order to correct for any dilution or mixing during transit, assuming deep water has a negligible ${ }^{228} \mathrm{Ra}$ activity. This approach assumes that there are no additional 
inputs of $\mathrm{Ra}$ from the slope after the water leaves the shelf. The ${ }^{228} \mathrm{Ra} /{ }^{226} \mathrm{Ra}$ activity ratios measured between $500-1500 \mathrm{~m}$ at the HLY1502 stations closest to the slope $(14,57,60)$ ranged from $0.02-0.09$ but were all within error of 0 (excluding one sample with a ratio of $0.58 \pm 0.30$ that is questionable due a pump malfunction), indicating that inputs from the slope are unlikely to bias this calculation. Elevated oxygen and $\mathrm{SF}_{6}$ concentrations between $500-1500 \mathrm{~m}$ in the Makarov Basin also indicate recent ventilation (Smethie and Swift, 2018), and the atmospheric source of these tracers support recent contact with the shelf.

The ${ }^{228} \mathrm{Ra} /{ }^{226} \mathrm{Ra}$ activity ratios observed in the recently ventilated water at station 19 (above the Mendeleyev Ridge in the Canadian Basin) and station 32 (in the Amundsen Basin) were $0.15 \pm 0.02$ and $0.16 \pm 0.01$, respectively (Figures $6 \mathrm{c}$ and $7 \mathrm{c}$ ). This intermediate water was likely formed during brine rejection over the shelf and subducted through the St. Anna Trough in the Kara Sea (Rudels et al., 1994). We therefore use historical observations of the ${ }^{228} \mathrm{Ra} /{ }^{226} \mathrm{Ra}$ activity ratio from the Kara Sea as the shelf endmember. Using the average Kara shelf ratio of $2.1 \pm 0.6$ (Rutgers van der Loeff et al., 2003), the intermediate water age at stations 19 and 32 is $22 \pm 2 \mathrm{y}$ and $21 \pm 2 \mathrm{y}$, respectively. Because similar mid-water column enrichments were not observed in the Canada Basin, the intermediate water in this basin must be ventilated on time scales greater than 30 years, after which time any ${ }^{228} \mathrm{Ra}$ enrichment would not be detectable. This is consistent with the current understanding of intermediate water circulation, which indicates that water flows through the Makarov Basin before reaching the Canada Basin (Rudels et al., 1994).

Rising shelf inputs of $\mathrm{Ra}$ as a result of climate change could bias this calculation towards older ages (Kipp et al., 2018; Rutgers van der Loeff et al., 2018), but because the Kara and Laptev Sea measurements were made 20 y before the HLY1502 transect, they are likely representative of endmember ratios at the time the intermediate water was subducted. These ages also agree well with water mass ages estimated from $\mathrm{SF}_{6}$ concentrations measured on the HLY1502 expedition: Smethie and Swift (2018) determined ventilation time scales of 15-18 y for Makarov Basin intermediate waters and 27+ y for Canada Basin intermediate waters. Amundsen Basin intermediate water ventilation times have been estimated to be approximately $18 \mathrm{y}$, based on $\mathrm{SF}_{6}$ concentrations and ${ }^{228}$ Ra activities (Rutgers van der Loeff et al., 2018).

These basin-specific constraints on intermediate water ventilation time scales provide important baselines against which future changes can be monitored. Climate change is causing shifts in freshwater storage that may affect brine formation: increased runoff may inhibit brine creation during periods of ice growth, but longer open water seasons allow storms to increase mixing and reduce stratification (McClelland et al., 2012). Additionally, the amplitude of the annual ice formation and melt cycle is increasing, and ice is being transported farther during its lifetime (Newton et al., 2017). Continued monitoring of ${ }^{228} \mathrm{Ra}$ activities in Arctic intermediate waters may help determine whether these freshwater changes will impact intermediate water formation and transport times.

\subsection{5 ${ }^{226} \mathrm{Ra}-\mathrm{Si}$ correlations}

Radium-226 shows a positive correlation with $\mathrm{Si}$, but the slope of the relationship varies with depth (Figure 21) (Si concentrations from Kadko et al., 2016). In the Pacific-influenced upper water column $(\sim 50-400 \mathrm{~m})$, the slope of the ${ }^{226} \mathrm{Ra}-\mathrm{Si}$ correlation (in units of $10^{3} \mathrm{dpm} \mathrm{mol}^{-}$ ${ }^{1}$ ) is $0.15 \pm 0.02$ (Figure 21a). The ${ }^{226} \mathrm{Ra}-\mathrm{Si}$ relationship in the upper $1000 \mathrm{~m}$ of the North Pacific and Bering Sea was determined to be $0.10 \pm 0.01$ based on data collected during the GEOSECS 
expedition in 1969 (Stations 217-219; Chung, 1980) and HLY1502 Station 1 (Charette and Moore, 2017; Kadko et al., 2016). The increase in the ${ }^{226} \mathrm{Ra}-\mathrm{Si}$ slope between the Bering Sea and the Arctic halocline must therefore occur during the transit of water through the Bering Strait and across the Chukchi Shelf. This may result from ${ }^{226} \mathrm{Ra}$ addition via shelf sediments; at a Si concentration of $\sim 30-40 \mu \mathrm{mol} \mathrm{L}{ }^{-1}$, the ${ }^{226}$ Ra activity of North Pacific waters was $\sim 10 \mathrm{dpm}$ $100 \mathrm{~L}^{-1}$ compared with ${ }^{226} \mathrm{Ra}$ activities in the Arctic basin of $\sim 12-14 \mathrm{dpm} 100 \mathrm{~L}^{-1}$ over the same range of Si values (Figure S7). A change in the biological uptake ratio of ${ }^{226} \mathrm{Ra}$ and Si could also contribute to differences between the two basins. It is unlikely that the shift in the ${ }^{226} \mathrm{Ra}-\mathrm{Si}$ slope resulted from river influence, as this would increase both the ${ }^{226} \mathrm{Ra}$ activities and $\mathrm{Si}$ concentrations. The slope of the ${ }^{226} \mathrm{Ra}-\mathrm{Si}$ relationship in Arctic water is also influenced by low${ }^{226} \mathrm{Ra}$, low-Si waters between $\sim 250-400 \mathrm{~m}$. These low concentrations could result from mixing with the underlying Atlantic layer, or from biological uptake.

In the Atlantic layer between $400-1500 \mathrm{~m}$, the slope of the ${ }^{226} \mathrm{Ra}-\mathrm{Si}$ correlation is $0.20 \pm 0.11$ (Figure 21b). This water enters the Arctic partly through the Fram Strait and partly through the Barents and Kara Seas (Rudels et al., 1994) such that the ${ }^{226} \mathrm{Ra}-\mathrm{Si}$ relationship should be similar to that observed in the Greenland and Norwegian Seas. Based on measurements from the Transient Tracers in the Ocean (TTO) and GEOSECS programs, the ${ }^{226} \mathrm{Ra}$-Si correlation in the Greenland Sea is $0.20 \pm 0.02$ (TTO stations $144-159$ and GEOSECS station 17, excluding five samples with ${ }^{226} \mathrm{Ra}<6 \mathrm{dpm} 100 \mathrm{~L}^{-1}$ due to likely biological influence) (Broecker et al., 1976; Key et al., 1992). Thus, the ${ }^{226} \mathrm{Ra}-\mathrm{Si}$ relationship determined for the Arctic intermediate waters matches that of the source waters, and is not noticeably changed during transit over the Barents and Kara Seas

Below $1500 \mathrm{~m}$, the slope of the ${ }^{226} \mathrm{Ra}-\mathrm{Si}$ relationship increases significantly, indicating an addition of ${ }^{226} \mathrm{Ra}$ without an accompanying increase in Si (Figure $21 \mathrm{~b}$ ). The ${ }^{226} \mathrm{Ra}-\mathrm{Ba}$ relationships were similar to the ${ }^{226} \mathrm{Ra}-\mathrm{Si}$ correlations (L. Whitmore, pers. comm.). The increase in ${ }^{226} \mathrm{Ra}$ without a concomitant increase in $\mathrm{Ba}$ or $\mathrm{Si}$ indicates that the increase is not due to sinking particle remineralization, which would also impact these other tracers, but rather to benthic sediment inputs of ${ }^{226} \mathrm{Ra}$. Similar excess ${ }^{226} \mathrm{Ra}$ values have been observed in deep waters in other ocean basins (Broecker et al., 1976; Chung, 1980), and were first recorded in the Arctic over the Alpha Ridge in 1983 (Moore and Smith, 1986). Deviations from a linear ${ }^{226} \mathrm{Ra}-\mathrm{Ba}$ relationship have also been recently documented in the Makarov Basin, but similar ${ }^{226} \mathrm{Ra}$ enrichments have not been observed in the Amundsen Basin (Rutgers van der Loeff et al., 2018). Our measurements of relatively low ${ }^{226} \mathrm{Ra}$ activities at station 32 in the Amundsen Basin are similar to these previously documented low ${ }^{226} \mathrm{Ra}$ activities.

\subsubsection{Deep water residence times}

Radium-226 is constantly produced through the decay of ${ }^{230} \mathrm{Th}$ in sediments and is released into overlying bottom waters through diffusion, bioturbation, and sediment resuspension (Cochran and Krishnaswami, 1980). In the deep ocean, ${ }^{226} \mathrm{Ra}$ is removed from the water column through decay and mixing. To our knowledge, there are no hydrothermal vents in the Canadian Basin that could act as a source of ${ }^{226} \mathrm{Ra}$ to deep waters; although the Gakkel Ridge in the Eurasian Basin is hydrothermally active (Edmonds et al., 2003), it is unlikely that inputs from this ridge will be transported across the Lomonosov Ridge. The accumulation of ${ }^{226} \mathrm{Ra}$ in the deep Canadian Basin can therefore be used to estimate the residence time $\left(\tau_{\text {res }}\right)$ of the deep waters, using equation 3 (modified from Rutgers van der Loeff et al., 2018): 


$$
\tau_{\text {res }}=\frac{\mathrm{I}}{\mathrm{F}_{\mathrm{seds}}-\mathrm{I} \cdot \lambda_{226}}
$$

where I is the difference between the observed ${ }^{226} \mathrm{Ra}$ inventory and that which is expected based on the ${ }^{226} \mathrm{Ra}$-Si relationship of the source waters, $\lambda_{226}$ is the decay constant of ${ }^{226} \mathrm{Ra}$, and $\mathrm{F}_{\text {seds }}$ is the flux of ${ }^{226} \mathrm{Ra}$ from sediments. The expected ${ }^{226} \mathrm{Ra}$ activity was modeled based on the $\mathrm{Si}$ concentration at each depth where a ${ }^{226} \mathrm{Ra}$ sample was collected and the ${ }^{226} \mathrm{Ra}$-Si relationship in the Atlantic layer $\left({ }^{226} \mathrm{Ra}=(0.20 \pm 0.11) \times \mathrm{Si}+(7.0 \pm 0.8)\right)$, and then the ${ }^{226} \mathrm{Ra}$ inventory was determined from the difference between this model curve and the observed ${ }^{226}$ Ra profile below $1500 \mathrm{~m}$ (above this depth the model agreed with observations).

The flux of ${ }^{226} \mathrm{Ra}$ across the sediment-water interface was estimated based on the inventory of ${ }^{230} \mathrm{Th}$ in the sediment mixed layer. This inventory was converted to a flux of ${ }^{226} \mathrm{Ra}$ using the Cochran (1980) relationship, where the ${ }^{226} \mathrm{Ra}$ sediment flux varies as a function of the ${ }^{230} \mathrm{Th}$ inventory in the sediment mixed layer. The ${ }^{230} \mathrm{Th}$ inventory in sediments in the Makarov Basin was calculated from ${ }^{230}$ Th profiles measured in cores collected on the AOS-94 expedition (Huh et al., 1997). To our knowledge only one sediment profile of ${ }^{230} \mathrm{Th}$, collected from the T3 ice station $\left(83.03^{\circ} \mathrm{N}, 163.57^{\circ} \mathrm{W}\right)$, exists for the Canada Basin (Ku and Broecker, 1965). Because of the limited data for this basin, we used the range in inventories observed in cores from both basins to estimate the ${ }^{230} \mathrm{Th}$ inventory for Canada Basin sediments; we expect the ${ }^{230} \mathrm{Th}$ inventories in Makarov and Canada Basin sediments to be similar because ${ }^{230}$ Th deposition in sediments depends in part on water column depth (Bacon and Anderson, 1982) and the bottom depths of the two basins are comparable. Using supported ${ }^{210} \mathrm{~Pb}$ activities in these AOS-94 cores as a proxy for ${ }^{226} \mathrm{Ra}$ activities, ${ }^{226} \mathrm{Ra}$ reaches equilibrium with ${ }^{230} \mathrm{Th}$ approximately $5 \mathrm{~cm}$ below the sediment-water interface (at $\sim 10 \mathrm{dpm} \mathrm{g}^{-1}$ ) (Huh et al., 1997). The ${ }^{226} \mathrm{Ra} /{ }^{230} \mathrm{Th}$ activity ratios reported for the T3 sediment core also indicate that equilibrium is reached between $5 \mathrm{~cm}$ and 10 $\mathrm{cm}\left(\mathrm{Ku}\right.$ and Broecker, 1965). Above this depth, it is assumed that ${ }^{226} \mathrm{Ra}$ produced through decay of ${ }^{230} \mathrm{Th}$ can be lost via diffusion into the overlying water column, thus ${ }^{230} \mathrm{Th}$ inventories were integrated down to $5 \mathrm{~cm}$ in order to estimate the flux of ${ }^{226} \mathrm{Ra}$ across the sediment-water interface. The ${ }^{230} \mathrm{Th}$ inventories in the top $5 \mathrm{~cm}$ of the three cores available from the Makarov Basin were $60-70 \mathrm{dpm} \mathrm{cm}{ }^{-2}$. These inventories correspond to estimated ${ }^{226} \mathrm{Ra}$ fluxes of $\sim 0.02-$ $0.03 \mathrm{dpm} \mathrm{cm}^{-2} \mathrm{y}^{-1}$ (Cochran, 1980). The ${ }^{230} \mathrm{Th}$ inventory in the top $5 \mathrm{~cm}$ of the T3 core from the Canada Basin was $90 \mathrm{dpm} \mathrm{cm}{ }^{-2}$, which corresponds to a ${ }^{226} \mathrm{Ra}$ flux of $\sim 0.035 \mathrm{dpm} \mathrm{cm}^{-2} \mathrm{y}^{-1}$ (Cochran, 1980). These values are well within the range of estimates for other ocean basins (0.002-0.2 dpm cm ${ }^{-2} \mathrm{y}^{-1}$; Cochran, 1980). Based on the observed deficit of ${ }^{226} \mathrm{Ra}$ with respect to ${ }^{230} \mathrm{Th}$ in a core collected on the Mendeleyev Ridge, Not et al. (2008) estimated a slightly higher ${ }^{226} \mathrm{Ra}$ flux of $0.043 \mathrm{dpm} \mathrm{cm}^{-2} \mathrm{y}^{-1}$. A larger flux would serve to decrease the residence time estimates.

The residence time of deep water in the Makarov Basin was determined to be $400-650 \mathrm{y}$ based on the ${ }^{226} \mathrm{Ra}$ profile at station 30 (Figure 10) and the range in the ${ }^{226} \mathrm{Ra}$ flux from sediments in the Makarov basin. This value is similar to previous estimates of $\sim 300-550 \mathrm{y}$ (Rutgers van der Loeff et al., 2018; Schlosser et al., 1997; Tanhua et al., 2009). The deep waters at stations 48, 52, and 57 in the deep Canada Basin (Figure 10) were determined to have residence times of 130 $-270 \mathrm{y}$ based on the range of ${ }^{226} \mathrm{Ra}$ fluxes estimated for sediments in both the Makarov and Canada Basins. These residence times are shorter than previous estimates of $\sim 300-450 \mathrm{y}$ (Schlosser et al., 1997; Tanhua et al., 2009). However, this calculation is very sensitive to the ${ }^{230}$ Th inventory, and integrating the AOS-94 cores to $3 \mathrm{~cm}$, the maximum mixed layer thickness 
(Clough et al., 1997; Smith et al., 2003), instead of $5 \mathrm{~cm}$ yields a ${ }^{230}$ Th inventory of $40-50 \mathrm{dpm}$ $\mathrm{cm}^{-2}$. This correlates to a ${ }^{226} \mathrm{Ra}$ flux of $\sim 0.01-0.015 \mathrm{dpm} \mathrm{cm}^{-2} \mathrm{y}^{-1}$ and a residence time of $330-$ $610 \mathrm{y}$, which is in better agreement with previous estimates. This residence time estimate should therefore be refined with more measurements of ${ }^{230} \mathrm{Th}$ and ${ }^{226} \mathrm{Ra}$ in sediments collected from the central Canada Basin.

\section{CONCLUSIONS}

We measured radium isotopes in the Western Arctic from the Chukchi Shelf to the North Pole on the 2015 HLY1502 transect. By combining this new dataset with previously unpublished data collected in the Chukchi Sea and southern Canada Basin in the late 1990s and early 2000s, as well as a regional circulation model of the Chukchi Sea, we have identified persistent shelf signatures of $\mathrm{Ra}$ in surface waters and the halocline, and seasonal variability in ${ }^{228} \mathrm{Ra}$ and ${ }^{226} \mathrm{Ra}$ activities over the shelf. Radium-228 activities were highest in the Transpolar Drift and at the Chukchi shelfbreak, indicating strong shelf influence in these regions. Observations and modeling results indicate that inputs of Ra from the Chukchi Shelf are highest in the fall. The timescale of halocline ventilation with respect to inputs from the Chukchi shelfbreak jet was estimated to be $\leq 14-17 \mathrm{y}$.

Radium-228 enrichment in intermediate waters above the Mendeleyev Ridge and in the Amundsen Basin suggest recent communication with shelf waters; ${ }^{228} \mathrm{Ra} /{ }^{226} \mathrm{Ra}$ activity ratios were used to determine ventilation time scales of approximately $20 \mathrm{y}$ for these water masses. The lack of a similar ${ }^{228} \mathrm{Ra}$ enrichment in the Canada Basin indicates that intermediate water in this basin has been isolated from the shelf for at least $30 \mathrm{y}$. Radium-226 activities were high in the deep Makarov and Canada Basins, and deviated from the intermediate water ${ }^{226} \mathrm{Ra}-\mathrm{Si}$

relationship due to sediment inputs. Based on these ${ }^{226} \mathrm{Ra}$ enrichments, the residence time of deep waters in the Makarov and Canada Basins were estimated to be $400-650 \mathrm{y}$ and $130-270 \mathrm{y}$, respectively. These residence time estimates could be improved with more measurements of ${ }^{226} \mathrm{Ra}$ and ${ }^{230} \mathrm{Th}$ in sediments in the Canadian Basin.

Changes in the Arctic climate are likely to affect shelf-basin interactions and freshwater storage in this basin. This dataset provides important baseline observations and residence time estimates for intermediate and deep waters in the Western Arctic. Continued monitoring of radium isotopes in the Arctic could help track changes brought about by rising air and sea temperatures in this region. Specifically, changes in shelf-derived material inputs may increase as ice cover decreases over shelves and allows for more water column mixing; due to its shelf source and low biological and particle reactivity, ${ }^{228} \mathrm{Ra}$ can be used to trace these changes in sediment fluxes to the open ocean. The ventilation timescales provided by ${ }^{228} \mathrm{Ra} /{ }^{226} \mathrm{Ra}$ activity ratios can also be used to monitor whether changes in brine formation over the shelves impact the residence time of intermediate waters. Future studies should focus on constraining seasonal variability, and on providing Ra measurements from the currently under-sampled Eastern Chukchi and East Siberian Seas.

\section{Acknowledgements}

We are very grateful to D. Kadko for sharing the SBI, AWS-2000, and SHEBA radium datasets, to B. Pickart for many discussions and suggestions that helped in the interpretation and presentation of the data, and to M. Spall for creating the sediment tracer model and generating 
the associated figures. We thank the captain and crew of the USCGC Healy (HLY1502) and the chief scientists D. Kadko and W. Landing for coordinating a safe and successful expedition. We thank the members of the pump team, P. Lam, E. Black, S. Pike, X. Yang, and M. Heller for their assistance with sample collection and for their unfailingly positive attitudes during this 65day expedition. We also appreciate sampling assistance from P. Aguilar and M. Stephens, and MATLAB assistance from B. Corlett, A. Pacini, P. Lin, and M. Li. This work was funded by NSF awards OCE-1458305 to M.A.C. and OCE-1458424 to W.S.M. This research was conducted with Government support under and awarded by a DoD, Air Force Office of Scientific Research, National Defense Science and Engineering Graduate (NDSEG) Fellowship awarded to L.E.K., 32 CFR 168a. 


\section{References}

Aagaard, K., Carmack, E.C., 1989. The role of sea ice and other fresh water in the Arctic circulation. J. Geophys. Res. 94, 14485-14498.

Aagaard, K., Coachman, L.K., Carmack, E., 1981. On the halocline of the Arctic Ocean. Deep Sea Res. Part A, Oceanogr. Res. Pap. 28, 529-545. doi:10.1016/0198-0149(81)90115-1

Arrigo, K.R., Mills, M.M., van Dijken, G.L., Lowry, K.E., Pickart, R.S., Schlitzer, R., 2017. Late Spring Nitrate Distributions Beneath the Ice-Covered Northeastern Chukchi Shelf. J. Geophys. Res. Biogeosciences 122, 2409-2417. doi:10.1002/2017JG003881

Bacon, M.P., Anderson, R.F., 1982. Distribution of thorium isotopes between dissolved and particulate forms in the deep sea. J. Geophys. Res. 87, 2045-2056. doi:10.1029/JC087iC03p02045

Bacon, M.P., Huh, C.A., Moore, R.M., 1989. Vertical profiles of some natural radionuclides over the Alpha Ridge, Arctic Ocean. Earth Planet. Sci. Lett. 95, 15-22. doi:10.1016/0012821X(89)90164-7

Broecker, W.S., Goddard, J., Sarmiento, J.L., 1976. The distribution of ${ }^{226}$ Ra in the Atlantic Ocean. Earth Planet. Sci. Lett. 32, 220-235. doi:10.1016/0012-821X(76)90063-7

Carmack, E., Chapman, D.C., 2003. Wind-driven shelf/basin exchange on an Arctic shelf: The joint roles of ice cover extent and shelf-break bathymetry. Geophys. Res. Lett. 30, 1778. doi:10.1029/2003GL017526

Carmack, E., Wassmann, P., 2006. Food webs and physical-biological coupling on pan-Arctic shelves: Unifying concepts and comprehensive perspectives. Prog. Oceanogr. 71, 446-477. doi:10.1016/j.pocean.2006.10.004

Carmack, E.C., Yamamoto-Kawai, M., Haine, T.W.N., Bacon, S., Bluhm, B.A., Lique, C., Melling, H., Polyakov, I. V., Straneo, F., Timmermans, M.L., Williams, W.J., 2016. Freshwater and its role in the Arctic Marine System: Sources, disposition, storage, export, and physical and biogeochemical consequences in the Arctic and global oceans. J. Geophys. Res. G Biogeosciences 121, 675-717. doi:10.1002/2015JG003140

Chan, L.H., Edmond, J.M., Stallard, R.F., Broecker, W.S., Chung, Y.C., Weiss, R.F., Ku, T.L., 1976. Radium and barium at GEOSECS stations in the Atlantic and Pacific. Earth Planet. Sci. Lett. 32, 258-267. doi:10.1016/0012-821X(76)90066-2

Charette, M.A., Moore, W.S., 2017. Radium and thorium isotopes measured in the Western Arctic as part of the 2015 US GEOTRACES Arctic Cruise on the USCGC Healy (HLY1502) from August to October 2015. Biological and Chemical Oceanography Data Management Office (BCO-DMO). Dataset version 2017. URL: http://lod.bcodmo.org/id/dataset/718440

Charette, M.A., Morris, P.J., Henderson, P.B., Moore, W.S., 2015. Radium isotope distributions during the US GEOTRACES North Atlantic cruises. Mar. Chem. 177, 184-195. doi:10.1016/j.marchem.2015.01.001

Chung, Y., 1980. Radium-barium-silica correlations and a two-dimensional radium model for the world ocean. Earth Planet. Sci. Lett. 49, 309-318. doi:10.1016/0012-821X(80)90074-6

Chung, Y., Craig, H., 1980. ${ }^{226}$ Ra in the Pacific Ocean. Earth Planet. Sci. Lett. 49, 267-292. doi:10.1016/0012-821X(80)90072-2

Clough, L.M., Jr., W.G.A., Cochran, K., Barnes, K., P. Renaud, P., Aller, R., 1997. Bioturbation, biomass, and infaunal abundance in the sediments of the Arctic Ocean. Deep Sea Res. Part II. 44, 1683-1704. doi:10.1016/S0967-0645(97)00052-0 
Cochran, J.K., 1980. The flux of ${ }^{226}$ Ra from deep-sea sediments. Earth Planet. Sci. Lett. 49, 381392. doi:10.1016/0012-821X(80)90080-1

Cochran, J.K., Krishnaswami, S., 1980. Radium, thorium, uranium, and ${ }^{210} \mathrm{~Pb}$ in deep-sea sediments and sediment pore waters from the North Equatorial Pacific. Am. J. Sci. 280, 849-889.

Codispoti, L.A., Flagg, C.N., Swift, J.H., 2009. Hydrographic conditions during the 2004 SBI process experiments. Deep. Res. Part II Top. Stud. Oceanogr. 56, 1144-1163. doi:10.1016/j.dsr2.2008.10.013

Corlett, W.B., Pickart, R.S., 2017. The Chukchi slope current. Prog. Oceanogr. 153, 50-65. doi:10.1016/j.pocean.2017.04.005

Edmonds, H.N., Michael, P.J., Baker, E.T., Connelly, D.P., Snow, J.E., Langmuir, C.H., Dick, H.J.B., Mühe, R., German, C.R., Graham, D.W., 2003. Discovery of abundant hydrothermal venting on the ultraslow-spreading Gakkel ridge in the Arctic Ocean. Nature 421, 252-256. doi:10.1038/nature01351

Gong, D., Pickart, R.S., 2016. Early summer water mass transformation in the eastern Chukchi Sea. Deep. Res. Part II Top. Stud. Oceanogr. 130, 43-55. doi:10.1016/j.dsr2.2016.04.015

Günther, F., Overduin, P.P., Sandakov, A. V., Grosse, G., Grigoriev, M.N., 2013. Short- and long-term thermo-erosion of ice-rich permafrost coasts in the Laptev Sea region. Biogeosciences 10, 4297-4318. doi:10.5194/bg-10-4297-2013

Henderson, P.B., Morris, P.J., Moore, W.S., Charette, M.A., 2013. Methodological advances for measuring low-level radium isotopes in seawater. J. Radioanal. Nucl. Chem. 296, 357-362. doi:10.1007/s10967-012-2047-9

Huh, C.A., Pisias, N.G., Kelley, J.M., Maiti, T.C., Grantz, A., 1997. Natural radionuclides and plutonium in sediments from the western Arctic Ocean: Sedimentation rates and pathways of radionuclides. Deep. Res. Part II Top. Stud. Oceanogr. 44, 1725-1743. doi:10.1016/S0967-0645(97)00040-4

Jakobsson, M., 2002. Hypsometry and volume of the Arctic Ocean and its constituent seas. Geochemistry, Geophys. Geosystems 3, 1-18. doi:10.1029/2001GC000302

Kadko, D., Aagaard, K., 2009. Glimpses of Arctic Ocean shelf-basin interaction from submarine-borne radium sampling. Deep Sea Res. Part I Oceanogr. Res. Pap. 56, 32-40. doi:10.1016/j.dsr.2008.08.002

Kadko, D., Landing, W.M., Cutter, G.A., 2016. CTD-ODF bottles from GEOTRACES-Arctic Section cruise HLY1502. Biological and Chemical Oceanography Data Management Office (BCO-DMO). Dataset version 2016-09-01. URL: http://lod.bco-dmo.org/id/dataset/646825

Kadko, D., Muench, R., 2005. Evaluation of shelf-basin interaction in the western Arctic by use of short-lived radium isotopes: The importance of mesoscale processes. Deep. Res. Part II Top. Stud. Oceanogr. 52, 3227-3244. doi:10.1016/j.dsr2.2005.10.008

Kadko, D., Pickart, R.S., Mathis, J., 2008. Age characteristics of a shelf-break eddy in the western Arctic and implications for shelf-basin exchange. J. Geophys. Res. 113. doi:10.1029/2007JC004429

Kaufman, A., Trier, R.M., Broecker, W.S., Feely, H.W., 1973. Distribution of ${ }^{228}$ Ra in the world ocean. J. Geophys. Res. 78, 8827-8848. doi:10.1029/JC078i036p08827

Kenison Falkner, K., Macdonald, R.W., Carmack, E.C., Weingartner, T., 2013. The Potential of Barium as a Tracer of Arctic Water Masses, in: The Polar Oceans and Their Role in Shaping the Global Environment. pp. 63-76. doi:10.1029/GM085p0063

Key, R.M., Brewer, R.L., Stockwell, J.H., Guinasso, N.L., Schink, D.R., 1979. Some improved 
techniques for measuring radon and radium in marine sediments and in seawater. Mar. Chem. 7, 251-264. doi:10.1016/0304-4203(79)90042-2

Key, R.M., Moore, W.S., Sarmiento, J.L., 1992. Transient tracers in the ocean north Atlantic study final data report for 228Ra and 226Ra. Technical Report \#92-2. Princeton.

Kim, G., Hussain, N., Church, T.M., 2003. Tracing the advection of organic carbon into the subsurface Sargasso Sea using a ${ }^{228} \mathrm{Ra} /{ }^{226} \mathrm{Ra}$ tracer. Geophys. Res. Lett. 30. doi:10.1029/2003gl017565

Kipp, L.E., Charette, M.A., Moore, W.S., Henderson, P.B., Rigor, I.G., 2018. Increased fluxes of shelf-derived materials to the central Arctic Ocean. Sci. Adv. 4. doi:10.1126/sciadv.aao1302

$\mathrm{Ku}, \mathrm{T} .-\mathrm{L} .$, Broecker, W.S., 1965. Rates of sedimentation in the Arctic ocean. Prog. Oceanogr. 4, 95-104. doi:10.1016/0079-6611(65)90043-1

Large, W.G., Mcwilliams, J.C., Doney, S.C., 1994. Oceanic Vertical Mixing - a Review and a Model with a Nonlocal Boundary-Layer Parameterization. Rev. Geophys. 32, 363-403. doi:10.1029/94rg01872

Li, M., R.S. Pickart, M.A. Spall, T.J. Weingartner, P. Lin, G.W.K. Moore, and Y. Qi, submitted. Circulation of the Chukchi Sea shelfbreak and slope from moored timeseries.

Li, Q., Chen, M., Jia, R., Zeng, J., Lin, H., Zheng, M., Qiu, Y., 2017. Transit time of river water in the Bering and Chukchi Seas estimated from $\delta^{18} \mathrm{O}$ and radium isotopes. Prog. Oceanogr. 159, 115-129. doi:10.1016/j.pocean.2017.08.004

Lowry, K.E., Pickart, R.S., Mills, M.M., Brown, Z.W., van Dijken, G.L., Bates, N.R., Arrigo, K.R., 2015. The influence of winter water on phytoplankton blooms in the Chukchi Sea. Deep. Res. Part II Top. Stud. Oceanogr. 118, 53-72. doi:10.1016/j.dsr2.2015.06.006

Luo, D., Wu, Q., Jin, H., Marchenko, S.S., Lü, L., Gao, S., 2016. Recent changes in the active layer thickness across the northern hemisphere. Environ. Earth Sci. 75. doi:10.1007/s12665015-5229-2

Marshall, J., Hill, C., Perelman, L., Adcroft, A., 1997. Hydrostatic, quasi-hydrostatic, and nonhydrostatic ocean modeling. J. Geophys. Res. Ocean. 102, 5733-5752. doi:10.1029/96JC02776

Mathis, J.T., Pickart, R.S., Hansell, D.A., Kadko, D., Bates, N.R., 2007. Eddy transport of organic carbon and nutrients from the Chukchi Shelf: Impact on the upper halocline of the western Arctic Ocean. J. Geophys. Res. 112. doi:10.1029/2006JC003899

McClelland, J.W., Holmes, R.M., Dunton, K.H., Macdonald, R.W., 2012. The Arctic Ocean Estuary. Estuaries and Coasts 35, 353-368. doi:10.1007/s12237-010-9357-3

Moore, M., Smith, N., 1986. Disequilibria between ${ }^{226} \mathrm{Ra},{ }^{210} \mathrm{~Pb}$ and ${ }^{210} \mathrm{Po}$ in the Arctic Ocean and the implications for chemical modification of the Pacific water inflow. Earth Planet. Sci. Lett. 77, 285-292.

Moore, W.S., Dymond, J., 1991. Fluxes of ${ }^{226}$ Ra and barium in the Pacific Ocean: The importance of boundary processes. Earth Planet. Sci. Lett. 107, 55-68. doi:10.1016/0012$821 \mathrm{X}(91) 90043-\mathrm{H}$

Muench, R.D., Gunn, J.T., Whitledge, T.E., Schlosser, P., Smethie, W., 2000. An Arctic Ocean cold core eddy. J. Geophys. Res. 105, 23997. doi:10.1029/2000JC000212

Muench, R.D., Schumacher, J.D., Salo, S.A., 1988. Winter currents and hydrographic conditions on the northern central Bering Sea shelf. J. Geophys. Res. 93, 516-526. doi:10.1029/JC093iC01p00516

Newton, R., Pfirman, S., Tremblay, B., DeRepentigny, P., 2017. Increasing transnational sea-ice exchange in a changing Arctic Ocean. Earth's Futur. 5, 633-647. 
doi:10.1002/2016EF000500

Not, C., Hillaire-Marcel, C., Ghaleb, B., Polyak, L., Darby, D., $2008 .{ }^{210} \mathrm{~Pb}-{ }^{226} \mathrm{Ra}-{ }^{230} \mathrm{Th}$ systematics in very low sedimentation rate sediments from the Mendeleev Ridge (Arctic Ocean). Can. J. Earth Sci. 45, 1207-1219. doi:10.1139/E08-047

Pacini, A., Pickart, R.S., Moore, G.W.K., Nobre, C., Bahr, F., Våge, K., Arrigo, K.R., submitted. Characteristics and transformation of Pacific winter water on the Chukchi Sea shelf in latespring.

Paquette, R.G., Bourke, R.H., 1974. Observations on the coastal current of Arctic Alaska. J. Mar. Res. 32, 195-207.

Pasqualini, A., Schlosser, P., Newton, R., Koffman, T.N., 2017. U.S. GEOTRACES Arctic Section Ocean Water Hydrogen and Oxygen Stable Isotope Analyses. Interdisciplinary Earth Data Alliance (IEDA). doi:10.1594/IEDA/100633

Pickart, R.S., Nobre, C., Lin, P., Arrigo, K.R., Ashjian, C.J., Berchok, C., Cooper, L.W., Grebmeier, J.M., Hartwell, I., He, J., Itoh, M., Kikuchi, T., Nishino, S., Vagle, S., submitted. Seasonal to mesoscale variability of water masses and atmospheric conditions in Barrow Canyon, Chukchi Sea.

Pickart, R.S., Moore, G.W.K., Mao, C., Bahr, F., Nobre, C., Weingartner, T.J., 2016. Circulation of winter water on the Chukchi shelf in early Summer. Deep. Res. Part II Top. Stud. Oceanogr. 130, 56-75. doi:10.1016/j.dsr2.2016.05.001

Pickart, R.S., Pratt, L.J., Torres, D.J., Whitledge, T.E., Proshutinsky, A.Y., Aagaard, K., Agnew, T.A., Moore, G.W.K., Dail, H.J., 2010. Evolution and dynamics of the flow through Herald Canyon in the western Chukchi Sea. Deep Sea Res. Part II Top. Stud. Oceanogr. 57, 5-26. doi:10.1016/j.dsr2.2009.08.002

Pickart, R.S., Weingartner, T.J., Pratt, L.J., Zimmermann, S., Torres, D.J., 2005. Flow of wintertransformed Pacific water into the Western Arctic. Deep. Res. Part II Top. Stud. Oceanogr. 52, 3175-3198. doi:10.1016/j.dsr2.2005.10.009

Rainville, L., Woodgate, R.A., 2009. Observations of internal wave generation in the seasonally ice-free Arctic. Geophys. Res. Lett. 36, L23604. doi:10.1029/2009GL041291

Rawlins, M.A., Steele, M., Holland, M.M., Adam, J.C., Cherry, J.E., Francis, J.A., Groisman, P.Y., Hinzman, L.D., Huntington, T.G., Kane, D.L., Kimball, J.S., Kwok, R., Lammers, R.B., Lee, C.M., Lettenmaier, D.P., McDonald, K.C., Podest, E., Pundsack, J.W., Rudels, B., Serreze, M.C., Shiklomanov, A., Skagseth, Ø., Troy, T.J., Vörösmarty, C.J., Wensnahan, M., Wood, E.F., Woodgate, R., Yang, D., Zhang, K., Zhang, T., 2010. Analysis of the Arctic System for Freshwater Cycle Intensification: Observations and Expectations. J. Clim. 23, 5715-5737. doi:10.1175/2010JCLI3421.1

Rudels, B., Jones, E.P., Anderson, L.G., Kattner, G., 1994. On the Intermediate Depth Waters of the Arctic Ocean, in: Johannessen, O.M., Muench, R.D., Overland, J.E. (Eds.), The Polar Oceans and Their Role in Shaping the Global Environment. American Geophysical Union, Washington, D.C., pp. 33-46. doi:10.1029/GM085p0033

Rutgers van der Loeff, M., Cai, P., Stimac, I., Bauch, D., Hanfland, C., Roeske, T., Moran, S.B., 2012. Shelf-basin exchange times of Arctic surface waters estimated from ${ }^{228} \mathrm{Th} /{ }^{228} \mathrm{Ra}$ disequilibrium. J. Geophys. Res. 117, C03024. doi:10.1029/2011JC007478

Rutgers van der Loeff, M., Key, R.M., Scholten, J., Bauch, D., Michel, A., 1995. ${ }^{228}$ Ra as a tracer for shelf water in the Arctic Ocean. Deep Sea Res. Part II Top. Stud. Oceanogr. 42, $1533-1553$.

Rutgers van der Loeff, M., Kipp, L., Charette, M.A., Moore, W.S., Black, E., Stimac, I., Charkin, 
A., Bauch, D., Valk, O., Karcher, M., Krumpen, T., Casacuberta, N., Smethie, W., Rember, R., 2018. Radium Isotopes across the Arctic Ocean show Time Scales of Water Mass Ventilation and Increasing Shelf Inputs. J. Geophys. Res. Ocean. doi: $10.1029 / 2018 J C 013888$

Rutgers van der Loeff, M., Kuhne, S., Wahsner, M., Holtzen, H., Frank, M., Ekwurzel, B., Mensch, M., Rachold, V., 2003. ${ }^{228} \mathrm{Ra}$ and ${ }^{226} \mathrm{Ra}$ in the Kara and Laptev seas. Cont. Shelf Res. 23, 113-124. doi:10.1016/S0304-4203(98)00070-X

Sanial, V., Kipp, L.E., Henderson, P.B., van Beek, P., Reyss, J.-L., Hammond, D.E., Hawco, N.J., Saito, M.A., Resing, J.A., Sedwick, P., Moore, W.S., Charette, M.A., 2018. Radium228 as a tracer of dissolved trace element inputs from the Peruvian continental margin. Mar. Chem. 201, 20-34. doi:10.1016/j.marchem.2017.05.008

Schlosser, P., Bayer, R., Bönisch, G., Cooper, L.W., Ekwurzel, B., Jenkins, W.J., Khatiwala, S., Pfirman, S., Smethie, W.M., 1999. Pathways and mean residence times of dissolved pollutants in the ocean derived from transient tracers and stable isotopes. Sci. Total Environ. 237-238, 15-30. doi:10.1016/S0048-9697(99)00121-7

Schlosser, P., Kromer, B., Ekwurzel, B., Bönisch, G., McNichol, A., Schneider, R., von Reden, K., Östlund, H.G., Swift, J.H., 1997. The first trans-Arctic 14C section: comparison of the mean ages of the deep waters in the Eurasian and Canadian basins of the Arctic Ocean. Nucl. Instruments Methods Phys. Res. Sect. B Beam Interact. with Mater. Atoms 123, 431437. doi:10.1016/S0168-583X(96)00677-5

Shimada, K., Carmack, E.C., Hatakeyama, K., Takizawa, T., 2001. Varieties of shallow temperature maximum waters in the Western Canadian Basin of the Arctic Ocean. Geophys. Res. Lett. 28, 3441-3444. doi:10.1029/2001GL013168

Smethie, W.M., Swift, J.H., 2018. Distribution of CFCs and $\mathrm{SF}_{6}$ Measured on the 2015 GEOTRACES and Repeat Hydrography cruises to the Arctic Ocean, in: Ocean Sciences Meeting. Portland, OR.

Smith, J.N., Moran, S.B., Macdonald, R.W., 2003. Shelf-basin interactions in the Arctic Ocean based on $210 \mathrm{~Pb}$ and $\mathrm{Ra}$ isotope tracer distributions. Deep Sea Res. Part I Oceanogr. Res. Pap. 50, 397-416. doi:10.1016/S0967-0637(02)00166-8

Spall, M.A., Pickart, R.S., Li, M., Itoh, M., Lin, P., Kikuchi, T., Qi, Y., in revision. Transport of Pacific Water into the Canada Basin. JGR-Oceans.

Spall, M.A., 2007. Circulation and water mass transformation in a model of the Chukchi Sea. J. Geophys. Res. Ocean. 112, 1-18. doi:10.1029/2005JC003364

Steele, M., Morison, J., Ermold, W., Rigor, I., Ortmeyer, M., Shimada, K., 2004. Circulation of summer Pacific halocline water in the Arctic Ocean. J. Geophys. Res. 109. doi:10.1029/2003JC002009

Swift, J.H., Kadko, D.C., Smethie, W.M., Becker, S.M., Barna, A., Cummiskey, J., Gum, J., Miller, M.T., Schatzman, C., 2016. The Arctic Ocean Then and Now: Preliminary Hydrographic Data from the 2015 US GEOTRACES Arctic Expedition, in: Ocean Sciences Meeting. New Orleans, Louisiana, USA.

Tanhua, T., Jones, E.P., Jeansson, E., Jutterström, S., Smethie, W.M., Wallace, D.W.R., Anderson, L.G., 2009. Ventilation of the arctic ocean: Mean ages and inventories of anthropogenic CO2 and CFC-11. J. Geophys. Res. Ocean. 114. doi:10.1029/2008JC004868

Timmermans, M.-L., Toole, J., Proshutinsky, A., Krishfield, R., Plueddemann, A., 2008. Eddies in the Canada Basin, Arctic Ocean, Observed from Ice-Tethered Profilers. J. Phys. Oceanogr. 38, 133-145. doi:10.1175/2007JPO3782.1 
Trimble, S.M., Baskaran, M., Porcelli, D., 2004. Scavenging of thorium isotopes in the Canada Basin of the Arctic Ocean. Earth Planet. Sci. Lett. 222, 915-932. doi:10.1016/j.eps1.2004.03.027

van Beek, P., François, R., Conte, M., Reyss, J.L., Souhaut, M., Charette, M., 2007. ${ }^{228} \mathrm{Ra} /{ }^{226} \mathrm{Ra}$ and ${ }^{226} \mathrm{Ra} / \mathrm{Ba}$ ratios to track barite formation and transport in the water column. Geochim. Cosmochim. Acta 71, 71-86. doi:10.1016/j.gca.2006.07.041

Walvoord, M.A., Voss, C.I., Wellman, T.P., 2012. Influence of permafrost distribution on groundwater flow in the context of climate-driven permafrost thaw: Example from Yukon Flats Basin, Alaska, United States. Water Resour. Res. 48, W07524. doi:10.1029/2011WR011595

Weingartner, T., Aagaard, K., Woodgate, R., Danielson, S., Sasaki, Y., Cavalieri, D., 2005. Circulation on the north central Chukchi Sea shelf. Deep. Res. Part II Top. Stud. Oceanogr. 52, 3150-3174. doi:10.1016/j.dsr2.2005.10.015

Weingartner, T.J., Cavalieri, D.J., Aagaard, K., Sasaki, Y., 1998. Circulation, dense water formation, and outflow on the northeast Chukchi Shelf. J. Geophys. Res. Ocean. 103, $7647-$ 7661. doi:10.1029/98JC00374

Williams, W.J., Carmack, E.C., 2015. The "interior" shelves of the Arctic Ocean: Physical oceanographic setting, climatology and effects of sea-ice retreat on cross-shelf exchange. Prog. Oceanogr. 139, 24-41. doi:10.1016/j.pocean.2015.07.008

Woodgate, R.A., Aagaard, K., Weingartner, T.J., 2005a. A year in the physical oceanography of the Chukchi Sea: Moored measurements from autumn 1990-1991. Deep. Res. Part II Top. Stud. Oceanogr. 52, 3116-3149. doi:10.1016/j.dsr2.2005.10.016

Woodgate, R.A., Aagaard, K., Weingartner, T.J., 2005b. Monthly temperature, salinity, and transport variability of the Bering Strait through flow. Geophys. Res. Lett. 32. doi:10.1029/2004GL021880 
Table 1. HLY1502 station locations, bottom depths, and type of samples collected.

\begin{tabular}{|c|c|c|c|c|}
\hline Station & $\begin{array}{l}\text { Latitude } \\
\left({ }^{\circ} \mathbf{N}\right)\end{array}$ & $\begin{array}{l}\text { Longitude } \\
\left({ }^{\circ} \mathbf{E}\right)\end{array}$ & $\begin{array}{l}\text { Bottom Depth } \\
\text { (m) }\end{array}$ & $\begin{array}{l}\text { Type of samples } \\
\text { collected }\end{array}$ \\
\hline 1 & 60.18 & -179.09 & 735 & Surface + water column \\
\hline 2 & 62.21 & -171.58 & 49 & Surface + water column \\
\hline 3 & 64.01 & -166.65 & 49 & Surface + water column \\
\hline 4 & 65.80 & -168.61 & 33 & Surface only \\
\hline 5 & 66.33 & -168.90 & 54 & Surface only \\
\hline 6 & 68.00 & -168.11 & 58 & Surface + water column \\
\hline 7 & 73.48 & -168.86 & 57 & Surface only \\
\hline 8 & 73.98 & -168.80 & 118 & Surface only \\
\hline 9 & 74.50 & -168.87 & 191 & Surface only \\
\hline 10 & 75.00 & -170.47 & 270 & Surface + water column \\
\hline 11 & 75.45 & -170.57 & 260 & Surface only \\
\hline 12 & 75.78 & -171.29 & 358 & Surface only \\
\hline 13 & 75.94 & -171.67 & 1717 & Surface only \\
\hline 14 & 76.55 & -173.21 & 2200 & Surface + water column \\
\hline 15 & 77.33 & -175.04 & 2255 & Surface only \\
\hline 16 & 77.75 & -176.25 & 1846 & Surface only \\
\hline 17 & 78.15 & -176.76 & 1135 & Surface only \\
\hline 18 & 78.98 & -175.71 & 1010 & Surface only \\
\hline 19 & 79.98 & -175.03 & 2100 & Surface + water column \\
\hline 20 & 80.24 & -177.66 & 2099 & Surface only \\
\hline 21 & 80.66 & -179.89 & 2046 & Surface only \\
\hline 22 & 81.23 & 179.12 & 1480 & Surface only \\
\hline 23 & 81.56 & 176.87 & 2227 & Surface only \\
\hline 24 & 82.48 & 175.02 & 2468 & Surface only \\
\hline 25 & 83.15 & 173.13 & 2394 & Surface only \\
\hline 26 & 83.74 & 174.58 & 2960 & Surface + water column \\
\hline 27 & 84.82 & 170.71 & 2938 & Surface only \\
\hline 28 & 85.86 & 167.11 & 3335 & Surface only \\
\hline 29 & 86.51 & 173.47 & 3740 & Surface only \\
\hline 30 & 87.55 & 179.46 & 3949 & Surface + water column \\
\hline 31 & 88.40 & -176.70 & 3932 & Surface only \\
\hline 32 & 89.99 & 22.08 & 4246 & Surface + water column \\
\hline 33 & 89.96 & -58.45 & 4236 & Surface only \\
\hline 34 & 89.95 & -92.70 & 4236 & Surface only \\
\hline 35 & 89.33 & -149.44 & 4221 & Surface only \\
\hline 36 & 89.08 & -150.49 & 3312 & Surface only \\
\hline 37 & 88.88 & -149.72 & 1273 & Surface only \\
\hline 38 & 87.83 & -148.46 & 2825 & Surface + water column \\
\hline
\end{tabular}




\begin{tabular}{|l|l|l|l|l|}
\hline 39 & 87.77 & -148.96 & 3857 & Surface only \\
\hline 40 & 86.72 & -148.72 & 2550 & Surface only \\
\hline 41 & 85.83 & -150.18 & 3417 & Surface only \\
\hline 41.5 & 85.80 & -150.57 & 3417 & Surface only \\
\hline 42 & 85.72 & -150.61 & 3417 & Surface only \\
\hline 43 & 85.14 & -149.87 & 2702 & Surface + water column \\
\hline 44 & 84.17 & -150.02 & 2204 & Surface only \\
\hline 45 & 83.34 & -150.06 & 2002 & Surface only \\
\hline 46 & 82.49 & -149.84 & 2854 & Surface + water column \\
\hline 47 & 81.27 & -149.96 & 3026 & Surface only \\
\hline 48 & 80.43 & -149.41 & 3810 & Surface + water column \\
\hline 49 & 79.75 & -149.57 & 3859 & Surface only \\
\hline 50 & 78.74 & -147.95 & 3878 & Surface only \\
\hline 51 & 78.19 & -147.83 & 3810 & Surface only \\
\hline 52 & 77.50 & -147.97 & 3830 & Surface + water column \\
\hline 53 & 77.01 & -148.83 & 3829 & Surface only \\
\hline 54 & 76.52 & -149.52 & 3825 & Surface only \\
\hline 55 & 76.25 & -150.12 & 3825 & Surface only \\
\hline 56 & 75.06 & -150.33 & 3884 & Water column only \\
\hline 57 & 73.40 & -156.69 & 3570 & Surface + water column \\
\hline 58 & 73.19 & -157.83 & 3465 & Surface only \\
\hline 59 & 73.06 & -158.59 & 2569 & Surface only \\
\hline 60 & 73.01 & -158.67 & 900 & Surface + water column \\
\hline 61 & 72.81 & -159.84 & 110 & Surface + water column \\
\hline 62 & 72.95 & -159.18 & 82 & Surface only \\
\hline 64 & 73.00 & -158.95 & 173 & Surface only \\
\hline 65 & 72.73 & -159.93 & 523 & Surface only \\
\hline 66 & 72.00 & -162.55 & 35 & Surface + water column \\
\hline & & & & \\
\hline
\end{tabular}




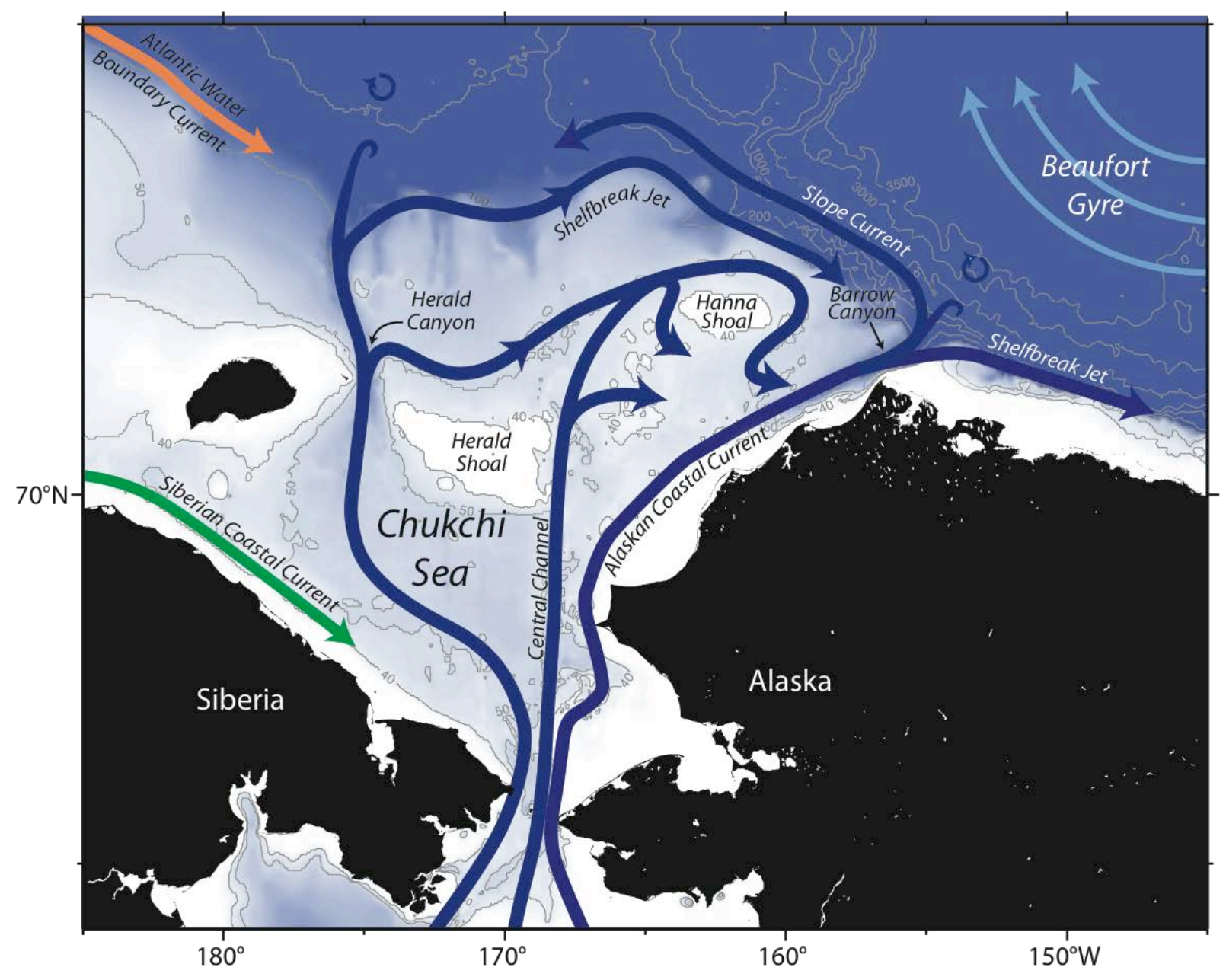

Figure 1. Schematic of water circulation in the Chukchi Sea, modified from Corlett and Pickart (2017). 


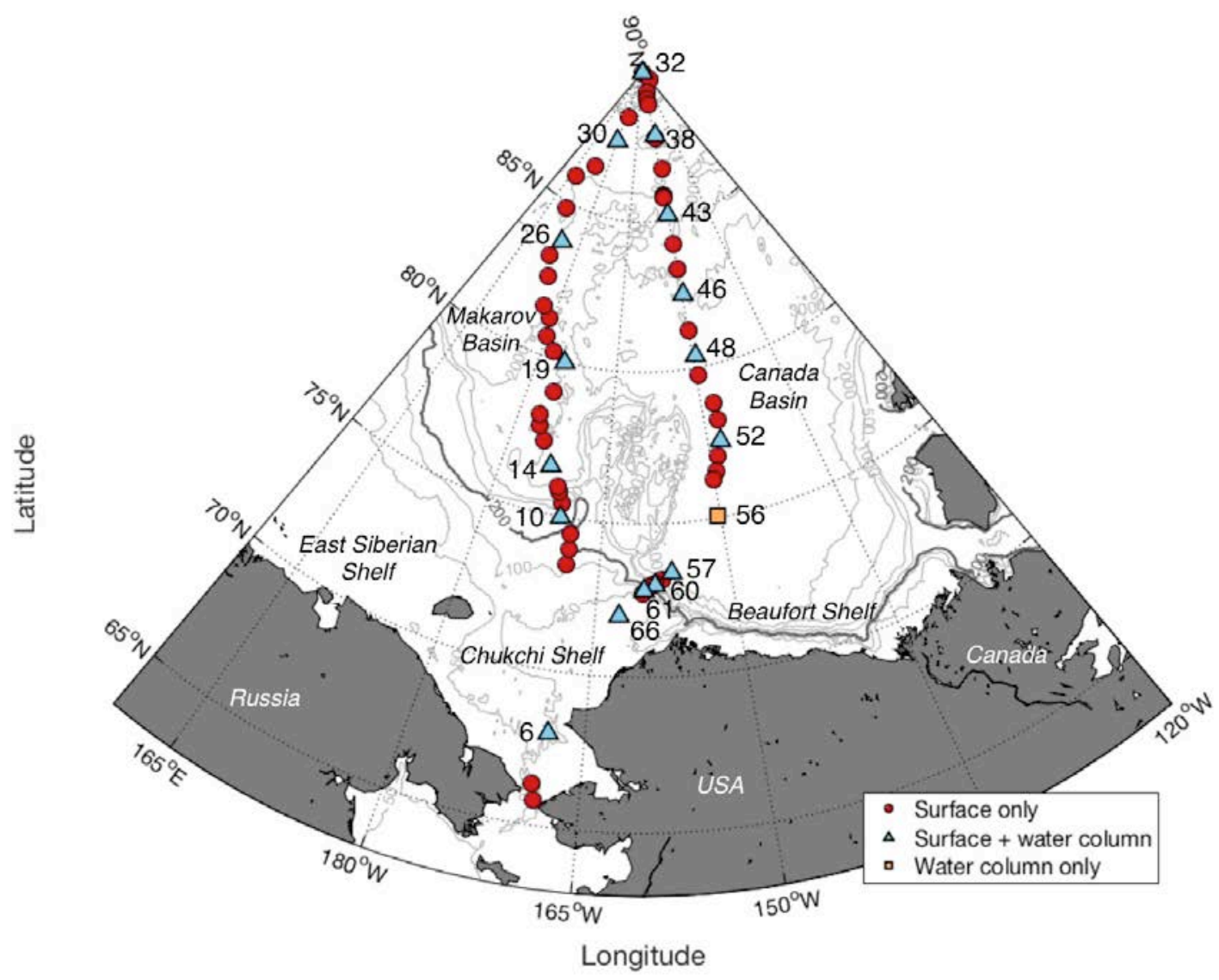

Figure 2. Locations sampled on the HLY1502 expedition (August 6 - October 10, 2015). Surface samples were collected at all stations except station 56, and water column samples were collected from selected stations. Stations that included water column sampling are numbered. Station locations and bottom depths are listed in Table 1. 


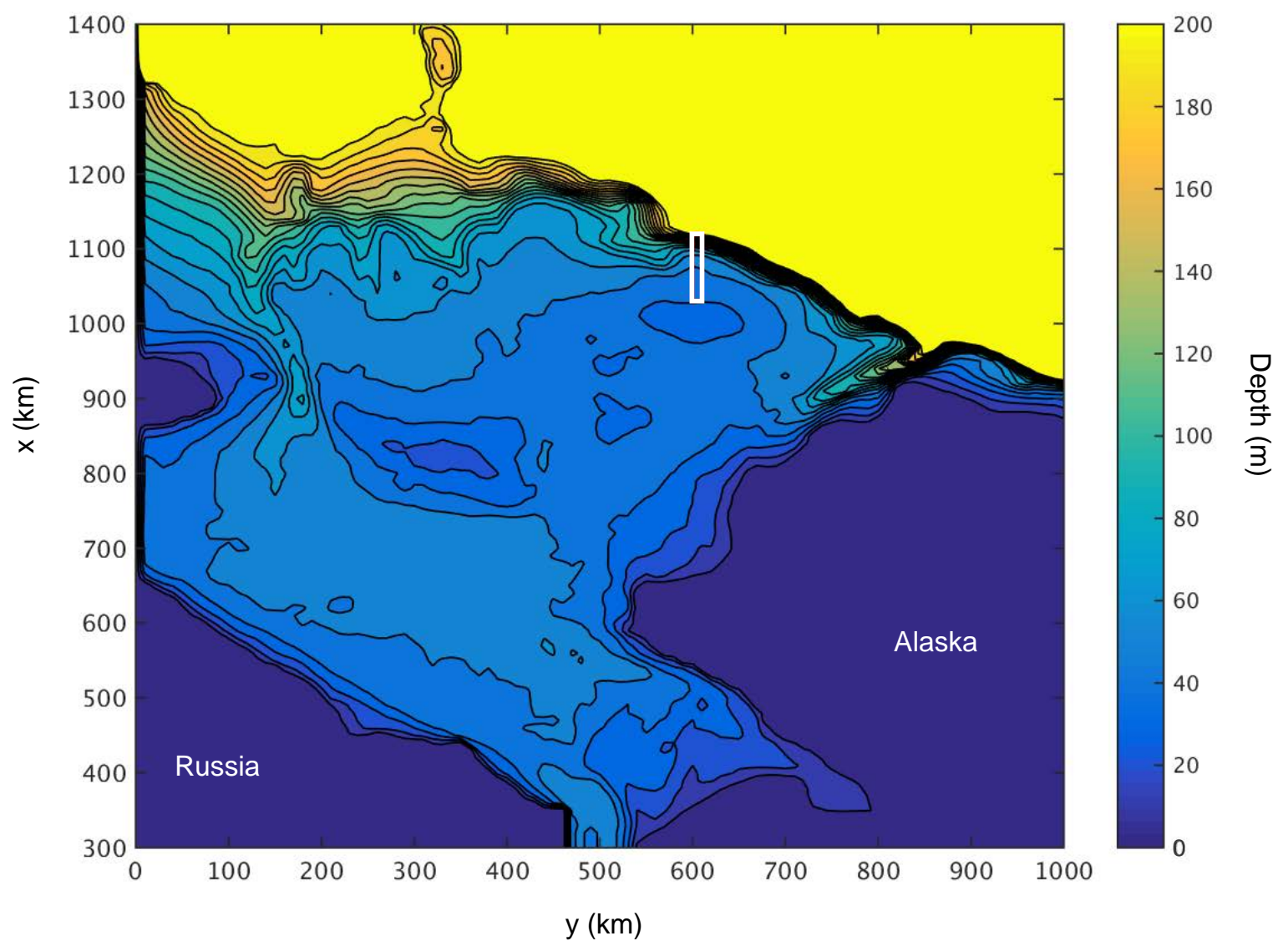

Figure 3. Domain of the sediment tracer model, with bottom topography shown as filled contours. The white box indicates the region used for comparison with SBI and GEOTRACES data in section 4.2.2. 


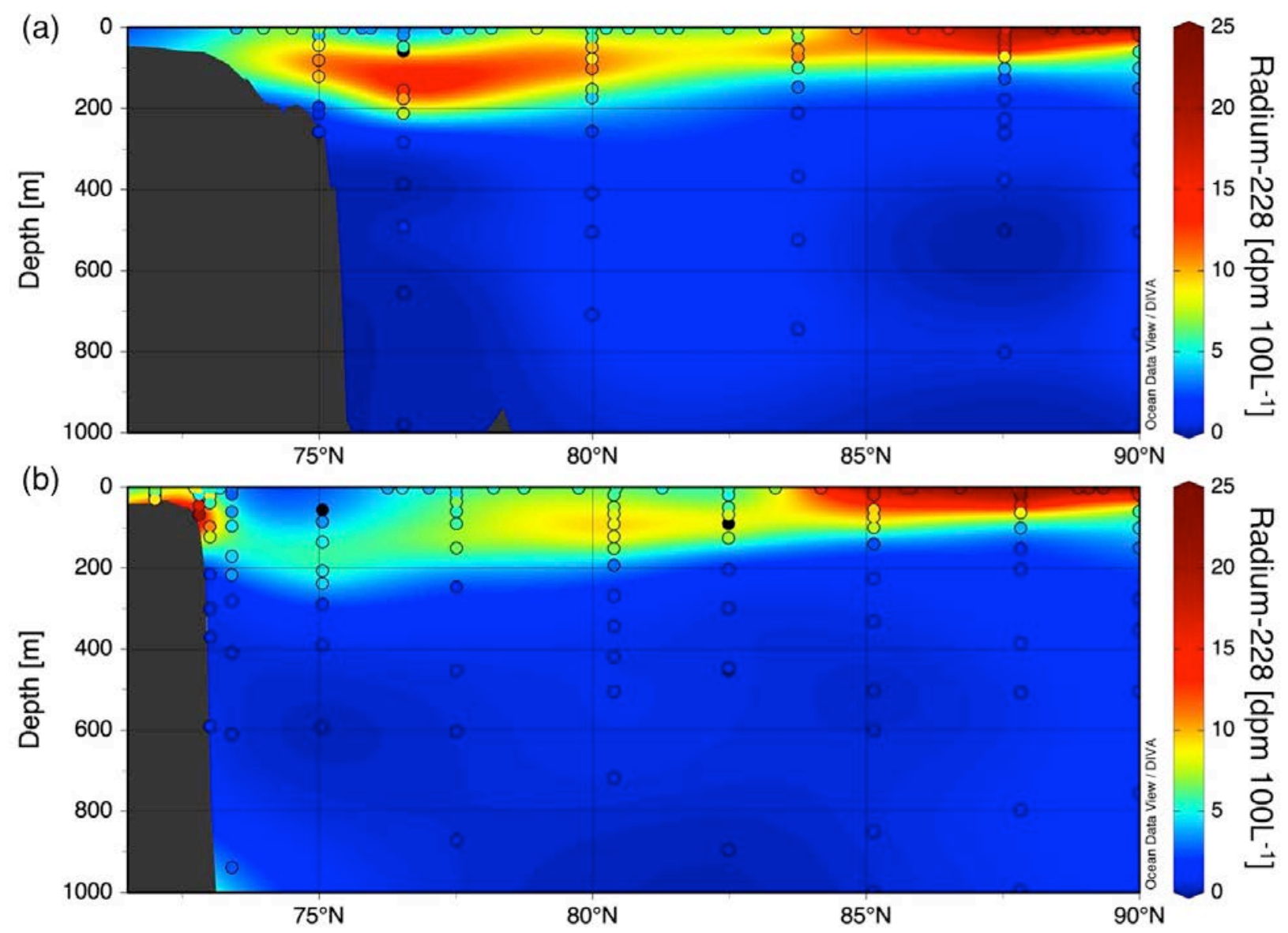

Figure 4. Radium-228 activities in surface waters on the (a) northbound and (b) southbound transects. Colored symbols indicate measured activities, and background shading represents interpolated activities calculated with Ocean Data View's DIVA gridding software. Black symbols indicate samples that were not collected due to failed pumps. 


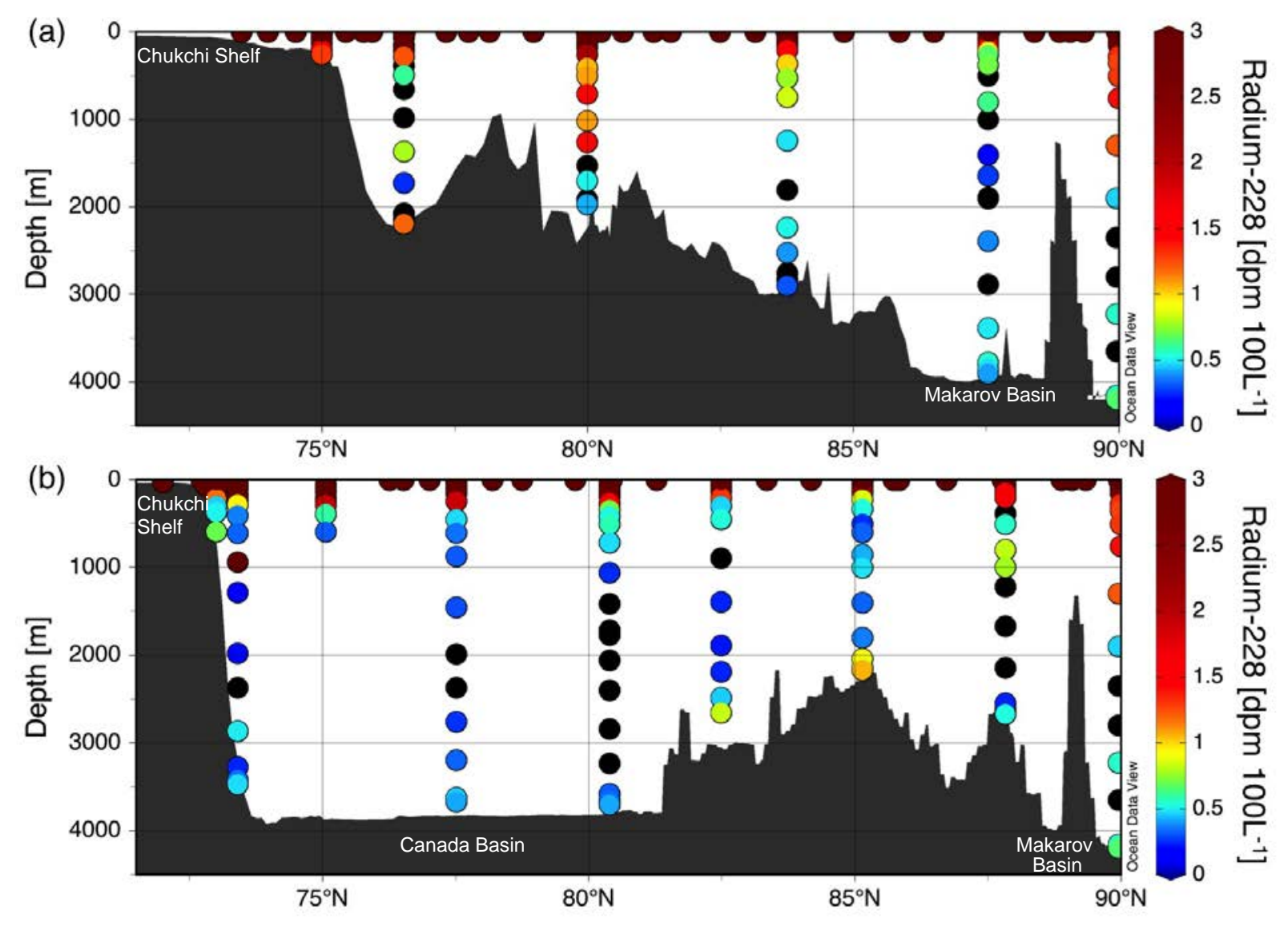

Figure 5. Radium-228 activities on the (a) northbound and (b) southbound transects. The colorbar is zoomed to highlight the gradient in deep water activities; all surface samples are

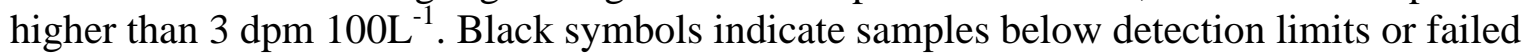
pumps. 

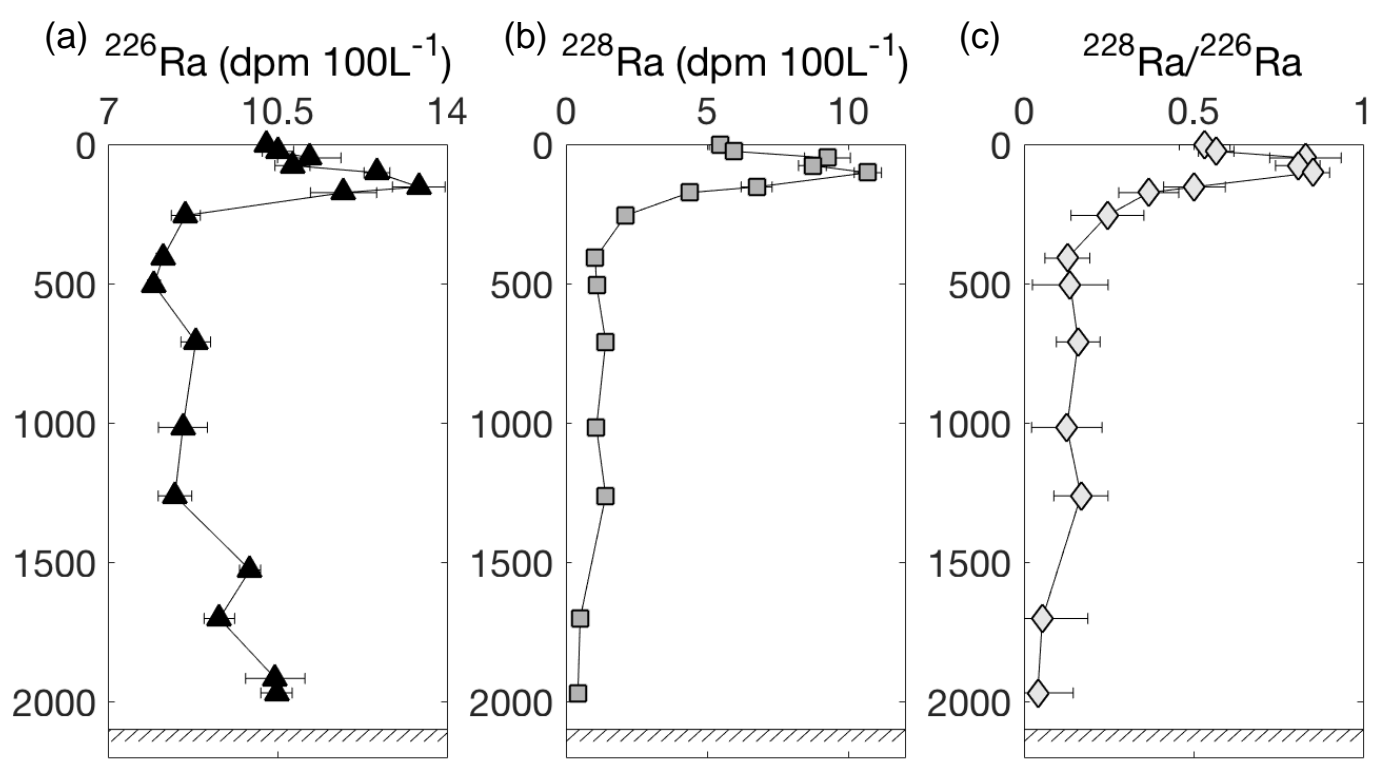

Figure 6. Depth profiles of (a) ${ }^{226} \mathrm{Ra}$, (b) ${ }^{228} \mathrm{Ra}$, and (c) the ${ }^{228} \mathrm{Ra} /{ }^{226} \mathrm{Ra}$ activity ratio at station 19, located over the Mendeleyev Ridge. 


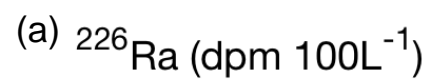

(b)

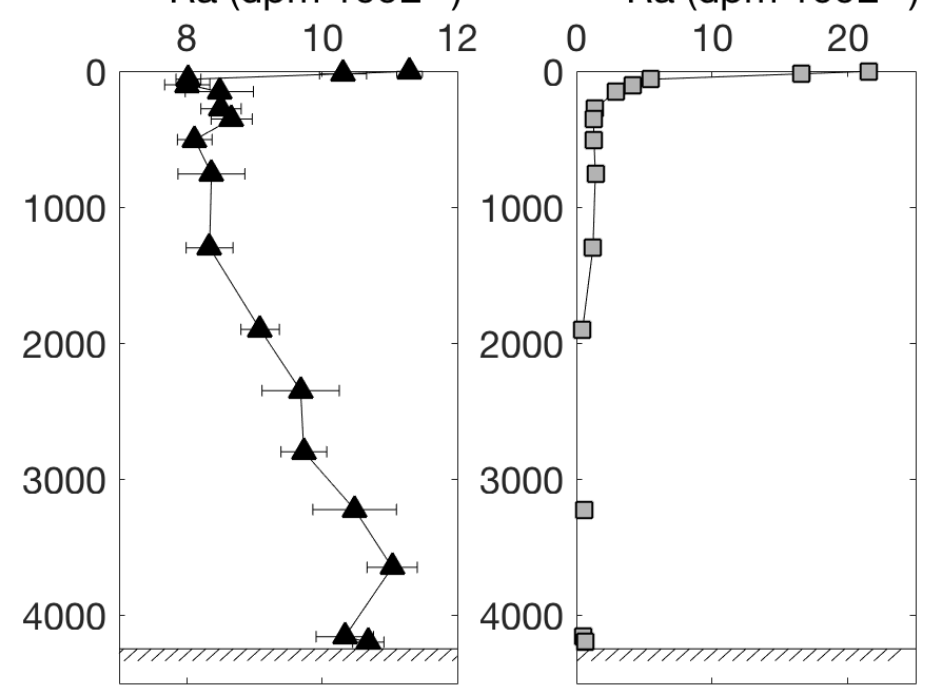

(c) ${ }^{228} \mathrm{Ra} /{ }^{226} \mathrm{Ra}$

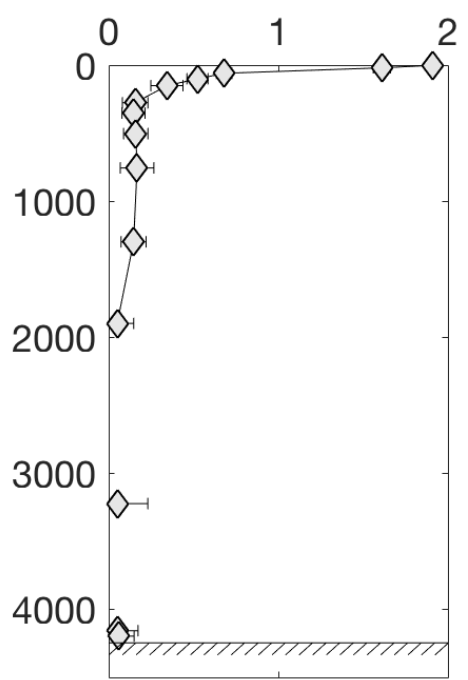

Figure 7. Depth profiles of (a) ${ }^{226} \mathrm{Ra}$, (b) ${ }^{228} \mathrm{Ra}$, and (c) the ${ }^{228} \mathrm{Ra} /{ }^{226} \mathrm{Ra}$ activity ratio at station 32 , located in the Amundsen Basin. 
(a)

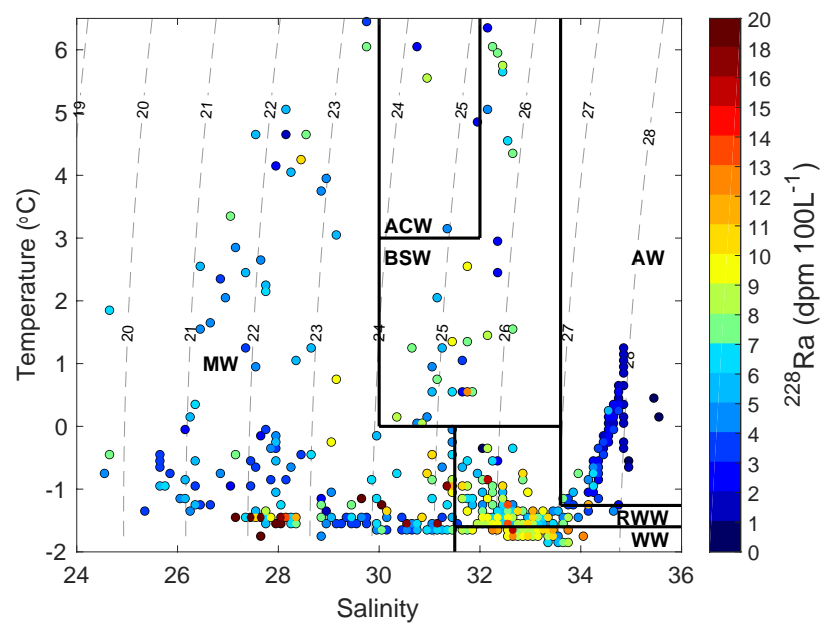

(b)

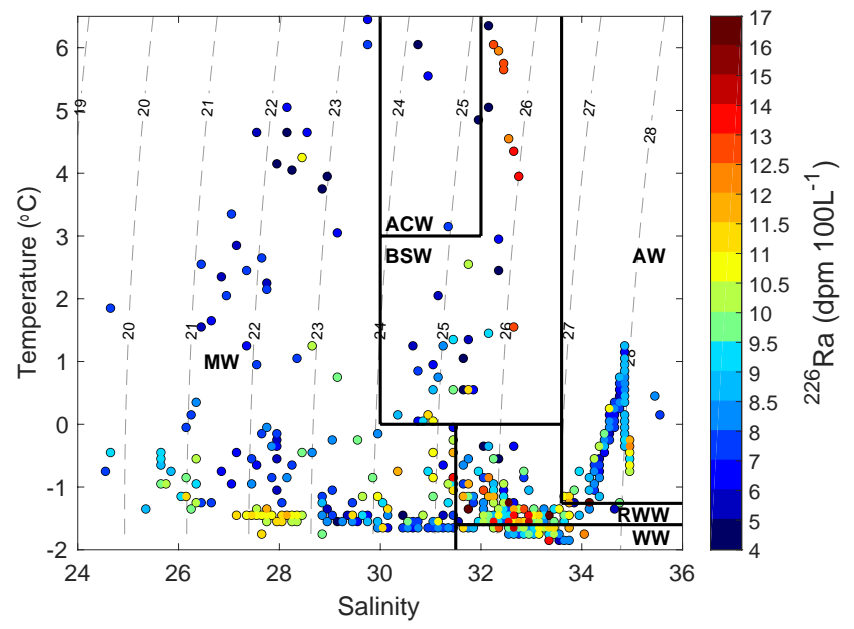

(c)

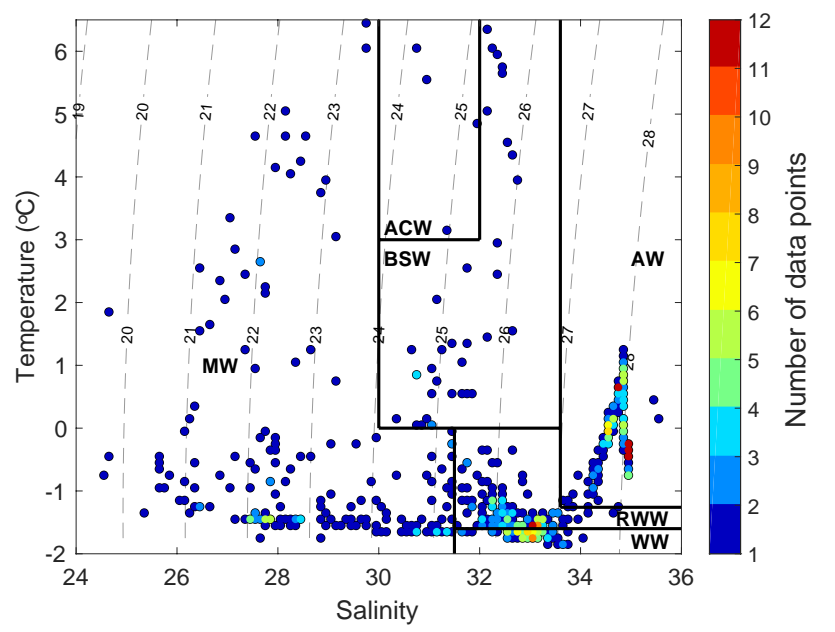

Figure 8. (a) Average ${ }^{228} \mathrm{Ra}$ activities and (b) average ${ }^{226} \mathrm{Ra}$ activities measured on the HLY1502 and SBI transects (HLY0201, HLY0203, HLY0402, HLY0403, HLY0404) in T-S space, and (c) the number of data points used to determine the averages in each grid cell. Black lines indicate water mass boundaries. $\mathrm{MW}=$ meltwater; $\mathrm{BSW}=$ Bering summer water; $\mathrm{WW}=$ newly ventilated Pacific winter water; RWW = remnant Pacific winter water; AW = Atlantic water; $\mathrm{ACW}=$ Alaskan coastal water. 

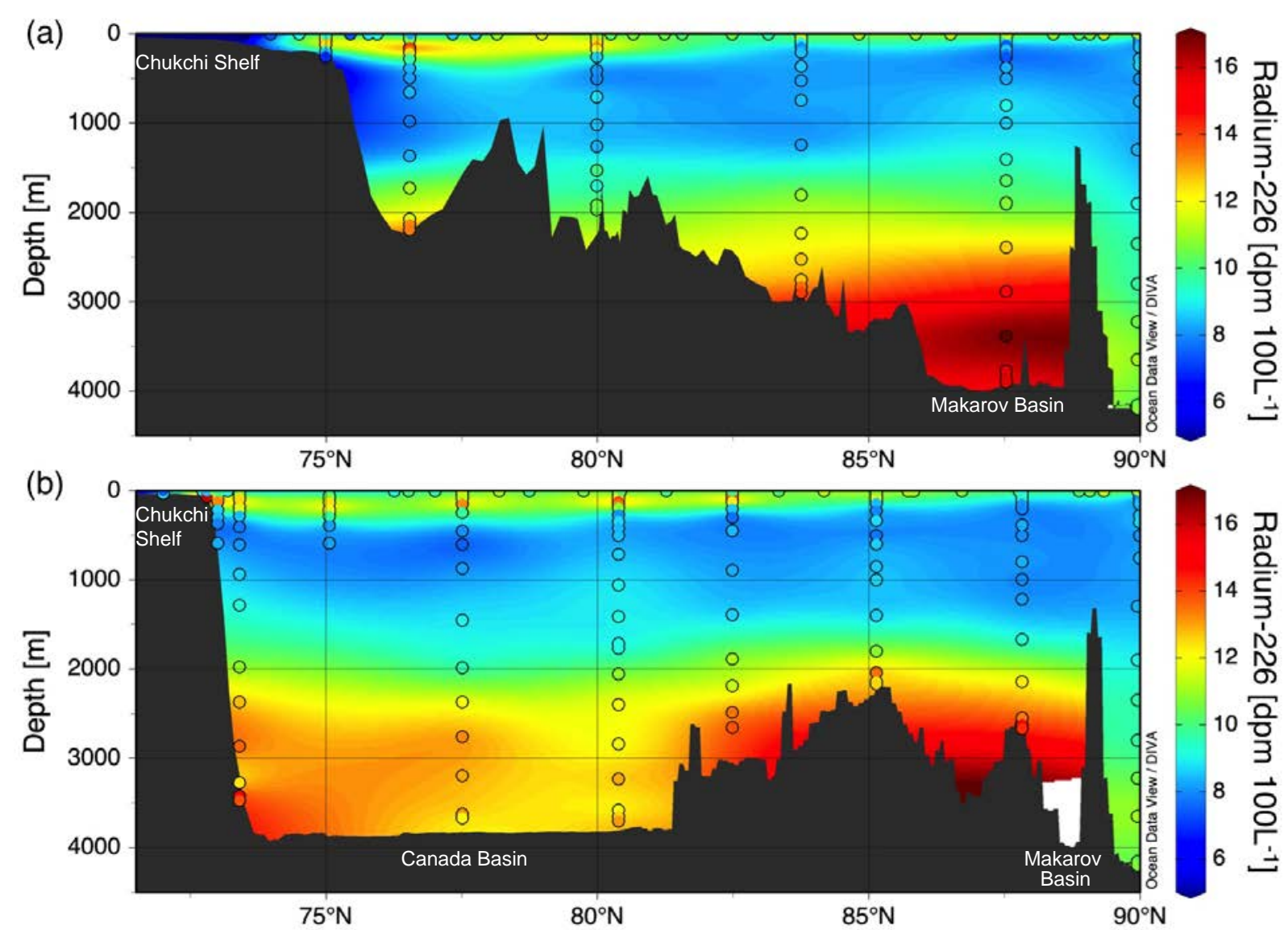

Figure 9. Radium-226 activities on the (a) northbound and (b) southbound transects. Colored symbols indicate measured activities, and background shading represents interpolated activities calculated with Ocean Data View's DIVA gridding software. 

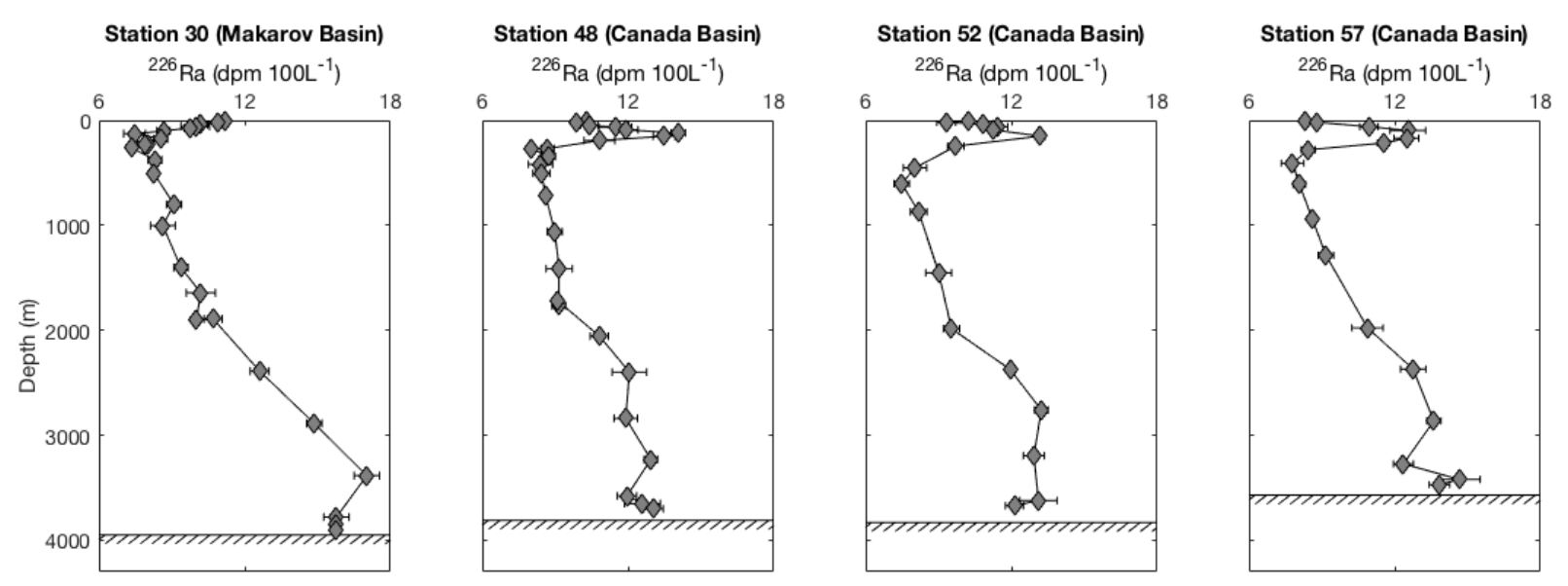

Figure 10. Radium-226 activities measured at stations in the deep (bottom depth $>3500 \mathrm{~m}$ ) Makarov and Canada Basins. Hatched line indicates bottom depth. 

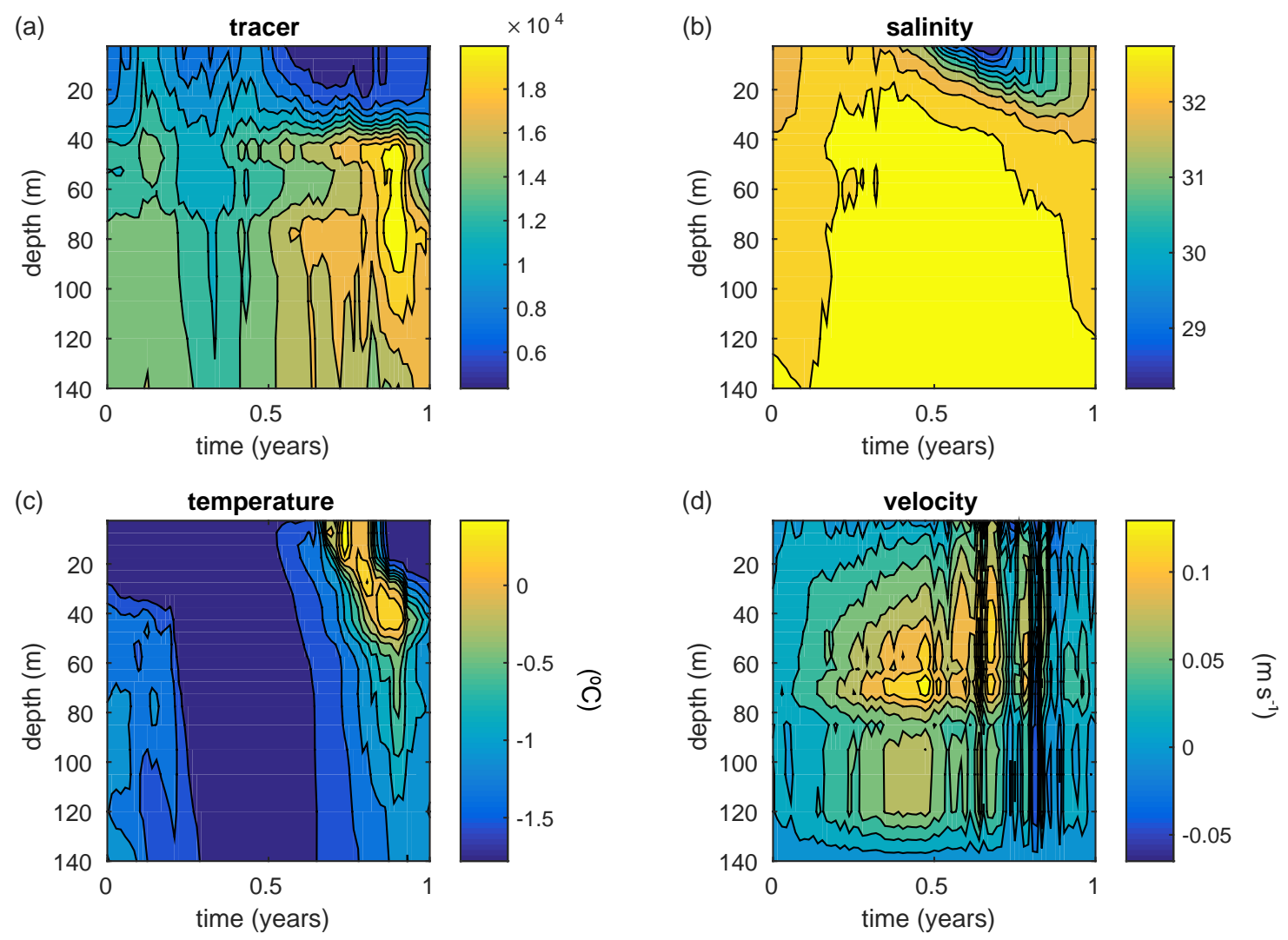

Figure 11. Modeled (a) tracer concentrations, (b) salinity, (c) temperature, and (d) zonal velocity as a function of depth and time averaged over the domain shown by the white box in Figure 2. An annual average of the four model years is shown; the complete four-year time series is shown in Supplementary Figure 5. The model run starts in January such that 0 represents January 1 and 1 is December 31 . 

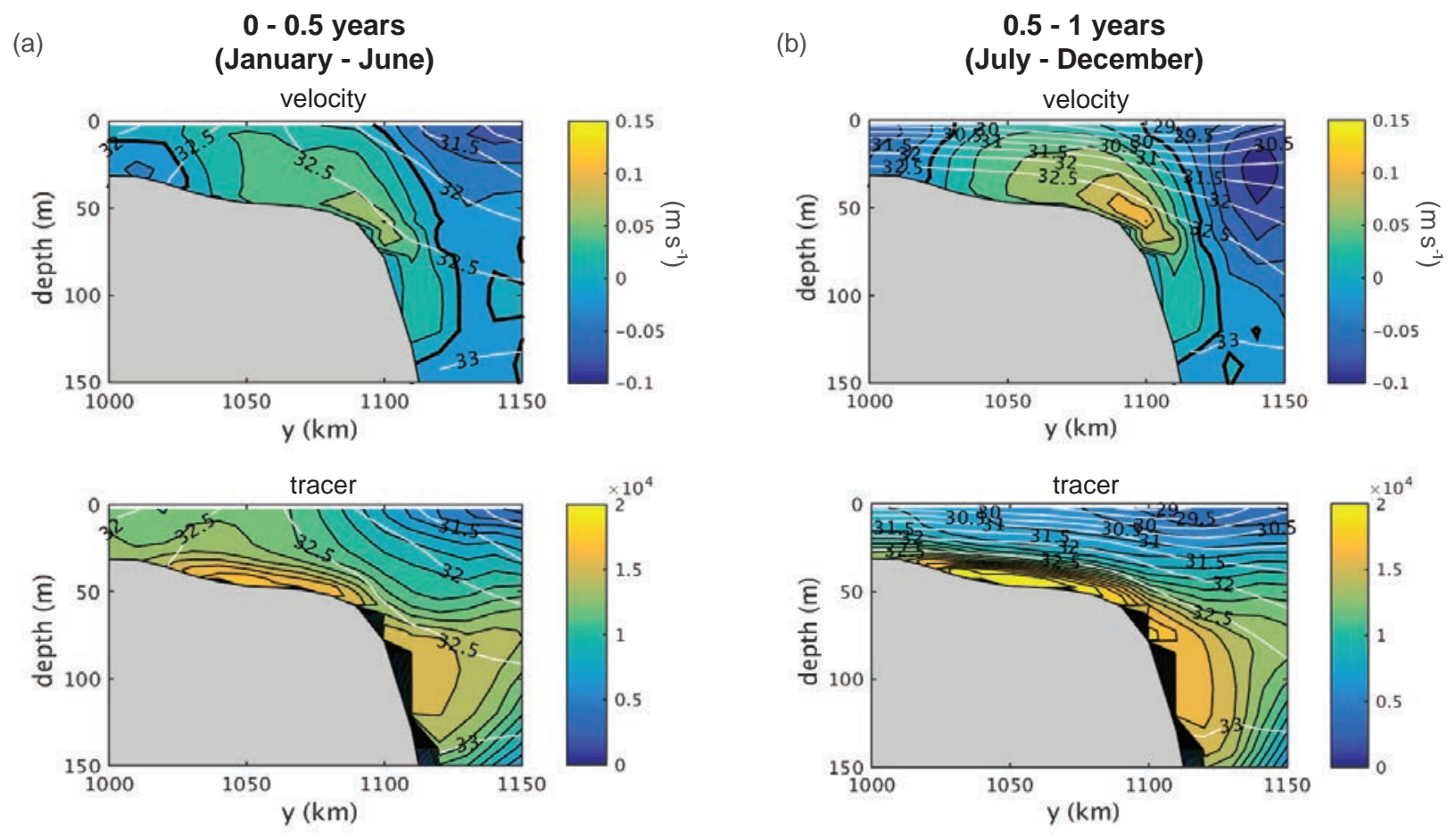

Figure 12. Modeled zonal velocity and tracer concentrations averaged over (a) January - June and (b) July - December of year 3 of the model run. White contours indicate salinity. The section domain is the mid-longitude transect of the white box shown in Figure 2. 
(a)

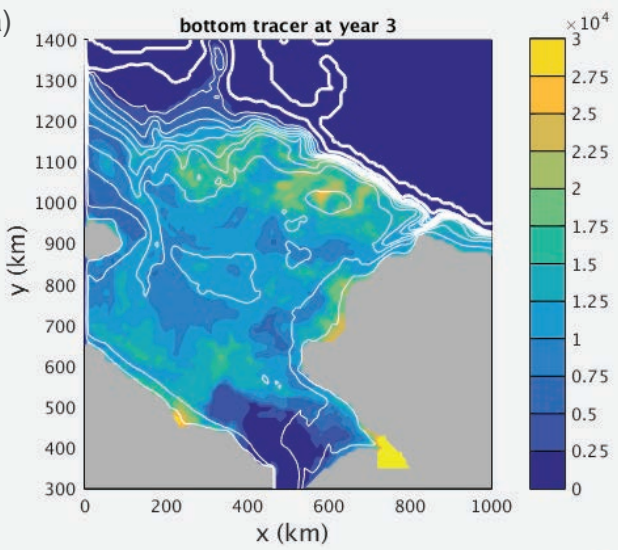

(c)

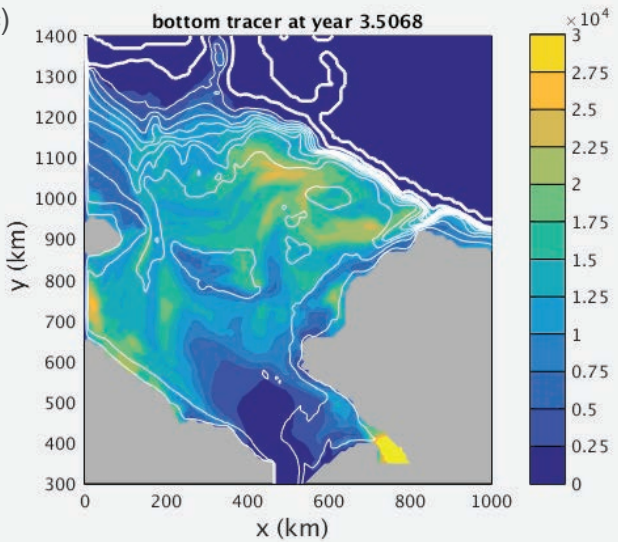

(b)

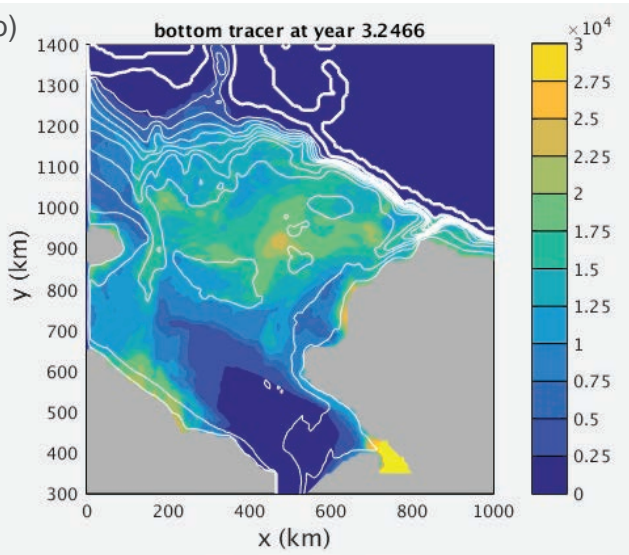

(d)

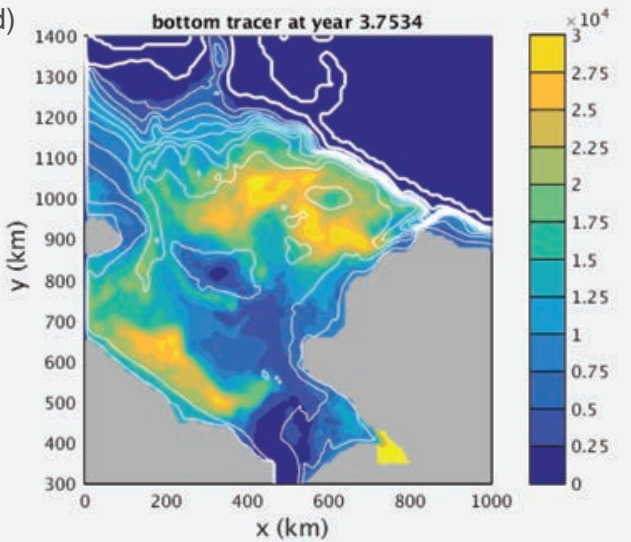

Figure 13. Concentrations of the sediment tracer (arbitrary units) in bottom waters over the Chukchi Shelf in year 3 of the model run. Model frames are shown for (a) January (year 3), (b) March (year 3.25), (c) June (year 3.5), and (d) September (year 3.75). Similar patterns were observed in years 1 and 2. 

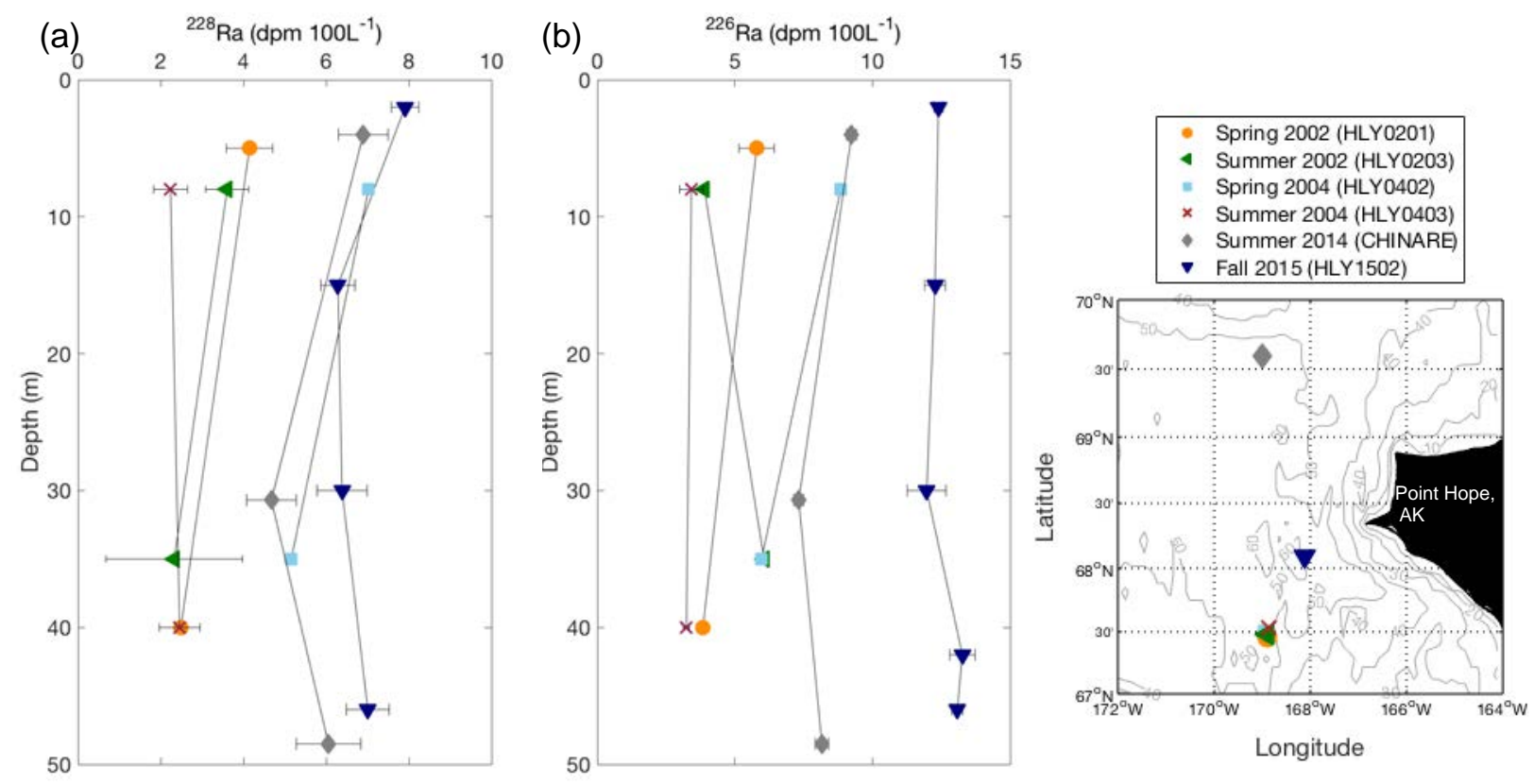

Figure 14. (a) ${ }^{228} \mathrm{Ra}$ and (b) ${ }^{226} \mathrm{Ra}$ activities measured over the Chukchi Shelf. Data were collected during the HLY1502 (this study), HLY0201 (D. Kadko, unpublished data), HLY0203 (D. Kadko, unpublished data), HLY0402 (D. Kadko, unpublished data), HLY0403 (D. Kadko, unpublished data), and CHINARE (Li et al., 2017) expeditions. The HLY0201 and HLY0402 samples were collected in May - June 2002 and 2004, respectively, the HLY0203 and HLY0403 samples were collected in July - August 2002 and 2004, respectively, the CHINARE samples were collected between July and September 2014, and the HLY1502 samples were collected between August and October 2015. 


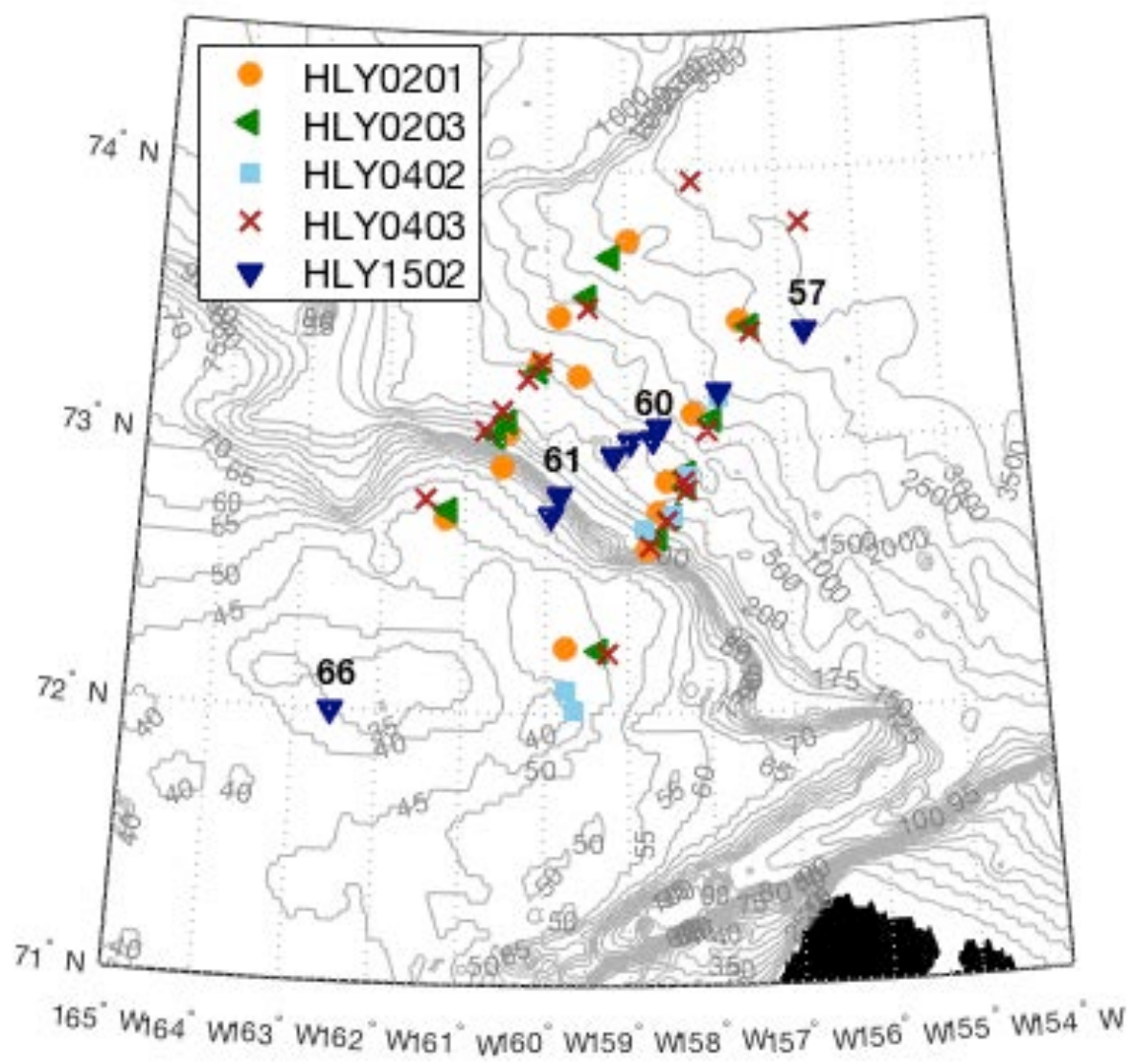

Figure 15. Locations of stations from the HLY1502 (dark blue triangles; this study) and SBI expeditions that were used to create the mean section plots shown in Figure 16. 
(a)

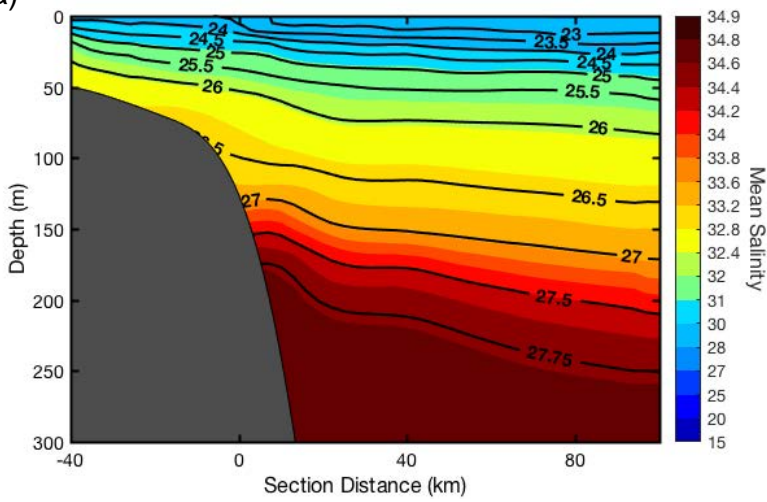

(c)

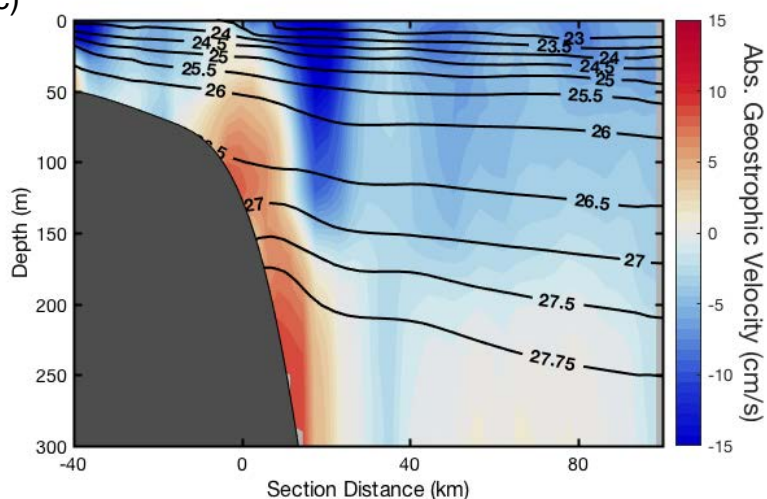

(e)

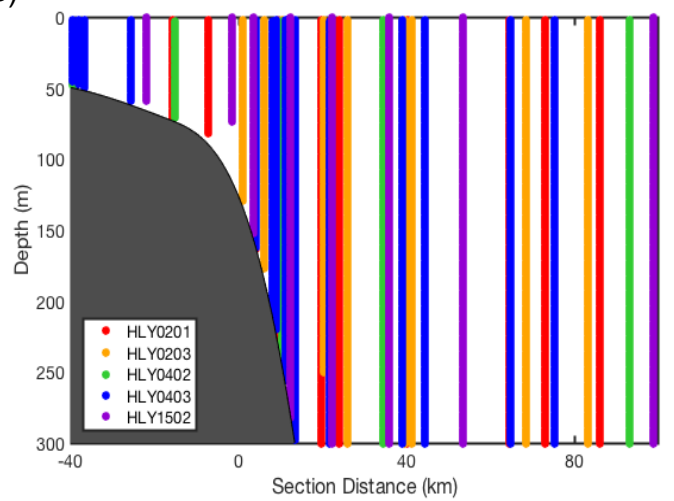

(b)

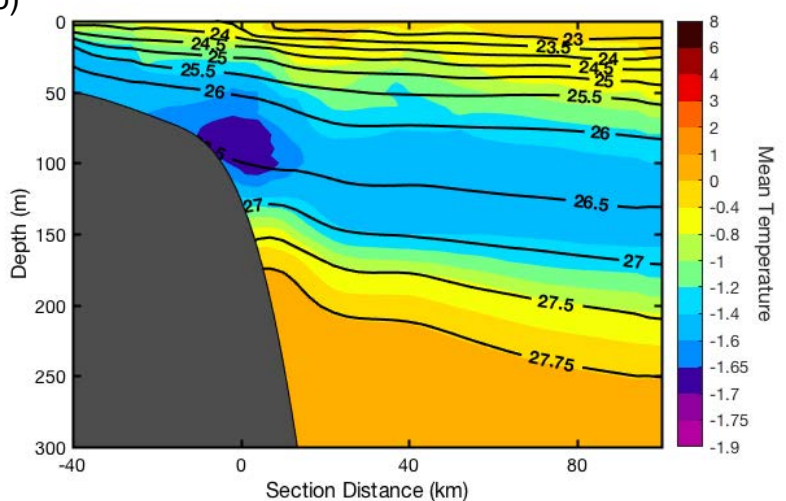

(d)

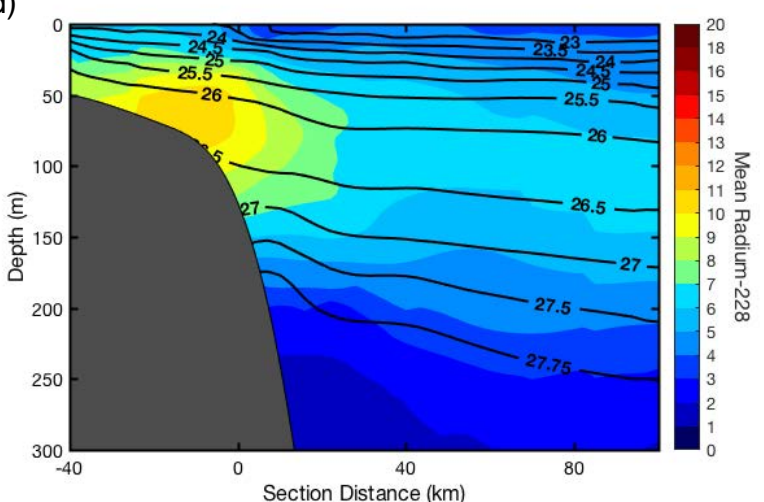

(f)

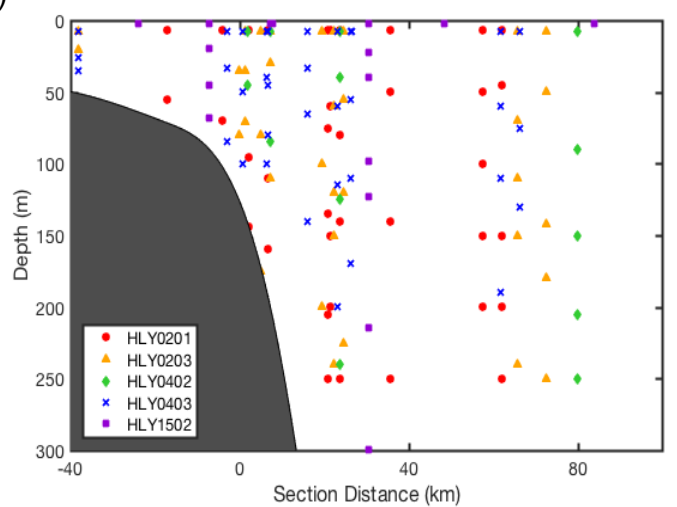

Figure 16. Mean section plots of (a) salinity, (b) temperature, (c) absolute geostrophic velocity, and (d) ${ }^{228}$ Ra activity, along with (e) CTD and (f) ${ }^{228}$ Ra sampling locations. Data from the Chukchi Shelf crossings shown in Figure 15 were used to calculate the mean sections; the colored symbols shown in (e) and (f) indicate the sampling locations of specific cruises. The data collected from the CTD sampling locations shown in (e) were used to create sections (a) - (c), and the ${ }^{228} \mathrm{Ra}$ data collected from the sampling locations shown in (f) were used to create section (d). 

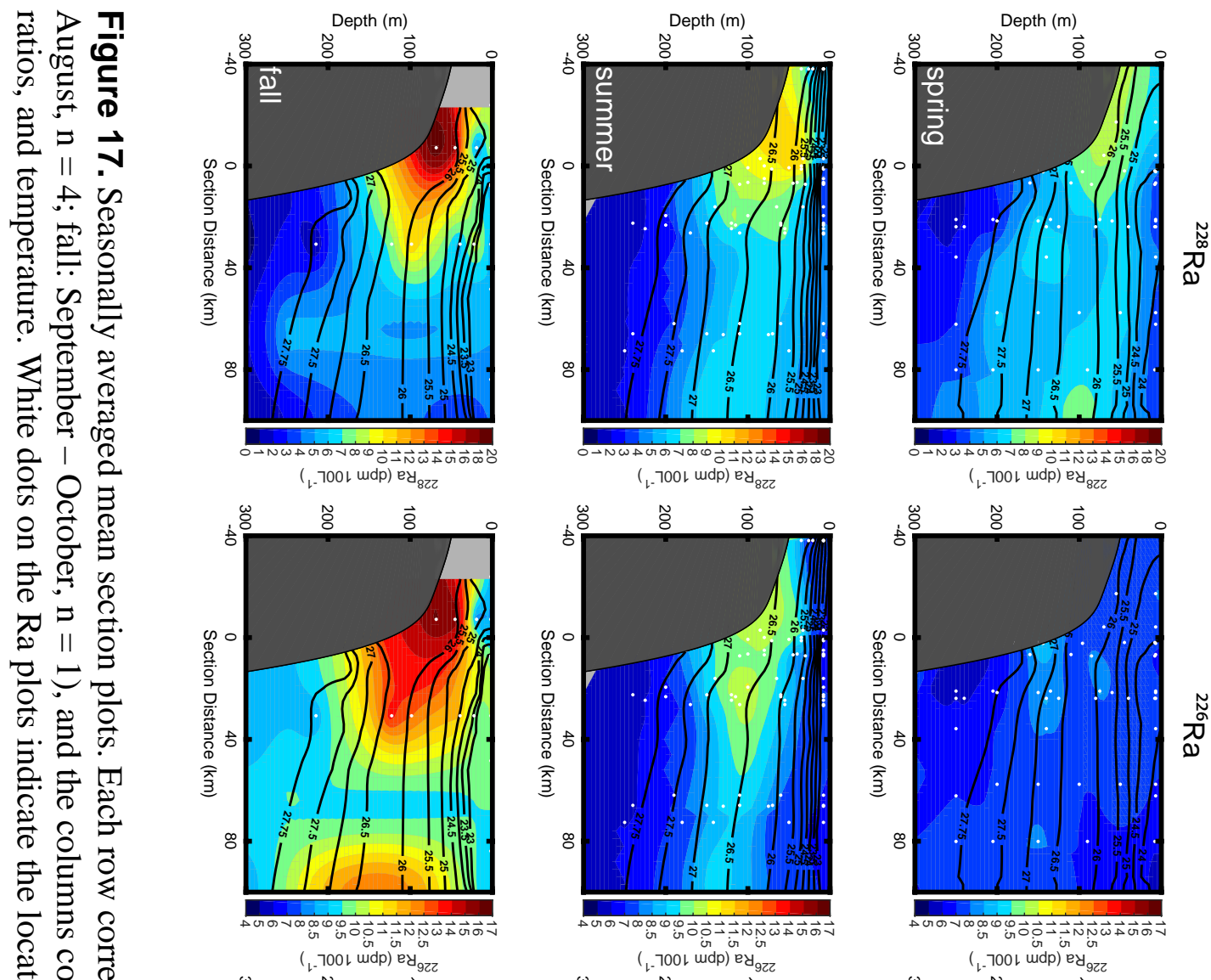

产通

융

官官
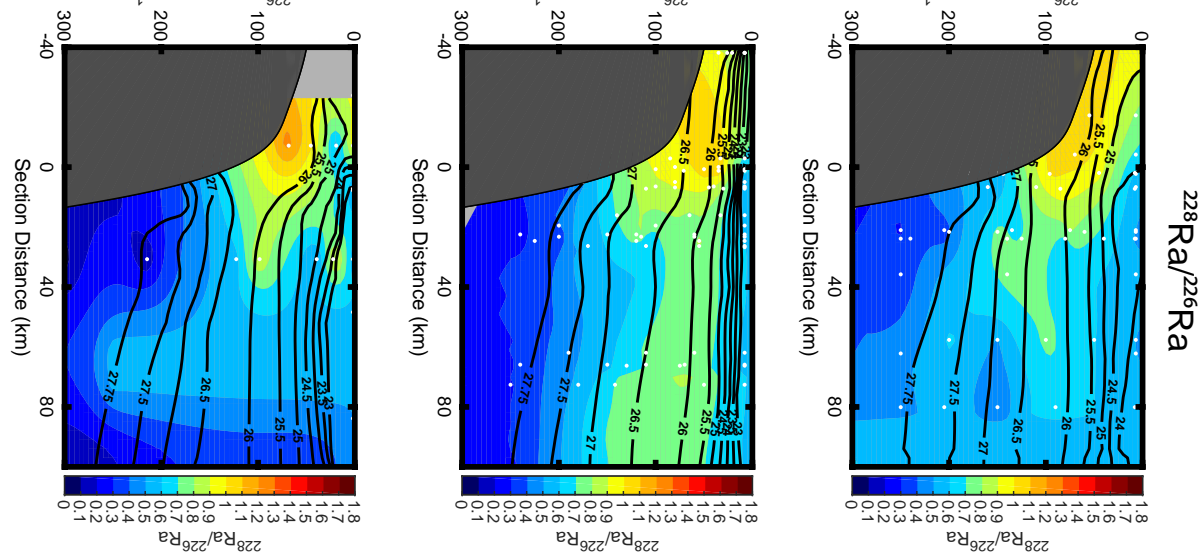

蛋 స్రై

乞ิ ڤે.

○号
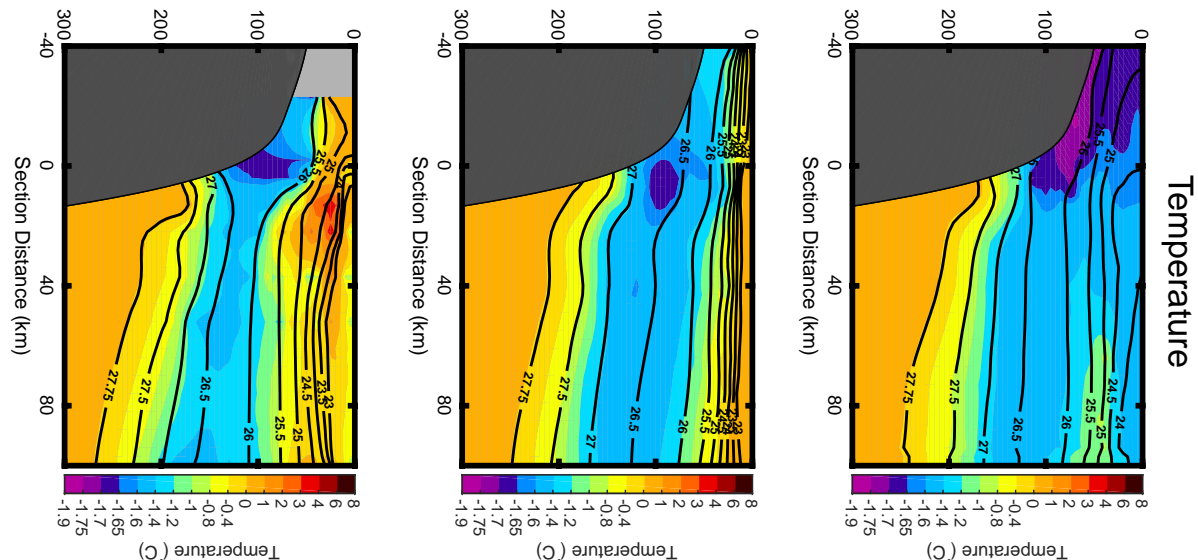

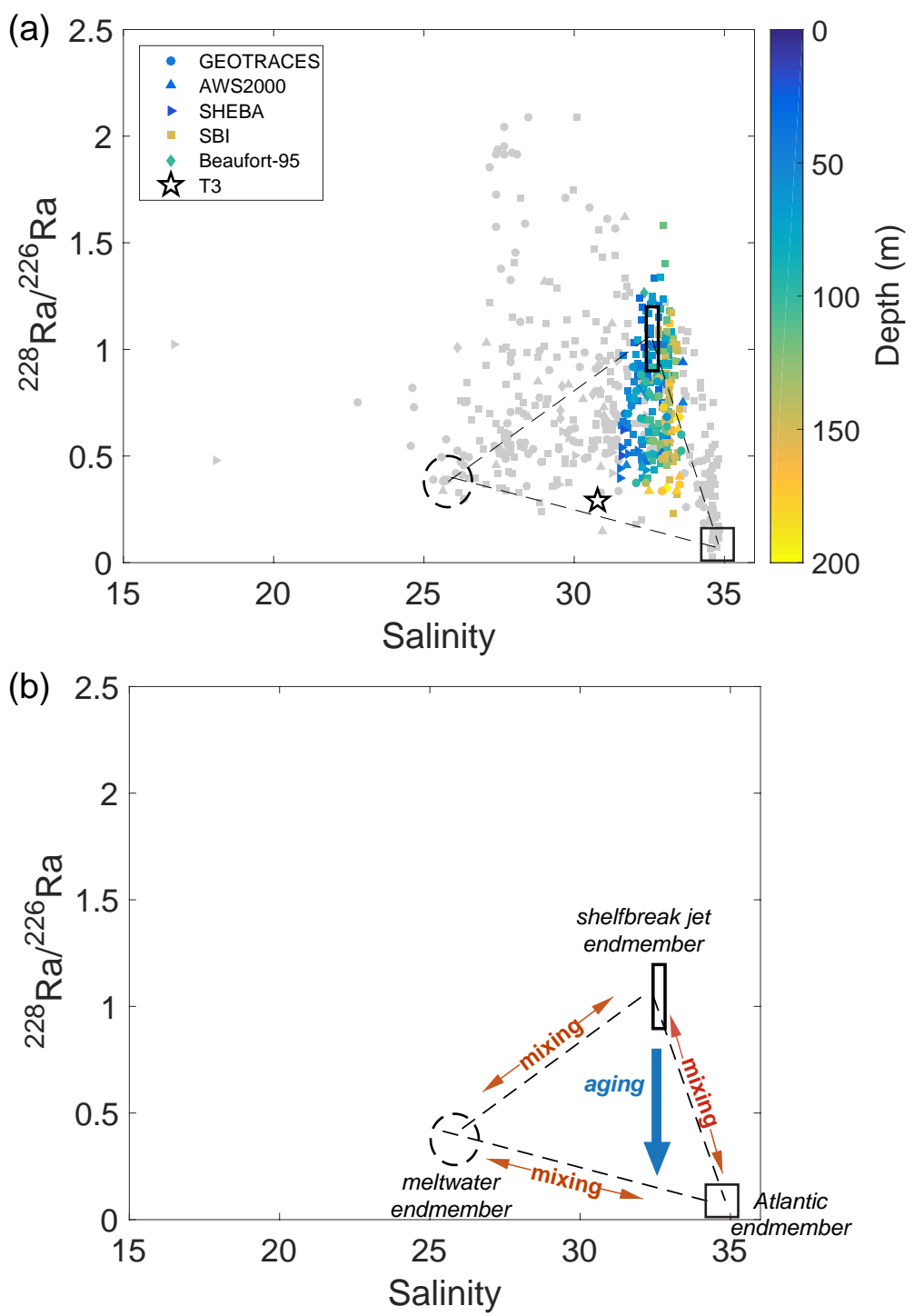

Figure 18. (a) ${ }^{228} \mathrm{Ra} /{ }^{226} \mathrm{Ra}$ activity ratio as a function of salinity for samples collected in Western Arctic surface waters $(\leq 200 \mathrm{~m})$. Symbol color indicates depth in the water column, and symbol shape indicates the sampling expedition. Only the samples collected in the T-S space occupied by WW or RWW are shown in color; these are the samples that likely originated from the shelfbreak jet endmember. The black box represents the shelf break jet endmember, the dashed circle denotes the meltwater endmember, and the black square indicates the Atlantic water endmember (see section 4.4.2.3). The activity ratio measured at ice station T3 in 1968 (Kaufman et al., 1973) is indicated by a white star. Error bars are not shown for clarity. (b) The positions of the shelfbreak jet, meltwater, and Atlantic water endmembers in ${ }^{228} \mathrm{Ra} /{ }^{226} \mathrm{Ra}-$ salinity space. Dashed lines indicate mixing between the endmembers, and the blue arrow shows the effect of aging on the ${ }^{228} \mathrm{Ra} /{ }^{226} \mathrm{Ra}$ activity ratio. 

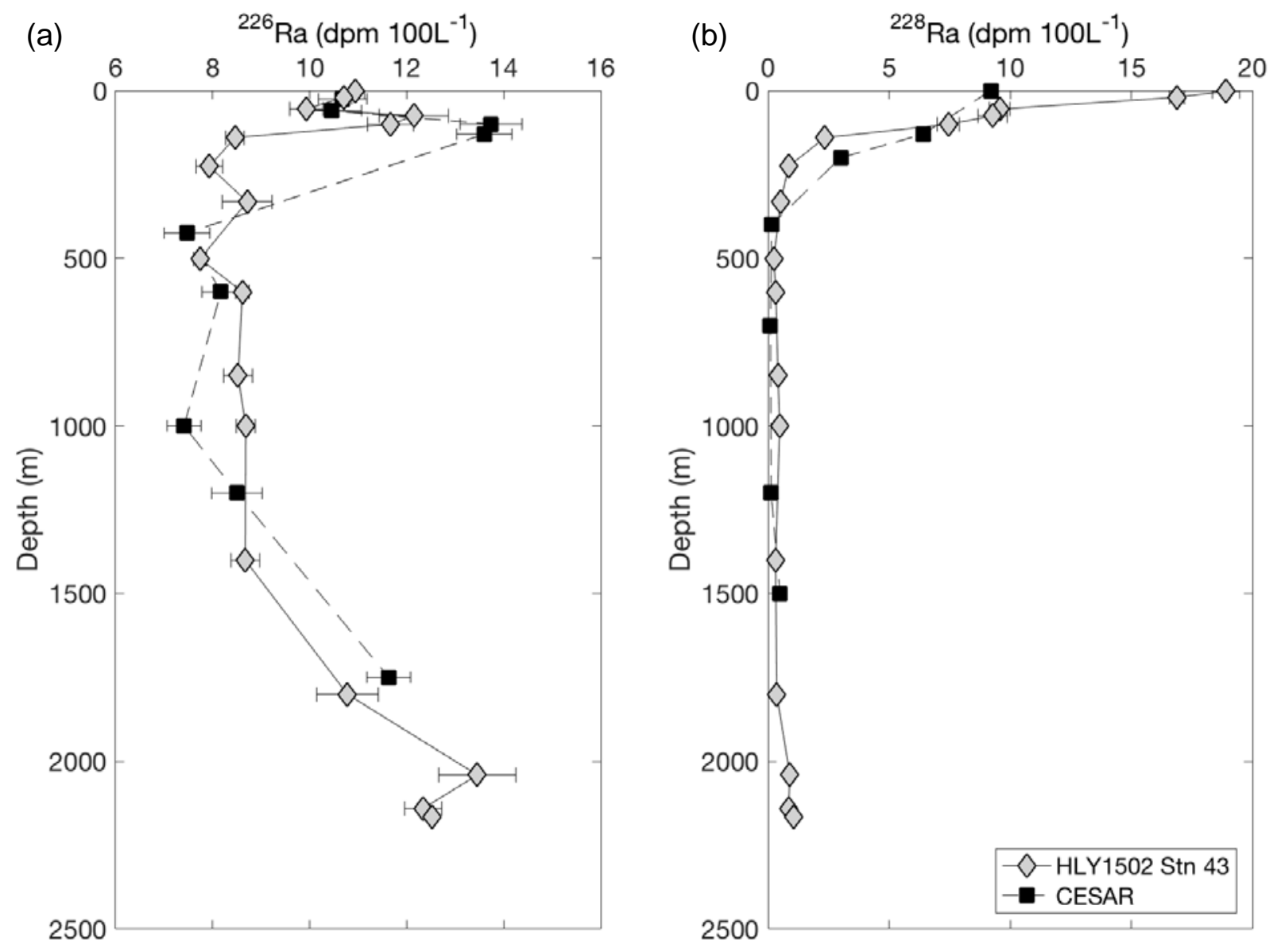

Figure 19. (a) ${ }^{226} \mathrm{Ra}$ and (b) ${ }^{228} \mathrm{Ra}$ profiles measured at the CESAR ice station in 1983 (Bacon et al., 1989; Moore and Smith, 1986) and on the HLY1502 expedition in 2015. Both stations were located above the Alpha Ridge. 


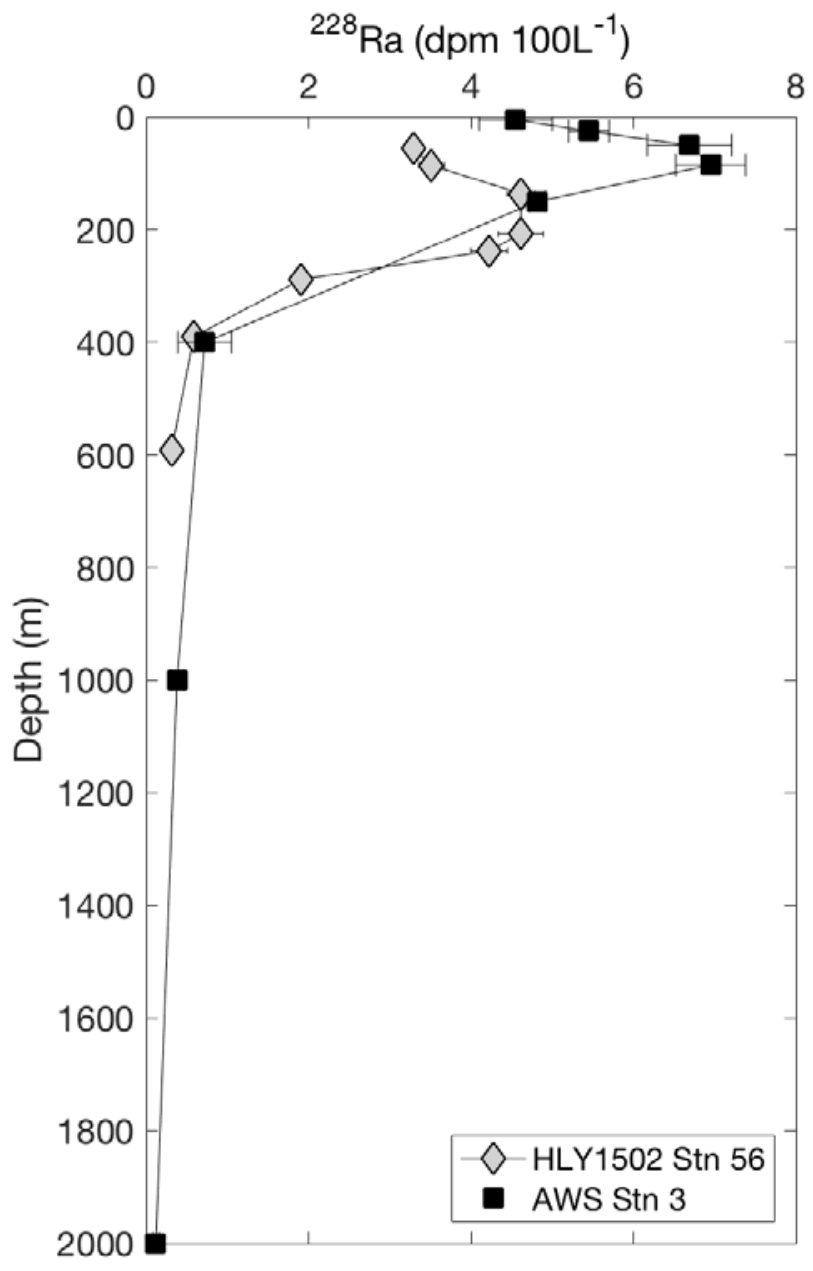

Figure 20. Radium-228 profiles measured in the Canada Basin in 2000 (AWS-2000; Trimble et al., 2004) and 2015 (HLY1502; this study). 

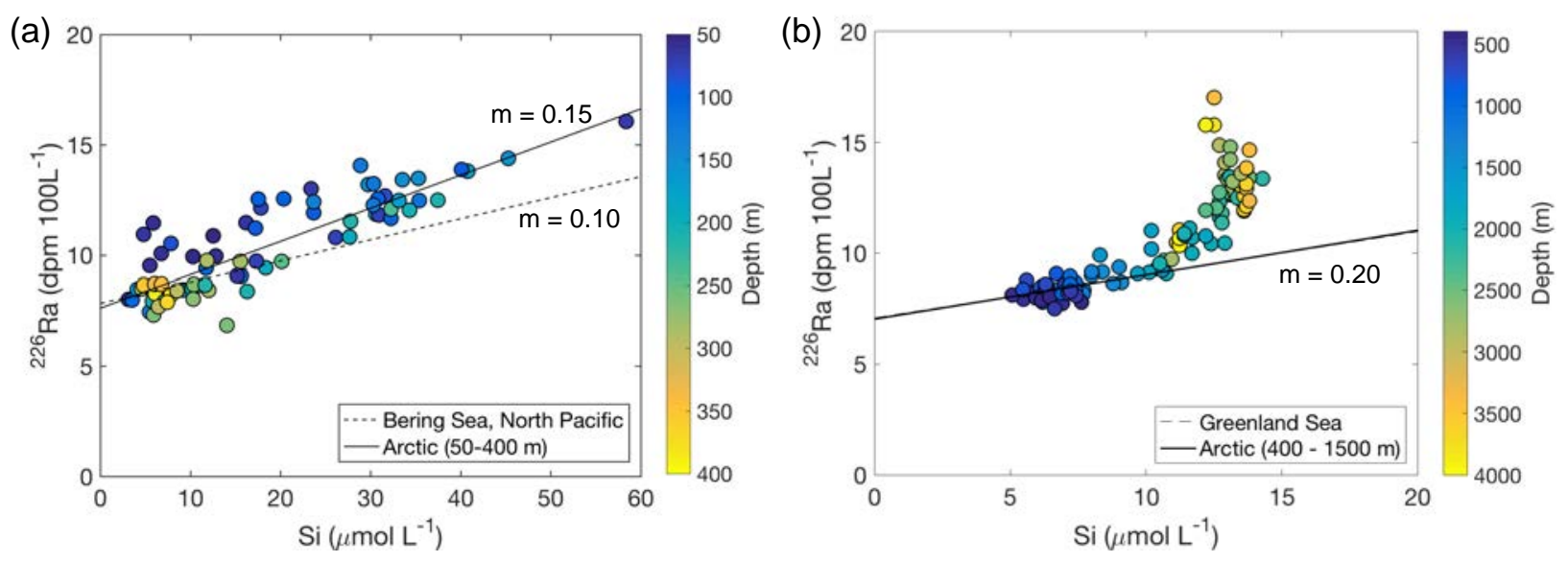

Figure 21. Radium-226 versus silica for (a) samples shallower than $400 \mathrm{~m}$ and (b) deeper than $400 \mathrm{~m}$. Dashed and solid lines show the ${ }^{226} \mathrm{Ra}-\mathrm{Si}$ relationships determined in various basins. The Arctic relationship between $400-1500 \mathrm{~m}$ and the relationship in the Greenland Sea have the same slope $(\mathrm{m})$, so the lines overlap. 
Supplementary Figures 

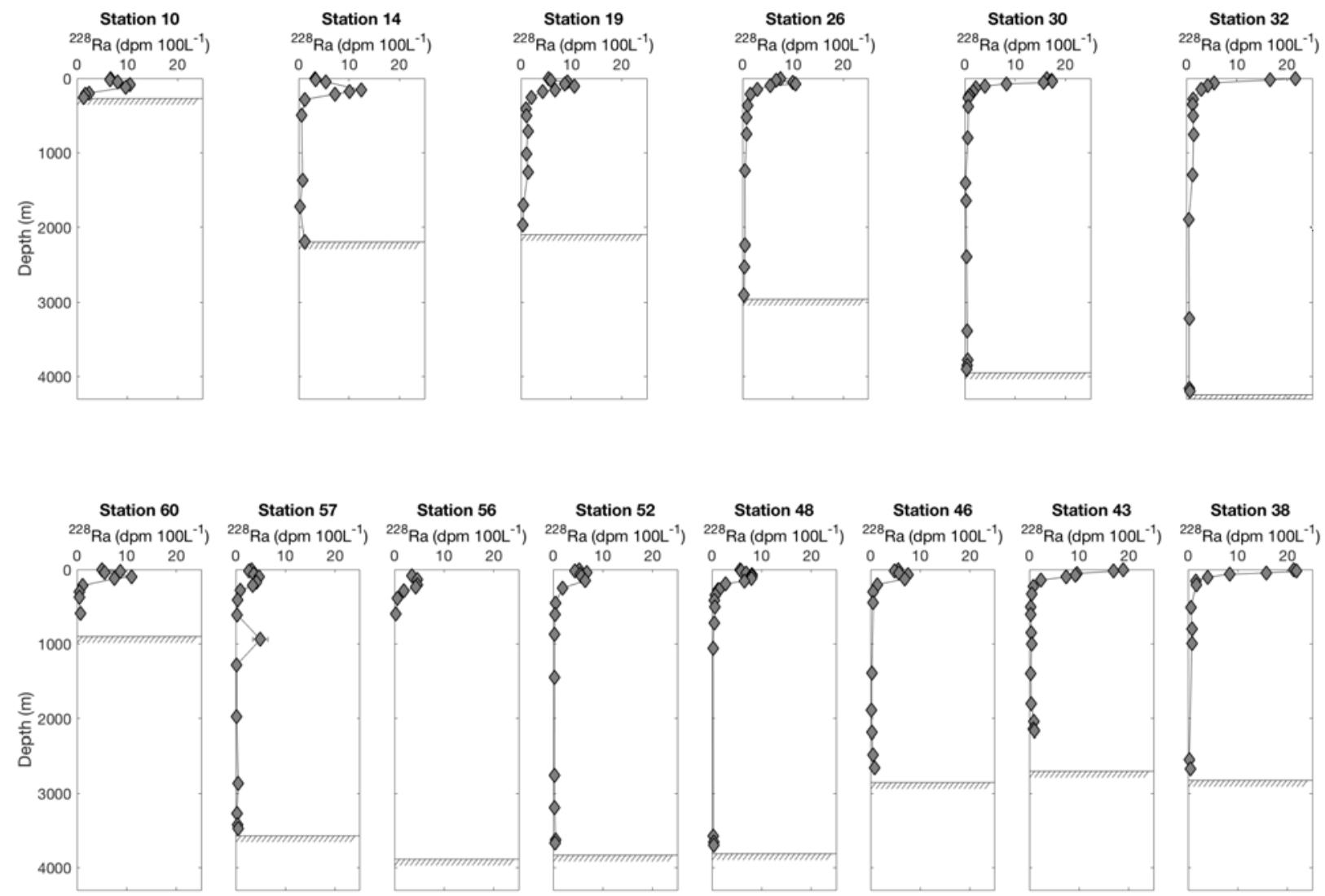

Figure S1. Radium-228 profiles measured at all stations. Profiles in the top row were collected on the northbound transect $\left(\sim 180^{\circ} \mathrm{W}\right)$ and profiles in the bottom row were collected on the southbound transect $\left(\sim 150^{\circ} \mathrm{W}\right)$. In both rows the stations closest to the Chukchi Shelf are on the left, and the stations closest to the North Pole are on the right. See Figure 2 for station locations. Hatched lines indicate bottom depth. 

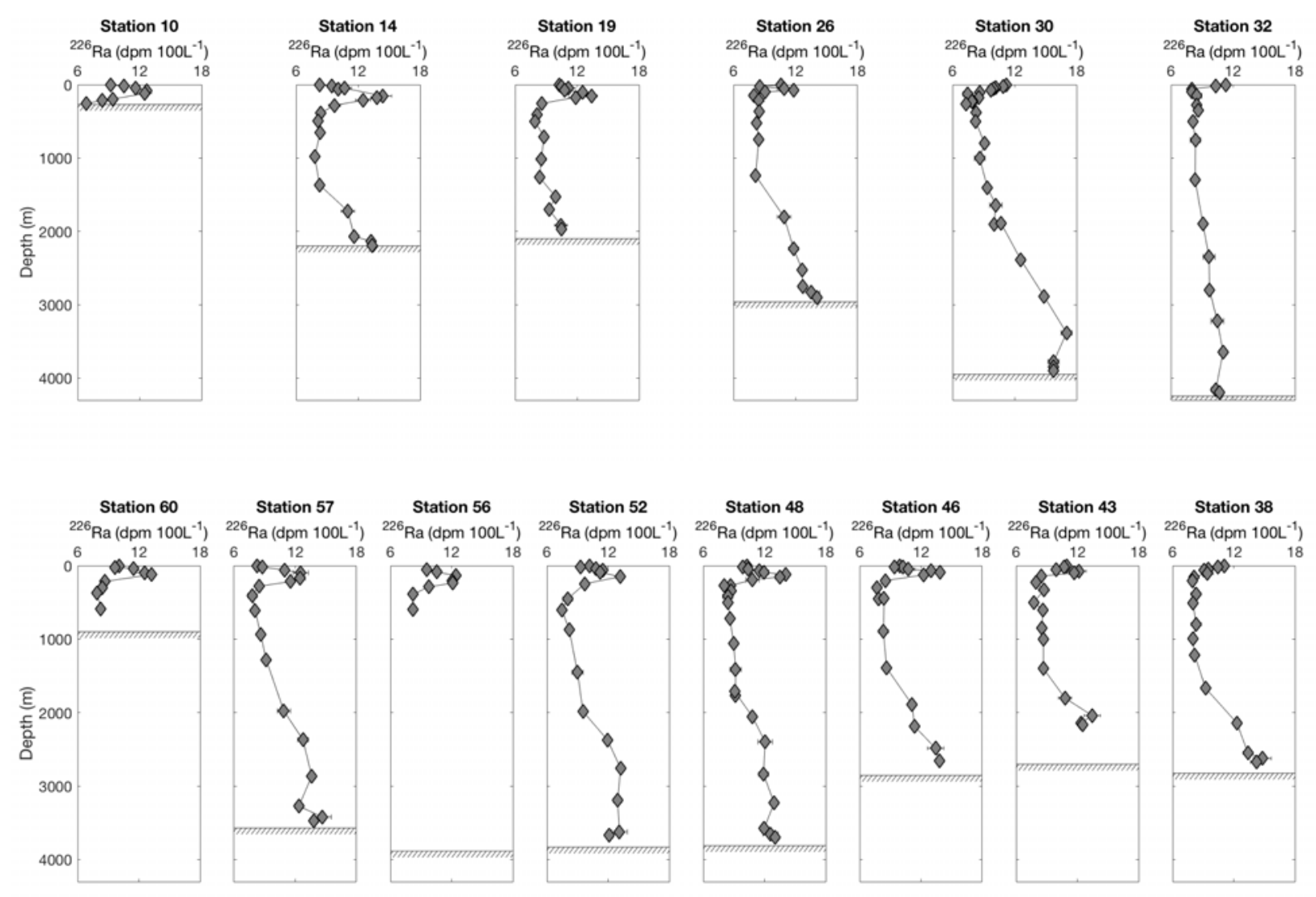

Figure S2. Radium-226 profiles measured at all stations. Profiles in the top row were collected on the northbound transect $\left(\sim 180^{\circ} \mathrm{W}\right)$ and profiles in the bottom row were collected on the southbound transect $\left(\sim 150^{\circ} \mathrm{W}\right)$. In both rows the stations closest to the Chukchi Shelf are on the left, and the stations closest to the North Pole are on the right. See Figure 2 for station locations. Hatched lines indicate bottom depth. 

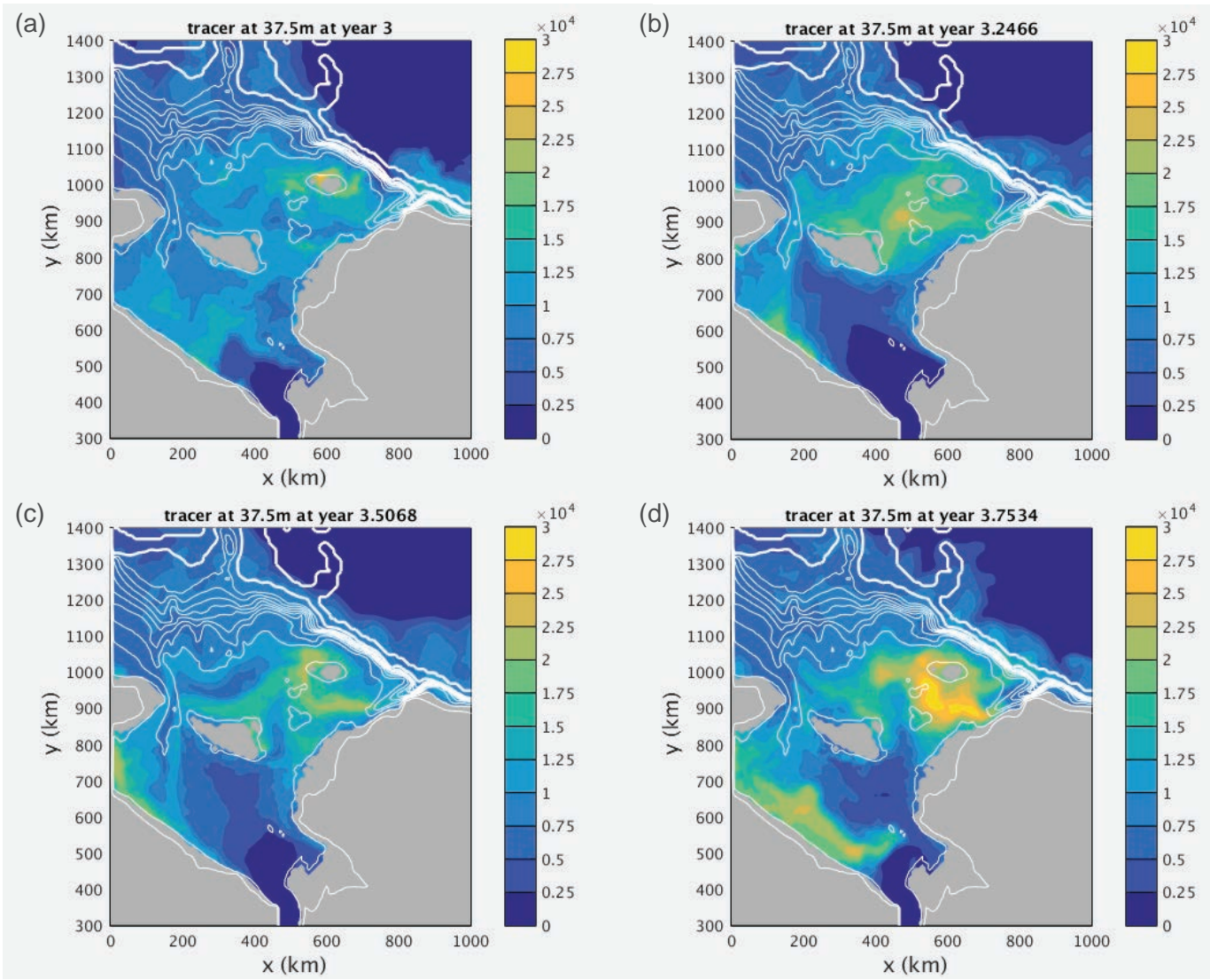

Figure S3. Concentrations of the sediment tracer (arbitrary units) at $37.5 \mathrm{~m}$ over the Chukchi Shelf in year 3 of the model run. Model frames are shown for (a) January (year 3), (b) March (year 3.25), (c) June (year 3.5), and (d) September (year 3.75). 
(a)

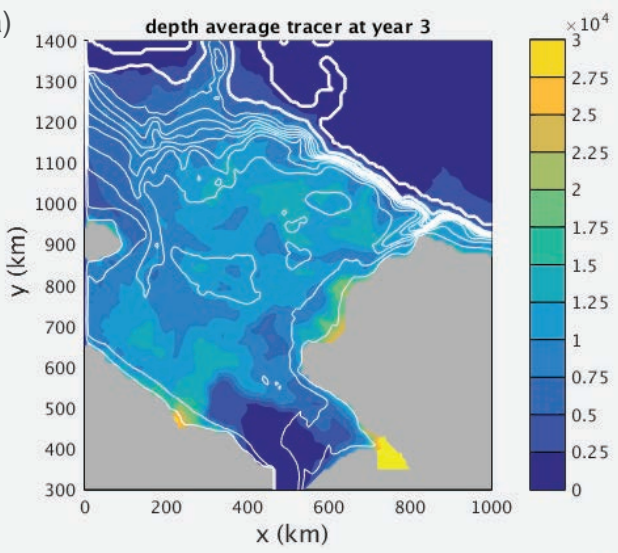

(c)

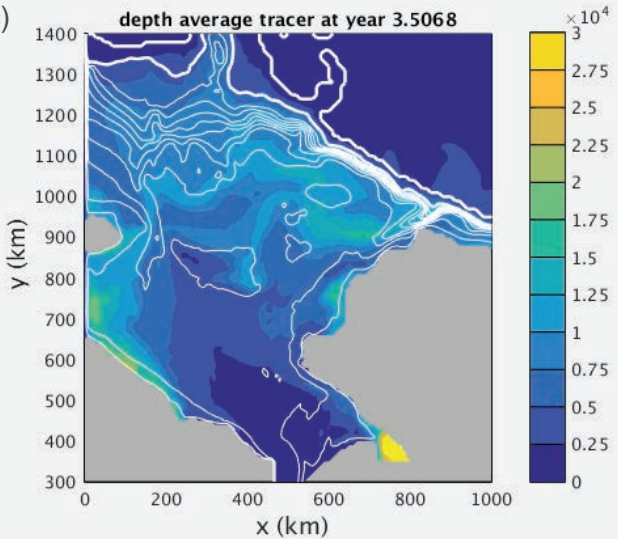

(b)

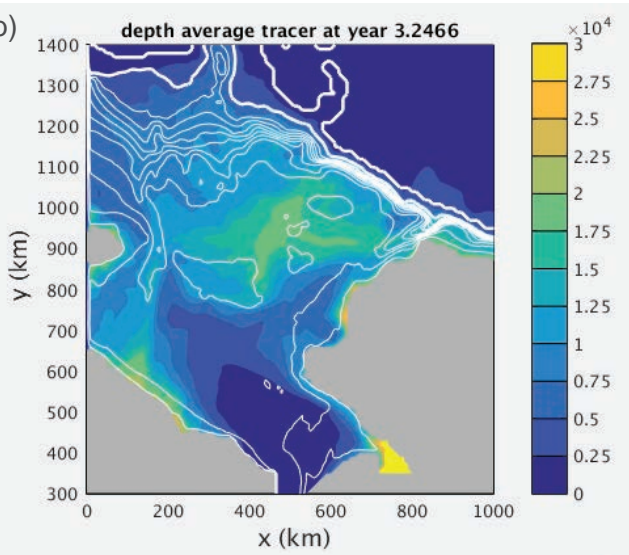

(d)

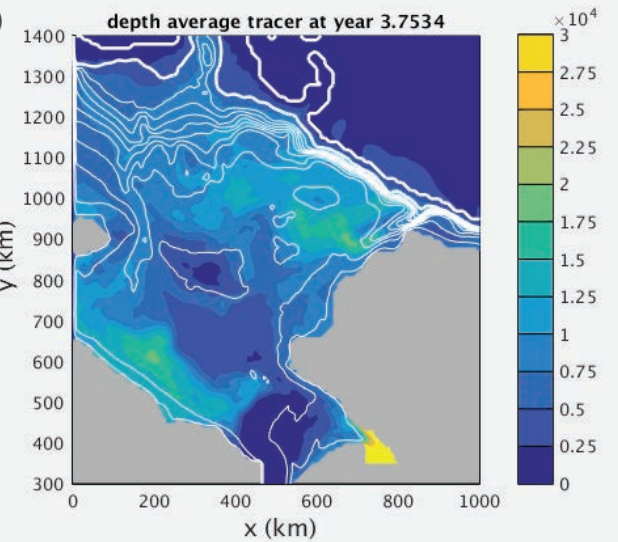

Figure S4. Depth-integrated concentrations of the sediment tracer (arbitrary units) over the Chukchi Shelf in year 3 of the model run. Model frames are shown for (a) January (year 3), (b) March (year 3.25), (c) June (year 3.5), and (d) September (year 3.75). 

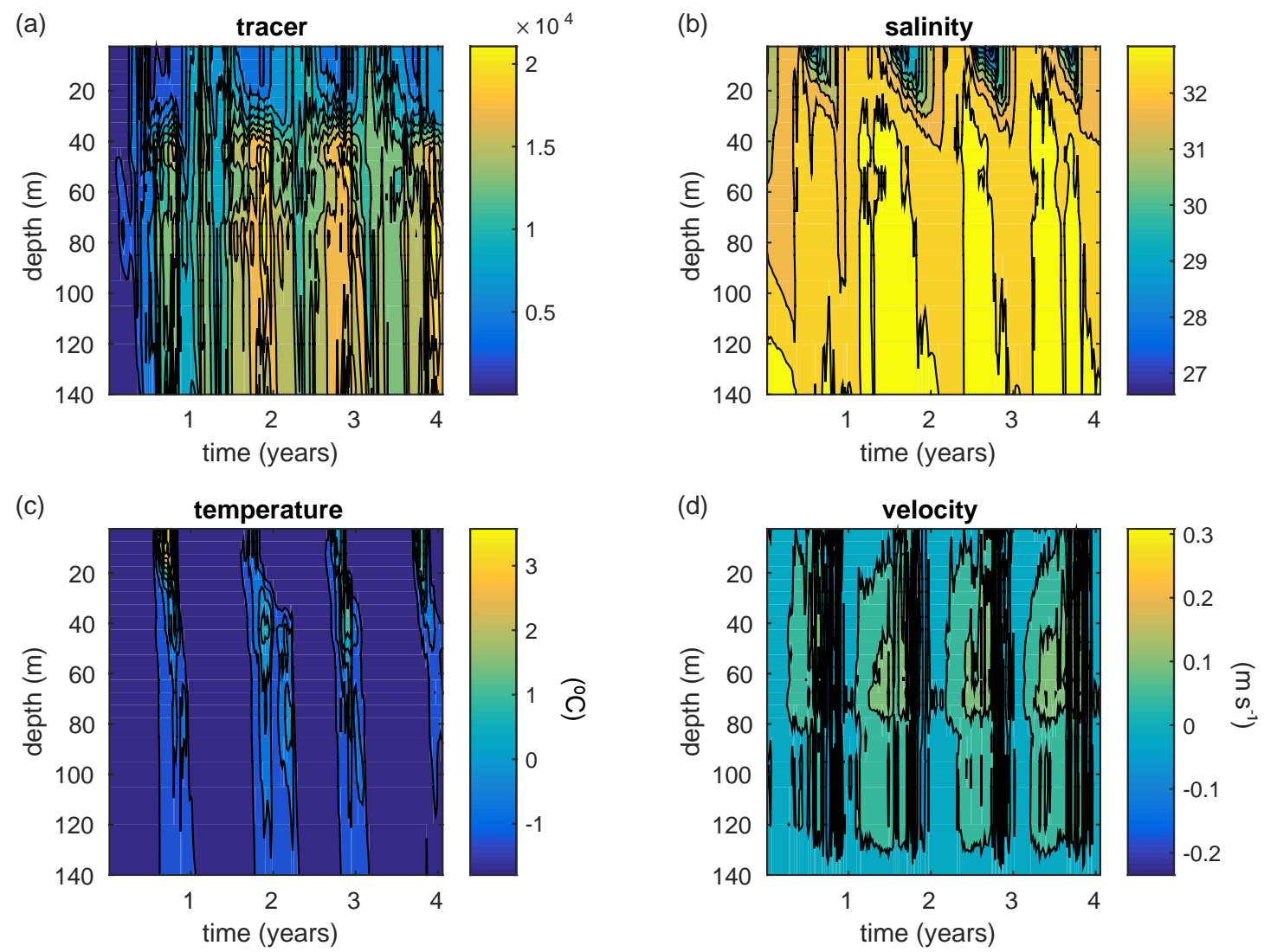

Figure S5. Modeled (a) tracer concentrations, (b) salinity, (c) temperature, and (d) zonal velocity as a function of depth and time averaged over the white box shown in Figure 2. The model run starts in January, so year 0 indicates January 1 of the first model year. 

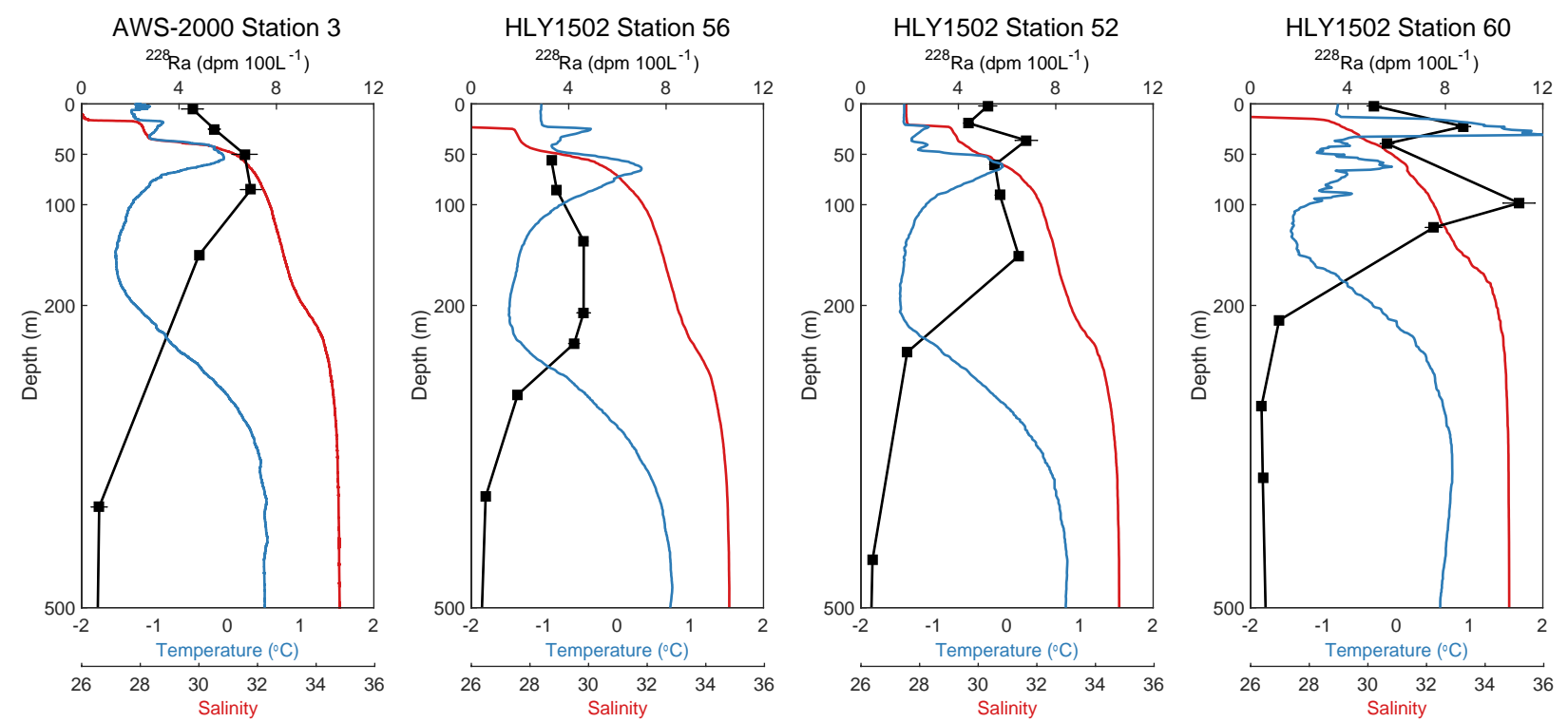

Figure S6. Radium-228, temperature, and salinity measured at AWS-2000 station 3 and HLY1502 stations 56, 52, and 60. 

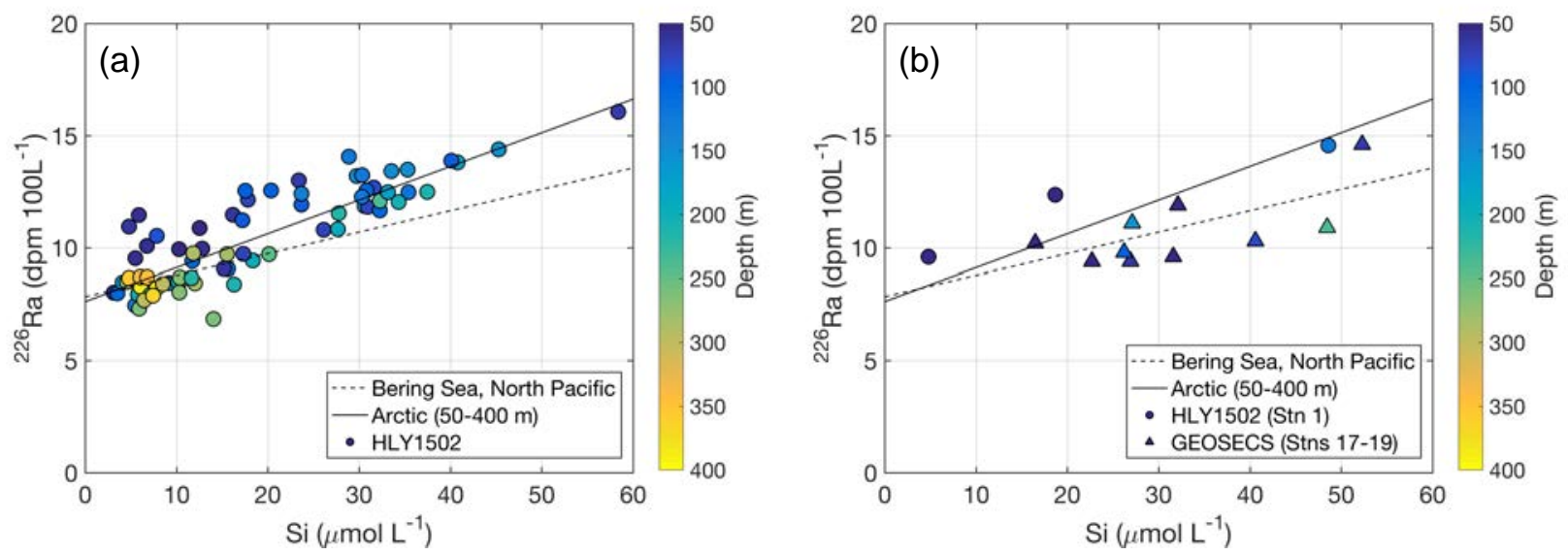

Figure S7. ${ }^{226} \mathrm{Ra}$-Si relationship for samples collected (a) in shelf-modified Pacific waters on the HLY1502 transect and (b) in the North Pacific and Bering Sea during the GEOSECS expedition (Chung, 1980). 


\title{
Chapter 5: Nutrients, trace metals, and radium isotopes in the Mackenzie River delta and estuary
}

\begin{abstract}
River discharge has an important influence on the chemistry of Arctic shelf seas and surface waters. In this study we examined the changes in nutrient, trace metal, and radium isotope distributions across the Mackenzie River delta and estuary after the freshet in June 2016. While inorganic nutrient, trace metal, and radium levels remained fairly constant through the delta, dissolved organic matter concentrations were $2-3.5$ times higher at the mouth of the river, reflecting inputs from the delta. In the estuarine mixing zone, radium isotope ratios indicated that both desorption from suspended sediments and benthic inputs from porewaters or groundwaters affected solute concentrations. Similarly, most of the measured trace metals $(\mathrm{Ba}, \mathrm{Mn}, \mathrm{Co}, \mathrm{Cu}$, $\mathrm{Ni}$ ) exhibited non-conservative addition in the freshwater-saltwater transition zone, while $\mathrm{Pb}$ was removed and $U$ was mixed conservatively. Inorganic nutrients were affected by both addition and removal processes in the estuary. Approximately $45 \%$ and $60 \%$ of dissolved organic carbon and nitrogen, respectively, were removed rapidly at low salinities, in contrast with previous studies suggesting conservative mixing through Arctic estuaries. This study provides some of the first estimates of trace element and isotope delivery from the Mackenzie River to the Western Arctic, and highlights the need to take deltaic and estuarine processes into account when determining the flux of riverine solutes to the coastal ocean.
\end{abstract}




\subsection{INTRODUCTION}

The Arctic Ocean receives $10 \%$ of global river discharge, despite containing only $\sim 1 \%$ of the global ocean volume (McClelland et al., 2012). Fluvial inputs are therefore an important control on the chemistry of this ocean basin. For example, river discharge is thought to contribute $25 \%$ of dissolved organic carbon to the central Arctic (Wheeler et al., 1997) and fluvial inputs of nitrogen support up to $8 \%$ of export production in the Western Arctic (Letscher et al., 2013). Further, river water has been suggested to be the most important source of dissolved iron to the central Arctic (Klunder et al., 2012). This freshwater source of nutrients, carbon, and trace metals is particularly important for biota living in Arctic surface waters because strong stratification limits nutrient inputs through upwelling (Macdonald et al., 1987). Rivers may exert an even larger impact on the Arctic in the future if discharge continues to increase (Rawlins et al., 2010).

The Mackenzie River, located in northwest Canada, is the $4^{\text {th }}$ largest river in the Arctic and delivers $316 \mathrm{~km}^{3}$ of freshwater to the Western Arctic each year (Holmes et al., 2012). It carries the largest sediment load of any Arctic river, $124 \mathrm{Mt} \mathrm{y}^{-1}$ (Carson et al., 1998; Holmes et al., 2002), most of which is sourced from the Canadian Cordillera on the western side of the 1.8 $\mathrm{M} \mathrm{km}^{2}$ drainage basin (Macdonald et al., 1998). The middle of the watershed lies in the Interior Plain, while the eastern side drains the Canadian Shield and contains three large headwater lakes that serve to moderate seasonal fluctuations in flow (Macdonald and $\mathrm{Yu}, 2006$ ). Because the drainage basin extends as far south as $53^{\circ} \mathrm{N}$, it contains varied ecosystems, geology, and permafrost coverage (Brown et al., 1998; Millot et al., 2003; Walker, 1998).

There is strong seasonal variability in both the water and sediment discharge from the Mackenzie, with the peak discharge occurring in spring (May-early June) following snowmelt. Typical flow rates range between $3,000-5,000 \mathrm{~m}^{3} \mathrm{~s}^{-1}$ during the winter baseflow, increasing to as much as 40,000 $\mathrm{m}^{3} \mathrm{~s}^{-1}$ during the freshet in early June (Macdonald and $\mathrm{Yu}, 2006$ ). The river branches into a delta around $67.5^{\circ} \mathrm{N}$, and forms three main channels. It is estimated that approximately $2 / 3$ of the discharge exits the delta through the Middle Channel, with the remainder being equally split between the West Channel to Mackenzie Bay and the East Channel to Kugmallit Bay (Macdonald and Yu, 2006). The delta contains >45,000 lakes, which can store and modify river water during periods of off-peak discharge (Emmerton et al., 2007, 2008a). Although the channels can be up to $30 \mathrm{~m}$ deep, the water depth at the mouth of the river shoals to $2 \mathrm{~m}$, a feature that is termed the "2-m ramp" by Reimnitz (2002). After passing over this $10-20$ $\mathrm{km}$ wide shoal, the river becomes a partially mixed estuary with a strong pycnocline around $10-$ $20 \mathrm{~m}$ (Carmack and Macdonald, 2002; Macdonald, 2000). Once discharged into the Beaufort Sea, the Mackenzie River plume is typically confined to the coastal region and is pushed eastward by the Coriolis force, eventually exiting the Arctic through the Canadian Archipelago (Guay et al., 2009; Karcher and Oberhuber, 2002; Taylor et al., 2003; Yamamoto-Kawai et al., 2005). Under favorable discharge and wind conditions, Mackenzie River water can be transported offshore and enter the Canada Basin (Carmack and Macdonald, 2002; Macdonald et al., 1999).

Solute concentrations in Arctic rivers are seasonally variable: the highest DOC concentrations are observed in spring during the freshet, as a result of snowmelt percolating through the organic rich upper soil layers before reaching the river (Finlay et al., 2006; Gordeev, 2000; Holmes et al., 2013, 2012). In contrast, peak nutrient concentrations are observed during the winter baseflow period, when groundwaters are the main source of water to the river (Finlay 
et al., 2006; Gordeev, 2000; Holmes et al., 2013, 2012). Rember and Trefry (2004) showed that trace metal $(\mathrm{Cu}, \mathrm{Pb}, \mathrm{Zn}, \mathrm{Fe})$ concentrations in Alaskan rivers were highest during the freshet due to inputs from snowmelt and upper soil layers, with the exception of $\mathrm{Ba}$, which remained relatively constant throughout the year. However, Pokrovsky et al. (2010) did not observe statistically different concentrations of Mn between periods of low and high discharge, and suggested that metal inputs from snowmelt are more likely to be important in smaller rivers.

The chemistry of the Mackenzie River undergoes significant changes during transit through its large delta and in the estuarine zone. Emmerton et al. (2008a) observed downstream increases in DOM through the delta and Macdonald et al. (1998) estimated that half of the sediment carried by the river is trapped in the delta. Concentrations of nutrients, DOM, and particulate organic matter are also modified by sedimentation, biological uptake, and dilution in the estuary (Emmerton et al., 2008b). Trace metals can be affected by adsorption or desorption from particles, flocculation, and dilution in estuarine mixing zones (e.g. Boyle et al., 1974, 1982, 1977; Shiller and Boyle, 1987; Sholkovitz, 1978). Guay and Falkner (1998) recorded a peak in Ba concentrations in the Mackenzie River around a salinity of 5, indicating desorption from suspended particles as the ionic strength of the water increased. Similar behavior has been observed for $\mathrm{Cu}, \mathrm{Ni}$, and $\mathrm{Cd}$ in the mixing zone of the Lena estuary (Guieu et al., 1996).

Due to differences in drainage basin topography and geology, the Mackenzie River exhibits distinctly different chemistry from the Eurasian Arctic rivers. The Eurasian river drainage basins consist mostly of tundra and taiga, while the presence of mountainous terrain in the Mackenzie watershed leads to more erosion and mineral weathering. As a result, the Mackenzie has higher $\mathrm{Ba}$, total alkalinity, and suspended sediment concentrations, while Eurasian rivers have higher DOC concentrations (Cooper et al., 2008; Gordeev, 2000; Guay and Falkner, 1998; Holmes et al., 2002). Eurasian and North American river inputs to the Arctic have been separated based on Ba (Guay and Falkner, 1998, 1997; Guay et al., 2009), alkalinity (Yamamoto-Kawai et al., 2005), and DOC (Guay et al., 1999).

Radium isotopes, produced naturally by the decay of thorium isotopes in sediments, have previously been used to trace fluvial inputs to the open ocean (Moore et al., 1986; Moore and Krest, 2004; Moore and Todd, 1993; Rutgers van der Loeff et al., 1995) and offer another tool for studying Mackenzie River changes in the estuary and inputs to the Arctic. Radium is primarily adsorbed to particles in freshwater but dissolved in seawater; this difference in chemistry is due to a change in the adsorption coefficient of Ra in fresh and saline waters, and to the decrease in particle concentration in open ocean waters (Li et al., 1977; Moore et al., 1995). The desorption from particles in the estuary, along with resuspension events that release Ra produced in estuarine and shelf sediments, causes estuaries to be a source of Ra to the open ocean (Elsinger and Moore, 1980; Key et al., 1985; Krest et al., 1999; Li et al., 1977; Li and Chan, 1979; Moore, 1992, 1981; Moore et al., 1995). Due to their varying half-lives (which determine the regeneration times), ratios of the four different $R a$ isotopes $\left({ }^{223} \mathrm{Ra}, \mathrm{t}_{1 / 2}=11.4 \mathrm{~d}\right.$; ${ }^{224} \mathrm{Ra}, \mathrm{t}_{1 / 2}=3.66 \mathrm{~d} ;{ }^{228} \mathrm{Ra}, \mathrm{t}_{1 / 2}=5.75 \mathrm{y} ;{ }^{226} \mathrm{Ra}, \mathrm{t}_{1 / 2}=1600 \mathrm{y}$ ) can be used to identify porewater and groundwater inputs to coastal systems (Charette, 2007; Moore, 1981; Moore et al., 1995; Rodellas et al., 2017). Additionally, because ${ }^{223} \mathrm{Ra}$ and ${ }^{224} \mathrm{Ra}$ decay on timescales of days, these isotopes can be applied to determine river plume mixing and advection rates (Moore, 2000a, 2000b; Moore and Krest, 2004; Rousseau et al., 2015).

While our understanding of the chemistry of the Mackenzie River freshwater endmember has improved in recent decades, largely through the efforts of the Arctic Great Rivers Observatory (A-GRO; arcticgreatrivers.org), few studies have investigated the chemical changes 
that occur in the delta and estuary (e.g. Emmerton et al., 2008a, 2008b; Tremblay et al., 2014). As the largest Arctic river draining North America, the Mackenzie influences the chemistry of the Beaufort Sea and surface waters in the Western Arctic (Carmack et al., 2004; Guay et al., 2009; Macdonald et al., 1987; Yamamoto-Kawai et al., 2005). Further, this river-influenced shelf water, which exits the Arctic through the Canadian Archipelago, can affect the nutrient balance and hence productivity in the North Atlantic Ocean (Guay et al., 2009; Torres-Valdés et al., 2013; Tremblay et al., 2015). In this study, we present measurements of dissolved trace metals, carbon, nutrients, Ra isotopes, alkalinity, and water isotopes collected from the Mackenzie River Delta and the freshwater-saltwater transition zone in the East Channel. This work provides the first measurements of Ra isotopes in North American Arctic rivers, and some of the first trace metal data for the Mackenzie Estuary. Solute concentrations in groundwater and Ra activities on suspended sediments are used to help identify possible controls on the river water chemistry. We use these results to investigate the impact of the delta and estuary on the river chemistry and the ultimate delivery of these species to the coastal Arctic Ocean.

\subsection{METHODS}

\subsubsection{Sample collection}

River water and suspended sediments samples were collected from the Mackenzie River Delta in the Northwest Territories of Canada between June 20 - 26, 2016 (Figure 1, Table 1). The river discharge at the time of sampling was $\sim 17,000 \mathrm{~m}^{3} \mathrm{~s}^{-1}$, about $20 \%$ below the June average, and the freshet in 2016 occurred earlier than normal ( May 18, compared to June 1; Figure 2) (Water Survey of Canada, 2018). Freshwater samples were collected from Tsiigehtchic, which is located $\sim 20 \mathrm{~km}$ upriver of the delta where the Arctic Red River joins the main stem of the Mackenzie. To obtain a sample integrating the combined signal of these two rivers, we collected water from a ferry as it crossed the Mackenzie just downriver of the Arctic Red River junction (Figure 1). The ferry fire hose was used to fill (5) 20L plastic containers that were subsequently subsampled on shore (MRD04). Because the water collected through the ferry fire hose may have become contaminated with trace metals, an additional sample (MRD05) was taken from the northern bank of the river using a PVC pole to collect water away from the riverbank; this station was located opposite the Red River inflow, and likely does not reflect the input of this river. Trace metal concentrations are not reported for MRD04. Additional freshwater (salinity < 1) samples were collected from a wharf in Inuvik, located in the middle of the delta on the East Channel (MRD06), and from a beach in Tuktoyaktuk, at the mouth of the East Channel (MRD11). Logistical constraints prevented sampling in the Middle and West Channels.

Estuary samples were collected from a small boat that crossed the salinity gradient in the mouth of the East Channel (MRD07-MRD10, MRD12-19). These stations were chosen to follow the path of the ARDEX sampling in 2004 (Emmerton et al., 2008b), with the spacing adjusted to the observed salinity gradient. These samples were collected from $0.5 \mathrm{~m}$ using a battery operated FloJet water pump. Two samples at the end of the transect (MRD16 and MRD17) were collected from $5 \mathrm{~m}$ and $9 \mathrm{~m}$, respectively, using a trace-metal clean 2L Niskin bottle with external springs and a Teflon coated interior. To collect enough water for Ra analysis at these stations, the Niskin bottle was repeatedly tripped at the desired depth and the water was combined into a 20L sample; 
these integrated Ra samples likely have a slightly different salinity than the other MRD16 and MRD17 subsamples.

Water samples were analyzed for salinity, temperature, alkalinity, water isotopes $\left(\delta^{18} \mathrm{O}\right.$, $\left.\delta^{2} \mathrm{H}\right)$, nitrate $\left(\mathrm{NO}_{3}{ }^{-}\right)$and nitrite $\left(\mathrm{NO}_{2}{ }^{-}\right)$, ammonium $\left(\mathrm{NH}_{4}{ }^{+}\right)$, phosphate $\left(\mathrm{PO}_{4}{ }^{3-}\right)$, silicate $\left(\mathrm{SiO}_{4}{ }^{-}\right)$, total nitrogen (TN), dissolved organic carbon (DOC), dissolved inorganic carbon (DIC), Ra isotopes $\left({ }^{223} \mathrm{Ra},{ }^{224} \mathrm{Ra},{ }^{228} \mathrm{Ra},{ }^{226} \mathrm{Ra}\right)$, manganese $(\mathrm{Mn})$, barium $(\mathrm{Ba})$, copper $(\mathrm{Cu})$, cobalt $(\mathrm{Co})$, nickel $(\mathrm{Ni})$, lead $(\mathrm{Pb})$, and uranium $(\mathrm{U})$. Trace element, water isotope, nutrient, and DOC samples were filtered through a $0.2 \mu \mathrm{m}$ capsule filter (Pall Acropak). Trace metal samples were stored in acid-cleaned $125 \mathrm{~mL}$ polyethylene bottles and acidified with $400 \mu \mathrm{L}$ of $3 \mathrm{M} \mathrm{HCl}$. Alkalinity and DIC samples were filtered through a $0.45 \mu \mathrm{m}$ capsule filter (Pall Aquaprep) and stored in $250 \mathrm{~mL}$ borosilicate glass bottles. Samples were preserved with $100 \mu \mathrm{L}$ of mercuric chloride after collection, and sealed with glass stoppers coated with APIEZON-L grease and held in place with rubber bands. Nutrient samples were stored in $20 \mathrm{~mL}$ acid-cleaned polyethylene vials and frozen until analysis. DOC samples were stored in pre-combusted amber borosilicate glass vials and frozen until analysis. Water isotope samples were stored in $2 \mathrm{~mL}$ borosilicate glass vials with no headspace and kept refrigerated until analysis.

Radium samples were collected by filtering water through an acrylic fiber or a cellulose cartridge coated in manganese oxide $\left(\mathrm{MnO}_{2}\right)$, which scavenges radium. Suspended sediments were removed by first filtering the water through a plug of raw acrylic fiber (fiber samples) or through $10 \mu \mathrm{m}$ and $1 \mu \mathrm{m}$ Hytrex polypropylene cartridges (cartridge samples). Fibers were used for small volume samples $(<100 \mathrm{~L})$, and water was either gravity filtered or pumped through the fiber at a flow rate of $<1 \mathrm{~L} \mathrm{~min}^{-1}$; this method quantitatively scavenges Ra from the water (Reid et al., 1979). For large volume samples, water was pumped through the $\mathrm{MnO}_{2}$-coated cartridges at flow rates of $4.5-5.8 \mathrm{~L} \mathrm{~min}^{-1}$; at these flow rates Ra extraction may not be $100 \%$ efficient, so smaller volume samples were also filtered through $\mathrm{MnO}_{2}$-coated fibers, and the Ra activities measured on the fibers were compared to those measured on the cartridges to determine the cartridge collection efficiencies, which ranged from $56-100 \%$, with an average of $75 \pm 13 \%$ $(1 \sigma)$.

In addition to the sampling in June 2016, a series of ${ }^{226} \mathrm{Ra}$ and ${ }^{228} \mathrm{Ra}$ samples were collected from the Mackenzie River at Tsiigehtchic and the Yukon River at Pilot Station with the assistance of the A-GRO. A $20 \mathrm{~L}$ sample of river water was collected every $2-3$ months between April 2015 and April 2016. After allowing the sample to sit for 24 hours, $1 \mathrm{~L}$ of water containing the majority of settled sediment was drained from the sample. The remaining water was filtered through a plug of raw acrylic fiber to remove any remaining sediments, and then through a $\mathrm{MnO}_{2}$-coated fiber to collect the $\mathrm{Ra}$ isotopes.

Groundwater samples were collected on the northern bank of the Mackenzie at Tsiigehtchic using piezometers inserted to $1 \mathrm{~m}$ below the sediment surface (MRD01-MRD03). Peristaltic pumps were used to draw the groundwater through the piezometers. We also attempted to sample groundwater in Tsiigehtchic, but were unable to extract water from the soils. Groundwaters were subsampled following the same procedure described above for river water samples. Only a small volume of water was collected from the second groundwater sample (MRD02) for Ra isotope analysis $(2.4 \mathrm{~L})$, which only permitted analysis of the longer-lived isotopes $\left({ }^{228} \mathrm{Ra},{ }^{226} \mathrm{Ra}\right)$. MRD03 was collected in the same location as MRD01, and due to low water yields this sample was only analyzed for salinity, water isotopes, nutrients, and trace metals. 
Suspended sediment samples were collected at stations MRD04, MRD05, MRD08, and MRD19 by filtering $1.5-4 \mathrm{~L}$ of river water through $90 \mathrm{~mm}$ diameter $0.22 \mu \mathrm{m}$ PES membrane filters (Millipore) (Table 1c). Filters were transported back to the lab in Woods Hole in polystyrene petri dishes. These samples were used to determine the suspended sediment concentrations in the river and the $\mathrm{Ra}$ isotope ratio on suspended sediments.

\subsubsection{Sample analysis}

\subsubsection{Water chemistry}

Temperature, $\mathrm{pH}$, and dissolved oxygen were measured using a YSI 600XLM sonde. Sensors were cleaned and calibrated each morning before sampling. The $\mathrm{pH}$ sensor was calibrated with 4.00, 7.00, and $10.00 \mathrm{pH}$ solutions from Fisher Scientific. Salinity was measured in the field using the YSI sonde to assist with the selection of station locations, and samples were also collected at each station in rinsed plastic bottles for analysis by salinometer at the Woods Hole Oceanographic Institution. Good agreement was observed between the two salinity measurements: the average offset was $0.01 \pm 0.23(1 \sigma)$. The salinity values measured on the salinometer are reported in all figures and tables except for Figure 3a, which shows the values measured with the YSI.

Suspended sediment concentrations were determined by dividing the weight of the collected sediments (difference between the sediment-laden filter weight and filter tare weight) by the volume of water filtered. Filters were dried at $50^{\circ} \mathrm{C}$ overnight before weighing.

\subsubsection{Radium isotopes}

Short-lived Ra activities were measured using the Radium Delayed Coincidence Counter (RaDeCC) system, which detects the alpha decays of the ${ }^{223} \mathrm{Ra}$ and ${ }^{224} \mathrm{Ra}$ daughter isotopes, ${ }^{219} \mathrm{Rn}$ and ${ }^{220} \mathrm{Rn}$, respectively (Moore and Arnold, 1996). Samples were analyzed as soon as possible after collection to minimize decay of ${ }^{223} \mathrm{Ra}$ and ${ }^{224} \mathrm{Ra}$ between collection and analysis. Samples collected in the East Channel were analyzed 3.5 - 5.5 days after collection. Radium-224 activities are not reported for the samples collected in Tsiigehtchic and Inuvik due to a long delay between collection and analysis ( 20 days $)$ that allowed a significant fraction of the ${ }^{224} \mathrm{Ra}$ to decay. Samples were re-analyzed 4 weeks and 2 months after analysis to determine the activities of ${ }^{224} \mathrm{Ra}$ and ${ }^{223} \mathrm{Ra}$ supported by ${ }^{228} \mathrm{Th}\left(\mathrm{t}_{1 / 2}=1.91 \mathrm{y}\right)$ and ${ }^{227} \mathrm{Ac}\left(\mathrm{t}_{1 / 2}=21.8 \mathrm{y}\right)$, respectively. The efficiency of the RaDeCC system was determined using a set of cartridge and fiber standards (Henderson et al., 2013).

After RaDeCC analysis, the samples were ashed in a muffle furnace at $820^{\circ} \mathrm{C}$ ( $48 \mathrm{~h}$ for cartridges, $24 \mathrm{~h}$ for fibers) and the ash was transferred to polystyrene vials and sealed with epoxy to prevent ${ }^{222} \mathrm{Rn}$ loss. Samples were then analyzed for ${ }^{228} \mathrm{Ra}$ and ${ }^{226} \mathrm{Ra}$ on high purity, well-type germanium detectors. The activity of ${ }^{228} \mathrm{Ra}$ was determined using the lines of ${ }^{228} \mathrm{Ac}$ (338 and 911 $\mathrm{keV})$, and ${ }^{226} \mathrm{Ra}$ was measured using the ${ }^{214} \mathrm{~Pb}$ line $(352 \mathrm{keV})$. Detector efficiencies were determined by measuring ashed fiber and cartridge standards, which were prepared using a standard solution containing ${ }^{226} \mathrm{Ra}$ and ${ }^{232} \mathrm{Th}$ with daughters in equilibrium. Radium activities are reported in units of decays per minute (dpm) per volume. Samples MRD12, MRD13, MRD18, and MRD19 were measured three times on three different detectors, and the error reported for 
these samples is the standard deviation of those measurements; for all other samples and for all

${ }^{223} \mathrm{Ra}$ and ${ }^{224} \mathrm{Ra}$ activities the errors represent analytical uncertainties $(1 \sigma)$.

The short-lived ${ }^{223} \mathrm{Ra}$ and ${ }^{224} \mathrm{Ra}$ were corrected for activities supported by their parent isotopes, ${ }^{227} \mathrm{Ac}$ and ${ }^{228} \mathrm{Th}$, respectively, and are reported as ${ }^{223} \mathrm{Ra}_{\mathrm{xs}}$ and ${ }^{224} \mathrm{Ra}_{\mathrm{xs}}$. The activities of ${ }^{227} \mathrm{Ac}$ and ${ }^{228} \mathrm{Th}$ in all samples were less than $0.5 \mathrm{dpm} 100 \mathrm{~L}^{-1}$ and $4 \mathrm{dpm} 100 \mathrm{~L}^{-1}$, respectively, thus this correction did not have a large effect on the ${ }^{223} \mathrm{Ra}$ and ${ }^{224} \mathrm{Ra}$ activities.

The ${ }^{228} \mathrm{Ra}$ and ${ }^{226} \mathrm{Ra}$ activities of suspended sediments were measured on the sediments collected on the PES membrane filters and on the Hytrex cartridges used as pre-filters for the high-volume samples. Only samples collected in freshwater (salinity $\sim 0.14$ ) were used for this measurement, in order to determine the ${ }^{228} \mathrm{Ra}$ and ${ }^{226} \mathrm{Ra}$ activities that are present on the particles before any desorption occurs as a result of ion exchange in the estuary. The PES membrane filters were dried overnight in a $50^{\circ} \mathrm{C}$ oven, and the dried sediments were scraped into a polystyrene vial and sealed with epoxy. To isolate the suspended sediments on the Hytrex cartridges, the cartridges were burned in a muffle furnace at $550^{\circ} \mathrm{C}$; this procedure removes organic coatings on the sediment grains, but the similarity between the Ra activities measured on these sediments and those collected on the PES filters (which were not burned) suggests that this procedure did not significantly affect the Ra measurements. After burning, the sediments were homogenized, transferred to polystyrene vials, and sealed with epoxy. Samples were then analyzed on gamma detectors as described above.

\subsubsection{Nutrients}

Nutrients were analyzed at the Woods Hole Oceanographic Institution Nutrient Analytical Facility using a four-channel segmented flow Seal AA3 HR Autoanalyzer. Calibrations were performed using chemicals purchased from Fisher Scientific. Certified Reference Materials from Kanso Co., LTD were used to verify the calibrations before processing samples. During the analysis, nitrite is converted to nitrate, thus the resulting concentrations are a sum of these two species and are reported as $\mathrm{NO}_{\mathrm{x}}$. The detection limits for $\mathrm{NH}_{4}{ }^{+}, \mathrm{NO}_{\mathrm{x}}, \mathrm{SiO}_{4}{ }^{-}$, and $\mathrm{PO}_{4}{ }^{3-}$ are $0.015 \mu \mathrm{M}, 0.040 \mu \mathrm{M}, 0.030 \mu \mathrm{M}$, and $0.009 \mu \mathrm{M}$, respectively.

\subsubsection{Dissolved organic matter}

Dissolved organic carbon (DOC) and total nitrogen (TN) were determined using a Shimadzu high-temperature TOC/TN instrument at the Woods Hole Research Center. Dissolved organic nitrogen (DON) concentrations were calculated by subtracting the sum of the $\mathrm{NO}_{\mathrm{x}}$ and $\mathrm{NH}_{4}{ }^{+}$concentrations from TN concentrations. The vials containing samples MRD01, MRD03, and MRD05 were broken during transport, thus no values are reported for these three samples.

\subsubsection{Dissolved inorganic carbon and alkalinity}

Alkalinity was measured using an automated titrator (AS-ALK2, Apollo SciTech Inc., Delaware, USA) and DIC was analyzed using a DIC auto-analyzer (AS-C3, Apollo SciTech, Inc., Delaware, USA) following the procedures described in Wang et al. (2016). Both systems were calibrated using the $\mathrm{CO}_{2}$ in seawater Certified Reference Material from Andrew Dickson at the Scripps Institution of Oceanography. 


\subsubsection{Trace metals}

Trace metals were measured at the Woods Hole Oceanographic Institution Plasma Mass Spectrometry Facility using an iCAP Qc inductively coupled plasma mass spectrometer (ICPMS). Freshwater samples were not diluted, samples with salinities between 1 and 10 were diluted by a factor of 5 , samples with salinities over 10 were diluted by a factor of 10 . All samples were diluted to a final concentration of $2 \%$ nitric acid. Indium was added to each sample as an internal yield tracer. Nitric acid blanks were analyzed after every set of 10 samples.

A river water certified reference material (SLRS-6) produced by the National Research Council of Canada (NRC) was analyzed at the beginning, middle, and end of the run, and the offset between the average concentrations measured on these runs $(\mathrm{n}=3)$ and the certified concentrations was $-7 \%$ for $\mathrm{Ba},+7 \%$ for $\mathrm{Cu},+16 \%$ for $\mathrm{Mn},+8 \%$ for $\mathrm{Ni},-2 \%$ for $\mathrm{Pb}$, and $-14 \%$ for $\mathrm{U}$ (Table 2). The precision (standard deviation/mean) of replicate analyses of the reference material $(\mathrm{n}=3$ ) was $3 \%$ for $\mathrm{Ba}, 7 \%$ for $\mathrm{Cu}, 16 \%$ for $\mathrm{Mn}, 10 \%$ for $\mathrm{Ni}, 7 \%$ for $\mathrm{Pb}$, and $10 \%$ for $\mathrm{U}$.

A trace element standard provided by Tristan Horner (WHOI) was used to create the standard curve. The dilutions used to create the standard curve were run at the mid-point of sample analysis to minimize bias from instrument drift over the course of the run. A 100x dilution of this standard was also run at the beginning, middle, and end of the run to ensure that instrument drift did not significantly change the measured concentrations; no consistent trends were observed in the metal concentrations measured during the run.

\subsubsection{Water isotopes}

The $\delta^{18} \mathrm{O}$ and $\delta^{2} \mathrm{H}$ content of water samples was determined at the UC Davis Stable Isotope Facility using a Laser Water Isotope Analyzer V2 (Los Gatos Research, Inc., Mountain View, CA, USA). Ratios are reported in per mil (\%o) relative to Vienna Standard Mean Ocean Water (VSMOW). The standard deviation for $\delta^{18} \mathrm{O}$ and $\delta^{2} \mathrm{H}$ values is 0.12 and 0.62 , respectively.

\subsection{RESULTS}

\subsubsection{Water chemistry}

Samples collected from Tsiigehtchic, Inuvik, Tuktoyaktuk, and the first half of the East Channel transect all had salinities less than 1 (MRD01 - MRD11; Table 1). Samples MRD09 and MRD10 were collected over the "2-m ramp" (Reimnitz, 2002); after this shoal the bathymetry deepened and salinity increased (Figure 3). At the farthest station, the salinity was 15.49 at the surface (MRD15) and 26.94 at $9 \mathrm{~m}$ (MRD17). The groundwater samples collected in Tsiigehtchic (MRD01 - MRD03) were slightly more acidic than the rest of the samples ( $\mathrm{pH}=$ $7.12-8.05)$ and were undersaturated in oxygen (9-37\%). MRD01 and MRD03 had low temperatures $\left(\sim 8^{\circ} \mathrm{C}\right)$, but the temperature of MRD02 was similar to other freshwater samples $\left(\sim 16^{\circ} \mathrm{C}\right)$. All of the samples collected on the transect were well-oxygenated (dissolved oxygen > $100 \%$ ) and had a $\mathrm{pH}$ of approximately 8.3 . Freshwater samples had $\delta^{18} \mathrm{O}$ values between $18.82 \%$ and $20.25 \%$ o, and $\delta^{2} \mathrm{H}$ values between $-151.11 \%$ and $-161.64 \%$ (Figure 4, Table 1). As

salinity increased in the estuary, ratios became heavier, and the most saline sample had $\delta^{18} \mathrm{O}$ and $\delta^{2} \mathrm{H}$ values of $-5.38 \%$ and $-44.33 \%$, respectively. Groundwater samples had water isotope values similar to the freshwater samples collected in Tsiigehtchic. 
The highest suspended sediment concentration, $200 \mathrm{mg} \mathrm{L}^{-1}$, was measured at MRD04, which includes sediment inputs from the Arctic Red River (Table 1c). The other sample collected in Tsiigehtchic (MRD05) had a slightly lower sediment loading of $170 \mathrm{mg} \mathrm{L}^{-1}$. This was similar to the value measured in the freshwater reaches of the East Channel transect (160 mg $\mathrm{L}^{-1}$; MRD08). There was a significant decrease in suspended sediment loading in the estuarine mixing zone, to $40 \mathrm{mg} \mathrm{L}^{-1}$ (MRD19).

\subsubsection{Radium isotopes}

The time series of ${ }^{228} \mathrm{Ra}$ and ${ }^{226} \mathrm{Ra}$ at Tsiigehtchic shows that $\mathrm{Ra}$ activities are highest in the summer after the freshet, and have a relative maximum during the period of low flow in the winter (January), though the ${ }^{228}$ Ra activity observed in January is within error of those observed in November and April (Figure 5a). The two isotopes had similar activities, and varied between $\sim 10-20 \mathrm{dpm} 100 \mathrm{~L}^{-1}$ (Table $3 \mathrm{a}$ ). The ${ }^{228} \mathrm{Ra} /{ }^{226} \mathrm{Ra}$ activity ratio varied around 1 , with minimum values in the early winter (November) and maximum values in the spring and summer of 2015 (Figure 5b). The 2016 spring and summer ratios were lower than those observed in 2015, but within error of the earlier measurements. The Yukon time series also shows high ${ }^{228} \mathrm{Ra}$ and ${ }^{226} \mathrm{Ra}$ activities ( $\left.20 \mathrm{dpm} \mathrm{100L}^{-1}\right)$ after the freshet in 2015 (Figure S1a; Table 4b). Activities were low in January $\left(\sim 5-10 \mathrm{dpm} 100 \mathrm{~L}^{-1}\right)$ but increased later in the winter and early spring before the 2016 freshet. The ${ }^{228} \mathrm{Ra} /{ }^{226} \mathrm{Ra}$ activity ratio in the Yukon was higher than that in the Mackenzie, and varied between 1.3 and 1.4 for most of the year, with a maximum ratio of $2.1 \pm 0.4$ observed in March (Figure S1b).

During the delta sampling in 2016, the ${ }^{228} \mathrm{Ra}$ and ${ }^{226} \mathrm{Ra}$ activities were $\sim 15-20 \mathrm{dpm}$ $100 \mathrm{~L}^{-1}$ in freshwater samples collected in Tsiigehtchic, Inuvik, and Tuktoyaktuk (Table 4). The ${ }^{228} \mathrm{Ra} /{ }^{226} \mathrm{Ra}$ activity ratio in most of the freshwater river samples (MRD04 - MRD10, salinity $\sim 0.14$ ) was between $0.8-1.1$. The ratio in the sample collected from the beach in Tuktoyaktuk (MRD11, salinity $=0.56$ ) was slightly higher, at $1.3 \pm 0.1$. The ${ }^{223} \mathrm{Ra}_{\mathrm{xs}}$ activities in freshwater (MRD04 - MRD11) varied between $1.2-4.5 \mathrm{dpm} 100 \mathrm{~L}^{-1}$, and the ${ }^{224} \mathrm{Ra}_{\mathrm{xs}}$ activity measured in Tuktoyaktuk (MRD11) was $20 \pm 2 \mathrm{dpm} \mathrm{100L}^{-1}$ (not measured in other freshwater samples, see 5.2.2.2). The ${ }^{224} \mathrm{Ra} /{ }^{228} \mathrm{Ra}$ activity ratio in this sample was $1.03 \pm 0.03$.

The variability of the Ra activities and other solute concentrations through the delta is represented in Figure 6, which shows the ratio of the downstream activities (East Channel freshwater, average of MRD07 - MRD10) to the upstream activities (Tsiigehtchic, average of MRD04 and MRD05) minus 1, such that a positive value indicates a downstream increase, and a negative value indicates a loss in the delta. The activities of ${ }^{228} \mathrm{Ra}$ and ${ }^{226} \mathrm{Ra}$ exhibited slight increases downstream, as did the ${ }^{228} \mathrm{Ra} /{ }^{226} \mathrm{Ra}$ activity ratio, while the ${ }^{223} \mathrm{Ra}_{\mathrm{xs}}$ activities decreased by a small amount.

Radium activities increased in the mid-salinity zone of the estuary (Figure 7, Table 4b), consistent with previous studies in lower latitude estuaries (Elsinger and Moore, 1980; Key et al., 1985; Li et al., 1977; Moore et al., 1995; Moore and Todd, 1993). Excess ${ }^{224} \mathrm{Ra}$ activities were also high in the saline samples collected at depth (MRD16, MRD17). The ${ }^{228} \mathrm{Ra} /{ }^{226} \mathrm{Ra}$ activity ratio was relatively constant around $1.1-1.2$ for most of the transect. The ${ }^{224} \mathrm{Ra} /{ }^{228} \mathrm{Ra}$ activity ratio increased from 1 to 1.5 between salinities 0.15 and 3.89. The ratio then decreased to a minimum of 0.6 at salinity 15.49 before increasing again in the saline samples collected at depth.

The two groundwater samples (MRD01, MRD02) had significantly different ${ }^{226} \mathrm{Ra}$ and

${ }^{228} \mathrm{Ra}$ isotope activities (Table $4 \mathrm{a}$ ). The ${ }^{226} \mathrm{Ra}$ activities were $25.3 \pm 0.8 \mathrm{dpm} 100 \mathrm{~L}^{-1}$ and $44 \pm 5$ 
dpm $100 \mathrm{~L}^{-1}$, while the ${ }^{228}$ Ra activities were $27 \pm 3 \mathrm{dpm} 100 \mathrm{~L}^{-1}$ and $68 \pm 13 \mathrm{dpm} 100 \mathrm{~L}^{-1}$. Excess ${ }^{223} \mathrm{Ra}$ was only measured in MRD01 due to the low volume filtered for MRD02, and was $4.1 \pm$ $0.7 \mathrm{dpm} 100 \mathrm{~L}^{-1}$. Radium variability in groundwater is common (Charette et al., 2008) and these activities are well within the range of those observed in other coastal regions (e.g. Charette et al., 2001; Dulaiova et al., 2006; Krest et al., 2000; Rama and Moore, 1996). Because both isotopes were higher in MRD02, the ${ }^{228} \mathrm{Ra} /{ }^{226} \mathrm{Ra}$ activity ratio was not as variable as the absolute activities; the two samples had ratios of $1.1 \pm 0.1$ and $1.5 \pm 0.2$. The average of these two measurements $(1.3 \pm 0.3)$ is taken to represent the typical groundwater activity ratio.

The average ${ }^{228} \mathrm{Ra}$ and ${ }^{226} \mathrm{Ra}$ activities measured on suspended sediments were $3.1 \pm 0.1$ $( \pm 1 \sigma, \mathrm{n}=4)$ and $3.4 \pm 0.1 \mathrm{dpm} \mathrm{g}^{-1}$, respectively (Table $\left.4 \mathrm{c}\right)$. These activities of ${ }^{228} \mathrm{Ra}$ are similar to those observed on suspended sediments in the freshwater reaches of the Amazon ( 2.2 - 3.4 $\mathrm{dpm} \mathrm{g}^{-1}$; Moore et al., 1995), and slightly higher than activities measured on suspended sediments in the Atchafalaya and Mississippi Rivers (1.93 - $2.09 \mathrm{dpm} \mathrm{g}^{-1}$; Krest et al., 1999). The ${ }^{226} \mathrm{Ra}$ activities on Mackenzie sediment are higher than those observed in the Amazon River (1.8 - $2.6 \mathrm{dpm} \mathrm{g}^{-1}$; Moore et al., 1995) and in the Mississippi and Atchafalaya Rivers (2.11 $2.50 \mathrm{dpm} \mathrm{g}^{-1}$; Krest et al., 1999). The suspended sediment ${ }^{228} \mathrm{Ra}$ and ${ }^{226} \mathrm{Ra}$ activities were also higher than those measured on most of the active layer and permafrost sediments collected from the delta $\left(1.1-3.1 \mathrm{dpm}{ }^{228} \mathrm{Ra} \mathrm{g}^{-1} ; 1.5-2.7 \mathrm{dpm}{ }^{226} \mathrm{Ra} \mathrm{g}^{-1}\right)$, although the average ${ }^{228} \mathrm{Ra}$ activity matched that of permafrost sediments collected in Tuktoyaktuk $\left(3.1 \pm 0.1 \mathrm{dpm} \mathrm{g}^{-1}\right)$ (Appendix Table 2). The average ${ }^{228} \mathrm{Ra} /{ }^{226} \mathrm{Ra}$ of the riverine sediment was $0.91 \pm 0.05$. Similar activity ratios have been observed in suspended sediments collected from the Amazon, Mississippi, and Atchafalaya Rivers (0.84 - 1.3; Key et al., 1985; Krest et al., 1999; Moore et al., 1995).

\subsubsection{Nutrients}

The average $\mathrm{NO}_{\mathrm{x}}$ and $\mathrm{NH}_{4}{ }^{+}$concentrations in the freshwater endmember at Tsiigehtchic (MRD04, MRD05) were similar: $1.68 \pm 0.78 \mu \mathrm{M}$ and $1.98 \pm 1.10 \mu \mathrm{M}$, respectively (Table 5a). The average concentrations of $\mathrm{PO}_{4}{ }^{3-}$ and $\mathrm{SiO}_{4}{ }^{-}$were $0.22 \pm 0.03 \mu \mathrm{M}$ and $63.2 \pm 5.2 \mu \mathrm{M}$, respectively. These freshwater nutrient concentrations are similar to values recorded in June by the A-GRO and Environment and Climate Change Canada (ECCC) water quality monitoring programs (Environment and Climate Change Canada, 2018; Holmes et al., 2018; Peterson et al., 2016). The A-GRO and ECCC programs provide records of Mackenzie River water chemistry beginning in 2003 and 2000, respectively, though some solutes are more frequently sampled than others. The sampling location for both of these studies was Tsiigehtchic, and dissolved solutes are defined as passing through a $0.45 \mu \mathrm{M}$ filter. Our average $\mathrm{NH}_{4}{ }^{+}$and $\mathrm{NO}_{\mathrm{x}}$ concentrations are higher and lower, respectively, than the June averages from these two monitoring programs (Figure 8a-d). The concentrations of $\mathrm{PO}_{4}{ }^{3-}$ and $\mathrm{SiO}_{4}{ }^{-}$observed during this study are similar to the A-GRO and ECCC June averages.

The inorganic nutrients showed small changes across the delta, based on the measurements collected at Tsiigehtchic, Inuvik, and the freshwater samples at the mouth of the East Channel near Tuktoyaktuk (Figure 6). $\mathrm{NO}_{\mathrm{x}}$ concentrations increased from $1.68 \mu \mathrm{M}$ to 2.40 $\mu \mathrm{M}$, while $\mathrm{NH}_{4}{ }^{+}$concentrations decreased from $1.98 \mu \mathrm{M}$ to $1.21 \mu \mathrm{M}$. Phosphate concentrations were constant at $\sim 0.22 \mu \mathrm{M}$, and $\mathrm{SiO}_{4}{ }^{-}$increased slightly from $63.2 \mu \mathrm{M}$ to $67.4 \mu \mathrm{M}$.

The concentrations of $\mathrm{NO}_{\mathrm{x}}, \mathrm{PO}_{4}{ }^{3-}$, and $\mathrm{SiO}_{4}{ }^{-}$initially dropped in the estuarine mixing zone, increased around salinity $4-6$, and then remained at relatively constant low values between salinity $8-16$ (Table $5 b$, Figure $9 \mathrm{a}-\mathrm{d}$ ). $\mathrm{NO}_{\mathrm{x}}$ and $\mathrm{PO}_{4}{ }^{3-}$ increased at higher salinities, 
while $\mathrm{SiO}_{4}{ }^{-}$concentrations remained low. Ammonium concentrations were low but variable, and the lowest concentration $(0.64 \mu \mathrm{M})$ was observed at salinity 6.10 , coincident with increases in $\mathrm{NO}_{\mathrm{x}}$ and $\mathrm{PO}_{4}{ }^{3-}$.

The estuarine nutrient concentrations can be compared to previous measurements in the East Channel made by Emmerton et al. (2008b), though our study took place during a period of higher discharge (this study: June, $\sim 17,000 \mathrm{~m}^{3} \mathrm{~s}^{-1}$; Emmerton et al.: July, $\sim 12,000 \mathrm{~m}^{3} \mathrm{~s}^{-1}$ ), and the filter size used in Emmerton et al. (2008b) $(1.2 \mu \mathrm{m})$ was larger than the one used in this study $(0.22 \mu \mathrm{m})$ (Figure 9). The estuarine concentrations of $\mathrm{NO}_{\mathrm{x}}$ and $\mathrm{SiO}_{4}{ }^{-}$were lower in 2016, while $\mathrm{PO}_{4}{ }^{3-}$ and $\mathrm{NH}_{4}{ }^{+}$concentrations were higher (most $\mathrm{NH}_{4}{ }^{+}$concentrations measured in the 2004 study were below their detection limit of $0.5 \mu \mathrm{M}$ ). The marine endmember concentrations of $\mathrm{NO}_{\mathrm{x}}, \mathrm{PO}_{4}{ }^{3-}$, and $\mathrm{SiO}_{4}{ }^{-}$were similar in both years. The $\mathrm{NO}_{\mathrm{x}}$ concentrations measured around salinity 6 were similar in both years $\left(3.0 \mu \mathrm{M}\right.$ in $2004,3.2 \mu \mathrm{M}$ in 2016), and $\mathrm{PO}_{4}{ }^{3-}$ concentrations had local maxima at this salinity during both transects. If total DIN is considered, the 2004 and 2016 concentrations are similar between salinities $0-10$ (with the exception of a low 2016 value at salinity 3.89), but the 2004 DIN concentrations fall below detection limits at higher salinities while the 2016 concentrations remain above $\sim 0.8 \mu \mathrm{M}$ (Figure S2).

Nutrient concentrations in groundwater were generally higher than those measured in the river (Table 5a). $\mathrm{NO}_{\mathrm{x}}$ concentrations were below detection in MRD02, but the concentrations observed in the other two groundwater samples were the highest observed during this study (3.4 $\mu \mathrm{M}$ and 3.3 $\mu \mathrm{M}$ in MRD01 and MRD03, respectively). Ammonium was also high in MRD01 and MRD03 (3.86 $\mu \mathrm{M}$ and 2.55 $\mu \mathrm{M}$, respectively), and was low but measurable in MRD02 (0.95 $\mu \mathrm{M})$. Phosphate and $\mathrm{SiO}_{4}{ }^{-}$concentrations were highest in MRD02 compared to the other groundwater samples.

\subsubsection{Dissolved organic matter}

The freshwater DOC concentration measured at Tsiigehtchic (MRD04) was $422 \mu \mathrm{M}$, similar to the June average recorded by the A-GRO $(472 \pm 99 \mu \mathrm{M})$, but lower than the ECCC June average $(679 \pm 221 \mu \mathrm{M})$ (Figure 8e). If all freshwater samples are considered (MRD04-10) the average freshwater DOC concentration is $685 \pm 219 \mu \mathrm{M}$. The DON concentration measured at Tsiigehtchic was $8.60 \mu \mathrm{M}$, slightly lower than the June average measured by the A-GRO (14 \pm $5 \mu \mathrm{M})$ and ECCC $(12 \pm 10 \mu \mathrm{M})$ (Figure 8f). The freshwater average DON in this study was 26.0 $\pm 14 \mu \mathrm{M}$.

Changes in DOM concentrations across the delta were more drastic than the changes in inorganic nutrient concentrations (Figure 6). While only slight increases were observed between Tsiigehtchic and Inuvik, DOC and DON concentrations approximately doubled and more than tripled, respectively, between Inuvik and Tuktoyaktuk (Table 5). The DOC and DON concentrations we observed in Tsiigehtchic and Inuvik are similar to those documented by Emmerton et al. (2008a) during a June 2004 survey of the delta. Those authors also observed higher concentrations towards the mouth of the river, but their maximum DOM concentrations were lower than the concentrations we measured in Tuktoyaktuk.

The concentrations of DOC and DON decreased rapidly in the initial stages of estuarine mixing: DON decreased by $\sim 1 / 3$ (from $\sim 30 \mu \mathrm{M}$ to $\sim 10 \mu \mathrm{M}$ ) and DOC decreased by $\sim 1 / 2$ (from $\sim 800 \mu \mathrm{M}$ to $\sim 400 \mu \mathrm{M}$ ) between salinities 0 and 3 (Figure 9e-f). After this initial loss, both DOC and DON displayed apparent conservative mixing. Emmerton et al. (2008b) found lower DOM 
concentrations in the freshwater reaches of the East Channel compared to those measured during this study, and did not observe similar losses at the first intrusion of salinity. Above a salinity of $\sim 3$, the DOC-salinity relationship observed in the July 2004 study was similar to our June 2016 transect, with conservative mixing towards a low-DOC marine endmember. However, DON increased towards a higher DON marine endmember in the 2004 study, in contrast with the decrease observed in 2016.

Dissolved organic matter concentrations are only available for one groundwater sample (MRD02). The concentrations of DOC and DON in this sample were $656 \mu \mathrm{M}$ and $24.7 \mu \mathrm{M}$, respectively. These values are higher than those in the river water measured in Tsiigehtchic, but lower than the concentrations at the freshwater end of the salinity transect (Table 5).

\subsubsection{Dissolved inorganic carbon and alkalinity}

River water concentrations of DIC and alkalinity in Tsiigehtchic were $\sim 1687 \mu \mathrm{mol} \mathrm{kg}{ }^{-1}$ and $\sim 1625 \mu \mathrm{mol} \mathrm{kg}{ }^{-1}$, respectively. Concentrations of both parameters remained relatively constant through the delta (Figure 6). The average freshwater concentration of DIC was $1703 \pm$ $30 \mu \mathrm{mol} \mathrm{kg}{ }^{-1}$, and the average alkalinity was $1632 \pm 20 \mu \mathrm{mol} \mathrm{kg}{ }^{-1}$. This DIC concentration agrees well with the flow-weighted average for the Mackenzie of $1716 \mu \mathrm{mol} \mathrm{kg}^{-1}$ (Tank et al., $2012 \mathrm{~b}$ ), while our alkalinity is higher than the flow-weighted average, $1540 \mu \mathrm{mol} \mathrm{kg}^{-1}$ (Cooper et al., 2008). In the estuary, DIC and alkalinity both increased from the fresh to marine endmembers, with apparent non-conservative removal beginning around salinity 8 (Figure 10). The highest levels of DIC and alkalinity were observed in groundwater, which had concentrations of $4760 \pm 2 \mu \mathrm{mol} \mathrm{kg}{ }^{-1}$ and $4353 \pm 32 \mu \mathrm{mol} \mathrm{kg}^{-1}$, respectively (Table 5a).

\subsubsection{Trace metals}

The trace metal concentrations measured in the river at Tsiigehtchic (MRD05) are similar to previous measurements made in the month of June by the A-GRO and ECCC water quality monitoring programs (Figure 11). The Co average from this study is approximately double the A-GRO average, but similar to the ECCC average. The $\mathrm{Cu}$ and $\mathrm{Pb}$ concentrations measured in this study were lower than the average values for the A-GRO and ECCC, but were within the standard deviation of the A-GRO averages.

Trace metal concentrations remained fairly constant across the delta (Figure 6, Table 6). Manganese was the most variable: concentrations of this element more than doubled between Tsiigehtchic and Inuvik, from $33 \pm 1 \mathrm{nM}$ to $75 \pm 1 \mathrm{nM}$, and decreased to $64 \pm 11 \mathrm{nM}$ in Tuktoyaktuk. Barium concentrations increased gradually from Tsiigehtchic to Inuvik to Tuktoyaktuk, and $\mathrm{Pb}$ concentrations decreased slightly in Tuktoyaktuk after remaining constant between Tsiigehtchic and Inuvik.

All of the trace metals except for $U$ were non-conservatively mixed in the estuary (Figure 12). Most metals ( $\mathrm{Ba}, \mathrm{Co}, \mathrm{Cu}, \mathrm{Mn}, \mathrm{Ni}$ ) exhibited non-conservative addition. Barium concentrations reached a maximum at a salinity of 2.9 , and concentrations in the saline endmember were lower than those in the freshwater reaches of the estuary. The profiles of Co and $\mathrm{Mn}$ were similar, with higher concentrations in the saline endmember compared to the freshwater endmember, and apparent addition throughout the estuary. Similarities were also apparent in the profiles of $\mathrm{Cu}$ and $\mathrm{Ni}$, which both increased at low salinities and then mixed relatively linearly through the rest of the estuary. Copper concentrations were lower in the saline 
endmember compared to freshwater values, but Ni concentrations were similar in both the freshwater and saline endmembers. In contrast to the other metals, $\mathrm{Pb}$ was removed rapidly in the estuary and remained at low levels through most of the transect, though elevated concentrations were measured in the samples collected at depth at higher salinities. Uranium behaved conservatively, with concentrations increasing linearly from low to high salinities.

Metal concentrations in groundwater were variable, but were generally higher than river water concentrations (Table 6a). The concentrations of $\mathrm{Mn}, \mathrm{Cu}, \mathrm{Ni}$, and $\mathrm{Pb}$ were highest in MRD01, while the concentrations of $\mathrm{Ba}$ and $\mathrm{U}$ were exceptionally high in MRD02.

\subsection{DISCUSSION}

\subsubsection{The freshwater endmember}

\subsubsection{Radium in Arctic rivers}

This study presents the first measurements of Ra isotopes in North American Arctic rivers, allowing for a comparison with the ${ }^{226} \mathrm{Ra}$ and ${ }^{228} \mathrm{Ra}$ activities previously measured in Eurasian river systems (Rutgers van der Loeff et al., 2003). The annual average ${ }^{228} \mathrm{Ra}$ activity in

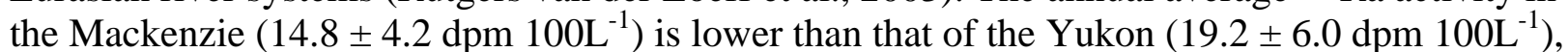

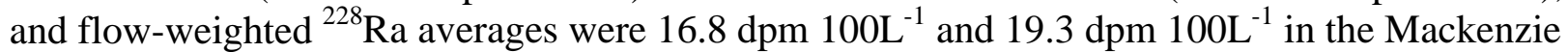
and Yukon, respectively. These North American river values are similar to the ${ }^{228} \mathrm{Ra}$ activity measured in the Lena in September $1999\left(15.9 \pm 7.8 \mathrm{dpm} 100 \mathrm{~L}^{-1}\right)$, but much lower than that observed in the Ob' in August-September 1993 (40.9 $\pm 3.7 \mathrm{dpm} 100 \mathrm{~L}^{-1}$ ) (Figure 13). The average ${ }^{226} \mathrm{Ra}$ activity in the Mackenzie was $15.2 \pm 4.0 \mathrm{dpm} 100 \mathrm{~L}^{-1}$, slightly higher than the

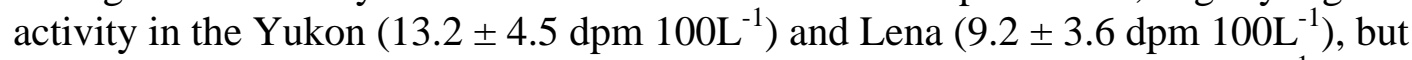
approximately half of the activity observed in the $\mathrm{Ob}^{\prime}\left(27.3 \pm 6.1 \mathrm{dpm} 100 \mathrm{~L}^{-1}\right)$. Flow weighted

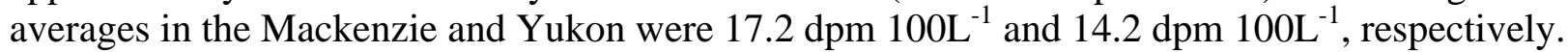
The ${ }^{226} \mathrm{Ra}$ and ${ }^{228} \mathrm{Ra}$ activities in the $\mathrm{Ob}$ ' and Lena Rivers were observed to decrease rapidly at the first salinity increase, which the authors attribute to flocculation of organic material (Rutgers van der Loeff et al., 2003). This pattern is not observed in the Mackenzie, which instead shows the predicted desorption pattern typical of lower latitude estuaries (see section 5.4.3.1). This may be due a combination of the much lower flow-weighted DOC concentration for the Mackenzie $(358 \mu \mathrm{M})$ as compared to the Lena $(917 \mu \mathrm{M})$ and Ob' $(825 \mu \mathrm{M})$ (Cooper et al., 2005), and its 10 times higher suspended sediment load (124 Mt y ${ }^{-1}$ compared to $20.7 \mathrm{Mt} \mathrm{y}^{-1}$ and $15.5 \mathrm{Mt} \mathrm{y}^{-1}$ for the Lena and Ob', respectively; Holmes et al., 2002). Any removal of Ra via flocculation in the Mackenzie is likely to be exceeded by input via desorption from suspended sediments.

This study also provides the first time series of Ra in an Arctic river, yielding insights into the seasonal variability of Ra activities. The ${ }^{228} \mathrm{Ra}$ and ${ }^{226} \mathrm{Ra}$ activities in the Mackenzie were highest after the freshet, but the relative activity maximum in January corresponds to a minimum in water flow, suggesting that discharge may not be the only control on Ra activities (Figure 5). The ${ }^{228} \mathrm{Ra} /{ }^{226} \mathrm{Ra}$ activity ratio of the groundwater samples in Tsiigehtchic was $1.3 \pm 0.3$, while the ratio on suspended sediments was $0.91 \pm 0.05$. The Mackenzie ${ }^{228} \mathrm{Ra} /{ }^{226} \mathrm{Ra}$ activity ratio remains close to 1 year-round, suggesting that solid-solution partitioning may be an important control on $\mathrm{Ra}$ activities throughout the year. This is supported by a strong correlation between $\mathrm{Ra}$ activities and total suspended solids (TSS) in the Mackenzie $\left(\mathrm{r}^{2}=0.84\right.$ for ${ }^{226} \mathrm{Ra}$ and 0.78 for ${ }^{228} \mathrm{Ra}$; Figure $5 \mathrm{c}$ and 14). However, more measurements of the ${ }^{228} \mathrm{Ra} /{ }^{226} \mathrm{Ra}$ activity ratio on suspended particles 
and groundwater from this catchment are needed to confirm this conclusion. The increase in Ra activities during January corresponds to higher $\mathrm{NO}_{3}{ }^{-}$concentrations during the winter (Figure 5c); this may reflect groundwater inputs, which carry high concentrations of nutrients (Dittmar and Kattner, 2003; Gordeev, 2000; Holmes et al., 2012).

\subsubsection{Water isotopes}

The average values of $\delta^{18} \mathrm{O}$ and $\delta^{2} \mathrm{H}$ measured in the freshwater samples $\left(\delta^{18} \mathrm{O} \sim-19.5 \%\right.$, $\delta^{2} \mathrm{H} \sim-155 \%$ o were similar to those measured in previous studies of the Mackenzie River (Cooper et al., 2008; Gibson et al., 2005; Yi et al., 2010) (Table 1). This freshwater $\delta^{18} \mathrm{O}$ value agrees well with the flow-weighted average of $-19.2 \%$ determined by Cooper et al. (2008) for the Mackenzie, and is slightly heavier than the value of $-21 \%$ estimated for Arctic runoff by Östlund and Hut (1984), likely due to the generally lower latitude origins of the Mackenzie (Cooper et al., 2005). The $\delta^{18} \mathrm{O}-\delta^{2} \mathrm{H}$ relationship for the samples collected in the estuary was $\delta^{2} \mathrm{H}$ $=7.9 \times \delta^{18} \mathrm{O}-2.3 \% \circ\left(\mathrm{r}^{2}=0.998\right)$ (Figure 4). This slope is greater than the one estimated by Yi et al. (2010) for the upstream Mackenzie River (6.0; between Great Slave Lake and Tsiigehtchic) and closer to that of the local mean water line for Inuvik (7.3; IAEA/WMO, 2018; Lacelle, 2011), suggesting that secondary evaporation and/or ice formation processes, which would result in a shallower slope, did not significantly affect the estuarine water balance during our sampling period.

Groundwater samples fall along the line defined by the river samples and have values similar to the fresh river water. A recent study in Barrow, Alaska, identified precipitation as the main source of water to the active layer in the summer (Throckmorton et al., 2016). However, these authors also found that melting seasonal ice in the active layer can become important later in the summer $(\sim$ September $)$. The isotopic values measured in near-surface permafrost in the Mackenzie Delta are similar to average precipitation values in this region $\left(\delta^{18} \mathrm{O} \sim-22 \%\right.$, $\delta^{2} \mathrm{H}$ not reported; Michel, 2011), but deeper ( $3 \mathrm{~m})$ permafrost and massive ground ice deposits in the northern part of the delta have lighter values that indicate a glacial water source $\left(\delta^{18} \mathrm{O} \sim-28 \%\right.$ o to $-32 \%$ o, $\delta^{2} \mathrm{H} \sim-225 \%$ o to -250\%o; Fritz et al., 2011; Mackay and Dallimore, 1992; Michel, 2011). We observed a similar pattern in shallow $(<1.5 \mathrm{~m})$ permafrost cores collected near Inuvik and in permafrost collected from the headwall of a retrogressive thaw slump in Tuktoyaktuk: the $\delta^{18} \mathrm{O}$ values in the Inuvik cores were $-20.18 \%$ o to $-25.31 \%$ and the $\delta^{2} \mathrm{H}$ values were $-156.9 \%$ o to $192.0 \%$, while $\delta^{18} \mathrm{O}$ and $\delta^{2} \mathrm{H}$ in the thaw slump permafrost were $-30.30 \%$ and $-239.7 \%$ (see Appendix). Because the near-surface permafrost isotope signatures are similar to precipitation values, it is currently difficult to separate the inputs of meteoric water and thawing permafrost to groundwaters and rivers. However, as deeper permafrost and massive ground ice have distinctly negative isotopic values, continued permafrost degradation under future climate conditions may result in thawed porewater inputs that are easier to identify.

\subsubsection{Changes across the delta}

The rise in DON and DOC from Tsiigehtchic to Inuvik to Tuktoyaktuk likely reflect inputs of DOM from the delta (Figure 6). Following the inundation of deltaic lakes and ponds during periods of high river discharge, particle settling improves water transparency and allows for autotrophic production, drawing down inorganic nutrient concentrations and increasing DOM concentrations (Emmerton et al., 2008a; Fisher and Parsley, 1979; Forsberg et al., 1988; Junk et 
al., 1989; Lesack et al., 1998; Maine et al., 2004; Tockner et al., 1999). The flooding of vegetation and soils can also lead to the leaching of DOM and nutrients, which are then carried back to the river as the water recedes (Emmerton et al., 2008a; Junk et al., 1989; Lesack et al., 1998); this process may be exacerbated in the Arctic by the presence of thermokarst (Tank et al., 2011). The chemistry of the Mackenzie River is therefore affected by interactions with lakes and flooded vegetation during the flooding of the delta in the freshet and subsequent drainage as the water level falls (Emmerton et al., 2007).

Emmerton et al. (2008a) created a biogeochemical model of these river-lake interactions in the Mackenzie River, and predicted a downstream increase in riverine DOM due to the "delta effect". A 2004 survey of the delta by these authors confirmed that concentrations of DOM were higher closer to the mouths of the Middle and West Channels (Emmerton et al., 2008a). The downstream increases of DON and DOC observed in this study are consistent with the predicted deltaic inputs of DOM. Because DOM concentrations were high in groundwater at Tsiigehtchic (MRD02), groundwater inputs could contribute to higher concentrations downstream. However, the concentrations in Tuktoyaktuk are higher than those observed in the groundwater (Table 5), indicating that other sources may also contribute.

The changes in inorganic nutrient concentrations observed in this study were not as large as those for DOM (Figure 6). The modeling results of Emmerton et al. (2008a) suggest that inorganic nutrients should be consumed during storage in the delta, with the exception of $\mathrm{NH}_{4}{ }^{+}$, which is predicted to increase because floodplain lakes have high $\mathrm{NH}_{4}{ }^{+}$concentrations as a result of organic matter degradation (Spears and Lesack, 2006). The decrease in $\mathrm{NH}_{4}{ }^{+}$concomitant with an increase in $\mathrm{NO}_{\mathrm{x}}$ suggests that the $\mathrm{NH}_{4}{ }^{+}$loss observed in this study may be due to nitrification, though the magnitude of these changes are small and could reflect natural variability. The increase in $\mathrm{NO}_{\mathrm{x}}$ could also be due to groundwater inputs, which had slightly higher nutrient concentrations, however this would likely increase both $\mathrm{NO}_{\mathrm{x}}$ and $\mathrm{NH}_{4}{ }^{+}(\mathrm{Table}$ 5a). The loss of $\mathrm{NH}_{4}{ }^{+}$contradicts the model and observations of Emmerton et al. (2008a), who detected 2-3 fold increases in $\mathrm{NH}_{4}{ }^{+}$(although even after this increase the concentrations observed during their 2004 survey were lower than those observed in this study). The increase in $\mathrm{SiO}_{4}{ }^{-}$recorded in 2016 is similar to the observations made in 2004, but inconsistent with model predictions (Emmerton et al., 2008a). The relatively constant $\mathrm{PO}_{4}{ }^{3-}$ concentrations in the delta are in contrast with both the decrease predicted by modeling and the increase observed in 2004 (Emmerton et al., 2008a), but are consistent with the observations of Tremblay et al. (2014), who did not observe significant changes in $\mathrm{PO}_{4}{ }^{3-}$ concentrations between Tsiigehtchic and Inuvik in May and June 2009.

The different DOM and nutrient patterns observed throughout the delta in 2016 and 2004 could be related to variability in river discharge or river-lake connection times. These differences would impact the number and type of lakes flooded, which could influence nutrient levels because lakes that are less frequently flushed with river water have different water chemistry and autotrophic species assemblages than those commonly connected to the river (Lesack et al., 1998; Squires et al., 2009; Squires and Lesack, 2002). Peak discharge was lower in 2016 compared to 2004, and the freshet occurred earlier than normal (May 18, compared to June 1; Figure 2) (Water Survey of Canada, 2018). If lakes were flooded earlier in the 2016 season, ice cover may have prevented complete water column mixing (Lesack et al., 1998). Further, Lesack and Marsh (2007) found that river-lake connection times are increasing in low elevation lakes due to sea level rise and changes in ice breakup, while connection times in higher elevation lakes may be decreasing. Although their analysis only extended through 2005, continued changes over 
the last decade may have contributed to differences between the 2004 and 2016 studies. Alternatively, differences between the two transects could reflect spatial variability: we measured the concentrations at the mouth of the East Channel, while Emmerton et al. (2008a) studied the Middle and West Channels. Differences between the outflows of these channels were reflected in a 2009 summer survey of the inner Beaufort Shelf: higher concentrations of DON and DOP were observed in Kugmallit Bay (mouth of the East Channel) compared to Mackenzie Bay (mouth of the West Channel), while $\mathrm{DOC}$ and $\mathrm{SiO}_{4}{ }^{-}$showed the opposite pattern (Tremblay et al., 2014). The relative importance of spatial versus temporal variability is likely different for different solutes, and is hard to asses without interannual data from the same sites in the delta.

The small changes in riverine nutrient concentrations observed throughout the delta during this study may indicate that primary production was dominated by macrophytes, which consume nutrients from lakebed sediments and are therefore more dependent on particulate nutrient delivery from the river instead of dissolved nutrient inputs (Squires and Lesack, 2003). The increase in DOM without much change in inorganic nutrients could also reflect leaching of organic rich soils or thermokarst inputs. Tank et al. (2011) found that thermokarst provided a significant source of DOM to lakes in the Mackenzie River Delta, and high DOM concentrations observed in the groundwater sample from Tsiigehtchic (MRD02) support this hypothesis. If thermokarst is the main control on the DOM concentrations, the larger inputs of DOM at the mouth of the delta in 2016 may reflect permafrost degradation between 2004 and 2016.

Changes in $\mathrm{Ra}$ activities and trace metal concentrations through the delta were generally not as significant as those for DOM (Figure 6). The long-lived ${ }^{228} \mathrm{Ra}$ and ${ }^{226} \mathrm{Ra}$ activities were the same within error at all three sampling sites. The ${ }^{223} \mathrm{Ra}_{\mathrm{xs}}$ activities were more variable; because of its shorter half-life, this isotope is more sensitive to changes in sources or sinks. The lower Ra activities in Inuvik may indicate reduced benthic sediment inputs to this part of the river (Table 4), but could also reflect lower sediment influence due to the fact that sampling was conducted from a pier, so the comparison between Tsiigehtchic and Tuktoyaktuk is more robust (Figure 6).

While most of the metal concentrations remained relatively constant through the delta, Mn concentrations doubled between Tsiigehtchic (MRD05) and Inuvik (MRD06) (Figure 6). Because $\mathrm{Mn}$ is a redox active metal, changes in oxygen levels in the sediments and overlying water column affect the speciation and solubility of this metal. Reducing sediments are a source of soluble Mn, which is oxidized much more slowly than Fe (Stumm and Morgan, 1996), and can be stabilized in estuaries by complexation with ligands or humic material (Oldham et al., 2017). Manganese reduction in floodplain lakes has previously been invoked to explain downstream increases of Mn in temperate river systems (Shim et al., 2017). This reductive sediment input may have contributed to the high concentrations observed in groundwater; the Mn concentrations in Tsiigehtchic groundwater were much higher than the river water concentration observed in MRD05, whereas the groundwater concentrations of the other metals were generally on the same order of magnitude as the river water concentrations. Groundwater inputs in the delta could therefore contribute to the observed Mn variability.

\subsubsection{Changes in the estuary}

\subsubsection{Benthic inputs of radium isotopes and nutrients}

All four radium isotopes increased in the freshwater-saltwater transition zone (Figure 7) due to salinity-induced desorption (ion exchange) from suspended and benthic sediments (e.g. Li 
et al., 1977; Moore et al., 1995). The peak Ra activities are observed between salinities 5 - 10, consistent with the majority of desorption occurring below salinities of 5 (Key et al., 1985;

Moore, 1981), though this process has been observed at up to a salinity of 25 (Gonneea et al., 2008; Key et al., 1985). The deviation of each isotope from the conservative mixing line was used to quantify this estuarine addition: ${ }^{228} \mathrm{Ra}$ and ${ }^{226} \mathrm{Ra}$ increased by $61 \%$ and $45 \%$, respectively, based on the activities measured at salinity 8.56 (Table 7). Excess ${ }^{223} \mathrm{Ra}$ and ${ }^{224} \mathrm{Ra}_{\mathrm{xs}}$ were highest at salinity 3.89 , and deviated from their conservative mixing lines by $115 \%$ and $163 \%$, respectively.

The observed increases in ${ }^{228} \mathrm{Ra}$ and ${ }^{226} \mathrm{Ra}$ in the estuary were $12.3 \mathrm{dpm} 100 \mathrm{~L}^{-1}$ and 8.7 dpm $100 \mathrm{~L}^{-1}$, respectively. To explain this increase from suspended sediment desorption alone, the river particles would have to release $23 \%$ and $15 \%$ of their total ${ }^{228} \mathrm{Ra}$ and ${ }^{226} \mathrm{Ra}$, respectively (Table $4 \mathrm{c})$. These values are slightly lower than a previous estimate ( $30 \%$ for both isotopes; Moore et al., 1995). The activity ratio of suspended sediments was $0.91 \pm 0.05$, thus a Ra source from desorption is expected to have a similar ratio. However, the estuarine ${ }^{228} \mathrm{Ra}$ and ${ }^{226} \mathrm{Ra}$ increase reflects a ${ }^{228} \mathrm{Ra} /{ }^{226} \mathrm{Ra}$ ratio of 1.4 , and the ${ }^{228} \mathrm{Ra} /{ }^{226} \mathrm{Ra}$ ratio measured in the estuary was consistently greater than 0.91 (Figure 7e). This may be due differences in surface available ${ }^{228} \mathrm{Ra}$ and ${ }^{226} \mathrm{Ra}$; for example, Krest et al. (1999) measured ratios of $0.84-0.91$ in bulk suspended sediments collected from the Mississippi and Atchafalaya Rivers, but found that ${ }^{228} \mathrm{Ra}$ and ${ }^{226} \mathrm{Ra}$ desorbed from the sediments in a ratio of 1.2.

The increased activity ratio in the estuary may also indicate influence from another source with a higher ${ }^{228} \mathrm{Ra} /{ }^{226} \mathrm{Ra}$ activity ratio than suspended sediments. Sediment porewater and groundwater inputs frequently have ${ }^{228} \mathrm{Ra} /{ }^{226} \mathrm{Ra}$ ratios greater than 1 due to the faster regeneration time of ${ }^{228} \mathrm{Ra}$ (Charette, 2007; Charette et al., 2001; Key et al., 1985; Krest et al., 1999; Rodellas et al., 2017). The average ${ }^{228} \mathrm{Ra} /{ }^{226} \mathrm{Ra}$ of groundwater collected in Tsiigehtchic was $1.3 \pm 0.3$, which is similar to the ratio of the estuarine increase in ${ }^{228} \mathrm{Ra}$ and ${ }^{226} \mathrm{Ra}$. The increase of the observed ${ }^{228} \mathrm{Ra} /{ }^{226} \mathrm{Ra}$ activity ratio to $\sim 1.1-1.2$ in the estuary may therefore also be driven by a local groundwater input or an input from sediment porewaters.

The ${ }^{224} \mathrm{Ra} /{ }^{228} \mathrm{Ra}$ activity ratio is also influenced by benthic inputs, which are enriched in ${ }^{224} \mathrm{Ra}$ over ${ }^{228} \mathrm{Ra}$ due to the shorter half-life of ${ }^{224} \mathrm{Ra}$ and thus faster regeneration time of ${ }^{224} \mathrm{Ra}$ in sediments (Moore, 2000a). In addition, decay of ${ }^{228} \mathrm{Ra}$ in the water column produces ${ }^{228} \mathrm{Th}$, which becomes adsorbed onto particle surfaces. When surface-bound ${ }^{228} \mathrm{Th}$ decays to produce ${ }^{224} \mathrm{Ra}$, this isotope is likely to become desorbed, therefore suspended sediments that settle out of the river can be an important source of ${ }^{224} \mathrm{Ra}$ (Moore et al., 1995). Due to the large delivery of sediments from the river and frequent storms that resuspend sediments (Carmack and Macdonald, 2002; Macdonald et al., 1998), the Mackenzie Estuary has the potential to be a sizeable source of excess ${ }^{224} \mathrm{Ra}$. The ${ }^{224} \mathrm{Ra} /{ }^{228} \mathrm{Ra}$ activity ratio was around 1 in the freshwater samples, but increased to $1.2-1.5$ in the mid-salinity range (Figure 7f). Because of the benthic sediment source of excess ${ }^{224} \mathrm{Ra}$, proximity to the riverbed will influence the ${ }^{224} \mathrm{Ra} /{ }^{228} \mathrm{Ra}$ activity ratio. Once the transect passed the $2 \mathrm{~m}$ shoal, the ${ }^{224} \mathrm{Ra} /{ }^{228} \mathrm{Ra}$ activity ratio in surface water $(0.5$ $\mathrm{m})$ began to decrease because of the isolation from the sediment source. This decrease must be due to decay of ${ }^{224} \mathrm{Ra}$, because dilution affects both isotopes.

The local benthic source indicated by the Ra isotope ratios may also have contributed to increased nutrients and DOC in the mid-salinity range. Radium isotopes have become well established as tracers of nutrient inputs through submarine groundwater discharge (see Charette et al., 2008 for a review) and have recently been applied to determine groundwater fluxes of nutrients to the Beaufort Sea and coastal Arctic Ocean (Lecher et al., 2016). The maxima of $\mathrm{NO}_{\mathrm{x}}$, 
$\mathrm{PO}_{4}{ }^{3-}$, and $\mathrm{SiO}_{4}{ }^{-}$between salinities $2.87-8.56$, coincident with the increase in ${ }^{228} \mathrm{Ra}^{226} \mathrm{Ra}$ and ${ }^{224} \mathrm{Ra} /{ }^{228} \mathrm{Ra}$, may therefore reflect groundwater inputs of these nutrients (de Sieyes et al., 2008; Jickells, 2005; Knee and Paytan, 2011; Slomp and Van Cappellen, 2004) (Figure 9). Benthic inputs of $\mathrm{PO}_{4}{ }^{3-}$ could also result from mobilization in reducing sediments: under oxic conditions, sediments are a sink of $\mathrm{PO}_{4}{ }^{3-}$ as a result of complexation with iron oxides, but if sediments become anoxic, the iron oxides are reduced and $\mathrm{PO}_{4}{ }^{3-}$ can be released (Charette and Sholkovitz, 2002; Froelich, 1988). Nitrification may contribute to the peak in $\mathrm{NO}_{\mathrm{x}}$ concentrations coincident with the drop in $\mathrm{NH}_{4}{ }^{+}$concentrations at salinity 6.10 ; this process can be associated with resuspended particulate material (Owens, 1986), and higher ${ }^{224} \mathrm{Ra} /{ }^{228} \mathrm{Ra}$ activity ratios in the midsalinity range support the possibility of a recent sediment resuspension event. Such a resuspension could also transport regenerated nutrients from sediment porewaters to the overlying water column (Statham, 2012). Possible groundwater or benthic inputs of DOC are indicated by a slight concentration increase between salinities of 2.87 and 10.26 (Couturier et al., 2016; Kim et al., 2012), however this addition could also reflect biological production of DOM in the estuary (Benner and Opsahl, 2001; Raymond and Bauer, 2001).

\subsubsection{Water mass ages in Kugmallit Bay}

The short-lived ${ }^{223} \mathrm{Ra}$ and ${ }^{224} \mathrm{Ra}$ isotopes have half-lives appropriate for determining the timescale of coastal mixing processes (e.g. Moore, 2000b, 2000a). These isotopes are added to the estuary through desorption from suspended and benthic sediments and through groundwater inputs, and they have negligible activities off the shelf, thus the ${ }^{223} \mathrm{Ra}_{\mathrm{xs}}$ and ${ }^{224} \mathrm{Ra}_{\mathrm{xs}}$ activities in Kugmallit Bay decrease from decay and mixing with the marine endmember (Figures 7c and 7d). Considering the ratio of the two isotopes (after correcting for parent isotope-supported activities) corrects for the effects of dilution, such that any decrease in the ratio must be due to decay. The progressive decrease in the ${ }^{224} \mathrm{Ra}_{\mathrm{xs}} /{ }^{223} \mathrm{Ra}_{\mathrm{xs}}$ activity ratio at stations MRD13-MRD15 (Figure 15) can therefore be used to determine the time elapsed since the water was in contact with sediments following the approach described in Moore (2000b) (Equation 1):

$$
\left(\frac{{ }^{224} \mathrm{Ra}_{\mathrm{xs}}}{{ }^{223} \mathrm{Ra}_{\mathrm{xs}}}\right)_{\mathrm{t}}=\left(\frac{{ }^{224} \mathrm{Ra}_{\mathrm{xs}}}{{ }^{223} \mathrm{Ra}_{\mathrm{xs}}}\right)_{0} \frac{\mathrm{e}^{-\lambda_{224} \cdot \mathrm{t}}}{\mathrm{e}^{-\lambda_{223} \cdot \mathrm{t}}}
$$

In this equation, $\left(\frac{{ }^{224} \mathrm{Ra}_{\mathrm{xs}}}{{ }^{223} \mathrm{Ra}_{\mathrm{xs}}}\right)_{0}$ is the initial ${ }^{224} \mathrm{Ra}_{\mathrm{xs}}{ }^{223} \mathrm{Ra}_{\mathrm{xs}}$ ratio (in samples recently in contact with sediments), $\left(\frac{{ }^{224} \mathrm{Ra}_{\mathrm{xs}}}{{ }^{223} \mathrm{Ra}_{\mathrm{xs}}}\right)$ is the ratio after time $t$ has elapsed, $\lambda_{224}$ is the decay constant of ${ }^{224} \mathrm{Ra}$ $\left(0.189 \mathrm{~d}^{-1}\right)$, and $\lambda_{223}$ is the decay constant of ${ }^{223} \mathrm{Ra}\left(0.061 \mathrm{~d}^{-1}\right)$. Using the ratio at MRD12 as the initial ${ }^{224} \mathrm{Ra}_{\mathrm{xs}}{ }^{223} \mathrm{Ra}_{\mathrm{xs}}$ ratio, the time elapsed at stations MRD13, MRD14, and MRD15 was determined to be $2.7 \mathrm{~d}, 5.8 \mathrm{~d}$, and $6.3 \mathrm{~d}$, respectively. These water mass ages are consistent with previous estimates that the nearshore region of the shelf is flushed on timescales of days (Macdonald and Yu, 2006). This method requires several assumptions: (1) that the source ratio is constant, (2) that there are no benthic inputs of ${ }^{223} \mathrm{Ra}$ and ${ }^{224} \mathrm{Ra}$ after leaving MRD12, which could bias the result towards younger ages, and (3) that the young estuarine water and old offshelf water are the only endmembers, as mixing with older water masses in the bay could bias the ratio towards older ages. Stratification in the estuary may help prevent additional benthic 
inputs of Ra to surface waters beyond the $2 \mathrm{~m}$ ramp, but more studies are needed to constrain the spatial variability of the ${ }^{224} \mathrm{Ra}_{\mathrm{xs}}{ }^{223} \mathrm{Ra}_{\mathrm{xs}}$ ratio across the bay.

\subsubsection{Removal of DOM in the estuary}

Although DOM is has been observed to behave conservatively in most Arctic estuaries (Dittmar and Kattner, 2003), the concentrations of DOC and DON in the Mackenzie River estuary decreased drastically, dropping by $\sim 1 / 2$ and $\sim 1 / 3$, respectively, at the first increase in salinity (Figure 9e-f). This may be due to flocculation of colloids, a known removal mechanism for DOM in estuaries (Sholkovitz, 1976; Sholkovitz et al., 1978). This consistent with the Whitehouse et al. (1989) study, which reported a $>50 \%$ decrease in organic carbon colloid concentrations for the Mackenzie River between salinity 0 and $\sim 5$. This is in contrast to the assumption of Letscher et al. (2013) that rapid removal of DOM at low salinities due to flocculation is insignificant in Arctic rivers.

Emmerton et al. (2008b) did not observe similar flocculation of organic matter during their July 2004 transect. This could be due to seasonal differences; lower suspended sediment concentrations later in the summer would reduce the potential for the particle-particle interactions that are a kinetic control on colloid flocculation (Stumm and Morgan, 1996). The unexpected loss of DOC could also result from a higher degree of lability in DOC discharged in the spring; Holmes et al. (2008) found that the DOC carried in Alaskan rivers during the freshet could undergo significant degradation, while DOC discharged during the summer was refractory. They attributed the decrease in lability to deepening active layers and longer flowpaths, which result in less interaction with organic rich surface layers that can enrich circulating waters in DOC, and a longer residence time in soils that allows more microbial DOC processing to occur before reaching the river. Although our samples were not collected during the period of peak discharge, the DOC may have retained some lability if flowpaths remained sufficiently short at the end of June. Recent studies have also suggested that DOC and DON are removed at varying rates across the estuary-shelf transition (Letscher et al., 2013; Tank et al., 2012a). After this initial drop, DOC and DON appear to mix conservatively, with possible non-conservative addition around salinity 5 (see section 5.4.3.1).

Estuarine processing of DOC is important for constraining DOC delivery to the Arctic and estimating DOC removal rates. Loss rates in Arctic surface waters have been estimated based on the difference between the DOC concentration measured in river freshwaters and the DOC concentration estimated by extrapolating DOC-salinity or DOC- $\delta^{18} \mathrm{O}$ relationships from samples collected in the open Arctic Ocean to freshwater endmembers (Hansell et al., 2004). However, this calculation is sensitive to the river endmember concentration of DOC, and a removal of DOC in the estuary, as observed here, would result in a lower effective river endmember and an overestimate of the riverine DOC source, leading to an overestimate of the amount of DOC removed in Arctic surface waters. Cooper et al. (2005) estimated a Mackenzie River DOC concentration of $\sim 250 \mu \mathrm{M}$ by assuming that $30 \%$ of the flow-weighted mean concentration $(358 \mu \mathrm{M})$ was removed over the shelf. This is significantly lower than the endmember concentration of $550 \pm 100 \mu \mathrm{M}$ used by Hansell et al. (2004). If the $50 \%$ loss of DOC observed in our June study is representative of conditions throughout the rest of the year, then our results suggest that the fraction of reactive DOC may be even higher than assumed by Cooper et al. (2005), and that the effective river endmember concentration could be as low as $\sim 180 \mu \mathrm{M}$ (taking the flow-weighted mean concentration from Cooper et al. (2005) as an initial 
value). This suggests that DOC removal rates in Arctic surface waters are lower than previously thought.

\subsubsection{Removal of nutrients, DIC, and alkalinity}

The presence of measurable DIN and $\mathrm{PO}_{4}{ }^{3-}$ throughout the estuary suggests that the system has not yet become nutrient limited. After the freshet, the suspended sediment load in the estuary is high enough that primary production is limited by light (Macdonald and Yu, 2006). When turbidity decreases at the end of summer, $\mathrm{P}$ is likely to be the limiting nutrient in the Mackenzie and nearshore Beaufort Shelf, while $\mathrm{N}$ is limiting in the Beaufort Sea and the rest of the Arctic (Carmack et al., 2004; Emmerton et al., 2008b; Tremblay et al., 2015).

The decrease in nutrient concentrations beginning around salinity 6 likely reflects biological uptake (Figure 9). Between salinities 6.10 and 10.26 the drawdown ratio of N:P (DIN:PO ${ }_{4}{ }^{3-}$ ) was 16, which matches the canonical Redfield ratio (Redfield, 1958) but is higher than typical Beaufort Sea ratios of $\sim 11-13$ (Tremblay et al., 2015). The loss of $\mathrm{PO}_{4}{ }^{3-}$ could also be due to abiotic processes such as complexation to iron oxides in sediments (Charette and Sholkovitz, 2002; Froelich, 1988), or removal associated with iron flocculation (Carmack et al., 2004). Although $\mathrm{NO}_{\mathrm{x}}$ concentrations decreased to levels below our detection limits $(<0.04 \mu \mathrm{M})$, $\mathrm{NH}_{4}{ }^{+}$concentrations remained around $1-1.5 \mu \mathrm{M}$; this may be due to $\mathrm{NH}_{4}{ }^{+}$inputs from $\mathrm{N}$ recycling and/or photoammonification of DON in the estuary (Le Fouest et al., 2013; Tank et al., 2012a; Xie et al., 2012). The Si:N drawdown ratio was 8 , which is much larger than typical values of $\sim 2$ in the Beaufort Sea (Tremblay et al., 2015). This discrepancy could be due to the aforementioned $\mathrm{N}$ recycling, or to abiotic removal of $\mathrm{Si}$ through reverse weathering, which has been shown to remove significant quantities of Si in estuaries (Presti and Michalopoulos, 2008).

Dissolved inorganic carbon and alkalinity typically exhibit conservative mixing in estuaries (e.g. Cai et al., 2010), though losses of DIC and alkalinity have been observed in some large temperate estuaries such as the Amazon (Ternon et al., 2000), Chesapeake (Wong, 1979), and Mississippi (Cai, 2003). While DIC can be lost through multiple biological and physical processes in the estuary, including primary production and outgassing of $\mathrm{CO}_{2}$, the main control on alkalinity is calcium carbonate $\left(\mathrm{CaCO}_{3}\right)$ precipitation or dissolution. Because DIC and alkalinity are lowest during the freshet, it is also possible that the apparent curvature reflects conservative mixing with a gradually increasing river endmember concentration (Cross et al., 2013; Wong, 1979). Extrapolating the DIC-salinity and alkalinity-salinity relationships observed in the three most saline samples (MRD15 - MRD17) results in an effective river endmember with an alkalinity of $\sim 1330 \mu \mathrm{mol} \mathrm{kg}{ }^{-1}$ and a DIC concentration of $\sim 1275 \mu \mathrm{mol} \mathrm{kg}^{-1}$. Alkalinity values of $\sim 1300-1400 \mu \mathrm{mol} \mathrm{kg}{ }^{-1}$ have been observed in the Mackenzie in the past, but in recent decades the minimum alkalinity has been $\sim 1600 \mu \mathrm{mol} \mathrm{kg}^{-1}$ (Tank et al., 2016). Similarly, this estimated DIC concentration is slightly less than values observed in the Mackenzie, which are typically $>1400 \mu \mathrm{mol} \mathrm{kg}^{-1}$ (Tank et al., 2012b). Mixing therefore does not appear to be the sole influence on DIC and alkalinity concentrations in the estuary.

The DIC and alkalinity losses in the Mackenzie Estuary were $200 \mu \mathrm{mol} \mathrm{kg}{ }^{-1}$ and 190 $\mu \mathrm{mol} \mathrm{kg}{ }^{-1}$, respectively, determined from the difference between the conservative mixing line and the observed concentrations at salinity 15.49. These deficits are similar to those observed in the Mississippi and Amazon, where biological activity was determined to be the controlling factor (Cai, 2003; Ternon et al., 2000). The non-conservative removal of DIC and alkalinity observed during this study coincides with the drop in inorganic nutrient concentrations, 
supporting a biological sink (Figures 9 and 10). If we assume that the entire alkalinity loss is due to $\mathrm{CaCO}_{3}$ precipitation, the corresponding loss of DIC from this process should be half the alkalinity loss, $95 \mu \mathrm{mol} \mathrm{kg}{ }^{-1}$. The remaining DIC loss $(105 \mu \mathrm{M})$ could be due to biological uptake or $\mathrm{CO}_{2}$ outgassing. The DIC loss rate can be approximated using the water mass ages determined from the ${ }^{224} \mathrm{Ra} /{ }^{228} \mathrm{Ra}$ activity ratio; the non-conservative removal of DIC and alkalinity begins at the salinity used as the initial ${ }^{224} \mathrm{Ra} /{ }^{228} \mathrm{Ra}$ value (MRD12, salinity $\left.=6.10\right)$. If the DIC loss of $105 \mu \mathrm{M}$ occurred over $6.3 \mathrm{~d}$ (MRD15, salinity =15.49), the loss rate was approximately $17 \mu \mathrm{M} \mathrm{d}^{-1}$. We can compare this to the estimate of integrated summer primary production determined by Tremblay et al. (2014) for the top $10 \mathrm{~m}$ of the neritic portion of the Beaufort Shelf (defined as inshore of the 20 salinity contour): $114 \times 10^{9} \mathrm{~g} \mathrm{C}$. Assuming this production was evenly distributed over the neritic shelf area $\left(4132 \mathrm{~km}^{2}\right)$ and the 62 day observation period, this corresponds to a production rate of approximately $4 \mu \mathrm{M} \mathrm{C} \mathrm{d}^{-1}$. This is an order of magnitude less than the estimate of DIC loss for our study, suggesting that $\mathrm{CO}_{2}$ outgassing may also have contributed to the DIC loss observed in 2016. Vallières et al. (2008) observed $\mathrm{CO}_{2}$ supersaturation throughout the East Channel in 2004, supporting this possibility.

\subsubsection{Non-conservative behavior of trace metals}

Trace metal concentrations in estuaries can be influenced by particle adsorption, desorption, or flocculation (Boyle et al., 1974, 1977; Shiller and Boyle, 1987; Sholkovitz, 1978). All of the trace metals measured in this study except $U$ exhibited non-conservative behavior in the estuary: $\mathrm{Ba}, \mathrm{Co}, \mathrm{Cu}, \mathrm{Mn}$, and $\mathrm{Ni}$ concentrations increased, while $\mathrm{Pb}$ was removed (Figure 12). The increases in metal concentrations during the transition from fresh to salt water are likely due to release from either suspended or benthic sediments as the ionic strength of the water increases, however, apparent non-conservative behavior could also result from temporal changes in the riverine input (Officer and Lynch, 1981) or an additional input from groundwater (Charette and Sholkovitz, 2006; Knee and Paytan, 2011).

The addition of $\mathrm{Ba}$ at low salinities has been well documented (Carroll et al., 1993; Coffey et al., 1997; Edmond et al., 1978; Guay and Falkner, 1998) and is due to desorption from suspended particles as $\mathrm{Ba}$ on particle surfaces is replaced by more abundant seawater cations. The behavior observed during this study is very similar to that recorded by Guay and Falkner (1998) in the East Channel of the Mackenzie Estuary in 1994, with the highest Ba concentrations occurring around a salinity of 5. The increase in $\mathrm{Ba}$ is coincident with the rise in the ${ }^{228} \mathrm{Ra} /{ }^{226} \mathrm{Ra}$ and ${ }^{224} \mathrm{Ra} /{ }^{228} \mathrm{Ra}$ activity ratios, indicating a possible porewater or groundwater source of $\mathrm{Ba}$ in addition to the expected input from particle desorption (Charette and Sholkovitz, 2006; Gonneea et al., 2013).

The behavior of $\mathrm{Mn}$ in estuaries is variable, but non-conservative addition attributed to particle desorption and release from reducing benthic sediments has been observed in multiple temperate estuaries (Bewers and Yeats, 1978; Byrd et al., 1990; Callaway et al., 1988; Chiffoleau et al., 1994; Edmond et al., 1985; Keeney-Kennicutt and Presley, 1986). The Cosalinity relationship is similar to the Mn-salinity curve, with significantly higher concentrations in the seawater endmember compared to the freshwater endmember and addition throughout the estuary. Cobalt does not exhibit consistent estuarine behavior, and can be removed (e.g. Church, 1986), conserved (e.g. Zhang, 1995), added (e.g. Chiffoleau et al., 1994; Windom et al., 1988) or exhibit a combination of removal and addition (e.g. Byrd et al., 1990). Cobalt and Mn exhibited similar behavior in the Seine Estuary; the authors attributed this to an affinity of Co for Mn- 
oxides and suggested a porewater source of these elements (Chiffoleau et al., 1994). The benthic inputs of Ra support the possibility of a porewater source of Mn and Co.

The profiles of $\mathrm{Ni}$ and $\mathrm{Cu}$ have similar shapes; both increase at low salinities and then mix relatively conservatively through the rest of the estuary. The estuarine behavior of these elements is variable, but they are commonly either conserved (Boyle et al., 1982; Church, 1986; Edmond et al., 1985; Shiller and Boyle, 1991; Windom et al., 1988), or added (Byrd et al., 1990; Chiffoleau et al., 1994; Edmond et al., 1985; Keeney-Kennicutt and Presley, 1986; Zhang, 1995) in the estuarine mixing zone. The behavior of $\mathrm{Cu}$ and $\mathrm{Ni}$ in estuaries is likely controlled by simple inorganic processes, such as sorption reactions and speciation changes with increasing ionic strength, as opposed to redox reactions occurring in benthic sediments (Chiffoleau et al., 1994; Edmond et al., 1985). Chiffoleau et al. (1994) and Edmond et al. (1985) observed rapid desorption of $\mathrm{Ni}$ at low salinities followed by dilution, similar to the trend observed in the Mackenzie. Additions of $\mathrm{Cu}$ and $\mathrm{Ni}$ have also been documented in the Lena Estuary; as there was no evidence of benthic inputs of trace metals in this estuary, this addition was attributed to desorption from riverine particles (Guieu et al., 1996). It is also possible that the pattern observed in the Mackenzie is the result of changing river endmember concentrations; the concentrations at higher salinities may be reflecting a mixture of seawater with a higher $\mathrm{Cu}$ and $\mathrm{Ni}$ river endmember, perhaps from the freshet that preceded our sampling period. The effective river endmember concentrations (determined by extrapolating the "linear" part of the metal-salinity relationship) for $\mathrm{Cu}$ and $\mathrm{Ni}$ were $28 \mathrm{nM}$ and $26 \mathrm{nM}$, respectively, which are within the range of freshwater concentrations observed by the A-GRO and ECCC monitoring programs

(Environment and Climate Change Canada, 2018; Holmes et al., 2018).

The significant removal of $\mathrm{Pb}$ observed in the estuary may be due to flocculation of colloids; Pb can be associated with Fe-oxides and organic colloids (Tanguy et al., 2011; Wen et al., 2008; Windom et al., 1988), which can flocculate in estuaries. The drop in Pb concentration coincides with a $\sim 50 \%$ decrease in DOC, supporting the hypothesis that aggregation of DOC colloids may have contributed to the removal of $\mathrm{Pb}$. While no relationship between $\mathrm{Pb}$ and $\mathrm{DOC}$ was observed in the Lena River (Guieu et al., 1996), a positive correlation was observed in the Severna Dvina and a large fraction of the $\mathrm{Pb}$ was found to be colloidal (Pokrovsky et al., 2010).

Uranium exhibits variable chemistry in estuaries: it can be removed through flocculation of organic matter or Fe-coated colloids, it can behave conservatively, or it can be added or removed through interactions with bottom sediments (Swarzenski et al., 2003, and references therein). The results of this study suggest that $U$ behaves conservatively in the Mackenzie Estuary, which is in contrast to the claim of Andersen et al. (2007) that $65 \%$ of U is lost in the Mackenzie Estuary and shelf. These authors based their estimate on the difference between freshwater values collected at Tsiigehtchic and the zero salinity intercept of the U-salinity relationship observed in the Canada Basin. Some of our U values do fall below the conservative mixing line, but the largest deviation represents a $10 \%$ decrease from conservative mixing. It is possible that a substantial removal of $U$ occurs on the outer Beaufort Shelf, beyond the reach of our survey area. Alternatively, the interpretation of the U-salinity relationship in Andersen et al. (2007) is sensitive to ice melt, and a larger contribution of low-U ice meltwater could balance a lower estimate of $U$ loss in the Mackenzie Estuary.

In order to quantify the changes in trace metal concentrations in the estuary, we determined the percent difference between the maximum (in the case of addition) or minimum (in the case of removal) metal concentration and the concentration expected based on the conservative mixing line. The highest Ba concentration was observed at salinity 6.10, and 
denotes a 30\% increase over the conservative mixing line. Cobalt and $\mathrm{Mn}$ increased $36 \%$ and $110 \%$, respectively, with peak concentrations at salinity 15.49. Copper and $\mathrm{Ni}$ were both highest at salinity 8.56 , representing increases of $24 \%$ and $31 \%$, respectively. Approximately $81 \%$ of the $\mathrm{Pb}$ was removed at the first increase of salinity (salinity $=2.87$ ).

These changes indicate that trace metal fluxes from the river to the coastal ocean cannot be determined based on freshwater metal concentrations alone, but should also be based on changes that occur in the estuary. Further, the delivery of trace metals is likely to be seasonally variable, due to changes in river discharge and the relative influences of different water sources throughout the year (Rember and Trefry, 2004). Based on this study, the Mackenzie River estuary serves to increase the riverine fluxes of $\mathrm{Ba}, \mathrm{Co}, \mathrm{Cu}, \mathrm{Mn}$, and $\mathrm{Ni}$ to the coastal Beaufort $\mathrm{Sea}$, and decrease the flux of $\mathrm{Pb}$.

\subsubsection{Fluxes of Ra, DOM, and trace metals from the Mackenzie River to the coastal ocean}

The estuarine changes documented in this study can be used to improve estimates of the ultimately delivery of solutes from the Mackenzie River to the coastal ocean. Flow-weighted average concentrations of $\mathrm{Ba}, \mathrm{DOC}$, and DON in the Mackenzie are available from previous studies (Table 7a). The average flow-weighted ${ }^{228} \mathrm{Ra}$ and ${ }^{226} \mathrm{Ra}$ activities were determined to be $16.8 \mathrm{dpm} 100 \mathrm{~L}^{-1}$ and $17.2 \mathrm{dpm}_{100 \mathrm{~L}^{-1}}$, respectively, based on the data from the time series at Tsiigehtchic (Table 3a). Assuming the estuarine behavior of these constituents remains relatively consistent throughout the year, the additions and removals documented in the East Channel in 2016 were used to adjust these flow-weighted averages, and the adjusted concentrations were multiplied by the average Mackenzie discharge $\left(316 \mathrm{~km}^{3} \mathrm{y}^{-1}\right.$, Holmes et al., 2012) to determine the annual fluxes (Table 7a). The annual fluxes of ${ }^{228} \mathrm{Ra}$ and ${ }^{226} \mathrm{Ra}$ were $8.6 \times 10^{13} \mathrm{dpm} \mathrm{y}^{-1}$ and $7.9 \times 10^{13} \mathrm{dpm} \mathrm{y}^{-1}$, respectively. These are lower than the ${ }^{228} \mathrm{Ra}$ and ${ }^{226} \mathrm{Ra}$ fluxes from the Amazon River $\left(10^{15} \mathrm{dpm} \mathrm{y}^{-1}\right)$ and Mississippi River $\left(10^{14} \mathrm{dpm} \mathrm{y}^{-1}\right)$, but similar to the ${ }^{228} \mathrm{Ra}$ and ${ }^{226} \mathrm{Ra}$ inputs from the Atchafalaya River $\left(10^{13} \mathrm{dpm} \mathrm{y}^{-1}\right)$ (Key et al., 1985; Krest et al., 1999; Moore et al., 1995). The DOC and DON fluxes were $6.4 \times 10^{10} \mathrm{~mol} \mathrm{y}^{-1}$ and $9.4 \times 10^{8} \mathrm{~mol} \mathrm{y}^{-1}$, respectively. Because the average DOC and DON freshwater concentrations were taken from the A-GRO, the DOC and DON flux estimates calculated in this study are $\sim 45 \%$ and $60 \%$ lower, respectively, than the annual estimates of Holmes et al. (2012), reflecting the estuarine removal. The flux of Ba from the Mackenzie was previously estimated by Guay and Falkner (1998) based on the effective river endmember in the East Channel, and their estimate $\left(1.6 \times 10^{8} \mathrm{~mol} \mathrm{y}^{-1}\right)$ agrees well with ours $\left(1.5 \times 10^{8} \mathrm{~mol} \mathrm{y}^{-1}\right)$.

Applying the estuarine changes we observed in 2016 to these annual averages assumes that the same estuarine processes occur year-round. Because the non-conservative changes observed in the estuary likely depend on particle and colloid fluxes, which vary depending on river discharge and season, estuarine transects at other times of year are vital to testing this assumption. Based on the similarity between the Ba-salinity relationships observed in April 1994 (Guay and Falkner, 1998) and June 2016 (this study), the assumption of consistent estuarine behavior likely holds for Ba. On the other hand, the lack of DOC and DON removal in the July 2004 Emmerton et al. (2008b) study indicate that this assumption may not be valid for DOM (possibly due to a higher degree of DOM lability in the spring, see section 5.4.3.3), and that our adjusted fluxes could underestimate the actual DOM delivery. 
We also used the freshwater average concentrations and estuarine changes measured during this study, along with the average Mackenzie discharge in June $2016\left(1.48 \mathrm{~km}^{3} \mathrm{~d}^{-1}\right.$; Water Survey of Canada, 2018), to determine fluxes for this specific month (Table 7b). The ${ }^{228} \mathrm{Ra}$ and ${ }^{226} \mathrm{Ra}$ fluxes for this time period were $4.6 \times 10^{11} \mathrm{dpm} \mathrm{d}^{-1}$ and $4.2 \times 10^{11} \mathrm{dpm} \mathrm{d}^{-1}$, respectively, and the Ba flux was $6.9 \times 10^{5} \mathrm{~mol} \mathrm{~d}^{-1}$. Assuming these represent typical June fluxes, we estimate that $\sim 15 \%$ of the annual ${ }^{228} \mathrm{Ra},{ }^{226} \mathrm{Ra}$, and Ba fluxes occur during June. The June fluxes of DOC and DON were $5.6 \times 10^{8} \mathrm{~mol} \mathrm{~d}^{-1}$ and $1.5 \times 10^{7} \mathrm{~mol} \mathrm{~d}^{-1}$, representing approximately $25 \%$ and $50 \%$ of the annual DOC and DON fluxes, respectively. However, because the June discharge in 2016 was $\sim 20 \%$ below the mean June discharge (Figure 2; Water Survey of Canada, 2018), this year may not be representative of average conditions. Holmes et al. (2012) estimated that 32\% of the annual DON flux and 36\% of the annual DOC flux occurs during May and June based on the concentrations measured in Tsiigehtchic.

The trace metal fluxes determined for June 2016 were $2.2 \times 10^{3} \mathrm{~mol} \mathrm{Co} \mathrm{d}^{-1}, 4.2 \times 10^{4} \mathrm{~mol}$ $\mathrm{Cu} \mathrm{d}^{-1}, 1.9 \times 10^{5} \mathrm{~mol} \mathrm{Mn} \mathrm{d}^{-1}, 3.8 \times 10^{4} \mathrm{~mol} \mathrm{Ni} \mathrm{d}^{-1}, 4.2 \times 10^{1} \mathrm{~mol} \mathrm{~Pb} \mathrm{~d}^{-1}$, and $4.0 \times 10^{3} \mathrm{~mol} \mathrm{U} \mathrm{d}^{-1}$. Recent evidence suggests that solute-particle interactions may be a dominant control on metal fluxes from estuaries; Samanta and Dalai (2018) found strong correlations between the discharge-normalized fluxes of $\mathrm{Cu}$ and $\mathrm{Ni}$ and the discharge-normalized flux of suspended sediments in major estuaries around the world. Based on the average June suspended sediment flux and water discharge in the Mackenzie, the suspended sediment concentration in June is approximately $525 \mathrm{mg} \mathrm{L}^{-1}$ (Holmes et al., 2002). Based on this value and the regression relationships determined by Samanta and Dalai (2018), the predicted estuarine concentrations of $\mathrm{Cu}$ and $\mathrm{Ni}$ are $28 \mathrm{nmol} \mathrm{L}^{-1}$ and $27 \mathrm{nmol} \mathrm{L}^{-1}$, respectively. The concentrations observed on our June 2016 transect (freshwater endmember + change in estuary; Table 7b) were $28 \mathrm{nmol} \mathrm{Cu} \mathrm{L}^{-1}$ and $26 \mathrm{nmol} \mathrm{Ni} \mathrm{L}{ }^{-1}$. The excellent agreement between the predicted and observed values is evidence that solute-particle interactions are the main control on the estuarine concentrations of these metals (see also section 5.4.3.5).

By using water discharge measured at Tsiigehtchic for both the annual and June 2016 flux calculations, we assume that changes occurring in the West and Middle Channels are similar to those observed in the East Channel. Tremblay et al. (2014) measured different distributions of salinity, inorganic nutrients, and DOM in Mackenzie Bay and Kugmallit Bay in 2009, which indicates that this assumption may be invalid, and highlights the need for future studies of the solute distributions in all three channels.

\subsection{CONCLUSIONS}

We investigated the effects of the Mackenzie River delta and estuary on the river chemistry and delivery of solutes to the coastal ocean during a June 2016 transect. This study provides the first measurements of Ra isotopes in Western Arctic rivers and some of the first trace metal measurements in the Mackenzie Estuary, improving our understanding of solute cycling in this important Arctic system. Significant increases in DOM between upstream and downstream sampling locations reflect inputs from the delta, while the concentrations and activities of inorganic nutrients, trace metals, and Ra isotopes were largely unchanged between Tsiigehtchic and Tuktoyaktuk. In the freshwater-saltwater transition zone, changes in the Ra isotope ratios indicated desorption from suspended riverine particles and possible benthic or groundwater inputs. The inorganic nutrients were affected by both biological uptake and this possible benthic source, while a significant fraction of DOM was rapidly lost in the early stages 
of estuarine mixing. Most dissolved trace metal concentrations increased in the estuary due to particle desorption or benthic inputs ( $\mathrm{Ba}, \mathrm{Co}, \mathrm{Cu}, \mathrm{Mn}, \mathrm{Ni}$ ), while $\mathrm{Pb}$ was removed at low salinities, and $\mathrm{U}$ behaved conservatively.

Together, these changes reflect the influence of the delta and the estuary on river chemistry, and indicate that fluxes based on freshwater endmembers alone are not representative of actual solute delivery to the coastal ocean. We calculated flux estimates based on the estuarine removal or addition observed in this study, using flow-weighted average concentrations to represent the freshwater starting point when possible. The resulting ${ }^{228} \mathrm{Ra},{ }^{226} \mathrm{Ra}$, and Ba fluxes were $8.6 \times 10^{13} \mathrm{dpm} \mathrm{y}^{-1}, 7.9 \times 10^{13} \mathrm{dpm} \mathrm{y}^{-1}$, and $1.5 \times 10^{8} \mathrm{~mol} \mathrm{y}^{-1}$, respectively. The DOC and DON fluxes $\left(6.4 \times 10^{10} \mathrm{~mol} \mathrm{y}^{-1}\right.$ and $9.4 \times 10^{8} \mathrm{~mol} \mathrm{y}^{-1}$, respectively) are lower than previous estimates by Holmes et al. (2012), but may be underestimates because this DOM removal is not observed year-round (Emmerton et al., 2008b). This estuarine removal indicates that DOM degradation rates based on freshwater DOM concentrations overestimate the actual rate of DOM removal in the Western Arctic basin, because they do not account for loss in the estuary.

For constituents without available annual flow-weighted averages, the flux for June 2016 was estimated. Assuming these fluxes are normal for the month of June, the delivery of ${ }^{228} \mathrm{Ra}$,

${ }^{226} \mathrm{Ra}$, and Ba during this month accounts for $\sim 15 \%$ of the annual fluxes, while the DOC and DON fluxes during June are $\sim 25 \%$ and $\sim 50 \%$ of the annual fluxes, respectively. These estimates are based on the conditions observed in the East Channel during June 2016; more studies are needed to assess the spatial (between channels) and temporal (between years and seasons) variability in the estuarine behavior of these species.

Future studies will also be important for monitoring climate-induced changes in the river chemistry and delivery of solutes through the estuary. The degradation of permafrost is likely to increase the major ion and nutrient concentrations in Arctic rivers (Frey et al., 2007b, 2007a; Frey and McClelland, 2009; Keller et al., 2010), and has already been implicated as the mechanism behind observed DOC and alkalinity increases in the Mackenzie (Tank et al., 2016). Changes in the estuary and over the shelf could further modify these variations in solute delivery. Arctic river discharge is increasing (McClelland et al., 2006; Rawlins et al., 2010), which may intensify stratification in the surface ocean but could also lead to stronger entrainment of deeper waters in the estuary (McClelland et al., 2012). These physical alterations could impact primary productivity if they shift the euphotic zone or nutricline (Tremblay et al., 2015). Increased delivery of $\mathrm{N}$ to the Beaufort Shelf is unlikely to relieve the $\mathrm{N}$ limitation on primary productivity in this region, but this change, along with the predicted increases in Si delivery, could affect the ratios of nutrients exported to the North Atlantic (Le Fouest et al., 2013). Because these modifications are already occurring, this study cannot provide baseline measurements against which climate-caused changes can be assessed, but it serves as an important time point in the continued monitoring of Arctic river and estuary chemistry.

\section{Acknowledgements}

Paul Henderson was a fantastic field work partner during our June 2016 trip to the Mackenzie Delta, and provided essential sample collection and logistical support. This work could not have been completed without the sampling assistance of Les Kutny in Tsiigehtchic, the sampling assistance of James Keevik in Tukoyaktuk, and the logistical support of the Aurora Research Institute. We appreciate the support of the members of the Arctic Great Rivers Observatory, and we thank Les Kutny for collecting time series samples at Tsiigehtchic and Edda Mutter for 
collecting time series samples at Pilot Station. We thank Paul Henderson and the WHOI Nutrient Analytical Facility for nutrient analyses; Gretchen Swarr and the WHOI Plasma Mass Spectrometry Facility for trace metal analyses; Anya Suslova (Woods Hole Research Center) for analyzing DOC and DON; Kate Morkeski, Eyal Wurgaft, and Shuzhen Song for measuring DIC and alkalinity; David Wellwood for measuring salinity; and Elvira Delgado and the UC Davis Stable Isotope Facility for water isotope analyses. Thanks to Jessica Dabrowski for assistance with ICP analyses and for creating the ArcGIS maps, Tristan Horner and Maureen Auro for sharing the trace element ICP standard and for helpful advice on ICP procedures, and Bernhard Peucker-Ehrenbrink for lending us the equipment used to collect suspended sediment samples, sharing his SLRS-6 CRM, and for thoughtful discussions. This project was funded by a Graduate Student Research Award from the North Pacific Research Board and a Woods Hole Oceanographic Institution Ocean Ventures Fund Award to L.E.K. This research was conducted with Government support under and awarded by DoD, Air Force Office of Scientific Research, National Defense Science and Engineering Graduate (NDSEG) Fellowship awarded to L.E.K., 32 CFR 168a. 


\section{References}

Andersen, M.B., Stirling, C.H., Porcelli, D., Halliday, A.N., Andersson, P.S., Baskaran, M., 2007. The tracing of riverine $U$ in Arctic seawater with very precise ${ }^{234} \mathrm{U} /{ }^{238} \mathrm{U}$ measurements. Earth Planet. Sci. Lett. 259, 171-185. doi:10.1016/j.epsl.2007.04.051

Benner, R., Opsahl, S., 2001. Molecular indicators of the sources and transformations of dissolved organic matter in the Mississippi river plume. Org. Geochem. 32, 597-611. doi:10.1016/S0146-6380(00)00197-2

Bewers, J.M., Yeats, P.A., 1978. Trace metals in the waters of a partially mixed estuary. Estuar. Coast. Mar. Sci. 7, 147-162. doi:10.1016/0302-3524(78)90071-3

Boyle, E., Collier, R., Dengler, A.T., 1974. On the chemical mass- balance in estuaries. Geochim. Cosmochim. Acta 38, 1719-1728. doi:10.1016/0016-7037(74)90188-4

Boyle, E.A., Edmond, J.M., Sholkovitz, E.R., 1977. The mechanism of iron removal in estuaries. Geochim. Cosmochim. Acta 41, 1313-1324. doi:10.1016/0016-7037(77)90075-8

Boyle, E.A., Huested, S.S., Grant, B., 1982. The chemical mass balance of the amazon plume-II. Copper, nickel, and cadmium. Deep Sea Res. Part A, Oceanogr. Res. Pap. 29, 1355-1364. doi:10.1016/0198-0149(82)90013-9

Brown, J., Ferrians, O.J.J., Heginbottom, J.A., Melnikov, E.S., 1998. Circum-Arctic Map of Permafrost and Ground Ice Conditions. Boulder, Colorado.

Byrd, J.T., Lee, K.W., Lee, D.S., Smith, R.G., Windom, H.L., 1990. The Behavior of Trace Metals in the Geum Estuary, Korea. Estuaries 13, 8-13. doi:10.2307/1351426

Cai, W.-J., Hu, X., Huang, W.-J., Jiang, L.-Q., Wang, Y., Peng, T.-H., Zhang, X., 2010. Alkalinity distribution in the western North Atlantic Ocean margins. J. Geophys. Res. 115, C08014. doi:10.1029/2009JC005482

Cai, W.J., 2003. Riverine inorganic carbon flux and rate of biological uptake in the Mississippi River plume. Geophys. Res. Lett. 30, 1997-2000. doi:10.1029/2002GL016312

Callaway, R.J., Specht, D.T., Ditsworth, G.R., 1988. Manganese and Suspended Matter in the Yaquina Estuary, Oregon. Estuaries 11, 217. doi:10.2307/1352007

Carmack, E.C., Macdonald, R.W., 2002. Oceanography of the Canadian Shelf of the Beaufort Sea: A Setting for Marine Life. Arctic 55, 29-45.

Carmack, E.C., Macdonald, R.W., Jasper, S., 2004. Phytoplankton productivity on the Canadian Shelf of the Beaufort Sea. Mar. Ecol. Prog. Ser. 277, 37-50. doi:10.3354/meps 277037

Carroll, J., Falkner, K.K., Brown, E.T., Moore, W.S., 1993. The role of the Ganges-Brahmaputra mixing zone in supplying barium and ${ }^{226}$ Ra to the Bay of Bengal. Geochim. Cosmochim. Acta 57, 2981-2990. doi:10.1016/0016-7037(93)90287-7

Carson, M.A., Jasper, J.N., Conly, F.M., 1998. Magnitude and Sources of Sediment Input to the Mackenzie Delta, Northwest Territories, 1974 - 94. Arctic 51, 116-124.

Charette, M.A., 2007. Hydrologic forcing of submarine groundwater discharge: Insight from a seasonal study of radium isotopes in a groundwater-dominated salt marsh estuary. Limnol. Oceanogr. 52, 230-239. doi:10.4319/lo.2007.52.1.0230

Charette, M.A., Buesseler, K.O., Andrews, J.E., 2001. Utility of radium isotopes for evaluating the input and transport of groundwater-derived nitrogen to a Cape Cod estuary. Limnol. Oceanogr. 46, 465-470. doi:10.4319/lo.2001.46.2.0465

Charette, M.A., Moore, W.S., Burnett, W.C., 2008. Uranium- and Thorium-Series Nuclides as Tracers of Submarine Groundwater Discharge, in: Radioactivity in the Environment. pp. 155-191. doi:10.1016/S1569-4860(07)00005-8 
Charette, M.A., Sholkovitz, E.R., 2002. Oxidative precipitation of groundwater-derived ferrous iron in the subterranean estuary of a coastal bay. Geophys. Res. Lett. 29, 85-1-85-4. doi:10.1029/2001GL014512

Charette, M.A., Sholkovitz, E.R., 2006. Trace element cycling in a subterranean estuary: Part 2. Geochemistry of the pore water. Geochim. Cosmochim. Acta 70, 811-826. doi:10.1016/j.gca.2005.10.019

Chiffoleau, J.F., Cossa, D., Auger, D., Truquet, I., 1994. Trace metal distribution, partition and fluxes in the Seine estuary (France) in low discharge regime. Mar. Chem. 47, 145-158. doi:10.1016/0304-4203(94)90105-8

Church, T.M., 1986. Biogeochemical factors influencing the residence time of microconstituents in a large tidal estuary, Delaware Bay. Mar. Chem. 18, 393-406. doi:10.1016/03044203(86)90020-4

Coffey, M., Dehairs, F., Collette, O., Luther, G., Church, T., Jickells, T., 1997. The Behaviour of Dissolved Barium in Estuaries. Estuar. Coast. Shelf Sci. 45, 113-121. doi:10.1006/ecss.1996.0157

Cooper, L.W., Benner, R., McClelland, J.W., Peterson, B.J., Holmes, R.M., Raymond, P.A., Hansell, D.A., Grebmeier, J.M., Codispoti, L.A., 2005. Linkages among runoff, dissolved organic carbon, and the stable oxygen isotope composition of seawater and other water mass indicators in the Arctic Ocean. J. Geophys. Res. Biogeosciences 110. doi:10.1029/2005JG000031

Cooper, L.W., McClelland, J.W., Holmes, R.M., Raymond, P.A., Gibson, J.J., Guay, C.K., Peterson, B.J., 2008. Flow-weighted values of runoff tracers $\left(\delta^{18} \mathrm{O}, \mathrm{DOC}, \mathrm{Ba}\right.$, alkalinity) from the six largest Arctic rivers. Geophys. Res. Lett. 35, 3-7. doi:10.1029/2008GL035007

Couturier, M., Nozais, C., Chaillou, G., 2016. Microtidal subterranean estuaries as a source of fresh terrestrial dissolved organic matter to the coastal ocean. Mar. Chem. 186, 46-57. doi:10.1016/j.marchem.2016.08.001

Cross, J.N., Mathis, J.T., Bates, N.R., Byrne, R.H., 2013. Conservative and non-conservative variations of total alkalinity on the southeastern Bering Sea shelf. Mar. Chem. 154, 100112. doi:10.1016/j.marchem.2013.05.012

de Sieyes, N.R., Yamahara, K.M., Layton, B.A., Joyce, E.H., Boehm, A.B., 2008. Submarine discharge of nutrient-enriched fresh groundwater at Stinson Beach, California is enhanced during neap tides. Limnol. Oceanogr. 53, 1434-1445. doi:10.4319/lo.2008.53.4.1434

Dittmar, T., Kattner, G., 2003. The biogeochemistry of the river and shelf ecosystem of the Arctic Ocean: a review. Mar. Chem. 83, 103-120. doi:10.1016/S0304-4203(03)00105-1

Dulaiova, H., Burnett, W.C., Wattayakorn, G., Sojisuporn, P., 2006. Are groundwater inputs into river-dominated areas important? The Chao Phraya River - Gulf of Thailand. Limnol. Oceanogr. 51, 2232-2247. doi:10.4319/lo.2006.51.5.2232

Edmond, J.M., Boyle, E.D., Drummond, D., Grant, B., Mislick, T., 1978. Desorption of barium in the plume of the Zaire (Congo) river. Netherlands J. Sea Res. 12, 324-328. doi:10.1016/0077-7579(78)90034-0

Edmond, J.M., Spivack, A., Grant, B.C., Ming-Hui, H., Zexiam; Chen Sung; Zeng Xiushau, C., 1985. Chemical dynamics of the Changjiang estuary. Cont. Shelf Res. 4, 17-36. doi:10.1016/0278-4343(85)90019-6

Elsinger, R.J., Moore, W.S., 1980. ${ }^{226}$ Ra behavior in the Pee Dee River-Winyah Bay estuary. Earth Planet. Sci. Lett. 48, 239-249. doi:10.1016/0012-821X(80)90187-9

Emmerton, C.A., Lesack, L.F.W., Marsh, P., 2007. Lake abundance, potential water storage, and 
habitat distribution in the Mackenzie River Delta, western Canadian Arctic. Water Resour. Res. 43. doi:10.1029/2006WR005139

Emmerton, C.A., Lesack, L.F.W., Vincent, W.F., 2008a. Mackenzie River nutrient delivery to the Arctic Ocean and effects of the Mackenzie Delta during open water conditions. Global Biogeochem. Cycles 22, 1-15. doi:10.1029/2006GB002856

Emmerton, C.A., Lesack, L.F.W., Vincent, W.F., 2008b. Nutrient and organic matter patterns across the Mackenzie River, estuary and shelf during the seasonal recession of sea-ice. J. Mar. Syst. 74, 741-755. doi:10.1016/j.jmarsys.2007.10.001

Environment and Climate Change Canada, 2018. Lower Mackenzie River Basin Long-term Water Quality Monitoring Data - Canada's North.

Finlay, J., Neff, J., Zimov, S., Davydova, A., Davydov, S., 2006. Snowmelt dominance of dissolved organic carbon in high-latitute watersheds: Implications for characterization and flux of river DOC. Geophys. Res. Lett. 33, 2-6. doi:10.1029/2006GL025754

Fisher, T.R., Parsley, P.E., 1979. Amazon lakes: Water storage and nutrient stripping by algae. Limnol. Oceanogr. 24, 547-553. doi:10.4319/lo.1979.24.3.0547

Forsberg, B.R., Devol, A.H., Richey, J.E., Martinelli, L.A., 1988. Factors controlling nutrient concentrations in Amazon floodplain lakes. Limnol. Ocean. 33, 41-56.

Frey, K.E., McClelland, J.W., 2009. Impacts of permafrost degradation on arctic river biogeochemistry. Hydrol. Process. 23, 169-182. doi:10.1002/hyp.7196

Frey, K.E., McClelland, J.W., Holmes, R.M., Smith, L.C., 2007a. Impacts of climate warming and permafrost thaw on the riverine transport of nitrogen and phosphorus to the Kara Sea. J. Geophys. Res. Biogeosciences 112. doi:10.1029/2006JG000369

Frey, K.E., Siegel, D.I., Smith, L.C., 2007b. Geochemistry of west Siberian streams and their potential response to permafrost degradation. Water Resour. Res. 43. doi:10.1029/2006WR004902

Fritz, M., Wetterich, S., Meyer, H., Schirrmeister, L., Lantuit, H., Pollard, W.H., 2011. Origin and characteristics of massive ground ice on Herschel Island (western Canadian Arctic) as revealed by stable water isotope and Hydrochemical signatures. Permafr. Periglac. Process. 22, 26-38. doi:10.1002/ppp.714

Froelich, P.N., 1988. Kinetic control of dissolved phosphate in natural rivers and estuaries: A primer on the phosphate buffer mechanism. Limnol. Oceanogr. 33, 649-668. doi:10.4319/lo.1988.33.4part2.0649

Gibson, J.J., Edwards, T.W.D., Birks, S.J., St Amour, N.A., Buhay, W.M., McEachern, P., Wolfe, B.B., Peters, D.L., 2005. Progress in isotope tracer hydrology in Canada. Hydrol. Process. 19, 303-327. doi:10.1002/hyp.5766

Gonneea, M.E., Morris, P.J., Dulaiova, H., Charette, M.A., 2008. New perspectives on radium behavior within a subterranean estuary. Mar. Chem. 109, 250-267. doi:10.1016/j.marchem.2007.12.002

Gonneea, M.E., Mulligan, A.E., Charette, M.A., 2013. Seasonal cycles in radium and barium within a subterranean estuary: Implications for groundwater derived chemical fluxes to surface waters. Geochim. Cosmochim. Acta 119, 164-177. doi:10.1016/j.gca.2013.05.034

Gordeev, V. V., 2000. River Input of Water, Sediment, Major Ions, Nutrients and Trace Metals from Russian Territory to the Arctic Ocean, in: Lewis, E.L., Jones, E.P., Lemke, P., Prowse, T.D., Wadhams, P. (Eds.), The Freshwater Budget of the Arctic Ocean. Springer Netherlands, Dordrecht, pp. 297-322. doi:10.1007/978-94-011-4132-1_14 
Guay, C.K., Falkner, K.K., 1997. Barium as a tracer of Arctic halocline and river waters. Deep

Sea Res. Part II Top. Stud. Oceanogr. 44, 1543-1569. doi:10.1016/S0967-0645(97)00066-0

Guay, C.K., Falkner, K.K., 1998. A survey of dissolved barium in the estuaries of major Arctic rivers and adjacent seas. Cont. Shelf Res. 18, 859-882. doi:10.1016/S0278-4343(98)000235

Guay, C.K., Klinkhammer, G.P., Falkner, K.K., Benner, R., Coble, P.G., Whitledge, T.E., Black, B., Bussell, F.J., Wagner, T.A., 1999. High-resolution measurements of dissolved organic carbon in the Arctic Ocean by in situ fiber-optic spectrometry. Geophys. Res. Lett. 26, 1007-1010. doi:10.1029/1999GL900130

Guay, C.K.H., McLaughlin, F.A., Yamamoto-Kawai, M., 2009. Differentiating fluvial components of upper Canada Basin waters on the basis of measurements of dissolved barium combined with other physical and chemical tracers. J. Geophys. Res. 114, C00A09. doi:10.1029/2008JC005099

Guieu, C., Huang, W.W., Martin, J.M., Yong, Y.Y., 1996. Outflow of trace metals into the Laptev Sea by the Lena River. Mar. Chem. 53, 255-267. doi:10.1016/0304-4203(95)000933

Hansell, D.A., Kadko, D., Bates, N.R., 2004. Degradation of Terrigenous Dissolved Organic Carbon in the Western Arctic Ocean. Science 304, 858-861. doi:10.1126/science.1096175

Henderson, P.B., Morris, P.J., Moore, W.S., Charette, M.A., 2013. Methodological advances for measuring low-level radium isotopes in seawater. J. Radioanal. Nucl. Chem. 296, 357-362. doi:10.1007/s10967-012-2047-9

Holmes, R.M., Coe, M.T., Fiske, G.J., Gurtovaya, T., McClelland, J.W., Shiklomanov, A.I., Spencer, R.G.M., Tank, S.E., Zhulidov, A. V., 2013. Climate Change Impacts on the Hydrology and Biogeochemistry of Arctic Rivers, in: Climatic Change and Global Warming of Inland Waters. John Wiley \& Sons, Ltd, Chichester, UK, pp. 3-26. doi:10.1002/9781118470596.ch1

Holmes, R.M., McClelland, J.W., Peterson, B.J., Shiklomanov, I.A., Shiklomanov, A.I., Zhulidov, A. V., Gordeev, V. V., Bobrovitskaya, N.N., 2002. A circumpolar perspective on fluvial sediment flux to the Arctic ocean. Global Biogeochem. Cycles 16. doi:10.1029/2001GB001849

Holmes, R.M., McClelland, J.W., Peterson, B.J., Tank, S.E., Bulygina, E., Eglinton, T.I., Gordeev, V. V., Gurtovaya, T.Y., Raymond, P.A., Repeta, D.J., Staples, R., Striegl, R.G., Zhulidov, A. V., Zimov, S.A., 2012. Seasonal and Annual Fluxes of Nutrients and Organic Matter from Large Rivers to the Arctic Ocean and Surrounding Seas. Estuaries and Coasts 35, 369-382. doi:10.1007/s12237-011-9386-6

Holmes, R.M., McClelland, J.W., Raymond, P.A., Frazer, B.B., Peterson, B.J., Stieglitz, M., 2008. Lability of DOC transported by Alaskan rivers to the Arctic Ocean. Geophys. Res. Lett. 35, 3-7. doi:10.1029/2007GL032837

Holmes, R.M., McClelland, J.W., Tank, S.E., Spencer, R.G.M., Shiklomanov., A.I., 2018. Arctic Great Rivers Observatory Water Quality Dataset, Version 20180417.

IAEA/WMO, 2018. Global Network of Isotopes in Precipitation. GNIP Database. URL: https://nucleus.iaea.org/wiser

Jickells, T., 2005. External inputs as a contributor to eutrophication problems. J. Sea Res. 54, 58-69. doi:10.1016/j.seares.2005.02.006

Junk, W.J., Bayley, P.B., Sparks, R.E., 1989. The flood-pulse concept in river-floodplain systems. Proc. Int. Large River Symp. Can. Spec. Publ. Fish. Aquat. Sci. 
Karcher, M.J., Oberhuber, J.M., 2002. Pathways and modification of the upper and intermediate waters of the Arctic Ocean. J. Geophys. Res. 107, 3049. doi:10.1029/2000JC000530

Keeney-Kennicutt, W.L., Presley, B.J., 1986. The geochemistry of trace metals in the Brazos River estuary. Estuar. Coast. Shelf Sci. 22, 459-477. doi:10.1016/0272-7714(86)90068-5

Keller, K., Blum, J.D., Kling, G.W., 2010. Stream geochemistry as an indicator of increasing permafrost thaw depth in an arctic watershed. Chem. Geol. 273, 76-81. doi:10.1016/j.chemgeo.2010.02.013

Key, R.M., Stallard, R.F., Moore, W.S., Sarmiento, J.L., 1985. Distribution and Flux of ${ }^{226}$ Ra and ${ }^{228} \mathrm{Ra}$ in the Amazon River Estuary. J. Geophys. Res. 90, 6995-7004. doi:10.1029/JC090iC04p06995

Kim, T.H., Waska, H., Kwon, E., Suryaputra, I.G.N., Kim, G., 2012. Production, degradation, and flux of dissolved organic matter in the subterranean estuary of a large tidal flat. Mar. Chem. 142-144, 1-10. doi:10.1016/j.marchem.2012.08.002

Klunder, M.B., Bauch, D., Laan, P., De Baar, H.J.W., Van Heuven, S., Ober, S., 2012. Dissolved iron in the Arctic shelf seas and surface waters of the central Arctic Ocean: Impact of Arctic river water and ice-melt. J. Geophys. Res. Ocean. 117. doi:10.1029/2011JC007133

Knee, K.L., Paytan, A., 2011. Submarine Groundwater Discharge, in: Treatise on Estuarine and Coastal Science. Elsevier, pp. 205-233. doi:10.1016/B978-0-12-374711-2.00410-1

Krest, J.M., Moore, W.S., Gardner, L.R., Morris, J.T., 2000. Marsh nutrient export supplied by groundwater discharge: Evidence from radium measurements. Global Biogeochem. Cycles 14, 167-176. doi:10.1029/1999GB001197

Krest, J.M., Moore, W.S., Rama, 1999. ${ }^{226} \mathrm{Ra}$ and ${ }^{228} \mathrm{Ra}$ in the mixing zones of the Mississippi and Atchafalaya Rivers: indicators of groundwater input. Mar. Chem. 64, 129-152. doi:10.1016/S0304-4203(98)00070-X

Lacelle, D., 2011. On the $\delta 1^{8} \mathrm{O}, \delta \mathrm{D}$ and D-excess relations in meteoric precipitation and during equilibrium freezing: Theoretical approach and field examples. Permafr. Periglac. Process. 22, 13-25. doi:10.1002/ppp.712

Le Fouest, V., Babin, M., Tremblay, J.-É., 2013. The fate of riverine nutrients on Arctic shelves. Biogeosciences 10, 3661-3677. doi:10.5194/bg-10-3661-2013

Lecher, A.L., Chien, C. Te, Paytan, A., 2016. Submarine groundwater discharge as a source of nutrients to the North Pacific and Arctic coastal ocean. Mar. Chem. 186, 167-177. doi:10.1016/j.marchem.2016.09.008

Lesack, L.F.W., Marsh, P., 2007. Lengthening plus shortening of river-to-lake connection times in the Mackenzie River Delta respectively via two global change mechanisms along the arctic coast. Geophys. Res. Lett. 34. doi:10.1029/2007GL031656

Lesack, L.F.W., Marsh, P., Hecky, R.E., 1998. Spatial and temporal dynamics of major solute chemistry among Mackenzie Delta lakes. Limnol. Oceanogr. 43, 1530-1543. doi:10.4319/lo.1998.43.7.1530

Letscher, R.T., Hansell, D.A., Kadko, D., Bates, N.R., 2013. Dissolved organic nitrogen dynamics in the Arctic Ocean. Mar. Chem. 148, 1-9. doi:10.1016/j.marchem.2012.10.002

Li, Y., Chan, L., 1979. Desorption of Ba and ${ }^{226} \mathrm{Ra}$ from river-borne sediments in the Hudson Estuary. Earth Planet. Sci. Lett. 43, 343-350. doi:10.1016/0012-821X(79)90089-X

Li, Y., Mathieu, G., Biscaye, P., Simpson, H.J., 1977. The Flux of ${ }^{226}$ Ra from estuarine and continental shelf sediments. Earth Planet. Sci. Lett. 37, 237-241. doi:10.1016/0012$821 \mathrm{X}(77) 90168-6$

Macdonald, R.W., 2000. Arctic Estuaries and Ice: A Positive-Negative Estuarine Couple, in: 
Lewis, E.L., Jones, E.P., Lemke, P., Prowse, T.D., Wadhams, P. (Eds.), The Freshwater Budget of the Arctic Ocean. Springer Netherlands, Dordrecht, pp. 383-407.

doi:10.1007/978-94-011-4132-1_17

Macdonald, R.W., Carmack, E.C., McLaughlin, F.A., Falkner, K.K., Swift, J.H., 1999. Connections among ice, runoff and atmospheric forcing in the Beaufort Gyre. Geophys. Res. Lett. 26, 2223-2226. doi:10.1029/1999GL900508

Macdonald, R.W., Solomon, S.M., Cranston, R.E., Welch, H.E., Yunker, M.B., Gobeil, C., 1998. A sediment and organic carbon budget for the Canadian Beaufort Shelf. Mar. Geol. 144, 255-273.

Macdonald, R.W., Wong, C.S., Erickson, P.E., 1987. The distribution of nutrients in the southeastern Beaufort Sea: Implications for water circulation and primary production. J. Geophys. Res. 92, 2939-2952. doi:10.1029/JC092iC03p02939

Macdonald, R.W., Yu, Y., 2006. The Mackenzie Estuary of the Arctic ocean. Handb. Environ. Chem. Vol. 5 Water Pollut. 5, 91-120. doi:10.1007/698-5-027

Mackay, J.R., Dallimore, S.R., 1992. Massive ice of the Tuktoyaktuk area, western Arctic coast, Canada. Can. J. Earth Sci. 29, 1235-1249. doi:10.1139/e92-099

Maine, M.A., Suñe, N.L., Bonetto, C., 2004. Nutrient concentrations in the Middle Paraná River: effect of the floodplain lakes. Arch. für Hydrobiol. 160, 85-103. doi:10.1127/00039136/2004/0160-0085

McClelland, J.W., Déry, S.J., Peterson, B.J., Holmes, R.M., Wood, E.F., 2006. A pan-arctic evaluation of changes in river discharge during the latter half of the 20th century. Geophys. Res. Lett. 33. doi:10.1029/2006GL025753

McClelland, J.W., Holmes, R.M., Dunton, K.H., Macdonald, R.W., 2012. The Arctic Ocean Estuary. Estuaries and Coasts 35, 353-368. doi:10.1007/s12237-010-9357-3

Michel, F.A., 2011. Isotope characterisation of ground ice in northern Canada. Permafr. Periglac. Process. 22, 3-12. doi:10.1002/ppp.721

Millot, R., Gaillardet, J., Dupré, B., Allègre, C.J., 2003. Northern latitude chemical weathering rates: clues from the Mackenzie River Basin, Canada. Geochim. Cosmochim. Acta 67, 1305-1329. doi:10.1016/S0016-7037(02)01207-3

Moore, W.S., 1981. Radium isotopes in the Chesapeake Bay. Estuar. Coast. Shelf Sci. 12, 713 723. doi:10.1016/S0302-3524(81)80067-9

Moore, W.S., 1992. Radionuclides of the uranium and thorium decay series in the estuarine environment, in: Ivanovich, M., Harmon, R.S. (Eds.), Uranium-Series Disequilibrium: Applications to Earth, Marine, and Environmental Science. Oxford University Press, New York, pp. 397-422.

Moore, W.S., 2000a. Determining coastal mixing rates using radium isotopes. Cont. Shelf Res. 20, 1993-2007. doi:10.1016/S0278-4343(00)00054-6

Moore, W.S., 2000b. Ages of continental shelf waters determined from ${ }^{223}$ Ra and ${ }^{224}$ Ra. J. Geophys. Res. Ocean. 105, 22117-22122. doi:10.1029/1999JC000289

Moore, W.S., Arnold, R., 1996. Measurement of ${ }^{223} \mathrm{Ra}$ and ${ }^{224} \mathrm{Ra}$ in coastal waters using a delayed coincidence counter. J. Geophys. Res. 101, 1321-1329. doi:10.1029/95JC03139

Moore, W.S., Astwood, H., Lindstrom, C., 1995. Radium isotopes in coastal waters on the Amazon shelf. Geochim. Cosmochim. Acta 59, 4285-4298. doi:10.1016/00167037(95)00242-R 
Moore, W.S., Krest, J., 2004. Distribution of ${ }^{223} \mathrm{Ra}$ and ${ }^{224} \mathrm{Ra}$ in the plumes of the Mississippi and Atchafalaya Rivers and the Gulf of Mexico. Mar. Chem. 86, 105-119. doi:10.1016/j.marchem.2003.10.001

Moore, W.S., Sarmiento, J.L., Key, R.M., 1986. Tracing the Amazon component of surface Atlantic water using ${ }^{228} \mathrm{Ra}$, salinity and silica. J. Geophys. Res. 91, 2574-2580.

Moore, W.S., Todd, J.F., 1993. Radium isotopes in the Orinoco estuary and eastern Caribbean Sea. J. Geophys. Res. Ocean. 98, 2233-2244. doi:10.1029/92JC02760

Officer, C.B., Lynch, D.R., 1981. Dynamics of mixing in estuaries. Estuar. Coast. Shelf Sci. 12, 525-533. doi:10.1016/S0302-3524(81)80079-5

Oldham, V.E., Miller, M.T., Jensen, L.T., Luther, G.W., 2017. Revisiting Mn and Fe removal in humic rich estuaries. Geochim. Cosmochim. Acta 209, 267-283. doi:10.1016/j.gca.2017.04.001

Östlund, H.G., Hut, G., 1984. Arctic Ocean water mass balance from isotope data. J. Geophys. Res. 89, 6373. doi:10.1029/JC089iC04p06373

Owens, N.J.P., 1986. Estuarine nitrification: A naturally occurring fluidized bed reaction? Estuar. Coast. Shelf Sci. 22, 31-44. doi:10.1016/0272-7714(86)90022-3

Peterson, B.J., Holmes, R.M., McClelland, J.W., Amon, R., Brabets, T., Gordeev, V. V., Guay, C., Milburn, D., Staples, R., Raymond, P.A., Shiklomanov, I., Striegl, R.G., Zhulidov, A., Gurtovaya, T., Zimov, S., 2016. PARTNERS Project Arctic River Biogeochemical Data. doi:10.18739/A2166T

Pokrovsky, O.S., Viers, J., Shirokova, L.S., Shevchenko, V.P., Filipov, A.S., Dupré, B., 2010. Dissolved, suspended, and colloidal fluxes of organic carbon, major and trace elements in the Severnaya Dvina River and its tributary. Chem. Geol. 273, 136-149. doi:10.1016/j.chemgeo.2010.02.018

Presti, M., Michalopoulos, P., 2008. Estimating the contribution of the authigenic mineral component to the long-term reactive silica accumulation on the western shelf of the Mississippi River Delta. Cont. Shelf Res. 28, 823-838. doi:10.1016/j.csr.2007.12.015

Rama, Moore, W.S., 1996. Using the radium quartet for evaluating groundwater input and water exchange in salt marshes. Geochim. Cosmochim. Acta 60, 4645-4652. doi:10.1016/S00167037(96)00289-X

Rawlins, M.A., Steele, M., Holland, M.M., Adam, J.C., Cherry, J.E., Francis, J.A., Groisman, P.Y., Hinzman, L.D., Huntington, T.G., Kane, D.L., Kimball, J.S., Kwok, R., Lammers, R.B., Lee, C.M., Lettenmaier, D.P., McDonald, K.C., Podest, E., Pundsack, J.W., Rudels, B., Serreze, M.C., Shiklomanov, A., Skagseth, Ø., Troy, T.J., Vörösmarty, C.J., Wensnahan, M., Wood, E.F., Woodgate, R., Yang, D., Zhang, K., Zhang, T., 2010. Analysis of the Arctic System for Freshwater Cycle Intensification: Observations and Expectations. J. Clim. 23, 5715-5737. doi:10.1175/2010JCLI3421.1

Raymond, P.A., Bauer, J.E., 2001. DOC cycling in a temperate estuary: A mass balance approach using natural. Limnol. Ocean. 46, 655-667. doi:10.4319/lo.2001.46.3.0655

Redfield, A.C., 1958. The biological control of chemical factors in the environment. Am. Sci. 46, 205-221.

Reid, D.F., Key, R.M., Schink, D.R., 1979. Radium, thorium, and actinium extraction from seawater using an improved manganese-oxide-coated fiber. Earth Planet. Sci. Lett. 43, 223 226. doi:10.1016/0012-821X(79)90205-X

Reimnitz, E., 2002. Interactions of River Discharge with Sea Ice in Proximity of Arctic Deltas: A Review. Polarforschung 70, 123-134. 
Rember, R.D., Trefry, J.H., 2004. Increased concentrations of dissolved trace metals and organic carbon during snowmelt in rivers of the alaskan arctic. Geochim. Cosmochim. Acta 68, 477-489. doi:10.1016/S0016-7037(03)00458-7

Rodellas, V., Garcia-Orellana, J., Trezzi, G., Masqué, P., Stieglitz, T.C., Bokuniewicz, H., Cochran, J.K., Berdalet, E., 2017. Using the radium quartet to quantify submarine groundwater discharge and porewater exchange. Geochim. Cosmochim. Acta 196, 58-73. doi:10.1016/j.gca.2016.09.016

Rousseau, T.C.C., Sonke, J.E., Chmeleff, J., van Beek, P., Souhaut, M., Boaventura, G., Seyler, P., Jeandel, C., 2015. Rapid neodymium release to marine waters from lithogenic sediments in the Amazon estuary. Nat. Commun. 6. doi:10.1038/ncomms8592

Rutgers van der Loeff, M., Key, R.M., Scholten, J., Bauch, D., Michel, A., 1995. ${ }^{228}$ Ra as a tracer for shelf water in the Arctic Ocean. Deep Sea Res. Part II Top. Stud. Oceanogr. 42, $1533-1553$.

Rutgers van der Loeff, M., Kuhne, S., Wahsner, M., Holtzen, H., Frank, M., Ekwurzel, B., Mensch, M., Rachold, V., 2003. ${ }^{228} \mathrm{Ra}$ and ${ }^{226} \mathrm{Ra}$ in the Kara and Laptev seas. Cont. Shelf Res. 23, 113-124. doi:10.1016/S0304-4203(98)00070-X

Samanta, S., Dalai, T.K., 2018. Massive production of heavy metals in the Ganga (Hooghly) River estuary, India: Global importance of solute-particle interaction and enhanced metal fluxes to the oceans. Geochim. Cosmochim. Acta 228, 243-258. doi:10.1016/j.gca.2018.03.002

Shiller, A.M., Boyle, E.A., 1987. Variability of dissolved trace metals in the Mississippi River. Geochim. Cosmochim. Acta 51, 3273-3277. doi:10.1016/0016-7037(87)90134-7

Shiller, A.M., Boyle, E.A., 1991. Trace elements in the Mississippi River Delta outflow region: Behavior at high discharge. Geochim. Cosmochim. Acta 55, 3241-3251. doi:10.1016/00167037(91)90486-O

Shim, M.J., Cai, Y., Guo, L., Shiller, A.M., 2017. Floodplain effects on the transport of dissolved and colloidal trace elements in the East Pearl River, Mississippi. Hydrol. Process. 31, 10861099. doi:10.1002/hyp.11093

Sholkovitz, E.R., 1976. Flocculation of dissolved organic and inorganic matter during the mixing of river water and seawater. Geochim. Cosmochim. Acta 40, 831-845. doi:10.1016/00167037(76)90035-1

Sholkovitz, E.R., 1978. The flocculation of dissolved Fe, Mn, Al, Cu, Ni, Co and Cd during estuarine mixing. Earth Planet. Sci. Lett. 41, 77-86. doi:10.1016/0012-821X(78)90043-2

Sholkovitz, E.R., Boyle, E.A., Price, N.B., 1978. The removal of dissolved humic acids and iron during estuarine mixing. Earth Planet. Sci. Lett. 40, 130-136. doi:10.1016/0012821X(78)90082-1

Slomp, C.P., Van Cappellen, P., 2004. Nutrient inputs to the coastal ocean through submarine groundwater discharge: controls and potential impact. J. Hydrol. 295, 64-86. doi:10.1016/j.jhydrol.2004.02.018

Spears, B.M., Lesack, L.F., 2006. Bacterioplankton production, abundance, and nutrient limitation among lakes of the Mackenzie Delta (western Canadian arctic). Can. J. Fish. Aquat. Sci. 63, 845-857. doi:10.1139/f05-264

Squires, M.M., Lesack, L.F.., 2002. Water transparency and nutrients as controls on phytoplankton along a flood-frequency gradient among lakes of the Mackenzie Delta, western Canadian Arctic. Can. J. Fish. Aquat. Sci. 59, 1339-1349. doi:10.1139/f02-085 
Squires, M.M., Lesack, L.F., 2003. The relation between sediment nutrient content and macrophyte biomass and community structure along a water transparency gradient among lakes of the Mackenzie Delta. Can. J. Fish. Aquat. Sci. 60, 333-343. doi:10.1139/f03-027

Squires, M.M., Lesack, L.F.W., Hecky, R.E., Guildford, S.J., Ramlal, P., Higgins, S.N., 2009. Primary Production and Carbon Dioxide Metabolic Balance of a Lake-Rich Arctic River Floodplain: Partitioning of Phytoplankton, Epipelon, Macrophyte, and Epiphyton Production Among Lakes on the Mackenzie Delta. Ecosystems 12, 853-872. doi:10.1007/s10021-009-9263-3

Statham, P.J., 2012. Nutrients in estuaries - An overview and the potential impacts of climate change. Sci. Total Environ. 434, 213-227. doi:10.1016/j.scitotenv.2011.09.088

Stumm, W., Morgan, J.J., 1996. Aquatic chemistry: chemical equilibria and rates in natural waters, 3rd ed. John Wiley \& Sons.

Swarzenski, P.W., Porcelli, D., Andersson, P.S., Smoak, J.M., 2003. The Behavior of U- and Thseries Nuclides in the Estuarine Environment. Rev. Mineral. Geochemistry 52, 577-606. doi: $10.2113 / 0520577$

Tanguy, V., Waeles, M., Gigault, J., Cabon, J.-Y., Quentel, F., Riso, R.D., 2011. The removal of colloidal lead during estuarine mixing: seasonal variations and importance of iron oxides and humic substances. Mar. Freshw. Res. 62, 329. doi:10.1071/MF10220

Tank, S.E., Lesack, L.F.W., Gareis, J.A.L., Osburn, C.L., Hesslein, R.H., 2011. Multiple tracers demonstrate distinct sources of dissolved organic matter to lakes of the Mackenzie Delta, western Canadian Arctic. Limnol. Oceanogr. 56, 1297-1309. doi:10.4319/lo.2011.56.4.1297

Tank, S.E., Manizza, M., Holmes, R.M., McClelland, J.W., Peterson, B.J., 2012a. The Processing and Impact of Dissolved Riverine Nitrogen in the Arctic Ocean. Estuaries and Coasts 35, 401-415. doi:10.1007/s12237-011-9417-3

Tank, S.E., Raymond, P.A., Striegl, R.G., McClelland, J.W., Holmes, R.M., Fiske, G.J., Peterson, B.J., 2012b. A land-to-ocean perspective on the magnitude, source and implication of DIC flux from major Arctic rivers to the Arctic Ocean. Global Biogeochem. Cycles 26. doi:10.1029/2011GB004192

Tank, S.E., Striegl, R.G., McClelland, J.W., Kokelj, S. V, 2016. Multi-decadal increases in dissolved organic carbon and alkalinity flux from the Mackenzie drainage basin to the Arctic Ocean. Environ. Res. Lett. 11, 054015. doi:10.1088/1748-9326/11/5/054015

Taylor, J.R., Falkner, K.K., Schauer, U., Meredith, M., 2003. Quantitative considerations of dissolved barium as a tracer in the Arctic Ocean. J. Geophys. Res. 108. doi:10.1029/2002JC001635

Ternon, J.., Oudot, C., Dessier, A., Diverres, D., 2000. A seasonal tropical sink for atmospheric CO2 in the Atlantic ocean: the role of the Amazon River discharge. Mar. Chem. 68, 183201. doi:10.1016/S0304-4203(99)00077-8

Throckmorton, H.M., Newman, B.D., Heikoop, J.M., Perkins, G.B., Feng, X., Graham, D.E., O’Malley, D., Vesselinov, V. V., Young, J., Wullschleger, S.D., Wilson, C.J., 2016. Active layer hydrology in an arctic tundra ecosystem: quantifying water sources and cycling using water stable isotopes. Hydrol. Process. 30, 4972-4986. doi:10.1002/hyp.10883

Tockner, K., Pennetzdorfer, D., Reiner, N., Schiemer, F., Ward, J. V, 1999. Hydrological connectivity, and the exchange of organic matter and nutrients in a dynamic river-floodplain system (Danube, Austria). Freshw. Biol. 41, 521-535. doi:10.1046/j.1365-

2427.1999.00399.x 
Torres-Valdés, S., Tsubouchi, T., Bacon, S., Naveira-Garabato, A.C., Sanders, R., McLaughlin, F.A., Petrie, B., Kattner, G., Azetsu-Scott, K., Whitledge, T.E., 2013. Export of nutrients from the Arctic Ocean. J. Geophys. Res. Ocean. 118, 1625-1644. doi:10.1002/jgrc.20063

Tremblay, J.-É., Anderson, L.G., Matrai, P., Coupel, P., Bélanger, S., Michel, C., Reigstad, M., 2015. Global and regional drivers of nutrient supply, primary production and $\mathrm{CO} 2$ drawdown in the changing Arctic Ocean. Prog. Oceanogr. 139, 171-196. doi:10.1016/j.pocean.2015.08.009

Tremblay, J.-É., Raimbault, P., Garcia, N., Lansard, B., Babin, M., Gagnon, J., 2014. Impact of river discharge, upwelling and vertical mixing on the nutrient loading and productivity of the Canadian Beaufort Shelf. Biogeosciences 11, 4853-4868. doi:10.5194/bg-11-4853-2014

Vallières, C., Retamal, L., Ramlal, P., Osburn, C.L., Vincent, W.F., 2008. Bacterial production and microbial food web structure in a large arctic river and the coastal Arctic Ocean. J. Mar. Syst. 74, 756-773. doi:10.1016/j.jmarsys.2007.12.002

Walker, H.J., 1998. Arctic Deltas. J. Coast. Res. 14, 718-738.

Wang, Z.A., Kroeger, K.D., Ganju, N.K., Gonneea, M.E., Chu, S.N., 2016. Intertidal salt marshes as an important source of inorganic carbon to the coastal ocean. Limnol. Oceanogr. 61, 1916-1931. doi:10.1002/lno.10347

Water Survey of Canada, 2018. Daily Discharge for Mackenzie River at Arctic Red River (10LC014). URL: https://wateroffice.ec.gc.ca/report/historical_e.html

Wen, L.-S., Warnken, K.W., Santschi, P.H., 2008. The role of organic carbon, iron, and aluminium oxyhydroxides as trace metal carriers: Comparison between the Trinity River and the Trinity River Estuary (Galveston Bay, Texas). Mar. Chem. 112, 20-37. doi:10.1016/j.marchem.2008.06.003

Wheeler, P.A., Watkins, J.M., Hansing, R.L., 1997. Nutrients , organic carbon and organic nitrogen in the upper water column of the Arctic Ocean: implications for the sources of dissolved organic carbon. Deep Sea Res. Part II Top. Stud. Oceanogr. 44, 1571-1592.

Whitehouse, B.G., Macdonald, R.W., Iseki, K., Yunker, M.B., McLaughlin, F.A., 1989. Organic carbon and colloids in the Mackenzie River and Beaufort Sea. Mar. Chem. 26, 371-378. doi:10.1016/0304-4203(89)90042-X

Windom, H., Smith, R., Rawlinson, C., Hungspreugs, M., Dharmvanij, S., Wattayakorn, G., 1988. Trace metal transport in a tropical estuary. Mar. Chem. 24, 293-305. doi:10.1016/0304-4203(88)90037-0

Wong, G.T.F., 1979. Alkalinity and pH in the southern Chesapeake Bay and theJames River estuary. Limnol. Oceanogr. 24, 970-977.

Xie, H., Bélanger, S., Song, G., Benner, R., Taalba, A., Blais, M., Le Fouest, V., Tremblay, J.-É., Babin, M., 2012. Photoproduction of ammonium in the southeastern Beaufort Sea and its biogeochemical implications. Biogeosciences 9, 3047-3061. doi:10.5194/bg-9-3047-2012

Yamamoto-Kawai, M., Tanaka, N., Pivovarov, S., 2005. Freshwater and brine behaviors in the Arctic ocean deduced from historical data of $\delta 1^{8} \mathrm{O}$ and alkalinity (1929-2002 A.D.). J. Geophys. Res. C Ocean. 110. doi:10.1029/2004JC002793

Yi, Y., Gibson, J.J., Hélie, J.F., Dick, T.A., 2010. Synoptic and time-series stable isotope surveys of the Mackenzie River from Great Slave Lake to the Arctic Ocean, 2003 to 2006. J. Hydrol. 383, 223-232. doi:10.1016/j.jhydrol.2009.12.038

Zhang, J., 1995. Geochemistry of Trace Metals from Chinese River/Estuary Systems: An Overview. Estuar. Coast. Shelf Sci. 41, 631-658. doi:10.1006/ecss.1995.0082 


\begin{tabular}{|c|c|c|c|c|c|c|c|c|c|c|c|c|}
\hline$\underset{\Xi}{\underline{0}}$ & 光 & 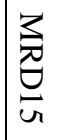 & 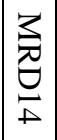 & $\underset{\omega}{\underset{0}{\sigma}}$ & 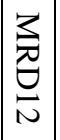 & $\underset{\infty}{\sigma}$ & $\frac{3}{\sigma}$ & 光 & 艿 & \begin{tabular}{l}
3 \\
\multirow{2}{*}{} \\
$\infty$ \\
$\infty$
\end{tabular} & 艿 & $\Xi \frac{\mathscr{E}}{\frac{\tilde{E}}{\sigma}}$ \\
\hline $\begin{array}{l}\frac{a}{N} \\
\frac{\sigma}{a} \\
a\end{array}$ & 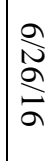 & 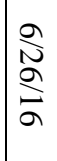 & 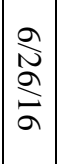 & 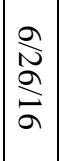 & 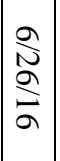 & 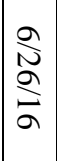 & $\left|\begin{array}{l}\hat{N} \\
\hat{\sigma} \\
\sigma\end{array}\right|$ & $\left|\begin{array}{c}a \\
\hat{N} \\
\pm \\
a\end{array}\right|$ & 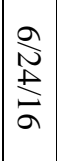 & 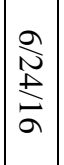 & 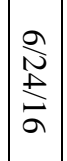 & 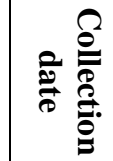 \\
\hline 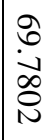 & 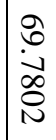 & 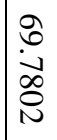 & $\begin{array}{l}a \\
\dot{b} \\
\text { yे } \\
\alpha\end{array}$ & 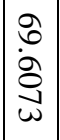 & $\begin{array}{l}0 \\
\dot{b} \\
w \\
\pm \\
+\end{array}$ & $\begin{array}{l}0 \\
0 \\
i n \\
1 \\
1 \\
+\end{array}$ & $\begin{array}{l}g \\
\dot{b} \\
\pm \\
\dot{+}\end{array}$ & 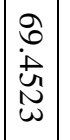 & 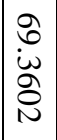 & $\begin{array}{l}0 \\
0 \\
\dot{0} \\
\infty \\
i\end{array}$ & $\begin{array}{l}a \\
0 \\
i \\
N \\
u\end{array}$ & 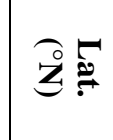 \\
\hline $\begin{array}{l}\omega \\
\omega \\
\dot{\omega} \\
\omega \\
\omega \\
0\end{array}$ & 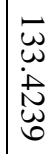 & 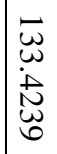 & $\begin{array}{l}\bar{w} \\
\omega \\
\dot{\omega} \\
\omega \\
\alpha \\
\alpha\end{array}$ & $\begin{array}{l}\vec{w} \\
w \\
\dot{\omega} \\
\sim \\
N\end{array}$ & $\mid \begin{array}{l}- \\
w \\
\omega \\
\dot{N} \\
w \\
\omega\end{array}$ & $\begin{array}{l}\vec{w} \\
\omega \\
\dot{\omega} \\
\beth \\
\beth\end{array}$ & 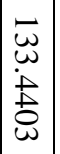 & $\begin{array}{l}\omega \\
\omega \\
\omega \\
\Delta \\
\vdots \\
\omega\end{array}$ & $\begin{array}{l}\vec{w} \\
\dot{\omega} \\
\dot{\vec{v}} \\
\dot{a} \\
\dot{\omega}\end{array}$ & $\mid$\begin{tabular}{c|}
$w$ \\
$\omega$ \\
$\omega$ \\
$\delta$ \\
0 \\
$\infty$
\end{tabular} & 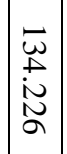 & 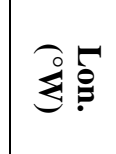 \\
\hline $\begin{array}{l}\vec{A} \\
\vec{A}\end{array}$ & $\overrightarrow{\vec{A}}$ & $\overrightarrow{\vec{A}}$ & $\begin{array}{l}\vec{\omega} \\
\dot{u}\end{array}$ & $\begin{array}{l}u \\
\infty \\
i \\
\omega\end{array}$ & $\begin{array}{l}u \\
\dot{\infty} \\
\infty\end{array}$ & $\begin{array}{l}1 \\
0 \\
0 \\
0\end{array}$ & 崩 & $\begin{array}{l}0 \\
0 \\
0 \\
\infty \\
u\end{array} \mid$ & $\begin{array}{l}0 \\
+ \\
\dot{0} \\
\omega\end{array}$ & $\begin{array}{l}\overrightarrow{0} \\
\dot{6} \\
0\end{array}$ & 0 & 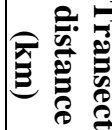 \\
\hline${ }_{0}^{\circ}$ & $\begin{array}{l}0 \\
i\end{array}$ & $\stackrel{\bullet}{\not}$ & $\begin{array}{l}u \\
\infty\end{array}$ & $\overrightarrow{0}$ & $\begin{array}{l}\omega \\
\dot{A}\end{array} \mid$ & $\begin{array}{l}\omega \\
\dot{0}\end{array}$ & $\begin{array}{l}\omega \\
\dot{0}\end{array}$ & $\stackrel{N}{\perp}$ & $\stackrel{\sim}{\sim}$ & $\begin{array}{l}n \\
\infty\end{array}$ & $\begin{array}{l}\infty \\
\infty \\
0\end{array}$ & छิ \\
\hline 6 & ur & in & ir & ir & ir & ir & ir & ir & ir & ir & ir & હ气 \\
\hline 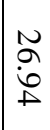 & $\stackrel{N}{\stackrel{N}{\infty}}$ & $\begin{array}{l}\vec{u} \\
\dot{\theta}\end{array}$ & $\begin{array}{l}\overrightarrow{0} \\
i \\
\alpha\end{array}$ & $\begin{array}{l}\infty \\
\dot{a} \\
\alpha\end{array}$ & $\begin{array}{l}9 \\
0\end{array}$ & $\begin{array}{l}\omega \\
w \\
\dot{0}\end{array}$ & 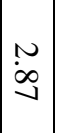 & $\stackrel{0}{\square}$ & $\stackrel{\circ}{\dot{D}}$ & $\begin{array}{l}0 \\
\dot{u}\end{array} \mid$ & $\stackrel{0}{\dot{u}}$ & 曾: \\
\hline$\stackrel{N}{\mathrm{~N}}$ & w & $\begin{array}{l}0 \\
\dot{1} 1 \\
0\end{array}$ & $\begin{array}{l}\bar{N} \\
\dot{u}\end{array}$ & $\begin{array}{l}\vec{N} \\
\dot{\omega} \\
\sigma\end{array}$ & $\mid \begin{array}{l}\vec{N} \\
\dot{\omega}\end{array}$ & $\underset{\stackrel{\vec{N}}{N}}{\vec{N}}$ & 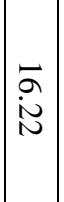 & $\begin{array}{l}\vec{u} \\
\dot{0}\end{array}$ & $\begin{array}{l}\vec{y} \\
\dot{y}\end{array}$ & $\mid$\begin{tabular}{c|}
+ \\
$\dot{0}$ \\
$\dot{0}$
\end{tabular} & $\vec{F}$ & 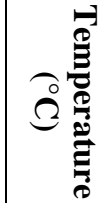 \\
\hline$\stackrel{\infty}{i}$ & $\begin{array}{l}\infty \\
\text { in }\end{array}$ & $\begin{array}{l}\infty \\
\doteq\end{array}$ & $\begin{array}{l}\infty \\
\dot{1} \\
N\end{array}$ & $\begin{array}{l}\infty \\
\dot{\omega} \\
\not\end{array}$ & $\begin{array}{l}\infty \\
\dot{\omega}\end{array}$ & $\begin{array}{l}\infty \\
\dot{w} \\
u\end{array}$ & $\begin{array}{l}\infty \\
\dot{\omega} \\
0\end{array}$ & $\mid \begin{array}{l}\infty \\
\dot{\omega} \\
\sim\end{array}$ & $\begin{array}{l}\infty \\
\dot{a} \\
\sigma\end{array}$ & $\begin{array}{l}\infty \\
\dot{\omega} \\
\omega\end{array}$ & $\begin{array}{l}\infty \\
\stackrel{\sim}{\perp} \\
\perp\end{array}$ & $\bar{T}$ \\
\hline $\overrightarrow{\bar{a}}$ & $\begin{array}{l}\bar{N} \\
\alpha\end{array}$ & 孞 & $\begin{array}{l}\vec{N} \\
\stackrel{0}{+} \\
\dot{D}\end{array}$ & $\begin{array}{l}\bar{N} \\
\stackrel{\circ}{\perp} \\
\dot{A}\end{array}$ & $\begin{array}{l}\vec{v} \\
\ddot{v}\end{array}$ & $\begin{array}{l}\vec{\sim} \\
\dot{v} \\
\forall\end{array}$ & $\vec{\sigma}$ & 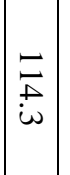 & $\begin{array}{l}\vec{F} \\
\vec{\omega}\end{array}$ & $\mid \begin{array}{l}\vec{\omega} \\
\omega \\
\dot{\omega}\end{array}$ & $\begin{array}{l}\overrightarrow{8} \\
\dot{8} \\
\text { in }\end{array}$ & 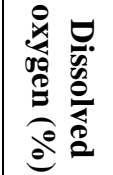 \\
\hline$\underset{+}{+}$ & à & $\begin{array}{l}\dot{8} \\
\dot{y} \\
\dot{y}\end{array}$ & $\begin{array}{l}\dot{\omega} \\
\ddot{\omega} \\
\dot{+}\end{array}$ & $\begin{array}{l}\dot{\vec{u}} \\
\ddot{u} \\
\dot{u}\end{array}$ & 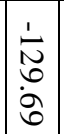 & 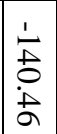 & 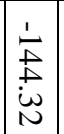 & $\begin{array}{l}\dot{1} \\
\dot{c} \\
\dot{\Delta} \\
\dot{\Delta}\end{array}$ & $\begin{array}{l}\dot{1} \\
\bar{r} \\
\dot{\omega} \\
u \\
u\end{array}$ & $\mid \begin{array}{l}\dot{y} \\
\bar{̆} \\
\dot{u} \\
\sigma\end{array}$ & $\begin{array}{l}\dot{\vec{u}} \\
\ddot{u} \\
\dot{\sim} \\
\dot{t}\end{array}$ & की \\
\hline$\stackrel{u}{\infty}_{\infty}^{i}$ & $\dot{\infty}$ & 它 & $\begin{array}{l}\dot{1} \\
\omega \\
\dot{\sigma} \\
\dot{\sigma}\end{array}$ & $\begin{array}{l}\dot{1} \\
\omega \\
\infty \\
\infty \\
\infty\end{array}$ & $\begin{array}{l}\dot{a} \\
\dot{\hat{\infty}} \\
\dot{\infty}\end{array}$ & $\begin{array}{l}i \\
\text { iv } \\
\text { in }\end{array}$ & $\begin{array}{l}\dot{1} \\
\infty \\
\dot{u} \\
\dot{u}\end{array}$ & $\begin{array}{l}\dot{1} \\
\infty \\
\dot{\omega} \\
N\end{array}$ & $\begin{array}{l}\dot{1} \\
\dot{0} \\
\dot{\partial}\end{array}$ & $\begin{array}{l}\dot{1} \\
\dot{0} \\
\dot{0}\end{array}$ & $\begin{array}{l}1 \\
\text { iे } \\
\text { î }\end{array}$ & $\overbrace{}^{\infty} e^{\infty}$ \\
\hline
\end{tabular}

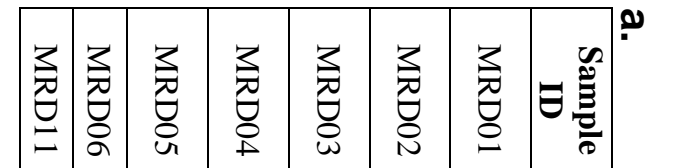

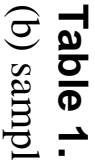

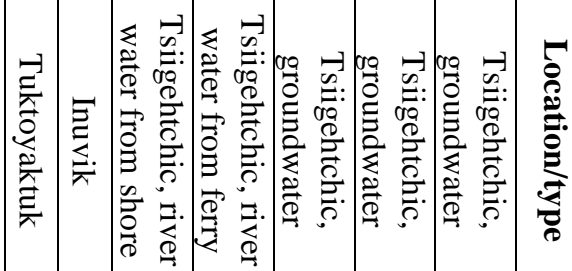

\& 5

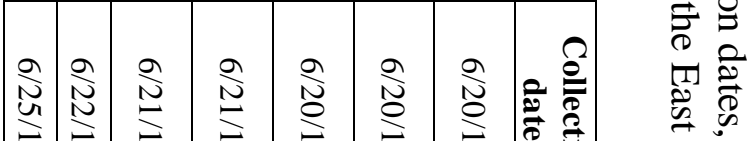

a

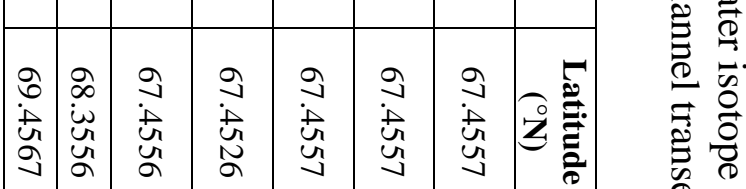

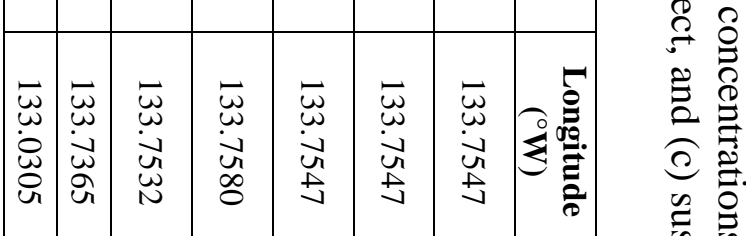

穴

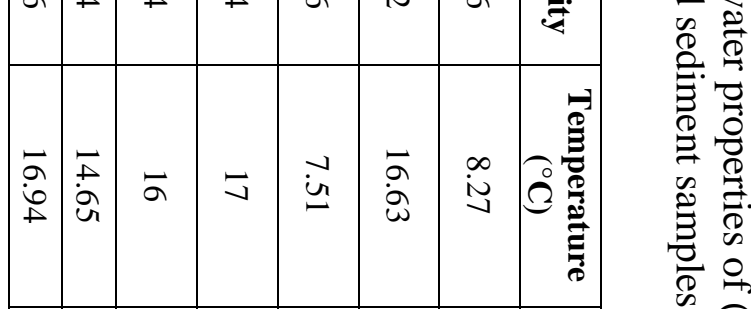

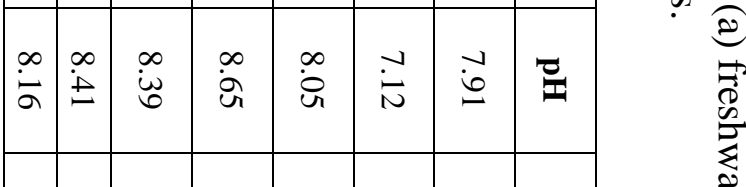

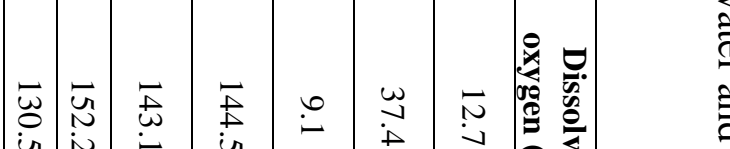

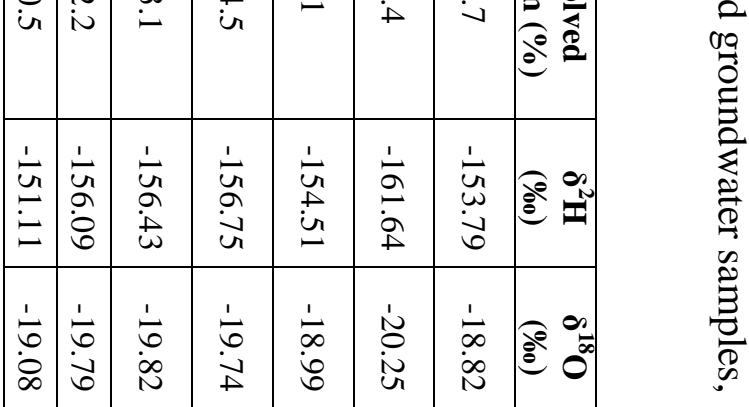




\begin{tabular}{|c|c|c|c|c|}
\hline $\begin{array}{l}\frac{3}{0} \\
\frac{\pi}{\sigma} \\
\frac{0}{0}\end{array}$ & 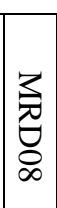 & 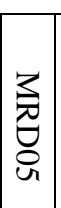 & \begin{tabular}{l}
3 \\
\multirow{0}{*}{} \\
0 \\
+ \\
+
\end{tabular} & 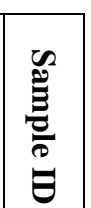 \\
\hline \begin{tabular}{l}
$N$ \\
$\infty$ \\
$\infty$ \\
\hdashline
\end{tabular} & $\stackrel{\ominus}{u}$ & $\mid \begin{array}{l}0 \\
\dot{1} \\
\end{array}$ & $\stackrel{\circ}{\vec{f}}$ & 岂 \\
\hline $\begin{array}{l}\mathbb{N} \\
\infty \\
\infty \\
\infty\end{array}$ & \begin{tabular}{c}
$\vec{P}$ \\
$\dot{D}$ \\
\hdashline
\end{tabular} & $\mid \begin{array}{l}n \\
0 \\
\vdots \\
1\end{array}$ & & 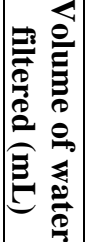 \\
\hline$\stackrel{\circ}{\mathrm{N}}$ & $\begin{array}{l}\text { in } \\
\text { I }\end{array}$ & $\mid \begin{array}{l}0 \\
\text { b }\end{array}$ & $\begin{array}{l}0 \\
\infty \\
\infty\end{array}$ & 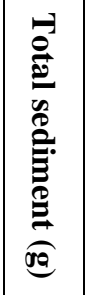 \\
\hline 志 & $\vec{a}$ & $\vec{d}$ & & 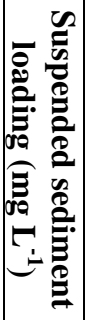 \\
\hline
\end{tabular}


Table 2. Results of estuarine standard reference material (SLRS-6) analysis. "-” indicates no measurement.

\begin{tabular}{|c|c|c|c|c|c|c|}
\hline & $\begin{array}{c}\text { SLRS-6 certified } \\
\text { values }\left(\mathbf{n g ~ g}^{-1}\right)\end{array}$ & Run 1 $\left(\mathbf{n g ~ g}^{-\mathbf{1}}\right)$ & Run 2 $\left(\mathbf{n g ~ g}^{-\mathbf{1}}\right)$ & Run 3 $\left(\mathbf{n g ~ g}^{-\mathbf{1}}\right)$ & $\begin{array}{c}\text { Average } \\
\text { offset }(\%)\end{array}$ & $\begin{array}{c}\text { Standard } \\
\text { deviation } \\
\left(\mathbf{n g ~ g}^{-\mathbf{1}}\right)\end{array}$ \\
\hline $\mathbf{B a}$ & $14.3 \pm 0.48$ & $12.99 \pm 0.15$ & $13.81 \pm 0.27$ & $13.17 \pm 0.24$ & $-7 \%$ & 0.43 \\
\hline $\mathbf{C u}$ & $24 \pm 1.8$ & $24.0 \pm 0.4$ & $25.9 \pm 0.2$ & $27.4 \pm 0.2$ & $7 \%$ & 1.7 \\
\hline $\mathbf{P b}$ & $0.17 \pm 0.026$ & $0.177 \pm 0.005$ & $0.169 \pm 0.001$ & $0.154 \pm 0.004$ & $-2 \%$ & 0.011 \\
\hline $\mathbf{M n}$ & $2.12 \pm 0.1$ & $2.06 \pm 0.06$ & $2.47 \pm 0.07$ & $2.83 \pm 0.06$ & $16 \%$ & 0.38 \\
\hline $\mathbf{N i}$ & $0.617 \pm 0.022$ & $0.596 \pm 0.036$ & $0.672 \pm 0.035$ & $0.724 \pm 0.030$ & $8 \%$ & 0.065 \\
\hline $\mathbf{U}$ & $0.0699 \pm 0.0034$ & - & $0.0648 \pm 0.0015$ & $0.0559 \pm 0.0024$ & $-14 \%$ & 0.0063 \\
\hline
\end{tabular}


Table 3. Time series of ${ }^{228} \mathrm{Ra},{ }^{226} \mathrm{Ra}$, and the ${ }^{228} \mathrm{Ra} /{ }^{226} \mathrm{Ra}$ activity ratio in (a) the Mackenzie River (Tsiigehtchic) and (b) the Yukon River (Pilot Station).

a.

\begin{tabular}{|c|c|c|c|}
\hline & $\begin{array}{c}{ }^{228} \mathbf{R a} \\
\left(\mathbf{d p m} \mathbf{1 0 0 L}{ }^{-1}\right)\end{array}$ & $\begin{array}{c}{ }^{226} \mathbf{R a} \\
\left(\mathbf{d p m} \mathbf{1 0 0 L}^{-1}\right)\end{array}$ & ${ }^{\mathbf{2 2 8}_{\mathbf{R a}}{ }^{\mathbf{2 2 6}} \mathbf{R a}}$ \\
\hline $4 / 24 / 15$ & $11.7 \pm 1.4$ & $11.1 \pm 0.6$ & $1.1 \pm 0.1$ \\
\hline $7 / 11 / 15$ & $19.1 \pm 1.8$ & $18.0 \pm 0.7$ & $1.1 \pm 0.1$ \\
\hline $9 / 13 / 15$ & $18.3 \pm 1.7$ & $19.1 \pm 0.8$ & $1.0 \pm 0.1$ \\
\hline $11 / 17 / 15$ & $9.6 \pm 1.5$ & $11.7 \pm 0.6$ & $0.8 \pm 0.2$ \\
\hline $1 / 31 / 16$ & $13.9 \pm 1.4$ & $13.9 \pm 0.5$ & $1.0 \pm 0.1$ \\
\hline $4 / 23 / 16$ & $11.0 \pm 1.3$ & $11.8 \pm 0.5$ & $0.9 \pm 0.1$ \\
\hline $6 / 21 / 16$ & $19.8 \pm 1.0$ & $20.8 \pm 0.4$ & $1.0 \pm 0.1$ \\
\hline Average & $14.8 \pm 4.2$ & $15.2 \pm 4.0$ & \\
\hline Flow-weighted average & 16.8 & 17.2 & \\
\hline & & & \\
\hline
\end{tabular}

b.

\begin{tabular}{|c|c|c|c|}
\hline & $\begin{array}{c}{ }^{\mathbf{2 2 8}} \mathbf{R a} \\
\left(\mathbf{d p m} \mathbf{1 0 0 L} \mathbf{L}^{\mathbf{1}}\right)\end{array}$ & $\begin{array}{c}{ }^{\mathbf{2 2 6}} \mathbf{R a} \\
(\mathbf{d p m} \mathbf{1 0 0 L}\end{array}$ & ${ }^{\mathbf{2 2 8}} \mathbf{R a}{ }^{\mathbf{2 2 6}} \mathbf{R a}$ \\
\hline $6 / 6 / 15$ & $16.7 \pm 3.7$ & $12.0 \pm 0.9$ & $1.4 \pm 0.3$ \\
\hline $8 / 18 / 15$ & $22.9 \pm 4.1$ & $18.0 \pm 0.9$ & $1.3 \pm 0.2$ \\
\hline $10 / 1 / 15$ & $21.4 \pm 2.8$ & $16.0 \pm 0.6$ & $1.3 \pm 0.2$ \\
\hline $1 / 16 / 16$ & $8.1 \pm 2.1$ & $5.5 \pm 0.8$ & $1.5 \pm 0.4$ \\
\hline $3 / 1 / 16$ & $24.6 \pm 4.7$ & $11.6 \pm 0.9$ & $2.1 \pm 0.4$ \\
\hline $4 / 1 / 16$ & $21.3 \pm 3.0$ & $15.7 \pm 0.7$ & $1.4 \pm 0.2$ \\
\hline Average & $19.2 \pm 6.0$ & $13.2 \pm 4.4$ & \\
\hline Flow-weighted average & 19.3 & 14.2 & \\
\hline
\end{tabular}




\begin{tabular}{|c|c|c|c|c|c|c|c|c|c|c|c|c|}
\hline$\underset{\Xi}{\underset{\sigma}{\sigma}}$ & $\underset{\sigma}{\frac{3}{\sigma}}$ & 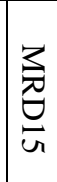 & 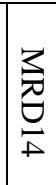 & $\underset{\omega}{\stackrel{\sigma}{\sigma}}$ & 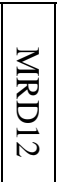 & $\underset{\infty}{\stackrel{z}{\sigma}}$ & $\begin{array}{l}3 \\
0 \\
\vec{\sigma}\end{array}$ & $\begin{array}{l}\stackrel{3}{0} \\
\underset{0}{0} \\
0\end{array}$ & 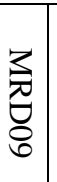 & $\underset{\infty}{\stackrel{2}{0}}$ & 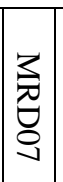 & 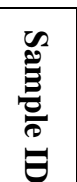 \\
\hline 0 & ur & i & ir & in & ir & ir & ir & ir & ir & ir & & $\widehat{E} \stackrel{8}{\Xi}$ \\
\hline
\end{tabular}

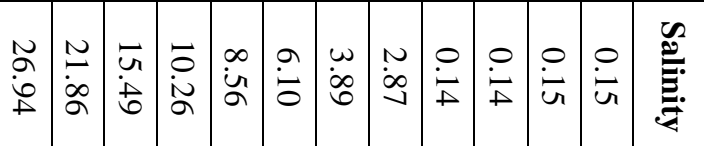

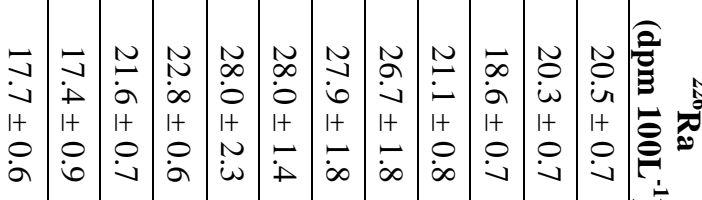

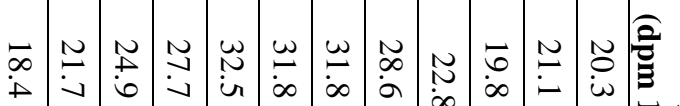

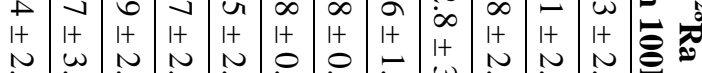

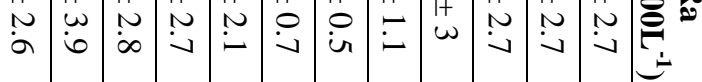

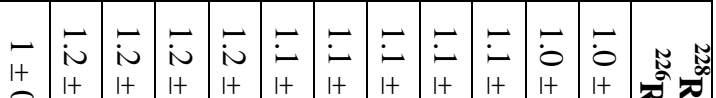

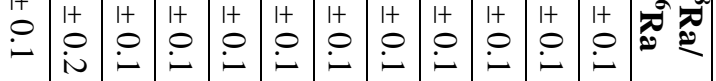

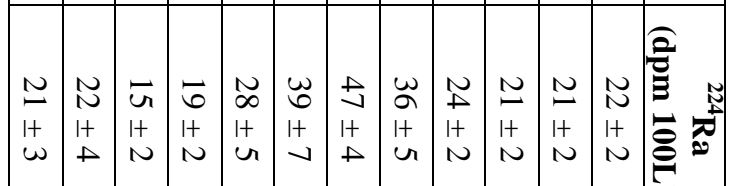

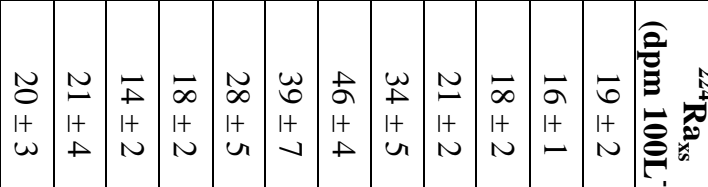

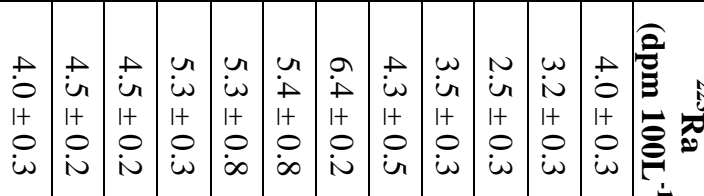

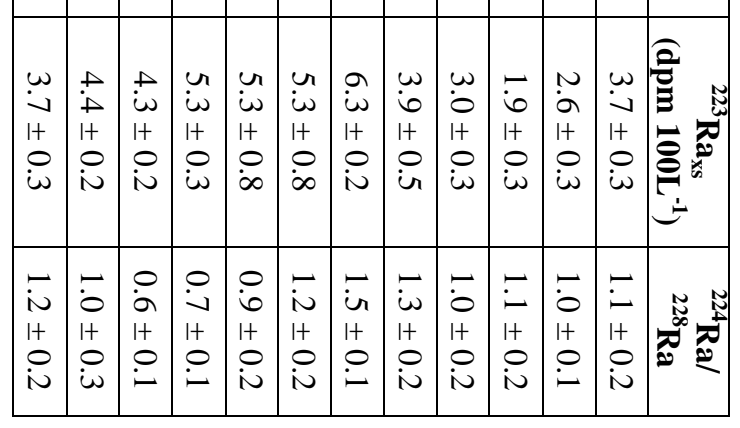

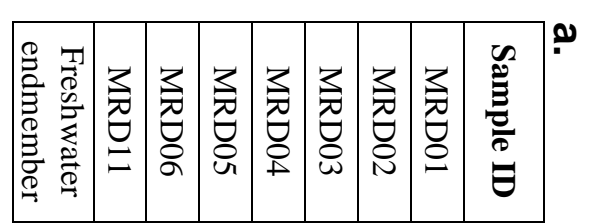

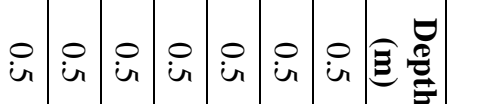

徜

ڤิ)

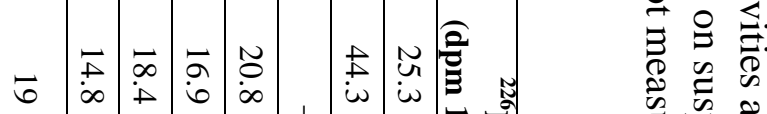

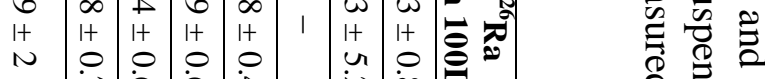

능

कृ ڤ

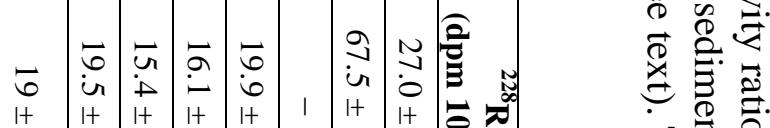

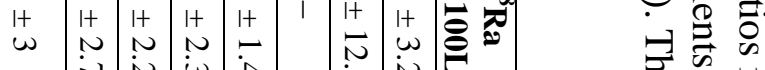

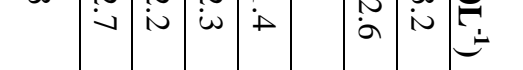

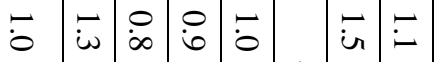

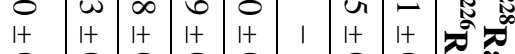

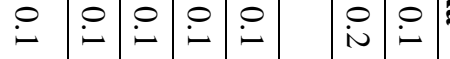

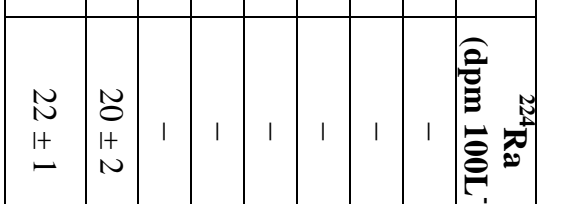

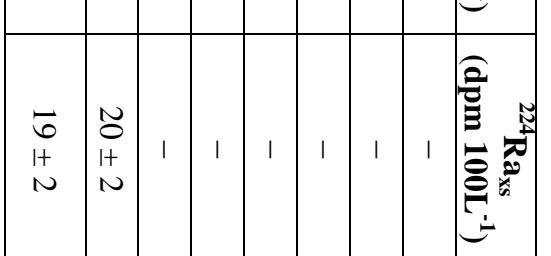

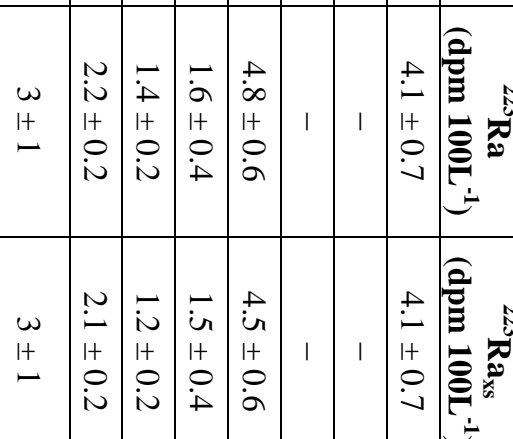

م $\Xi$

栗主

胥

召 气

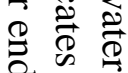

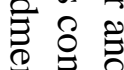

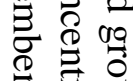

虫. 苛.

$\cong$ 요

¿ क ते

๑

)

完客䎡

Е. 응

๑ $\vec{\nabla}$

¿े.

空当

胥

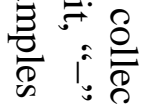

芯 $\stackrel{\vec{\Omega}}{\varrho}$

ज 气

冚. 零

广்

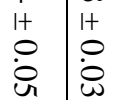




\begin{tabular}{|c|c|c|c|c|c|c|}
\hline 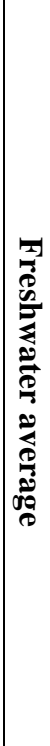 & 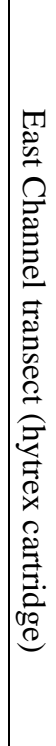 & 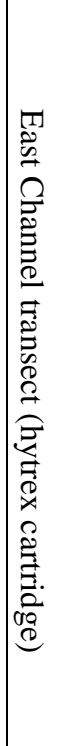 & 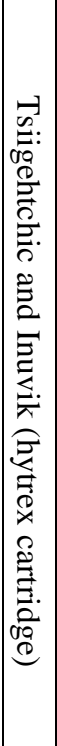 & 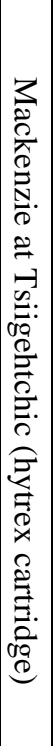 & 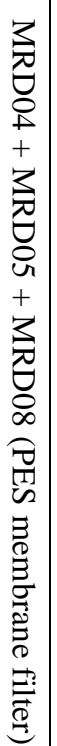 & 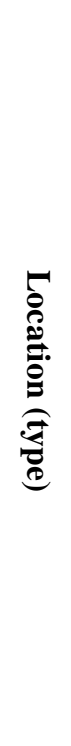 \\
\hline & $\begin{array}{l}n \\
\infty \\
\dot{y} \\
1 \\
\hat{\alpha} \\
\dot{0} \\
1\end{array}$ & $\stackrel{0}{\not}$ & $\stackrel{0}{\not}$ & $\stackrel{0}{\stackrel{0}{\perp}}$ & $\stackrel{\circ}{\not}$ & 弟: \\
\hline $\begin{array}{l}\omega \\
\omega \\
I+ \\
0 \\
0\end{array}$ & $\begin{array}{l}\omega \\
0 \\
1+ \\
0 \\
0\end{array}$ & $\begin{array}{l}\omega \\
\omega \\
1+ \\
0 \\
0\end{array}$ & $\begin{array}{l}\omega \\
i \\
1+ \\
0 \\
0\end{array}$ & $\begin{array}{l}\omega \\
\omega \\
1+ \\
o \\
.-\end{array}$ & $\begin{array}{l}w \\
i \\
+ \\
+ \\
O\end{array}$ & 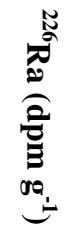 \\
\hline $\begin{array}{l}0 \\
0 \\
1+ \\
0 \\
0\end{array}$ & $\begin{array}{l}N \\
\text { U } \\
1+ \\
0 \\
\text { iv }\end{array}$ & $\begin{array}{l}N \\
\mathbf{6} \\
1+ \\
0 \\
\dot{\omega}\end{array}$ & $\mid \begin{array}{c}\omega \\
\dot{-1} \\
1+ \\
0 \\
\omega\end{array}$ & $\left|\begin{array}{c}w \\
0 \\
1+ \\
0 \\
i\end{array}\right|$ & $\left|\begin{array}{c}w \\
i \\
i \\
1+ \\
0 \\
D\end{array}\right|$ & 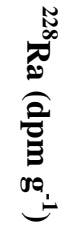 \\
\hline $\begin{array}{l}0 \\
\dot{6} \\
1+ \\
1+ \\
0 \\
\dot{0}\end{array}$ & $\begin{array}{l}0 \\
\infty \\
\infty \\
1+ \\
0 \\
0 \\
\infty\end{array}$ & $\begin{array}{l}0 \\
\dot{8} \\
1+ \\
1+ \\
0 \\
0\end{array}$ & \begin{tabular}{|c|}
0 \\
0 \\
1 \\
$1+$ \\
$1+$ \\
0 \\
$\dot{\infty}$ \\
$\infty$
\end{tabular} & $\begin{array}{c}0 \\
\dot{0} \\
1+ \\
1+ \\
0 \\
0 \\
0\end{array}$ & \begin{tabular}{|c|}
0 \\
$\dot{6}$ \\
-1 \\
$1+$ \\
0 \\
$\dot{D}$ \\
\end{tabular} & 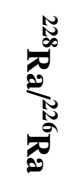 \\
\hline
\end{tabular}




\begin{tabular}{|c|c|c|c|c|c|c|c|c|c|c|c|c|}
\hline$\underset{\Xi}{\stackrel{z}{\sigma}}$ & 忞 & 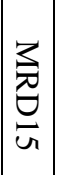 & $\frac{3}{\sigma}$ & 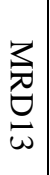 & $\frac{3}{\stackrel{3}{\sigma}}$ & $\underset{\substack{3 \\
\frac{\sigma}{\sigma}}}{\frac{3}{\infty}}$ & $\frac{3}{\sigma}$ & $\underset{3}{3}$ & 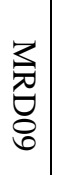 & \begin{tabular}{l}
3 \\
\multirow{2}{*}{} \\
$\stackrel{\infty}{\infty}$ \\
$\infty$
\end{tabular} & 完 & $\stackrel{\mathscr{E}}{\stackrel{\mathscr{E}}{E}}$ \\
\hline 0 & un & $\stackrel{0}{i}$ & ir & ir & ir & $\stackrel{\circ}{i n}$ & $\stackrel{0}{i}$ & in & $\stackrel{\circ}{i n}$ & $\stackrel{0}{i}$ & ir & હ \\
\hline $\mid \begin{array}{l}\tilde{2} \\
2 \\
\dot{\delta} \\
+\end{array}$ & $\begin{array}{c}N \\
\infty \\
\infty \\
\sigma\end{array}$ & $\begin{array}{l}\vec{r} \\
\dot{b}\end{array}$ & $\begin{array}{l}\overrightarrow{0} \\
\dot{N}\end{array}$ & $\begin{array}{l}\infty \\
\dot{\alpha} \\
\alpha\end{array}$ & $\hat{0}$ & $\begin{array}{l}\omega \\
\dot{\infty} \\
\dot{\theta}\end{array}$ & $\begin{array}{l}n \\
\infty \\
\infty \\
v\end{array}$ & $\stackrel{0}{\dot{I}}$ & $\stackrel{\circ}{\not}$ & $\stackrel{0}{\vec{u}}$ & $\stackrel{0}{\dot{u}}$ & 葛: \\
\hline$\dot{\omega}_{\infty}$ & $\S$ & $\S$ & $\leftleftarrows$ & 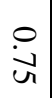 & $\underset{\omega}{\omega}$ & $\ddot{\vec{d}}$ & $\begin{array}{l}0 \\
\dot{u} \\
u\end{array}$ & $\begin{array}{l}n \\
0 \\
0\end{array}$ & $\begin{array}{c}N \\
\mathscr{L} \\
\infty\end{array}$ & $\vec{\circ}$ & $\begin{array}{l}N \\
\dot{\infty}\end{array}$ & 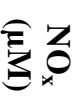 \\
\hline
\end{tabular}

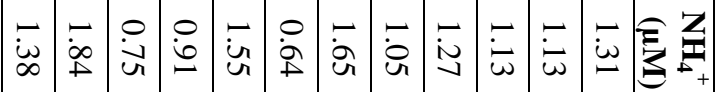

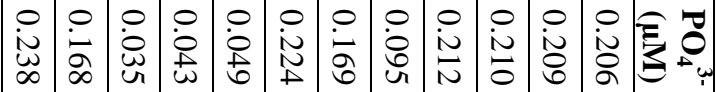

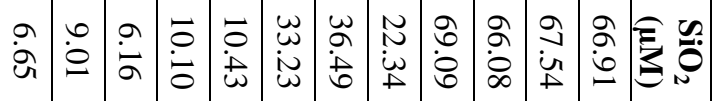

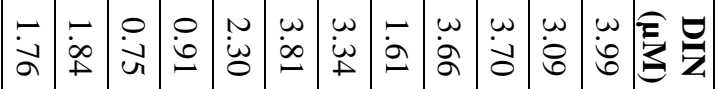

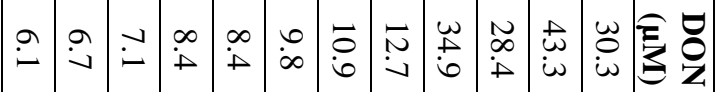

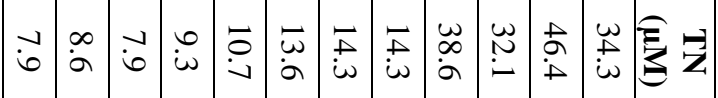

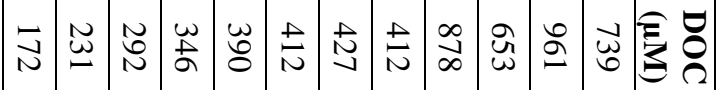

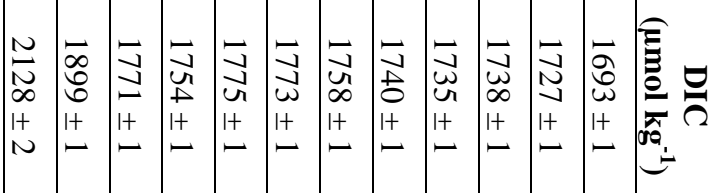

管

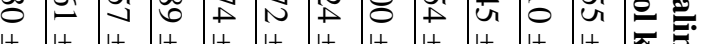

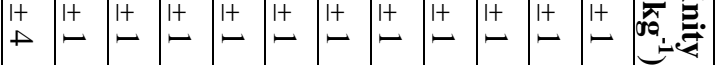

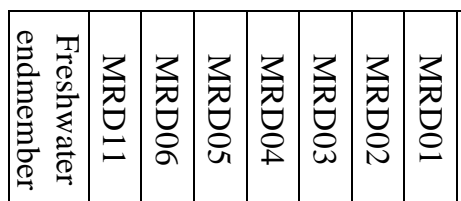

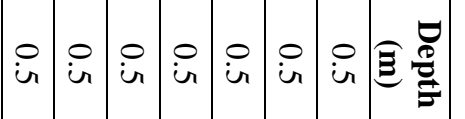

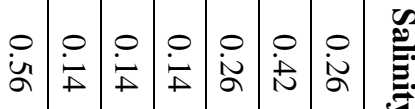

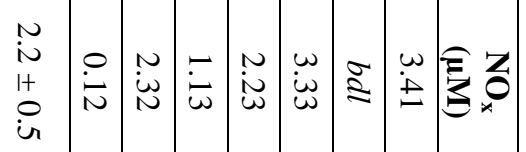

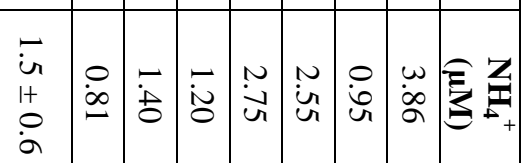

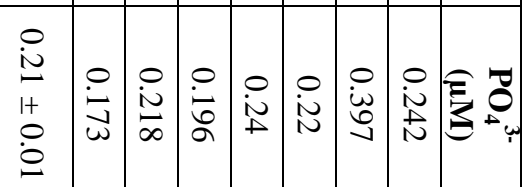

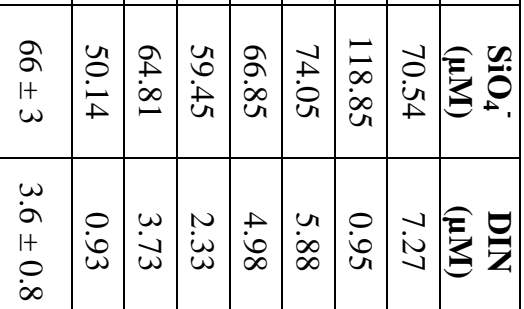

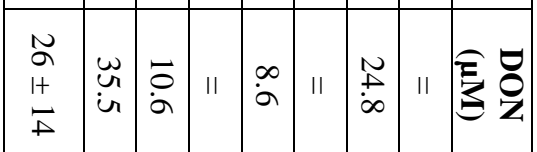

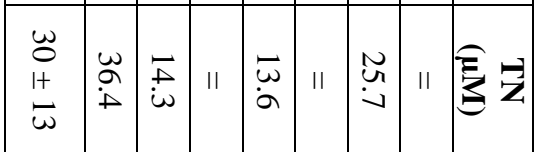

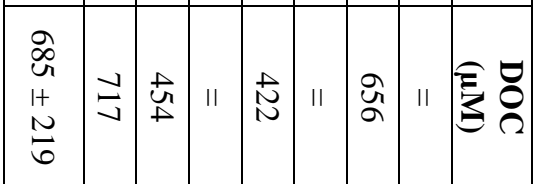

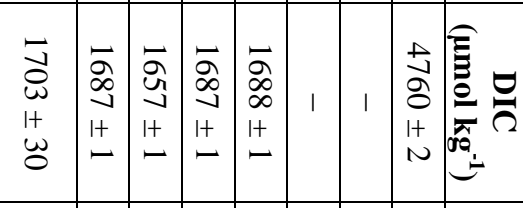

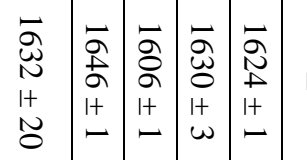

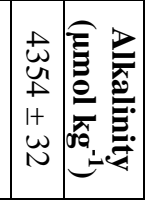

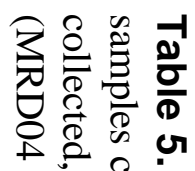

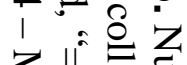

उ

융 웅

$\stackrel{\vec{B}}{\Xi}$.

क ज्ञ

淽

흥

¿.

$\sigma \stackrel{0}{\circ}$

궁

气

$\exists \stackrel{\circ}{\circ}$

จิ

궁

¿

बै

苍 8

实

ज. 苛

引 㐘

융

今

ब0

$\stackrel{\circ}{\circ}$

ङ.

$\notin$ 읭

$\stackrel{\vec{Q}}{\mathrm{Q}}$

丞

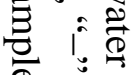

क

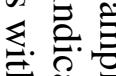

के

节. ڤ

¿

응

$\overline{0} \frac{0}{0}$ 


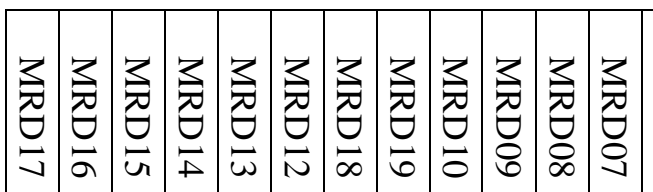

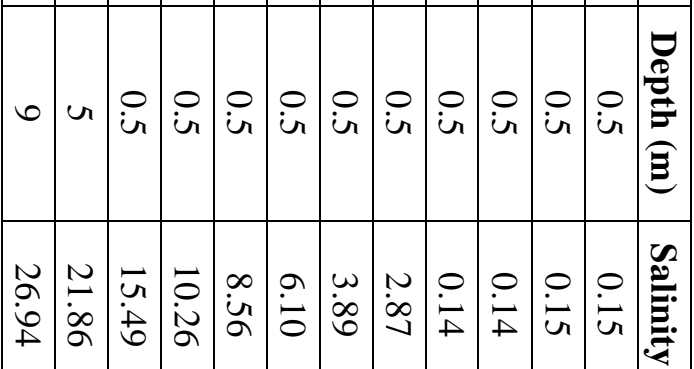

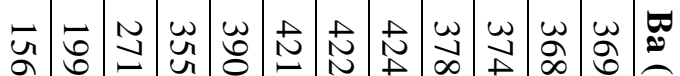

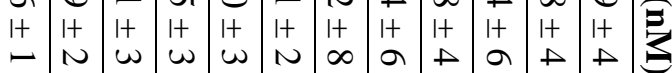

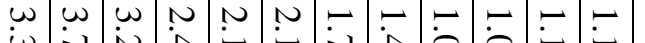

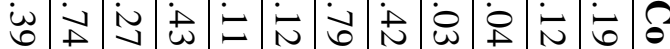

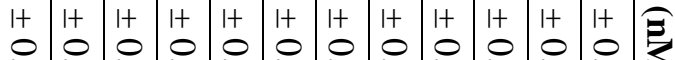

可

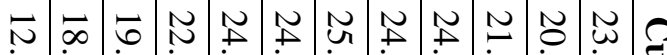

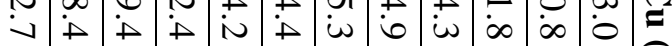

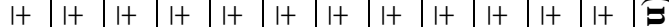

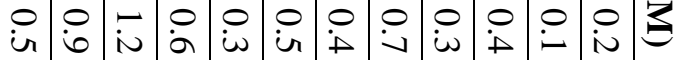

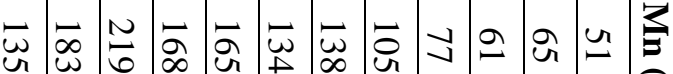

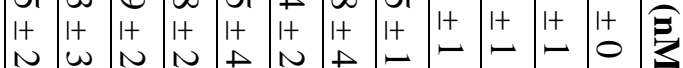

n w n n a n a

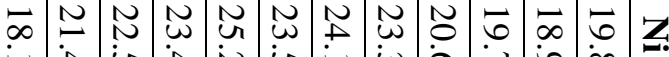

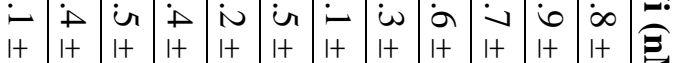

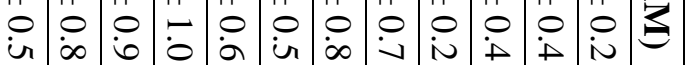

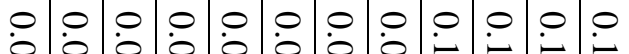

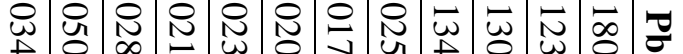

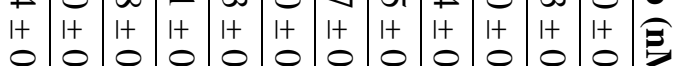

客

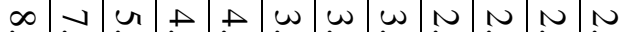

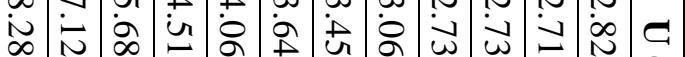

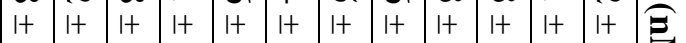

怘

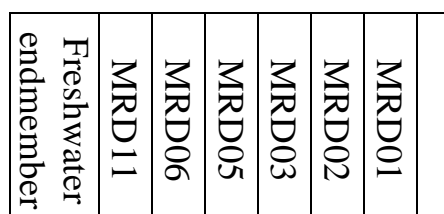



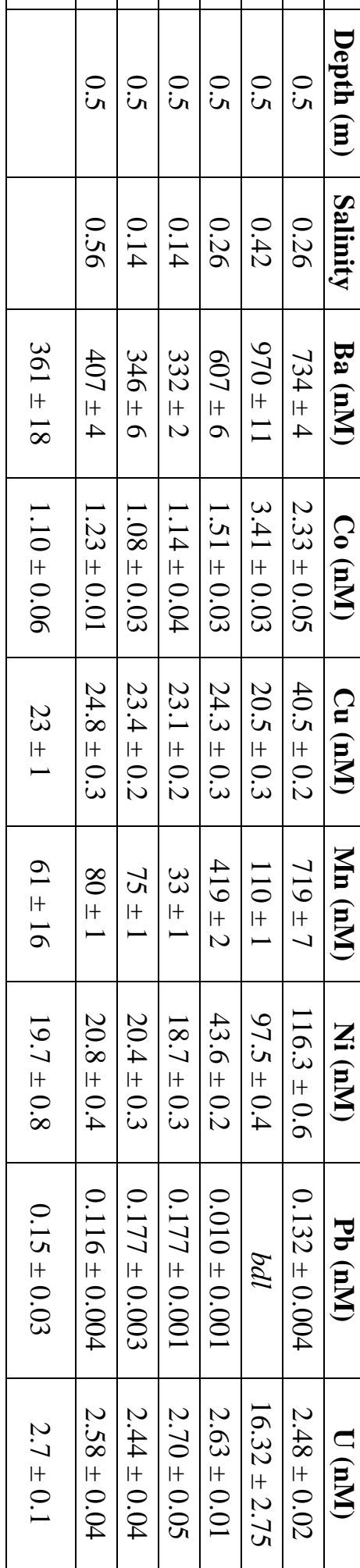

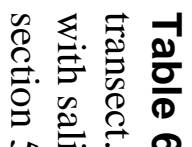

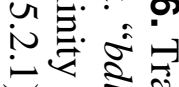

$=\underset{1 \wedge}{\approx}$

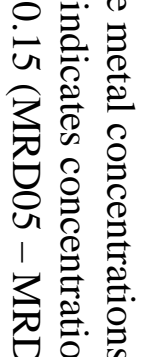

的

串

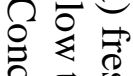

尺े

垔

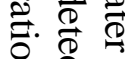

के है

$\bar{\Xi}$

苞

बi

E. 유

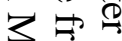

छ류

$\not \cong$

$\stackrel{\nabla}{Q}$

○) 气

흘

จ

츙

$\stackrel{9}{\rightarrow}$

$2 \cdot \frac{\pi}{8}$

‡ิ き

० ‡

ซु ڤึก

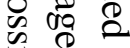

穴号

ᄋ छ.

总官

离.

흥.

放总 
Table 7. (a) Annual fluxes based on flow-weighted averages, the changes observed in the estuary, and the average Mackenzie discharge $\left(316 \mathrm{~km}^{3} \mathrm{y}^{-1}\right.$; Holmes et al., 2012). (b) June 2016 fluxes based on the freshwater concentrations observed during this study, the changes observed in the estuary, and the average Mackenzie discharge in June $2016\left(1.48 \mathrm{~km}^{3} \mathrm{~d}^{-1}\right.$; Water Survey of Canada, 2018).

a.

\begin{tabular}{|c|c|c|c|c|}
\hline & $\begin{array}{c}\text { Flow-weighted } \\
\text { average concentration }\end{array}$ & $\begin{array}{c}\text { Source of flow- } \\
\text { weighted average }\end{array}$ & $\begin{array}{c}\text { Change in } \\
\text { estuary }\end{array}$ & Flux \\
\hline${ }^{228} \mathrm{Ra}$ & $16.8 \mathrm{dpm} 100 \mathrm{~L}^{-1}$ & This study & $61 \%$ & $8.6 \times 10^{13} \mathrm{dpm} \mathrm{y}^{-1}$ \\
\hline${ }^{226} \mathrm{Ra}$ & $17.2 \mathrm{dpm} 100 \mathrm{~L}^{-1}$ & This study & $45 \%$ & $7.9 \times 10^{13} \mathrm{dpm} \mathrm{y}^{-1}$ \\
\hline $\mathrm{Ba}$ & $371 \mathrm{nM}$ & (Cooper et al., 2008) & $30 \%$ & $1.5 \times 10^{8} \mathrm{~mol} \mathrm{y}^{-1}$ \\
\hline DOC & $368 \mathrm{uM}$ & (Cooper et al., 2008) & $-45 \%$ & $6.4 \times 10^{10} \mathrm{~mol} \mathrm{y}^{-1}$ \\
\hline DON & $7.4 \mathrm{uM}$ & (Letscher et al., 2013) & $-60 \%$ & $9.4 \times 10^{8} \mathrm{~mol} \mathrm{y}^{-1}$ \\
\hline
\end{tabular}

b.

\begin{tabular}{|c|c|c|c|}
\hline & $\begin{array}{c}\text { Freshwater average } \\
\text { concentration }\end{array}$ & $\begin{array}{c}\text { Change in } \\
\text { estuary }\end{array}$ & Flux \\
\hline${ }^{228} \mathrm{Ra}$ & $19 \mathrm{dpm} 100 \mathrm{~L}^{-1}$ & $61 \%$ & $4.6 \times 10^{11} \mathrm{dpm} \mathrm{d}^{-1}$ \\
\hline${ }^{226} \mathrm{Ra}$ & $19 \mathrm{dpm} 100 \mathrm{~L}^{-1}$ & $45 \%$ & $4.2 \times 10^{11} \mathrm{dpm} \mathrm{d}^{-1}$ \\
\hline $\mathrm{Ba}$ & $361 \mathrm{nM}$ & $30 \%$ & $6.9 \times 10^{5} \mathrm{~mol} \mathrm{~d}^{-1}$ \\
\hline $\mathrm{Co}$ & $1.1 \mathrm{nM}$ & $36 \%$ & $2.2 \times 10^{3} \mathrm{~mol} \mathrm{~d}^{-1}$ \\
\hline $\mathrm{Cu}$ & $23 \mathrm{nM}$ & $24 \%$ & $4.2 \times 10^{4} \mathrm{~mol} \mathrm{~d}^{-1}$ \\
\hline $\mathrm{Mn}$ & $61 \mathrm{nM}$ & $110 \%$ & $1.9 \times 10^{5} \mathrm{~mol} \mathrm{~d}^{-1}$ \\
\hline $\mathrm{Ni}$ & $19.7 \mathrm{nM}$ & $31 \%$ & $3.8 \times 10^{4} \mathrm{~mol} \mathrm{~d}^{-1}$ \\
\hline $\mathrm{Pb}$ & $0.15 \mathrm{nM}$ & $-81 \%$ & $4.2 \times 10^{1} \mathrm{~mol} \mathrm{~d}^{-1}$ \\
\hline $\mathrm{U}$ & $2.7 \mathrm{nM}$ & conserved & $4.0 \times 10^{3} \mathrm{~mol} \mathrm{~d}^{-1}$ \\
\hline $\mathrm{DOC}$ & $685 \mathrm{uM}$ & $-45 \%$ & $5.6 \times 10^{8} \mathrm{~mol} \mathrm{~d}^{-1}$ \\
\hline $\mathrm{DON}$ & $26 \mathrm{uM}$ & $-60 \%$ & $1.5 \times 10^{7} \mathrm{~mol} \mathrm{~d}^{-1}$ \\
\hline
\end{tabular}




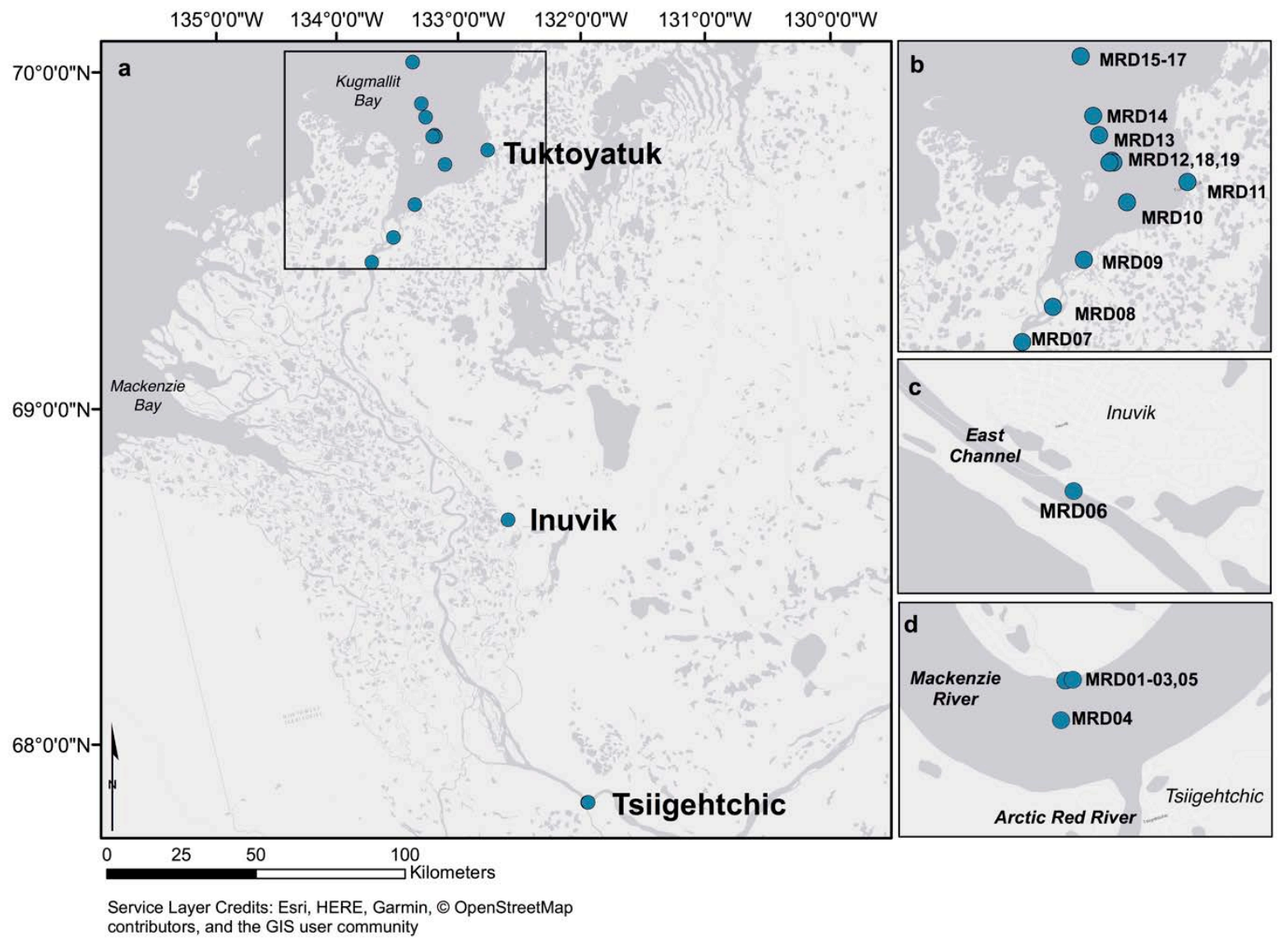

Figure 1. (a) Sampling locations in the Mackenzie River Delta. Locations of (b) the estuarine sampling near Tuktoyaktuk, (c) the sampling on the banks of the East Channel in Inuvik, and (d) the sampling in Tsiigehtchic are shown in the insets. The black box on the delta map shows the bounds of inset (b); the bounds of insets (c) and (d) are smaller than the size of the Inuvik and Tsiigehtchic sample markers. 


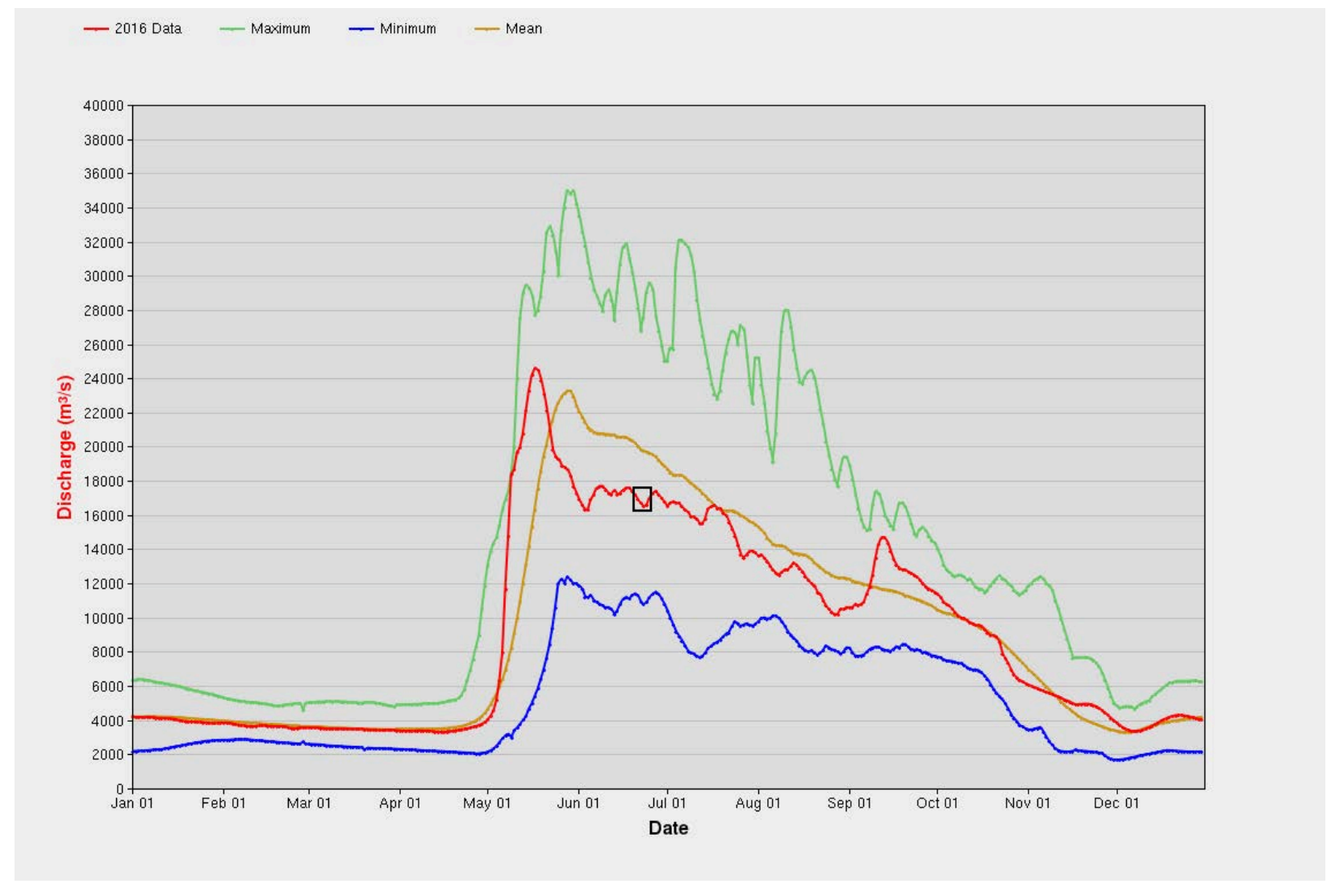

Figure 2. Water discharge data provided by the Water Survey of Canada (https://wateroffice.ec.gc.ca/report/historical_e.html). Discharge measured in 2016 (red) is compared to the maximum (green), minimum (blue), and median (gold) discharge observed during the period of record $(1972$ - 2016). The period of our June 2016 study is indicated with a black box. 

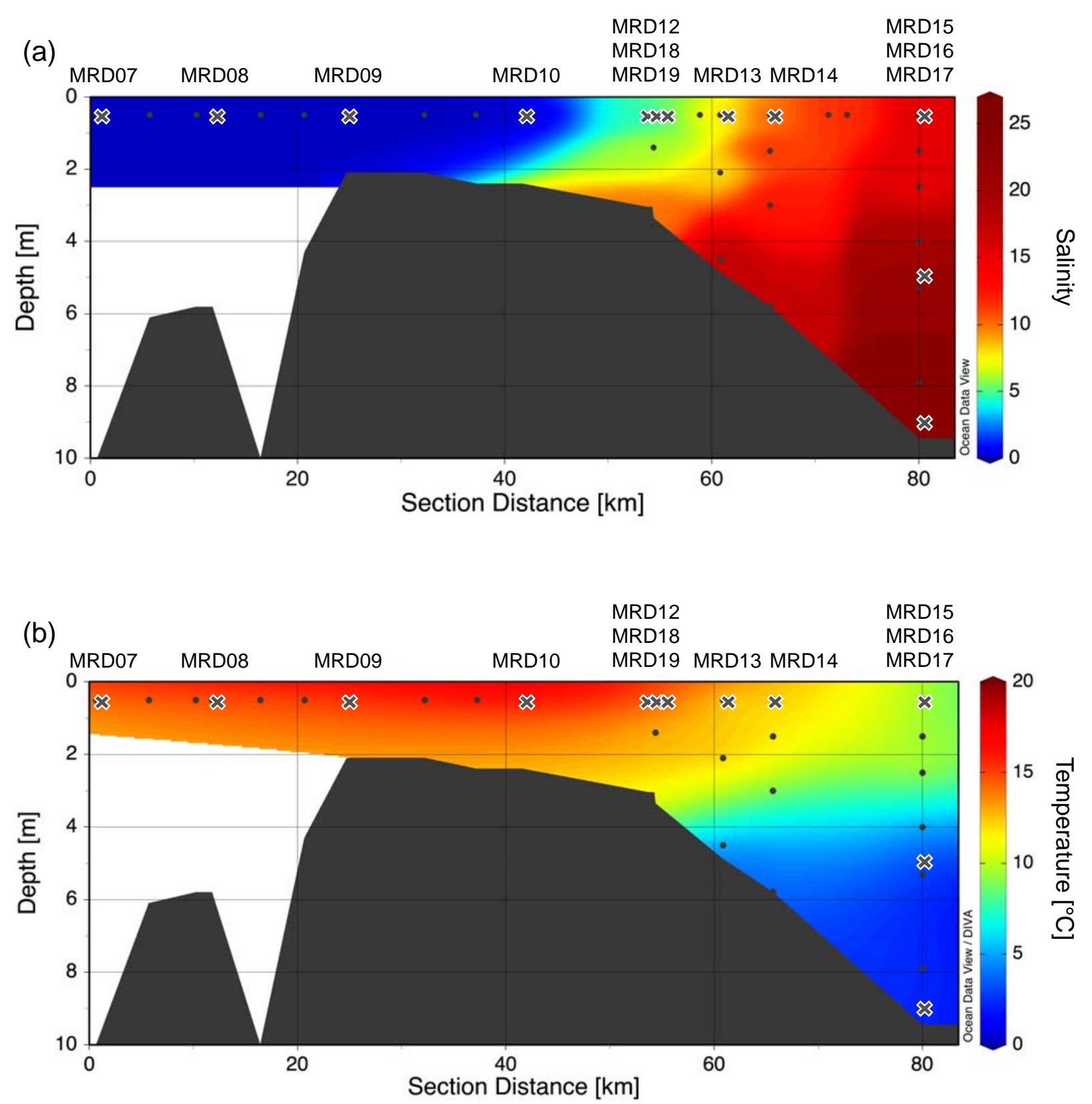

Figure 3. (a) Salinity and (b) temperature in the East Channel in June 2016. Outlined crosses denote stations where water samples were collected, dots show locations where temperature and salinity were measured. 


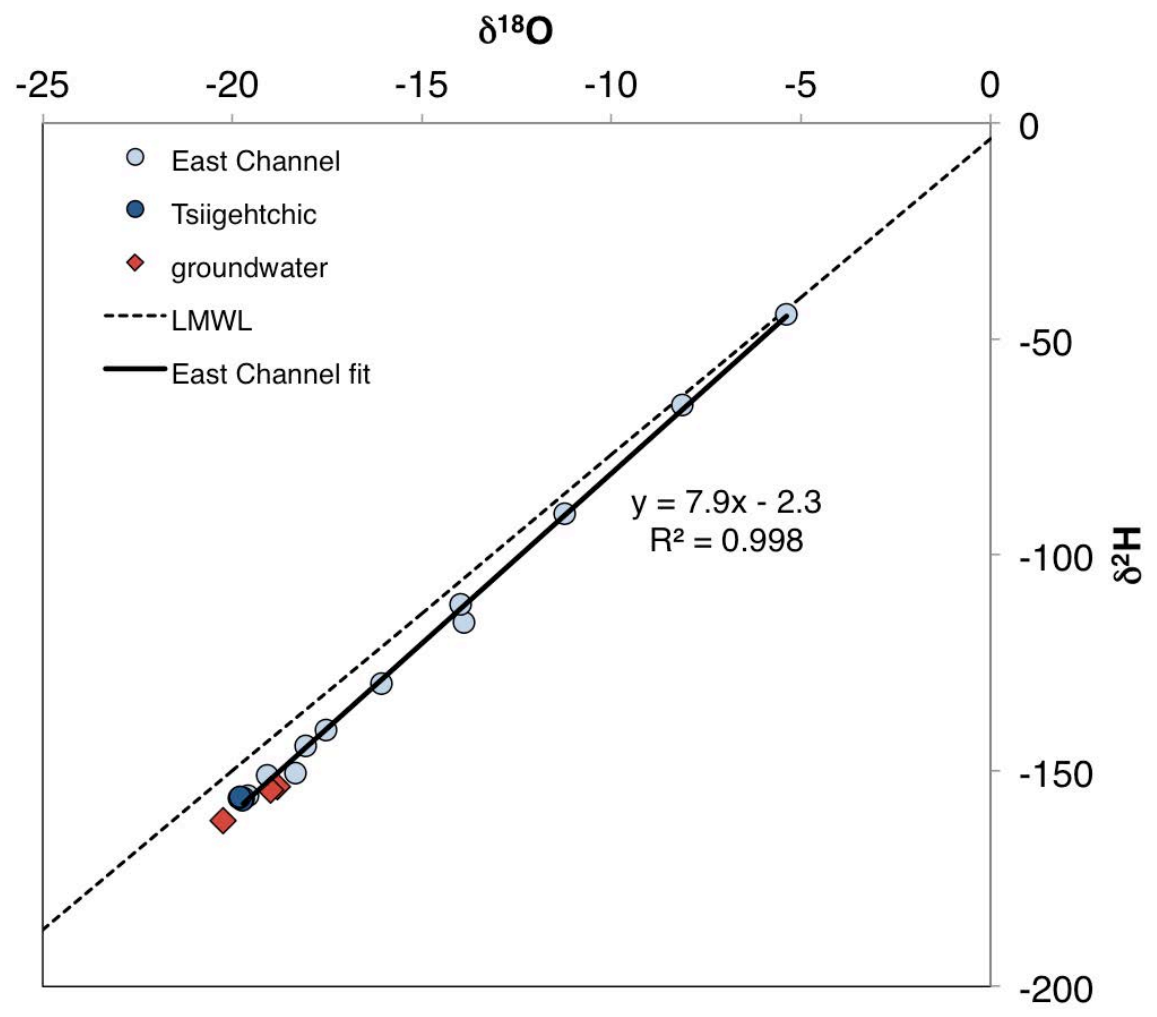

Figure 4. Water isotope values of groundwater (red diamonds) and water samples collected at Tsiigehtchic (dark blue circles) and in the East Channel (light blue circles). The local mean water line for Inuvik (LMWL; dashed line) is shown along with the linear fit to the East Channel data (bold line). 

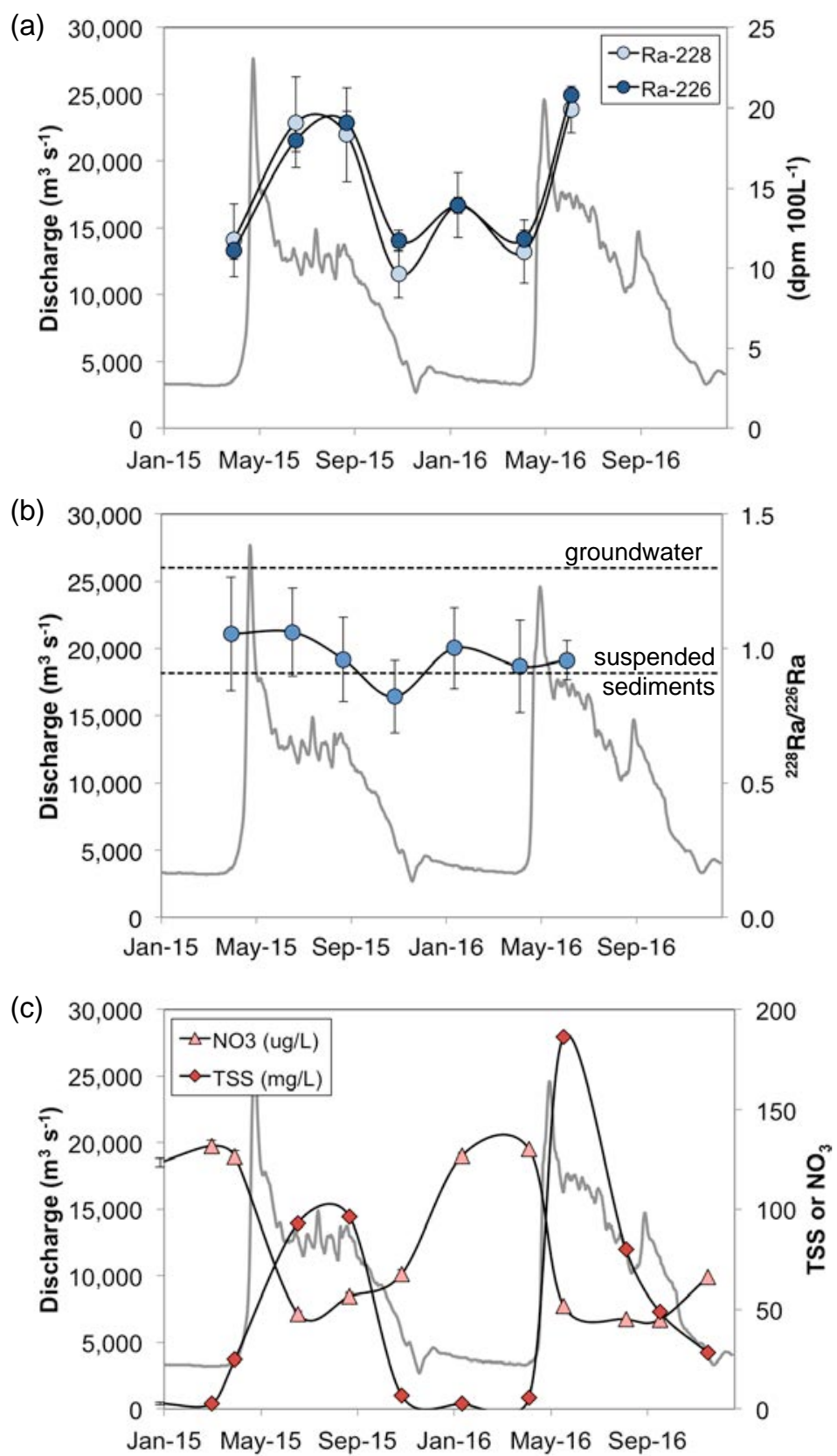

Figure 5. Time series of (a) ${ }^{228} \mathrm{Ra}$ and ${ }^{226} \mathrm{Ra}$, (b) the ${ }^{228} \mathrm{Ra} /{ }^{226} \mathrm{Ra}$ activity ratio, and (c) nitrate $\left(\mathrm{NO}_{3}{ }^{-}\right)$and total suspended solids (TSS) in the Mackenzie River at Tsiigehtchic. Nitrate and TSS were measured by the A-GRO (Holmes et al., 2018) and water discharge was reported by the Canada Water Office (Water Survey of Canada, 2018). Dashed lines in panel (b) represent the ${ }^{228} \mathrm{Ra} /{ }^{226} \mathrm{Ra}$ activity ratio measured in groundwaters and suspended sediments. 


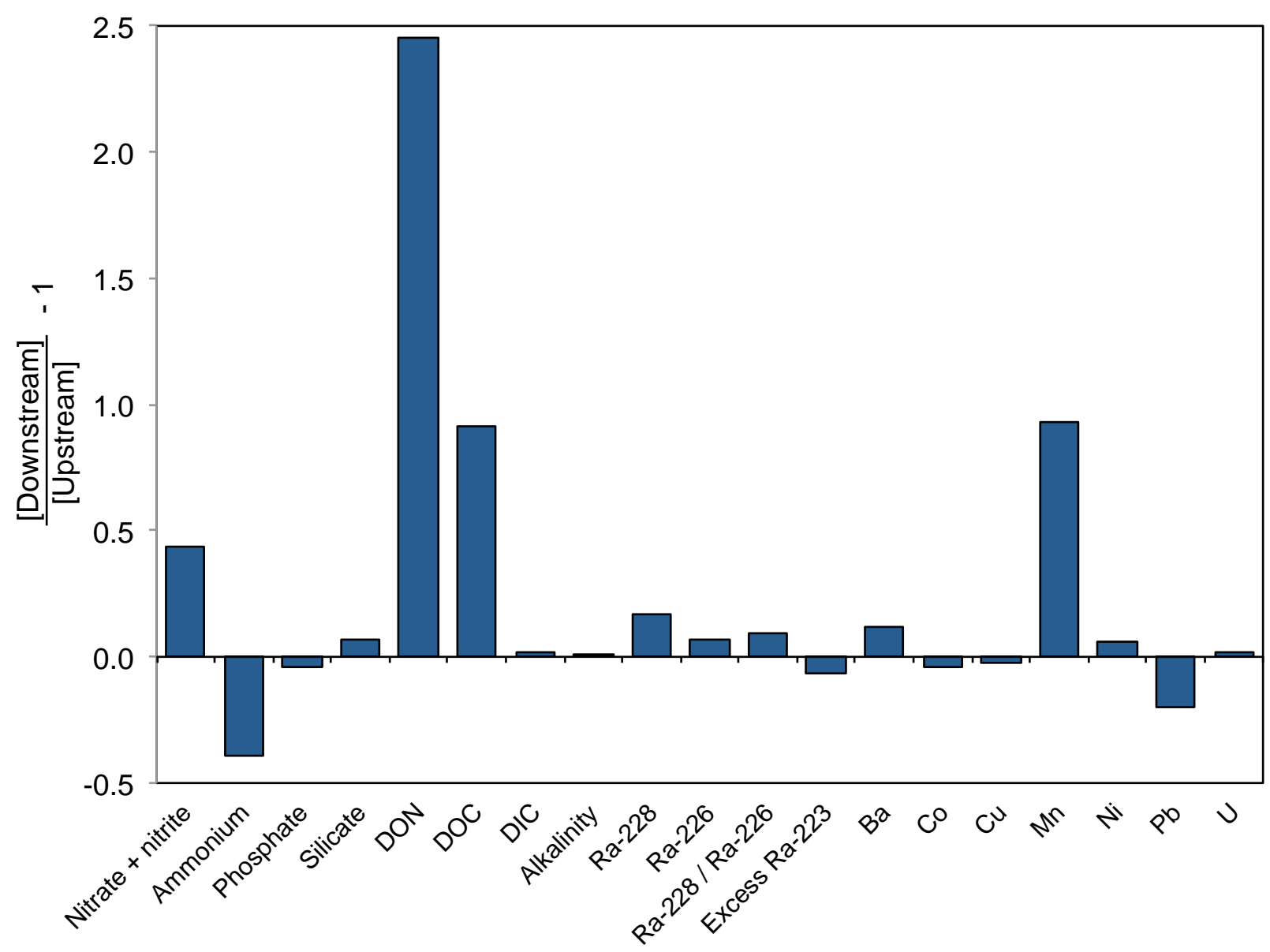

Figure 6. The ratio of the downstream concentration or activity (measured in East Channel freshwater, average of MRD07 - MRD10) to the upstream concentration or activity (measured in Tsiigehtchic, average of MRD04 and MRD05) minus 1. A positive value indicates an addition in the delta, while a negative value indicates a decrease in the delta. The ratio for the trace metals was determined using the upstream concentrations measured in MRD05 only. 
(a)

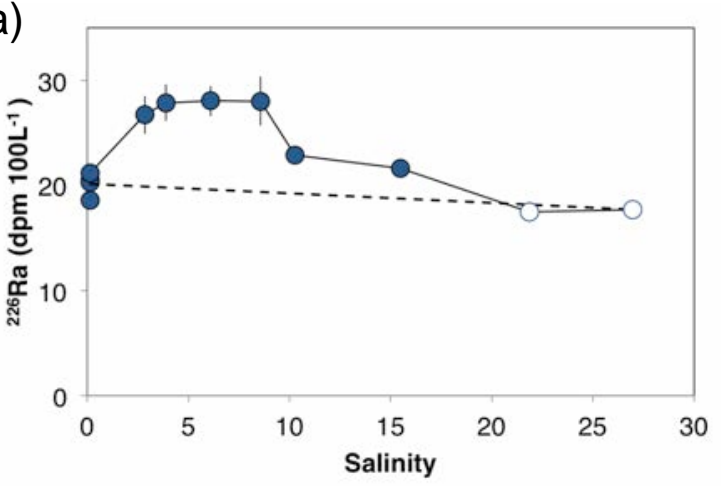

(c)
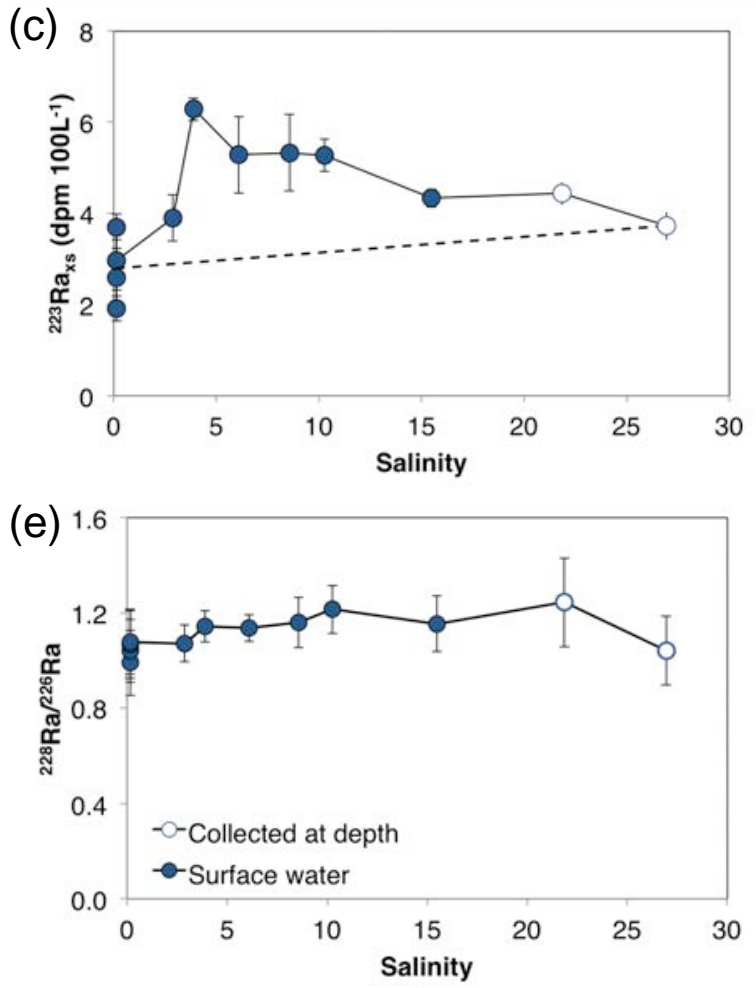

(b)

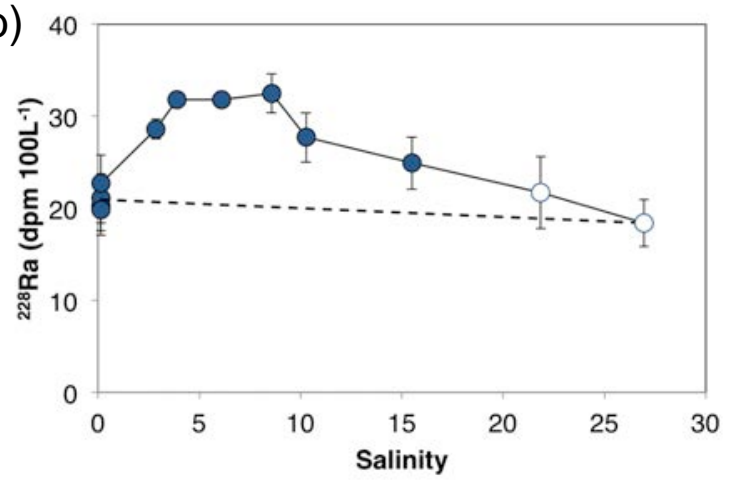

(d)

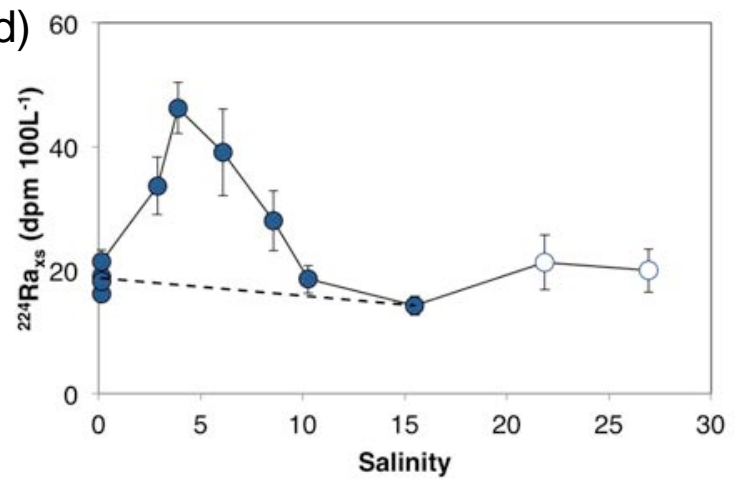

(f)

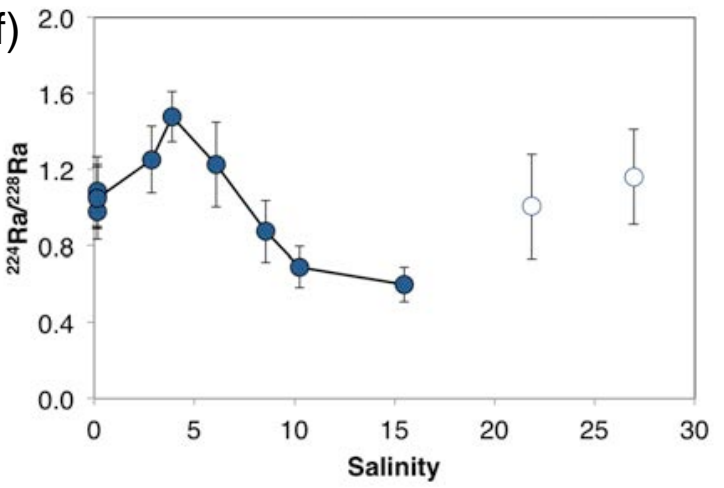

Figure 7. $(a-d)$ Radium activities and $(e-f)$ isotope ratios in the East Channel. Filled symbols represent samples collected from the surface and open symbols denote samples collected from depth. The dashed line represents conservative mixing between the fresh and marine endmembers. The mixing line was drawn to salinity 15 for ${ }^{224} \mathrm{Ra}_{\mathrm{xs}}$ because of additions from benthic sediments observed in the samples collected at depth. 
(a)

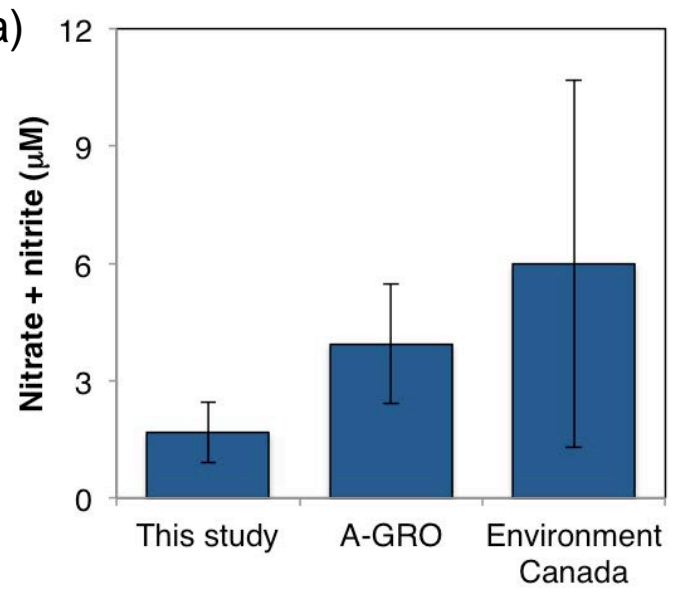

(c)

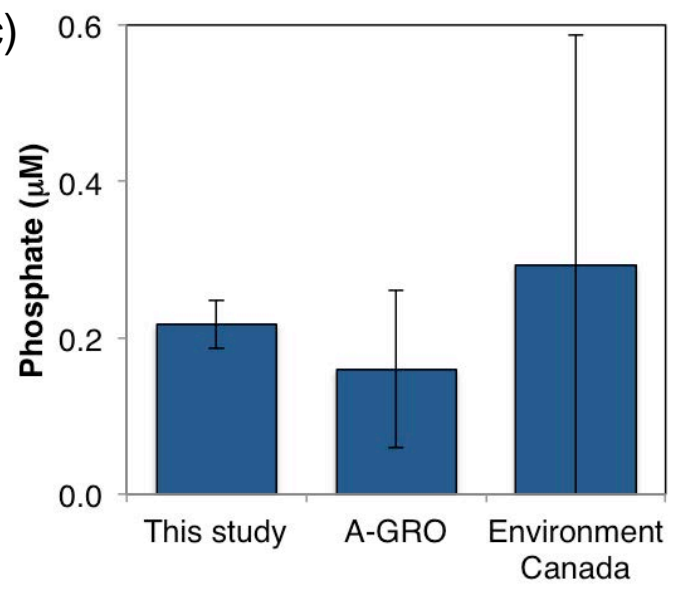

(e)

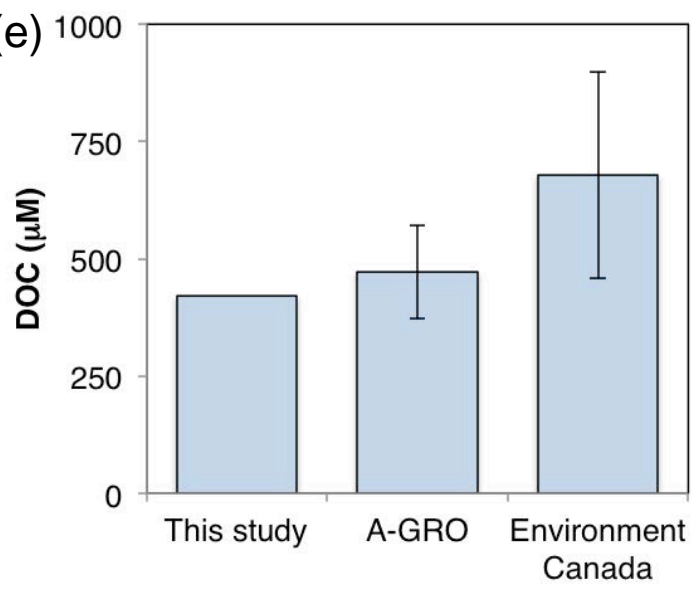

(b)

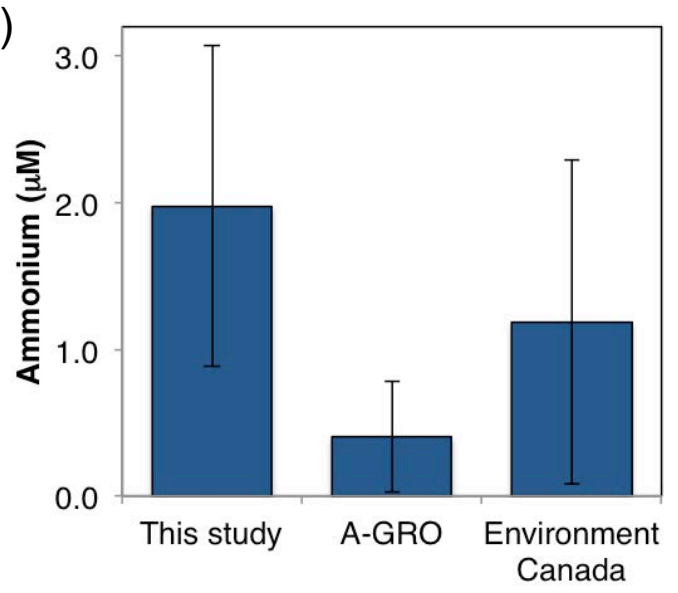

(d)

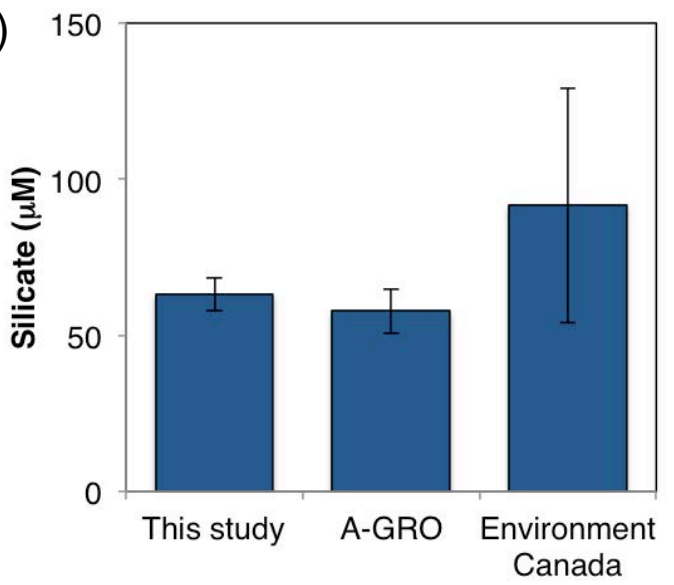

(f)

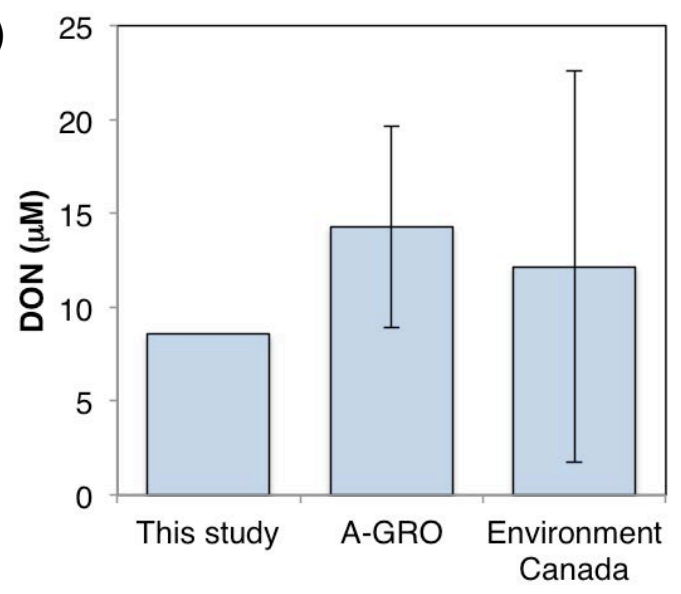

Figure 8. Nutrient (a-d), dissolved organic carbon (e), and dissolved organic nitrogen (f) concentrations measured at Tsiigehtchic in this study (MRD04, MRD05) compared to June averages measured at Tsiigehtchic by the Arctic Great Rivers Observatory (A-GRO) and Environment and Climate Change Canada (Environment Canada). Error bars represent standard deviations. 
(a)

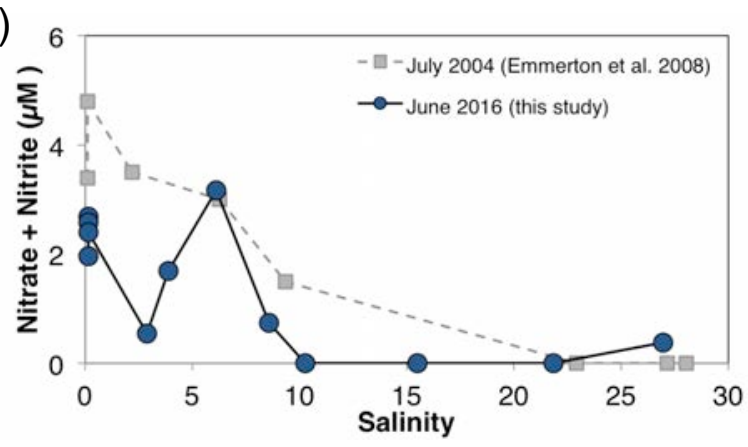

(c)

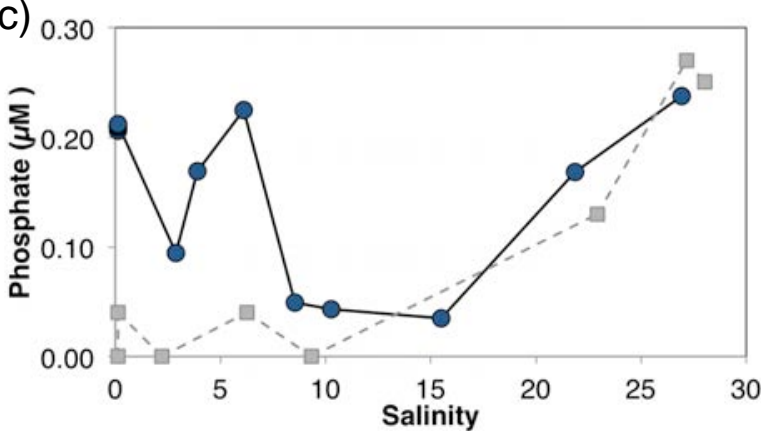

(e)

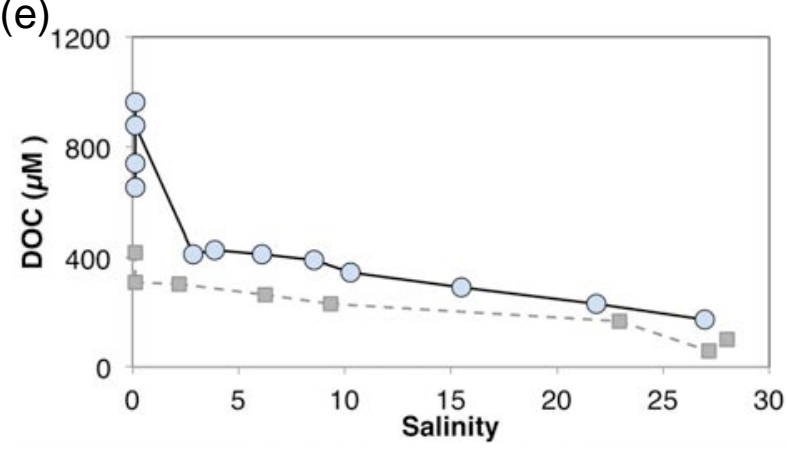

(b)

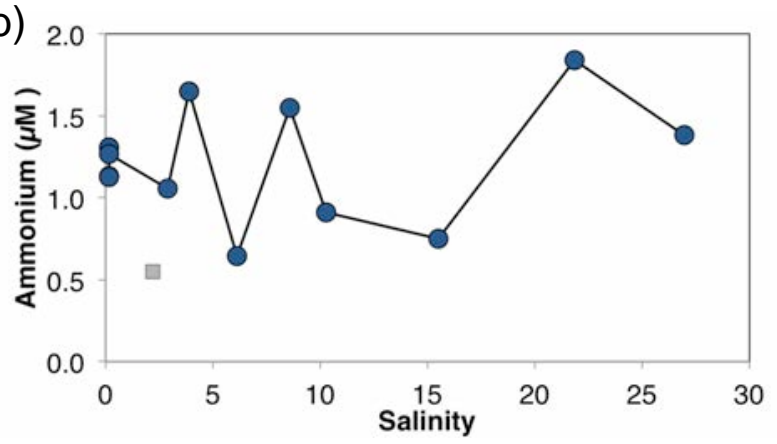

(d)

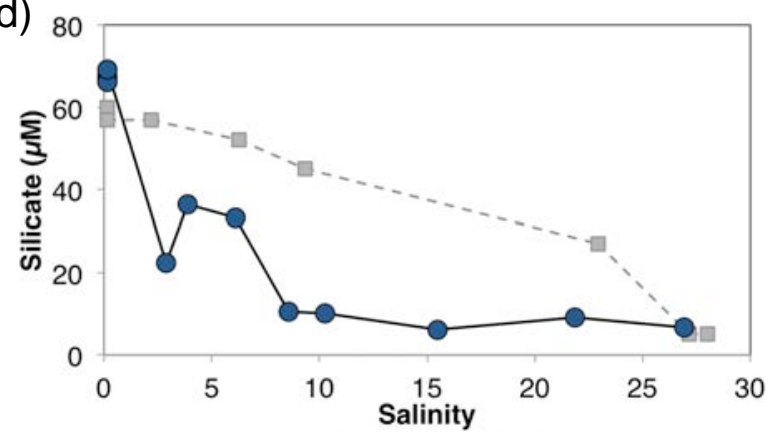

(f)

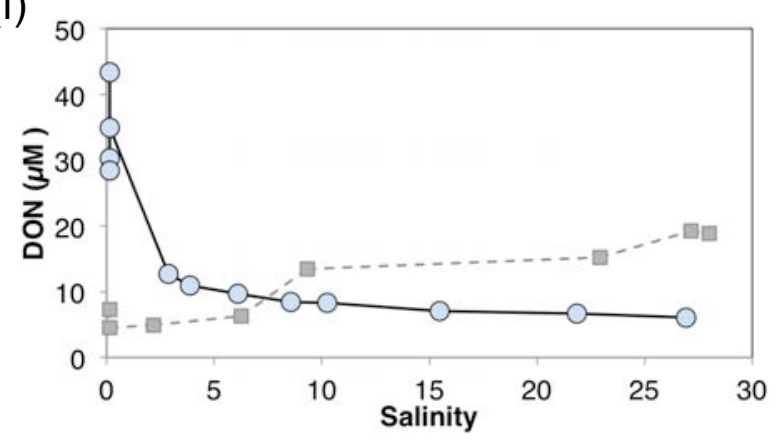

Figure 9. (a-d) Nutrient, (e) dissolved organic carbon, and (f) dissolved organic nitrogen concentrations in the East Channel. Blue symbols represent concentrations measured in June 2016 (this study), and grey symbols represent concentrations measured by Emmerton et al. (2008b) in July 2004. 

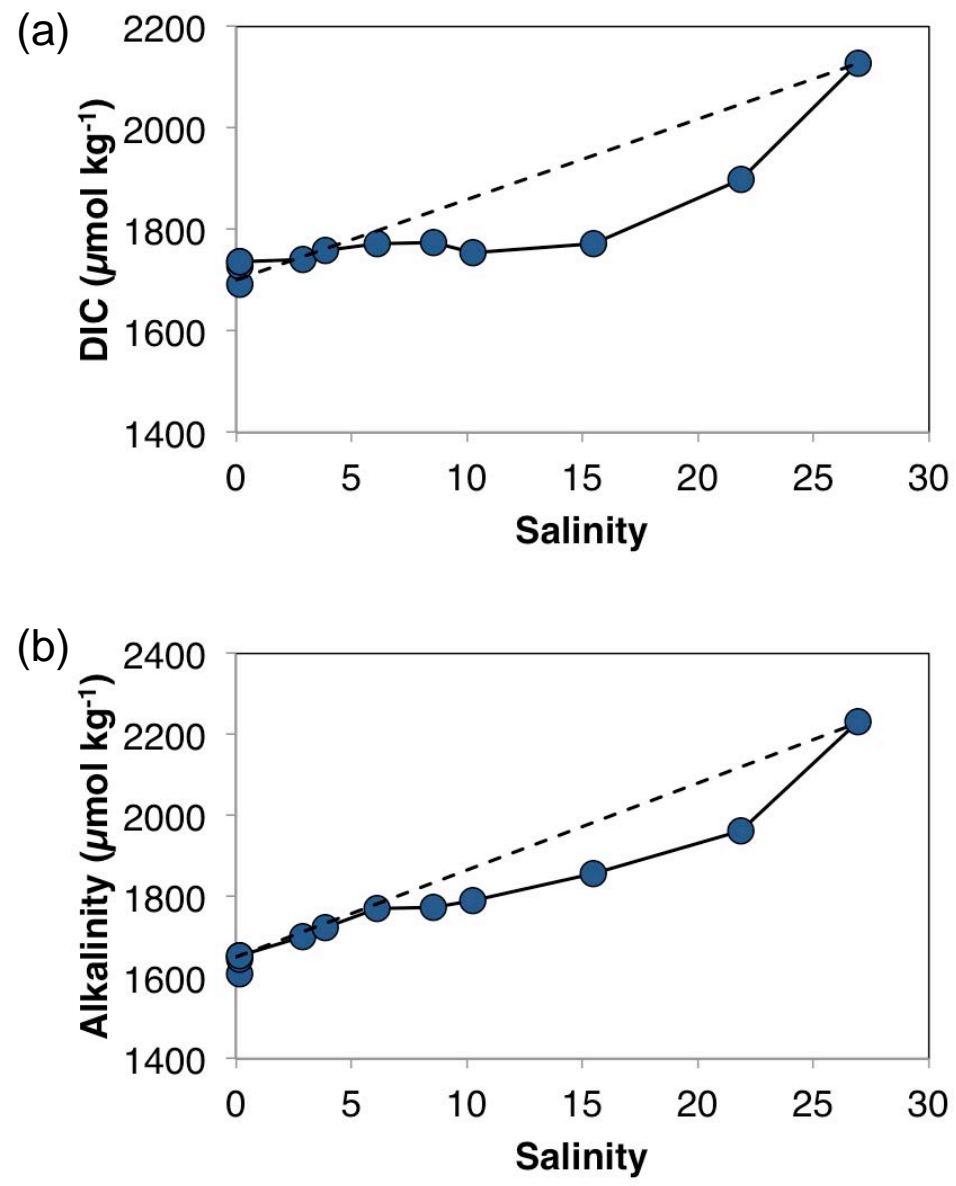

Figure 10. (a) Dissolved inorganic carbon and (b) alkalinity concentrations in the East Channel. The dashed line represents conservative mixing between the fresh and marine endmembers. 

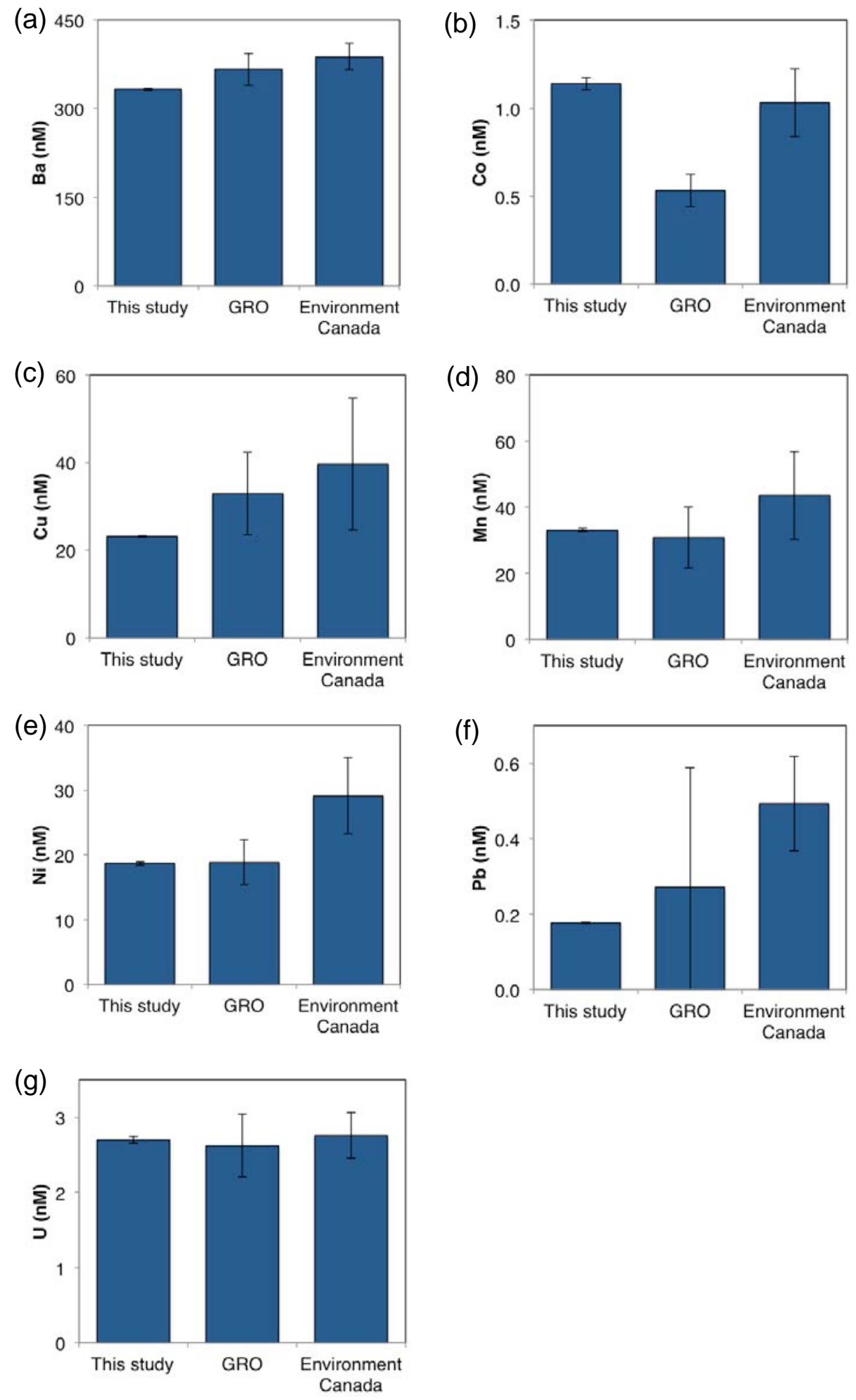

Figure 11. Trace metal concentrations measured at Tsiigehtchic in this study (MRD04, MRD05) compared to June averages measured at Tsiigehtchic by the Arctic Great Rivers Observatory (A-GRO) and Environment and Climate Change Canada (Environment Canada). Error bars represent standard deviations. 
(a)

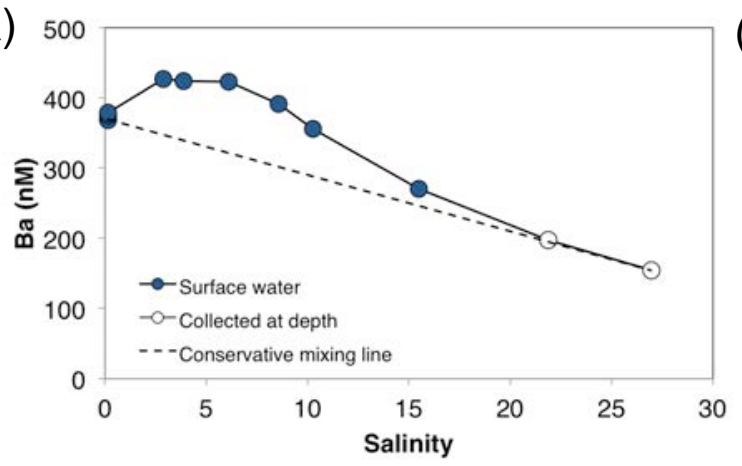

(c)

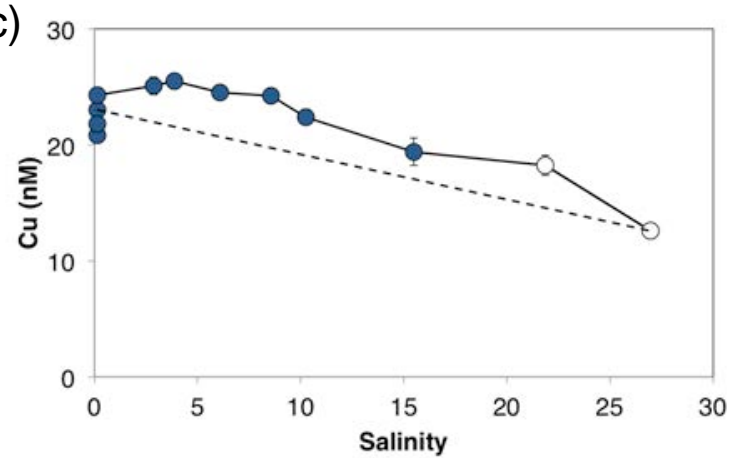

(e)

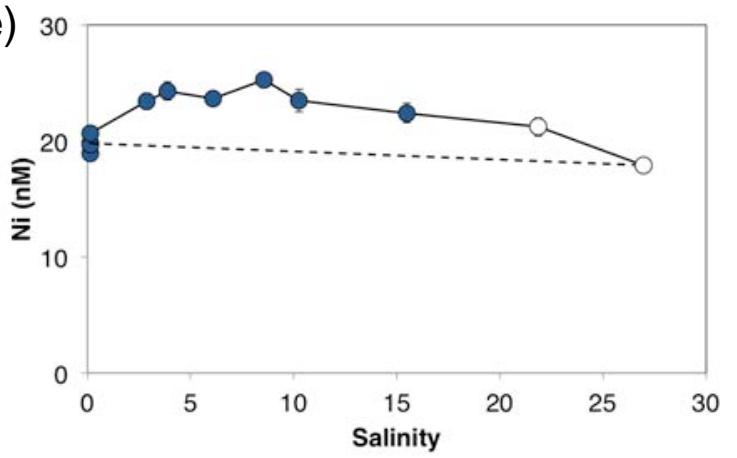

(g)

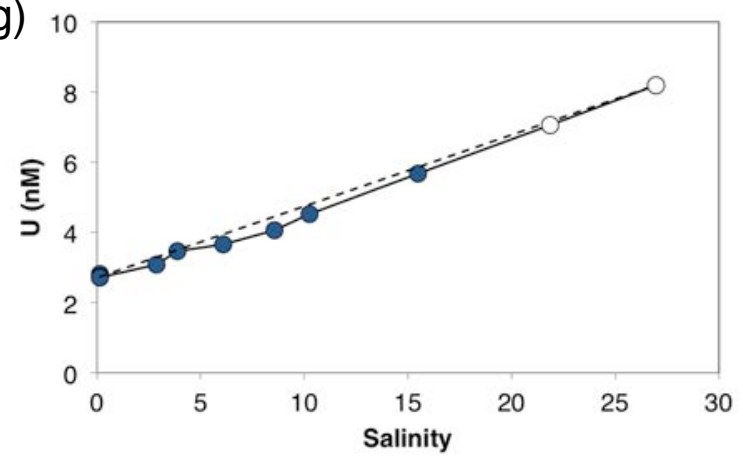

(b)

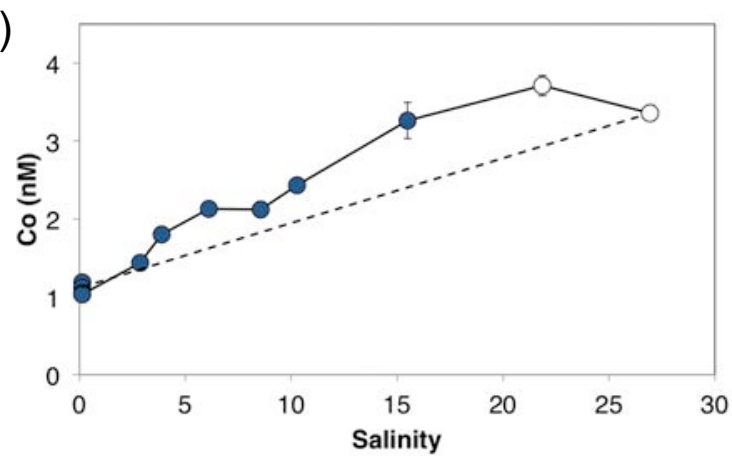

(d)

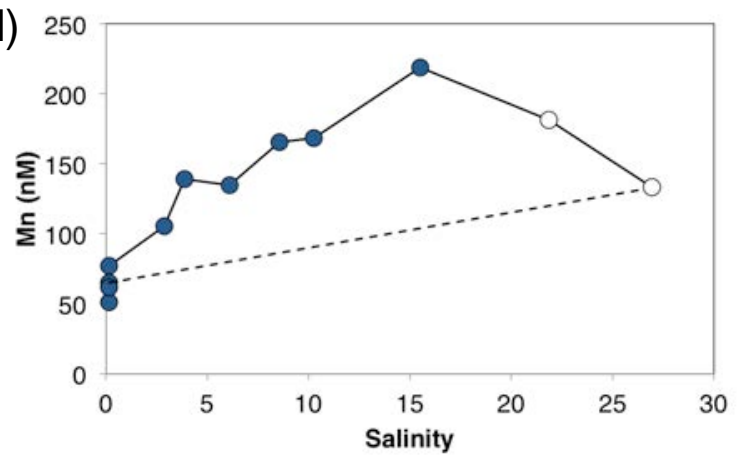

(f)

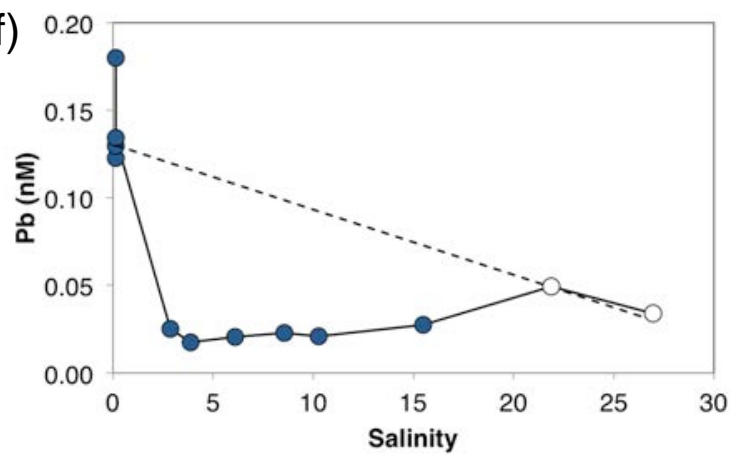

Figure 12. Trace metal concentrations in the East Channel. Filled symbols represent samples collected from the surface, open symbols denote samples collected from depth, and the dashed line represents conservative mixing between the fresh and marine endmembers. 
(a)

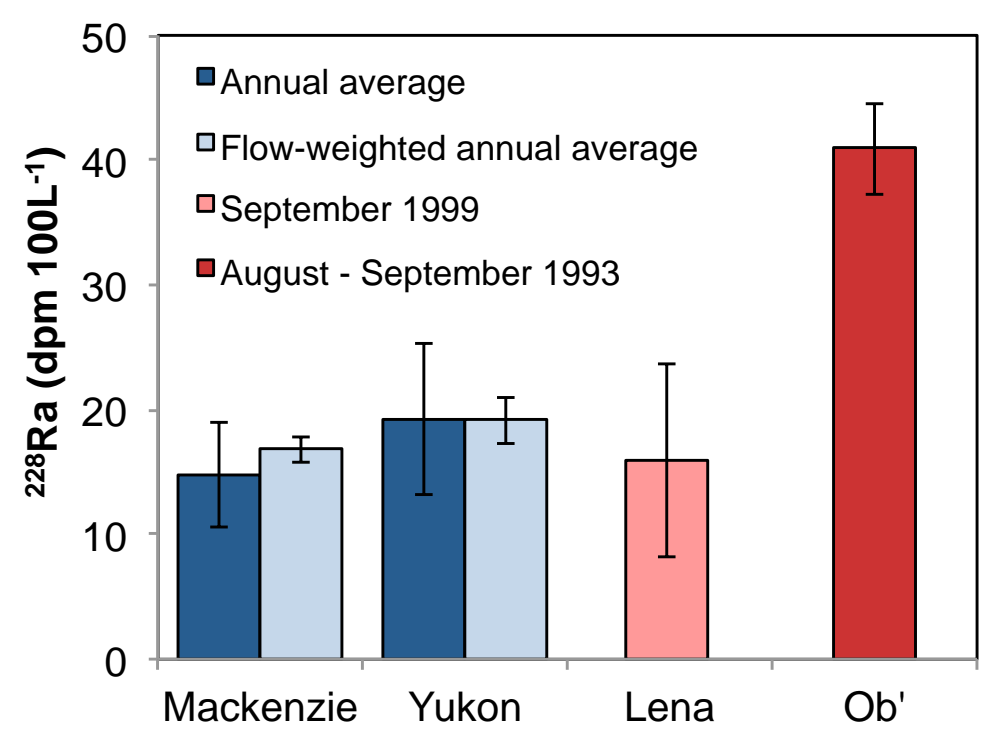

(b)

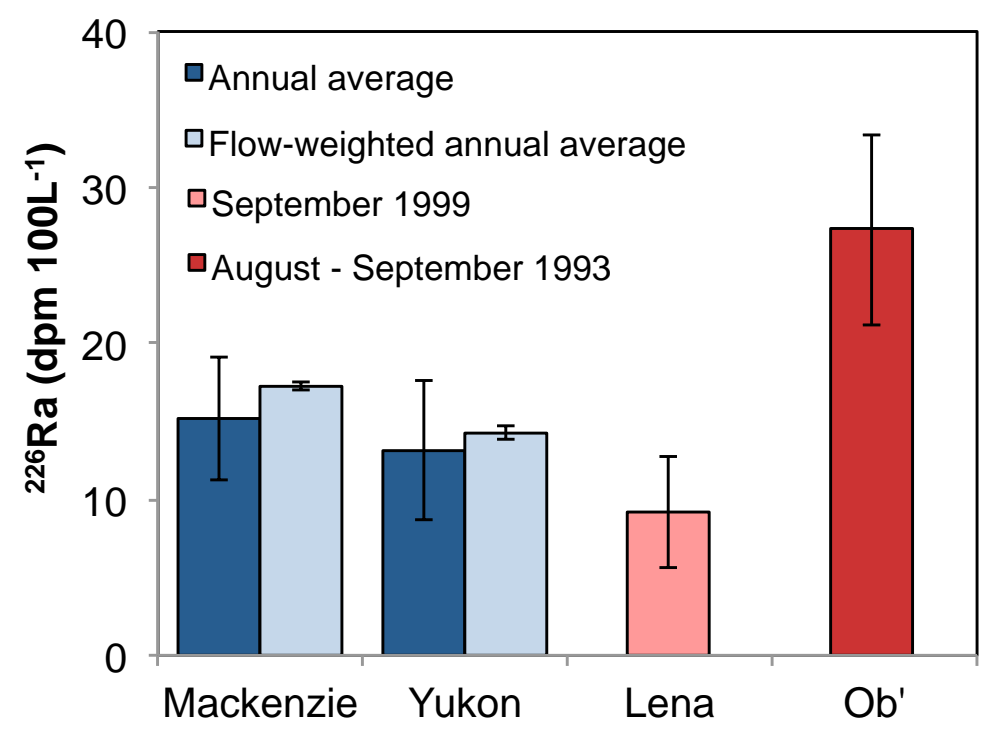

Figure 13. (a) ${ }^{228} \mathrm{Ra}$ and (b) ${ }^{226} \mathrm{Ra}$ activities in North American (blue) and Eurasian (red) Arctic rivers. Annual averages and flow-weighted averages calculated from data collected in 2015 2016 are shown for the Mackenzie and Yukon (this study); the Lena and Ob' activities are from Rutgers van der Loeff et al. (2003). Error bars on the Mackenzie and Yukon annual averages represent the standard deviation, error bars on the flow-weighted annual averages represent propagated Ra measurement error (error associated with the river discharge measurement is not accounted for). 


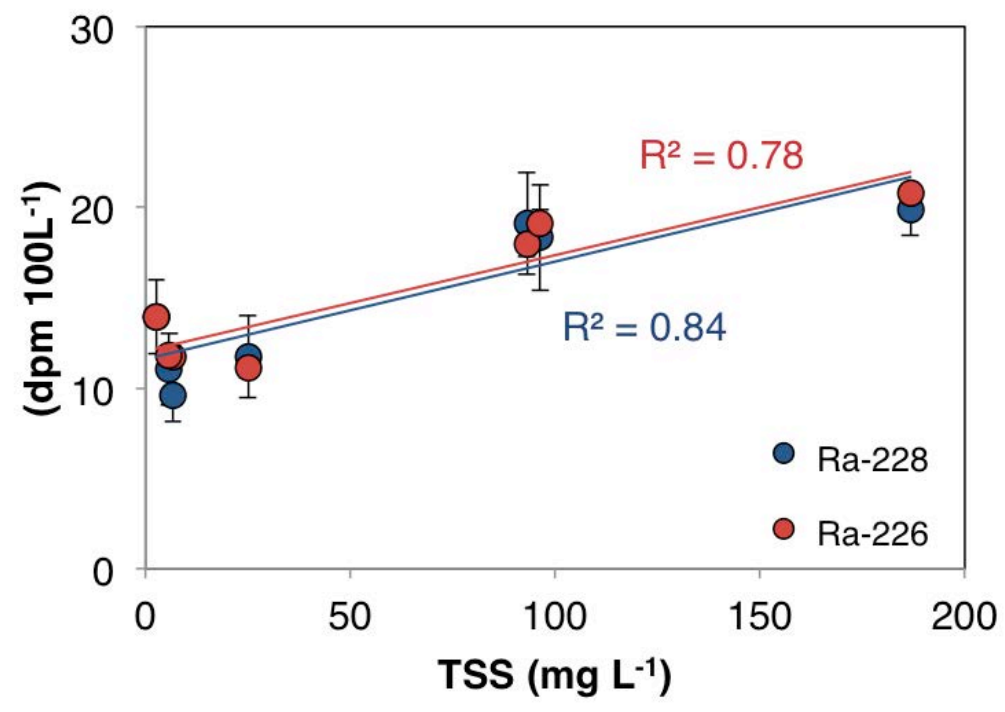

Figure 14. Relationship between (a) ${ }^{226} \mathrm{Ra}$ and total suspended solids (TSS) and (b) ${ }^{228} \mathrm{Ra}$ and TSS in the Mackenzie River. The regression lines and $\mathrm{R}^{2}$ values are also shown. 


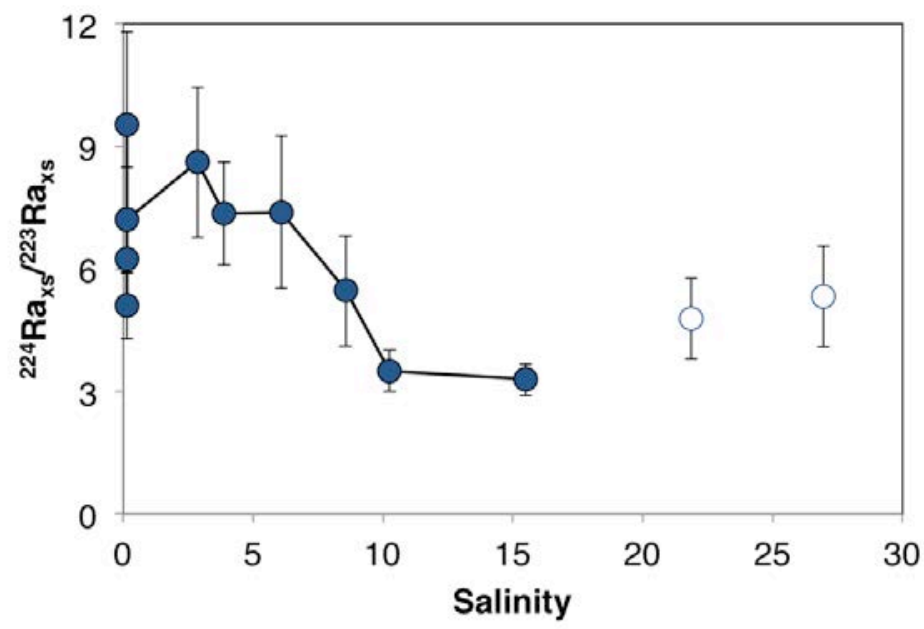

Figure 15. The ${ }^{224} \mathrm{Ra}_{\mathrm{xs}} \mathrm{S}^{223} \mathrm{Ra}_{\mathrm{xs}}$ activity ratio in the East Channel. Filled symbols represent samples collected from the surface and open symbols denote samples collected from depth. 
Supplementary Figures 

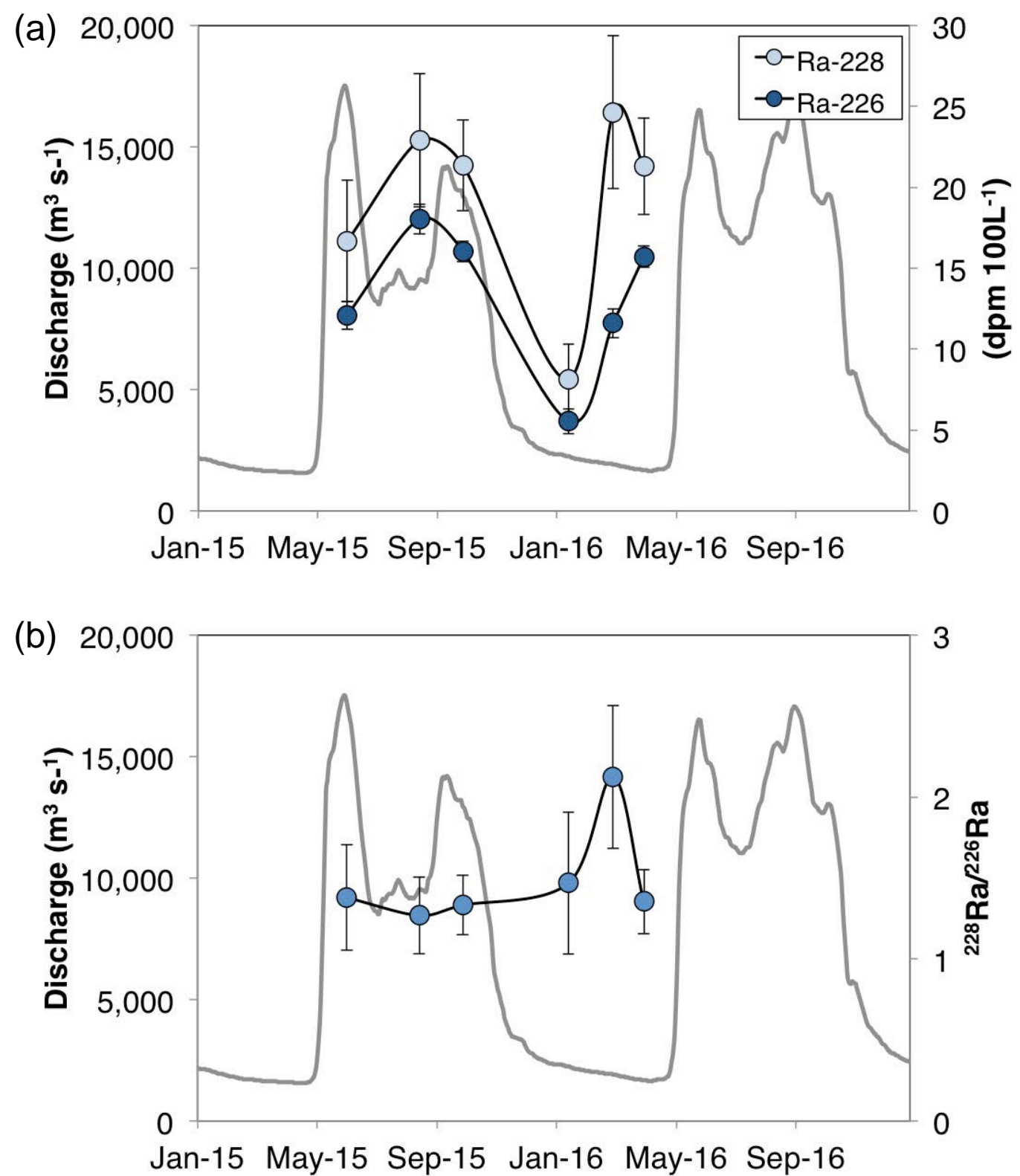

Figure S1. Time series of (a) ${ }^{228} \mathrm{Ra}$ and ${ }^{226} \mathrm{Ra}$ and (b) the ${ }^{228} \mathrm{Ra} /{ }^{226} \mathrm{Ra}$ activity ratio in the Yukon River at Pilot Station. Water discharge was reported by the U.S. Geological Survey. 


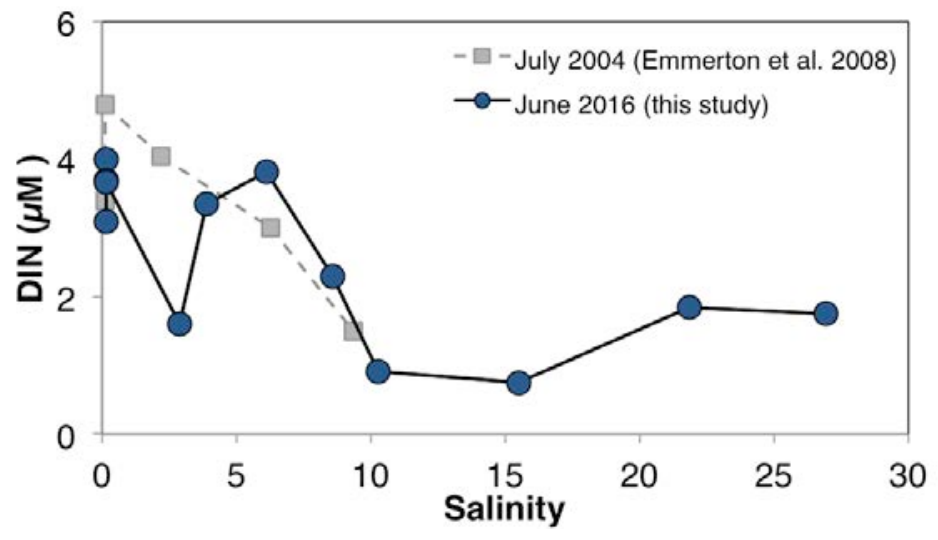

Figure S2. Dissolved inorganic nitrogen concentrations in the East Channel. Blue symbols represent concentrations measured in June 2016 (this study), and grey symbols represent concentrations measured by Emmerton et al. (2008b) in July 2004. 
224 


\section{Chapter 6: Summary and future research directions}


Radioactive isotopes are valuable tools for studying the sources, sinks, and cycling of nutrients, carbon, and trace elements and isotopes (TEIs) in oceanography. In this thesis I have applied radium isotopes $\left({ }^{223} \mathrm{Ra}: \mathrm{t}_{1 / 2}=11.4 \mathrm{~d},{ }^{224} \mathrm{Ra}: \mathrm{t}_{1 / 2}=3.66 \mathrm{~d},{ }^{226} \mathrm{Ra}: \mathrm{t}_{1 / 2}=1600 \mathrm{y},{ }^{228} \mathrm{Ra}: \mathrm{t}_{1 / 2}=\right.$ $5.75 \mathrm{y}$ ) as tracers of boundary inputs in the extremes of hot and cold environment from hightemperature hydrothermal vents to the frigid Arctic. The GEOTRACES program allowed me to collect Ra samples in unprecedented resolution in the open ocean, and by pairing those spatially large datasets with smaller, more detailed sample sets, I have improved our understanding of boundary inputs of TEIs to the coastal and open ocean.

In Chapter 2, I applied Ra isotopes as tracers of neutrally buoyant plume dynamics in the deep ocean; although the long-lived Ra isotopes have been used in the past to study hydrothermal processes, this is one of the first studies to employ the short-lived ${ }^{223} \mathrm{Ra}$ and ${ }^{224} \mathrm{Ra}$ in a hydrothermal setting. First, I compiled historical measurements of Ra isotopes in hydrothermal fluids in order to determine typical $\mathrm{Ra}$ isotope ratios in high and low temperature vent fluids; this summary approximately doubled the catalog of available ${ }^{224} \mathrm{Ra}$ measurements in hydrothermal fluids and quadrupled the number of available ${ }^{223} \mathrm{Ra}$ measurements. The differences between the observed vent fluid ratios and the ratios measured in neutrally buoyant plumes were then used to quantify the plume ages. The ages of young near-field $(<100 \mathrm{~km}$ from vent) plumes over the East Pacific Rise (EPR) and the Mid-Atlantic Ridge (MAR) were determined to be $\sim 1$ month and $\sim 5 \mathrm{~d}$, respectively, at the point of sampling. The half-life of ${ }^{228} \mathrm{Ra}$ makes it applicable for tracing processes occurring on decadal time scales; thus this isotope was used to establish the age of a plume emanating over $1000 \mathrm{~km}$ from the EPR. By pairing this age information with the concentrations of iron provided by Resing et al. (2015), I was able to establish that the residence time of dissolved iron in the plume was $9-20 \mathrm{y}$, with an upper limit of $50 \mathrm{y}$. This chapter therefore serves to address a key component of the GEOTRACES mission: to "quantify fluxes that control the distributions of key trace elements and isotopes in the ocean."

An important next step is to conduct a study wherein Ra isotopes can be measured in high-temperature fluids and the neutrally buoyant plume emanating from the same vent (and ideally the buoyant plume as well). This kind of process study would provide important insights into the spatial and temporal variability of isotope ratios, so that future studies can be designed to maximize the information gained from minimal sampling time. Future studies should also focus on constraining vent fluid ratios; studies across different ridge types and temperature gradients would help elucidate the processes controlling the observed ratios, and allow for better predictions of vent fluid ratios when they cannot be measured directly. Of course, the ultimate goal is to apply this technique to constrain the residence times of multiple TEIs in various types of hydrothermal environments. This information is needed to improve biogeochemical models and test hypotheses about how hydrothermal TEI inputs affect primary productivity in surface waters (Tagliabue et al., 2016, 2010).

Chapters 3 and 4 focused on sediment inputs from shelves and basins in the Western Arctic Ocean, an ocean that is unique because of its large shelf area and because of its susceptibility to climate change. Due to their sediment source, Ra isotopes are perfectly suited for tracing land-ocean exchange, and have great potential for tracking climate-induced changes in this ocean. In Chapter 3 I showed that these changes are already occurring; the levels of ${ }^{228} \mathrm{Ra}$ I observed in the central Arctic in 2015 were approximately double those measured in 2007. These high concentrations were transported to the central Arctic via the Transpolar Drift, a surface current originating over the shelf seas north of Russia. Using a mass balance approach, I concluded that this increase is likely due to amplified fluxes of shelf-derived materials to Arctic 
surface waters. Increased shelf inputs will not only affect Ra isotopes but also any nutrients and TEIs that have a shelf source, thus this chapter helps to address the question of how TEI distributions may change under future climate conditions.

Based on the number of ice-free days recorded over the East Siberian and Laptev Shelf Seas in the years preceding sampling in 2007 and 2015, I hypothesized that the rising shelf inputs are due to the loss of ice cover over these shallow shelves (Figure 1). This loss of sea ice allows for more wind-driven mixing and turbulence that carries Ra (and carbon, nutrients, and TEIs) from sediment porewaters into the overlying water column. In order to make predictions for how this system will continue to change in the future, we must test this hypothesis with (1) continued measurements of Ra in the Arctic, which will help elucidate temporal trends, and (2) studies of Ra over Arctic shelves, ideally those in the eastern Arctic, to determine whether the shelf source of $\mathrm{Ra}$ is increasing over wide areas of the Eurasian shelves or only in certain locations, and to help define the mechanism driving increased fluxes.

Paired studies of $\mathrm{Ra}$ and TEIs over the shelf and in rivers would also help determine the relative impacts of changing river chemistry and the changing shelf environment on surface waters that are eventually advected into the central Arctic. Because the Arctic receives a large amount of river discharge that traverses the shelf before reaching the open ocean, it is hard to determine whether TEI - Ra correlations in the open ocean are due to a common porewater source or due to a coincidental correlation acquired during the transit of river water over the shelf. More studies near the coast and over the shelves would improve our understanding of how river discharge is modified during its residence time over the shelf. While both river discharge and shelf inputs are likely to change due to rising Arctic temperatures, TEIs that have a significant shelf sediment source are best suited for monitoring with Ra isotopes.

In Chapter 4, I used ${ }^{228} \mathrm{Ra}$ and the ${ }^{228} \mathrm{Ra} /{ }^{226} \mathrm{Ra}$ activity ratio to examine the ventilation time scales of Arctic upper ocean and intermediate waters with respect to shelf inputs. Radium228 provided evidence of strong shelf influence near the Chukchi shelfbreak, and indicated that sediment inputs to the water column in this location are strongest during the fall. This input of Ra (and other shelf-derived materials) is transported to the Canada Basin in part through the Chukchi shelfbreak jet; using ${ }^{228} \mathrm{Ra} /{ }^{226} \mathrm{Ra}$ activity ratios, I estimated that this pathway ventilates the halocline on timescales of $\leq 14-17 \mathrm{y}$. The ${ }^{228} \mathrm{Ra} /{ }^{226} \mathrm{Ra}$ activity ratio was also applied to determine that intermediate waters in the Makarov and Canada Basins are ventilated with respect to shelf inputs on timescales of $\sim 20 \mathrm{y}$ and $30+\mathrm{y}$, respectively. These ventilation timescales may be altered in the future due to changes in the freshwater cycle and ice coverage over Arctic shelves (Carmack and Chapman, 2003; McClelland et al., 2012; Newton et al., 2017). We should therefore continue to use Ra isotopes to study shelf inputs in this region, and the values presented in Chapter 4 serve as a baseline against which future findings can be compared.

In this chapter I also report the first profiles of ${ }^{226} \mathrm{Ra}$ in the deep (>2000 $\mathrm{m}$ ) Canadian Basin. Benthic sediment-derived enrichments of ${ }^{226} \mathrm{Ra}$ were apparent, and the accumulation of ${ }^{226} \mathrm{Ra}$ was used to estimate the residence times of bottom waters. The residence times in the deep Makarov and Canada Basins were found to be $400-650$ y and $130-270 \mathrm{y}$, respectively. However, these ranges rely on estimates of the flux of ${ }^{226} \mathrm{Ra}$ from sediments, which have not been well characterized in the Arctic. A study of the ${ }^{226} \mathrm{Ra}$ flux from Western Arctic sediments, specifically focused on variability in the different basins, would help constrain these residence time estimates.

In Chapter 5 I presented a suite of trace metal, nutrient, dissolved organic matter, and $\mathrm{Ra}$ isotopes collected from the Mackenzie River Delta; this sample set provides some of the first 
measurements of TEIs in this important Arctic estuary and was used to show that the freshwater endmember concentrations of riverine solutes are significantly changed during transit through the delta and estuary. Levels of inorganic nutrients, trace metals, and Ra were fairly constant throughout the delta, but were considerably changed during estuarine mixing. Radium isotope activity ratios were used to identify benthic inputs in the freshwater-saltwater transition zone; this benthic source may have contributed to increased concentrations of nutrients and trace metals in the estuary. Particle desorption was shown to be an important control on the estuarine concentrations of Ra, barium, copper, and nickel. Dissolved organic matter (DOM) increased through the delta and were rapidly removed in the early stages of estuarine mixing, likely as a result of flocculation. These results highlight the importance of estuarine changes in solute concentrations, and suggest that estimates of DOM removal rates in the Arctic basin, which are based on freshwater endmember concentrations, may be overestimates.

Because of the large seasonal variability in river discharge, solute concentrations, and particle loads, the solute measurements made on this June 2016 transect cannot be extrapolated over the whole year. In order to better constrain fluxes of solutes from the Mackenzie, it is therefore important to collect more measurements over multiple seasons and years. Over the last decade, the Arctic Great Rivers Observatory has vastly improved our understanding of Arctic rivers by collecting year-round measurements of many solutes in the freshwater endmembers. Future work should therefore focus on sampling in the delta and estuary, in order to understand how seasonal changes in the freshwater endmember are manifested downstream. Sampling of active layer and permafrost porewaters would also aid predictions of how river water chemistry will respond to climate change. To this end, I have presented measurements of various solutes in the porewaters of active layer and permafrost sediments collected from the Mackenzie River Delta in the Appendix.

In summary, this thesis has shown how Ra isotopes can be applied to study boundary inputs in diverse ocean environments, and has improved our understanding of hydrothermal, fluvial, and continental sources of nutrients and trace metals to the coastal and open ocean. The GEOTRACES program has provided us with the opportunity to measure the large scale distributions of Ra isotopes and other TEIs in the world's oceans, and constraining the boundary inputs of these TEIs improves our ability to interpret these extensive datasets. Future research should continue to focus on identifying the Ra signatures of different endmembers, as well as their variability, in order to best utilize these isotopes as tracers in oceanography. While this thesis serves as an important contribution to our knowledge of current ocean chemistry, the cycling of elements in the ocean will undoubtedly shift as the ocean is affected by anthropogenic climate change. Radium isotopes are well suited as tools to help us study these changes. 


\section{References}

Carmack, E., Chapman, D.C., 2003. Wind-driven shelf/basin exchange on an Arctic shelf: The joint roles of ice cover extent and shelf-break bathymetry. Geophys. Res. Lett. 30, 1778. doi:10.1029/2003GL017526

McClelland, J.W., Holmes, R.M., Dunton, K.H., Macdonald, R.W., 2012. The Arctic Ocean Estuary. Estuaries and Coasts 35, 353-368. doi:10.1007/s12237-010-9357-3

Newton, R., Pfirman, S., Tremblay, B., DeRepentigny, P., 2017. Increasing transnational sea-ice exchange in a changing Arctic Ocean. Earth's Futur. 5, 633-647. doi:10.1002/2016EF000500

Resing, J.A., Sedwick, P.N., German, C.R., Jenkins, W.J., Moffett, J.W., Sohst, B.M., Tagliabue, A., 2015. Basin-scale transport of hydrothermal dissolved metals across the South Pacific Ocean. Nature 523, 200-203. doi:10.1038/nature14577

Tagliabue, A., Aumont, O., DeAth, R., Dunne, J.P., Dutkiewicz, S., Galbraith, E., Misumi, K., Moore, J.K., Ridgewell, A., Sherman, E., Stock, C., Vichi, M., Volker, C., Yool, A., 2016. How well do global ocean biogeochemistry models simulate dissolved iron distributions? Global Biogeochem. Cycles 30, 149-174. doi:10.1002/2015GB005289.Received

Tagliabue, A., Bopp, L., Dutay, J.-C., Bowie, A.R., Chever, F., Jean-Baptiste, P., Bucciarelli, E., Lannuzel, D., Remenyi, T., Sarthou, G., Aumont, O., Gehlen, M., Jeandel, C., 2010.

Hydrothermal contribution to the oceanic dissolved iron inventory. Nat. Geosci. 3, 252-256. doi:10.1038/ngeo818 


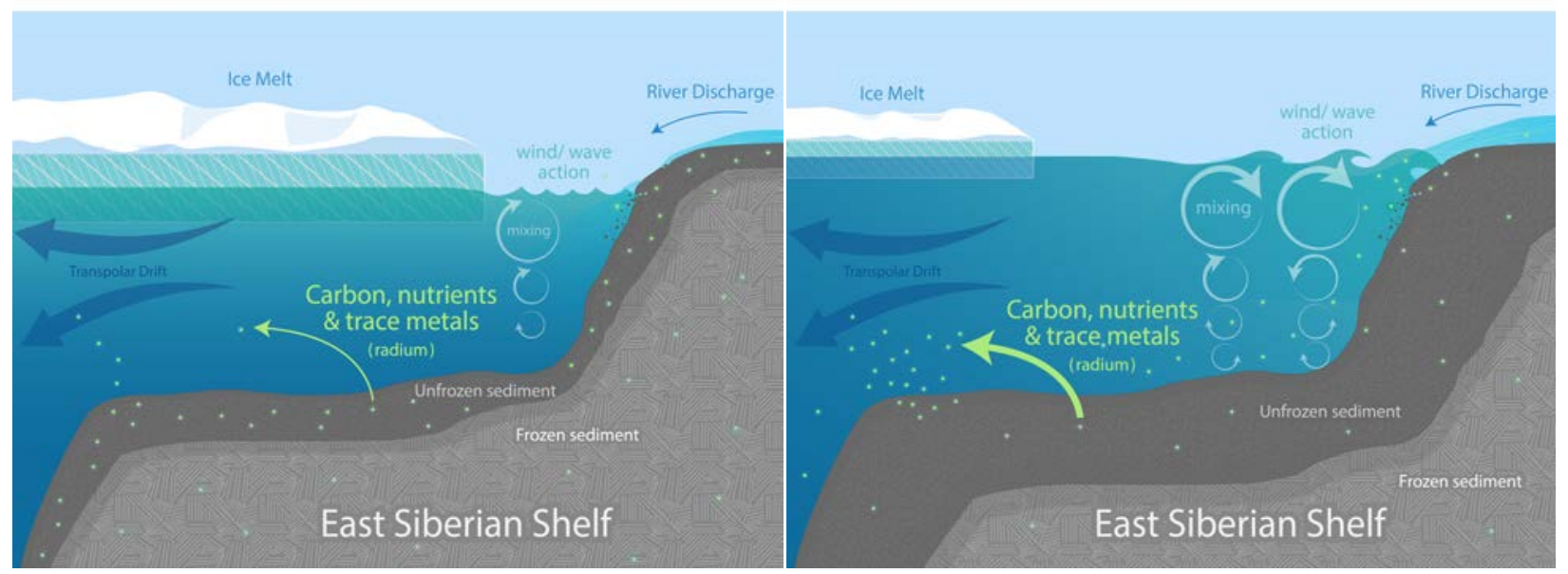

Figure 1. The loss of sea ice over Arctic shelves allows for more wind-driven mixing, which is likely driving the increased flux of shelf-derived materials. In 2015, higher levels of radium were observed in the Central Arctic compared to 2007. This may result from increased mixing over the shelf transporting more shelf-derived materials (including radium, nutrients, carbon, and trace metals; shown as green dots) from the sediments in to the overlying water column, where they can then be carried by the Transpolar Drift to the Central Arctic. Other climate-driven changes, such as increased river discharge and permafrost thaw, may also be affecting shelf inputs to the open ocean. Illustration by N. Renier, WHOI Graphics. 


\section{Appendix: Chemistry of permafrost porewaters in the Mackenzie River Delta}




\section{A.1 MOTIVATION}

Permafrost is widespread in the Arctic, encompassing over $22 \%$ of the exposed land surface area and extending onto the continental shelf (Figure 1) (Brown et al., 1998; Schuur et al., 2008). Permafrost currently serves as a large reservoir of carbon, nutrients, and trace elements and isotopes (TEIs) (Frey and McClelland, 2009, and references therein; Schuur et al., 2008). However, rising land and ocean temperatures are leading to the thawing of both terrestrial and subsea permafrost (Luo et al., 2016; Portnov et al., 2013; Shakhova et al., 2010), allowing the release of solutes that were previously trapped in sediments.

Permafrost can act as an impermeable barrier to groundwater flow (Williams and Van Everdingen, 1973), preventing solutes from being transported to the coastal ocean by rivers or groundwaters. As permafrost thaws, groundwater is likely to become a more important part of the Arctic hydrologic cycle (Frey and McClelland, 2009). Submarine groundwater discharge (SGD) through the seasonally thawed active layer (the thin soil layer above permafrost), has been shown to transport TEIs and nutrients to Arctic lakes and the coastal ocean (Lecher et al., 2016, 2015; Paytan et al., 2015). As active layers deepen due to permafrost degradation, the distinct geochemical signature that is associated with the less-weathered permafrost soils will be imparted to circulating groundwater and transported to rivers and the ocean. In northwest Canada, higher suspended sediment and solute concentrations were observed in streams in regions affected by permafrost degradation compared to streams in unaffected regions (Kokelj et al., 2013). Similarly, watersheds in permafrost-free regions of Siberia have been found to have higher concentrations of nutrients and major ions than watersheds underlain by permafrost (Frey et al., 2007b, 2007a).

Keller et al. (2010) used the shift in the ${ }^{87} \mathrm{Sr}:{ }^{86} \mathrm{Sr}$ ratio observed in Alaskan watersheds to deduce a deepening of the active layer. I hypothesize that the quartet of radium isotopes $\left({ }^{223} \mathrm{Ra}\right.$ :

$\left.\mathrm{t}_{1 / 2}=11.4 \mathrm{~d} ;{ }^{224} \mathrm{Ra}: \mathrm{t}_{1 / 2}=3.66 \mathrm{~d} ;{ }^{228} \mathrm{Ra}: \mathrm{t}_{1 / 2}=5.75 \mathrm{y} ;{ }^{226} \mathrm{Ra} ; \mathrm{t}_{1 / 2}=1600 \mathrm{y}\right)$ can similarly be used as a tracer of permafrost thaw. The active layer is likely to exhibit different Ra activity ratios than permafrost because it is more frequently flushed by groundwater. Ingrowth of an isotope is determined by its half-life, so the shorter-lived Ra isotopes will be regenerated more quickly after being flushed out of sediments, and the active layer should therefore exhibit higher short- to long- lived activity ratios than the permafrost. Higher ${ }^{228} \mathrm{Ra} /{ }^{226} \mathrm{Ra}$ activity ratios have previously been observed in marsh sediments that are flushed on semi-diurnal time scales compared to the less frequently flushed aquifer sands at their foundation (Charette, 2007). As the active layer deepens, groundwater will adopt the Ra activity ratio of the newly thawed soils and this signature, along with the TEIs and nutrients present in that layer, will eventually be transported to rivers. Measurements of the Ra activity ratios in permafrost, as well as concurrent measurements of river water signatures, can therefore be used to track changes that may signal an increase in active layer thaw depth and consequent changes in TEI and nutrient delivery to rivers and coastal zones.

To test this hypothesis, and to help quantify the reservoirs of nutrients and TEIs in permafrost in the Mackenzie River basin, I measured Ra isotopes, water isotopes $\left(\delta^{18} \mathrm{O}, \delta^{2} \mathrm{H}\right)$, nutrients $\left(\mathrm{NO}_{\mathrm{x}}, \mathrm{PO}_{4}{ }^{3-}, \mathrm{SiO}_{4}{ }^{-}\right)$, dissolved organic carbon and nitrogen (DOC, DON), and trace metals ( $\mathrm{Ba}, \mathrm{Co}, \mathrm{Cu}, \mathrm{Mn}, \mathrm{Ni}, \mathrm{Pb}, \mathrm{U})$ in porewaters of active layer and permafrost sediments collected near the Mackenzie River in the Northwest Territories, Canada. The activities of ${ }^{228} \mathrm{Ra}$ and ${ }^{226} \mathrm{Ra}$ were also measured in sediments for select samples. This appendix presents the data generated from these measurements, but does not include an interpretation of the results. 


\section{A.2 SAMPLE COLLECTION}

Active layer and permafrost samples were collected by two teams on two different sampling expeditions. During a trip to the Mackenzie River delta in June 2016 (Chapter 5), we collected samples in two locations: in a black spruce forest next to the Dempster Highway between Tsiigehtchic and Inuvik $\left(67.9986^{\circ} \mathrm{N}, 133.7365^{\circ} \mathrm{W}\right)$, and from the headwall of a retrogressive thaw slump in Tuktoyaktuk $\left(69.4560^{\circ} \mathrm{N}, 133.0025^{\circ} \mathrm{W}\right)$ (Table 1a). For a description of thaw slumps in the Mackenzie Delta and massive ground ice in Tuktoyaktuk, see Lantz and Kokelj (2008) and Mackay and Dallimore (1992). The sampling along Dempster Highway was conducted by removing the surface layer of moss, and collecting soil samples from the active layer (DH1; surface), active layer-permafrost boundary (DH2; 0.25 m), and permafrost (DH3; $\sim 0.5 \mathrm{~m}$ ) using a shovel. Permafrost was identified by the presence of frozen sediments, but there was no visible ice. Because the samples were collected early in the season (June) it is unlikely that the maximum thaw depth had been reached and these samples may therefore be more representative of the deep active layer than the true permafrost layer. Two active layer samples were collected from the top of the thaw slump in Tuktoyaktuk using a shovel (TS1, TS2), and permafrost was collected from the exposed face of the thaw slump $(\sim 3 \mathrm{~m}$ from the top of the headwall) using a titanium hammer (TS3). The permafrost collected from this location contained visible ice. Samples were not kept cold during transport, but were re-frozen upon delivery to Woods Hole Oceanographic Institution. The DH and TS samples were used to measure Ra isotope activities in the bulk sediments and in sediment desorption experiments. The thawed porewaters from TS3 were also analyzed for Ra and water isotopes. Thawing during storage should not affect $\mathrm{Ra}$ activities, but may have biased water isotope analyses by allowing equilibration with air in the headspace of the container.

The second set of samples consisted of permafrost cores collected near Inuvik in August 2016 by Steve Kokelj (Northwest Territories Geological Survey) and Justin Kokoszka (Simon Fraser University). The cores were $7.8 \mathrm{~cm}$ in diameter. The first core (NR2;68.3837 $\mathrm{N}$, $133.7605^{\circ} \mathrm{W}$ ) was $144 \mathrm{~cm}$ long, and the second core (AC; $\left.68.3127^{\circ} \mathrm{N}, 133.4816^{\circ} \mathrm{W}\right)$ was $102 \mathrm{~cm}$ long. These cores were split into sub-sections ranging from $4-30 \mathrm{~cm}$ long (Table 1b). Soil descriptions provided by Steve Kokelj and Justin Kokoszka are included in Table 1b. Samples were kept frozen during transport to Woods Hole Oceanographic Institution. Porewaters collected from these samples were analyzed for Ra isotopes, water isotopes, nutrients, trace metals, DOC, and DON.

\section{A.3 EXPERIMENTAL PROCEDURES AND RESULTS}

\section{A.3.1 Sediment-bound ${ }^{228} \mathrm{Ra}$ and ${ }^{226} \mathrm{Ra}$ activities (DH1-3, TS1-3)}

With the exception of TS3 (see section A.3.3), the DH and TS samples did not contain enough ice to allow for measurements of solutes in the thawed porewater. These samples were instead used to investigate the ${ }^{228} \mathrm{Ra}$ and ${ }^{226} \mathrm{Ra}$ activities of the sediments, and the activities of ${ }^{228} \mathrm{Ra}$ and ${ }^{226} \mathrm{Ra}$ that desorbed from sediments in fresh and saline water (see section A.3.2).

Sediments were dried in a $50^{\circ} \mathrm{C}$ oven until the weight was stable, and then $\sim 3 \mathrm{~g}$ of sediment from each sample was packed into polystyrene vials, sealed with epoxy to prevent

${ }^{222} \mathrm{Rn}$ loss, and aged for at least 3 weeks. Sediments were then analyzed by $\gamma$ spectrometry on high-purity, well-type germanium detectors. The activity of ${ }^{228} \mathrm{Ra}$ was measured using the lines 
for ${ }^{228} \mathrm{Ac}$ (338 and $\left.911 \mathrm{keV}\right)$, and the activity of ${ }^{226} \mathrm{Ra}$ was measured using the line for ${ }^{214} \mathrm{~Pb}(352$ $\mathrm{keV})$. Detector efficiencies were determined using a set of ashed cartridge standards prepared with a standard solution containing ${ }^{226} \mathrm{Ra}$ and ${ }^{232} \mathrm{Th}$ with daughters in equilibrium. Three aliquots of each sediment sample were analyzed, with the exception of TS3. The average ${ }^{228} \mathrm{Ra}$ and ${ }^{226} \mathrm{Ra}$ activities measured in the samples are shown in Table 2.

\section{A.3.2 Desorbable ${ }^{228} \mathrm{Ra}$ and ${ }^{226} \mathrm{Ra}$ activities (DH1-3, TS1-3)}

Desorption experiments were conducted by mixing $\sim 75 \mathrm{~g}$ of sediment (except for TS3, for which $\sim 50 \mathrm{~g}$ was used due to limited sediment availability) with $\sim 900 \mathrm{~mL}$ of water collected from the Mackenzie Estuary (see Chapter 5). The Mackenzie River water used in the experiment was first filtered through a $\mathrm{Mn}-\mathrm{O}_{2}$ coated fiber to remove any $\mathrm{Ra}$ that was initially present. Two salinities were used in order to compare the possible effects of permafrost being eroded into the Mackenzie River (salinity 0.6) and the coastal ocean (salinity 27). Water and sediment were mixed by vigorously shaking for 30 seconds, and left to sit overnight. Samples were re-shaken the following morning, and then vacuum filtered through $90 \mathrm{~mm}$ PES membrane filters with a $0.22 \mu \mathrm{m}$ pore size (Fisher/Millipore) set in an acid-cleaned plastic Buchner funnel. Filtrate was collected in an acid-cleaned polypropylene flask. The filtrate was circulated four times at $\sim 30$ $\mathrm{mL} \mathrm{min}^{-1}$ through a 5/8" diameter plastic column packed with $1.8 \mathrm{~g}$ of $\mathrm{MnO}_{2}$-coated acrylic fiber to preconcentrate Ra isotopes (Moore and Reid, 1973). The tubing and column were rinsed with Milli-Q water between samples. The fiber was rinsed three times with Ra-free Milli-Q to remove salts, and excess water was removed by squeezing. The fiber was then dried in a $50^{\circ} \mathrm{C}$ oven overnight, packed in a polystyrene tube to a density of $0.33-0.36 \mathrm{~g} \mathrm{~mL}^{-1}$, sealed with epoxy, aged for a minimum of 3 weeks, and counted on a $\gamma$ spectrometer as described in section A.3.1. A $900 \mathrm{~mL}$ blank was analyzed with each set of samples following the same procedures; salinity 0.6 water was used for one blank (Blank 1), and salinity 27 water was used for two blanks (Blanks 2 and 3).

In order to determine the $\gamma$ detector efficiency for this matrix $\left(1.8 \mathrm{~g}\right.$ of un-burned $\mathrm{MnO}_{2}$ coated acrylic fiber), a new standard was made by adding $1834 \mathrm{dpm}$ of a ${ }^{226} \mathrm{Ra}$ standard solution (SRM \#4967A) and $793 \mathrm{dpm}$ of a ${ }^{228} \mathrm{Ra}$ solution to $\sim 1000 \mathrm{~mL}$ of Milli-Q water and filtering this solution through $1.8 \mathrm{~g}$ of $\mathrm{MnO}_{2}$-coated acrylic fiber. These small amounts of added ${ }^{228} \mathrm{Ra}$ and ${ }^{226} \mathrm{Ra}$ were chosen to represent the low activities expected in the samples. The standard solution was passed over the fiber 6 times, and sodium hydroxide was added to increase the ( $\mathrm{pH} \sim 5)$ Milli$\mathrm{Q}$ solution to a $\mathrm{pH}$ of $\sim 7.8$. The fiber was then treated in the same way as the samples, and sealed in a polystyrene tube as described above. This new fiber standard was analyzed on all detectors at least once to determine the efficiency on each detector (Table 3), and it was run multiple times on multiple detectors to confirm that the activities were stable over time (Figure 2). After being passed through the fiber, the filtrate from the standard solution was transferred to a gas washing bottle, purged with helium, and sealed for 3 weeks to allow ${ }^{222} \mathrm{Rn}$ to reach equilibrium with

${ }^{226} \mathrm{Ra}$. The activity of ${ }^{226} \mathrm{Ra}$ in the filtrate was then determined using the ${ }^{222} \mathrm{Rn}$ emanation method described in Key et al. (1979) in order to determine the efficiency of Ra collection using this method of filtration. A negligible amount of ${ }^{226} \mathrm{Ra}$ was measured in this filtrate, indicating that all of the spiked ${ }^{226} \mathrm{Ra}$ (and presumably ${ }^{228} \mathrm{Ra}$ ) was effectively captured on the Mn fiber.

The ${ }^{228} \mathrm{Ra}$ and ${ }^{226} \mathrm{Ra}$ activities and the ${ }^{228} \mathrm{Ra} /{ }^{226} \mathrm{Ra}$ activity ratios measured in the filtrate from the desorption experiments are shown in Table 4. The filtrate collected from most of the freshwater desorption experiments had ${ }^{228} \mathrm{Ra}$ and ${ }^{226} \mathrm{Ra}$ activities below detection limits, but the 
experiments with saline water resulted in measurable activities. The percentage of ${ }^{226} \mathrm{Ra}$ that desorbed was determined based on the activities measured in the filtrate and the activities measured on corresponding sediments (see Table 2).

\section{A.3.3 ${ }^{226} \mathrm{Ra}$ activity and water isotopes in TS3 porewater}

Because TS3 was very ice rich, there was a significant amount of thawed porewater. This porewater was separated from sediments by centrifugation, and $2 \mathrm{~mL}$ was collected for water isotope analysis. Using a refractometer, the salinity of this porewater was determined to be $<1$. The remaining amount of porewater (approximately $300 \mathrm{~mL}$ ) was filtered through $1.8 \mathrm{~g}$ of $\mathrm{MnO}_{2}$-coated fiber and analyzed following the procedures described above for the filtrate in the desorption experiments. This sample was analyzed on the same $\gamma$ spectrometer (Ortec) twice, and the two runs were approximately two months apart. The activity of ${ }^{228} \mathrm{Ra}$ was below the detection limit on both runs. On the first run $(11 / 7 / 16)$ the ${ }^{226} \mathrm{Ra}$ activity was $1.4 \pm 0.2 \mathrm{dpm} \mathrm{L}{ }^{-1}$; on the second run $(1 / 21 / 17)$ it was $2.3 \pm 0.4 \mathrm{dpm} \mathrm{L}^{-1}$.

The $\delta^{18} \mathrm{O}$ and $\delta^{2} \mathrm{H}$ content of the porewater sample was determined at the UC Davis Stable Isotope Facility using a Laser Water Isotope Analyzer V2 (Los Gatos Research, Inc., Mountain View, CA, USA). The $\delta^{18} \mathrm{O}$ and $\delta^{2} \mathrm{H}$ values (reported in \%o relative to VSMOW) for this sample were $-239.7 \%$ and $-30.30 \%$, respectively. These values are very similar to those observed in massive ground ice on Peninsula Point, $20 \mathrm{~km}$ southeast of Tuktoyaktuk; at this location $\delta^{18} \mathrm{O}$ values were between $-32 \%$ and $-28 \%$, and $\delta^{2} \mathrm{H}$ values were between $-250 \%$ ond 225\%o (Mackay and Dallimore, 1992). Water isotopes in this range were also recorded in massive ground ice deposits and thaw slumps on Herschel Island, located offshore of the Yukon Coastal Plain (northwest of the Mackenzie Delta), and were attributed to a glacial water source (Fritz et al., 2011).

\section{A.3.4 Solutes in NR2 and AC permafrost porewaters}

Thawed permafrost porewaters in the NR2 and AC cores were separated from sediments and analyzed for a variety of solutes. The first core section to be processed (AC-2) was divided into subsections using an acid-cleaned polytetrafluoroethylene wedge and a titanium hammer. These sections were placed (one at a time) in a Buchner funnel over a polypropylene vacuum flask (both acid-cleaned), and gradually thawed in a fridge overnight. The thawed porewaters were allowed to drip into the flask through a $90 \mathrm{~mm}$ PES membrane filter with a $0.22 \mu \mathrm{m}$ pore size (Fisher/Millipore), and once the core section was completely thawed, the remaining porewaters were vacuum filtered. The remaining sediment was removed from the funnel and the next core subsection was added, so that the filtrate collected in the flask was the accumulation of porewaters from the entire AC-2 section. This procedure took over two days, which was problematic because core processing spanning multiple days allows for the short-lived Ra isotopes to decay significantly, and may also lead to changes in the chemistry of the porewaters due to solute leaching from sediments in the slowly thawing core. The processing procedure was therefore changed for the remaining core sections, as described below.

To facilitate faster thawing, core sections were broken into small pieces using the polytetrafluoroethylene wedge and titanium hammer. These subsections thawed over a period of $0.5-3$ hours, and were filtered as soon as possible upon thawing (the maximum time elapsed between removal from the freezer and filtration was $\sim 8$ hours). Thawed core sections were 
placed in the acid-cleaned Buchner funnel, and porewaters were vacuum filtered through a PES membrane filter $(0.22 \mu \mathrm{m}$ pore size $)$ into an acid-cleaned polypropylene flask.

Permafrost filtrate was subsampled for trace metals $(\sim 8 \mathrm{~mL})$, nutrients $(\sim 10 \mathrm{~mL})$, DOC and total nitrogen $(\mathrm{TN})(\sim 20 \mathrm{~mL})$, and water isotopes $(2 \mathrm{~mL})$. The remaining volume was used for Ra isotope analysis. Because each core subsection produced only a small volume of porewater, the following sections were combined for Ra analysis: AC-3, AC-4, AC-5, and AC-6 were combined into one sample called "AC" ( $680 \mathrm{~mL})$; NR2-1 was kept as its own sample, referred to as "NR2 top" ( $640 \mathrm{~mL})$; NR2-2, NR2-3, and NR2-4 were combined to form "NR2 mid" ( $~ 840 \mathrm{~mL})$; and NR2-5, NR2-6, and NR2-7 were combined into "NR2 bottom" ( 680 mL). The AC-2 porewaters were not combined with the porewaters collected from the other AC core sections because of the long processing time for this section, which allowed for significant ${ }^{223} \mathrm{Ra}$ and ${ }^{224} \mathrm{Ra}$ decay that would have biased the integrated sample activities. Only a small amount of porewater was extracted from AC-7 $(\sim 60 \mathrm{~mL})$, and this entire volume was used for trace metal, nutrient, DOC/TN, and water isotope subsampling. Trace metal, nutrient, DOC, and water isotope samples were filtered through $0.22 \mu \mathrm{m}$ Sterivex filters. Trace metal samples were acidified with $25 \mu \mathrm{L}$ of $3 \mathrm{M} \mathrm{HCl}$. Nutrient and DOC samples were frozen until analysis, and water isotope samples were kept refrigerated.

Within 24 hours of filtration, the remaining volume of thawed permafrost porewater was filtered through $1.8 \mathrm{~g}$ of $\mathrm{MnO}_{2}$-coated fiber as described in section A.3.2 above. Fibers were rinsed with Ra-free Milli-Q water, partially dried by squeezing out excess water, and analyzed on Radium Delayed Coincidence Counters (RaDeCCs), which measure the activities of the shortlived ${ }^{223} \mathrm{Ra}$ and ${ }^{224} \mathrm{Ra}$ through their daughter isotopes ${ }^{219} \mathrm{Rn}$ and ${ }^{220} \mathrm{Rn}$, respectively (Moore and Arnold, 1996). Sample activities were decay corrected to the time of filtration through the $\mathrm{MnO}_{2}$ coated fiber. The samples were re-analyzed after four weeks and again after two months to determine the activities of ${ }^{224} \mathrm{Ra}$ and ${ }^{223} \mathrm{Ra}$ supported by their parent isotopes, ${ }^{228} \mathrm{Th}$ and ${ }^{227} \mathrm{Ac}$, respectively. The efficiency of the detectors was determined using a set of fiber standards. The standards are housed in cartridges that are $\sim 50 \%$ larger than the cartridges that were used to run the samples; this difference in cartridge size affects the efficiency of Rn detection. A smaller fiber housing will increase the efficiency, because there is less "dead space" in which the ${ }^{219} \mathrm{Rn}$ and ${ }^{220} \mathrm{Rn}$ can decay without being registered by the detector. Using the equations outlined in Moore and Cai (2013) that relate the volume of dead space to the theoretical detector efficiency, I estimated that the use of the smaller fiber housings was likely to increase the ${ }^{220} \mathrm{Rn}$ detection efficiency by $\sim 3 \%$, and the ${ }^{219} \mathrm{Rn}$ detection efficiency by $\sim 4 \%$. These differences are much less than the errors on the short-lived Ra isotope activities, so I did not make a correction for this difference in efficiency.

After RaDeCC analyses were complete, samples were transferred to a (different) fiber housing that was purged with helium and sealed for at least three weeks to allow for ${ }^{222} \mathrm{Rn}$ ingrowth. Samples were then analyzed via ${ }^{222} \mathrm{Rn}$ emanation and scintillation counting to measure ${ }^{226} \mathrm{Ra}$, following the method described by Key et al. (1979). Fiber standards containing $20 \mathrm{dpm}$ ${ }^{226} \mathrm{Ra}$ (NIST certified) were analyzed in the same way (and same cartridges) as the samples. Finally, fibers were dried in a $50^{\circ} \mathrm{C}$ oven, placed in polystyrene tubes and sealed with epoxy, and ${ }^{228} \mathrm{Ra}$ and ${ }^{226} \mathrm{Ra}$ activities were measured using the $\gamma$ spectrometry method described in section A.3.2. Detector efficiencies were determined using the small volume fiber standard described in section A.3.2.

Trace metal samples were analyzed using an iCAP Qc inductively coupled plasma mass spectrometer (ICP-MS) at the Woods Hole Oceanographic Institution Plasma Mass Spectrometry 
Facility. Samples were diluted 100 times, with the exception of NR2-3, which was diluted 200 times, to a final matrix of $2 \%$ nitric acid. A standard curve was created using a trace element standard provided by Tristan Horner (WHOI). The standard curve was analyzed in the middle of the ICP run to minimize bias introduced by instrument drift; standard dilutions were also analyzed at the beginning, middle, and end of the run to ensure that drift did not significantly change the concentrations of elements measured in the standard. Indium was used as an internal yield tracer, and a river water certified reference material (SLRS-6) produced by the National Research Council of Canada (NRC) was analyzed along with the samples. The offset between the average concentrations measured on three analyses of SLRS- 6 and the certified concentrations was $-7 \%$ for $\mathrm{Ba},+7 \%$ for $\mathrm{Cu},+16 \%$ for $\mathrm{Mn},+8 \%$ for $\mathrm{Ni},-2 \%$ for $\mathrm{Pb}$, and $-14 \%$ for $\mathrm{U}$ (Table 2). The precision (standard deviation/mean) of replicate analyses of the reference material $(\mathrm{n}=3)$ was $3 \%$ for $\mathrm{Ba}, 7 \%$ for $\mathrm{Cu}, 16 \%$ for $\mathrm{Mn}, 10 \%$ for $\mathrm{Ni}, 7 \%$ for $\mathrm{Pb}$, and $10 \%$ for $\mathrm{U}$. All sample concentrations were corrected for the average metal concentrations measured in four Milli-Q water blanks processed in the same way as the permafrost samples.

Nutrients (nitrate + nitrite, $\mathrm{NO}_{\mathrm{x}}$; ammonium, $\mathrm{NH}_{4}{ }^{+}$; phosphate, $\mathrm{PO}_{4}{ }^{3-}$-; and silicate, $\mathrm{SiO}_{4}{ }^{-}$) were analyzed on a four-channel segmented flow Seal AA3 HR Autoanalyzer at the Woods Hole Oceanographic Institution Nutrient Facility. The instrument was calibrated with Fisher Scientific chemicals before each run and Certified Reference Materials BV-0053 and BW-0296 from Kanso Co., LTD were used to verify the calibrations before processing samples. The average recoveries were $102 \%$ for $\mathrm{NO}_{\mathrm{x}}, 100 \%$ for $\mathrm{PO}_{4}{ }^{3-}$, and $96 \%$ for $\mathrm{SiO}_{4}{ }^{-}$. The detection limits for $\mathrm{NO}_{\mathrm{x}}$, $\mathrm{NH}_{4}{ }^{+}, \mathrm{PO}_{4}{ }^{3-}$, and $\mathrm{SiO}_{4}{ }^{-}$are $0.040 \mu \mathrm{M}, 0.015 \mu \mathrm{M}, 0.009 \mu \mathrm{M}$, and $0.030 \mu \mathrm{M}$, respectively.

DOC and TN were measured at the Woods Hole Research Center using a Shimadzu hightemperature TOC/TN instrument. Sample concentrations were corrected for the DOC and TN concentrations measured in the average of four Milli-Q water blanks processed in the same way as the samples. Dissolved organic nitrogen (DON) concentrations were calculated by subtracting the total inorganic nitrogen concentration $\left(\mathrm{NO}_{\mathrm{x}}+\mathrm{NH}_{4}{ }^{+}\right)$from the $\mathrm{TN}$ concentration.

Water isotopes were measured by temperature conversion elemental analysis (TC/EA) at the University of Wyoming Stable Isotope Facility. The $\delta^{18} \mathrm{O}$ and $\delta^{2} \mathrm{H}$ of samples was determined using a Thermo Scientific DeltaV Plus that was run in continuous flow mode and connected to a Thermo Flash HT elemental analyzer. The resulting gases $\left(\mathrm{CO}_{2}\right.$ and $\left.\mathrm{H}_{2}\right)$ were separated using gas chromatography, sent to an open split interface (ConFlo IV), and then analyzed using isotope ratio mass spectrometry (IRMS). A quality assurance reference material was run with the samples to monitor instrument precision, and quality control materials with isotopic values bracketing those of the samples were used to correct the $\delta^{18} \mathrm{O}$ and $\delta^{2} \mathrm{H}$ values of the samples. The data met all quality assurance and quality control criteria: the standard deviation for the four runs of the quality assurance material was $0.77 \%$ o for $\delta^{2} \mathrm{H}$ and $0.18 \%$ ofor $\delta$ ${ }^{18} \mathrm{O}$, and the average measured values of the quality control reference materials matched the known values. The sample $\delta^{18} \mathrm{O}$ and $\delta^{2} \mathrm{H}$ values are reported in \%o relative to Vienna Standard Mean Ocean Water (VSMOW).

Results of these analyses are summarized in Table 5. Radium-228 and ${ }^{223}$ Ra were below detection in the majority of permafrost filtrate (Table $5 \mathrm{c}$ ). The ${ }^{223} \mathrm{Ra} /{ }^{226} \mathrm{Ra}$ activity ratio was not determined for the sample with measurable ${ }^{223} \mathrm{Ra}$ because the propagated error was 100 times larger than the resulting ratio. The activities of ${ }^{226} \mathrm{Ra}$ measured through $\gamma$ spectrometry were higher than those measured through ${ }^{222} \mathrm{Rn}$ emanation; the ${ }^{222} \mathrm{Rn}$ emanation method only detects surface-bound ${ }^{226} \mathrm{Ra}$, so the higher $\gamma$ values may reflect the presence of ${ }^{226} \mathrm{Ra}$ within fine sediments trapped in the acrylic fibers. The ${ }^{228} \mathrm{Ra} /{ }^{226} \mathrm{Ra}$ activity ratio for NR2 bottom is 
computed using the activities of both isotopes measured via $\gamma$ spectrometry. A comparison between the water isotopes measured in the permafrost samples (including TS3; see section A.3.3) and those measured in Mackenzie River fresh, estuarine, and ground waters (see Chapter $5)$ is shown in Figure 3.

\section{Acknowledgements}

This work could not have been completed without Paul Henderson, who was integral to the collection of the DH and TS samples, and Steve Kokelj and Justin Kokoszka, who generously collected the AC and NR2 permafrost cores for us. Les Kutny and James Keevik provided sampling assistance in Inuvik and Tuktoyaktuk, respectively, and the Aurora Research Institute in Inuvik provided logistical support. Thanks to Paul Henderson and the WHOI Nutrient Analytical Facility for nutrient analyses; Gretchen Swarr and the WHOI Plasma Mass Spectrometry Facility for trace metal analyses; Anya Suslova for DOC and DON analyses; Kate Morkeski, Eyal Wurgaft, and Shuzhen Song for measuring DIC and alkalinity; and the University of Wyoming Stable Isotope Facility for water isotope analyses. Jessica Dabrowski provided assistance with ICP analyses, Tristan Horner and Maureen Auro provided the trace element ICP standard, and Bernhard Peucker-Ehrenbrink provided the SLRS-6 certified reference material for ICP analyses. This project was funded by a Graduate Student Research Award from the North Pacific Research Board and a Woods Hole Oceanographic Institution Ocean Ventures Fund Award to L.E.K. This research was conducted with Government support under and awarded by DoD, Air Force Office of Scientific Research, National Defense Science and Engineering Graduate (NDSEG) Fellowship awarded to L.E.K., 32 CFR 168a. 


\section{References}

Brown, J., Ferrians, O.J.J., Heginbottom, J.A., Melnikov, E.S., 1998. Circum-Arctic Map of Permafrost and Ground Ice Conditions. Boulder, Colorado.

Charette, M.A., 2007. Hydrologic forcing of submarine groundwater discharge: Insight from a seasonal study of radium isotopes in a groundwater-dominated salt marsh estuary. Limnol. Oceanogr. 52, 230-239. doi:10.4319/lo.2007.52.1.0230

Frey, K.E., McClelland, J.W., 2009. Impacts of permafrost degradation on arctic river biogeochemistry. Hydrol. Process. 23, 169-182. doi:10.1002/hyp.7196

Frey, K.E., McClelland, J.W., Holmes, R.M., Smith, L.C., 2007a. Impacts of climate warming and permafrost thaw on the riverine transport of nitrogen and phosphorus to the Kara Sea. J. Geophys. Res. Biogeosciences 112. doi:10.1029/2006JG000369

Frey, K.E., Siegel, D.I., Smith, L.C., 2007b. Geochemistry of west Siberian streams and their potential response to permafrost degradation. Water Resour. Res. 43. doi:10.1029/2006WR004902

Fritz, M., Wetterich, S., Meyer, H., Schirrmeister, L., Lantuit, H., Pollard, W.H., 2011. Origin and characteristics of massive ground ice on Herschel Island (western Canadian Arctic) as revealed by stable water isotope and Hydrochemical signatures. Permafr. Periglac. Process. 22, 26-38. doi:10.1002/ppp.714

IAEA/WMO, 2018. Global Network of Isotopes in Precipitation. GNIP Database. URL: https://nucleus.iaea.org/wiser

Keller, K., Blum, J.D., Kling, G.W., 2010. Stream geochemistry as an indicator of increasing permafrost thaw depth in an arctic watershed. Chem. Geol. 273, 76-81. doi:10.1016/j.chemgeo.2010.02.013

Key, R.M., Brewer, R.L., Stockwell, J.H., Guinasso, N.L., Schink, D.R., 1979. Some improved techniques for measuring radon and radium in marine sediments and in seawater. Mar. Chem. 7, 251-264. doi:10.1016/0304-4203(79)90042-2

Kokelj, S. V., Lacelle, D., Lantz, T.C., Tunnicliffe, J., Malone, L., Clark, I.D., Chin, K.S., 2013. Thawing of massive ground ice in mega slumps drives increases in stream sediment and solute flux across a range of watershed scales. J. Geophys. Res. Earth Surf. 118, 681-692. doi:10.1002/jgrf.20063

Lantz, T.C., Kokelj, S. V., 2008. Increasing rates of retrogressive thaw slump activity in the Mackenzie Delta region, N.W.T., Canada. Geophys. Res. Lett. 35, L06502. doi:10.1029/2007GL032433

Lecher, A.L., Chien, C. Te, Paytan, A., 2016. Submarine groundwater discharge as a source of nutrients to the North Pacific and Arctic coastal ocean. Mar. Chem. 186, 167-177. doi:10.1016/j.marchem.2016.09.008

Lecher, A.L., Kessler, J., Sparrow, K., Garcia-Tigreros Kodovska, F., Dimova, N., Murray, J., Tulaczyk, S., Paytan, A., 2015. Methane transport through submarine groundwater discharge to the North Pacific and Arctic Ocean at two Alaskan sites. Limnol. Oceanogr. doi:10.1002/lno.10118

Luo, D., Wu, Q., Jin, H., Marchenko, S.S., Lü, L., Gao, S., 2016. Recent changes in the active layer thickness across the northern hemisphere. Environ. Earth Sci. 75. doi:10.1007/s12665015-5229-2

Mackay, J.R., Dallimore, S.R., 1992. Massive ice of the Tuktoyaktuk area, western Arctic coast, Canada. Can. J. Earth Sci. 29, 1235-1249. doi:10.1139/e92-099 
Moore, W.S., Arnold, R., 1996. Measurement of ${ }^{223}$ Ra and ${ }^{224}$ Ra in coastal waters using a delayed coincidence counter. J. Geophys. Res. 101, 1321-1329. doi:10.1029/95JC03139

Moore, W.S., Cai, P., 2013. Calibration of RaDeCC systems for ${ }^{223}$ Ra measurements. Mar. Chem. 156, 130-137. doi:10.1016/j.marchem.2013.03.002

Moore, W.S., Reid, D.F., 1973. Extraction of radium from natural waters using manganeseimpregnated acrylic fibers. J. Geophys. Res. 78, 8880-8886. doi:10.1029/JC078i036p08880

Paytan, A., Lecher, A.L., Dimova, N., Sparrow, K.J., Kodovska, F.G.-T., Murray, J., Tulaczyk, S., Kessler, J.D., 2015. Methane transport from the active layer to lakes in the Arctic using Toolik Lake, Alaska, as a case study. Proc. Natl. Acad. Sci. U. S. A. 112, 3636-40. doi:10.1073/pnas.1417392112

Portnov, A., Smith, A.J., Mienert, J., Cherkashov, G., Rekant, P., Semenov, P., Serov, P., Vanshtein, B., 2013. Offshore permafrost decay and massive seabed methane escape in water depths $>20 \mathrm{~m}$ at the South Kara Sea shelf. Geophys. Res. Lett. 40, 3962-3967. doi:10.1002/grl.50735

Schuur, E. a. G., Bockheim, J., Canadell, J.G., Euskirchen, E., Field, C.B., Goryachkin, S. V., Hagemann, S., Kuhry, P., Lafleur, P.M., Lee, H., Mazhitova, G., Nelson, F.E., Rinke, A., Romanovsky, V.E., Shiklomanov, N., Tarnocai, C., Venevsky, S., Vogel, J.G., Zimov, S. A., 2008. Vulnerability of Permafrost Carbon to Climate Change: Implications for the Global Carbon Cycle. Bioscience 58, 701. doi:10.1641/B580807

Shakhova, N., Semiletov, I., Salyuk, A., Yusupov, V., Kosmach, D., Gustafsson, O., 2010. Extensive methane venting to the atmosphere from sediments of the East Siberian Arctic Shelf. Science 327, 1246-50. doi:10.1126/science.1182221

Williams, J.R., Van Everdingen, R.O., 1973. Groundwater investigations in permafrost regions of North America: a review, in: Permafrost North American Contribution 2nd International Permafrost Conference, Yakutsk, USST. National Academy of Sciences, Washington, D.C., pp. 435-446. 
Table 1. Sample descriptions and collection locations.

a. Samples collected by L. Kipp and P. Henderson. The DH samples were collected on 6/21/16, and the TS samples were collected on 6/25/16. The ice content is the ratio of the water weight (difference between the initial core weight and the weight of the dried sediments postprocessing) over the initial core weight.

\begin{tabular}{|c|c|c|c|l|}
\hline $\begin{array}{c}\text { Sample } \\
\text { ID }\end{array}$ & $\begin{array}{c}\text { Lat. } \\
\left({ }^{\circ} \mathbf{N}\right)\end{array}$ & $\begin{array}{c}\text { Lon. } \\
\left({ }^{\circ} \mathbf{W}\right)\end{array}$ & $\begin{array}{c}\text { Approx. ice } \\
\text { content }(\%)\end{array}$ & \multicolumn{1}{|c|}{ Sample description } \\
\hline DH1 & 67.9986 & 133.4679 & 50 & $\begin{array}{l}\text { Active layer. Carefully removed top layer of moss, } \\
\text { then collected sediment sample with shovel }\end{array}$ \\
\hline DH2 & 67.9986 & 133.4679 & 30 & $\begin{array}{l}\text { Sediment partially frozen, interface between } \\
\text { permafrost and active layer, collected with shovel }\end{array}$ \\
\hline DH3 & 67.9986 & 133.4679 & 30 & $\begin{array}{l}\text { Frozen sediment (but no visible ice), collected with } \\
\text { shovel }\end{array}$ \\
\hline TS1 & 69.4560 & 133.0025 & 40 & $\begin{array}{l}\text { Active layer, collected using shovel from top of } \\
\text { thaw slump }\end{array}$ \\
\hline TS2 & 69.4560 & 133.0025 & 50 & $\begin{array}{l}\text { Active layer, collected using shovel from top of } \\
\text { thaw slump }\end{array}$ \\
\hline TS3 & 69.4560 & 133.0025 & 65 & $\begin{array}{l}\text { Permafrost, collected using titanium hammer from } \\
\text { exposed face of thaw slump, very ice-rich }\end{array}$ \\
\hline
\end{tabular}

b. Samples provided by S. Kokelj and J. Kokoszka. The AC samples were collected on 8/8/16 and the NR2 samples were collected on 8/7/16. The ice content is the ratio of the water weight (difference between the initial core weight and the weight of the dried sediments postprocessing) over the initial core weight.

\begin{tabular}{|c|c|c|c|c|c|}
\hline $\begin{array}{l}\text { Sample } \\
\text { ID }\end{array}$ & $\begin{array}{l}\text { Lat. } \\
\left({ }^{\circ} \mathbf{N}\right)\end{array}$ & $\begin{array}{l}\text { Lon. } \\
\left({ }^{\circ} \mathbf{W}\right)\end{array}$ & $\begin{array}{l}\text { Depth } \\
\text { (cm) }\end{array}$ & $\begin{array}{l}\text { Approx. ice } \\
\text { content }(\%)\end{array}$ & Sample Description \\
\hline AC-1 & 68.3127 & 133.4816 & $0-40$ & & $\begin{array}{l}\text { Active layer. Organic dark peaty. Grass } \\
\text { and soil, not in core form. }\end{array}$ \\
\hline AC-2 & 68.3127 & 133.4816 & $40-50$ & 75 & $\begin{array}{l}\text { Frozen organic active layer. Charcoal } \\
\text { layer at surface. }\end{array}$ \\
\hline $\mathrm{AC}-3$ & 68.3127 & 133.4816 & $50-63$ & 80 & Peat with ice. \\
\hline $\mathrm{AC}-4$ & 68.3127 & 133.4816 & $63-80$ & 85 & \\
\hline $\mathrm{AC}-5$ & 68.3127 & 133.4816 & $80-91$ & 90 & Dark peat with woody inclusions. \\
\hline AC-6 & 68.3127 & 133.4816 & $91-98$ & 80 & $\begin{array}{l}\text { Charcoal layer. Increasing ice and } \\
\text { mineral soil content with depth. }\end{array}$ \\
\hline AC-7 & 68.3127 & 133.4816 & $98-102$ & 60 & $\begin{array}{l}\text { Icy transition to clayey material with } \\
\text { some organic conclusions. (lake } \\
\text { sediment) }\end{array}$ \\
\hline NR2-1 & 68.3837 & 133.7605 & $25-38$ & 95 & $\begin{array}{l}\text { Organic rich base of active layer. Pool } \\
\text { ice from } 35-38 \mathrm{~cm} \text {, showing successive } \\
\text { freezing layers. Decrease in organic } \\
\text { richness with increasing mineral } \\
\text { richness. }\end{array}$ \\
\hline NR2-2 & 68.3837 & 133.7605 & $38-56$ & 75 & $\begin{array}{l}\text { Thin lenses of segregated ice. Yellow- } \\
\text { orange oxidized till, clayey-silt. } \\
\text { Lenticular-segregated. }\end{array}$ \\
\hline NR2-3 & 68.3837 & 133.7605 & $56-72$ & 75 & Lenticular and ataxitic. \\
\hline
\end{tabular}




\begin{tabular}{|c|l|l|l|l|l|}
\hline NR2-4 & 68.3837 & 133.7605 & $72-93$ & 90 & $\begin{array}{l}\text { Organic rich. Roots and tree stems. } \\
\text { Upper core, light fibrous peat. Lower } \\
\text { half, darker layers with charcoal. } \\
\text { Charcoal layer at 85 - 88cm. }\end{array}$ \\
\hline NR2-5 & 68.3837 & 133.7605 & $92-114$ & 50 & $\begin{array}{l}\text { Thick ice lenses up to 1cm, ataxitic } \\
\text { structure. Organic inclusions and woody } \\
\text { material in upper core and at bottom. } \\
\text { Flux of charcoal observed throughout. } \\
\text { Mineral soil is slightly oxidized yellow- } \\
\text { grey color. Lower core is grey. }\end{array}$ \\
\hline NR2-6 & 68.3837 & 133.7605 & $114-134$ & 50 & $\begin{array}{l}\text { Ataxitic. Lower core: increasing ice } \\
\text { content with depth. Ice lenses up to 3 - } \\
\text { 4cm thick. Upper core: organics present. } \\
\text { Decreasing organic presence with depth. } \\
\text { Fine grain sediments are grey. }\end{array}$ \\
\hline NR2-7 & 68.3837 & 133.7605 & $134-144$ & 60 & \begin{tabular}{l} 
Ataksitic. No visible organics. \\
\hline
\end{tabular}
\end{tabular}


Table 2. The activities of ${ }^{228} \mathrm{Ra}$ and ${ }^{226} \mathrm{Ra}$ and the ${ }^{228} \mathrm{Ra} /{ }^{226} \mathrm{Ra}$ activity ratios measured in permafrost and active layer sediments. Three aliquots of each sample were analyzed, with the exception of TS3. Standard errors are shown (measurement error is shown for TS3).

\begin{tabular}{|c|c|c|c|c|}
\hline Sample ID & Sediment type & $\begin{array}{c}{ }^{228} \mathrm{Ra} \\
\left(\mathrm{dpm} \mathrm{g}^{-1}\right)\end{array}$ & $\begin{array}{c}{ }^{226} \mathrm{Ra} \\
\left(\mathrm{dpm} \mathrm{\textrm {g } ^ { - 1 }}\right)\end{array}$ & ${ }^{228} \mathbf{R a} /{ }^{226} \mathrm{Ra}$ \\
\hline DH1 & Active layer & $2.1 \pm 0.2$ & $2.1 \pm 0.2$ & $1.0 \pm 0.1$ \\
\hline $\mathrm{DH} 2$ & Active layer-permafrost boundary & $2.0 \pm 0.1$ & $2.2 \pm 0.1$ & $0.9 \pm 0.1$ \\
\hline DH3 & Permafrost & $2.2 \pm 0.1$ & $2.1 \pm 0.1$ & $1.1 \pm 0.1$ \\
\hline TS1 & Active layer & $1.6 \pm 0.2$ & $1.7 \pm 0.1$ & $1.0 \pm 0.1$ \\
\hline TS2 & Active layer & $1.1 \pm 0.2$ & $1.5 \pm 0.1$ & $0.7 \pm 0.1$ \\
\hline TS3 & Permafrost & $3.1 \pm 0.1$ & $2.7 \pm 0.1$ & $1.1 \pm 0.1$ \\
\hline
\end{tabular}


Table 3. Gamma detector efficiencies for a $1.8 \mathrm{~g}$ fiber standard. The efficiencies reported for Canberra 1 and Canberra 2 represent the average \pm standard deviation for multiple runs.

\begin{tabular}{|c|c|c|c|c|}
\hline Detector & $\mathbf{3 3 8} \mathbf{~ k e V}$ & $\mathbf{3 5 2} \mathbf{~ k e V}$ & $\mathbf{9 1 1} \mathbf{~ k e V}$ & Number of runs \\
\hline Canberra 1 & $21.5 \pm 0.7 \%$ & $23.9 \pm 0.2 \%$ & $7.2 \pm 0.2 \%$ & 8 \\
\hline Canberra 2 & $20.2 \pm 0.8 \%$ & $22.3 \pm 0.2 \%$ & $6.8 \pm 0.2 \%$ & 9 \\
\hline Canberra 3 & $22.8 \%$ & $23.3 \%$ & $7.5 \%$ & 1 \\
\hline Ortec & $23.3 \%$ & $25.6 \%$ & $7.5 \%$ & 1 \\
\hline
\end{tabular}


Table 4. The ${ }^{228} \mathrm{Ra}$ and ${ }^{226} \mathrm{Ra}$ activities (reported in dpm per gram of sediment desorbed) and the ${ }^{228} \mathrm{Ra} /{ }^{226} \mathrm{Ra}$ activity ratio measured in desorption experiment filtrate. A comparison between the desorbed activities and the activities measured on sediments (reported in Table 2) was used to determine the percent of ${ }^{226} \mathrm{Ra}$ that desorbed. *indicates that the ${ }^{228} \mathrm{Ra}$ activity was based on the $338 \mathrm{keV}$ line only, $b d l$ indicates below detection limits, - indicates cannot be determined.

\begin{tabular}{|c|c|c|c|c|c|c|}
\hline $\begin{array}{c}\text { Sample } \\
\text { ID }\end{array}$ & Sediment type & Salinity & ${ }_{\left(\mathrm{dpm} \mathrm{g}^{-1}\right)}^{{ }^{228} \mathrm{Ra}}$ & $\begin{array}{c}{ }^{226} \mathbf{R a} \\
\left(\mathrm{dpm} \mathrm{g}^{-1}\right)\end{array}$ & ${ }^{228} \mathrm{Ra} /{ }^{226} \mathrm{Ra}$ & $\begin{array}{c}{ }^{226} \mathbf{R a} \\
\text { desorbed } \\
(\%)\end{array}$ \\
\hline DH1 & Active layer & 0.6 & $b d l$ & $b d l$ & - & - \\
\hline $\mathrm{DH} 2$ & $\begin{array}{c}\text { Active layer- } \\
\text { permafrost boundary }\end{array}$ & 0.6 & $b d l$ & $b d l$ & - & - \\
\hline DH3 & Permafrost & 0.6 & $b d l$ & $b d l$ & - & - \\
\hline TS1 & Active layer & 0.6 & $\begin{array}{l}0.008 \pm \\
0.003 *\end{array}$ & $\begin{array}{c}0.005 \pm \\
0.001\end{array}$ & $1.7 \pm 0.4$ & $0.3 \%$ \\
\hline TS2 & Active layer & 0.6 & $b d l$ & $\begin{array}{c}0.007 \pm \\
0.001\end{array}$ & - & $0.5 \%$ \\
\hline TS3 & Permafrost & 0.6 & $b d l$ & $b d l$ & - & - \\
\hline Blank 1 & & 0.6 & $b d l$ & $b d l$ & - & - \\
\hline DH1 & Active layer & 27 & $\begin{array}{c}0.072 \pm \\
0.008\end{array}$ & $\begin{array}{l}0.041 \pm \\
0.002\end{array}$ & $1.8 \pm 0.1$ & $1.9 \%$ \\
\hline $\mathrm{DH} 2$ & $\begin{array}{c}\text { Active layer- } \\
\text { permafrost boundary }\end{array}$ & 27 & $\begin{array}{c}0.049 \pm \\
0.010\end{array}$ & $\begin{array}{l}0.041 \pm \\
0.002\end{array}$ & $1.2 \pm 0.2$ & $1.9 \%$ \\
\hline DH3 & Permafrost & 27 & $\begin{array}{c}0.060 \pm \\
0.007\end{array}$ & $\begin{array}{c}0.044 \pm \\
0.002\end{array}$ & $1.4 \pm 0.1$ & $2.1 \%$ \\
\hline TS1 & Active layer & 27 & $\begin{array}{l}0.040 \pm \\
0.006\end{array}$ & $\begin{array}{c}0.043 \pm \\
0.001\end{array}$ & $0.9 \pm 0.1$ & $2.6 \%$ \\
\hline TS2 & Active layer & 27 & $\begin{array}{c}0.030 \pm \\
0.007\end{array}$ & $\begin{array}{c}0.034 \pm \\
0.002\end{array}$ & $0.9 \pm 0.2$ & $2.3 \%$ \\
\hline TS3 & Permafrost & 27 & $\begin{array}{c}0.055 \pm \\
0.010\end{array}$ & $\begin{array}{c}0.053 \pm \\
0.003\end{array}$ & $1.0 \pm 0.2$ & $1.9 \%$ \\
\hline Blank 2 & & 27 & $b d l$ & $b d l$ & - & - \\
\hline Blank 3 & & 27 & $b d l$ & $b d l$ & - & - \\
\hline
\end{tabular}


Table 5. Chemistry of permafrost porewaters.

a. Water isotopes, nutrients, and dissolved organic matter measured in the AC and NR2 permafrost cores. $b d l$ indicates concentrations below detection limits.

\begin{tabular}{|c|c|c|c|c|c|c|c|c|c|c|c|}
\hline $\begin{array}{c}\text { Sample } \\
\text { ID }\end{array}$ & $\begin{array}{c}\text { Depth } \\
\mathbf{r a n g e} \\
(\mathbf{c m})\end{array}$ & $\begin{array}{c}\boldsymbol{\delta}^{2} \mathbf{H} \\
(\%)\end{array}$ & $\begin{array}{c}\boldsymbol{\delta}^{\mathbf{1 8}} \mathbf{O} \\
(\%)\end{array}$ & $\begin{array}{c}\mathbf{N O}_{\mathbf{x}} \\
(\boldsymbol{\mu M})\end{array}$ & $\begin{array}{c}\mathbf{N H}_{4}{ }^{+} \\
(\boldsymbol{\mu M})\end{array}$ & $\begin{array}{c}\mathbf{P O}_{4}{ }^{3-} \\
(\boldsymbol{\mu M})\end{array}$ & $\begin{array}{c}\mathbf{S i O}_{4}^{-} \\
(\boldsymbol{\mu M})\end{array}$ & $\begin{array}{c}\mathbf{D I N} \\
(\boldsymbol{\mu M})\end{array}$ & $\begin{array}{c}\mathbf{D O N} \\
(\boldsymbol{\mu M})\end{array}$ & $\begin{array}{c}\mathbf{D O C} \\
(\boldsymbol{\mu M})\end{array}$ & $\begin{array}{c}\mathbf{T N} \\
(\boldsymbol{\mu M})\end{array}$ \\
\hline AC-2 & $40-50$ & -156.9 & -21.0 & 7.2 & 210 & 2.4 & 6 & 217 & 706 & 17880 & 923 \\
\hline AC-3 & $50-63$ & -160.6 & -20.7 & 0.4 & 60 & 1.3 & 1 & 61 & 2734 & 56390 & 2795 \\
\hline AC-4 & $63-80$ & -159.6 & -20.5 & 0.3 & 88 & 2.0 & 1 & 88 & 4278 & 60500 & 4366 \\
\hline AC-5 & $80-91$ & -158.6 & -20.4 & 0.1 & 88 & 0.9 & 1 & 88 & 3579 & 35870 & 3666 \\
\hline AC-6 & $91-98$ & -157.7 & -20.2 & $b d l$ & 87 & 0.2 & 1 & 87 & 2922 & 40340 & 3009 \\
\hline AC-7 & $98-102$ & -158.8 & -20.2 & 0.9 & 88 & 0.2 & 3 & 89 & 2277 & 23760 & 2366 \\
\hline NR2-1 & $25-38$ & -183.7 & -23.6 & 5.6 & 64 & 14.2 & 22 & 70 & 239 & 7320 & 309 \\
\hline NR2-2 & $38-56$ & -172.2 & -22.4 & 2.6 & 87 & 0.9 & 34 & 90 & 255 & 9680 & 345 \\
\hline NR2-3 & $56-72$ & -175.8 & -23.0 & 0.9 & 429 & 2.7 & 35 & 430 & 743 & 28250 & 1173 \\
\hline NR2-4 & $72-93$ & -180.6 & -23.6 & 2.8 & 282 & 1.3 & 44 & 285 & 602 & 26420 & 888 \\
\hline NR2-5 & $92-114$ & -189.8 & -24.6 & 3.1 & 360 & 0.7 & 34 & 363 & 682 & 16280 & 1045 \\
\hline NR2-6 & $114-134$ & -192.0 & -25.3 & 6.2 & 377 & 0.9 & 24 & 384 & 654 & 13470 & 1038 \\
\hline NR2-7 & $134-144$ & -187.6 & -24.5 & 12.5 & 82 & 0.2 & 17 & 95 & 357 & 3850 & 452 \\
\hline
\end{tabular}

b. Trace metals measured in the AC and NR2 permafrost cores.

\begin{tabular}{|c|c|c|c|c|c|c|c|c|}
\hline $\begin{array}{c}\text { Sample } \\
\text { ID }\end{array}$ & $\begin{array}{c}\text { Depth } \\
\text { range } \\
(\mathbf{c m})\end{array}$ & $\begin{array}{c}\mathbf{M n} \\
(\mathbf{n M})\end{array}$ & $\begin{array}{c}\mathbf{C o} \\
(\mathbf{n M})\end{array}$ & $\begin{array}{c}\mathbf{N i} \\
(\mathbf{n M})\end{array}$ & $\begin{array}{c}\mathbf{C u} \\
(\mathbf{n M})\end{array}$ & $\begin{array}{c}\mathbf{B a} \\
(\mathbf{n M})\end{array}$ & $\begin{array}{c}\mathbf{P b} \\
(\mathbf{n M})\end{array}$ & $\begin{array}{c}\mathbf{U} \\
(\mathbf{n M})\end{array}$ \\
\hline AC-2 & $40-50$ & $80 \pm 5$ & $30 \pm 1$ & $203 \pm 4$ & $58 \pm 3$ & $1680 \pm 30$ & $1.58 \pm 0.07$ & $0.44 \pm 0.01$ \\
\hline AC-3 & $50-63$ & $100 \pm 6$ & $39 \pm 2$ & $123 \pm 2$ & $52 \pm 3$ & $950 \pm 10$ & $1.25 \pm 0.06$ & $0.68 \pm 0.05$ \\
\hline AC-4 & $63-80$ & $760 \pm 20$ & $30 \pm 1$ & $97 \pm 4$ & $61 \pm 2$ & $660 \pm 10$ & $1.22 \pm 0.05$ & $0.89 \pm 0.07$ \\
\hline AC-5 & $80-91$ & $1300 \pm 20$ & $13 \pm 1$ & $89 \pm 5$ & $22 \pm 2$ & $500 \pm 4$ & $0.5 \pm 0.05$ & $0.62 \pm 0.04$ \\
\hline AC-6 & $91-98$ & $6280 \pm 30$ & $15 \pm 1$ & $56 \pm 3$ & $21 \pm 1$ & $990 \pm 10$ & $0.66 \pm 0.03$ & $0.91 \pm 0.02$ \\
\hline AC-7 & $98-102$ & $9400 \pm 300$ & $11 \pm 0$ & $87 \pm 4$ & $66 \pm 3$ & $1240 \pm 20$ & $1.36 \pm 0.04$ & $0.59 \pm 0.02$ \\
\hline NR2-1 & $25-38$ & $480 \pm 7$ & $25 \pm 1$ & $92 \pm 3$ & $48 \pm 2$ & $210 \pm 4$ & $1.67 \pm 0.09$ & $1.14 \pm 0.04$ \\
\hline NR2-2 & $38-56$ & $740 \pm 20$ & $47 \pm 1$ & $180 \pm 10$ & $87 \pm 3$ & $317 \pm 5$ & $6.22 \pm 0.22$ & $9.72 \pm 0.27$ \\
\hline NR2-3 & $56-72$ & $1010 \pm 20$ & $81 \pm 3$ & $280 \pm 10$ & $68 \pm 4$ & $1100 \pm 30$ & $8.49 \pm 0.24$ & $17.86 \pm 0.14$ \\
\hline NR2-4 & $72-93$ & $1350 \pm 10$ & $101 \pm 2$ & $420 \pm 10$ & $106 \pm 4$ & $1260 \pm 20$ & $3.02 \pm 0.05$ & $4.8 \pm 0.09$ \\
\hline NR2-5 & $92-114$ & $1930 \pm 10$ & $78 \pm 3$ & $250 \pm 10$ & $82 \pm 1$ & $260 \pm 10$ & $2.59 \pm 0.15$ & $7.1 \pm 0.16$ \\
\hline NR2-6 & $114-134$ & $1180 \pm 30$ & $43 \pm 1$ & $183 \pm 7$ & $59 \pm 5$ & $220 \pm 10$ & $4.82 \pm 0.37$ & $6.6 \pm 0.12$ \\
\hline NR2-7 & $134-144$ & $1870 \pm 20$ & $45 \pm 1$ & $142 \pm 5$ & $43 \pm 1$ & $107 \pm 3$ & $1.77 \pm 0.09$ & $1.28 \pm 0.02$ \\
\hline
\end{tabular}


c. Radium isotopes measured in the $\mathrm{AC}$ and NR2 permafrost porewaters. $b d l$ indicates activities below the detection limits.

\begin{tabular}{|c|c|c|c|c|c|c|}
\hline Sample ID & $\begin{array}{c}\text { Depth } \\
\text { range }(\mathbf{c m})\end{array}$ & $\begin{array}{c}{ }^{\mathbf{2 2 6}} \mathbf{R a} \\
\left(\mathbf{d p m} \mathbf{L}^{-\mathbf{1}}\right) \\
(\mathrm{Rn} \text { line })\end{array}$ & $\begin{array}{c}{ }^{\mathbf{2 2 6}} \mathbf{R a} \\
\left(\mathbf{d p m} \mathbf{L}^{-\mathbf{1}}\right) \\
(\gamma \text { spectrometry) }\end{array}$ & $\begin{array}{c}{ }^{\mathbf{2 2 8}} \mathbf{R a} \\
\left(\mathbf{d p m} \mathbf{L}^{-\mathbf{1}}\right)\end{array}$ & $\begin{array}{c}{ }^{\mathbf{2 2 4}} \mathbf{R a} \\
\left(\mathbf{d p m} \mathbf{L}^{-\mathbf{1}}\right)\end{array}$ & $\begin{array}{c}{ }^{\mathbf{2 2 4}} \mathbf{R a}_{\mathbf{x s}} \\
\left(\mathbf{d p m} \mathbf{L}^{-\mathbf{1}}\right)\end{array}$ \\
\hline AC & $50-98$ & $0.1 \pm 0.05$ & $b d l$ & $b d l$ & $0.1 \pm 0.04$ & $0.09 \pm 0.06$ \\
\hline NR2 top & $25-38$ & $0.1 \pm 0.06$ & $0.44 \pm 0.08$ & $b d l$ & $0.35 \pm 0.06$ & $0.34 \pm 0.08$ \\
\hline NR2 mid & $38-93$ & $0.91 \pm 0.06$ & $1.5 \pm 0.1$ & $b d l$ & $0.78 \pm 0.09$ & $0.72 \pm 0.1$ \\
\hline NR2 bottom & $92-144$ & $0.36 \pm 0.06$ & $0.82 \pm 0.1$ & $1 \pm 0.3$ & $0.7 \pm 0.1$ & $0.48 \pm 0.12$ \\
\hline
\end{tabular}

C. (continued)

\begin{tabular}{|c|c|c|c|c|c|c|}
\hline Sample ID & $\begin{array}{c}\text { Depth } \\
\text { range }(\mathrm{cm})\end{array}$ & 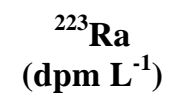 & $\begin{array}{c}{ }^{223} \mathbf{R a}_{\mathrm{xs}} \\
\left(\operatorname{dpm~L} \mathbf{L}^{-1}\right)\end{array}$ & ${ }^{224} \mathbf{R a}_{\mathrm{xS}}{ }^{228} \mathrm{Ra}$ & ${ }^{224} \mathbf{R a}_{\mathrm{xs}}{ }^{226} \mathrm{Ra}$ & ${ }^{228} \mathrm{Ra} /{ }^{226} \mathrm{Ra}$ \\
\hline $\mathrm{AC}$ & $50-98$ & $b d l$ & $b d l$ & $b d l$ & $b d l$ & $b d l$ \\
\hline NR2 top & $25-38$ & $b d l$ & $b d l$ & $b d l$ & $0.8 \pm 0.1$ & $b d l$ \\
\hline NR2 mid & $38-93$ & $0.07 \pm 0.05$ & $0.07 \pm 0.05$ & $b d l$ & $0.5 \pm 0.1$ & $b d l$ \\
\hline NR2 bottom & $92-144$ & $b d l$ & $b d l$ & $0.5 \pm 0.3$ & $0.6 \pm 0.2$ & $1.3 \pm 0.3$ \\
\hline
\end{tabular}




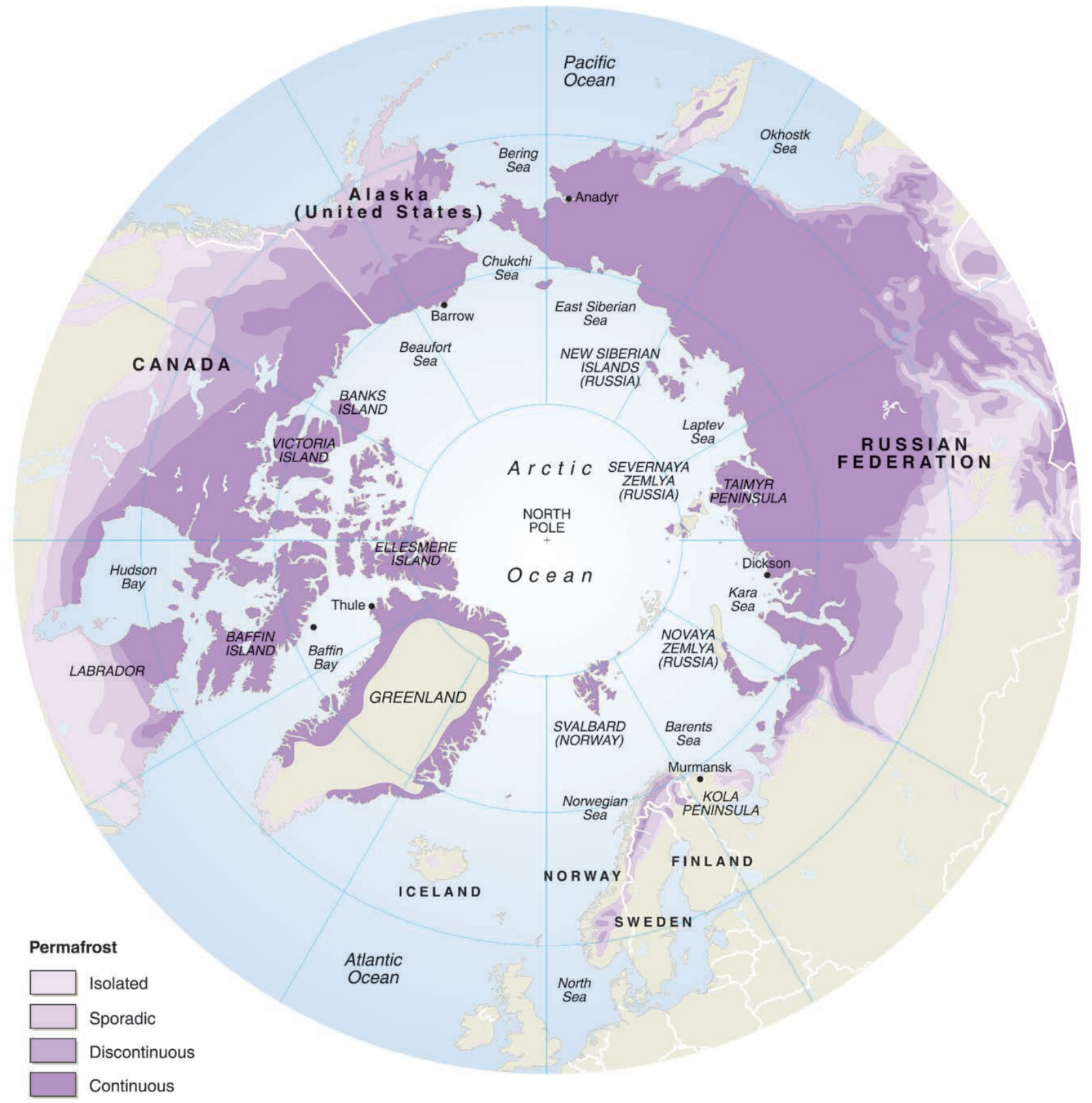

Figure 1. Distribution of permafrost in the Arctic. Figure from Schuur et al. (2008), based on permafrost distribution reported by Brown et al. (1998). 
(a)

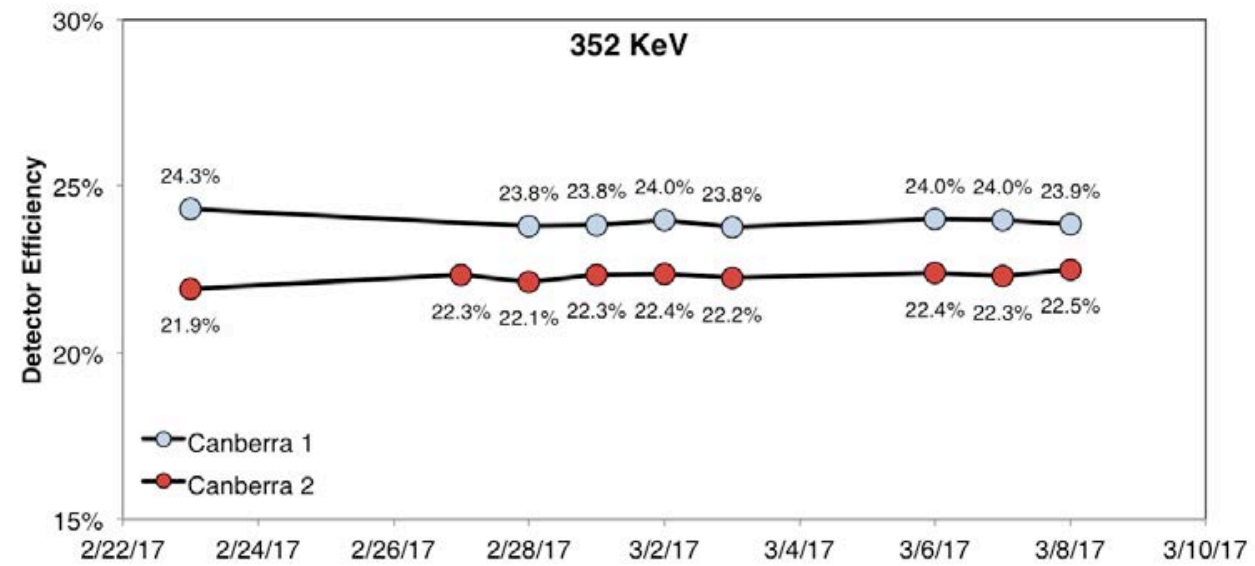

(b)

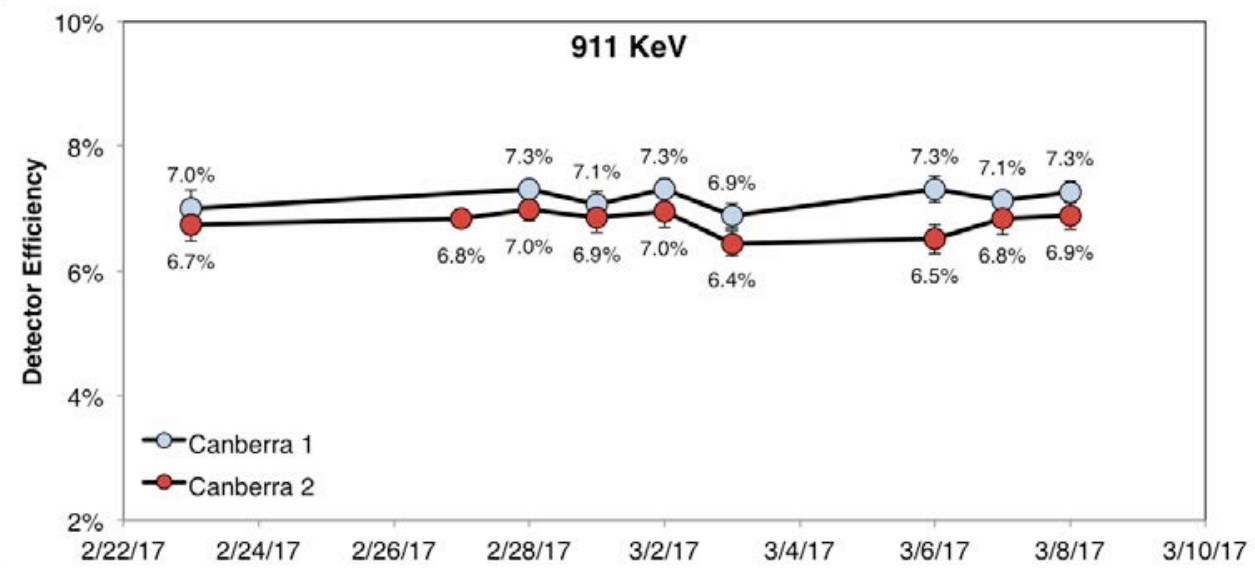

(c)

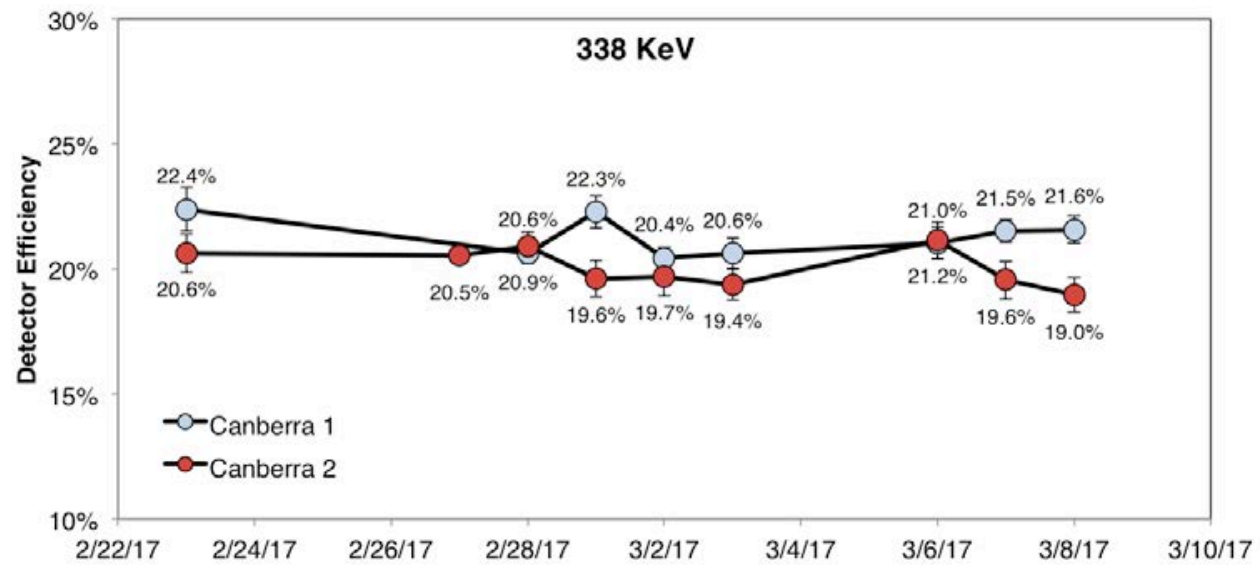

Figure 2. Detector efficiency for the (a) $352 \mathrm{keV}$ line, (b) $911 \mathrm{keV}$ line, and (c) $338 \mathrm{keV}$ line for the $1.8 \mathrm{~g}$ fiber standard described in section A.3.2. Error bars in panel (a) are smaller than the symbols. 


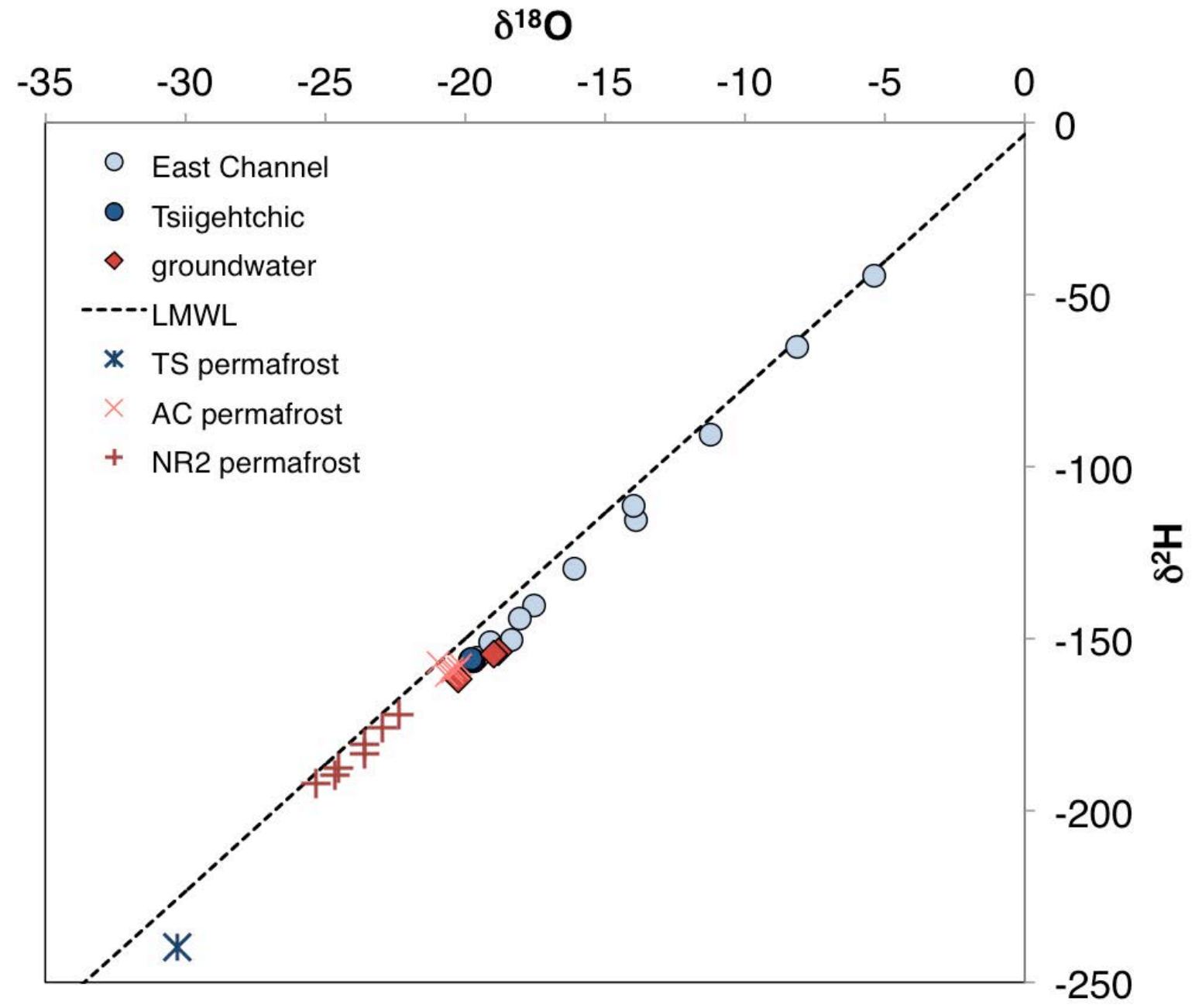

Figure 3. Water isotopes measured in permafrost samples (TS3, AC, NR2) compared to those measured in the Mackenzie River Delta (see Chapter 5 for description of Mackenzie River Delta samples). The local mean water line for Inuvik is also shown (IAEA/WMO, 2018). 